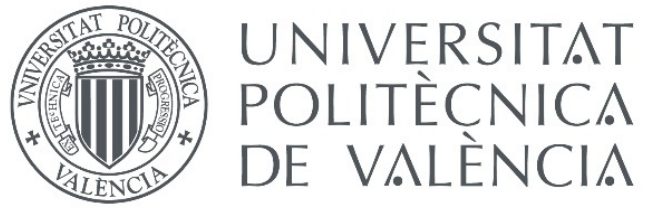

\title{
NUMERICAL MODELLING OF UHPFRC: FROM THE MATERIAL TO THE STRUCTURAL ELEMENT
}

\author{
PhD THESIS
}

Author:

Eduardo José Mezquida Alcaraz

Supervisors:

PhD. Juan Navarro Gregori

Prof. Pedro Serna Ros

València, Spain

March 2021

UNIVERSITAT POLITÈCNICA DE VALÈNCIA

PROGRAMA DE DOCTORADO EN INGENIERÍA DE LA CONSTRUCCIÓN 



\title{
NUMERICAL MODELLING OF UHPFRC: FROM THE MATERIAL TO THE STRUCTURAL ELEMENT
}

\author{
by
}

Eduardo José Mezquida Alcaraz

\section{$\mathrm{PhD}$ THESIS}

Submitted in fulfilment of the requirements for the degree of Doctor of Philosophy in Building

Engineering from the Departamento de Ingeniería de la Construcción y de Proyectos de Ingeniería Civil of the Universitat Politècnica de València

Supervisors:

PhD. Juan Navarro Gregori

Prof. Pedro Serna Ros

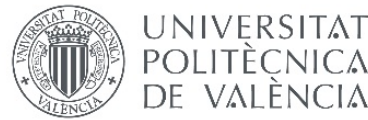

Universitat Politècnica de València

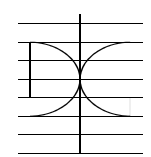

Departamento de Ingeniería de la Construcción y de Proyectos de Ingeniería Civil

\section{IIIITIECH}

Instituto de Ciencia y Tecnología del Hormigón

External evaluation committee:

$\mathrm{PhD}$. Héctor Cifuentes Bulte, Universidad de Sevilla

Prof. Emmanuel Denarié, École Polytechnique Fédérale de Lausanne

Prof. Barzin Mobasher, University of Arizona

Thesis committee:

Prof. Marco Di Prisco, Politecnico di Milano

Prof. Gonzalo Francisco Ruiz López, Universidad de Castilla-La Mancha

Prof. Emmanuel Denarié, École Polytechnique Fédérale de Lausanne

March 2021, València, Spain 

To Cristina and Anna 



\section{Acknowledgements}

I want to express my gratitude to the members of the jury and reviewers who generously spent their time to check and improve my work with their insightful and valuable comments. For me it has been a great honour that well-known prominent researchers in the field accepted this task. Thank you very much: Prof. Emmanuel Denarié, Prof. Marco Di Prisco, Prof. Gonzalo Francisco Ruiz López, Prof. Barzin Mobasher and PhD. Héctor Cifuentes Bulte.

M'agradaria donar les gràcies al meu director de tesi Juan Navarro Gregori. Moltes gràcies Juan per haver confiat en mi i per haver-me ensenyat un camí en el món de la investigació i del modelat des del primer moment. Has estat present en tot el meu període de creixement com a enginyer i investigador des de que vaig escomençar el projecte final de carrera fins la tesi doctoral. Per a mi eres com un germà major al Poli. Moltíssimes gràcies per tot.

M'agradaria donar les gràcies al meu director de tesi Pedro Serna Ros. Moltes gràcies Pedro per haver-me ensenyat tant en el món de la investigació i en el dia a dia, i per haver-me confiat tot el que poguera necessitar en qualsevol moment. Eres tota una institució i, per a mi, és tot un orgull haver sigut doctorand teu.

M'agradaria donar les gràcies a tres amics molt especials: Marta Roig Flores, Francisco Ortiz Navas i Francisco Martorell Romero (Paco). Moltes gràcies per regalar-me grans moments, per la vostra amistat i ajuda, per treballar colze amb colze i per compartir el dia a dia a l'ICITECH. També estic molt agraït a grans amics i companys de l'ICITECH amb els que he tingut l'oportunitat de treballar, col-laborar i compartir bons moments: Alberto Negrini, Hesam Doostkami, Juan Ángel López, Fleur Spitters, Marta Caballero, 
Sidiclei Formagini, Majid Khorami, Carlos Meléndez i Vicent Penadés. Voldria fer extensible el meu agraïment a tota la comunitat de l'ICITECH i de l'Escola de Camins de la UPV.

M'agradaria donar les gràcies a la meua família per absolutament tot en aquesta vida. Als meus pares Eduardo i Joana i a la meua germana Cristina perquè sense vosaltres no haguera sigut capaç d'arribar tan lluny en res. Ho sou tot per a mi. Voldria donar les gràcies al meu cunyat Javi per ser un germà per a mi. Voldria donar les gràcies a la meua parella Anna per ser la llum, el color i l'alegria de la meua vida i la causa de la meua felicitat. Vos estime. 


\section{Abstract}

Ultra-high performance fibre-reinforced concrete (UHPFRC) can be considered a modern and enhanced evolution of fibre-reinforced concrete (FRC) that is able to produce marked mechanical properties and high durability. These characteristics can allow UHPFRC to be considered a competitive construction material if its production and properties are optimised, and if an adequate modelling strategy that allows an effective structural design to take advantage of this material's enhanced properties is defined.

The majority of research that has dealt with UHPFRC in the past 20 years has been related to strain-hardening behaviour (SH-UHPFRC). This behaviour ensures excellent mechanical properties and durability, but with a high initial cost related to raw materials, pouring system, curing and heat treatment once the UHPFRC is cast. The study of the behaviour of UHPFRC with strain-softening (SS-UHPFRC) has been considered to a lesser extent and this could result in the possibility of reducing the use of these raw materials in its manufacture.

The main objective of the present $\mathrm{PhD}$ thesis is to develop a complete methodology for the numerical modelling of UHPFRC from the material level to structural elements. It intends to contribute to advanced knowledge of mechanical UHPFRC behaviour to lead to a numerically modelling proposal that is useful for structural modelling and design that allows options for this material to be competitive in the construction market. Optimised UHPFRC material constitutive behaviour, characterised by a direct reliable defined procedure, is considered in the proposed modelling methodology to take advantage of these properties, and to lead to an efficient structural design from the mechanical and economical points of view. 
Is it necessary to produce SH-UHPFRC to obtain excellent properties? Is it possible to develop SS-UHPFRC that leads to lower initial costs and to maintain competitive mechanical and durability properties that result in an effective structural design? The development of low strain-hardening and SS-UHPFRC would lead to reduce its mechanical properties, but they can be optimised if they are studied and controlled.

The thesis addresses some of these questions by studying tensile UHPFRC behaviour to cover a wide range of tensile constitutive behaviours from SH-UHPFRC to SSUHPFRC. It intends to propose a reliable tensile characterisation process and a reliable finite element model capable of accurately simulating the response of UHPFRC specimens and reinforced structural elements.

An extensive experimental and numerical campaign with 227 unreinforced four-point bending test (4PBT) specimens with amounts of smooth-straight $(13 / 0.20)$ steel fibres of $1.53-1.66 \%\left(120-130 \mathrm{~kg} / \mathrm{m}^{3}\right)$ in volume and with $2.00 \%\left(160 \mathrm{~kg} / \mathrm{m}^{3}\right)$, which represents SS-UHPFRC and SH-UHPFRC tensile behaviours, was carried out to set up a direct tensile characterisation procedure involving SS-UHPFRC and SH-UHPFRC. The direct procedure's development and validity are ensured by a reliable non-linear finite element model (NLFEM). Numerical validation was carried out and is decisive for performing the direct procedure to characterise the tensile behaviour of both SS and SH-UHPFRC herein developed accurately, simply and reliably.

With the experimental programme herein, a predictive application for estimating tensile UHPFRC parameters was developed. The prediction offers reliable results. The application is simple and direct, and avoids variability in the characterisation procedure due to possible misinterpretations in its application.

In addition, a second experimental programme, which includes reinforced concrete flexural beams on different scales, with 36 UHPFRC reinforced short beams with 130 and $160 \mathrm{~kg} / \mathrm{m}^{3}$ of steel fibres and two full-scale long beams, was carried out and modelled with the NLFEM herein developed including major effects due to the interaction between UHPFRC and reinforcement bars. Additionally, reinforced UHPFRC tensile bars from a recent experimental campaign performed by other researchers were modelled with the NLFEM. The model considers shrinkage effects, tension stiffening behaviour and 3D effects due to the particularities of the test, which provide very accurate results compared to those obtained with the experimental tests.

As a result of this PhD thesis, an accurate NLFEM was obtained to model reinforced UHPFRC structural elements. The results of the model compared to the experimental ones demonstrate not only the reliability of the developed NLFEM, but also the coherence of the developed direct procedure to characterise tensile UHPFRC behaviour in both strain-softening and strain-hardening in reinforced flexural and direct tensile structural elements. Consequently, a complete and effective methodology for numerical UHPFRC modelling from the material level to structural elements is proposed. 


\section{Resum}

El formigó de molt alt rendiment reforçat amb fibres (UHPFRC) pot ser considerat com una moderna i millorada evolució del formigó reforçat amb fibres (FRC) capaç de desenvolupar grans propietats mecàniques $i$ una alta durabilitat. Aquestes característiques podem dur a considerar l'UHPFRC com a material de construcció competitiu si la seua producció i les seues propietats són optimitzades i si es defineix una adequada estratègia de modelització que permeta un disseny estructural efectiu capaç d'aprofitar les propietats millorades d'aquest material.

La majoria de la recerca vinculada amb l'UHPFRC durant els últims vint anys està relacionada amb el comportament d'enduriment per deformació (SH-UHPFRC). Amb aquest comportament, s'asseguren grans propietats mecàniques i durabilitat però amb alts costos inicials derivats dels materials base necessaris per a la seua fabricació, del sistema d'abocament, del curat i del tractament tèrmic una vegada l'UHPFRC és fabricat. L'estudi del comportament de l'UHPFRC amb reblaniment per deformació (SSUHPFRC), que podria resultar amb l'estalvi d'aquests costos inicials, ha estat considerat en menor mesura.

El principal objectiu de la present tesi es el desenvolupament d'una completa metodologia per al modelat numèric de l'UHPFRC des del nivell material fins arribar als elements estructurals. Es pretén contribuir a l'avanç del coneixement del comportament mecànic de l'UHPFRC per mitjà d'un procediment per al modelat numèric útil per al modelat $\mathrm{i}$ disseny estructural que permeta fer que aquest material siga competitiu al mercat de la construcció. En la metodologia de modelat proposta, es considera un comportament constitutiu de l'UHPFRC optimitzat per mitjà d'un procediment directe $\mathrm{i}$ 
fiable amb el qual s'aprofiten els avantatges del material, resultant en un disseny estructural eficient des del punt de vista mecànic i econòmic.

És necessari produir SH-UHPFRC per a aconseguir grans propietats mecàniques? És possible generar SS-UHPFRC amb el qual queden reduïts els costs inicials mantenint unes propietats mecàniques $\mathrm{i}$ de durabilitat competitives que comporten un disseny estructural efectiu? El desenvolupament d'UHPFRC amb baix enduriment per deformació i de SS-UHPFRC pot reduir les seues propietats mecàniques però, si són adequadament estudiades i controlades, aquests podrien ser optimitzats.

La tesi aborda algunes d'aquestes qüestions per mitjà de l'estudi del comportament a tracció de l'UHPFRC que va des de SH-UHPFRC fins SS-UHPFRC. Es pretén dur a terme una proposta de procediment fiable per a caracteritzar el comportament constitutiu a tracció i definir un model numèric d'elements finits fiable per a modelar amb precisió la resposta de provetes i elements estructurals armats d'UHPFRC.

Per a definir el procediment directe per a caracteritzar a tracció tant SH-UHPFRC com SS-UHPFRC, s'ha dut a terme una campanya experimental i numèrica en la que s'ha analitzat el resultat d'assajar 227 provetes sense armadura fabricades amb UHPFRC amb quantitats de fibres curtes i llises d'acer de $120-130 \mathrm{~kg} / \mathrm{m}^{3}$ i $160 \mathrm{~kg} / \mathrm{m}^{3}$, assajades a flexió per mitjà de l'assaig a quatre punts (4PBT). El desenvolupament i la validació de l'esmentat procés són assegurats per mitjà d'un model no lineal d'elements finits (NLFEM) fiable. La validació numèrica duta a terme ha estat decisiva per a que aquest procediment siga precís, simple i fiable.

Utilitzant aquesta campanya experimental, s'ha desenvolupat una aplicació predictiva per a estimar els paràmetres que defineixen el comportament constitutiu a tracció de l'UHPFRC. Aquesta aplicació és simple i directa i evita la possible variabilitat produïda per males interpretacions en l'aplicació del procés.

A més a més, també s'ha dut a terme una segon campanya experimental constituïda per bigues d'UHPFRC armades a flexió amb diferents escales: 36 bigues curtes amb $130 \mathrm{i}$ $160 \mathrm{~kg} / \mathrm{m}^{3}$ de fibres i dos bigues llargues de gran escala. Aquesta campanya s'ha modelat amb el NLFEM ací desenvolupat incloent efectes importants deguts a la interacció de l'UHPFRC amb les barres d'armat. Addicionalment, també s'han modelat amb el NLFEM tirants d'UHPFRC armats a tracció provinents d'una campanya experimental d'altra investigació. El model considera efectes deguts a la retracció, al 3D i comportament tensió stiffening que generen resultats molt precisos quan es comparen amb els resultats experimentals.

Per tant, com a resultat de la present tesi doctoral, s'ha obtingut un model d'elements finits capaç de modelar amb precisió elements estructurals d'UHPFRC armats. Els resultats del model comparats amb els resultats experimentals no sols demostren la fiabilitat del NLFEM dut a terme sinó que també la coherència del procediment directe desenvolupat per a caracteritzar el comportament constitutiu a tracció de l'UHPFRC als dos casos, tant per a SH-UHPFRC com SS-UHPFRC, tant en elements estructurals 
armats a flexió com amb elements estructurals armats a tracció directa. Conseqüentment, $s$ 'ha proposat una metodologia completa i efectiva per al modelat numèric de l'UHPFRC des del nivell material fins arribar als elements estructurals. 


\section{Resumen}

El hormigón de muy alto rendimiento reforzado con fibras (UHPFRC) puede ser considerado como una moderna y mejorada evolución del hormigón reforzado con fibras (FRC) capaz de desarrollar grandes propiedades mecánicas y una alta durabilidad. Estas características pueden llevar a considerar el UHPFRC como un material de construcción competitivo si su producción y sus propiedades son optimizadas y si se define una adecuada estrategia de modelización que permita un diseño estructural efectivo capaz de aprovechar las propiedades mejoradas de este material.

La mayoría de la investigación vinculada con el UHPFRC durante los últimos veinte años está relacionada con el comportamiento de endurecimiento por deformación (SHUHPFRC). Con este comportamiento se aseguran grandes propiedades mecánicas y de durabilidad, pero con altos costes iniciales derivados de los materiales base necesarios para su fabricación, del sistema de vertido, del curado y del tratamiento térmico tras su fabricación. El estudio del comportamiento del UHPFRC con reblandecimiento por deformación (SS-UHPFRC), que podría resultar en un ahorro de estos costos iniciales, ha estado considerado en menor medida.

El principal objetivo de la presente tesis es el desarrollo de una completa metodología para el modelado numérico del UHPFRC desde el material hasta el elemento estructural. Se pretende contribuir al avance del conocimiento del comportamiento mecánico del UHPFRC obteniendo como resultado un procedimiento para la modelización numérica que permita el modelado y diseño estructural que permitiría hacer que este material fuera competitivo para ser utilizado en el mercado de la construcción. En la metodología de modelado propuesta, se considera un comportamiento constitutivo del UHPFRC optimizado por medio de un procedimiento directo y fiable con el que se aprovechan las 
ventajas del material, resultando en un diseño estructural eficiente desde el punto de vista mecánico y económico.

¿Es necesario producir SH-UHPFRC para conseguir grandes propiedades mecánicas? ¿Es posible generar SS-UHPFRC de manera que queden reducidos los costos iniciales y se mantengan unas propiedades mecánicas y de durabilidad competitivas que comporten un diseño estructural efectivo? El desarrollo de UHPFRC con bajo endurecimiento por deformación y de SS-UHPFRC puede reducir sus propiedades mecánicas, pero si son adecuadamente estudiadas y controladas, éstos podrían ser optimizados.

La tesis aborda algunas de estas cuestiones a través del estudio del comportamiento a tracción que va desde SH-UHPFRC hasta SS-UHPFRC. Se pretende llevar a cabo una propuesta de procedimiento fiable para caracterizar el comportamiento constitutivo a tracción y definir un modelo numérico de elementos finitos fiable para modelar con precisión la respuesta de probetas y elementos estructurales armados de UHPFRC.

Para definir el procedimiento directo para caracterizar a tracción tanto SH-UHPFRC como SS-UHPFRC, se ha llevado a cabo una campaña experimental y numérica en la que se ha analizado el resultado de ensayar 227 probetas sin armadura fabricadas con UHPFRC con cantidades de fibras cortas y lisas de acero de $120-130 \mathrm{~kg} / \mathrm{m}^{3}$ y $160 \mathrm{~kg} / \mathrm{m}^{3}$, ensayadas a flexión a través del ensayo a cuatro puntos (4PBT). El desarrollo y la validación de dicho proceso se respaldan mediante un modelo no lineal de elementos finitos (NLFEM) fiable. La validación numérica llevada a cabo ha sido decisiva para que este procedimiento sea preciso, simple y fiable.

Utilizando esta campaña experimental, se ha desarrollado una aplicación predictiva para estimar los parámetros que definen el comportamiento constitutivo a tracción del UHPFRC. Esta aplicación es simple y directa y evita la posible variabilidad producida por malas interpretaciones en la aplicación del proceso.

Además, se ha llevado a cabo una segunda campaña experimental constituida por vigas de UHPFRC armadas a flexión con diferentes escalas: 36 vigas cortas con 130 y $160 \mathrm{~kg} / \mathrm{m}^{3}$ de fibras y dos vigas largas. Esta campaña experimental se ha modelado con el NLFEM aquí desarrollado teniendo en cuenta efectos importantes debidos a la interacción del UHPFRC con las barras de armado. También se han modelado con el NLFEM tirantes de UHPFRC armados de una campaña experimental de otra investigación. El modelo considera efectos debidos a la retracción, al 3D y comportamiento tensión stiffening que generan resultados muy precisos cuando se comparan con los resultados experimentales.

Por tanto, como resultado de la presente tesis doctoral, se ha obtenido un modelo de elementos finitos capaz de modelar con precisión elementos estructurales de UHPFRC armados. Los resultados no sólo demuestran la fiabilidad del NLFEM llevado a cabo sino también la coherencia del procedimiento desarrollado para caracterizar el comportamiento constitutivo a tracción del UHPFRC para los dos casos, tanto SHUHPFRC como SS-UHPFRC, tanto en elementos estructurales armados a flexión como 
en elementos estructurales armados a tracción directa. Consecuentemente se ha propuesto una metodología completa y efectiva para el modelado numérico del UHPFRC que va desde el material hasta el elemento estructural. 


\section{Contents}

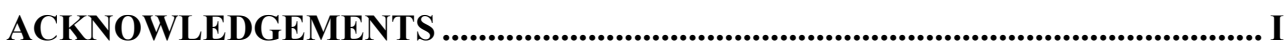

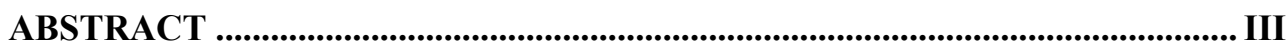

RESUM

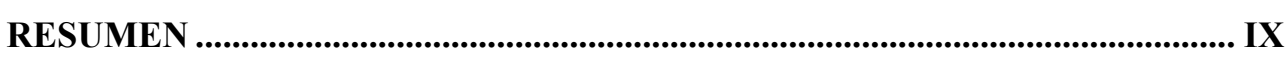

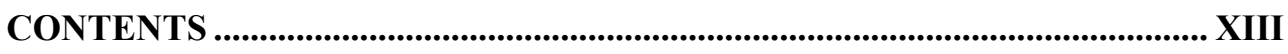

LIST OF FIGURES...................................................................................

LIST OF TABLES...............................................................................................XXXI

LIST OF ABBREVIATIONS AND NOTATION............................................XXXIII

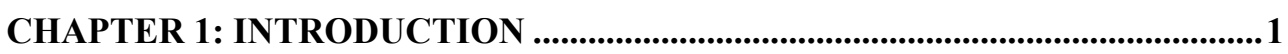

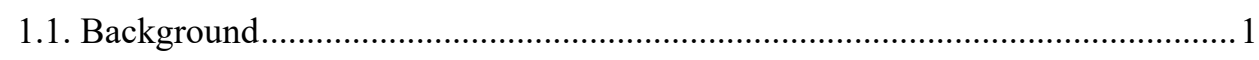

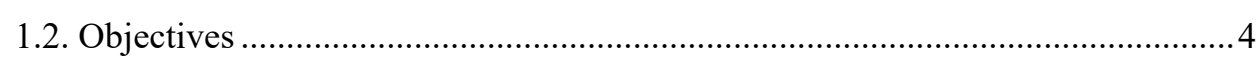

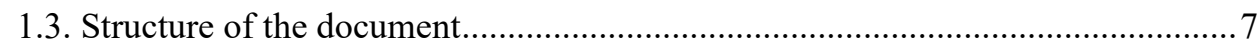

CHAPTER 2: STATE OF THE ART ............................................................9

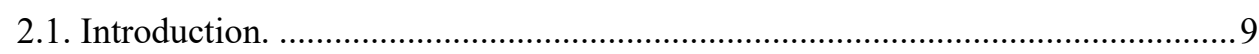

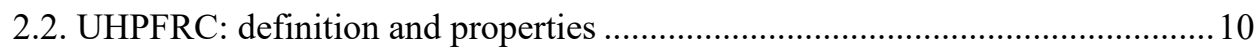

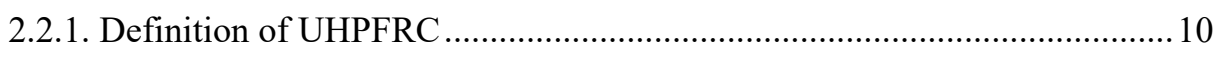

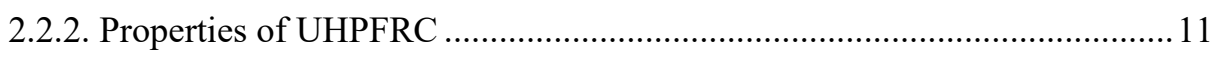




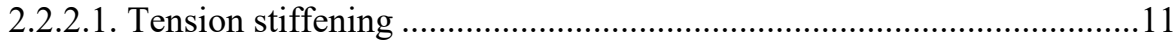

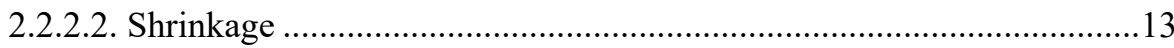

2.3. Mechanical characterisation of UHPFRC tensile behaviour ...............................16

2.3.1. UHPFRC uniaxial tensile response .........................................................17

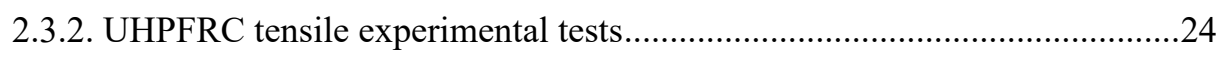

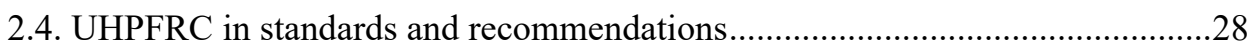

2.4.1. UHPFRC constitutive behaviour and experimental tests.............................28

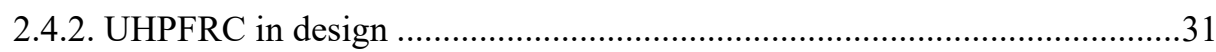

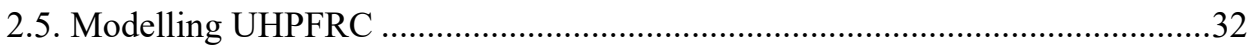

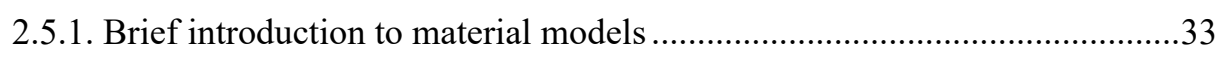

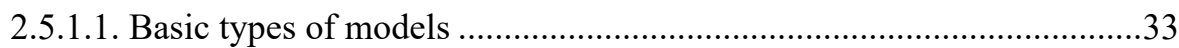

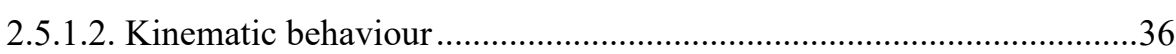

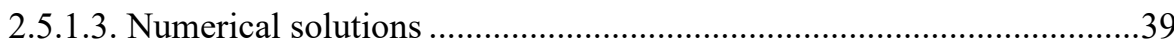

2.5.2 Models and computational methods in structural analysis ............................40

2.5.2.1. Finite difference method. ........................................................................ 40

2.5.2.2. Boundary element method. .................................................................41

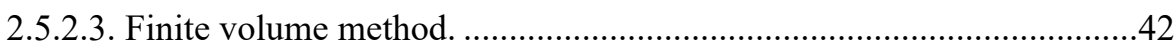

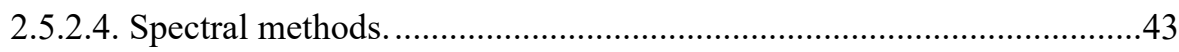

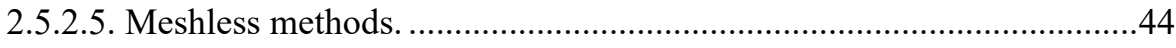

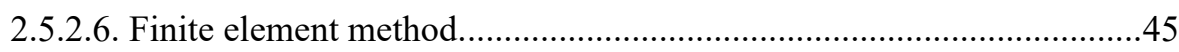

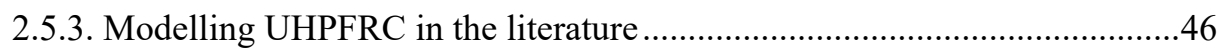

2.5.3.1 Material characteristics and FEM calibration ........................................49

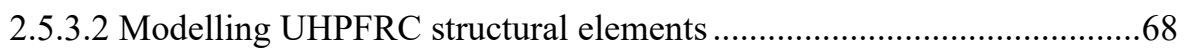

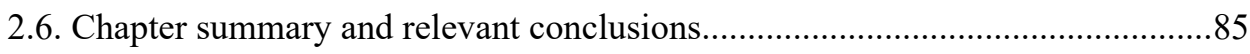

CHAPTER 3: PROPOSED CONSTITUTIVE MATERIAL MODELS ...................91

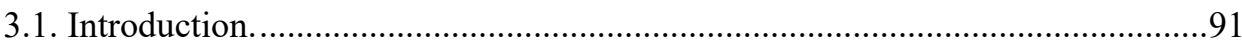

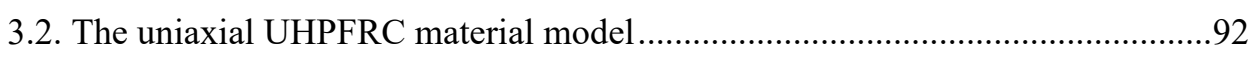

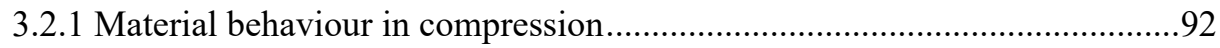

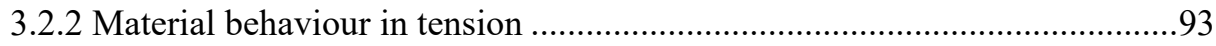

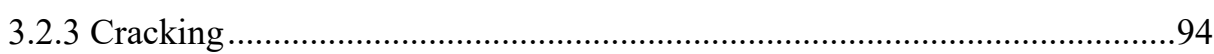




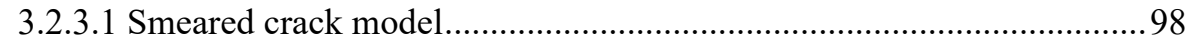

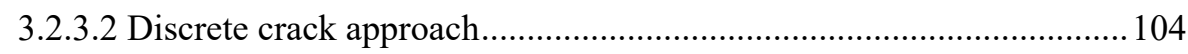

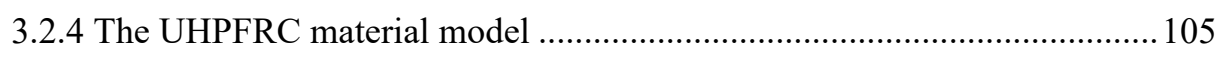

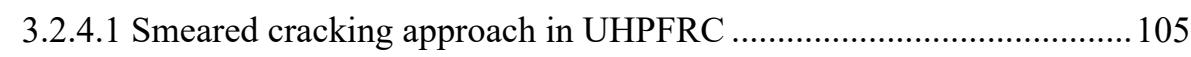

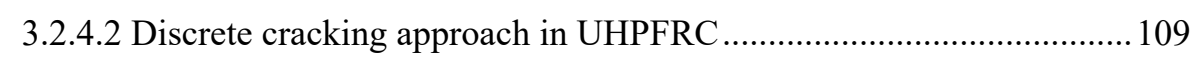

3.2.5 Determining constitutive UHPFRC parameters ........................................... 110

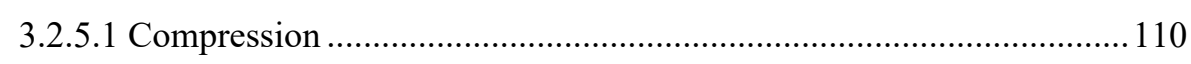

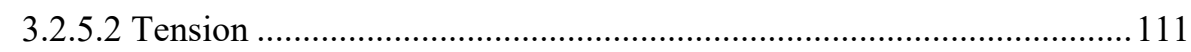

3.3. Multiaxial constitutive UHPFRC behaviour .................................................112

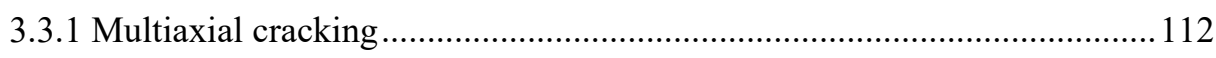

3.3.2 Multiaxial smeared crack model...........................................................115

3.4. Reinforcement steel uniaxial constitutive behaviour......................................... 121

3.5. Bond between concrete and reinforcement steel bars........................................122

3.6. Chapter summary and relevant conclusions .................................................124

CHAPTER 4: NUMERICAL MODEL: DEFINITION AND IMPLEMENTATION

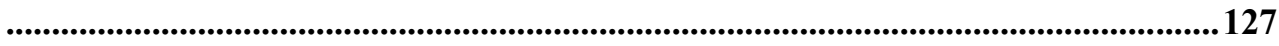

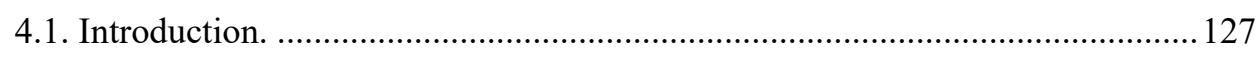

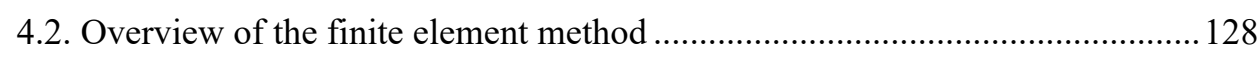

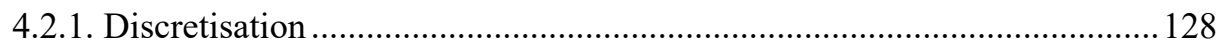

4.2.2. Solution strategies for nonlinear analysis ................................................ 132

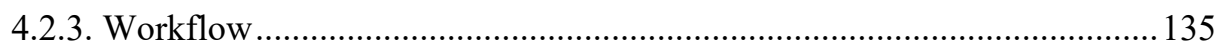

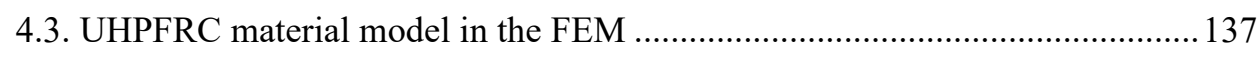

4.3.1. Adaptation of the smeared cracking approach to the FEM ........................137

4.3.2. Inobjectivity of the strain-softening continuum material models.............. 142

4.3.3. Adaptation of the discrete cracking approach to the FEM .......................... 146

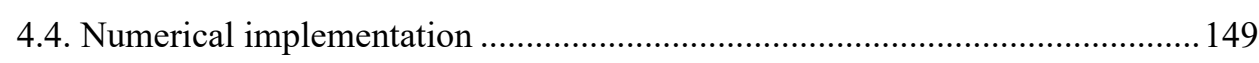

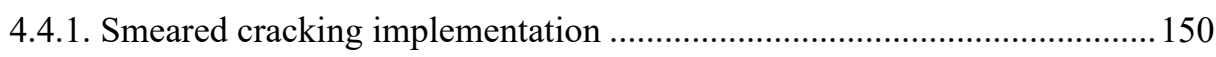

4.4.1.1. Loading and Unloading Determination ............................................... 152

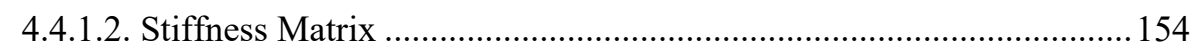

4.4.1.3. Lateral Expansion Effects due to Poisson's Ratio ................................ 160

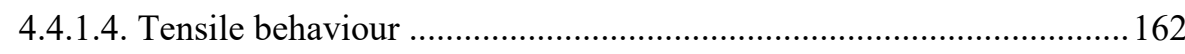




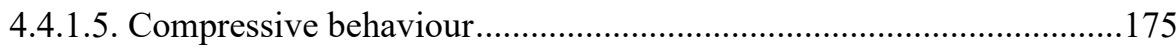

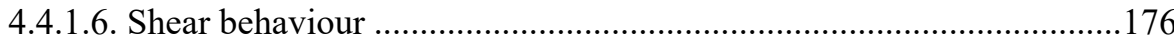

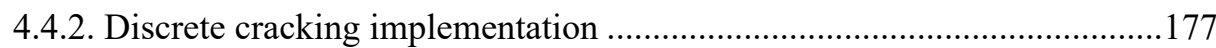

4.4.3. Constitutive behaviour for interface elements implementation. ................177

4.4.3.1. Discrete cracking constitutive behaviour of UHPFRC ..........................179

4.4.3.2. Bond-slip constitutive behaviour between reinforcement and UHPFRC 180

4.4.4. Implementation of the constitutive behaviour in tension for reinforcement steel. 181

4.5. Chapter summary and relevant conclusions...................................................185

CHAPTER 5: DIRECT PROCEDURE TO CHARACTERISE THE UHPFRC TENSILE CONSTITUTIVE BEHAVIOUR ..............................................................189

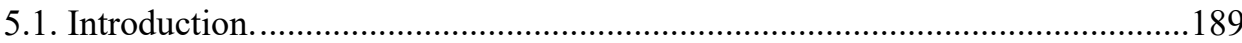

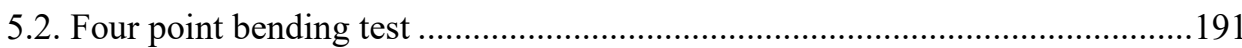

5.3. Strain-hardening UHPFRC and material validation .........................................193

5.3.1. Numerical non-linear finite element modelling (NLFEM) .........................194

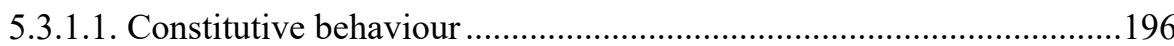

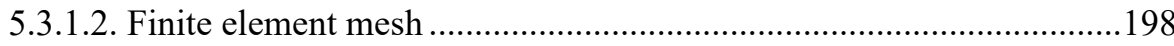

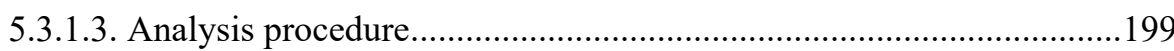

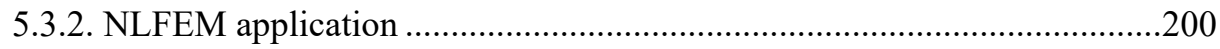

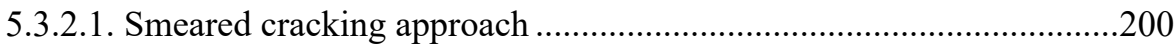

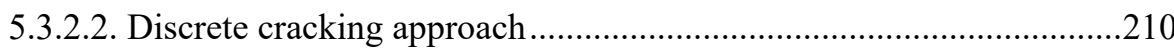

5.4. Strain-softening UHPFRC: characterisation of the tensile constitutive behaviour 225

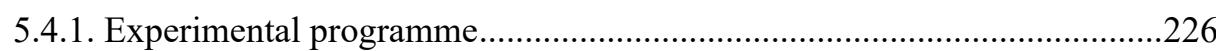

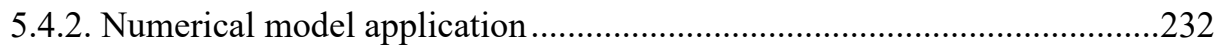

5.5. Direct procedure: UHPFRC tensile constitutive behaviour...............................241

5.5.1. Characteristic UHPFRC tensile constitutive behaviour..............................242

5.5.2. Predicting application to obtain UHPFRC tensile constitutive behaviour.246

5.6. Chapter summary and relevant conclusions.....................................................249

CHAPTER 6: UHPFRC: REINFORCED ELEMENTS............................................253

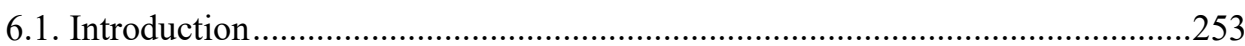

XVI 


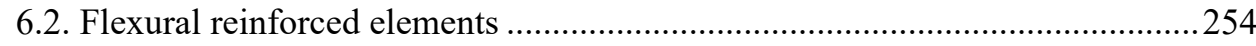

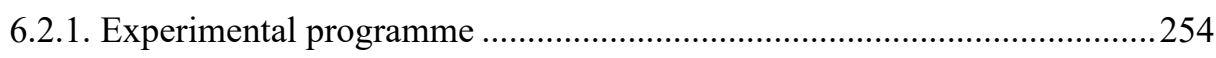

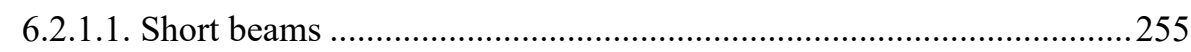

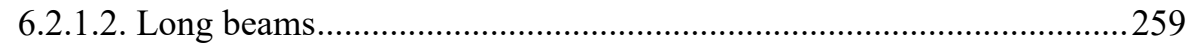

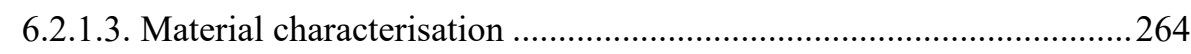

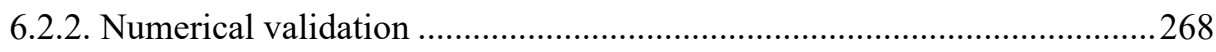

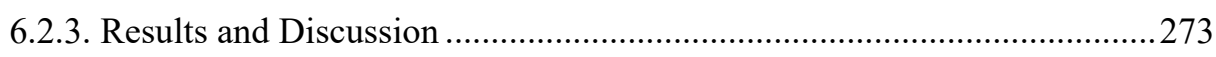

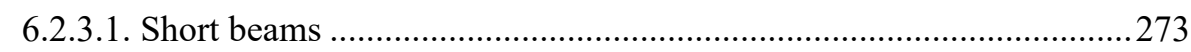

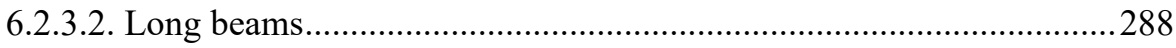

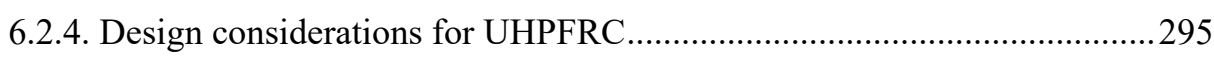

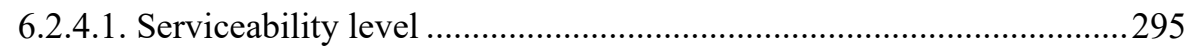

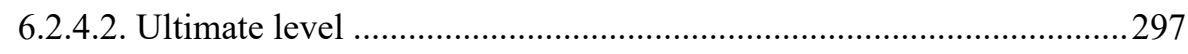

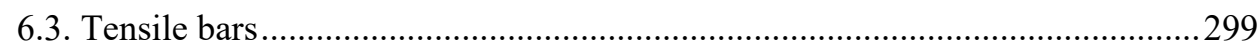

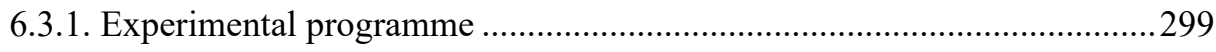

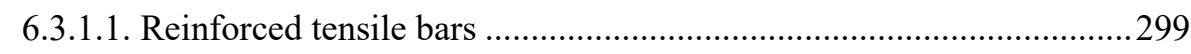

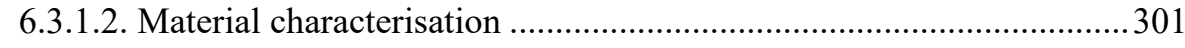

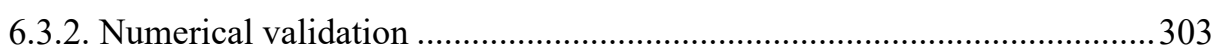

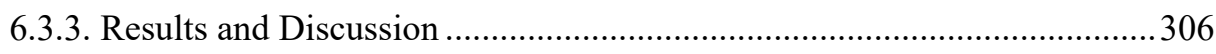

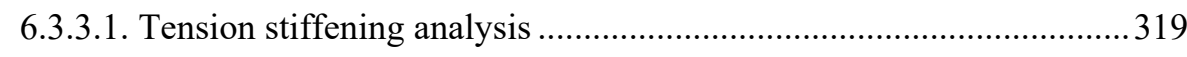

6.3.3.2. 3D-NLFEM-multicrack detailed application.........................................323

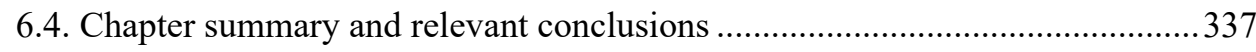

CHAPTER 7: CONCLUSIONS AND FUTURE RESEARCH LINES...................341

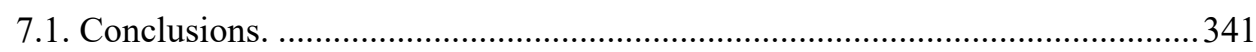

7.1.1. On UHPFRC characterisation and modelling up to the present-day..........343

7.1.2. On the definition and implementation of the UHPFRC model. ...................344

7.1.3. On a direct procedure to characterise tensile UHPFRC behaviour. ............345

7.1.4. On the modelling of reinforced UHPFRC flexural and tensile elements. . 347

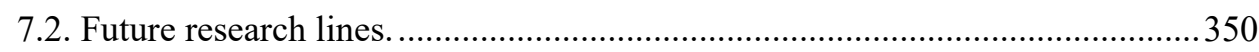

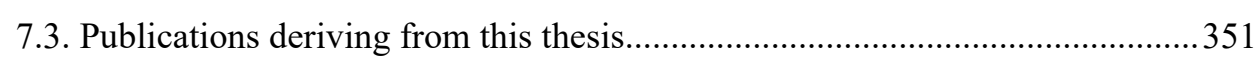

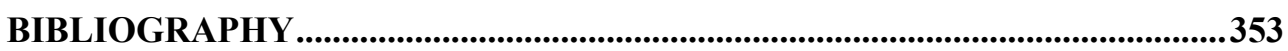




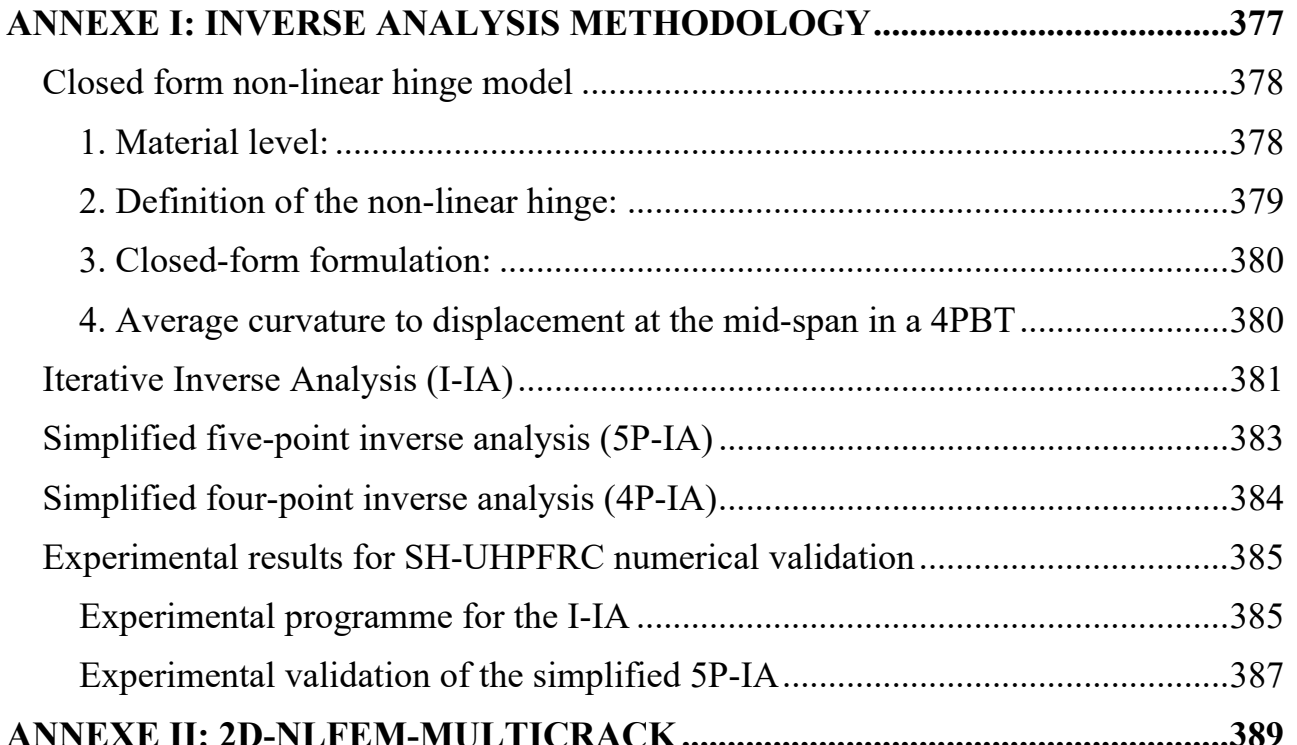




\section{List of figures}

CHAPTER 1: INTRODUCTION

Figure 1.1 Tensile UHPFRC behaviour when considering SH and SS

Figure 1.2 Publications per year containing the words: "UHPFRC", "strain-hardening"

UHPFRC and "strain softening" UHPFRC. Data obtained from Google Scholar on

23 December, 2020

\section{CHAPTER 2: STATE OF THE ART}

Figure 2.1 Qualitative stress-strain curve for UHPFRC tension member (Leutbecher 2008)

Figure 2.2 Shrinkage versus time for specimens with and without initial heat treatment

in (Gowripalan and Gilbert 2000)

Figure 2.3 General classification of FRC according to its tensile and flexural behaviour based in (Naaman and Reinhardt 2006)

Figure 2.4 cementitious composites' classification by (Wille et al. 2014).................... 19

Figure 2.5 (a) Typical stress-strain response of SH FRC composites, (b) typical stresscrack opening response of SS FRC composites and (c) generalised typical stresselongation response of FRC for modelling suggested in (Naaman and Reinhardt 2006)

Figure 2.6 Tensile behaviour of FRC and HPFRCC (Naaman 2003) ...........................22

Figure 2.7 Typical $\sigma-\varepsilon / \mathrm{w}$ for SH-UHPFRC in (Wille et al. 2014) .............................23

Figure 2.8 Uniaxial $\sigma-\varepsilon / \mathrm{w}$ response for plain concrete in MC2010 ((fib) 2013)......24 
Figure 2.9 Direct tensile tests (a) dog bones, (b) unnotched prisms and (c) notched prisms in (Wille et al. 2014)

Figure 2.10 (a) beam in bending with crack localisation in the microcracked region in (Spasojevic et al. 2008) and (b) Multi-microcracking in a UHPFRC specimen notched 3PBT according to EN-14651 in (López 2017) …………………….........26

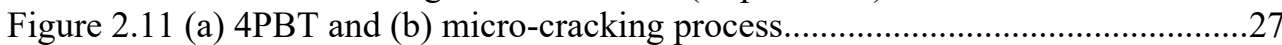

Figure 2.12 Idealised stress-strain relationship in tension proposed by (Gowripalan and Gilbert 2000).

Figure 2.13 (a) uniaxial tensile test, (b) tensile behaviour and (c) proposed perfect elastoplastic model for design in (Japan Society of Civil Engineers 2008)...........29

Figure 2.14 Idealised tensile response of UHPC in (Russell et al. 2013) ......................29

Figure 2.15 Tensile constitutive law (a) strain-hardening (T3), (b) low strain-hardening (T2) and (c) strain-softening (T1) in (AFGC 2013) .............................................30

Figure 2.16 Constitutive tensile behaviour (a) stress-strain part and (b) stress-crack opening part in (Swiss Society of Engineers and Architects SIA 2016) ................31

Figure 2.17 Basic types of model: (a) continuum models, (b) discrete models, (c) continuum models with discontinuities (Jirásek 2017).........................................33

Figure 2.18 Kinematic description with one strong discontinuity ................................36

Figure 2.19 Constitutive behaviour for cohesive crack model ......................................37

Figure 2.20 Kinematic description with two weak discontinuities ................................37

Figure 2.21 Constitutive behaviour for smeared crack model .......................................38

Figure 2.22 Kinematic description with no discontinuities ............................................38

Figure 2.23 Constitutive behaviour for regularised continuum model with softening ..39

Figure 2.24 3-point bending test set up (Kang et al. 2010).............................................50

Figure 2.25 (a) inverse analysis procedure and (b) simplified tri-linear softening curve, where $V_{f}$ is the fibre volume ratio; $l_{f}$ the fibre length and $a_{f t}, b_{f t}, a_{f 1}, b_{f 1}, b_{w 1}, a_{w 2}$, $b_{\mathrm{w} 2}, a_{\mathrm{wc}}$ and $b_{\mathrm{wc}}$ are experimental coefficients (Kang et al. 2010).......................51

Figure 2.26 (a) 3PBT scheme, (b) dog bones for direct tensile test and (c) cylinders for compression test (Hassan et al. 2012; Mahmud et al. 2013)..................................52

Figure 2.27 (a) Prototype of the proposed testing method and (b) FEM of the prototype (Pyo and El-Tawil 2015).

Figure 2.28 UHPFRC specimens used in the testing method (a) after testing for impact and (b) after a lower strain-rate testing (Pyo and El-Tawil 2015) .........................54

Figure 2.29 Uniaxial tensile test setup in (Wille et al. 2012)........................................55

Figure 2.30 (a) dog-bone geometry, (b) direct tensile test and (c) stress-strain response from tensile test (Lampropoulos et al. 2016) ............................................................56

Figure 2.31 (a) tensile and (b) compressive constitutive material behaviour assumed for UHPFRC in the FEM (Lampropoulos et al. 2016)..............................................56

Figure 2.32 Strain/crack distribution in the FEM of UHPFRC (a) direct tensile test and (b) 4PBT layers (Lampropoulos et al. 2016).

Figure 2.33 Strain/crack distribution in the FEM strengthened RC beams with (a) UHPFRC layer in the tensile side, (b) UHPFRC layer in the compressive side and (c) UHPFRC three side jacked (Lampropoulos et al. 2016). 
Figure 2.34 (a) Finite Element Mesh used to model the 3PBT and (b) experimental test at failure (Yoo et al. 2017b)

Figure 2.35 UHPFRC matrix softening curve defined by (Kang and Kim 2011) .........59

Figure 2.36 (a) Test setup and geometry for direct tensile test and (b) Test setup for compression test in (Krahl et al. 2018)

Figure 2.37 Third Point Bending Test setup and geometry in (Krahl et al. 2018) ........61

Figure 2.38 (a) FEM to simulate cyclic tension and compression (b) FE discretisation for 4PBT in (Krahl et al. 2018)

Figure 2.39 (a) cross section (in $\mathrm{mm}$ ) and reinforcement of the beam tested at (b) 4PBT

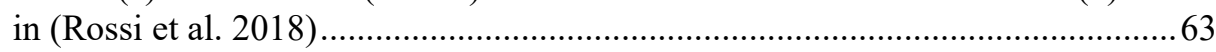

Figure 2.40 FE mesh of the 3PBT notched small beams in (Rossi et al. 2018) .............64

Figure 2.41 (a) FEM of the 4PBT reinforced beam and (b) load-deflection response compared to the experimental results in (Rossi et al. 2018) ....................................64

Figure 2.42 Experimental setup and geometry of the flexural beams used in (Yin et al. 2019a) . .66

Figure 2.43 UHPFRC characterisation tests: (a) unnotched 3PBT and (b) compression

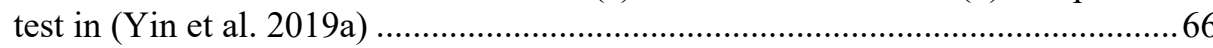

Figure 2.44 (a) Cracking pattern of a 3PBT and Damage model for FEM; (b) Singleelement model for compression and tension in (Yin et al. 2019a)....

Figure 2.45 Geometry of the full-scale beams cast in (Singh et al. 2017): (a) B25-1 and B25-2, (b) B15-1 and (c) B15-2.

Figure 2.46 Experimental setup of the full-scale beams carried out in in (Singh et al. 2017): (a) B25-1 and B25-2, (b) B15-1, (c) B15-2 and (d) location of the strain gauges on concrete surface.

Figure 2.47 (a) Crack damage in the FEM and (b) experimental cracking pattern (Singh et al. 2017)

Figure 2.48 (a) Experimental setup and (b) FEM of the cantilever beams in (Sadouki et al. 2017)

Figure 2.49 Plain concrete constitutive behaviour for the FEM in (Sadouki et al. 2017)

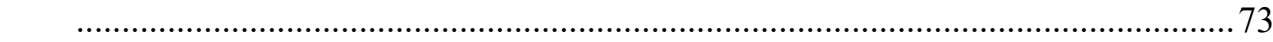

Figure 2.50 UHPFRC constitutive behaviour for the FEM in (Sadouki et al. 2017) ....73

Figure 2.51 Proposed bond interface model by means of equivalent beam elements at the interface in (Yin et al. 2019b)

Figure 2.52 Experimental 3PBT setup used in (Yin et al. 2019b) ..............................75

Figure 2.53 Some of the cross section beams used to validate FEM in (Yin et al.

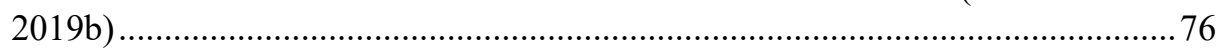

Figure 2.54 Interfacial traction-separation behaviour used in (Sakr et al. 2019) ..........77

Figure 2.55 (a) Experimental shear wall from (Altin et al. 2013), (b) cross section of the shear wall simulated in (Sakr et al. 2019)and (c) test setup from (Altin et al. 2013)

Figure 2.56 FEM results. Plastic strain and yielding zones for SW-2 configuration RC shear wall strengthened with UHPFRC and R-UHPFRC in (Sakr et al. 2019).....78 
Figure 2.57 (a) Slabs' dimensions and reinforcement, (b) section A-A (dimensions in $\mathrm{cm}$ ) in (Zhang et al. 2019)

Figure 2.58 Test setup for (a) PBM loading case and (b) NBM loading case in (Zhang et al. 2019)

Figure 2.59 FEM mesh of (a) 3PBT for the non-damaged RC slab (b), preloading of the RC slap under flexure-torsion loading; (c) second stage NBM 3PBT for one strengthened slab and (d) second stage PBM 3PBT for the other strengthened slab in (Zhu et al. 2020).

Figure 2.60 FEM simulations of (a) 3PBT for the non-damaged RC slab (b), preloading of the RC slap under flexure-torsion loading; (c) second stage NBM 3PBT for one strengthened slab and (d) second stage PBM 3PBT for the other strengthened slab in (Zhu et al. 2020)....

Figure 2.61 FEM of characterisation UHPFRC tests (a) compression and (b) tension in (Naeimi and Moustafa 2020)

Figure 2.62 (a) geometry and (b) FEM of the bridge bent (Naeimi and Moustafa 2020)

\section{CHAPTER 3: PROPOSED CONSTITUTIVE MATERIAL MODELS}

Figure 3.1 Adopted uniaxial compressive stress-strain material UHPFRC behaviour..93 Figure 3.2 Uniaxial tensile material behaviour adopted by (a) SH-UHPFRC and (b) SSUHPFRC

Figure 3.3 (a) Cracking at the mesoscale level and (b) uniaxial stress-strain behaviour at the macroscale level (Häussler-Combe 2015)...................................................96

Figure 3.4 Strain localisation on a tension bar (Häussler-Combe 2015) .......................96

Figure 3.5 The smeared crack model concept.....................................................99

Figure 3.6 The smeared crack model softening stress-total strain material relation....101

Figure 3.7 Smeared crack model transformation when $\mathrm{Le}=\mathrm{bw}($ Leexact)

Figure 3.8 Inaccuracy depending on Le when Le $>>>$ bw .........................................103

Figure 3.9 Mesh size dependency of the softening part of the material law in the smeared crack model

Figure 3.10 The UHPFRC smeared tensile stress-total strain relation assumed by the smeared cracking approach..............................................................................106

Figure 3.11 The UHPFRC smeared crack model ....................................................109

Figure 3.12 The developed discrete cracking approach...........................................110

Figure 3.13 (a) Cubic specimen and (b) compression test..........................................111

Figure 3.14 4PBT (also known as a ThirdPBT) used to characterise tensile UHPFRC behaviour in this work: (a) geometry and (b) experimental setup .......................112

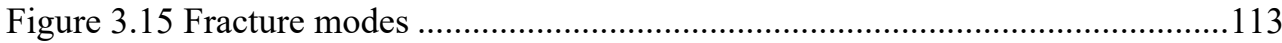

Figure 3.16 Cohesive crack model and assumed $\sigma-\varepsilon / w$ constitutive UHPFRC behaviour

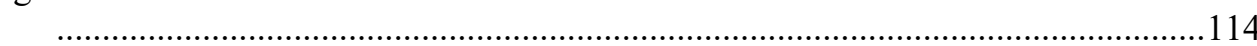

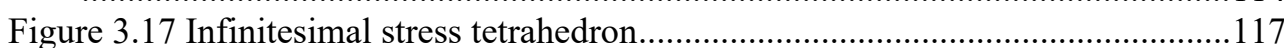


Figure 3.18 (a) Element coordinate system and stress space. (b) Crack coordinate system and stress space.....

Figure 3.19 Crack plane stresses in the local crack coordinate system and the element coordinate system

Figure 3.20 Uniaxial stress-strain tensile constitutive behaviour for reinforcement steel

Figure 3.21 (a) Bond-slip mechanism and (b) constitutive material bond-slip behaviour

\section{CHAPTER 4: NUMERICAL MODEL: DEFINITION AND IMPLEMENTATION}

Figure 4.1 Finite element discretisation of the continuum 129

Figure 4.2 Incremental-iterative procedure in a nonlinear FE analysis

Figure 4.3 Non-linear analysis under (a) load control and (b) direct displacement control

Figure 4.4 Experimental test under (a) load control and (b) displacement control ..... 135

Figure 4.5 Finite element method workflow ............................................................ 136

Figure 4.6 Tensile bar: (a) material model, (b) FEM .................................................. 139

Figure 4.7 Mesh size dependency of the softening part of the material law in the smeared crack model obtained in phase 3 in the FEM

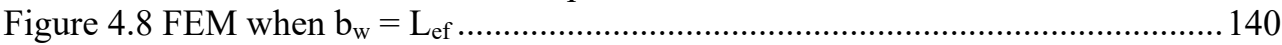

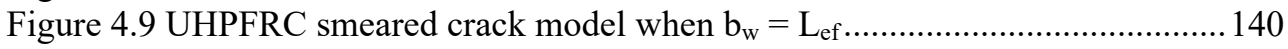

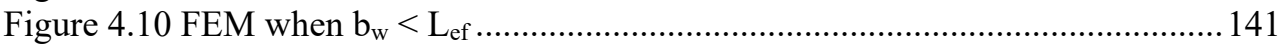

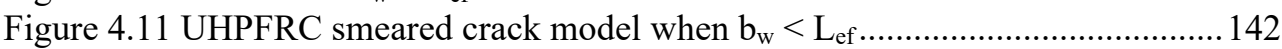

Figure 4.12 Constitutive continuum $\sigma-\varepsilon_{\mathrm{t}}$ model for UHPFRC in phase 2 depending on the $\mathrm{L}_{\mathrm{ef}}$ chosen.

Figure 4.13 Tensile bar (a) P-u response and (b) $\varepsilon$-x response along the bar for the continuum model in phase 2 depending on the $\mathrm{L}_{\mathrm{ef}}$ chosen.

Figure 4.14 Discrete cracking approach in tensile bar (a) loading stage 1 and (b) loading stage 2 .

Figure $4.15 \sigma-\varepsilon_{\mathrm{mt}}$ curve for the smeared cracking approach in the continuum and $\sigma-\mathrm{w}$ curve for the crack interface in loading stage 1 ....

Figure $4.16 \sigma-\varepsilon_{\mathrm{mt}}$ curve for the smeared cracking approach in the continuum and $\sigma-\mathrm{w}$ curve for the crack interface in loading stage 2 .

Figure 4.17 Loading-unloading-reloading conditions, damage variables and unloading constrains. 153

Figure 4.18 Predefined fédération internationale du béton/International Federation for Structural Concrete (fib) working groups tension softening curve for Total Strain Crack model (DIANA (Software) 2017).

Figure 4.19 (a) Finite element mesh (dimensions in $\mathrm{mm}$ ) and (b) Load-CMOD model responses of the CLWL-DCB specimen in (Rots 1988). 


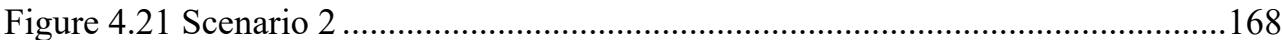

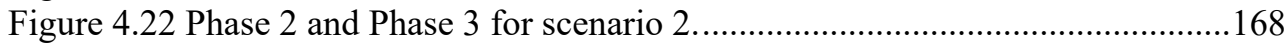

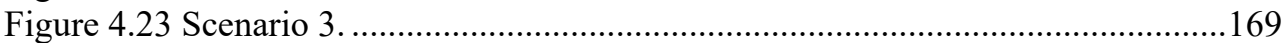

Figure 4.24 Phase 2 and Phase 3 for scenario 3...................................................170

Figure 4.25 Stress-strain relationship adopted for Diana implementation....................171

Figure 4.26 UHPFRC constitutive model implementation for I-IA and 5P-IA............174

Figure 4.27 UHPFRC constitutive model implementation for 4P-IA. ........................174

Figure 4.28 CEB-FIP Model Code 1990 compressive curve (DIANA (Software) 2017)

Figure 4.29 Constant shear retention for Total Strain Crack models (DIANA

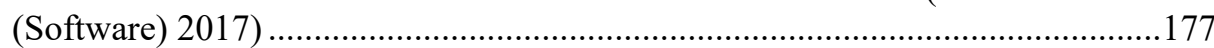

Figure 4.30 Two-dimensional interface element ........................................................177

Figure 4.31 Discrete cracking interface constitutive behaviour ................................179

Figure 4.32 Multilinear stress-crack opening law for discrete crack interface .............180

Figure 4.33 Cubic function for bond-slip (Dorr 1980) .............................................181

Figure 4.34 Stress-total strain constitutive behaviour in tension of steel for the

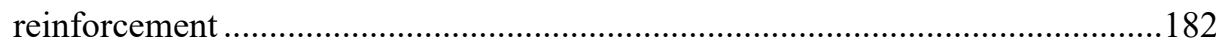

Figure 4.35 Tresca and Von Mises yield condition (in $\pi$ and rendulic plane)............184

\section{CHAPTER 5: DIRECT PROCEDURE TO CHARACTERISE THE UHPFRC TENSILE CONSTITUTIVE BEHAVIOUR}

Figure 5.1 (a) Four-Point Bending Test and (b) micro-cracking process and macrocrack

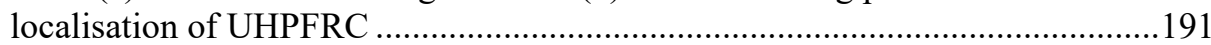

Figure 5.2 Specimen size and degrees of freedom for the 4PBT.................................192

Figure 5.3 4PBT set up (left) and resulting P- $\delta$ curves (right) ..................................193

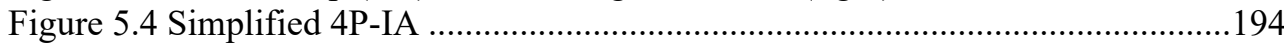

Figure 5.5 CQ16M (left) and CL12I (right) (DIANA (Software) 2017) ......................198

Figure 5.6 Interface-relative displacements for the Discrete Cracking Approach.......199

Figure 5.7 Element sizes $\left(\mathrm{L}_{\mathrm{ef}}\right)$ used in the NLFEM for the smeared cracking approach

Figure 5.8 NLFEM smeared cracking approach $\sigma-\delta$ curves vs experimental $\sigma-\delta$ curve for $\mathrm{h}=100 \mathrm{~mm}$ specimen 6 .

Figure 5.9 NLFEM smeared cracking approach $\sigma-\delta$ curves for $\mathrm{L}_{\mathrm{ef}}=10 \mathrm{~mm}$ and different analysis vs experimental $\sigma-\delta$ curve for $\mathrm{h}=100 \mathrm{~mm}$ specimen $6 \ldots \ldots \ldots \ldots . .204$

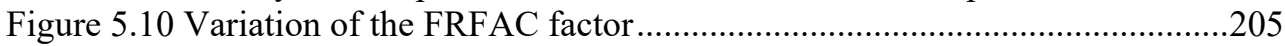

Figure 5.11 Positions of the crack in the random 2D-NLFEM for $\mathrm{L}_{\mathrm{ef}}=10 \mathrm{~mm} \ldots \ldots \ldots . .206$

Figure 5.12 2D-NLFEM $\sigma-\delta$ curves with $\mathrm{L}_{\mathrm{ef}}=10 \mathrm{~mm}$ vs experimental $\sigma-\delta$ curve for $\mathrm{h}$ $=100 \mathrm{~mm}$ specimen 6 .

Figure 5.13 2D-NLFEM $\sigma-\delta$ curves with $\mathrm{L}_{\mathrm{ef}}=5,10$ and $20 \mathrm{~mm}$ vs experimental $\sigma-\delta$

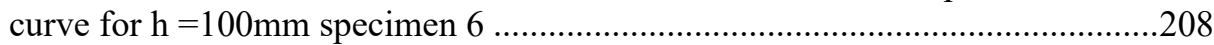


Figure $5.1410 \mathrm{~mm}$ crack bandwidth for the random analysis (R3) smeared cracking approach of $\mathrm{h}=100 \mathrm{~mm}$ specimen 6 ....

Figure 5.15 4PBT discrete cracking approach 2D-NLFEM representation. ................211

Figure 5.16 Discrete and smeared cracking approaches 2D-NLFEM $\sigma-\delta$ curves vs experimental $\sigma-\delta$ curve for $h=100 \mathrm{~mm}$ specimen 6 .

Figure 5.17 Equivalent bending stress-displacement at mid-span curves using different mesh sizes in the discrete cracking approach

Figure $5.18 \sigma-\delta$ at the mid-span curves for the $\mathrm{h}=50 \mathrm{~mm}$ specimens from Table A-I. 1 in Annexe I

Figure $5.19 \sigma-\delta$ at the mid-span curves for the $\mathrm{h}=100 \mathrm{~mm}$ specimens from Table A-I.1 in Annexe I.

Figure $5.20 \sigma-\delta$ at the mid-span curves for the $\mathrm{h}=150 \mathrm{~mm}$ specimens from Table A-I.1 in Annexe I

Figure $5.21 \sigma-\delta$ at the mid-span curves for the $\mathrm{h}=50 \mathrm{~mm}$ specimen 5 from Table A-I.1.

Figure 5.22 a) analysis continuation approach equivalent bending stress-displacement at mid-span curve for $\mathrm{h}=50 \mathrm{~mm}$ specimen $5 ; \mathrm{b}$ ) detail of a)

Figure 5.23 Equivalent $\sigma-\delta$ at mid-span curves for $\mathrm{L} / \mathrm{h}=4.5$ (specimen 1) with hinge length of $1.5 \mathrm{~h}, \mathrm{~h}$ and $\mathrm{h} / 2(\mathrm{~h} 2)$.

Figure 5.24 Equivalent $\sigma-\delta$ at mid-span curves for $\mathrm{L} / \mathrm{h}=3$ (specimens 3 ) with hinge length of $\mathrm{h}$ and $\mathrm{h} / 2(\mathrm{~h} 2)$

Figure $5.25 \sigma-\phi \cdot h$ curves for the $\mathrm{h}=50 \mathrm{~mm}$ specimen 2 , the $\mathrm{h}=100 \mathrm{~mm}$ specimen 5 and the $\mathrm{h}=150 \mathrm{~mm}$ specimen 3 .

Figure 5.26 Equivalent bending stress $(\sigma)$ versus the average strain at different depth positions $\left(\varepsilon_{\mathrm{c}}\right.$, and $\left.\varepsilon_{\mathrm{t}}\right)$ for the $\mathrm{h}=50 \mathrm{~mm}$ specimen 2

Figure 5.27 Equivalent bending stress $(\sigma)$ versus the average strain at different depth positions $\left(\varepsilon_{\mathrm{c}}, \varepsilon_{\mathrm{m}}\right.$, and $\left.\varepsilon_{\mathrm{t}}\right)$ for the $\mathrm{h}=100 \mathrm{~mm}$ specimen 5 .

Figure 5.28 Equivalent bending stress $(\sigma)$ versus the average strain at different depth positions $\left(\varepsilon_{\mathrm{c}}, \varepsilon_{\mathrm{m}}\right.$, and $\left.\varepsilon_{\mathrm{t}}\right)$ for the $\mathrm{h}=150$ specimen 3

Figure 5.29 Normal stresses and crack strains: specimen $4, \mathrm{~L} / \mathrm{h}=4.5, \mathrm{l}_{\mathrm{c}}=1.5 \mathrm{~h}$.........224

Figure 5.30 Constitutive behaviour of UHPFRC with SH and SS ...........................226

Figure 5.31 Four-Point Bending Test (4PBT) .......................................................22

Figure $5.32 \sigma-\delta$ curves for the specimens with $160 \mathrm{~kg} / \mathrm{m}^{3}$ (left) and $120-130 \mathrm{k} / \mathrm{m}^{3}$ of fibres (right)

Figure 5.33 Constitutive behaviour for UHPFRC specimens with $160 \mathrm{~kg} / \mathrm{m} 3$ of fibres

Figure 5.34 Constitutive behaviour for UHPFRC specimens with $120-130 \mathrm{~kg} / \mathrm{m}^{3}$ of fibres

Figure 5.35 P- $\delta$ curves for the specimens with similar $f_{t}$ values

Figure $5.36 \mathrm{P}-\delta$ curves for the specimens with similar energy.

Figure 5.37 Specimen with SH (left); specimen with SS (right) 


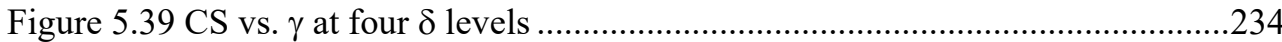

Figure 5.40 A1exp vs. A1model, A2exp vs. A2model ...............................................235

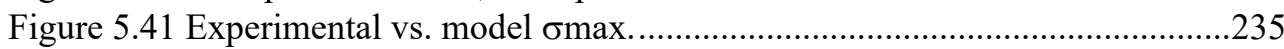

Figure $5.42 \sigma-\delta$ response of the $\mathrm{f}_{\mathrm{tu}}$ variation in a strain-softening behaviours specimen.

Figure $5.43 \sigma-\delta$ response of the $\varepsilon_{\text {tu }}$ variation in a strain-softening behaviour specimen.

Figure 5.44 Relation var (\%) - $\gamma: 160 \mathrm{~kg} / \mathrm{m}^{3}$ and $130 \mathrm{~kg} / \mathrm{m}^{3}$ of fibres (left) and bilinear

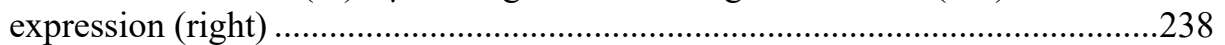

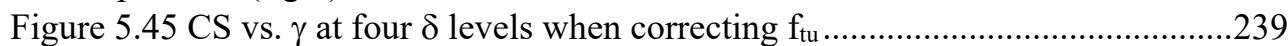

Figure 5.46 A1exp vs. A1model, A2exp vs. A2model when correcting $\mathrm{f}_{\mathrm{tu}} \ldots \ldots \ldots \ldots \ldots \ldots . . .240$

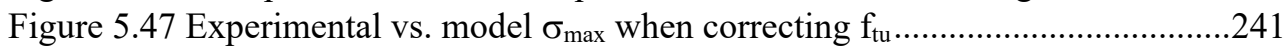

Figure 5.48 Characteristic $\sigma-\delta$ curve for the $160 \mathrm{~kg} / \mathrm{m}^{3}$ and $120-130 \mathrm{~kg} / \mathrm{m}^{3}$ steel fibre

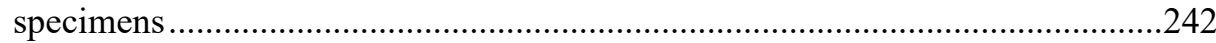

Figure 5.49 Intersection between elastic slope and the $\delta$ axis ..................................243

Figure 5.50 Elastic slope corrected (left) and the slopes of $\mathrm{S}_{0}, \mathrm{~S}_{75}$ and $\mathrm{S}_{40}$ (right).....244

Figure 5.51 Determination of the four key points...................................................244

Figure 5.52 Characteristic $\sigma-\delta$ curves: 2 D-NLFEM using corrected tensile parameters

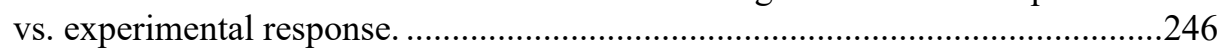

Figure 5.53 UHPFRC Tensile constitutive parameters: predicted values vs. real values. 248

\section{CHAPTER 6: UHPFRC: REINFORCED ELEMENTS}

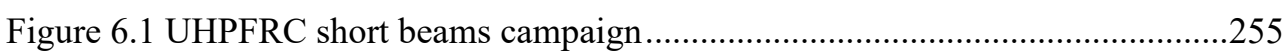

Figure 6.2 First reinforcement setting for short beams ..........................................256

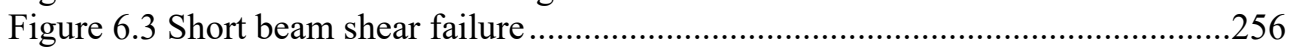

Figure 6.4 Reinforced UHPFRC short beam. Final geometry details (units in mm)...257

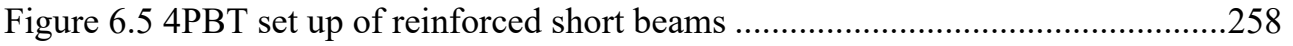

Figure 6.6 Experimental 4PBT $\sigma-\delta$ curves for specimens with 130 (left) and 160 (right)

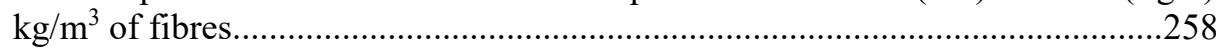

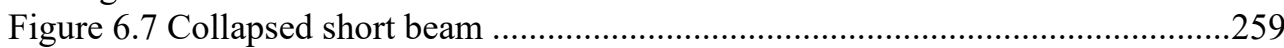

Figure 6.8 Long beams: (a) geometry (in $\mathrm{mm}$ ), (b) reinforcement details and (c) displacement transducer's position .....................................................................260

Figure 6.9 UHPFRC long beams: (a) general view of casting zone and (b) testing setup

Figure 6.10 Testing frame details: (a) intermediate beam and loading plates, (b) sliding support, (c) fixed support and (d) hinged platform ............................................261

Figure 6.11 Load-deflection curve at the mid-span section (left) and load-curvature

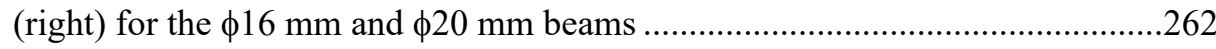

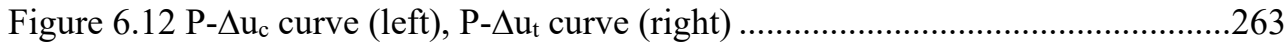

Figure $6.13 \sigma-\varepsilon_{\text {comp }}$ curve (left), $\sigma-\varepsilon_{\text {tens }}$ curve (right) ................................................263

XXVI 
Figure 6.14 Microcracking (left) and collapse (right) of a long beam .......................264

Figure 6.15 Compression test (left) and 4PBT (right) ................................................264

Figure 6.16 (a) 4PBT and (b) constitutive tensile law from the 4P-IA application.....265

Figure $6.17 \sigma-\delta$ curve from 4 PBT of the (a) $130 \mathrm{~kg} / \mathrm{m}^{3}$ and (b) $160 \mathrm{~kg} / \mathrm{m}^{3}$ specimens

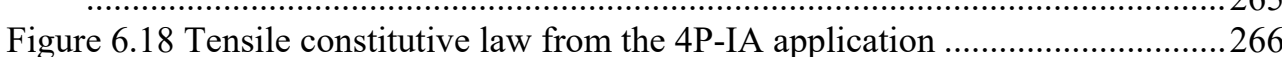

Figure 6.19 Stress-strain diagram to characterise reinforcement steel in tension .......268

Figure 6.20 Finite elements for 2D model: (a) CQ16M and (b) CL12I (DIANA

(Software) 2017)

Figure 6.21 Finite elements for 3D model: (a) CX60 and (b) CQ48I (DIANA

(Software) 2017)

Figure 6.22 2D mesh for reinforced short beams 4PBT ..........................................2. 271

Figure 6.23 2D mesh for reinforced long beams 4PBT ...........................................2. 272

Figure 6.24 3D mesh for reinforced short beams 4PBT .......................................272

Figure 6.25 Experimental vs. numerical $\sigma-\delta$ charact. response for $5 \%, 50 \%$ and $95 \%$

.274

Figure 6.26 Behaviour of discrete cracking approach at failure for short beams ........274

Figure 6.27 Shrinkage stress 3D NLFEM: (a) reinforcement and (b) UHPFRC ........276

Figure 6.28 Comparison between the NLFEM approaches for $160 \mathrm{~kg} / \mathrm{m}^{3}$ of steel fibres

Figure $6.29 \sigma-\delta$ curves for discrete NLFEM 2D for $130 \mathrm{~kg} / \mathrm{m}^{3}$ and 3D for $160 \mathrm{~kg} / \mathrm{m}^{3}$

Figure 6.30 2D-NLFEM_130kg_50\%, shrinkage stresses at 49 days......................2. 279

Figure 6.31 2D-NLFEM_130kg_50\%, stresses in the elastic branch $(\sigma=5 \mathrm{MPa}) \ldots . .279$

Figure 6.32 2D-NLFEM_130kg_50\%, stress and crack width for $\sigma=20 \mathrm{MPa} \ldots \ldots \ldots .280$

Figure 6.33 2D-NLFEM_130kg_50\%, stresses and crack widths at the collapse level

Figure 6.34 3D-NLFEM $160 \mathrm{~kg} 50 \%$, shrinkage stresses at 49 days........................2. 282

Figure 6.35 3D-NLFEM_160kg 50\%, stresses in the elastic branch $(\sigma=5 \mathrm{MPa}) \ldots . .283$

Figure 6.36 3D-NLFEM_160kg 50\%, stress and crack width for $\sigma=20 \mathrm{MPa} \ldots \ldots . .283$

Figure 6.37 3D-NLFEM_160kg_50\%, stresses and crack widths at the collapse level

Figure 6.38 2D-NLFEM $\sigma-\delta$ curves for different values of $\gamma$

Figure 6.39 Crack pattern for CP1 constitutive parameters with $\gamma_{\mathrm{c}}=1.25$...............287

Figure 6.40 Crack pattern for CP2 constitutive parameters with $\gamma_{\mathrm{c}}=1.09$.................287

Figure 6.41 Crack pattern for CP3 constitutive parameters with $\gamma_{\mathrm{c}}=0.91 \ldots \ldots \ldots \ldots \ldots . .287$

Figure 6.42 Crack pattern for CP4 constitutive parameters with $\gamma_{\mathrm{c}}=0.81$...............288

Figure $6.43 \sigma-\delta$ curves for JE-1 (left) and JE-2 (right) .............................................28

Figure 6.44 Shrinkage stresses for JE-1 at UHPFRC (top) and reinforcement (bottom)

at 49 days.

290

Figure 6.45 Shrinkage stresses for JE-2 at UHPFRC (top) and reinforcement (bottom)

at 49 days 
Figure 6.46 Shrinkage stresses at the mid-span section for JE-1 (left) and JE-2 (right) at 49 days. 292

Figure 6.47 Crack opening and reinforcement stresses at $30 \mathrm{MPa}$ and at collapse for the JE-1 beam. 293

Figure 6.48 Crack opening and reinforcement stresses at $20 \mathrm{MPa}$ and at collapse for the JE- 2 beam... .293

Figure 6.49 Moment-curvature diagram for JE1 and JE2. .294

Figure $6.50 \sigma-\varepsilon$ at mid span section at the top (left) and at the bottom (right) of JE-1295 Figure $6.51 \sigma-\varepsilon$ at mid span section at the top (left) and at the bottom (right) of JE-2295 Figure 6.52 Deflection comparison of long beams with tension-stiffening factors $\beta . .297$ Figure 6.53 Flexure strength estimation of the JE-2 beam: (a) constitutive law assumed, (b) strain diagram, and (c) stress and force diagram........................................29

Figure 6.54 Geometry of the tensile bar specimen (Navarro Laguarda 2018) ............299

Figure 6.55 Tensile bar test setup (Navarro Laguarda 2018) .......................................300

Figure 6.56 Displacement transducers distribution at each of the four faces of the bar (units in $\mathrm{mm}$ )

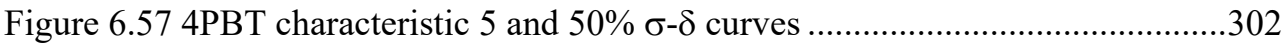

Figure 6.58 Mesh for the discrete 2D-NLFEM of tensile bars ......................................303

Figure 6.59 Mesh for the discrete 3D-NLFEM of UHPFRC tensile bars.....................304

Figure 6.60 Secondary macrocracks appearing in the smeared part of the discrete 2DNLFEM.

Figure 6.61 FEM mesh for the 3D model with interfaces ...........................................305

Figure 6.62 Random distribution of tensile properties (FRCFAC) …..........................305

Figure 6.63 Experimental and numerical P- $\Delta \mathrm{u}$ response for 60x60 tensile bars ..........307

Figure 6.64 Experimental and numerical P- $\Delta$ u response for $80 \times 80$ tensile bars ..........307

Figure 6.65 Experimental and numerical P- $\Delta \mathrm{u}$ response for 100x100 tensile bars ......308

Figure 6.66 FRCFAC random distribution for the 3D-NLFEM-multicrack 60x60, $\phi 12$, $80 \% \mathrm{sh}_{\text {inc }}$ bar

Figure 6.67 P- $\Delta \mathrm{u}$ response of $60 \times 60, \phi 12$ tensile bar and the NLFEM with $80 \%$ of $\mathrm{sh}_{\text {inc }}$

Figure $6.68 \mathrm{P}-\Delta \mathrm{u}$ response of $60 \times 60, \phi 12$ tensile bar and the NLFEM with $80 \%$ and $40 \%$ of $\mathrm{sh}_{\text {inc }}$

Figure 6.69 P- $\Delta \mathrm{u}$ comparison for 60x60 tensile bar ..................................................316

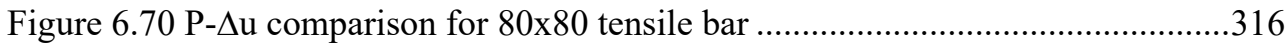

Figure $6.71 \mathrm{P}-\Delta \mathrm{u}$ comparison for $100 \mathrm{x} 100$ tensile bar ................................................317

Figure 6.72 Section of the tensile bar vs 3Deffect from 3D-NLFEM-multicrack ........319

Figure 6.73 Tension stiffening analysis for $60 x 60$ tensile bars ...................................321

Figure 6.74 Tension stiffening analysis for $80 \times 80$ tensile bars ....................................321

Figure 6.75 Tension stiffening analysis for $100 \times 100$ tensile bars ...............................322

Figure $6.76 \mathrm{P}-\Delta \mathrm{u}$ response for the $100 \times 100 ; \phi 16$ specimen compared to the $3 \mathrm{D}$ NLFEM-multicrack. 
Figure 6.77 UHPFRC stresses in solid elements in $\mathrm{x}$ direction, stresses in the reinforcement and in the interface elements at shrinkage phase 325

Figure 6.78 Shrinkage stresses in UHPFRC at $0.12 \mathrm{~m}$ (left) and $0.26 \mathrm{~m}$ (right) from the active extreme.

Figure 6.79 Shrinkage stresses at mid span section $(0.50 \mathrm{~m}$ from the extremes of the tensile bar).

Figure 6.80 Shrinkage stresses at $0.04 \mathrm{~m}$ from the active extreme of the tensile bar...327

Figure 6.81 UHPFRC stresses in solid elements in $\mathrm{x}$ direction, stresses in the reinforcement, stresses in the interface elements and stress flow in the principal directions at elastic uncracked phase (at $40 \mathrm{kN}$ ).

Figure 6.82 UHPFRC stresses in $\mathrm{x}$ direction at $0.04 \mathrm{~m}, 0.12 \mathrm{~m}, 0.26 \mathrm{~m}$ and $0.50 \mathrm{~m}$ from the active extreme during the elastic uncracked phase (at $40 \mathrm{kN}$ )

Figure 6.83 UHPFRC stresses in solid elements in $\mathrm{x}$ direction, stresses in the reinforcement, stresses in the interface elements and stress flow in the principal directions in the microcrack stabilisation phase (at $90 \mathrm{kN})$.

Figure 6.84 UHPFRC stresses in $\mathrm{x}$ direction at $0.04 \mathrm{~m}, 0.12 \mathrm{~m}, 0.26 \mathrm{~m}$ and $0.50 \mathrm{~m}$ from the active extreme during the microcrack stabilisation phase (at $90 \mathrm{kN})$

Figure 6.85 Cracking pattern in $\mathrm{x}$ direction at the microcrack stabilisation phase (at $90 \mathrm{kN}$ ): crack representation between $0-0.10 \mathrm{~mm}$ (1); between $0-0.45 \mathrm{~mm}(2)$; between $0-0.50 \mathrm{~mm}$ crack section detailed; between $0-0.50 \mathrm{~mm}$ crack section detailed rotated (4).

Figure 6.86 Tensile analysis of a partial macrocracked section (left) and $\sigma-\varepsilon$ diagram of node 6347 located in the macrocrack zone (right).

Figure 6.87 FRCFAC random distribution in all the tensile bar (left) and in $0.46 \mathrm{~m}$ section (right)....

Figure 6.88 UHPFRC stresses in solid elements, stresses in the reinforcement and stresses in the interface elements in $\mathrm{x}$ direction and stress flow in the principal directions in the collapse moment.

Figure 6.89 Cracking pattern in $\mathrm{x}$ direction in the collapse: crack representation between $0-0.10 \mathrm{~mm}$ (1); between $0-0.45 \mathrm{~mm}$ (2); between $0-0.50 \mathrm{~mm}$ crack section detailed; between $0-0.50 \mathrm{~mm}$ crack section detailed rotated (4).

\section{ANNEXE I: INVERSE ANALYSIS METHODOLOGY}

Figure A-I.1 Four-point bending test (also known as third-point bending test) used to characterise the UHPFRC tensile behaviour in this work: (a) geometry and (b) experimental setup.

Figure A-I.2 Uniaxial tensile material behaviour adopted for SH-UHPFRC ...............379

Figure A-I.3 Stress-strain relationship (above) for different stages (below) in (López 2017).

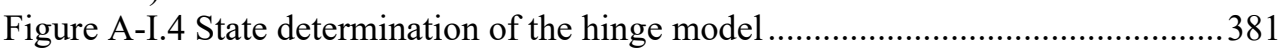

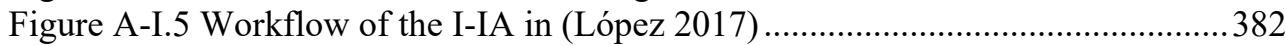

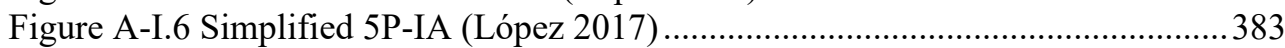




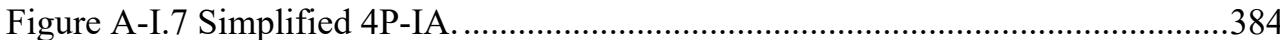

Figure A-I.8 Experimental programme in appendix I in (López 2017) .........................386

\section{ANNEXE II: 2D-NLFEM-MULTICRACK}

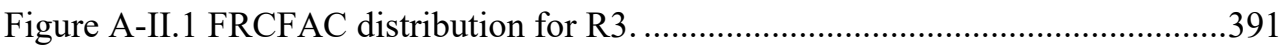

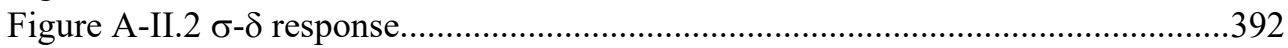

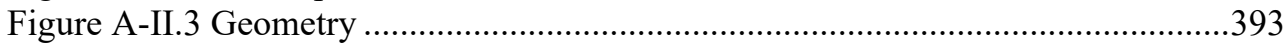

Figure A-II.4 Zoom of the composed finite elements...............................................393

Figure A-II.5 Finite element mesh...........................................................................394

Figure A-II.6 Stresses in $\mathrm{x}$ direction at level 1 for R3 ................................................394

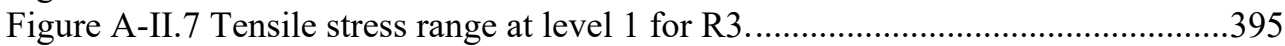

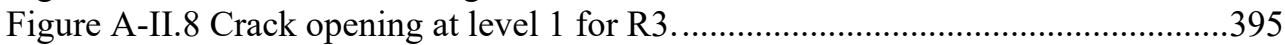

Figure A-II.9 Stresses in $\mathrm{x}$ direction at level 2 for R3 ..............................................396

Figure A-II.10 Tensile stress range at level 2 for R3 .................................................396

Figure A-II.11 Crack opening at level 2 for R3 ........................................................397 


\section{List of tables}

CHAPTER 5: DIRECT PROCEDURE TO CHARACTERISE THE UHPFRC TENSILE CONSTITUTIVE BEHAVIOUR

Table 5.1 FRCFAC random field generation in the smeared 2D-NLFEM .................205 Table 5.2 Analyses' properties for $\mathrm{h}=50 \mathrm{~mm}$ specimen $5 \ldots \ldots \ldots \ldots \ldots \ldots \ldots \ldots \ldots \ldots \ldots \ldots \ldots \ldots . .218$

Table 5.3 Tensile constitutive parameters for the specimens with similar $f_{t}$ values....230 Table 5.4 Tensile constitutive parameters for the specimens with similar energy ......231 Table 5.5 Constitutive tensile parameters from applying 4P-IA and $\mathrm{f}_{\mathrm{tu}}$ variation.......237

Table 5.6 Constitutive tensile parameters from applying 4P-IA and $\varepsilon_{\text {tu }}$ variation ......238

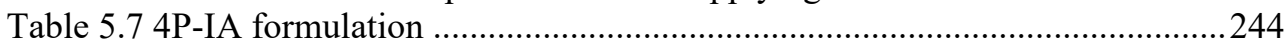

Table 5.8 Characteristic constitutive tensile parameters for $120-130$ and $160 \mathrm{~kg} / \mathrm{m}^{3}$ of fibre UHPFRC

Table 5.9 Corrected characteristic constitutive parameters for $120-130$ and $160 \mathrm{~kg} / \mathrm{m}^{3}$ of fibre UHPFRC

Table 5.10 The predicted characteristic constitutive tensile parameters for 120-130 and $160 \mathrm{~kg} / \mathrm{m}^{3}$ of fibre UHPFRC .

\section{CHAPTER 6: UHPFRC: REINFORCED ELEMENTS}

Table 6.1 Characteristic constitutive tensile parameters and softening-correction .....267

Table 6.2 Shrinkage values for UHPFRC of short beams ............................................2.275

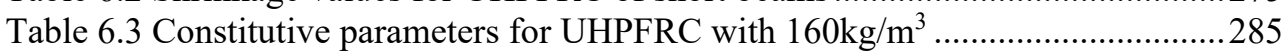

Table 6.4 Mechanical UHPFRC properties for long beams .......................................2. 288

Table 6.5 Shrinkage values at 49 days for long beams...............................................28 
Table 6.6 Cross-section flexural stiffness under serviceability conditions...................296

Table 6.7 Comparison between the predicted and experimental values at failure.......298

Table 6.8 Tensile test specimens from experimental programme from (Khorami et al. $2019,2020)$

Table 6.9 Mechanical characterisation for UHPFRC tensile bars ..................................302

Table 6.10 Shrinkage values for UHPFRC with the $50 \%$ characteristic behaviour of

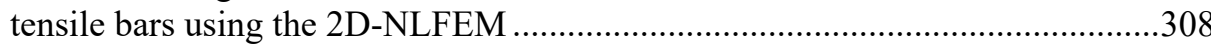

Table 6.11 Random field in 3D-NLFEM-multicrack $60 \times 60, \phi 12,80 \% \mathrm{sh}_{\text {inc }}$ bar.........311

Table $6.12 \mathrm{sh}_{\text {inc }}, \mathrm{sh}_{\text {inc3D }}$ and 3D effect for tensile bars ..............................................317

Table $6.13 \varepsilon_{\mathrm{cs} U H P F R C}, \varepsilon_{\mathrm{cs} U H P F R C 3 D}$ and $\varepsilon_{3 \text { Deffects }}$ for tensile bars....................................318

\section{ANNEXE I: INVERSE ANALYSIS METHODOLOGY}

Table A-I.1 I-IA Constitutive tensile parameters from (López 2017) 386

Table A-I.2 5P-IA Constitutive tensile parameters ( $\sigma-\varepsilon$ branch) from (López 2017) 387

Table A-I.3 5P-IA Constitutive tensile parameters ( $\sigma-\mathrm{w}$ branch) for $\mathrm{L} / \mathrm{h}=3$ from (López 2017)

Table A-I.4 5P-IA Constitutive tensile parameters ( $\sigma-\mathrm{w}$ branch) for $\mathrm{L} / \mathrm{h}=4.5$ from (López 2017)

ANNEXE II: 2D-NLFEM-MULTICRACK

Table A-II.1 Mechanical UHPFRC properties for HB3C-2 specimen 390

Table A-II.2 Random field in 2D-NLFEM-multicrack for HB3C-2 specimen 


\section{List of abbreviations and notation}

Institutions:

AASHTO American Association of State Highway and Transportation Officials

ACHE Asociación Científico-Técnica del Hormigón Estructural / Spanish Scientific and Technical Association for Structural Concrete

ACI American Concrete Institute

AFGC

Association Française de Génie Civil

DAfStB Deutscher Ausschuss für Stahlbeton / German Association for Reinforced Concrete

DIN Deutsches Institut für Normung / German institute for standardisation

FHWA Federal Highway Administration (USA)

fib

The International Federation for Structural Concrete

ISO

International Organization for Standardization

JSCE

Japan Society of Civil Engineers

RILEM Réunion Internationale des Laboratoires et Experts des Matériaux, systèmes de construction et ouvrages (The International Union of Laboratories and Experts in Constructioni Materials, Systems and Structures)

SETRA Service d"etudes Technique des Routes et Autoroutes 
SIA Swiss Society of Engineers and Architects

UNE Asociación Española de Normalización

Concrete types and materials:

$\mathrm{CC} \quad$ Conventional Concrete

FRC Fibre-Reinforced Concrete

HPC High-Performance Concrete

HPFRCC High-Performance Fibre-Reinforced Cement Composite

NRC Normal Strength Concrete

RC Reinforced Concrete

RPC Reactive Powder Concrete

NR-UHPFRC UHPFRC without reinforcement bars

R-UHPFRC UHPFRC with reinforcement bars

SFRC Steel-Fibre Reinforced Concrete

SH-UHPFRC Strain-Hardening Ultra-High Performance Fibre-Reinforced Concrete

SS-UHPFRC Strain-Softening Ultra-High Performance Fibre-Reinforced Concrete

UHPC Ultra-High Performance Concrete

UHPFRC Ultra-High Performance Fibre-Reinforced Concrete

Mechanics:

BEM Boundary Element Method

corlen Correlation length

CS Coefficient of accuracy

FDM Finite Difference Method

FVM Finite Volume Method

4P-IA Simplified Four-Point Inverse Analysis

5P-IA Simplified Five-Point Inverse Analysis

3PBT Three-Point Bending Test

4PBT Four-Point Bending Test

XXXIV 
CDP Concrete Damage Plasticity

CZM Cohesive Zone Model

FE Finite Element

FEA Finite Element Analysis

FEM Finite Element Model

FRCFAC Factor that multiplies the values of the UHPFRC tension stress in the constitutive behaviour of the NLFEM

IA Inverse Analysis

I-IA Iterative Inverse Analysis

NBM Negative Bending Moment

NLFEM Non-linear Finite Element Model

ODE Ordinary differential equations

PBM Positive Bending Moment

PBP-IA Point-by-Point Inverse Analysis

PDE Partial Differential Equation

R1, R2,.. Run 1, Run 2, ..

RUN 1, RUN 2;... Run 1, Run 2, ..

SLS Serviceability Limit State

stddev Standard deviation

ThirdPBT Unnotched Third-Point Bending Test

ULS Ultimate Limit State

Technics and devices

CMOD Crack Mouth Opening Displacement

COD Crack Opening Displacement

DT Displacement Transducer

LVDT Linear Variable Differential Transformer 


\author{
Capital Greek letters \\ $\Delta \quad$ Variation \\ $\Delta L \quad$ Length increase \\ $\Delta u \quad$ Displacement jump \\ $\Delta u_{t}{ }^{0} \quad$ Limit slip value for the Dörr function for bond-slip behaviour \\ considered in the model in DIANA software \\ $\Delta u_{c} \quad$ Displacement from the compression horizontal displacement transducer \\ $\Delta u_{t} \quad$ Displacement from the tension horizontal displacement transducer
}

Small Greek Letters

$\alpha_{k} \quad$ Internal damage variable in DIANA software

$\alpha_{p} \quad$ Peak strain in the compressive stress-strain function considered in DIANA software

$\beta \quad$ Shear retention factor and also tension-stiffening factor

$\beta_{\varepsilon c r} \quad$ Factor for reducing the peak strain in the compressive stress-strain function considered in DIANA software

$\beta_{\sigma c r} \quad$ Factor for reducing the peak stress in the compressive stress-strain function considered in DIANA software

$\gamma \quad$ Hardening ratio: $f_{t u} / f_{t}$ and also shear strain

$\gamma_{c} \quad$ Corrected hardening ratio: $f_{\text {tud }} f_{t}$

$\delta \quad$ Displacement (deflection) at mid-span section

$\delta_{c} \quad$ Displacement transducer measurements at the most compressed fibre of the section measured by the LVDT in that position and also intersection of the linear elastic slope of the $\sigma-\delta$ curve with the $\delta$ axis

$\delta_{\text {corr }} \quad$ Correction of the mid-span deflection $\delta$ in the 4P-IA

$\delta_{m} \quad$ Displacement transducer measurements at the middle fibre of the section measured by the LVDT in that position

$\delta_{t} \quad$ Displacement transducer measurements at the most tensioned fibre of the section measured by the LVDT in that position

$\delta_{\text {omaxexp }} \quad$ Experimental deflection upon maximum experimental stress

XXXVI 
$\varepsilon$

$\varepsilon_{D I A N A}$

$\varepsilon_{1}$

$\varepsilon_{2}$

$\varepsilon_{3}$

$\varepsilon_{c}$

$\varepsilon_{c, D I A N A}$

$\varepsilon_{c c}$

$\varepsilon_{\text {comp }}$

$\varepsilon_{c t}$

$\varepsilon_{c r}$

$\varepsilon_{c r, m}$

$\varepsilon_{c s}$

$\varepsilon_{C S U H P F R C}$

$\varepsilon_{C S U H P F R C 3 D}$

E3Deffects

$\varepsilon_{f t}$

$\varepsilon_{m}$

$\varepsilon_{m, e f}$

$\varepsilon_{m, e f, D I A N A}$

$\varepsilon_{m t}$
Strain

Strain for DIANA software

Strain in the principal direction 1

Strain in the principal direction 2

Stress in the principal direction 3

Strain at the most compressed fibre of the section, strain associated to the concrete compressive strength $f_{c}$ and also mean cracked strain value of strain function $\varepsilon_{c}(x)$

Mean cracked strain using $b_{w, D I A N A}$

Tensile strain

Strain at the mid-span section at the compression displacement transducer's height for long beams

Strain associated to the tensile strength $f_{t}$

Strain associated with zero stresses

Mean total strain associated with zero stresses for the overall element by applying the smeared crack model

Total shrinkage strain of concrete obtained on the testing day using Eurocode 2

Total shrinkage strain of UHPFRC in the 2D model (2D shrinkage)

Total shrinkage strain of UHPFRC in the 3D model (3D shrinkage)

Strain due to the $3 \mathrm{D}$ effects

Strain associated to the tensile strength $f_{t}$.

Strain at the middle fibre of the section and also mean total strain for the overall element by applying the smeared crack model

Mean total strain for the overall finite element by applying the smeared crack model

Mean total strain for the overall finite element obtained from the smeared crack model using $b_{w, D I A N A}$

Mean tensile total strain for the overall element by applying the smeared crack model 


\begin{tabular}{|c|c|}
\hline$\varepsilon_{m t, e f}$ & $\begin{array}{l}\text { Mean tensile total strain for the overall finite element by applying the } \\
\text { smeared crack model }\end{array}$ \\
\hline$\varepsilon_{m t c}$ & $\begin{array}{l}\text { Total strain at zero stress for the overall element by applying the } \\
\text { smeared crack model }\end{array}$ \\
\hline$\varepsilon_{m t c, e f}$ & $\begin{array}{l}\text { Total strain at zero stress for the overall finite element by applying the } \\
\text { smeared crack model }\end{array}$ \\
\hline$\varepsilon_{m t d}$ & $\begin{array}{l}\text { Total strain associated to the strength at the change of slope in the } \\
\text { softening branch } f_{t d} \text { for the overall element by applying the smeared } \\
\text { crack model }\end{array}$ \\
\hline$\varepsilon_{m t d, e f}$ & $\begin{array}{l}\text { Total strain associated to the strength at the change of slope in the } \\
\text { softening branch } f_{t d} \text { for the overall finite element by applying the } \\
\text { smeared crack model }\end{array}$ \\
\hline$\varepsilon_{p}$ & $\begin{array}{l}\text { Strain in the compressive stress-strain function considered in DIANA } \\
\text { software }\end{array}$ \\
\hline$\varepsilon_{s t}$ & Reinforcement steel tensile strain \\
\hline$\varepsilon_{\text {stel }}$ & Strain associated to the reinforcement steel tensile strength $f_{s t}$ \\
\hline$\varepsilon_{\text {stu }}$ & Strain associated to the reinforcement steel ultimate tensile strength $f_{\text {stu }}$ \\
\hline$\varepsilon_{t}$ & Strain at the most tensioned fibre of the section and also tensile strain \\
\hline$\varepsilon_{t e l}$ & Strain associated to the tensile strength $f_{t}$ \\
\hline$\varepsilon_{\text {tens }}$ & $\begin{array}{l}\text { Strain at the mid-span section at the tension displacement transducer's } \\
\text { height for long beams }\end{array}$ \\
\hline$\varepsilon_{t c}$ & Total strain at zero stress \\
\hline$\varepsilon_{t c, D I A N A}$ & Total strain at zero stress for DIANA software \\
\hline$\varepsilon_{t 0}$ & Total strain at zero stress considered in the 4P-IA \\
\hline $\mathcal{E}_{t 0, D I A N A}$ & Total strain at zero stress considered in the 4P-IA for DIANA software \\
\hline$\varepsilon_{t d}$ & $\begin{array}{l}\text { Total strain associated to the strength at the change of slope in the } \\
\text { softening branch } f_{t d}\end{array}$ \\
\hline$\varepsilon_{t d, D I A N A}$ & $\begin{array}{l}\text { Total strain associated to the strength at the change of slope in the } \\
\text { softening branch } f_{t d} \text { for DIANA software }\end{array}$ \\
\hline$\varepsilon_{t d, \text { elastic }}$ & $\begin{array}{l}\text { The elastic part of the total strain associated to the strength at the change } \\
\text { of slope in the softening branch } f_{t d}\end{array}$ \\
\hline
\end{tabular}




\begin{tabular}{|c|c|}
\hline$\varepsilon_{t d, \text { inelastic }}$ & $\begin{array}{l}\text { The inelastic part of the total strain associated to the strength at the } \\
\text { change of slope in the softening branch } f_{t d}\end{array}$ \\
\hline$\varepsilon_{t u}$ & Total strain associated to the ultimate tensile strength $f_{t u}$ \\
\hline$\varepsilon_{t u, D I A N A}$ & $\begin{array}{l}\text { Total strain associated to the ultimate tensile strength } f_{t u} \text { for DIANA } \\
\text { software }\end{array}$ \\
\hline$\varepsilon_{u n c}$ & Uncracked strain \\
\hline$\varepsilon_{\text {uncl }}$ & $\begin{array}{l}\text { Uncracked strain that generates a tensile state in the elastic branch of } \\
\text { the } \sigma-\varepsilon \text { UHPFRC constitutive behaviour }\end{array}$ \\
\hline$\varepsilon_{\text {unc } 2}$ & $\begin{array}{l}\text { Uncracked strain that generates a tensile state in the softening branch of } \\
\text { the } \sigma-\varepsilon \text { UHPFRC constitutive behaviour }\end{array}$ \\
\hline$\varepsilon_{x}$ & Strain in $\mathrm{x}$ direction \\
\hline$\phi$ & Curvature and also diameter \\
\hline$\phi_{n}$ & Normalised average curvature \\
\hline$v$ & Poisson's ratio \\
\hline$\sigma$ & Stress \\
\hline$\sigma_{l}$ & $\begin{array}{l}\text { Stress that generates a tensile state in the elastic branch of the } \sigma-\varepsilon \\
\text { UHPFRC constitutive behaviour and also stress in the principal } \\
\text { direction } 1\end{array}$ \\
\hline$\sigma_{2}$ & $\begin{array}{l}\text { Stress that generates a tensile state in the softening branch of the } \sigma-\varepsilon \\
\text { UHPFRC constitutive behaviour and also stress in the principal } \\
\text { direction } 2\end{array}$ \\
\hline$\sigma_{3}$ & Stress in the principal direction 3 \\
\hline$\sigma_{c c}$ & Concrete tensile stress \\
\hline$\sigma_{f 1}$ & Equivalent bending stress \\
\hline$\sigma_{p c}$ & Concrete post cracking strength \\
\hline$\sigma_{t}$ & Tensile stress \\
\hline$\sigma_{\exp }$ & Experimental stress \\
\hline$\sigma_{\text {model }}$ & Stress obtained from the model \\
\hline$\sigma_{\max }$ & Maximum value of $\sigma$ \\
\hline$\sigma_{x}$ & Stress in $\mathrm{x}$ direction \\
\hline
\end{tabular}




$\begin{array}{ll}\tau & \text { Bond stress } \\ \xi & b_{w} / L_{e} \text { ratio }\end{array}$

Capital Roman Letters:

$A_{c} \quad$ Area of concrete

$A_{e f} \quad$ Finite element area

$A_{s} \quad$ Area of reinforcement steel

A1 The energy of the $\sigma-\delta$ curve delimited by $\delta_{\text {omaxexp }}$

$A 1_{\text {exp }} \quad$ The energy of the experimental $\sigma-\delta$ curve delimited by $\delta_{\text {omaxexp }}$

$A 1_{\text {model }} \quad$ The energy of the model $\sigma-\delta$ curve delimited by $\delta_{\text {omaxexp }}$

A2 The energy of the $\sigma-\delta$ curve delimited by $1.25 \delta_{\text {omaxexp }}$

$A 2_{\text {exp }} \quad$ The energy of the experimental $\sigma-\delta$ curve delimited by $1.25 \delta_{\text {omaxexp }}$

$A 2_{\text {model }} \quad$ The energy of the model $\sigma-\delta$ curve delimited by $1.25 \delta_{\text {omaxexp }}$

D Overall beam depth

E Elastic modulus

$E^{*} \quad$ Unloading modulus

$E_{c} \quad$ Concrete elastic modulus

$E_{s} \quad$ Reinforcement steel elastic modulus

$E A_{I} \quad$ Axial stiffness for the elastic response for an uncracked UHPFRC steel reinforced tensile bar

$E A_{\text {II }} \quad$ Axial stiffness for the bare steel reinforced tensile bar

$E I_{c r} \quad$ Flexural stiffness calculated when considering the contribution of only the uncracked concrete part

$E I_{\text {exp }} \quad$ Experimental flexural stiffness

$F_{c} \quad$ Force in the surrounding concrete body

$F_{s} \quad$ Rebar force

$G \quad$ Shear modulus

$G_{F} \quad$ Mode-I fracture energy, surfacic-crack energy or crack energy

I Moment of inertia

XL 


\begin{tabular}{|c|c|}
\hline$I_{e}$ & Effective moment of inertia \\
\hline$K$ & Fibre orientation coefficient \\
\hline$L$ & Length or span \\
\hline$L_{e}$ & Element length \\
\hline$L_{e f}$ & Finite element length \\
\hline$L e_{\text {exact }}$ & Exact element length that represents the situation in which $L_{e}=b_{w}$ \\
\hline Lefexact & Exact finite element length that represents the situation where $L_{e f}=b_{w}$ \\
\hline Lefexact,DIANA & Lefexact solution when $b_{w, \text { DIANA }}$ is used \\
\hline$L_{c}$ & Characteristic element length \\
\hline$L_{f}$ & Fibre length \\
\hline$M$ & Bending moment \\
\hline$M_{u, \exp }$ & Maximum bending moment achieved in the test \\
\hline$M_{u, c a l}$ & Maximum bending moment calculated \\
\hline$N$ & Axial force \\
\hline$N_{c}$ & Axial concrete force \\
\hline$N_{f}$ & Axial fibre force \\
\hline$N_{s}$ & Axial reinforcement steel force \\
\hline$N_{x}, N_{y}, N_{z}$ & $\begin{array}{l}\text { The number of grid lines used in the Cholesky decomposition for the } \\
\text { random field generation in } \mathrm{x} \text { direction, in } \mathrm{y} \text { direction and in } \mathrm{z} \text { direction }\end{array}$ \\
\hline$P$ & Load \\
\hline$P_{c r}$ & Load where microcracking appears \\
\hline$P_{1}$ & $\begin{array}{l}\text { Load that generates a tensile state in the elastic branch of the } \sigma-\varepsilon \\
\text { UHPFRC constitutive behaviour }\end{array}$ \\
\hline$P_{2}$ & $\begin{array}{l}\text { Load that generates a tensile state in the softening branch of the } \sigma-\varepsilon \\
\text { UHPFRC constitutive behaviour }\end{array}$ \\
\hline$S_{e}$ & Section of the element \\
\hline$S_{t}$ & Surface \\
\hline SH & Strain-hardening \\
\hline$S S$ & Strain-softening \\
\hline$T$ & Bond force flow \\
\hline
\end{tabular}


V

Domain that represents the body or structure considered as a continuum

$V_{e}$

Volume of the element

$V_{e f}$

Volume of the finite element

$V_{f}$

Fibre volume

\section{Small Roman Letters:}

$b$

$\bar{b}$

Specimen width

External volume forces

$b_{w}$

Process zone or crack bandwidth or localised band

$b_{w, D I A N A}$

Process zone or crack bandwidth or localised band defined by DIANA software

$d \quad$ Specimen depth, displacement and also distance between crack surface and mid-span measure at most compressed face considered in the 4PIA

Distance between the displacement transducers

$f \quad$ Force

$f_{c} \quad$ Compressive strength

$f_{c, c y l}$

Compressive strength obtained in a cylinder

$f_{c f}$

Stress in the compressive stress-strain function considered in DIANA software

$f_{\text {ext }} \quad$ External forces

$f_{\text {int }} \quad$ Internal forces

$f_{p}$

Peak stress value for the compressive stress-strain function considered in DIANA software

$f_{s t} \quad$ Reinforcement steel tensile strength

$f_{\text {stu }} \quad$ Reinforcement steel ultimate tensile strength

$f_{t} \quad$ Tensile strength

$f_{t d} \quad$ Strength at the change of slope in the softening branch

$f_{t u} \quad$ Ultimate tensile strength

$f_{\text {tuc }} \quad$ Ultimate tensile strength corrected by the softening correction 
$g_{f}$

$g_{f, \text { DIANA }}$

$g_{f m}$

$g_{f m, e f}$

$g_{f m, e f, D I A N A}$

$h$

$h_{b}$

l

$l_{d t}$

$l_{f}$

$l_{g}$

$m$

$p_{n} p_{s}, p_{t}$

$r_{k}$

$s h_{\text {inc }}$

$s h_{\text {inc } 3 D}$

$\bar{t}$

$u$

$u_{e f}$

$u_{f t}$

$u_{f t, e f}$

var
Volume-specific crack energy in Mode-I dissipated in the $b_{w}$

Volume-specific crack energy in Mode-I dissipated in the $b_{w, D I A N A}$

Volume-specific crack energy in Mode-I dissipated in the overall element by applying the smeared crack model

Volume-specific crack energy in Mode-I dissipated in the overall finite element by applying the smeared crack model

Volume-specific crack energy in Mode-I dissipated in the overall finite element by applying the smeared crack model in DIANA software

Process zone, crack bandwidth or localised band and also specimen depth

Numerically resolved band of localised strain or numerical crack band

Specimen length

Separation between compression and tension displacement transducers for long beams

Fibre length

Initial gage length of the displacement transducers for long beams

Initial slope of the linear part of the $\sigma-\delta$ curve

Normal and sliding components of the surface traction vector $\mathbf{p}$

Unloading constraints

Slip and also gage length

Percentage of shrinkage increment in the 2D model

Percentage of shrinkage increment in the 3D model

External surface forces

Total displacement or elongation in the element and also perimeter circumference

Total displacement or elongation in the finite element

Total displacement or elongation in the element associated to the tensile strength $f_{t}$

Total displacement or elongation in the finite element associated to the tensile strength $f_{t}$

The increment in $f_{t u}$ to obtain $f_{\text {tuc }}$ in the softening correction 


\begin{tabular}{|c|c|}
\hline$w$ & Crack opening \\
\hline$w_{c}$ & Crack opening at zero stress \\
\hline$w_{c, D I A N A}$ & Crack opening at zero stress for DIANA software \\
\hline$w_{d}$ & Crack opening at the change of slope in the softening branch \\
\hline $\mathcal{W}_{d, D I A N A}$ & $\begin{array}{l}\text { Crack opening at the change of slope in the softening branch considered } \\
\text { in the DIANA software }\end{array}$ \\
\hline$w_{f t u}$ & Crack opening at ultimate tensile strength $f_{t u}$ \\
\hline$w_{f t u, D I A N A}$ & Crack opening at ultimate tensile strength $f_{t u}$ for DIANA software \\
\hline$w_{n} w_{s}, w_{t}$ & Normal and slidding components of the crack width vector $\mathbf{w}$ \\
\hline$w_{0}$ & Crack opening at zero stress considered in the 4P-IA \\
\hline$w_{0, D I A N A}$ & $\begin{array}{l}\text { Crack opening at zero stress considered in the 4P-IA for DIANA } \\
\text { software }\end{array}$ \\
\hline$w_{2}$ & $\begin{array}{l}\text { Crack opening that generates a tensile state in the softening branch of } \\
\text { the } \sigma-\varepsilon \text { UHPFRC constitutive behaviour }\end{array}$ \\
\hline$x_{0}$ & Location of the neutral axis \\
\hline
\end{tabular}

Bold Small Roman Letters

$\bar{b} \quad$ Vector of external body forces

d Displacement vector of the nodal displacements of the finite element

n Normal vector to the tangential cracking plane

p Surface traction vector

u Displacement vector of a point in the finite element

w Crack width vector

df $\quad$ Force vector

Bold Capital Roman Letters

B Strain-displacement matrix

D Constitutive stiffness matrix

D secant Constitutive secant stiffness matrix

D Dangent $_{\text {Constitutive tangent stiffness matrix }}$

XLIV 
$\mathbf{D}_{\mathrm{nn}}$

$\mathbf{D}_{\theta \theta}$

$\mathbf{D}_{\mathrm{n} \theta}, \mathbf{D}_{\theta \mathrm{n}}$

E

K

$\mathbf{K}_{\mathbf{e}}$

L

$\mathbf{N}$

$\mathbf{P}$

Q

$\mathbf{R}$

S

T

W

Y

Tangent stiffness sub-matrix of the normal components of the local (crack) strain

Tangent stiffness sub-matrix of the shear components of the local strain

Tangent stiffness sub-matrices representing the coupling terms between the normal and the shear strain

Strain tensor

Stiffness matrix

Stiffness matrix of each element

Incidence matrix

Matrix that contains the shape functions

Projection matrix

Coordinate transformation matrix

Rotation matrix

Matrix containing all the $\sigma$ - $\delta$ experimental curves for the predicting application

Strain transformation matrix

Matrix used for updating the internal variables $\alpha_{k}$

Matrix containing the responses (tensile parameters) of each curve (column) of $\mathbf{S}$ for the predicting application

\section{Bold Small Greek Letters}

$\alpha$

$\boldsymbol{\varepsilon}_{c}$

$\boldsymbol{\varepsilon}_{m}$

$\varepsilon$

$\tilde{\varepsilon}$

$\boldsymbol{\varepsilon}_{c}$

$\sigma$
Internal damage variables vector

Mean strain vector

Mean total strain vector for the overall element by applying the smeared crack model

Symmetric strain tensor

Equivalent uniaxial strain vector

Mean strain vector in the crack coordinate system

Cauchy stress tensor 
Functions

$d\left(\varepsilon_{m}\right) \quad$ Compliance function for the smeared crack model for the cracked element

$\varepsilon_{c}(x) \quad$ Cracked strain in the softening branch of the $\sigma-\varepsilon$ curve

$\varepsilon_{\text {unc }}(x) \quad$ Uncracked strain in the linear and hardening branch of the $\sigma-\varepsilon$ curve

$\sigma(\kappa) \quad$ Uniaxial yield strength function

$f(\sigma, \eta, \kappa) \quad$ Yield function of Von Mises

$f_{\text {unc }}\left(\mathcal{E}_{\text {unc }}\right) \quad$ Linear and hardening parts of the $\sigma-\varepsilon$ curve represented by the elastic law

$f_{c}\left(\varepsilon_{c}\right) \quad$ Softening part represented of the $\sigma-\varepsilon$ curve represented by the descending inelastic law

$f_{j}(\alpha, \varepsilon) \quad$ Uniaxial stress-strain relation

$f_{n}\left(w_{n}\right) \quad$ Relation law for the normal component of the traction vector $\mathbf{p}$ and the normal component of the crack width vector $\mathbf{w}$

$f_{s}\left(w_{s}\right), f_{s}\left(w_{t}\right) \quad$ Relation law for the sliding components of the traction vector $\mathbf{p}$ and the sliding components of the crack width vector $\mathbf{w}$

$f_{T}(s) \quad$ Function that relates stress and slip displacement in the interface zone

$g_{j}(\alpha, \varepsilon) \quad$ Loading-unloading function

$B(x) \quad$ Strain-displacement functions

$B(x) \quad$ Constitutive functions

$N(x) \quad$ Shape functions

$u(x) \quad$ Displacement field 


\section{Chapter 1}

\section{Introduction}

\subsection{Background}

Ultra-high performance fibre-reinforced concrete (UHPFRC) can be considered a modern and enhanced evolution of fibre-reinforced concrete (FRC), with compressive strength above $150 \mathrm{MPa}$, tensile strength higher than $7 \mathrm{MPa}$ and flexural strength between $15-40 \mathrm{MPa}$. This very high strength, along with other properties, such as self-compacting, are accomplished given its special dosage with a low water/binder ratio (below 0.25 ) and fine grained mix which result in a dense microstructure. Moreover, the presence of highstrength and high-modulus fibres can improve concrete ductility, among other interesting properties depending on their quantities in a tailored dosage. In order to mix these components without workability problems and to ensure homogeneous mixing, it is essential to use effective superplasticisers. The optimum dense microstructure and superplasticiser combination is the main cause of special UHPFRC properties. In addition to dosage, it is necessary to consider the pouring system, curing and an optional heat treatment after casting UHPFRC. This whole process results in mechanical strainhardening UHPFRC, and also in very good durability properties, which mean long-term cost-effective structures given their minimum maintenance.

However, the special dosage and the particular curing system followed to cast strainhardening UHPFRC (SH-UHPFRC) can imply a high initial cost that is not always compensated by an effective structural design capable of taking advantage of this material's enhanced properties. This fact, together with lack of reliable UHPFRC mechanical characterisation development and its implementation in structural concrete 
design codes, have generally limited its presence to relatively few applications as nonstructural components or to only a few of relatively structural relevance, such as bridge deck joints and retrofitting damaged elements. Consequently, great UHPFRC structural projects are mainly restricted to specialised companies.

In order to lower the initial cost and optimise mechanical properties to make UHPFRC accessible, one study line could be to pay attention to the idea of limiting UHPFRC strain-hardening tensile behaviour, and even going to strain-softening for tensile behaviour up to ultimate tensile strength $\left(f_{t u}\right)$, as depicted in Figure 1.1. The development of low strain-hardening and strain-softening UHPFRC (SS-UHPFRC) would reduce its mechanical properties, but they could be optimised if they are studied and controlled for by considering the structural design combined with traditional rebars. This would lower the initial UHPFRC cost by, for example, reducing the amount of steel fibres used in its dosage or by following a less strict pouring and curing system.
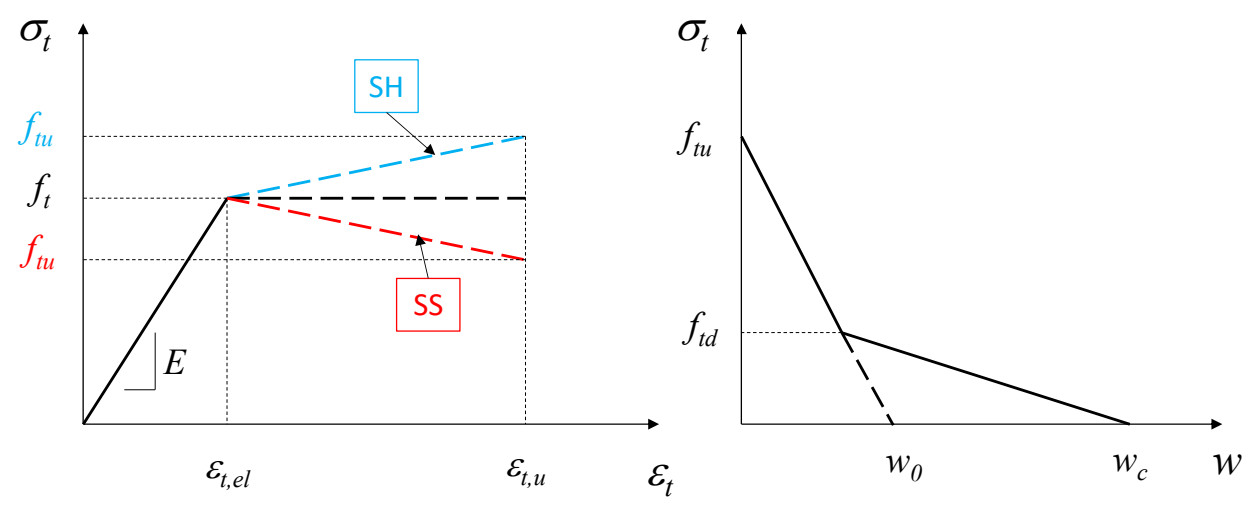

Figure 1.1 Tensile UHPFRC behaviour when considering SH and SS

Apart from reducing the initial cost due to the optimisation of its mechanical properties, it is necessary to develop reliable design codes that take advantage of considerable UHPFRC properties that allow effective structures. To do so, it is necessary to develop appropriate models capable of accurately simulating UHPFRC material behaviour by considering its particular cracking process and the consequences of its interaction with traditional reinforcement. These models must be able to reproduce the response of reinforced UHPFRC structural elements from a robust and adequate definition of material models and a coherent modelling strategy in order to sufficiently obtain accurate results that make UHPFRC structural designs competitive.

Therefore, in order to make UHPFRC an efficient and economically competitive material for structural designs and applications, it is necessary to define a complete modelling strategy. This is based on a clear and robust definition of material models and their 
interaction, a suitable numerical technique that allows complex analyses to be performed and an easy-to-run UHPFRC material characterisation procedure for both SH and SSUHPFRC to accurately establish constitutive material parameters for modelling.

Today UHPFRC can be considered a relatively modern material because its presence has become more notorious with the development of material technology and techniques in recent years. The study of mix designs, the availability of enhanced fine materials and the development of modern chemical superplasticisers have facilitated UHPFRC progress in the past 20 years and, more specifically, in the last decade.

Figure 1.2 shows the research publications on UHPFRC in the last 20 years. We can see how UHPFRC studies have increased in the past decade. Moreover, this figure also represents publications about SH-UHPFRC and SS-UHPFRC constitutive behaviour in tension. The study of SH-UHPFRC follows the same trend as that of UHPFRC. The tendency seems to lie in obtaining UHPFRC that exhibits strain-hardening tensile behaviour up to ultimate tensile strength $\left(f_{t u}\right)$ to ensure its superb properties, mainly in tension. However, the figure reveals that there is hardly any research on SS-UHPFRC. Moreover, for the vast majority of research into tensile SS-UHPFRC constitutive behaviour in the figure, the term SS-UHPFRC refers to the softening part of the curve from $f_{t u}$ onwards, and not to the behaviour up to $f_{t u}$. Hence the idea of studying tensile UHPFRC behaviour with low hardening, or even soft softening, up to $f_{t u}$ to optimise its mechanical properties and to reduce initial cost has not yet been sufficiently addressed and offers no guarantee. Is it possible to use SS-UHPFRC for reliable structural designs? What are the consequences for the mechanical tensile behaviour of SS-UHPFRC compared to SH-UHPFRC? Is it possible to reliably characterise the tensile behaviour of a whole range of constitutive UHPFRC behaviours towards an effective structural design capable of taking advantage of the material's enhanced properties? Are the traditional models developed for modelling conventional reinforced concrete applicable to UHPFRC?

The present thesis addresses some of these key questions by studying mechanical UHPFRC behaviour and covering a wide range of tensile constitutive behaviours from SH-UHPFRC to SS-UHPFRC in order to offer a reliable tensile characterisation process and reliable robust finite element numerical modelling capable of accurately simulating the response of UHPFRC specimens and reinforced structural elements. Consequently, a complete effective methodology for the numerical modelling of UHPFRC from the material level to structural elements is proposed as the main topic of this doctoral thesis. 


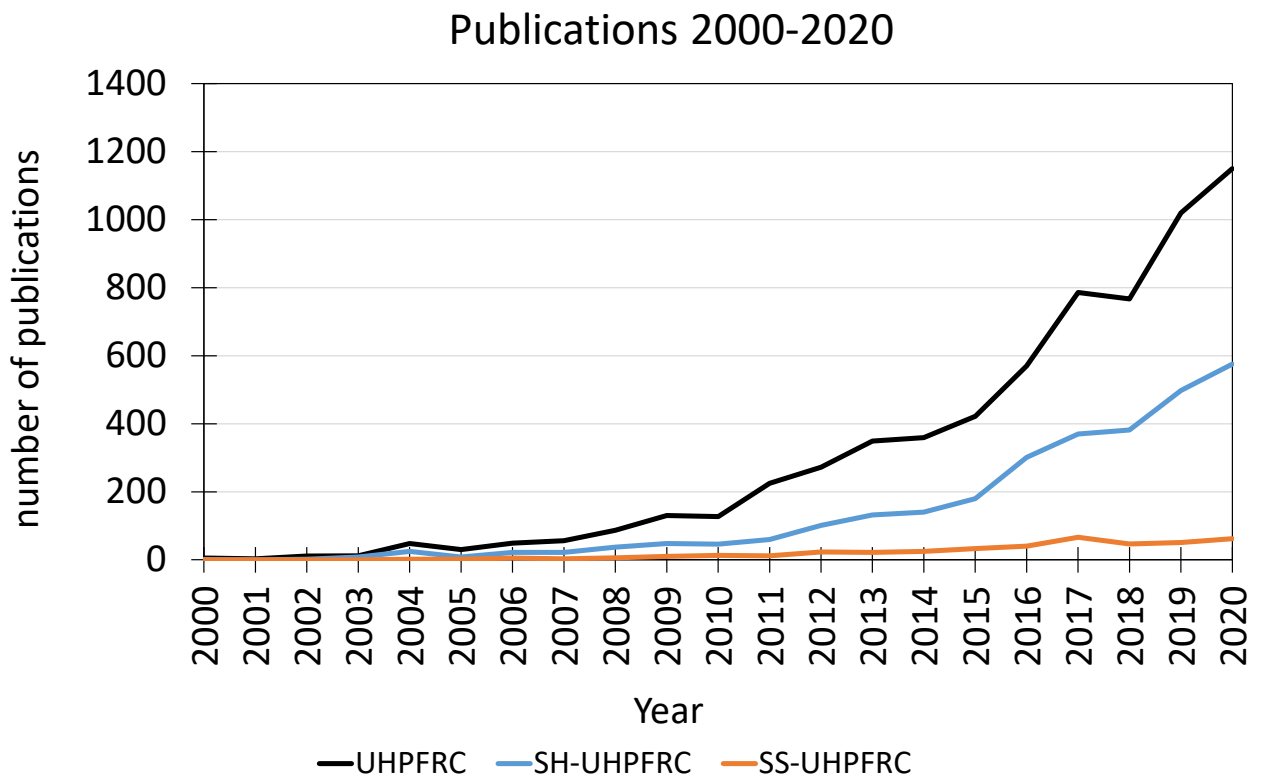

Figure 1.2 Publications per year containing the words: "UHPFRC", "strainhardening" UHPFRC and "strain softening" UHPFRC. Data obtained from Google Scholar on 23 December, 2020.

\subsection{Objectives}

For UHPFRC structural designs, it is necessary to define a complete methodology to model UHPFRC that facilitates the comprehension of its superb mechanical properties, and to incorporate them into the modelling process in order to take advantage of these properties, and to obtain an efficient structural design from the mechanical and economical points of view.

To face this challenge, the main objective of this thesis is to develop a complete methodology for the numerical modelling of UHPFRC from the material level to structural elements. The intention of this thesis to make a substantial contribution to advanced knowledge of mechanical UHPFRC behaviour towards competitive material that can be generally used in structural modelling and design. For this purpose, it is necessary to characterise the constitutive behaviours of both SH-UHPFRC and SSUHPFRC. It is also essential to implement it into the framework of an adequate theoretical material model that describes their particular cracking processes and the interaction with reinforcement bars by taking into account major effects like shrinkage or tension stiffening with a suitable definition of the bond between them. In order to 
simulate structural behaviour, the model needs to be implemented in a reliable methodology to establish a robust numerical model based on the non-linear structural analysis. This will allow material behaviour to be considered until its final consequences to simulate an optimised structural response in two and three dimensions (2D and 3D), which will take into account the heterogeneity of UHPFRC mechanical properties due to the variability associated with the casting process, pouring system or fibre orientation, among others.

The main objective of this thesis is fulfilled by achieving the following sequenced specific objectives:

1. Study and refer the current state of knowledge about the main concepts relating to UHPFRC definition and tensile characterisation, the modelling basic concepts related to material constitutive models, computational methods and numerical solution strategies, to set the basis of a general UHPFRC numerical modelling methodology. A literature review of the main research works related to UHPFRC characterisation for modelling, the calibration of UHPFRC finite element models, and their extension and application to structural elements in the last decade

2. Evaluate existing material models and the modelling strategies developed for conventional concrete, and consider their adaptation and particularisation to UHPFRC modelling. To do so, it is necessary to establish the material's response. This entails defining the constitutive behaviour of the materials to be used: constitutive 1D behaviour, how does this 1D behaviour work when it is extrapolated to other dimensions?: e.g., 2D and 3D, and how the material's particularities, such as cracking, shrinkage and bonding with reinforced UHPFRC, are defined in the model. This is the first step and the core of the model, which must be correctly defined and controlled to subsequently adapt the element and/or structural reality by means of: more or less complex geometry, boundary and load conditions, a suitable finite element type and an analysis method. It is important to bear in mind that the material model has to be linked with its element and the structural function, and vice versa

3. Based on the previous particular objective: implementing the proposed theoretical model into a non-linear finite element model (NLFEM) for UHPFRC that goes from the simple constitutive 1D definition at the material level to complex behaviour when this material works and is integrated into an element with increasing complexity, and is subject to boundary conditions, the interaction with other materials and elements (e.g. reinforcement) and works in $2 \mathrm{D}$ or $3 \mathrm{D}$ directions. This generates the basis to integrate it into a general body; that is, when this element works together with other elements to cover a structural objective. So it is necessary to establish how this material will behave in different directions and how theoretical models are implemented into the numerical technique defining it. It is necessary to assemble the comprehensive numerical model to carry out the structural analysis by considering the boundary 
conditions, the distribution of the mechanical properties of the materials that define the structure, type of loads, etc.

4. Study the implementation of the developed NLFEM in the particular case of using a certain finite element package commercial software, and adapt the material's model to the capabilities of commercial software

5. Establish a simple and direct procedure able to characterise the tensile material behaviour of UHPFRC with sufficient reliability in both cases: SH-UHPFRC and SS-UHPFRC behaviour in tension. This defines the main material parameters necessary to describe the UHPFRC for the material model. To get this purpose, the following steps are considered in this work:

- Develop an experimental programme of 4PBT UHPFRC unreinforced specimens that covers a wide range of SS and SH constitutive UHPFRC behaviours. This experimental programme can constitute a reference experimental database for other research groups and, therefore, its creation implies a specific objective

- Model unreinforced 4PBT to experimentally characterise tensile UHPFRC behaviour by means of the NLFEM, and validate, adapt and improve an existing inverse analysis method for SH-UHPFRC to achieve constitutive SS-UHPFRC behaviour. Moreover, with the database obtained from the experimental $4 \mathrm{PBT}$ programme and the NLFEM, any inverse analysis method can be evaluated and adapted

- Develop a predicting application to describe tensile constitutive UHPFRC behaviour directly from the experimental 4PBT curve implemented as input to avoid any variability associated with misinterpretations of the characterisation process

6. Improve and adapt the NLFEM to model reinforced UHPFRC elements and evaluate the coherence of the direct procedure previously developed to characterise the tensile behaviour of both SS-UHPFRC and SH-UHPFRC. For this purpose, the following steps are considered:

- Develop an experimental programme that includes reinforced flexural UHPFRC beams on different scales to cover a wide range of SS and SH constitutive UHPFRC

- Model the UHPFRC flexural beams from the experimental programme carried out by means of an improved NLFEM that includes important effects due to the interaction between UHPFRC and reinforcement bars

- Model the UHPFRC tensile bars from a recent experimental programme by another researcher by means of an improved NLFEM that includes important effects due to the interaction between UHPFRC and reinforcement bars and the tensile test's particularities

Fulfilling the above sequenced specific objectives helps to achieve the main aim of this thesis: develop a complete methodology for the numerical modelling of UHPFRC from the material level to structural elements. 


\subsection{Structure of the document}

Therefore, in order to describe the process set out above to fulfil the general and specific objectives established herein, the document includes seven chapters.

Chapter 1. The background, objectives and structure of the present document are included.

Chapter 2. A review to set the main concepts related to the UHPFRC definition and tensile characterisation is carried out. Then, modelling basic concepts related to material constitutive models, computational methods and numerical solution strategies are addressed to set the basis of the NLFEM for the UHPFRC herein developed. A literature review of the main research works about UHPFRC characterisation for modelling, the calibration of UHPFRC finite element models, and their extension and application to structural elements in the last decade, is considered.

Chapter 3. The theoretical definition of the material models is proposed. The material models defined for conventional concrete are considered and redefined for UHPFRC. With UHPFRC, the constitutive uniaxial (1D) model, and the models adopted to be extrapolated to the multiaxial case (2D and 3D), are proposed. Afterwards, the way that the parameters describing UHPFRC constitutive behaviour are obtained is proposed: the 4PBT used as the experimental test and the inverse analysis to derive the tensile parameters from the experimental bending curve. Moreover, the uniaxial behaviour of the reinforcement steel and that of bond-slip between reinforcement and UHPFRC are also defined.

Chapter 4. A general idea of the workflow of the finite element method is presented in order to set the integration of the material models in the method. Then a finite element software is used to carry out the numerical implementation. The study of how software integrates the material models, and how they are used in the non-linear analysis to implement the material models for UHPFRC, steel reinforcement and the interface behaviour between them defined in Chapter 3 to the software's particularities, are addressed.

Chapter 5. The developed numerical 2D-NLFEM is used to establish a simple and reliable direct procedure to characterise the tensile UHPFRC behaviour in both cases: SH-UHPFRC and SS-UHPFRC behaviours. The unreinforced 4PBT to experimentally characterise tensile UHPFRC behaviour is modelled and an inverse analysis method to achieve constitutive SH-UHPFRC behaviour is validated, adapted and improved to be used for SS-UHPFRC. To do so, an experimental programme of more than 2004 PBT UHPFRC specimens covering a wide range of SS and SH constitutive UHPFRC behaviours was developed, tested and numerically modelled by the 2D-NLFEM. Moreover, from the experimental database generated in the experimental 4PBT programme carried out and the developed direct procedure used to characterise the UHPFRC behaviour, a predicting application was created in which the parameters 
describing UHPFRC tensile constitutive behaviour were obtained from the experimental 4PBT curve implemented as input.

Chapter 6. The NLFEM is validated for reinforced UHPFRC structural elements. To this end, the NLFEM was run considering such important effects like tension stiffening and UHPFRC shrinkage. At this point, the NLFEM also incorporated the reinforcement bars and the bond-slip behaviour between UHPFRC and reinforcement. In the first part of this chapter, an experimental programme comprising 36 reinforced UHPFRC flexural short beams and two full-scale reinforced UHPFRC flexural beams was carried out, tested and modelled by 2D and 3D-NLFEM. In the second part of this chapter, a full complete 3D-NLFEM-multicrack that is able to model 3D effects, the random distribution of strength that simulates concrete heterogeneity and the complexity of reinforced UHPFRC tensile bars from an experimental programme from another work, is carried out. A particular concept of a finite element capable of incorporating the constitutive material model of UHPFRC more accurately in the 3D-NLFEM-multicrack is proposed: the composed finite element. In this chapter, the coherence of implementing into the model the UHPFRC tensile behaviour obtained by the direct procedure for structural UHPFRC modelling is examined.

Chapter 7. Finally, the main conclusions drawn from the research conducted in this doctoral thesis are presented, and the future research lines that derived from this thesis are proposed.

Two annexes have been added to this thesis:

Annexe I. The main characteristics of the inverse analysis methodology chosen to obtain the tensile constitutive behaviour for SH-UHPFRC from the experimental unreinforced 4 PBT equivalent bending stress-deflection at the mid-span curve are briefly recalled.

Annexe II. An example of applying the 2D-NLFEM-multicrack to model unreinforced $4 \mathrm{PBT}$ with the composed finite element concept proposed in Chapter 6 is provided. 


\section{Chapter 2}

\section{State of the Art}

\subsection{Introduction.}

Ultra-high performance fibre-reinforced concrete (UHPFRC) could be comprehended in the category of special concretes. Since its apparition in the mid-1990s as enhanced construction material, an special interest has been generated that has led to publications of scientific work related to the development of the material from material science, mechanical behaviour and analytical theories mainly started from plain concrete, reinforced concrete and fibre reinforced concrete. All of these have derived in the application of UHPFRC in non-structural elements such as pavements and connectors, strengthening structural elements such as beams, shear walls and columns, and in structural elements such as long scale beams and pedestrian bridges. In order to extend its application at structural level, standards and recommendations based on adaptations from plain concrete and empirical experiences have been developed worldwide. In this sense, to be able to apply this material and its technology to more complex structural elements with particular geometries and load configurations it is necessary to increase the knowledge of the mechanical advantages in order to optimise the design and comprehend its internal behaviour. These reasons lead to the development of numerical modelling from material to structural level. To get this, it is necessary to characterise adequately the UHPFRC mechanical behaviour to know its material properties in order to stablish its relations and compatibilities with other materials and, therefore, simulate with reliability the structural response. 
In this chapter a state of the art of the process of modelling structural members of UHPFRC has been developed. The concept of UHPFRC can cover more or less enhanced properties with respect to plain concrete with a wide range of values. In this chapter, a definition of UHPFRC is done trying to set it in the context of this research. The main properties of UHPFRC considered for modelling are described. Attending to the special characteristics of UHPFRC a study of the adequate expression of the tensile constitutive behaviour and the experimental test and procedure able to facilitate its obtaining is done. Moreover, the main standards and recommendations of UHPFRC are commented and how they address its characterisation and design. A brief introduction to material models, the numerical solutions and computational methods in structural analysis has been carried out to set the main objective of this research work related to numerical modelling of tensile behaviour of UHPFRC. Then, a selection of distinguished modelling works are described keeping attention in UHPFRC experimental characterisation and numerical modelling at specimen and structural levels. Finally, a summary and the main conclusions of the chapter are described.

\subsection{UHPFRC: definition and properties}

\subsubsection{Definition of UHPFRC}

Ultra-high performance fibre-reinforced concrete (UHPFRC) can be considered an advanced modernisation of conventional (CC) and fibre-reinforced (FRC) concretes. It integrates specialised knowledge into its dosage and high technology to be produced and poured, which can strongly influence its mechanical properties and structural response. A very dense microstructure, due to its low water/binder ratio (w/b below 0.25 ), finegrained mix and adequate high-strength steel fibre content lead to compressive strength above $150 \mathrm{MPa}$, tensile strength higher than $7 \mathrm{MPa}$ and flexural strength between 15 40MPa. All these advantages imply slender lightweight structures compared to conventional reinforced concrete constructions. However, due to the high cement content (about $800 \mathrm{~kg} / \mathrm{m}^{3}$ ) and its mix design, UHPFRC can be prone to suffer high shrinkage at early ages. Therefore, slender UHPFRC structures can be vulnerable to shrinkage cracking in the manufacturing stage (Fang et al. 2020; Fehling et al. 2014; Xie et al. 2018; Yoo et al. 2015a; Yoo and Banthia 2016).

In the last 20 years, many studies about these UHPFRC aspects have been done. The influence of the composition and mix design, together with the casting process, play an important role in UHPFRC mechanical properties (Arora et al. 2018; Yu et al. 2014, 2015; Zhou and Uchida 2017a). The presence of fibres and their influence on mechanical behaviour, which depends on fibre orientation, fibre content and composition, bond between fibres and concrete matrix, have been addressed by taking their form into account (Abrishambaf et al. 2017; Yoo et al. 2016, 2015b; Zhou and Uchida 2017b). Its dense hardened cement matrix, which virtually has no capillarity pores, prevents the penetration of aggressive substances and reduces the risk of corrosion. This fact confers 
UHPFRC another important property apart from strength: durability. Its special mix design also leads to facilitating procedures, such as self-healing (Ferrara et al. 2016, 2017, 2018; Kim et al. 2019; Wang et al. 2014).

\subsubsection{Properties of UHPFRC}

In this work, the behaviour of concrete is addressed considering a short-term time scale, which is related to the type and duration of load application. The load is applied slowly and therefore the immediate response of the material specimen can be studied. In this case, the loading speed does not affect the stress-strain response of concrete and this is only influenced by the magnitude of the load applied. Consequently, effects that are extended beyond the application time of the load such as creep and relaxation are not addressed.

In the context of this work and with the aim of developing a complete numerical model to simulate the tensile behaviour of UHPFRC, two main properties have been studied in detail as they have direct influence at the moment when the UHPFRC's experimental tests are carried out: tension stiffening and shrinkage.

\subsubsection{Tension stiffening}

The tension-stiffening behaviour of reinforced concrete (RC) and FRC is fundamental for the characterisation of crack widths and separation. It is directly related to the crack pattern and effects such as shrinkage, and also to the determination of the tensile response of FRC members with bar reinforcement (Albitar et al. 2018; Bischoff 2003, 2008; Deluce 2011; Kaklauskas et al. 2018). The tension-stiffening effect depends mainly on the load carrying capacity of the concrete and the bond stress-slip response between the concrete and reinforcement. The presence of fibres with their random distribution improves the tensile strength and brittleness of concrete composites. Moreover, the addition of fibres also improves the bond strength between concrete matrix and reinforcement due to their influence in concrete tensile fracture energy (Bandelt and Billington 2016; Chao et al. 2009). Therefore, the enhanced mechanical properties mainly in tensile behaviour obtained from UHPFRC lead to consider their important influence in tension stiffening-behaviour. In this $\mathrm{PhD}$ research, the tension-stiffening phenomena has been considered taking into account not only the collaboration of the tensile strength from the concrete between cracks, but also considering the residual strength in the proper crack.

Relevant research into tension-stiffening has been addressed for UHPFRC. To better understand the serviceability behaviour of concrete structures, Sturm et al. (Sturm et al. 2018) developed and extended a non-linear tension-stiffening approach to FRC and UHPFRC by considering its particular strain-hardening stress-strain relation prior to macrocracking. In this case, analytical closed-form solutions were developed for the crack spacing by means of the CEB-FIP bond slip curve and for the load slip behaviour considering a simplified linear ascending relationship. They obtained reliable results 
when validated the model with a wide range of FRC including UHPFRC. Hung et al. (Hung et al. 2019) suggested a constitutive model capable of reasonably representing the tension-stiffening behaviour of UHPFRC up to failure. Tensile responses of steelreinforced UHPFRC samples were evaluated using multiple performance measures, including damage pattern, stiffness, load-deformation relation, rebar strain and tensionstiffening behaviour of UHPFRC. Rahdar and Ghalehnovi (Rahdar and Ghalehnovi 2016) analysed the tension-stiffening effect in UHPC by means of direct tensile tests with circular cross sections and a rebar positioned in the centre. They proposed an equation to explain with good accuracy the post-cracking zone based on the ratio of cover thickness to rebar diameter and the reinforcement percentage. Khorami et al. (Khorami et al. 2020) developed a similar procedure of evaluating the tension-stiffening behaviour by steel reinforced bars but, in this case, using UHPFRC in squared sections in different amounts of 13/0.2 smooth high strength fibres: 80 and $160 \mathrm{~kg} / \mathrm{m}^{3}$. Using their proposed novel test method, they were able to analyse accurately the interaction between the UHPFRC matrix and the reinforcement considering the tension stiffening effect. $\mathrm{Na}$ and Kwak (Na and Kwak 2011) developed a numerical model to simulate the nonlinear behaviour of UHPFRC based on the concept of equivalent uniaxial strain. They simulated the tension-stiffening effect by means of a criterion based on the force equilibriums, compatibility conditions, and bond stress-slip relationship in an idealised axial member. To validate the analytical model developed, it was implemented in a finite element model and successfully compared to experimental results of UHPFRC beams. Fehling et al. (Fehling et al. 2014) and Leutbecher (Leutbecher 2008) considered the influence of the high UHPFRC shrinkage strain in members under tension and bending. Figure 2.1 represents the qualitative stress-strain behaviour of an UHPFRC steel reinforced tension member. The presence of the reinforcement does not allow the free UHPFRC shrinkage deformation and consequently an internal restraint appears which generates a negative "pre-strain" deriving in compressive stresses ("A" in Figure 2.1) in the steel bar. Because of this, concrete is in tension before the application of the external load which generates a reduction in the cracking load level ("B" in Figure 2.1). They also considered that the internal restraint has still influence on the cracking force during the single crack formation phase ("C" in Figure 2.1). However, no influence of shrinkage internal restraint was considered on tension stiffening during the stabilised cracking phase ("D" in Figure 2.1), although shrinkage influences the crack widths. 


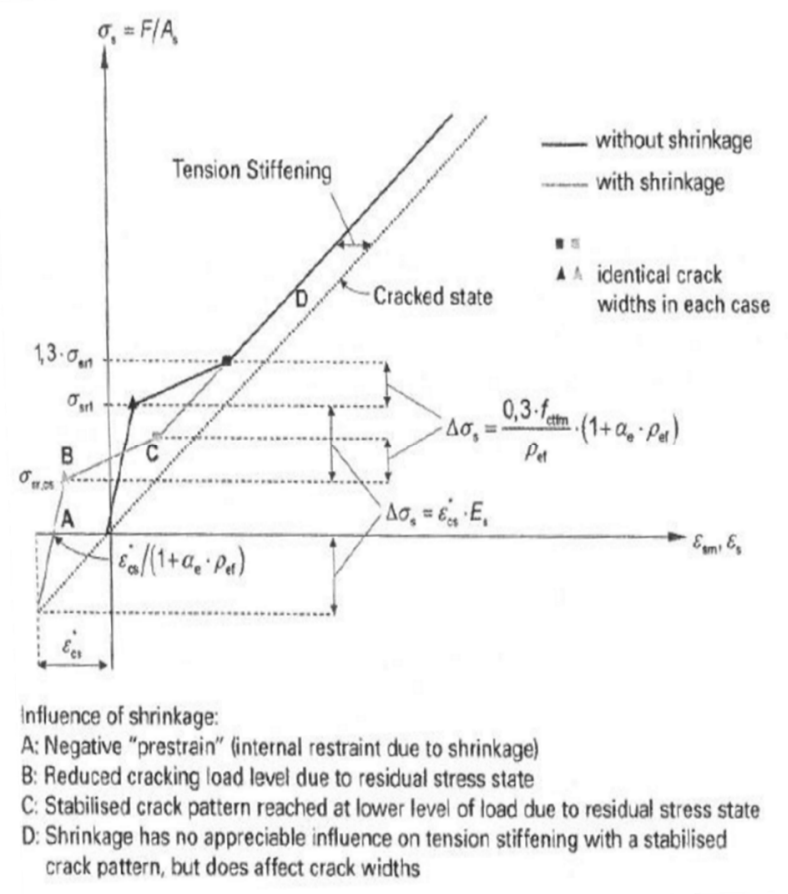

Figure 2.1 Qualitative stress-strain curve for UHPFRC tension member (Leutbecher 2008)

\subsubsection{Shrinkage}

Due to its lower water/cement ratio (w/c) UHPFRC is prone to suffer high levels of shrinkage at early stages, specially autogenous shrinkage. The low water content results in reduced drying shrinkage of UHPC in the long-term but causes severe autogenous shrinkage when compared to normal strength concrete (Fang et al. 2020; Koh et al. 2011; Xie et al. 2018). In this sense, it is important to control the shrinkage values for this kind of concrete due to its influence in generating internal stresses where the reinforcement is positioned or due to the boundary conditions. In the direction of take profit of the enhanced mechanical UHPFRC properties in comparison to plain concrete, the result could be more reduced sections and therefore slender structures. If the high value of shrinkage is considered it is possible that in reinforced slender sections UHPFRC stresses near the reinforcement could be higher even near the concrete tensile strength and, consequently, could generate notorious influence in the bearing capacity of the structure. 
Soliman and Nehdi (Soliman and Nehdi 2011) studied the influence of drying conditions on autogenous shrinkage in UHPC at early-age. They evaluated the autogenous shrinkage in UHPC without fibres under different conditions of temperature and ambient humidity. The control mixture was considered with a w/c ratio of 0.22 and 0.25 . They obtained values of total shrinkage strain for the first 7 days near $0.9 \mathrm{~mm} / \mathrm{m}$. They concluded that curing had essential influence in early-age deformations. Yoo et al. (Yoo et al. 2013a) investigated the effect of adding shrinkage reducing admixture on UHPFRC properties: fluidity, compressive strength, tensile and flexural behaviours, and the influence of fibre distribution related to fibre orientation, fibre dispersion, number of fibres and packing density on the flexural behaviour. They used UHPFRC with a water/binder $(\mathrm{w} / \mathrm{b})$ ratio of 0.2 and a $2 \%$ in volume $\left(157 \mathrm{~kg} / \mathrm{m}^{3}\right)$ of $13 \mathrm{~mm}$ length and 0.2 $\mathrm{mm}$ diameter (13/0.2) of smooth and high strength steel fibres. They obtained values of autogenous shrinkage near $0.65 \mathrm{~mm} / \mathrm{m}$ for the control mixture. Following with this research, Yoo et al. (Yoo et al. 2014a) studied the effect of shrinkage reducing admixture and expansive admixture on the shrinkage and cracking behaviours of restrained UHPFRC slabs at early stage. They obtained free shrinkage strain values near 0.8-0.95 $\mathrm{mm} / \mathrm{m}$ from UHPFRC with $\mathrm{w} / \mathrm{b}$ ratio of 0.2 and $2 \%$ in volume of $13 / 0.2$ smooth and high strength steel fibres. Moreover, in (Yoo et al. 2015a) they investigated the effect of shrinkage-reducing admixture on free and restrained autogenous behaviours of UHPFRC using different reinforcement rations. They studied the stress produced as a result of the restrained shrinkage by the rebar using UHPFRC with $0.2 \mathrm{w} / \mathrm{b}$ ratio and $2 \%$ in volume of 13/0.2 smooth high strength fibre. They obtained autogenous shrinkage strains a 30 days near $0.76 \mathrm{~mm} / \mathrm{m}$ for the control mixture and shrinkage stresses near $4.5 \mathrm{MPa}$, depending on the reinforcement ratio. They concluded that stresses related to shrinkage decreased with the reinforcement ratio. Yalçinkaya and Yazici (Yalçınkaya and Yazıcı 2017) studied early-age shrinkage of UHPFRC with high volume mineral admixtures. They used UHPFRC with a w/c ratio between $0.25-0.50$ and $2 \%$ in vol. of $6 \mathrm{~mm}$ length and $0.16 \mathrm{~mm}$ diameter of steel straight fibres. They obtained autogenous shrinkage strain values for the control mix near $0.45 \mathrm{~mm} / \mathrm{m}$ at $20^{\circ} \mathrm{C}$ and $0.60 \mathrm{~mm} / \mathrm{m}$ at $30^{\circ} \mathrm{C}$ and total shrinkage near $0.60 \mathrm{~mm} / \mathrm{m}$ at $20{ }^{\circ} \mathrm{C}$ and $0.95 \mathrm{~mm} / \mathrm{m}$ at $30^{\circ} \mathrm{C}$ of temperature. From this study it could be extracted that an increase in ambient temperature increased the drying shrinkage and accelerated the development of shrinkage in the first few hours. Xie et al. (Xie et al. 2018) carried out an experimental study to characterise the autogenous and drying shrinkage of UHPC without fibres and $w / b$ ratio of 0.15 . They obtained autogenous shrinkage strains near $0.64 \mathrm{~mm} / \mathrm{m}$ and free total shrinkage strains near 0.8 $\mathrm{mm} / \mathrm{m}$ at 50 days. They concluded that the autogenous shrinkage had more effect than the drying shrinkage on total shrinkage of the UHPCs. Fang et al. (Fang et al. 2020) reported the influence of steel fibres properties on the shrinkage of UHPFRC. In this study, the effects of fibre volume fraction, fibre type and aspect ratio on shrinkage of UHPFRC were experimentally investigated. They used UHPFRC with $\mathrm{w} / \mathrm{c}$ of 0.15 and fibre volume from 0 to $2.5 \%$ in vol. of different kinds of steel fibres. They obtained shrinkage strain in the range of 0.3 to $0.9 \mathrm{~mm} / \mathrm{m}$ depending on the type of steel fibre and the amount. They concluded that the use of discrete steel fibres into UHPC matrix could 
influence significantly the total and autogenous shrinkage. An increase of fibre volume fraction could lead to a reduction in both the total and the autogenous shrinkage. Moreover, fibres with higher aspect ratio can reduce also the total and autogenous shrinkage of UHPFRC.

Now, the main standards and recommendations are revised from the shrinkage point of view. In Australia, the recommendations of Ductal ${ }^{\circledR}$ properties (Gowripalan and Gilbert 2000) consider a value of endogenous shrinkage strain for Ductal's Reactive Powder Concrete (RPC) of $0.5 \mathrm{~mm} / \mathrm{m}$. They propose the curve depicted in Figure 2.2 depending on the initial heat treatment or not.

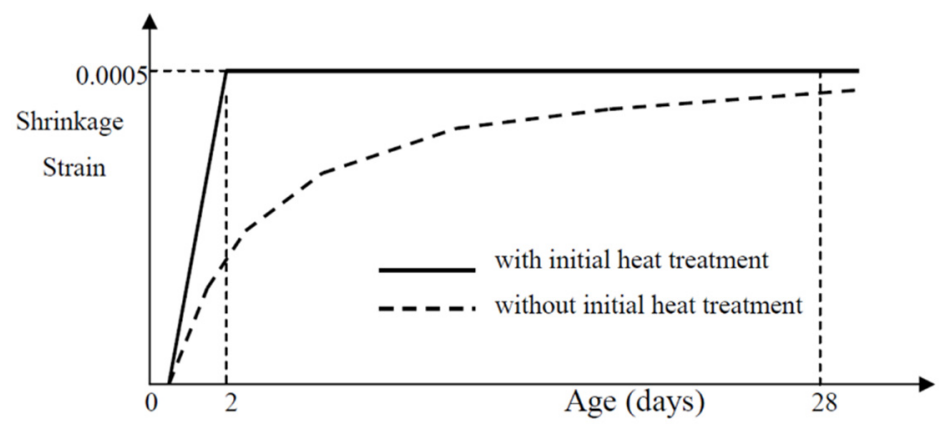

Figure 2.2 Shrinkage versus time for specimens with and without initial heat treatment in (Gowripalan and Gilbert 2000)

In the Japan Society of Civil Engineering considerations (Japan Society of Civil Engineers 2008), the shrinkage shall be obtained by means of experimental results from (JIS A 6202:2017 2017) appendix or (JIS 2010) considering material properties, mix proportions, ambient humidity and sectional profiles and dimensions of the members.

In the USA, the FHWA (Federal Highway Administration) (Russell et al. 2013) refers to the standard test (C157 2006) to measure the drying shrinkage beginning after concrete has hardened. To measure the autogenous shrinkage it refers to "other methods". According to several authors, the FHWA proposes values of total shrinkage that could be included in the range of 0.50 to $0.90 \mathrm{~mm} / \mathrm{m}$.

The French standard for UHPFRC (Association Francaise de Normalisation 2016a; b), which is based on recommendations (AFGC 2013), proposes, if nothing about heat treatment is known during the preliminary design phase, the following indicative values for long term effects:

- If there is not heat treatment: $0.55 \mathrm{~mm} / \mathrm{m}$ for endogenous shrinkage (autogenous shrinkage) and $0.15 \mathrm{~mm} / \mathrm{m}$ for drying shrinkage in an outdoor environment with an average relative humidity of about 50 to $70 \%$. Consequently, a total shrinkage strain of $0.70 \mathrm{~mm} / \mathrm{m}$. 
- For heat treatment of what the standard considers the first type in its point 1.8: $0.55 \mathrm{~mm} / \mathrm{m}$ for total shrinkage, for an outdoor environment with a relative humidity of 50 to $70 \%$.

- For heat treatment of what the standard considers the second type in its point 1.8: total shrinkage of $0.55 \mathrm{~mm} / \mathrm{m}$ before the end of the heat treatment, after which the total shrinkage is nil.

The Swiss standard (Swiss Society of Engineers and Architects SIA 2016) considers both parts of the shrinkage: endogenous (autogenous) and drying. For UHPFRC without heat treatment it proposes the Expression (2.1):

$$
\varepsilon_{U S}(t)=\varepsilon_{U s \infty} \cdot e^{\frac{c}{\sqrt{t+d}}}
$$

where the values of the coefficients are: $c=-2.48, d=-0.86$ and the time $t$ is expressed in days. For UHPFRC made with CEM I, the Swiss standard can admit as the final value of shrinkage $\varepsilon_{U s, \infty}=0.6-0.8 \mathrm{~mm} / \mathrm{m}$. If UHPFRC is made with other types of cement, sometimes shrinkage plays a major role. In this case, it will be necessary to carry out tests.

Therefore, from this brief review it can be concluded that UHPFRC exhibits higher values of shrinkage strain than plain concrete due to its low w/c ratio. The shrinkage effect in UHPFRC is dependent on mixing proportions and special additions, ambient temperature, humidity, curing conditions, geometry of the specimens, diameter and distribution of reinforcement bars and amount, distribution, aspect ratio and geometry of the steel reinforcement fibres. Thus, as stated in Fehling et al. (Fehling et al. 2014), it seems logical to assume as a reference, depending on cement contend and mix design, a total shrinkage strain in the range of $0.6-0.9 \mathrm{~mm} / \mathrm{m}$ for the design of specimens made from non-heat-treated, low capillaries UHPFRC (with w/c ratio $\leq 0.25$ ).

\subsection{Mechanical characterisation of UHPFRC tensile behaviour}

As it is stated previously, UHPFRC could be considered an advanced modernisation of FRC. In order to be able to exploit its special mechanical properties it is important to characterise them adequately. It is necessary that the mechanical characterisation represents the nature of the real material behaviour to allow the development of reliable analytical and numerical models. In this case, the tensile behaviour is addressed. As this is a distinguished property of UHPFRC, it is necessary to describe it with a high level of detail and accuracy. Consequently, it is necessary to reflect the mechanical properties expected from the reality in an adequate tensile response. In this sense, it is important to use the appropriate experimental test capable of representing the mechanical behaviour leading to obtain the defined tensile response. 


\subsubsection{UHPFRC uniaxial tensile response}

As UHPFRC could be considered a special type of FRC with enhanced properties, the same basic principle of classification of FRC can be applied to UHPFRC. In this sense, a general classification of fibre-reinforced concrete according to its tensile stress-strain response and its flexural load-deflection response is shown in Figure 2.3. It is important to distinguish between the tensile behaviour and flexural one and how they are related in the case of UHPFRC. When tensile behaviour is considered, it is possible to find FRC that exhibits strain-hardening or strain-softening behaviour in tension. For the case of those concretes exhibiting strain-softening behaviour in tension, it can be distinguished between deflection-hardening or deflection-softening behaviour in bending. For the case of concretes that exhibit strain-hardening behaviour in tension, it is important to remark that all of them exhibit deflection-hardening behaviour in bending.

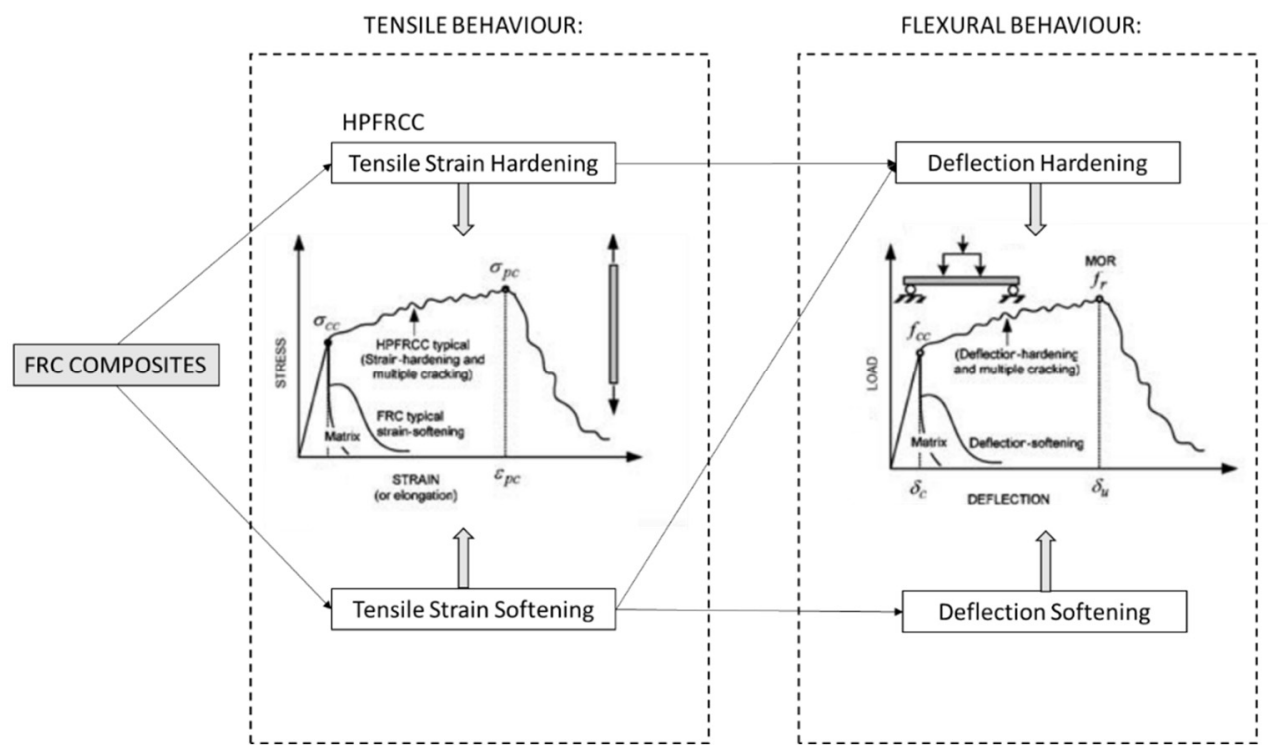

Figure 2.3 General classification of FRC according to its tensile and flexural behaviour based in (Naaman and Reinhardt 2006).

Wille et al. (Wille et al. 2014) described the cementitious composites in the classification shown in Figure 2.4 based on the criteria proposed by Naaman and Reinhardt (Naaman and Reinhardt 2006) in Figure 2.3. This classification is composed of 5 levels depending on the concrete behaviour both in direct tensile and bending: (level 0) for non-fibre reinforced concrete or plain concrete; (level 1) defined by tensile strain-softening and deflection-softening that could refer, for example, traditional FRC; (level 2) defined by tensile strain-softening and deflection-hardening; (level 3) defined by tensile strain- 
hardening and deflection-hardening; (level 4) defined by tensile strain-hardening, deflection-hardening and high energy absorbing. The parameters used to define the classification in Figure 2.4 are: tensile stress $\sigma_{c c}$ and its associated strain $\varepsilon_{c c}$, elastic modulus $E_{c c}$, composite ultimate tensile strength or post-cracking strength $\sigma_{p c}$, modulus of rupture $\sigma_{f 1}$ and equivalent bending strength $\sigma_{f 2}$. In this work, strain-softening UHPFRC (SS-UHPFRC) and strain-hardening UHPFRC (SH-UHPFRC) are addressed. Therefore following the criteria in Figure 2.4, what is considered SS-UHPFRC in this work would be characterised by a behaviour located between level 2 and level 3 whereas what is considered SH-UHPFRC would correspond to both levels 3 and 4.

UHPFRC can be defined as a hydraulic cement-based composite material that combines three technologies in concrete: (i) high characteristic compressive strength; (ii) ductile behaviour under tension due to the presence of fibres, which can or cannot provide a pseudo strain-hardening stress-strain response accompanied by multiple cracking depending on fibre volumetric fraction, the fibre aspect ratio, and also the fibre distribution inside the structural element; (iii) a special selection of fine and ultrafine aggregates that provides dense particle packing, high durability and a certain degree of flowability (López 2017). In this way, UHPFRC that manifests a strain-hardening response can be considered a special type of high-performance fibre-reinforced cement composite (HPFRCC) (López et al. 2015a). Accordingly, HPFRCC can be characterised as all concrete that exhibits strain-hardening tensile stress-strain response (see Figure 2.3) accompanied by multiple cracking and relatively large energy absorption capacity. As it is considered a HPFRCC, strain-hardening UHPFRC exhibits also deflectionhardening response (see Figure 2.3 and Figure 2.4). Consequently, a standard mechanical characterisation test must provide the definition of the strain-hardening behaviour, commonly described as a stress-strain relationship, and also the subsequent softening behaviour when the macrocrack takes place. As macrocrack formation is a discrete phenomenon, this behaviour may be based on a fracture mechanics approach and be described using a similar stress-crack opening relationship to that proposed in (Casanova and Rossi 1996; Olesen 2001; Ostergaard et al. 2005; Pedersen 1996; Stang and Olesen 1998). 

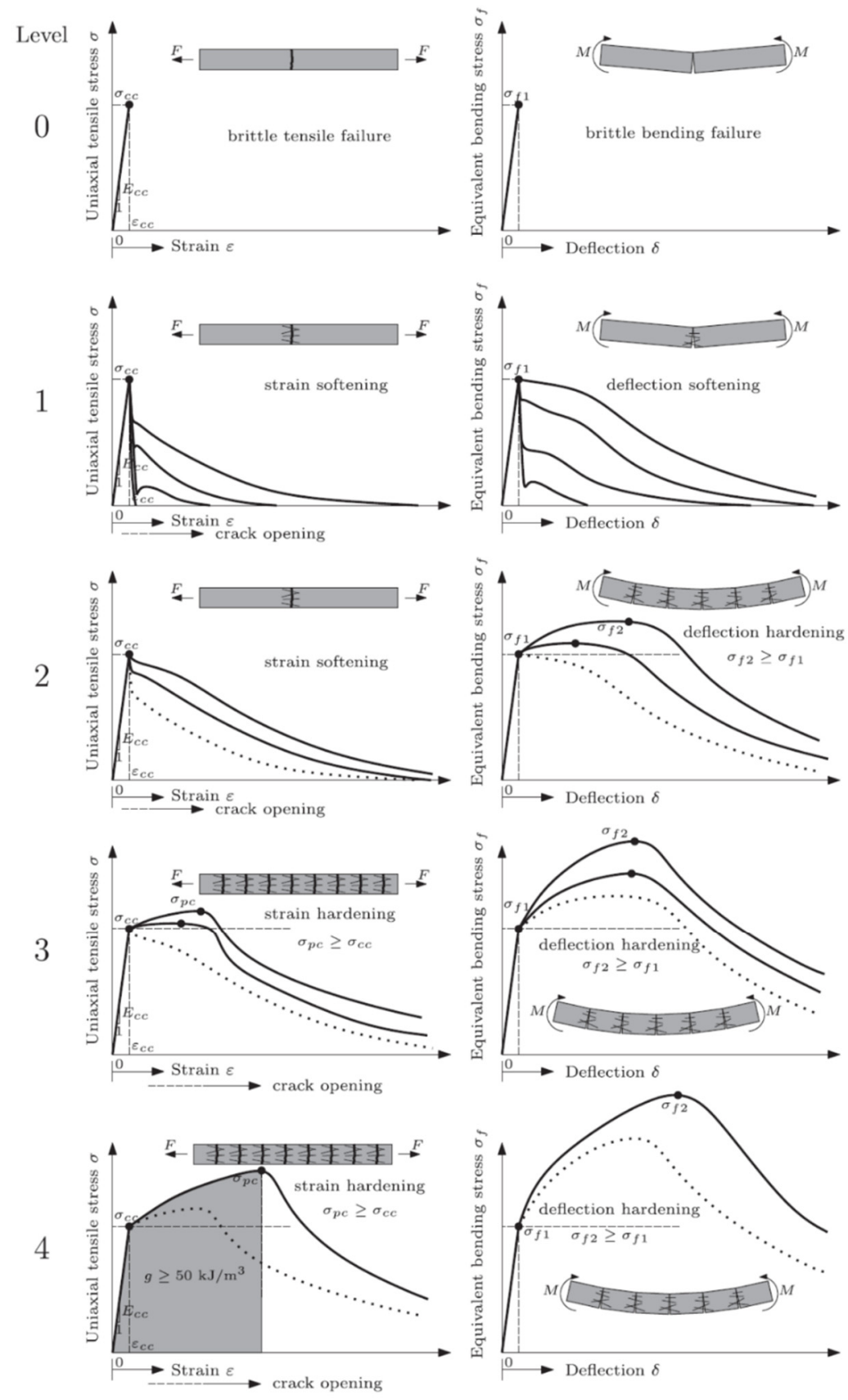

Figure 2.4 cementitious composites' classification by (Wille et al. 2014) 
For modelling purposes, it is possible to define the tensile stress-strain law of FRC composites by means of "strain-hardening" (SH) or "strain-softening" (SS), as it is shown in Figure 2.3. Naaman and Reinhardt (Naaman and Reinhardt 2006) defined the typical tensile behaviour of FRC in both cases as it is shown in Figure 2.5(a) and Figure 2.5(b). These figures show also the key points required for characterising a particular experimental curve for modelling. For strain-hardening FRC composites (Figure 2.5(a)), the stress of point 2 cannot be higher than that of point 3 or lower than that of point 1 . Moreover, it could be possible that point 2 is aligned with point 1 and point 3 . In the case of strain-softening FRC composites (Figure 2.5(b)), point 5 can have a stress lower or higher than that at point 4 , and point 6 can be aligned with points 5 and 7 , or its stress can be in between the stress of these two points. Figure 2.5(a) and Figure 2.5(b) can be united as shown in Figure 2.5(c) generating the complete stress-elongation curve of SH FRC composites under direct tension. It shows the strain path up to the peak point (point 3 or macrocrack localisation) and the following crack opening path till crack opening at zero stress (point 7). The seven points represented in Figure 2.5(c) can cover near all the curves that can be obtained from experimental tensile tests. Many times it is not necessary to use all of them for modelling purposes, e.g. if points 1, 2 and 3 in Figure $2.5(\mathrm{c})$ are considered the same, the response obtained is similar to that for $\mathrm{SS}$ represented at Figure 2.5(b).

When the fracture mechanism of cement based materials is represented by means of $\sigma-$ $\varepsilon /$ w diagram (see Figure 2.6) it is possible to differentiate two main parts (Switek 2008): pre-peak and post-peak part. The pre-peak part contains the elastic deformation and the possible hardening phase. The energy dissipated in this part is a consequence of the deformation process that involves all volume of the specimen (volumetric part). For materials that exhibit strain-hardening behaviour, a microcraking stage takes place that is developed until the localisation point appears (point B in Figure 2.6), where microcracks are concentrated in a macrocrack. From this point onwards, the post-peak part of the diagram reflects the opening of the localised crack and only a surfacic dissipation of energy is developed. This is, the energy is dissipated in a localised band or process zone corresponding to the crack formation. The B-C part of tensile diagram is considered the softening branch, where a decrease of stress is produced while the displacement or crack opening is increased. 
(a)

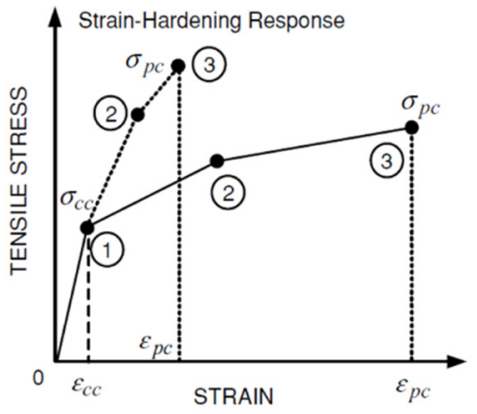

(b)

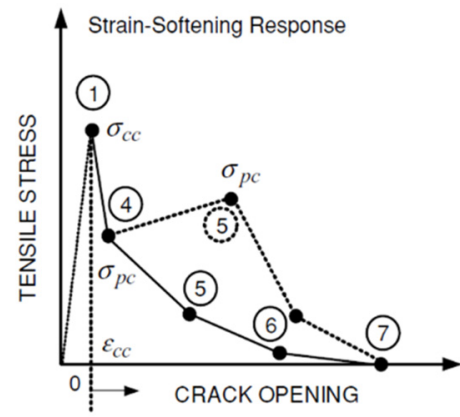

(c)

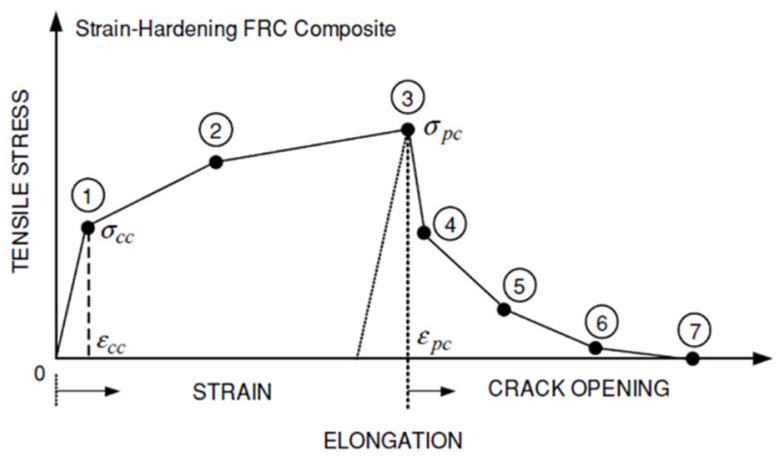

Figure 2.5 (a) Typical stress-strain response of SH FRC composites, (b) typical stresscrack opening response of SS FRC composites and (c) generalised typical stresselongation response of FRC for modelling suggested in (Naaman and Reinhardt 2006)

For the case of quasi-brittle materials such as FRC, the volumetric part of dissipated energy can be neglected if it is compared to the surfacic part of energy dissipation (see Figure 2.6). In the softening part, the energy is completely released in a localised band or process zone corresponding to crack formation. Thus, for materials with notorious volumetric or bulk energy dissipation, as is the case of HPFRCC (see Figure 2.6), the overall energy dissipated in the deformation process needs to be considered in its two parts: volumetric and surfacic. 


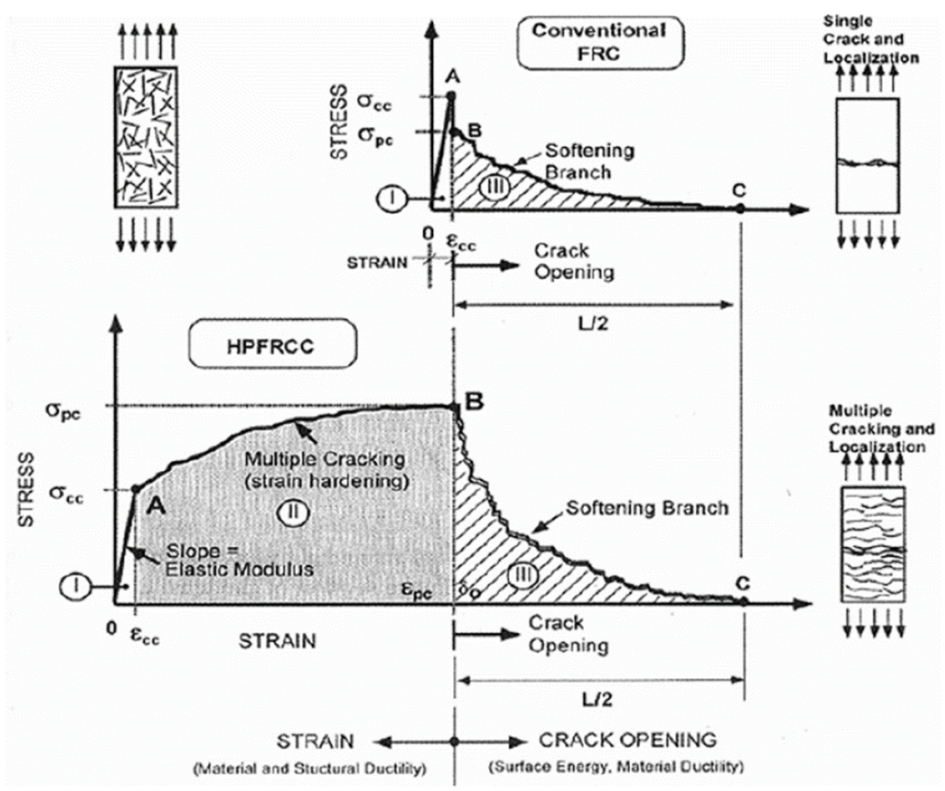

Figure 2.6 Tensile behaviour of FRC and HPFRCC (Naaman 2003)

In this sense Wille et al. (Wille et al. 2014) described the typical $\sigma-\varepsilon / \mathrm{w}$ for SHUHPFRC tested under direct tension dividing it in three parts (see Figure 2.7):

- Part I: where the linear elastic response is expressed by means of stress-strain parameters up to tensile strength $\left(f_{t}\right)$ and its associated tensile strain $\left(\varepsilon_{t}\right)$.

- Part II: corresponds to the strain hardening part expressed also by means of stressstrain parameters up to the ultimate tensile strength $\left(f_{t u}\right)$ and its associated ultimate tensile strain $\left(\varepsilon_{t u}\right)$. As it is SH-UHPFRC, $f_{t u}>f_{t}$. The energy dissipated in part I and part II in the deformation process corresponds to the volumetric energy and involves all the volume of the specimen (as explained above in Figure 2.6). This part is independent of the specimen size. This part is associated with the multicracking phase that is characteristic for SH-UHPFRC.

- Part III: corresponds to the softening part expressed by means of stress-crack opening up to the crack opening at zero stress $\left(w_{c}\right)$ associated to the fibre length divided by two. The area covered by this part is limited by the softening branch and the unloading branch from $f_{t u}$ and is related to the surfacic energy (area based) or dissipated energy per crack surface area (as explained above in Figure 2.6). This part is dependent of the specimen size. 
Chapter 2: State of the Art

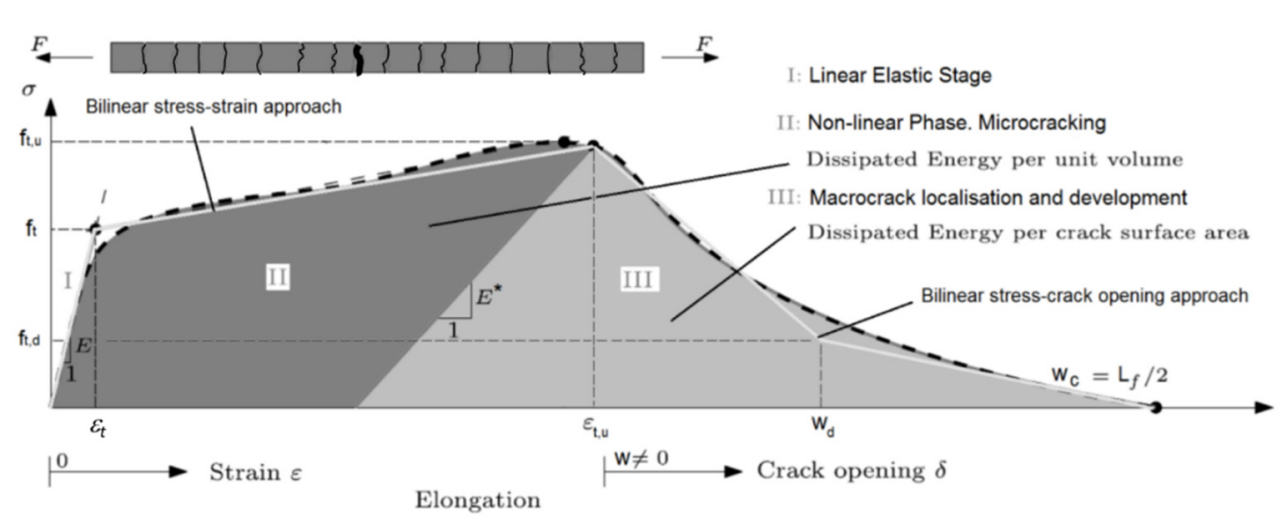

Figure 2.7 Typical $\sigma-\varepsilon / w$ for SH-UHPFRC in (Wille et al. 2014)

For plain concrete, the MC2010 ((fib) 2013) defines a simplification of the uniaxial tensile behaviour following a quadrilinear relationship (see Figure 2.8). This quadrilinear response can be divided in two main blocs: a bilinear relationship expressed by means of stress-strain behaviour for the part I (elastic) and part II (strain hardening), and a bilinear relationship expressed in terms of stress-crack opening for part III (softening). This simplification done for plain concrete can be extended and adapted to UHPFRC, as it is shown in Figure 2.7. In this case, the uniaxial tensile behaviour is defined by eight parameters: (i) elastic modulus $(E)$; (ii) cracking strength or tensile strength $\left(f_{t}\right)$ which according to (Wille et al. 2014) it is defined as the fictitious point of transition from ideal linear elastic to best fitted linear strain-hardening behaviour; (iii) ultimate tensile strength $\left(f_{t u}\right)$ defined as the maximum tensile strength; (iv) its associated ultimate strain $\left(\varepsilon_{t u}\right)$; (v) the unloading modulus $\left(E^{*}\right)$ which is of importance to clearly differentiate between the energy dissipated during strain hardening (volumetric energy) and during the softening (surface energy); (vi) the strength at the change of slope in the softening branch $\left(f_{t d}\right)$, which according to the bilinear models developed for concrete can be defined as a percentage of the ultimate strength; (vii) its associate crack opening $\left(w_{d}\right)$; and (viii) the crack opening at zero stress, usually named as characteristic crack opening $\left(w_{c}\right)$ which is commonly expressed as the maximum fibre length $\left(l_{f}\right)$ divided by 2 . 

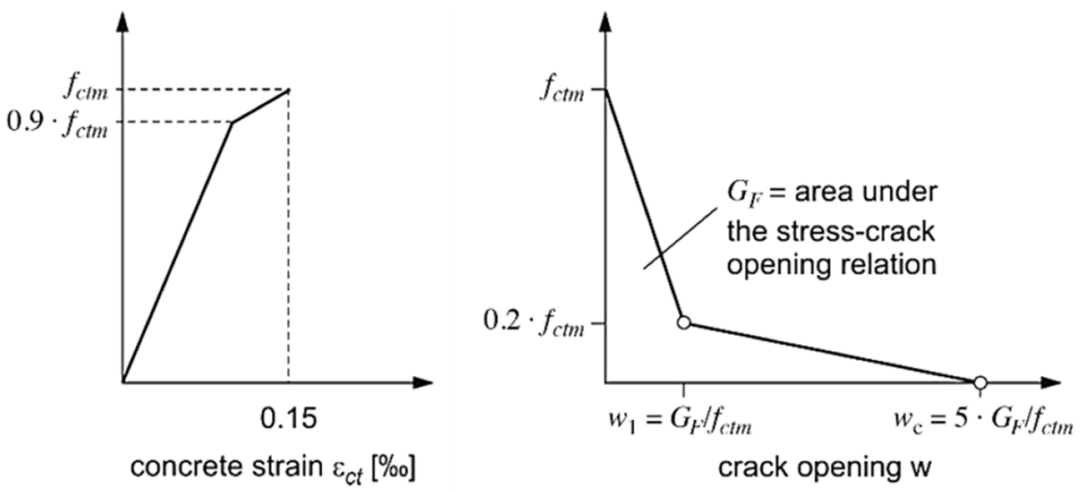

Figure 2.8 Uniaxial $\sigma-\varepsilon / w$ response for plain concrete in MC2010 ((fib) 2013)

\subsubsection{UHPFRC tensile experimental tests}

Nowadays, the characterisation of UHPFRC tensile behaviour remains a challenge. No agreement on the standard test set up, advisability of notch, or even specimen shape and size, has been reached yet. Mainly, UHPFRC tensile properties are determined using uniaxial tensile tests and bending tests. In this sense, the test setup to characterise the tensile behaviour of UHPFRC must be able to provide the parameters necessary to define its uniaxial tensile behaviour above defined in Figure 2.7.

With the idea of capturing the strain hardening behaviour in tension a great variety of dog-bone shapes have been used in the past (see Figure 2.9(a)). They all are characterised by a middle part with nearly constant section to facilitate the hardening response, larger cross sections near the supports to avoid the failure in those points and a smooth transition between these two sections (Wille et al. 2014). Unnotched prisms and cylinders (see Figure 2.9(b)) have been investigated being useful to obtain the elastic behaviour prior to cracking in SH-UHPFRC, and they could be appropriate to capture the strain hardening behaviour or not depending if they are side glued or top glued (Cunha et al. 2011; Denarié et al. 2003; Roth et al. 2010; Zhang et al. 2000). Notched specimens are better for the investigation of the softening part but they are not suitable for characterising elastic and strain hardening of UHPFRC tensile behaviour (see Figure 2.9(c)). Even though in direct tensile tests the tensile behaviour is directly obtained without having to resort to inverse analysis methodologies and high computational effort for backward calculation of the material tensile response, their experimental setup is complicated and requires specific preparation for alignment and gripping the specimen that frequently leads to inaccurate results (Hassan et al. 2012; Mallat and Alliche 2011). These drawbacks have derivate the efforts in the development of suitable easy-toconduct tests (Graybeal and Baby 2013; Kanakubo 2006; Ostergaard et al. 2005; Qian and Li 2007; Wille et al. 2014). 
(a)

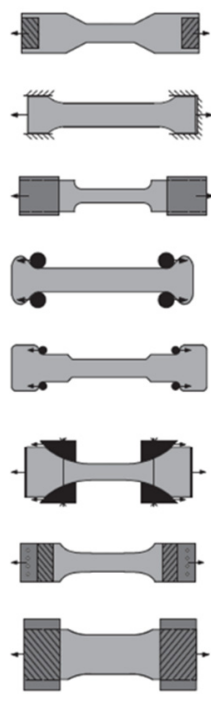

(b)
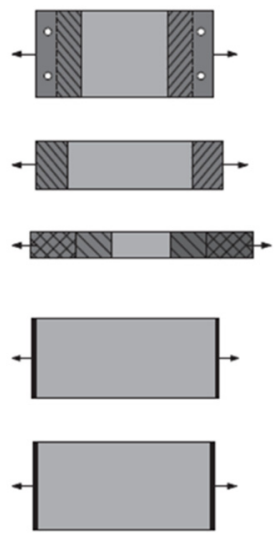

(c)
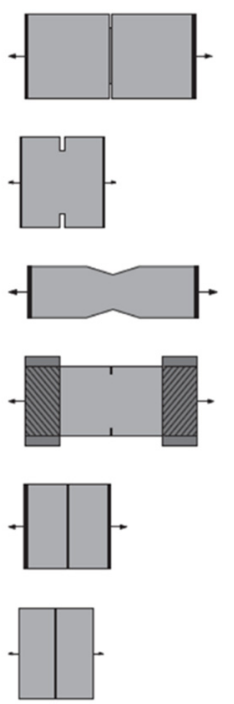

Figure 2.9 Direct tensile tests (a) dog bones, (b) unnotched prisms and (c) notched prisms in (Wille et al. 2014)

Bending tests are quite extended tests to obtain the tensile properties of concrete due to the simplicity concerning their experimental setup. They are considered a simpler alternative compared to direct tensile tests. However, their experimental results require more extensive interpretations and the use of inverse analysis methodologies to derive the tensile properties from the bending curve. It can be distinguished two types of bending test: notched three-point bending tests (3PBTs), mainly used to characterise the post-cracking law in strain-softening materials and unnotched four-point bending tests (4PBTs), mainly used to characterise the strain hardening behaviour in strain-hardening materials.

The notched three-point bending tests (3PBTs) are considered suitable to obtain the stress-crack opening relationship in strain-softening materials such as FRC. These materials have not significant inelastic deformations located at the notch plane and, consequently, all the energy released in the deformation process of the crack formation is because of the fracture by means of a single crack along the notch plane (surfacic energy). However, for the case of SH-UHPFRC and considering the depth of the notch defined in EN-14651 (DIN EN 14651 2007), an extended zone in the vicinity of the notch will be under plastic deformations after the first crack appears as a consequence of the prior microcracking phase generated (Spasojevic et al. 2008) (see Figure 2.10(a)). Consequently, multiple cracks may appear in this zone during the test (see Figure 
2.10(b)). As traditional inverse analysis for 3PBT such as in MC2010 ((fib) 2013) are developed considering localised crack and not microcracking phase, they lead to an overestimation of tensile properties in strain-hardening materials (López 2017), whereas in other cases they may underestimate the post-cracking energy of the tensile behaviour (Rossi et al. 2018). Therefore, no clear results are obtained from 3PBTs when they are applied to strain-hardening materials.

(a)

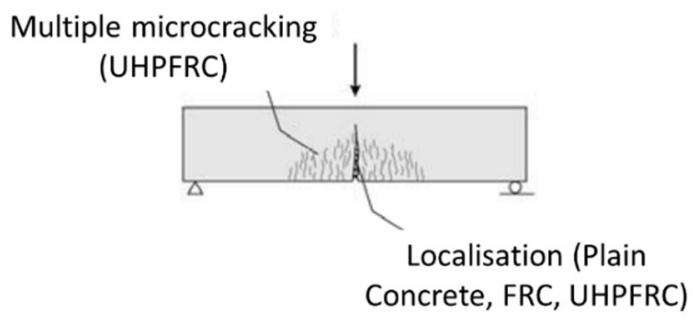

(b)

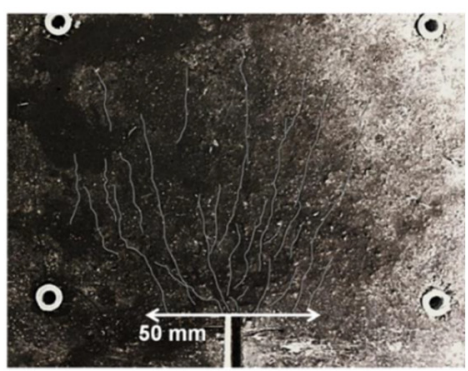

Figure 2.10 (a) beam in bending with crack localisation in the microcracked region in (Spasojevic et al. 2008) and (b) Multi-microcracking in a UHPFRC specimen notched 3PBT according to EN-14651 in (López 2017)

As notched 3PBTs do not make the characterisation of strain-hardening behaviour possible and uniaxial tensile tests are difficult to perform, unnotched four-point bending tests (4PBTs) arise as the best ones to obtain the tensile properties of UHPFRC. They allow a large area between the loading points with a relatively constant bending moment, so the micro-cracking process that characterises this kind of concrete is free to develop (see Figure 2.11). At first, when they were considered for FRC, the variability of the results obtained from unnotched 4PBTs was higher compared to the notched 3PBTs. However, this variability was reduced if the influence of the macrocrack's position was considered in the analysis of the unloading response in unnotched 4PBTs (Amin et al. 2015; Chanvillard 2000; Chanvillard and Rigaud 2003; Gopalaratnam and Gettu 1995; López 2017). Nevertheless, as they are bending tests, they require running an inverse analysis methodology to derive tensile properties based on the obtained results. 
(a)

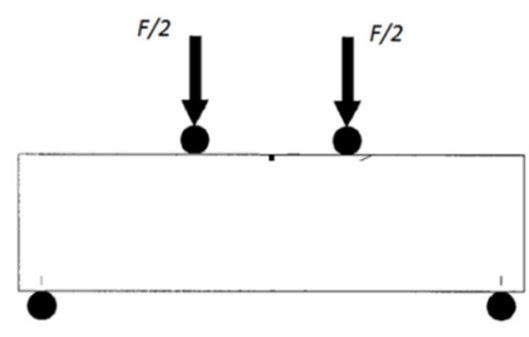

(b)

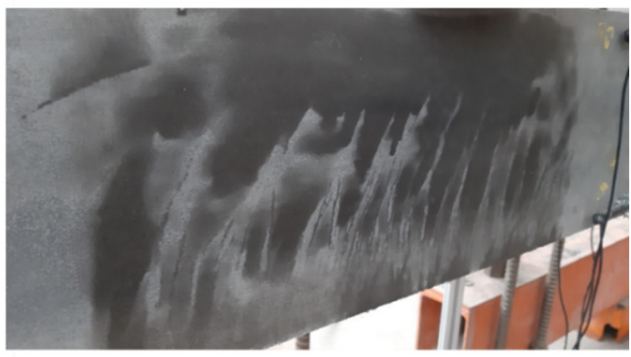

Figure 2.11 (a) 4PBT and (b) micro-cracking process

In line with this, different inverse analysis methods have been developed to obtain the parameters that constitute UHPFRC tensile behaviour from 4PBTs (Baby et al. 2012, 2013a; Gröger, Johannes, Viet tue, Nguyen, Wille 2012; Kanakubo 2006; López et al. 2015a; Maalej and Li 1994; Ostergaard et al. 2005; Qian and Li 2007; Rigaud et al. 2012; Soranakom and Mobasher 2007; Tailhan et al. 2004). Two kinds are mainly considered: simplified methods defined from the key points extracted from experimental 4PBT; methods defined from the complete experimental curve. The latter can also be divided into iterative and point-by-point methods. In point-by-point inverse methods, the shape of the UHPFRC tensile stress-strain relation is not necessarily assumed (Baby et al. 2012; Rigaud et al. 2012). With iterative ones, a constitutive behaviour has to be previously defined to apply the analytical or numerical process to obtain a response that can be compared to the experimental response and to, consequently, start the iterative process. Several analytical methods based on closed-form formulations and numerical methods based, in turn, on nonlinear 2D-FEM using fracture mechanics to obtain the theoretical curve in load-deflection, load-strain or load-curvature terms can be found in (Kanakubo 2006; Ostergaard et al. 2005; Soranakom and Mobasher 2007; Tailhan et al. 2004). These methods are based on the complete experimental curve and are indicated for computer analyses. As these methods are normally accurate, they are employed in the research field. Simplified methods resort to a few specific points from the results obtained with 4PBT (AFGC 2013; Kanakubo 2006; López et al. 2017, 2016; Swiss Society of Engineers and Architects SIA 2016). The idea of developing these simplified methods lies in their direct application to structural design or quality control so they are "easy to conduct". Even though these methods seem easy to apply, they are not completely accurate and objective, and are subjected to variations depending on the type of application. 


\subsection{UHPFRC in standards and recommendations}

At this point, it is important to introduce how standards and design rules consider and obtain the tensile constitutive behaviour of UHPFRC. In this direction, as a result of its evolution, UHPFRC is starting to be considered also for design in recommendations, standards and design codes worldwide.

\subsubsection{UHPFRC constitutive behaviour and experimental tests}

Australia follows the recommendations of Ductal ${ }^{\circledR}$ properties (Gowripalan and Gilbert 2000) which, for tensile constitutive behaviour, propose using experimental notched cylinder direct tensile tests as a source, namely trilinear stress-strain behaviour in which the two first lines represent perfect elastoplastic behaviour and the third is the softening branch until zero stress (see Figure 2.12). The yielding tensile stress is considered at $5 \mathrm{MPa}$ with an elastic strain of 0.0001 . The ultimate tensile strain at the end of the plastic branch is considered at $\varepsilon_{t, p}=0.16 L_{f} / 1.2 D \leq 0.004$, where $L_{f}$ is the length of fibres, $D$ the overall beam depth and, finally, the strain at zero stress is considered $\varepsilon_{t, u}=L_{f} / 1.2 D$ $\leq 0.01$.

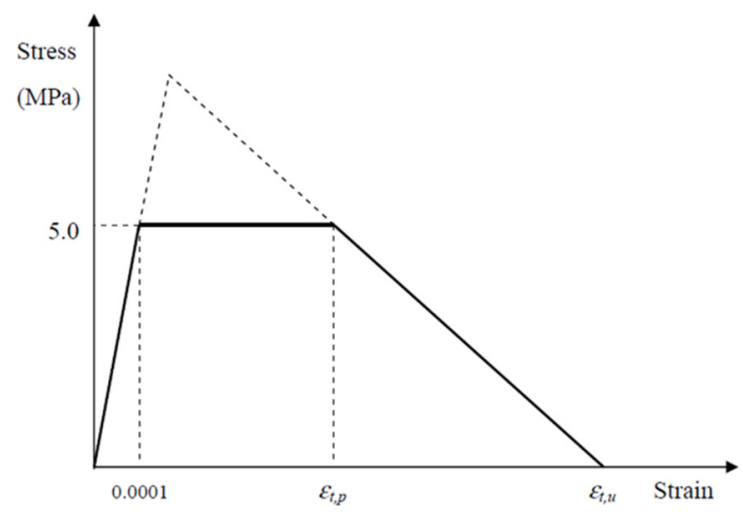

Figure 2.12 Idealised stress-strain relationship in tension proposed by (Gowripalan and Gilbert 2000)

In the Japan Society of Civil Engineering considerations (Japan Society of Civil Engineers 2008), a uniaxial direct tensile test is performed (see Figure 2.13(a)). As a result, the tensile curve is defined by the tensile yield strength and the ultimate tensile strength and strain (Figure 2.13(b)). The Japan recommendations consider only strainhardening tensile behaviour. For calculations however, they propose a perfect elastoplastic model (Figure 2.13(c)). When the design-cross-sectional strength is underestimated in an analysis, the tensile stress-strain relation should be appropriately reevaluated, and the failure mode also needs to be confirmed with a model that appropriately reflects the stress-strain relation of HPFRCC. 
(a)

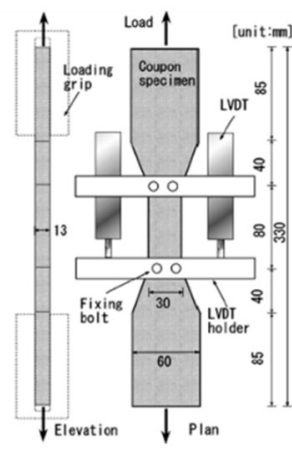

(b)

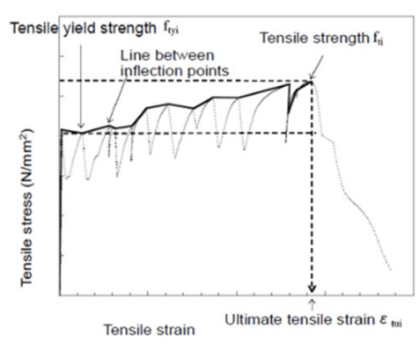

(c)

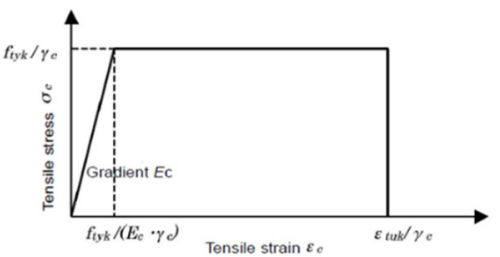

Figure 2.13 (a) uniaxial tensile test, (b) tensile behaviour and (c) proposed perfect elastoplastic model for design in (Japan Society of Civil Engineers 2008)

In the USA, the FHWA (Federal Highway Administration) (Russell et al. 2013) refers to the UHPC idealised response with strain-hardening behaviour in tension obtained from direct tensile tests (Figure 2.14). Graybeal reported tensile strength measurements using flexural prisms (by considering inverse analyses to obtain their tensile constitutive response), split cylinders, mortar briquettes and direct tension tests of cylinders depending on the heat treatment. Adaptation of standards for conventional concrete has been made to make it appropriate to quantitatively assess the post-cracking tensile response of UHPC. However, this seems appropriate for setting the response in the direction of strain-hardening UHPFRC tensile behaviour.

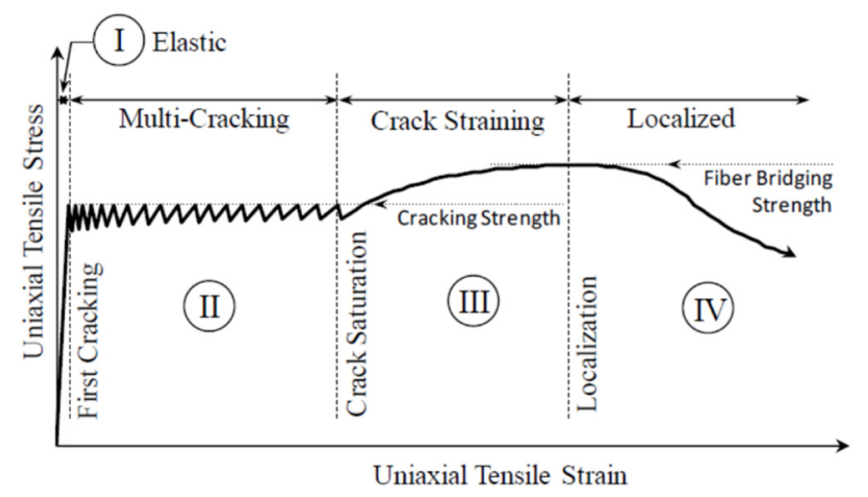

Figure 2.14 Idealised tensile response of UHPC in (Russell et al. 2013)

The French standard for UHPFRC (Association Francaise de Normalisation 2016a; b), which is based on recommendations (AFGC 2013), proposes classifying UHPFRC tensile behaviour into three classes: T1 ("strain-softening fibre-reinforced concrete"): 
those UHPFRC in which both the average and characteristic $f_{t u}$ (ultimate tensile strength) values are lower than $f_{t}$ (yielding tensile stress); T2 ("low strain-hardening fibrereinforced concrete"): those in which the characteristic $f_{t u}$ value is lower than $f_{t}$, but is not the average value; T3 ("high strain-hardening concrete"): those in which both the average and characteristic $f_{t u}$ values are higher than $f_{t}$. Figure 2.15 illustrates examples of the constitutive tensile law of the three classes considered. Depending on the UHPFRC class, a different tensile constitutive law can be used. For classes T1 and T2, the parameters required to determine tensile law derive from notched 3PBTs and the associated inverse analysis procedure; for class $\mathrm{T} 3$, an unnotched 4PBT and the associated inverse analysis are needed. Regardless of class type, the French standard applies two different tests: one to determine cracking strength and another to determine other tensile parameters. Moreover, the specimen geometry for the characterisation test depends on fibre length and structural size.

(a)

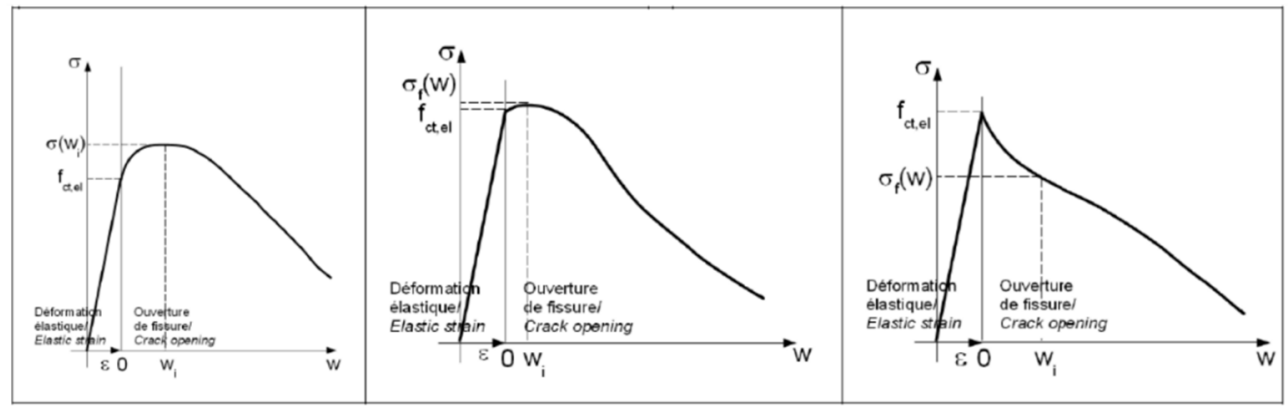

Figure 2.15 Tensile constitutive law (a) strain-hardening (T3), (b) low strainhardening (T2) and (c) strain-softening (T1) in (AFGC 2013).

The Swiss standard (Swiss Society of Engineers and Architects SIA 2016) considers the following to be indicative values of UHPFRC tensile parameters: $E=40-60 \mathrm{GPa}, f_{t}=7$ $12 \mathrm{MPa}, f_{t u}=7-15 \mathrm{MPa}, \varepsilon_{t u}=0-3.5 \%$ (strain at ultimate tensile strength) and $G_{F U}=15-$ $25 \mathrm{~kJ} / \mathrm{m}^{2}$ (specific energy at failure) for types UA and UB. The tensile constitutive behaviour is defined in two parts: stress-strain behaviour for the elastic and hardening part and stress-crack opening for the softening part. Figure 2.16 shows the tensile behaviour where $w_{\max }$ corresponds to half the maximum fibre length. To define tensile behaviour, two experimental tests can be used: dog-bone direct tensile tests to obtain the force-displacement experimental curve; a $4 \mathrm{PBT}$ and a simplified inverse analysis to derive the tensile response from the experimental load-deflection on the mid-span curve from 4PBT. The Swiss standard classifies UHPFRC into types U0, UA and UB according to tensile parameters: $f_{t, k}, f_{t u, k} / f_{t, k}$ and $\varepsilon_{t u k}$, that is: $f_{t, k} \geq 7 \mathrm{MPa}$ for U0 and UA and $f_{t, k} \geq 8.5$ for UB, $f_{t u, k} / f_{t, k}>0.7$ for U0, $f_{t u, k} / f_{t, k}>1.1$ for UA and $f_{t u, k} / f_{t, k}>1.2$ for UB, $\varepsilon_{t u k}$ $(\%)=f_{t} / E$ for U0 $\varepsilon_{t u k}(\%)>1.5$ for UA and $\varepsilon_{t u k}(\% o)>2$ for UB. 
(a)

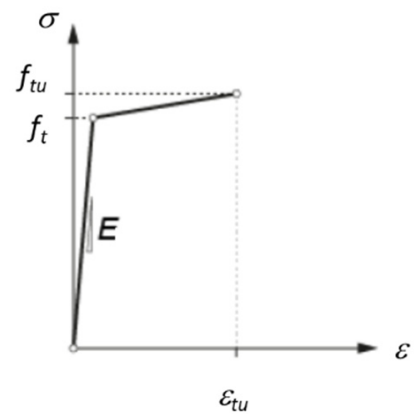

(b)

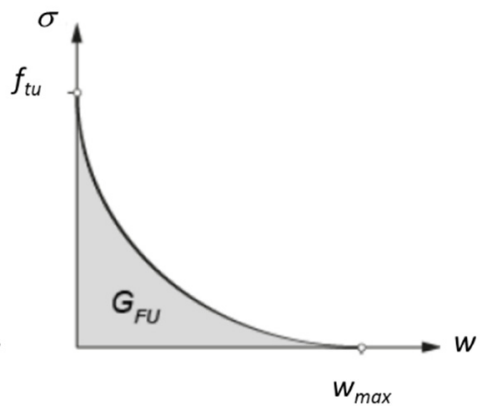

Figure 2.16 Constitutive tensile behaviour (a) stress-strain part and (b) stress-crack opening part in (Swiss Society of Engineers and Architects SIA 2016)

\subsubsection{UHPFRC in design}

In Australia, the recommendations of Ductal ${ }^{\circledR}$ properties (Gowripalan and Gilbert 2000) provide guidelines to design prestressed concrete beams cast using Ductal's Reactive Powder Concrete (RPC). Recommendations follow the philosophy of the limit state approach according to the design requirements of the Australian Standard for Concrete Structures AS3600-1994 (“AS 3600-1994. Concrete Structures.” 1994).

The Japan Society of Civil Engineering considerations (Japan Society of Civil Engineers 2008) address the design and construction of high-performance fibre-reinforced cement composites (HPFRCC) and steel-reinforced structures. They assume that the design process for HPFRCC structures are based on Standard Specifications for Concrete Structures ((JSCE) 2007), in which limit states corresponding to each performance requirement are prescribed. These recommendations exclude non reinforced HPFRCC structures. For these cases, they refer to the Standard Specification for Concrete Structures.

In the USA, the Federal Highway Administration (Russell et al. 2013) delivered a report that presents the state of the art for applying UHPFRC on highway transportation infrastructures. For design purposes, it summarises information available about the structural design of UHPFRC members corresponding mainly to articles in the AASHTO Load \& Resistance Factor (LRFD) Bridge Design Specifications ("AASHTO LRFD Bridge Design Specifications" 2012).

The French standard for UHPFRC (Association Francaise de Normalisation 2016a; b) is related to recommendations (AFGC 2013) and follows the plan of Eurocode 2 (The European Union Per Regulation 305/2011 and Directive 98/34/EC 2004) for structural 
design purposes based on a limit state design in conjunction with the partial factor method.

The Swiss standard (CT 2015) is an adaptation of UHPFRC to the proper national standards for concrete design (Association 2003), and is also based on the limit state design.

Therefore, it can be concluded from the principal standards and recommendations for UHPFRC structural design that they are practically all adaptations from CC design codes.

\subsection{Modelling UHPFRC}

As it is well known, the recommendations and standards for the case of UHPFRC are developed to design simple and statically determinate structures at ultimate limit state. Mainly they are conceived as an adaptation of conventional concrete to UHPFRC. When more complex structures in terms of more complex loading situations, statically indeterminate structures or more detailed analyses such as cracking in the serviceability limit state are addressed, it becomes necessary to consider more sophisticated methods to analyse these structures. Is in these scenarios where modelling is considered the best approach for design structures and to study them in detail. In this sense, modelling gives a detailed control of the material response analysed at material level and how this material behaves when it is integrated at structural level by itself or in combination with other materials. It is possible to study the best way to define its properties and which is its contribution to a more general structural purpose leading to optimise the synergy among the materials and the structure.

For modelling, it is necessary to understand the material behaviour and define it in a proper way at material level as it is going to be used in advanced structural analysis by means, for example, of non-linear physical and/or geometrical analysis leading the material response to its ultimate capacity. Following this idea, in this section, the basic type of material models definitions are presented, with their kinematic expressions and the way to obtain the numerical solutions. As the mathematical definition of the structural analysis leads to differential equations that have complex analytical solutions it becomes necessary to appeal to computational numerical techniques where the equilibrium between computational sources and accuracy of the numerical solution must be controlled in order to get the most optimised results. Therefore, the most generalised computational methods developed for numerical analysis are briefly described leading to the finite element method that arises as the most expanded method in civil engineering and structural analysis and the method used in this $\mathrm{PhD}$ work.

In the final part of this section, a literature review of the modelling of UHPFRC in the last decade has been addressed with the idea of highlight how it is characterised at material level, how are its material properties calibrated and validated, which approaches 
and numerical model techniques are used and what are the accuracy and reliability of the model developed and, finally, how it is modelled when it is integrated at structural level.

\subsubsection{Brief introduction to material models}

Here, in this section, a brief mention to the main classes of models defined to represent the mechanical behaviour of the materials is addressed with the idea to stablish a general framework to put in order the concepts used to develop the model in this work. The objective is not to go deep in mathematical developments and theories. Therefore, this introduction is considered from a conceptual point of view.

\subsubsection{Basic types of models}

The objective of a constitutive model is to set a mathematical relation between the deformation and the forces transmitted by the elementary entities in which a general body can be separated. Basically it can be established three types of constitutive material models: continuum models, discrete models and continuum models with discontinuities (Jirásek 2017). In the case of continuum models (Figure 2.17(a)), the entity is considered as an infinitesimal volume and the constitutive model or material behaviour can be described by means of stress-strain laws or by generalised moment-curvature relationships. Furthermore, in the case of discrete models (Figure 2.17(b)), the relation is stablished between internal forces and relative displacements considered at the edge of sections of finite entities in which the general body is divided. Continuum models with discontinuities (Figure 2.17(c)) could be considered a midway between continuum and discrete models. These models can be defined by a combination of continuous and discontinuous perspective. A clear example of this could be when the bulk material deformation is described by stress-strain relationship and the localised fracture is considered by means of a force-displacement discontinuity.

(a)
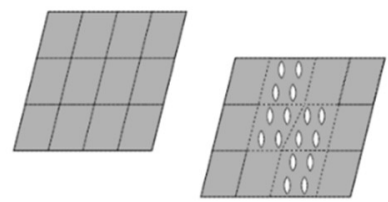

(b)

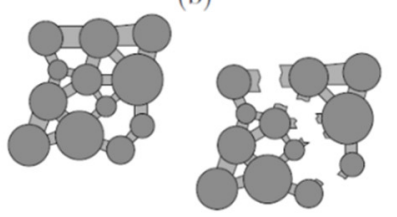

(c)

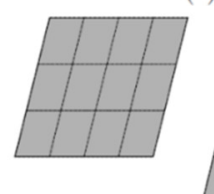

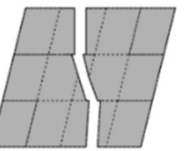

Figure 2.17 Basic types of model: (a) continuum models, (b) discrete models, (c) continuum models with discontinuities (Jirásek 2017)

\section{Continuum models}

Elastic models could be considered the simplest type of continuum models expressed by means of stress-strain relationship. A basic example of these could be the Hooke's law of isotropic linear elasticity. Elastic models could become more complex considering 
orthotropic or more general anisotropy concepts and nonlinear elastic models by means of hyperelasticity or hypoelasticity.

The theory of plasticity provides a wide and extended range of possibilities from the continuum constitutive models point of view. Maybe the most popular is the flow theory of plasticity that is considered a generalisation of the work of Tresca (Tresca 1869), Saint-Venant (Saint-Venant 1871), Lévy (Lévy 1871) and von Mises (Mises 1913) formulated in the stress space (Jirásek 2017) or in the strain space (Naghdi and Trapp 1975). Other alternative approaches are the total theory of plasticity (Ilyushin 1946), multi-surface plasticity (Dafalias and Popov 1975; Krieg 1975), the endochronic theory (Valanis 1978), hypoplasticity (Kolymbas 1977) or generalised plasticity (Lubliner 1991). These theories commonly split the total strain into an elastic strain component and a plastic one, and consider constant elastic stiffness.

The damage theories consider a progressive degradation of the stiffness moduli. In its simplest version (isotropic damage model) the damage is represented by a scalar parameter (Kachnov 1958). More complex damage theories consider the damage as an anisotropic property by means of a family of vectors (Fonseka and Krajcinovic 1981; Krajcinovic and Fonseka 1981), second-order tensor (Vakulenko and Kachanov 1971), fourth-order tensor (Chaboche 1982) or even more.

The smeared crack models are a type of constitutive models developed to model the tensile behaviour of concrete (De Borst and Nauta 1985; Cope et al. 1980; Gupta and Akbar 1984; Rashid 1968; Suidan and Schnobrich 1973). As it happens with the plasticity, these models separate the total strain into an elastic strain component and an inelastic component, here denoted as cracking strain. This inelastic strain is generated as a consequence of the crack opening and it is directly related to the traction transmitted through the crack. The use of smeared crack models are very extended to model cracking concrete in commercial finite element software. Smeared crack concepts can be classified into fixed and rotating smeared approaches (Rots 1988). Concerning the fixed approach the orientation of the crack is fixed during the entire computational process and the shear tractions across the crack are considered using a defined retention factor. On the other hand, the rotating approach lets that the crack co-rotate with the axes of principal strain. Moreover, there is an intermediate option defined as fixed multidirectional smeared crack approach where the orientation of the crack is updated in stepwise process following a threshold angle.

The reality of the material modelling can be very complex as more deep and accurate analyses are developed to improve the material and structural response. Therefore, it is frequent to combine two or more basic models above described. For example, in the case of concrete the combination of damage and plasticity is used for certain models (Lubliner et al. 1989).

One of the most important advantages of continuum models and the principal reason of their extended applicability is that it is not necessary to know previously the crack path, 
as the damage is modelled as a continuum in all body. However, as their constitutive laws are expressed generally in terms of stress-average strain, when they are employed in computational methods in structural analysis such as the finite element method, they may become mesh size dependent if the constitutive law is not adequately scaled or corrected (Switek 2008). This is an important characteristic that is addressed in this work and has direct relation in the modelling analysis results.

\section{Continuum models with discontinuities}

These kind of models could be considered a hybrid solution where the advantages of the continuum and discrete models are taken into account. The idea is to improve the continuum consideration by displacement discontinuities where individual deformation patterns are localised, such as macroscopic cracks (macrocracks). Therefore, the continuous part of the model is described using a stress-strain constitutive behaviour (e.g. linear elastic or inelastic law) while the discrete discontinuity is modelled taking into account an initiation and propagation criteria to activate, for example, a tractionseparation law. This is the reason why in the continuum models with discontinuities it is necessary to know, previously, the crack path.

The theory of linear elastic fracture mechanics considers a pre-existing crack where the propagation starts when the stress at the tip reaches a certain value. The direction of the propagation, in this theory, is defined, for example, by the maximum shear stress (Erdogan and Sih 1963), by the maximum energy release rate (Hussain et al. 1974) or by the minimum density of strain energy (Sih 1974).

The fictitious crack model (Hillerborg et al. 1976) set a traction-separation constitutive law that describes the gradual loss of cohesion through the crack path.

In the discrete crack approach (Ngo and Scordelis 1967), where, even though its name, the crack is discrete and the rest of the material is modelled as a continuum, the structure is discretised using finite elements and cracks are considered as discontinuities between them. On the other hand, in the embedded crack approach (Klisinski et al. 1991) the displacement discontinuities are considered in the body of the finite element.

\section{Discrete models}

Discrete models are built assembling elementary entities of finite size: bars, beams, springs...In these models, the elastic properties of the entity (e.g. a beam) can be derived from a continuum model and, in this sense, the elementary entity of a discrete model will behave close to a finite element of a discretised continuum model. However, in the nonlinear range, the model is built directly using the equations that govern the response of the finite-sized entity. This elementary entity often could be a macroscopic structural element such as a concrete beam of a building. For this case, the constitutive law could be obtained from experiments or simulations of the entity by means of more refined 
model. An extended application of discrete models is at microstructure level by means of particle models related, for example, to the numerical concrete (Roelfstra et al. 1985).

\subsubsection{Kinematic behaviour}

The mechanical behaviour of concrete, which is considered a quasibrittle material, is characterised by the localisation of damage in narrow zones (also known as process zones) where a gradual development of macroscopic stress-free cracks takes place as a consequence of strain concentration. To build the model it is necessary to consider a kinematic description that is directly related to the constitutive law for the cracking material. Therefore, taking into account the regularity of the displacement field, $\mathrm{u}(\mathrm{x})$, it is possible to set three types of kinematic behaviour (Jirásek 2017). From the discontinuity curve for the case of 2D (a surface for 3D), the strain curve can be obtained as the differentiation of the displacement field for the three types of kinematic behaviour considered.

The first one is related to strong discontinuities (Figure 2.18) which can be considered jumps in displacements across the discontinuity curve. Consequently, the strain field is represented by a constant or regular part and a singular point where the jump is located. This strong discontinuity represents the crack. This is, for example, the case for the linear elastic fracture mechanics approach (classified before as a continuum constitutive model with discontinuities) when it is applied to a very large scales where the damage process zone is negligible compared to the size of the entire body. In this case, the strong discontinuity is considered as stress-free. Other case that emerges from this kinematic approach is represented by the cohesive crack models. In these models, the cohesive traction depends on the displacement jump $(\Delta \mathrm{u})$, although the development of the process zone is conditioned also by strains (or stresses) in the tangential plane. Consequently, in this case, the strong discontinuity is defined by its proper constitutive law, set as a traction-separation behaviour that complements the stress-strain constitutive behaviour defined for the continuous part of the body (see Figure 2.19). The area under the traction-separation law is considered as the energy necessary to generate a stress-free crack of a unit area. This energy is defined as the Mode-I fracture energy, $G_{F}$.
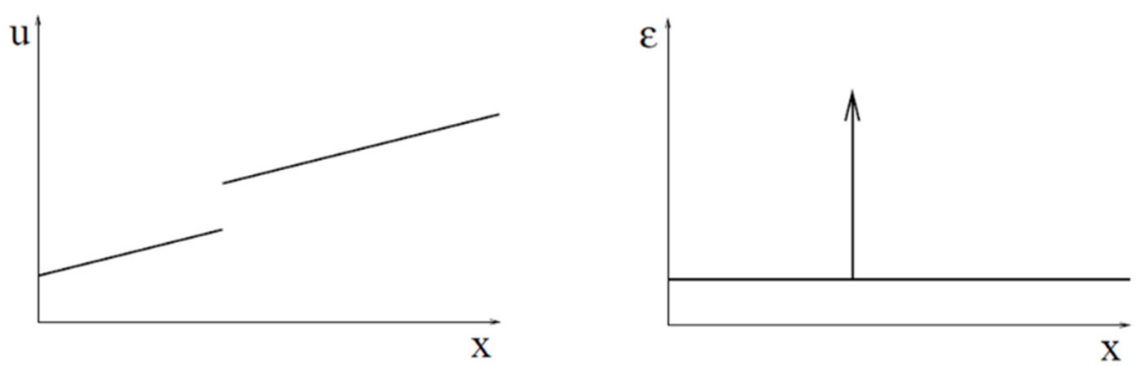

Figure 2.18 Kinematic description with one strong discontinuity 

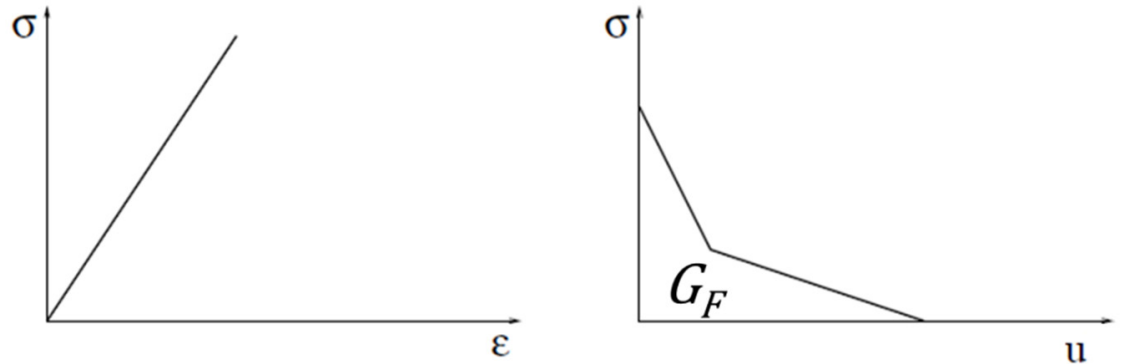

Figure 2.19 Constitutive behaviour for cohesive crack model

The second type of kinematic model is that related to localised bands bounded by two weak discontinuities, where the displacement field is preserved continuous although certain components of the strain field have a jump (Figure 2.20). The band between discontinuities is related to a damage process zone with more or less constant density of microdefects. In these models, it is possible to distribute the inelastic effects uniformly through the width of the band with a finite thickness $h$. This is the case of the smeared crack models, classified before as continuum constitutive models. The smeared crack models transform the traction-separation law into a stress-strain law that relates the stress transmitted by the localised band to the average inelastic strain in that band (see Figure 2.21). If $[[\mathrm{u}]]$ is the normal component of the displacement jump, the inelastic normal strain is obtained as $\varepsilon_{\mathrm{i}}=[[\mathrm{u}]] / \mathrm{h}$, and its corresponding area under the softening curve, $G_{F}$ $/ h$, is translated now as the energy spent per unit volume of the localised band. Sometimes, as it happens with the continuum damage mechanics (continuum constitutive model), a law that directly links the stress to the total strain can be used, instead of splitting the constitutive law into the elastic (or basic part) and inelastic part (or the part activated after localisation).
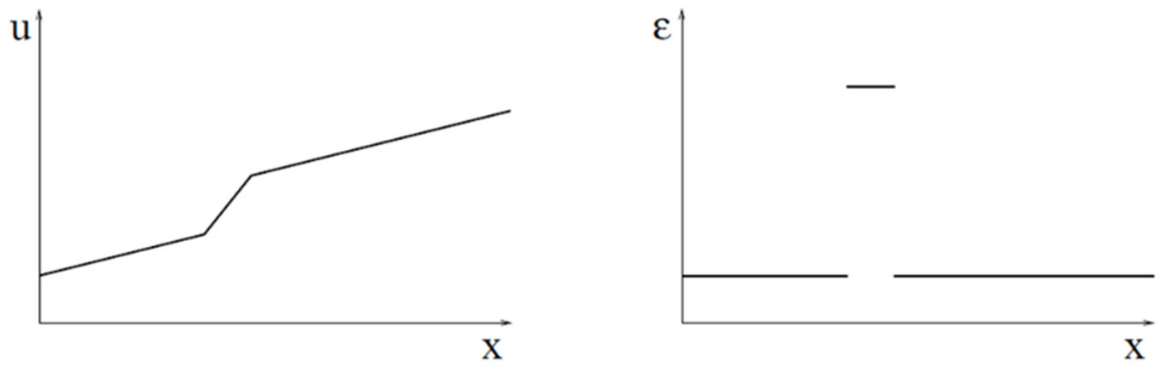

Figure 2.20 Kinematic description with two weak discontinuities 

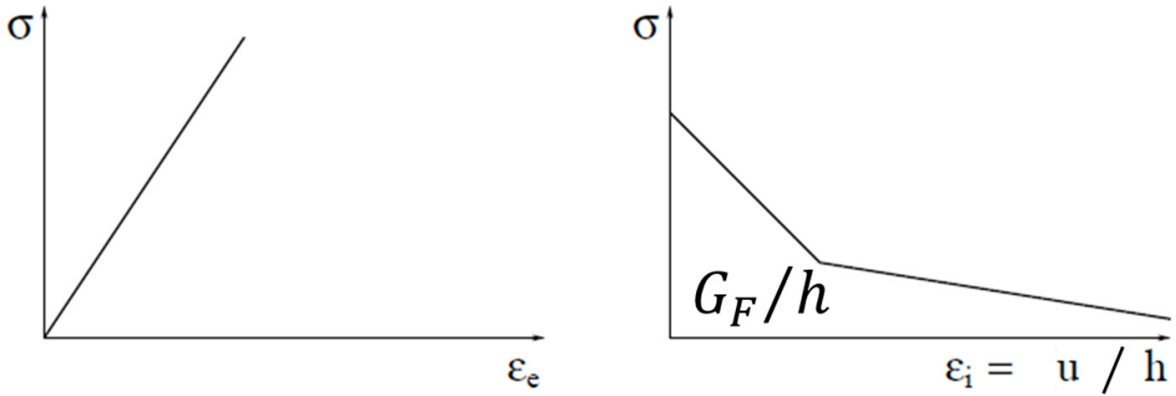

Figure 2.21 Constitutive behaviour for smeared crack model

The third type of kinematic behaviour corresponds to the most regular description that uses a continuously differentiable displacement field with no discontinuities (Figure 2.22) and, therefore, the strain field remains continuous. In this case, strain localisation takes place by large strains lumped in a narrow band, with a continuous transition to smaller strains in the vicinities of the body. This is related to a damage process zone with higher concentration of defects around its centre. Strain fields that are continuous even after the beginning of localisation can be obtained by more complex regularisation techniques (Figure 2.23). They can be based on different forms of enriched continuum models. This kind of enrichments traditionally uses a parameter defining a characteristic length of the material and related to the spacing and size of heterogeneities that control the width of the localised zone.
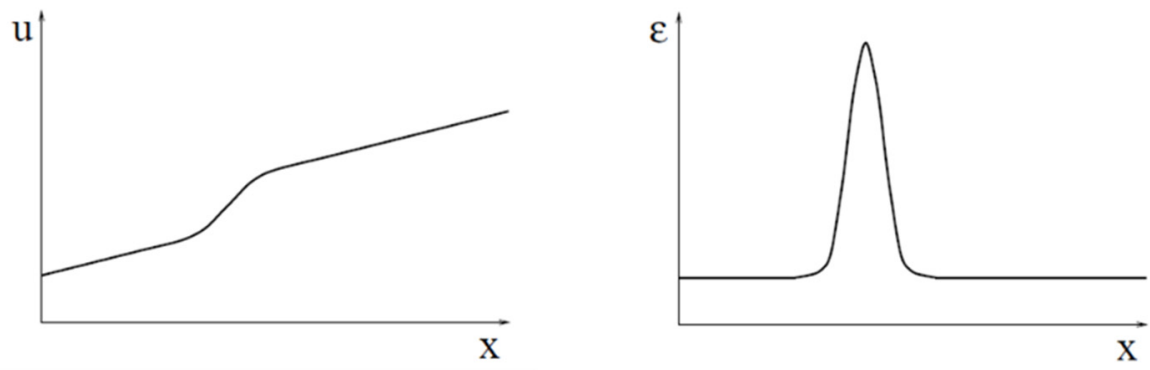

Figure 2.22 Kinematic description with no discontinuities 


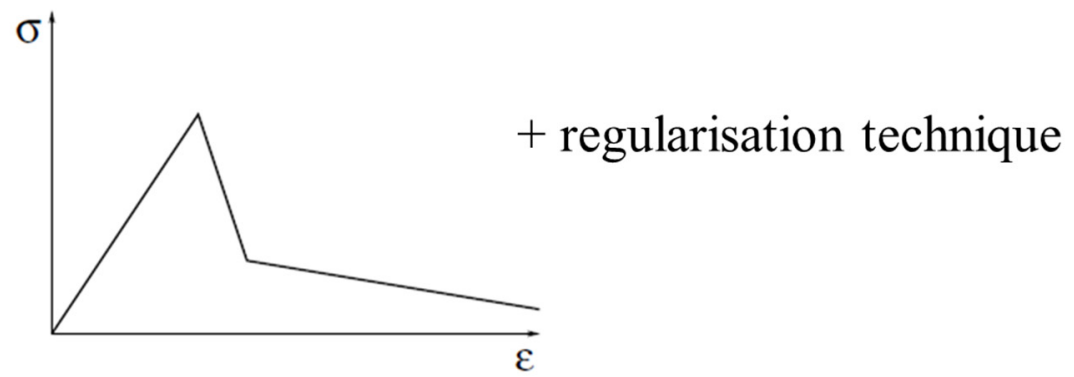

Figure 2.23 Constitutive behaviour for regularised continuum model with softening

\subsubsection{Numerical solutions}

The common idea to all types of models described before is that the particularities of the kinematic response of the localised process zone can be solved either by standard finite elements, that frequently requires fine meshes or constant remeshing, or by special enrichments used together with a relatively coarse mesh.

The case of a strong discontinuity can be addressed using interface elements situated between $2 \mathrm{D}$ or $3 \mathrm{D}$ elements used to divide the general body. This implies to know beforehand the discontinuity or crack path. However, the crack path is not obvious and, therefore, it could be previously unknown. In this case it is necessary to consider other solutions such as frequent remeshing or the use of enhanced finite elements that have enrichments in their standard shape functions by means of special discontinuous functions (Dvorkin et al. 1990; Klisinski et al. 1991).

The models of localised bands of finite thickness can be approximated by finite elements without the need of introducing interface elements, but the band must be aligned with the mesh lines, if not, spurious stresses (stress locking) could be generated. In these cases, the thickness of the band is related to the size of the finite elements and, the softening part of the stress-strain constitutive behaviour, needs to be accordingly adjusted. Other alternative could be the use of enhanced elements with embedded localisation bands that let the modelling of these bands with arbitrary direction respect to the mesh lines and arbitrary thickness (Belytschko et al. 1988; Sluys 1997).

In the case of kinematic models with no discontinuities it is necessary to employ fine discretisation meshes in standard finite elements in order to be able to capture the steep strain gradients. Other alternative could be the use of special enriched finite elements adapted to these particularities (Belytschko et al. 1990; Fish and Belytschko 1990), as it happens with the other cases previously described. 
From all of the aspects treated it can be concluded that, depending on the perspective that the modelling of the crack is addressed, it is necessary to consider the type of constitutive behaviour that is fully related to the kinematic behaviour and, according to these, the model will respond more or less accurately depending on the numerical technique adopted to solve the problem. The possibility of using enriched finite elements is not frequent when a commercial software of finite elements is used, so it is necessary to take into account the alternatives and the particularities of each software in order to develop the appropriate model using standard finite elements and interfaces.

\subsubsection{Models and computational methods in structural analysis}

From a strict point of view, the vast majority of the structures in civil engineering such as plates, beams, tanks, roofs, bridges and dams should be considered as continuum structural systems with an infinite number of degrees of freedom. Therefore, to know their response when they are subjected to external loadings it should be necessary to integrate the corresponding equilibrium differential equations. This is, their behaviour is not possible to be expressed accurately as a function of a small number of discrete variables. In this sense, to carry out a rigorous analysis of these structures, it is necessary the integration of the differential equations that define the equilibrium of a generic differential element that is part of them. However, the geometry of these structures, the boundary conditions, the distribution of the mechanical properties of the materials that define the structure, the type of loads, etc. lead to make this kind of analysis so hard or even impossible. Consequently, in practise, it is necessary to use more simplified methods in order to let approximated structural analyses with sufficient accuracy and reliability. The most universal and extended technique applicable to problems with arbitrary geometry and boundary conditions in civil and structural engineering actually is the finite element method.

The finite element method is one of the existing numerical techniques that let to approximate the behaviour of a structure with an infinite number of degrees of freedom to another with more or less the same physical and geometrical properties but with a finite number of degrees of freedom. Therefore, equilibrium equations can be expressed by an algebraic system of simultaneous equations with a limited number of variables. However, with the same objective, in certain disciplines other numerical methods such as the finite difference method, boundary element method, finite volume method, spectral methods or meshless methods are used.

\subsubsection{Finite difference method.}

The advances in numerical computing and new techniques facilitate accurate and fast solution of complex boundary value problems. Finite difference methods are used to solve problems related to diffusion theory, heat transfer, fluid mechanics, structural analysis, electrostatics, magnetism, and other engineering fields (Kerlin and Upadhyaya 2019). 
The finite difference approximations for derivatives are one of the simplest and oldest methods to solve differential equations. It was first developed by L. Euler (Euler 1768), in one dimension of space and was probably extended to two dimensions by C. Runge (Runge 1908). The expansion of finite difference techniques in numerical applications started in the early 1950s and their development was increased due to the rise of computers that bring a convenient framework for dealing with complex problems of science and technology. Theoretical results have been obtained during the last five decades regarding the accuracy, stability and convergence of the finite difference method for partial differential equations (Blazek 2015; Choi et al. 1993; Dow 1999; Sadd 2014; Shaoxian and Shizhu 2019; Yam and Cheng 1993).

The principle of finite difference methods is close to the numerical concepts used to solve ordinary differential equations (ODE). It consists in approximating the differential operator by replacing the derivatives in the equation using differential quotients. The domain is partitioned in space and in time and approximations of the solution are computed at the space or time points. The error between the numerical solution and the exact one is obtained by the error done by going from a differential operator to a difference operator. The objective of a finite difference method for solving an ordinary differential equation (ODE) is to transform a calculus problem into an algebra problem (Hoffman and Frankel 2018).

For computations that need high accuracy, the extra effort in making boundary-fitted meshes and the associated complications of such meshes for the implementation may be an important disadvantage mainly in structural and civil engineering problems.

\subsubsection{Boundary element method.}

Boundary integral equations are considered a classical tool for the analysis of boundary value problems for partial differential equations (Antes 2010; Costabel 1986). The concept of "boundary element method" (BEM) is related to any method for the approximate numerical solution of these boundary integral equations. The approximate solution of the boundary value problem solved by BEM has the particular characteristic that it is an exact solution of the differential equation in the domain and is parametrised by a finite set of parameters situated on the boundary (Carlton 2012; Leo and Elzein 2001; Matsumoto et al. 2003; Poljak 2018; SADD 2005; Vigé 2010).

Some advantages of BEM can be considered in comparison to other numerical methods such as finite element methods or finite differences:

1. Only the boundary of the domain is necessary to be discretised.

2. Exterior problems with unbounded domains but bounded boundaries are considered as easily as interior problems.

3. There are some applications in which the physically pertinent data are given by the boundary values of the solution or its derivatives and not by the solution in the interior of the domain. These data is possible to be gotten directly from the solution of boundary 
integral equations while, in case of finite element methods, boundary values obtained are in general not very accurate.

4. The solution inside the domain is approximated with a considerable high convergence rate and the same convergence rate is kept for all derivatives of any order of the solution in the considered domain. However, there are difficulties when the solution has to be evaluated close to, but not on the boundary.

On the other hand, some difficulties with BEM have to be considered:

1. Boundary integral equations require the consideration of a fundamental solution of the differential equation. This is possible only for linear partial differential equations with constant or some particularly variable coefficients. Problems with heterogeneities or nonlinear differential equations are generally not accessible by pure BEM.

2. For a considered boundary value problem there are different boundary integral equations and, for each of them, several numerical approximation methods. In this way, in every BEM application several choices must be done. To evaluate the different possibilities, it is necessary to do mathematical analysis and, therefore, the BEM application could be considered an incomplete tool.

3. If the boundary has edges and corners and is not smooth, the solution of the BEM has singularities at the boundary. This can happen also if the boundary conditions are discontinuous.

\subsubsection{Finite volume method.}

The Finite Volume Method (FVM) is a discretisation method for the approximation of a single or a system of partial differential equations expressing the conservation, or balance, of one or more quantities. These partial differential equations (PDEs) are known as conservation laws; they can be from different nature such as elliptic, parabolic or hyperbolic, and they are considered in models in different fields such as physics, biophysics, chemistry, image processing, finance, dynamic reliability, computational fluid mechanics... They explain the relations between partial derivatives of unknown fields such as temperature, concentration, pressure, molar fraction, density of electrons or probability density function, with respect to variables within the domain under consideration: space, time... (Aleksendrić and Carlone 2015; Ciarlet et al. 1990; Feistauer et al. 2003; Mazumder 2016a; Neill and Hashemi 2018; Rapp 2017)

As it happens in the case of the finite element method, a mesh is used. The mesh discretises the domain where the space variable is defined. The elements of the mesh are known as control volumes. The integration of the PDE over each control volume results in a balance equation. The set of balance equations is consequently discretised with respect to a set of discrete variables. The main issue is the discretisation of the fluxes at the boundaries of each control volume. To be efficient from the FVM perspective, the numerical fluxes need to be conservative (the flux entering in a control volume from its neighbour must be the opposite of the one entering in the neighbour from the control 
volume) and consistent (the numerical flux of a regular function interpolation tends to the continuous flux as the mesh size disappears).

In some occasions, it is also possible to discretise the fluxes at the boundaries of the control volume by the finite difference method (FDM). The difference of the FVM with respect to the FDM is that the discretisation is carried out on the local balance equations, instead of in the PDE: the fluxes on boundaries of the control volumes are discretised, instead of the continuous differential operator. The resulting system of discrete equations depends on a discrete or finite set of variables, and could be either linear or non linear. This system is then solved exactly or approximately, using for example direct or iterative solvers in the case of linear equations and fixed point or Newton type methods in the case of nonlinear equations.

\subsubsection{Spectral methods.}

Spectral methods are a type of numerical methods employed in applied mathematics and scientific computing to numerically solve partial differential equations using the weighted residuals technique. In spectral methods, the solution is approximated as an expansion in terms of spectral basis functions. In this case, the basis functions are infinitely differentiable global (non-local) functions defined over a whole domain, as could be the case of trigonometric functions, Chebyshev polynomials and Legendre polynomials, leading to consider the spectral methods different from the finite-element and finite-difference methods. Spectral methods have a very high spatial accuracy for the case of well-behaved problems and, therefore, they are suitable for the numerical simulation of accurately predicting flows with a wide range of dynamically significant scales of motion (Elmo et al. 1999; Fischer and Tufo 2000; Kang and Suh 2008; Mazumder 2016b; Nevo 2006; Semenza 2006).

In contrast to finite difference methods, spectral methods are global methods, where the computation at any given point depends not only on information at surrounding points, but also on information from the complete domain. They have a great convergence as they converged exponentially. This makes them more accurate than local methods. Global methods are better to local methods when the solution changes considerably in time or space, when very high spatial resolution is required and when long time integration is needed.

Spectral methods were developed by Steven Orszag in 1969 (Orszag 1969) related to Fourier series methods for periodic geometry problems, polynomial spectral methods for finite and unbounded geometry problems, pseudospectral methods for highly nonlinear problems and spectral iteration methods for fast solution of steady-state problems. Two different approaches are normally used for the implementation of the spectral method: a Galerkin or a Tau approach.

In comparison to finite element methods, spectral methods are computationally less expensive, but they are less accurate for problems with complicated geometries and discontinuous coefficients. 


\subsubsection{Meshless methods.}

As the name "meshless methods" covers a wide range of numerical techniques, it is difficult to set a clear starting date for these methods. However, the first works could be attributed to those reporting extension of the finite difference methods to general irregular or unstructured grids in the early 1960s (Manzari 2013).

Meshless methods are considered a type of techniques for solving boundary/initial value partial differential equations where geometry representation and numerical discretisation are addressed based on nodes or particles. Meshless methods are independent of a particular mesh topology, therefore no element connectivity is required. However, in practice, there are some meshless methods in which it is necessary to consider some kind of background mesh at least in one step of the implementation.

In modern engineering there are many practical methods which analysis requires modelling of problems with time-dependent geometry or boundary conditions. Conventional mesh-based methods such as the finite volume and finite element methods are less efficient in cases related to large element deformations and/or element entanglement. This could be evident in the case of problems involving discontinuities and moving boundaries. Standard mesh-based techniques address these problems using adaptive remeshing techniques. This is, the computational mesh (grid) is remeshed either globally or locally to represent the deformed geometry correctly. However, this technique presents two disadvantages. The first one is the considerable time consumption related to the generation of a new mesh and its possible derived problems. A clear example of this is the generation of meshes for complex 3D geometries using automatic mesh generators. The second disadvantage is that the mapping of the state variables from the old mesh to the new one can produce significant computational numerical errors and uncertainties.

Some of the advantages of meshless methods could be:

1. Problems related to large deformations can be addressed considering that the connectivity among nodes is generated during the computation and can change in time during the process.

2. There are no constraints imposed from the system geometry, and the system can evolve far from the initial conditions.

3. Nodes can be added in the regions where refinement is necessary. Therefore, the accuracy of the solution is able to be very well controlled.

4. Complex geometries can be accurately represented by particles.

5. The particles map onto the mass density of the fluid, leading automatically to higher resolution in the high-density regions.

6. Very simple implementation process. 
If the physical principle is considered, meshless (particle) methods can be classified as deterministic and probabilistic. Moreover, they can be classified as strong and weak formulations of the associated partial differential equations. The current trend in computational methods is to use particle methods both as discretisation tools and physical models for continuum physics simulation (Bourantas et al. 2018; Stach 2014; Wang and Qin 2019a; b; c).

\subsubsection{Finite element method.}

The finite element (FE) method could be considered nowadays one of the best procedures for the analysis of engineering structures in one, two and three dimensions under the action of different types of external solicitations. The direct analogy between the matrix analysis of structures (Livesley 1975; Przemieniecki 1985) and the finite element method leads to a better comprehension of the latter contributing to its widespread and diffusion in the civil and structural engineering field.

From the structural engineering point of view, the FE method could be considered as an extrapolation of the matrix structural analysis method for bars to the continuum structural analysis. In this direction, the first attempts for solving bi-dimensional elasticity problems with matrix technics by means of the division of the continuum in bar elements arose in the early 1940s (Hrennikoff 1941; McHenry 1943). In 1943 the concept of "continuum element" was introduced for the first time by (Courant 1943) to solve plane elasticity problems by means of the division of the analysis domain in triangular "elements" considering a polynomial variation of the solution. The massive appearance and fast development of the computer's technology in the $60 \mathrm{~s}$ lead to a great progress of the methods based in matrix analysis techniques, now free of the technology limitations to solve systems of equations. Is in this moment when the FE method becomes stablished as an appropriate procedure to solve a wide range of physics and engineering problems. It is worth denoting that its first applications in this context are related to structural analysis and especially in structural applications in aeronautical engineering (Argyris and Kelsey 1960; Turner et al. 1956). In fact, Clough (Clough 1960) in 1960 was the first who suggested the term "finite elements" related to the analysis of plane elasticity problems. From those dates to the present the finite element method has reached a great development in its applications to another fields such as mechanical engineering, electromagnetic, biomedicine, geo-mechanics, industrial product development, music science applications... (Al-Momani and Rawabdeh 2008; Carlson 2011; Cui et al. 2009; Jin 2015; Kuhlemeyer and Lysmer 1973; Moratal 2012; Zienkiewicz et al. 2000). Therefore, with the support of the computer development technology and the increasing complexity of a wide range of fields of the science and engineering, the FE method has become one of the most widespread numerical methods and a powerful technique for the resolution of diverse and complex problems in different engineering fields.

In the PhD work developed herein, the finite element method has been used to carry out the structural non-linear analysis of UHPFRC flexural and tensile elements to study the 
tensile behaviour due to its direct relation to the structural and civil engineering field and its widespread development worldwide through applications and computational software. Material theories and models have been developed and adapted to the finite element method through scientific and technical research during the last fifty years. Therefore, the material model developed for UHPFRC in Chapter 3 is adapted and implemented to the finite element workflow explained in Chapter 4 of the present work.

\subsubsection{Modelling UHPFRC in the literature}

In the literature, it is possible to find numerical models for UHPFRC using finite element modelling (FEM). Frequently, the concrete material model available in FE packages is validated with the limited number of tests conducted on material and structural members (Singh et al. 2017).

To model a structural element using UHPFRC it is necessary, first, to characterise the material properties in order to define in the FEM the material behaviour. Depending on the material model that is going to be used, e.g. damage-plasticity model, smeared crack model or fictitious crack model among others, its implementation and its adaptation to a FEM software could be simpler or not. To implement the material constitutive behaviour in the FEM it is necessary to take into account at least compressive and tensile parameters. The compressive parameters such as compressive strength are obtained from cubical or cylindrical compression tests. For the case of tensile parameters, they are mainly obtained from direct tensile tests where the stress-strain response is directly obtained or bending tests which need inverse analysis procedures to obtain the tensile response from the experimental bending curve. These constitute the previous tests to characterise the material behaviour. Once the material is defined, the FEM is commonly calibrated modelling, for example, the proper tensile test or by means of bending tests. Is in this stage where is also important to define and calibrate special effects that can describe and determine the particular behaviour of UHPFRC such as shrinkage effect, tension stiffening or interfacial behaviour between UHPFRC and other materials. Therefore is very frequent to find in the literature works where previous tests are done to characterise the material model and then, the FEM is calibrated by bending test from experimental reinforced beams. Once the FEM is well defined and calibrated, the jump to more complex structural elements considering more complex loading situations could be considered straightforward.

In this sense, to build a reliable model able to simulate the tensile response of UHPFRC structural elements with certain accuracy, it seems logical to follow a basic sequence from the beginning at material level towards the structural complex level. It is necessary to adequately define the constitutive UHPFRC tensile behaviour at material level and characterise its parameters from experimentally reliable characterisation tests. Then, a suitable material model able to represent the particular UHPFRC tensile response characterised by a considerable volumetric (bulk) energy during the elastic and hardening or softening part before the macrocrack apparition, and the surfacic (crack) 
energy released during the subsequent softening behaviour from the macrocrack apparition onwards must be set. The UHPFRC material model generated is implemented in the finite element method in order to be able to discretise the continuum body of a structural element and carry out a structural analysis. As the finite element technique is an extended computational method, it is frequent to use commercial software. Therefore, it is necessary to consider the aspects of the implementation of the material model and its interactions with other materials that compose the model for a particular software. The material models considering particular properties (such as the shrinkage), the geometry of the structural element, the possible interaction with other geometries by means of interface transitions, the type and disposition of finite elements to define the mesh, the boundary conditions, the definition of the loads and the analysis strategy constitute the steps that lead to more or less complex and accurate FEM.

All these modelling aspects concerning to UHPFRC can be identified in recent research works during the last ten years, where the characterisation of UHPFRC constitutive behaviour is addressed to develop and calibrate the FEM.

To define the tensile behaviour of UHPFRC with different amounts of fibres (from $0 \%$ to $6 \%$ in vol.), experimental characterisation tests by means of direct tensile test (Krahl et al. 2018; Lampropoulos et al. 2016; Mahmud et al. 2013; Naeimi and Moustafa 2020; Pyo et al. 2015; Sadouki et al. 2017; Sakr et al. 2019; Singh et al. 2017; Zhu et al. 2020) and 3PBT or 4PBT with inverse analysis (Kang et al. 2010; Krahl et al. 2018; Rossi et al. 2018; Yin et al. 2019a; b; Yoo et al. 2017b) have been carried out.

To define the UHPFRC material model the option of continuum models are extensively used by means of the concrete damage-plasticity model (Krahl et al. 2018; Mahmud et al. 2013; Sakr et al. 2019; Singh et al. 2017; Yin et al. 2019b; a; Zhu et al. 2020), the smeared crack model (Lampropoulos et al. 2016; Naeimi and Moustafa 2020; Sadouki et al. 2017), including concrete properties such as the shrinkage (Lampropoulos et al. 2016), and the isotropic elastic-plastic model (Pyo et al. 2015). To avoid the mesh size dependency of the continuum models, the finite element size has been calibrated to obtain the adequate size to fit the experimental results in (Singh et al. 2017; Yin et al. 2019a).

The option of continuum models with discontinuities where the crack path can be situated by means of interface elements is also employed. (Kang et al. 2010) used an inverse analysis methodology from (Uchida and Kurihara 1995) that incorporated the discrete cracking approach by means of the fictitious crack model (Hillerborg et al. 1976) in a FEM where the crack was situated in the notch of the 3PBT. (Yoo et al. 2017b) modelled the 3PBT using an adaptation of the idea of the discrete cracking approach situating an interface element in the notch position defined by its proper tractionseparation law where even the effect of fibre-bridging was included. The elements outside the considered cracked area (in the continuum part) were modelled to exhibit linear elastic response. (Rossi et al. 2018) defined what could be considered an evolution of the discrete cracking approach by means of a random creation of kinematic 
discontinuities applying a random spatial distribution of mechanical properties, such as the Young's modulus and the tensile strength, in the cracking formation process where cracks were represented by interface elements. Linear interface elements were located between all the volume elements that modelled the reinforcement bars to allow cracks to cross the rebars. The influence of the fibre orientation was also considered in this research in the particular process of the specimens casting.

In addition, the interaction between UHPFRC matrix and the reinforcement bars is frequently considered as embedded reinforcement in concrete (Naeimi and Moustafa 2020; Sadouki et al. 2017; Sakr et al. 2019; Singh et al. 2017; Yin et al. 2019a; Zhu et al. 2020). In this sense, full bond is assumed between the reinforcement bars and concrete behaviour. It is also possible to use interface elements with a defined bond-slip behaviour between concrete and reinforcement (Rossi et al. 2018). The same idea is adapted to define interactions between two layers of different concretes in retrofitted or strengthened elements by means of perfect bond (Sadouki et al. 2017), contact interface elements (Lampropoulos et al. 2016; Sakr et al. 2019; Yin et al. 2019b) or special definition of interface behaviour to simulate connectors (Zhu et al. 2020).

When the finite element model (FEM) is built, it is calibrated modelling the geometry of the proper tests used to characterise experimentally the parameters of the constitutive UHPFRC model or by bending tests. Direct UHPFRC tensile tests have been modelled in (Lampropoulos et al. 2016; Naeimi and Moustafa 2020; Pyo and El-Tawil 2015) and compared to the experimental response. Unreinforced 3PBTs in (Mahmud et al. 2013; Rossi et al. 2018; Yoo et al. 2017b) and 4PBTs (Krahl et al. 2018) are also modelled and calibrated comparing to experimental results. From these calibrations to assure the reliability of the basic FEM, the model can be extended in complexity and enriched with more details in order to model more sophisticated structural elements such as composed, strengthened or retrofitted elements (Lampropoulos et al. 2016; Sadouki et al. 2017; Sakr et al. 2019; Yin et al. 2019b; Zhu et al. 2020), reinforced full scale beams (Rossi et al. 2018; Sadouki et al. 2017; Singh et al. 2017; Yin et al. 2019a; b), shear walls (Sakr et al. 2019), slabs (Zhu et al. 2020) or bridge columns (Naeimi and Moustafa 2020).

As the finite element method is an extended and very well adapted computational method to the structural and civil engineering, there are available sophisticated software packages able to exploit the advantages and the capacity of the computer technology that are used in UHPFRC modelling research such as ABAQUS-FEA in (Krahl et al. 2018; Mahmud et al. 2013; Sakr et al. 2019; Singh et al. 2017; Zhu et al. 2020), DIANA-FEA in (Naeimi and Moustafa 2020; Sadouki et al. 2017; Yoo et al. 2017b), ATENA in (Lampropoulos et al. 2016) and LS-DYNA in (Pyo and El-Tawil 2015; Yin et al. 2019a; b), among others. It is important to understand the way of working of the software that is used, the fundamental theory and the way of implement and use the models that it offers.

In the following, the most representative literature research works related to UHPFRC modelling in the last decade and just treated before are described in more detail to show 
how can be addressed the modelling of UHPFRC and what are the strategies followed by the different researchers in this field. They are separated in two main groups depending on their principal objective: material characteristics and FEM calibration for works focused mainly in the basic part of UHPFRC modelling, and modelling UHPFRC structural elements for works focused in the modelling on more complex structures.

\subsubsection{Material characteristics and FEM calibration}

The material characteristics and the calibrations for the numerical model can be obtained generally from the results of experimental programmes, such as uniaxial tensile tests (Abrishambaf et al. 2017; Graybeal and Baby 2013; Lampropoulos et al. 2016; Liu et al. 2016; Pyo et al. 2015, 2016; Rahdar and Ghalehnovi 2016; Singh et al. 2017; Tran et al. 2015; Wille et al. 2014, 2010), bending tests (Baby et al. 2012; Kanakubo 2006; Kang et al. 2010; López et al. 2015b; Mahmud et al. 2013; Singh et al. 2017; Wan et al. 2016; Yang et al. 2010; Yoo and Banthia 2015) and biaxial tests (Lee et al. 2017; Tysmans et al. 2015; Yoo et al. 2015b).

In this section a literature review of the UHPFRC characterisation and material modelling of the last 10 years has been done. The research works here described contains the main steps to characterise and model UHPFRC followed in the work carried out in this $\mathrm{PhD}$ document. In all of them, it is possible to find the main points to characterise and model UHPFRC at material level as a previous step to extend the modelling to UHPFRC structural elements.

For modelling UHPFRC it is important to set the way of experimentally characterise the material behaviour of UHPFRC both in compression (cylindrical, cubical specimens) and in tension (direct tensile tests, bending tests: 3PBT and 4PBT and the inverse analysis needed) to obtain the material parameters to define the constitutive material model and, thus, the parameters of the theoretical material model used (continuum models, discrete models, continuum models with discontinuities or combination of them explained in Section 2.5.1.). Once the UHPFRC is characterised and described at material level, to build the FEM it is necessary to define correctly the FE mesh, the geometry, the boundary conditions, the load definition and the interactions with other materials (interface properties, bond-slip, random distribution of fibres...) that are going to compose the FEM. All of them must be in accordance to the particularities of the material model used and implemented in the finite element workflow. Moreover, the type of analysis (linear, non-linear...) and the solution strategy (e.g. incrementaliterative procedure by means of incremental displacement or load control and iterative Newton methods for non-linear analysis) must be defined as they have direct relation to the solution convergence and computational effort. All this process must derive in accurate and reliable solutions when the numerical results are compared to the experimental ones. 


\subsection{Kang et al. 2010}

In order to study the effects of the fibre content on the tensile fracture properties of UHPFRC, Kang et al. (Kang et al. 2010) considered UHPFRC with 6 levels of high strength (13/0.2) steel fibre content: $0 \%$ in vol., $1 \%\left(78.50 \mathrm{~kg} / \mathrm{m}^{3}\right), 2 \%\left(157 \mathrm{~kg} / \mathrm{m}^{3}\right), 3 \%$ $\left(235.50 \mathrm{~kg} / \mathrm{m}^{3}\right), 4 \%\left(314 \mathrm{~kg} / \mathrm{m}^{3}\right), 5 \%\left(392.50 \mathrm{~kg} / \mathrm{m}^{3}\right)$ and $6 \%\left(471 \mathrm{~kg} / \mathrm{m}^{3}\right)$, keeping constant the water/cement $(\mathrm{W} / \mathrm{C})$ ratio in 0.25 . To characterise the UHPFRC tensile behaviour, five 100x100x $400 \mathrm{~mm}$ 3PBT specimens with a notch of $4 \mathrm{~mm}$ wide per each UHPFRC mixture were cast. One LVDT was set in each side of the specimen to measure the deflection at mid-span and a clip-gauge set in the bottom of the specimen to measure the crack width at the position of the notch (Figure 2.24).
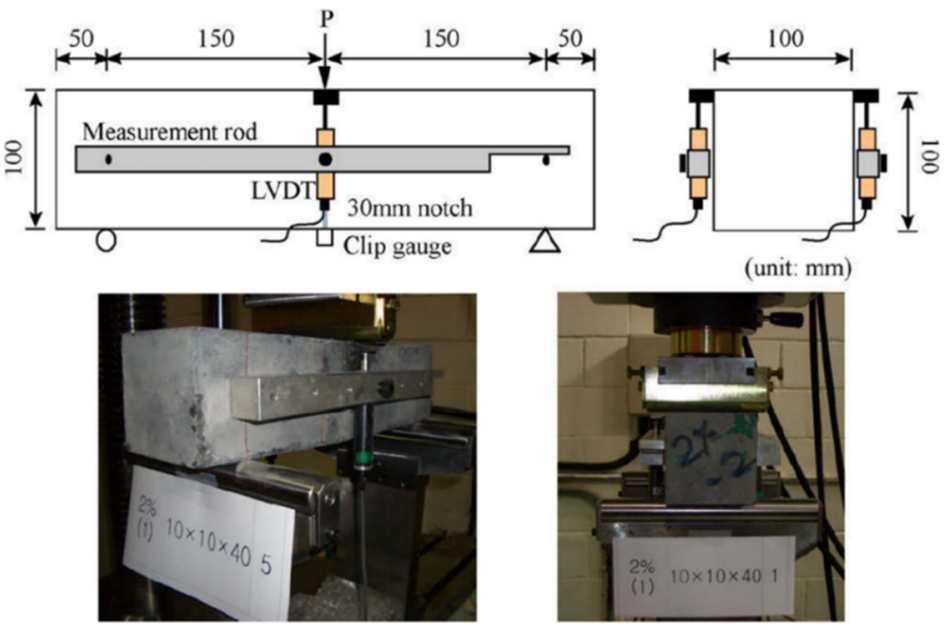

Figure 2.24 3-point bending test set up (Kang et al. 2010)

To characterise the tensile behaviour of the UHPFRC, they applied the inverse analysis method suggested by Uchida and Kurihara (Uchida and Kurihara 1995) to determine the tensile fracture model. This method uses the load $(\mathrm{P})$-displacement $(\delta)$ (deflection) curves obtained from the $3 \mathrm{PBT}$ to perform an inverse analysis using a finite element model (FEM) and a poly-linear approximation method. The poly-linear approximation method used, first developed by (Kitsutaka 1993), consists in the determination step by step of a softening stress $(\sigma)$-crack opening $(w)$ concrete response using the fictitious crack model (Hillerborg et al. 1976) to obtain the numerical P- $\delta$ curve from the FE application and comparing to the experimental 3PBT curves in an inverse analysis. As a result, the so called "primitive cohesive tensile stress-crack width softening curve" is obtained for UHPFRC. Figure 2.25(a) shows the procedure. 

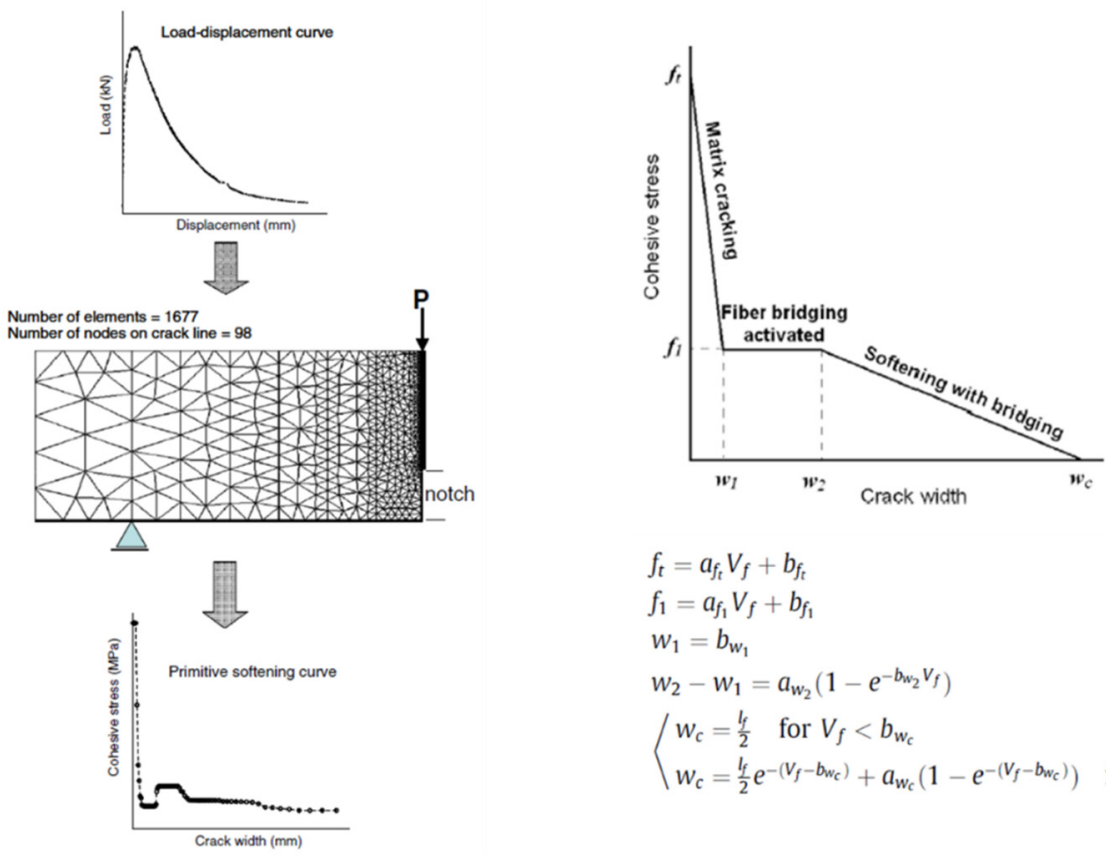

$$
\begin{aligned}
& f_{t}=a_{f_{t}} V_{f}+b_{f_{t}} \\
& f_{1}=a_{f_{1}} V_{f}+b_{f_{1}} \\
& w_{1}=b_{w_{1}} \\
& w_{2}-w_{1}=a_{w_{2}}\left(1-e^{\left.-b_{w_{2}} V_{f}\right)}\right. \\
& \left\langle\begin{array}{l}
w_{c}=\frac{l_{f}}{2} \text { for } V_{f}<b_{w_{c}} \\
w_{c}=\frac{l_{c}}{2} e^{-\left(V_{f}-b_{w_{c}}\right)}+a_{w_{c}}\left(1-e^{-\left(V_{f}-b_{w_{c}}\right)}\right) \text { for } V_{f} \geqslant b_{w_{c}}
\end{array}\right.
\end{aligned}
$$

Figure 2.25 (a) inverse analysis procedure and (b) simplified tri-linear softening curve, where $V_{f}$ is the fibre volume ratio; $l_{f}$ the fibre length and $a_{f t}, b_{f t}, a_{f 1}, b_{f 1}, b_{w 1}, a_{w 2}, b_{w 2}$, $a_{w c}$ and $b_{w c}$ are experimental coefficients (Kang et al. 2010).

Even though the primitive softening curve obtained is the most adjusted solution from the inverse analysis, it could be considered too complex to implement it in a FE analysis or structural design. In this study, the primitive softening curve first obtained is approximated in a proposed simplified tri-linear softening curve that represents the softening behaviour of UHPFRC depending on five parameters that are dependent on the fibre volume ratio. It has an initial softening branch due to matrix cracking and a bridging plateau region followed by a final softening branch (see Figure 2.25(b)). The simulations done with the primitive softening curve and the simplified tri-linear softening curve showed reliable results when compared to the experimental 3PBTs in terms of: peak loads, displacements at peak and $\sigma-\delta$ curves.

\subsection{Mahmud et al. 2013}

Mahmud et al. (Mahmud et al. 2013) studied the size effects on the flexural strength of notched UHPFRC beams by 3PBTs. The size effect is considered as the loss of structural strength while the size of the structure increases. To carry out the study they cast fifteen beams to be tested in 3PBT with five different depth $\mathrm{d}=30 \mathrm{~mm}, 60 \mathrm{~mm}, 90 \mathrm{~mm}, 120$ $\mathrm{mm}$ and $150 \mathrm{~mm}$, and the same width $\mathrm{b}=150 \mathrm{~mm}$ and span $\mathrm{l}=500 \mathrm{~mm}$. The UHPFRC 
used in the experimental programme had a $2 \%$ by volume $\left(157 \mathrm{~kg} / \mathrm{m}^{3}\right)$ of $13 \mathrm{~mm}$ length and $0.2 \mathrm{~mm}$ diameter $(13 / 0.2)$ steel fibres content. To characterise the mechanical behaviour of UHPFRC, uniaxial tensile tests with dog-bone specimens were done to characterise the tensile behaviour and cylindrical compressive test for the compressive behaviour (Hassan et al. 2012) (Figure 2.26).
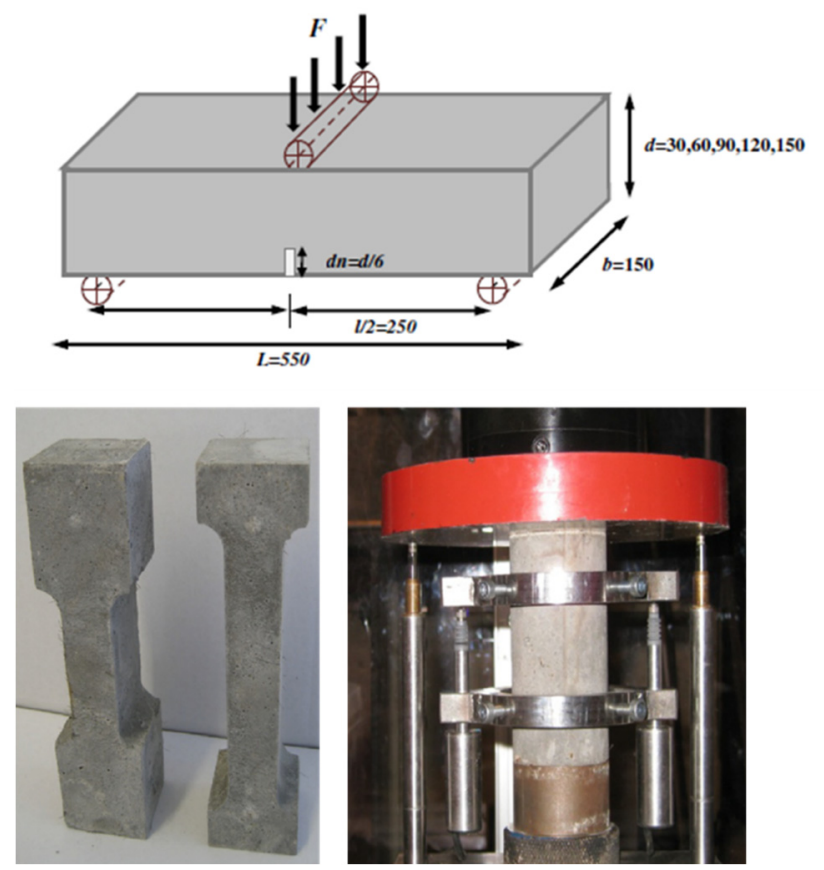

Figure 2.26 (a) 3PBT scheme, (b) dog bones for direct tensile test and (c) cylinders for compression test (Hassan et al. 2012; Mahmud et al. 2013)

In this work, non-linear FE simulations were conducted using the concrete damage plasticity (CDP) model in ABAQUS and the material properties extracted from uniaxial tensile and compressive laboratory tests. In the FE model (FEM) they assumed that fibres are uniformly distributed in the matrix and, therefore, the UHPFRC was modelled as a homogeneous material. As they performed a direct tensile test, there was no need to use an inverse analysis method to define the constitutive UHPFRC tensile behaviour. With the idea of avoiding the mesh dependence, instead of using the stress $(\sigma)$-strain $(\varepsilon)$ constitutive relation, they calculated the equivalent stress (or traction)-crack opening displacement (COD) and the tensile fracture and compressive plastic behaviour were completed by specifying the evolution laws of damage that represents the stiffness degradation. The five depth tested beams were modelled and also more beams with depth $\mathrm{d}=180 \mathrm{~mm}, 210 \mathrm{~mm}, 240 \mathrm{~mm}$ and $300 \mathrm{~mm}$. 
From this work, very interesting results were obtained. The macrocracks at failure in some of the beams showed a tortuous pattern that could be attributed to the random distribution and random orientation of the fibres. The final failure in the softening region is dependent on fibre pull-out across the concrete crack and, moreover, fibre pull-out depends on the type and length of the fibre. The deformation at this stage is related to half the length of the fibre. Even though they obtained reliable results with the simulation of the FEM when it was compared to the experimental 3PBTs, the model response was not completely accurate when homogeneous hypothesis of UHPFRC properties were adopted, especially in shallow depths. The reason could be the considerable scatter in the experimental results due to random distributions of discontinuous short steel fibres. Therefore, maybe only heterogeneous models that take into account the effects of random distribution of fibres are able to simulate this scatter accurately.

\subsection{Pyo and El-Tawil 2015}

Pyo and El-Tawil (Pyo and El-Tawil 2015) proposed that the length of the tensile loading regime complicates the development of test setups that can capture the full tensile response at high strain rates. According to these authors, analytical and FEM were used to propose modifications to an existing test setup to enable it to conduct the accurate and practical testing of UHPFRC specimens in direct tension at high strain rate.

The testing method for testing strain-hardening cementitious composites such as UHPFRC carried out in this work is based on a modification of the Strain Energy Frame Impact Machine (SEFIM) developed by Tran and Kim (Kim et al. 2011; Tran and Kim 2012, 2013). This special test to characterise UHPFRC in direct tension works by applying displacement to the pull bar and then the load frame stores elastic energy. After sudden failure of the coupler, stored elastic energy in the load frame is transmitted to the specimen by means of a load pulse. Therefore, the stress of the specimen is measured using strain gages attached to a transmitter bar and strain is calculated by post-processing images of the specimen using a high speed camera. The modification proposed by Pyo and El-Tawil (Pyo and El-Tawil 2015) consists on a longer transmitter bar. As in the SEFIM, elastic energy is stored in the energy bars and released when the coupler breaks under increasing loads applied to the pull bar. Tensile load is transmitted from the energy bars to the UHPFRC specimen via a load transfer member. A prototype of this test method was built and modelled using a FEM (see Figure 2.27). The UHPFRC specimens have the form shown in Figure 2.28. 


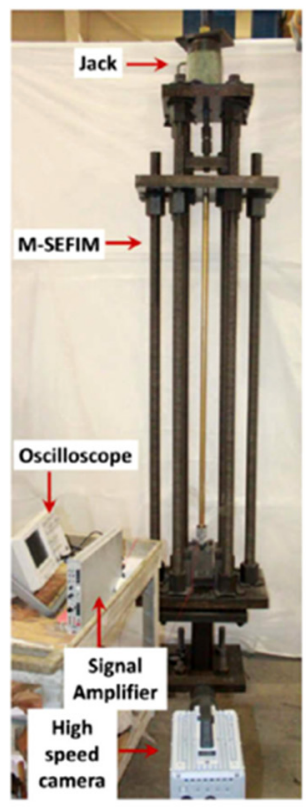

(a)

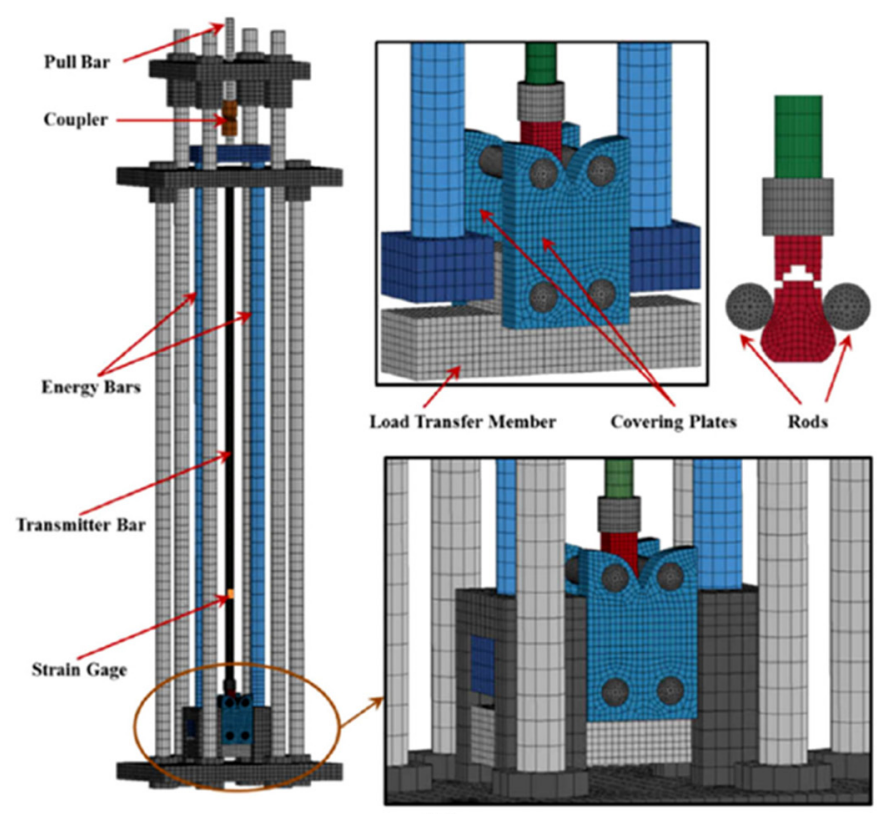

(b)

Figure 2.27 (a) Prototype of the proposed testing method and (b) FEM of the prototype (Pyo and El-Tawil 2015)

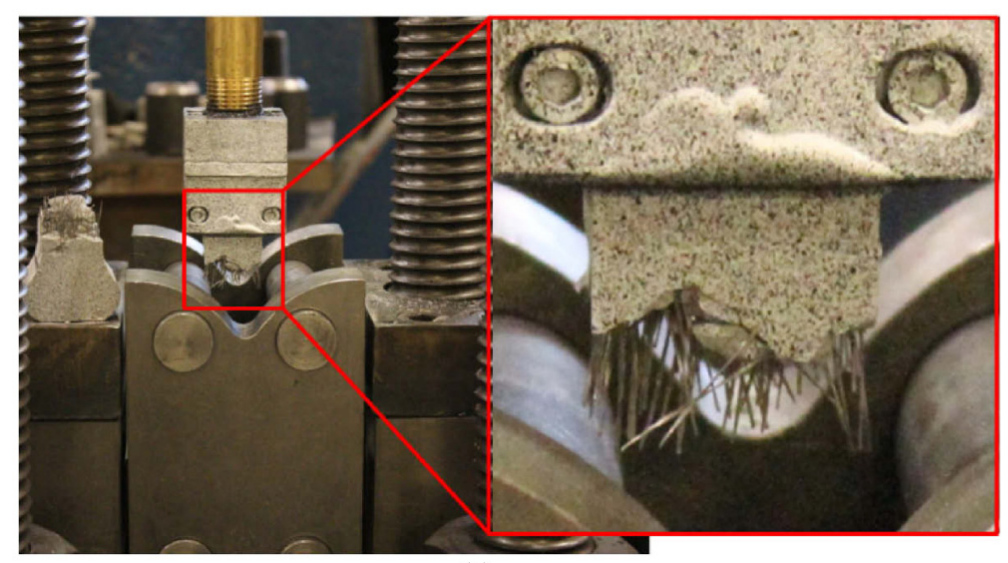

(a)

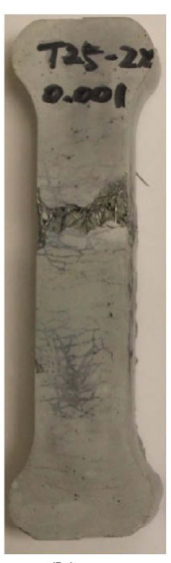

(b)

Figure 2.28 UHPFRC specimens used in the testing method (a) after testing for impact and (b) after a lower strain-rate testing (Pyo and El-Tawil 2015) 
In this case, an isotropic elastic-plastic material model was used to model UHPFRC behaviour in the LS-DYNA commercial FE program. This material model can represent separate stress vs plastic strain responses for compression and tension. The tensile load applied on the pull bar is performed by means of displacement control at the extreme of the pull bar. Very accurate results were obtained by the simulations carried out by the FEM when compared to the measured uniaxial responses of UHPFRC tests carried out in (Wille et al. 2012) (see Figure 2.29).

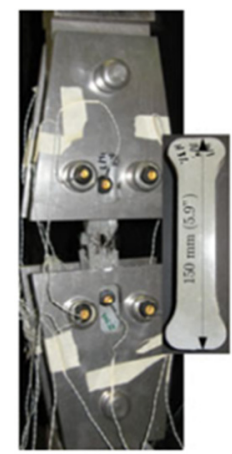

a) Test

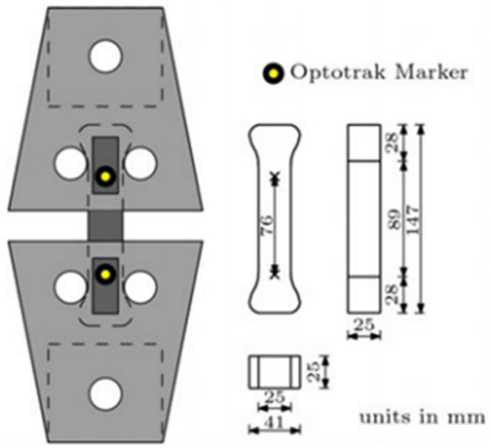

b) Specimen geometry and fixture

Figure 2.29 Uniaxial tensile test setup in (Wille et al. 2012)

\subsection{Lampropoulos et al. 2016}

Lampropoulos et al. (Lampropoulos et al. 2016) studied the efficiency of using UHPFRC to strengthen existing reinforced concrete $(\mathrm{RC})$ beams. In their work, dog bone-shaped specimens, tested under direct tensile loading, were carried out to characterise the tensile behaviour of UHPFRC in a numerical model using FEM with the ATENA FE software (see Figure 2.30). The fibre content used to cast the UHPFRC was 3\% in volume $\left(235.5 \mathrm{~kg} / \mathrm{m}^{3}\right)$. The compressive strength of $164 \mathrm{MPa}$ was obtained by means of standard compressive cube test $(100 \mathrm{~mm}$ size $)$. The average tensile strength from 6 dog-bones specimens tested was found in $12 \mathrm{MPa}$ and the elastic Young's modulus $(E) 57.5 \mathrm{GPa}$. 
(a)

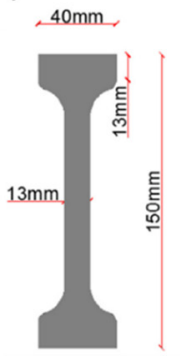

(b)

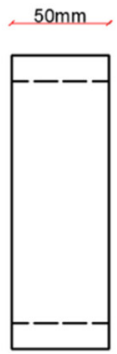

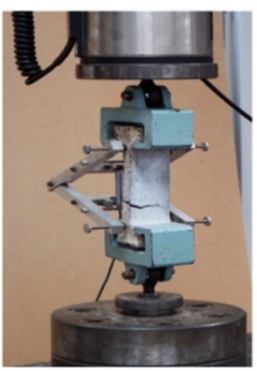

(c)

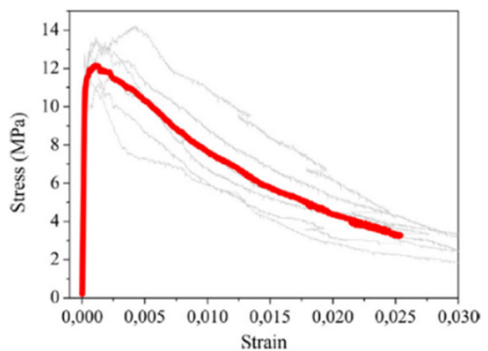

Figure 2.30 (a) dog-bone geometry, (b) direct tensile test and (c) stress-strain response from tensile test (Lampropoulos et al. 2016)

In this case, UHPFRC was modelled using a smeared crack model where tensile behaviour was defined by elastic behaviour up to the initiation of microcracking, followed by a second linear part into the strain-hardening phase with multiple microcracking. Then from the macrocrack formation at ultimate strength onwards the strain softening phase took place, which was modelled by a bi-linear model (see Figure 2.31(a)). The compressive constitutive behaviour was defined by means of an ascending compressive branch based on the formula recommended by CEB-FIP model code 90 (MC90 1993), and the following softening law that was linearly descending from the peak stress until a limit compressive strain, which was defined by the plastic displacement and the band size, using the fictitious compression plane model (Červenka et al. 2013) (see Figure 2.31(b)).

(a)

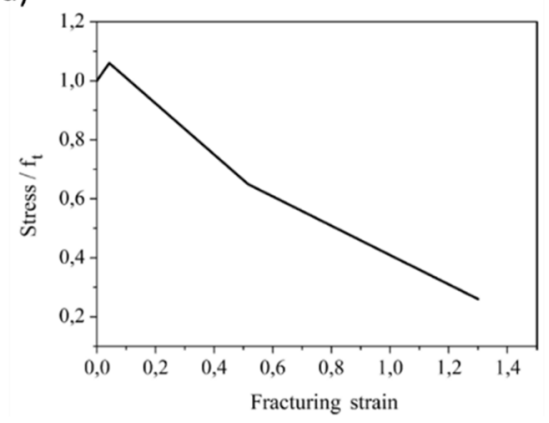

(b)

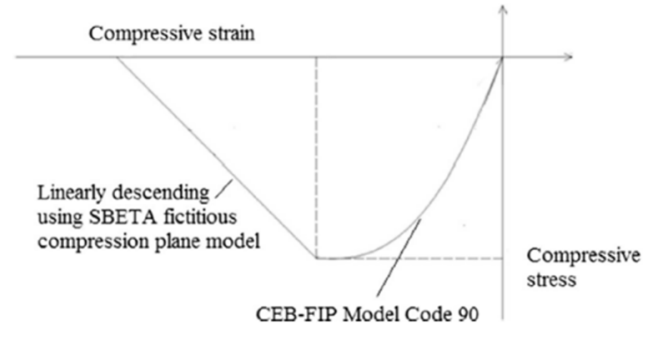

Figure 2.31 (a) tensile and (b) compressive constitutive material behaviour assumed for UHPFRC in the FEM (Lampropoulos et al. 2016).

The experimental tensile test was modelled to calibrate the model under direct tensile loading obtaining reliable results (Figure 2.32(a)). Moreover, the reliability of the numerical model was validated using the further experimental results of UHPFRC layers 
tested with flexural 4PBT (Figure 2.32(b)) obtaining accurate results with a little difference attributed to the fibre orientation.

(a)

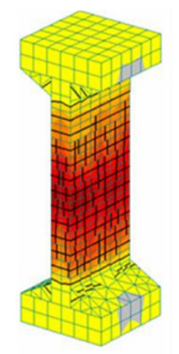

(b)

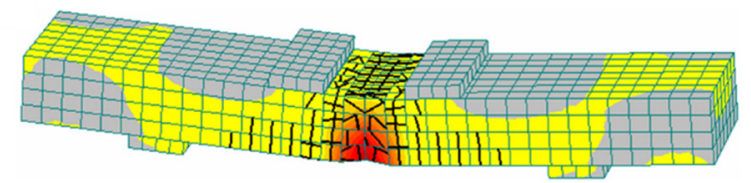

Figure 2.32 Strain/crack distribution in the FEM of UHPFRC (a) direct tensile test and (b) 4PBT layers (Lampropoulos et al. 2016).

To model the 4PBT strengthened RC beams using UHPFRC layers in the three positions considered: in the tensile side (Figure 2.33(a)), the compressive side (Figure 2.33(b)) and three sides with a jacked (Figure 2.33(c)), the FEM was improved considering two important effects: the interface between the old (RC) and the new concrete (UHPFRC) and the shrinkage of the new concrete (UHPFRC). The interface between the initial RC beam and the UHPFRC was modelled using special two dimensional elements with a coefficient of friction equal to 1.5 and cohesion 1.9 MPa. The UHPFRC shrinkage was modelled by means of a negative volumetric strain value of 565 microstrains applied to the elements of the UHPFRC layers and jackets, based on the experimental results carried out on this subject. As a result, a very complete and reliable model was built able to be used for parametric studies of UHPFRC tensile strength, sensitivity of UHPFRC shrinkage strain and evaluation of the strengthened UHPFRC technique in comparison to the traditional strengthened $\mathrm{RC}$ technique.
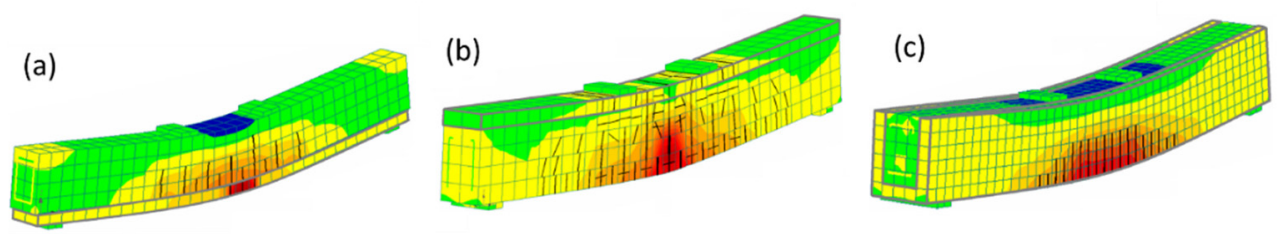

Figure 2.33 Strain/crack distribution in the FEM strengthened RC beams with (a) UHPFRC layer in the tensile side, (b) UHPFRC layer in the compressive side and (c) UHPFRC three side jacked (Lampropoulos et al. 2016). 


\subsection{Yoo et al. 2017}

In Yoo et al. (Yoo et al. 2017b), a non-linear FE analysis was performed to simulate the flexural behaviour of UHPFRC beams. For this study, two different tension-softening curves obtained from a micromechanics-based analysis and an inverse analysis were incorporated.

An experimental programme consisting on 3PBT of UHPFRC beams with four different $13 \mathrm{~mm}$ length and $0.2 \mathrm{~mm}$ diameter (13/0.2) steel fibres fibre volume fractions $\left(V_{f}=1 \%\right.$, $2 \%, 3 \%$, and $4 \%$ ) developed in a previous study (Yoo et al. 2013b) was adopted. The geometry of the specimens was 100x100x400 mm. A notch of $10 \mathrm{~mm}$ was done at the mid-span length of the specimen, and a span length of $300 \mathrm{~mm}$ was set. To measure the deflection at mid span of the beams, linear variable differential transformer (LVDT) was installed on both sides of the specimen and, to measure crack mouth opening displacement (CMOD), a clip was attached at the notch of the beam.

In order to verify the micromechanics-based fibre-bridging curve obtained from two different fibre orientations, a finite element model (FEM) was developed using the commercial software DIANA (2007). To model the UHPFRC of the 3PBT, a four-node quadrilateral isoparametric plane stress element (Q8MEM) based on linear interpolation and Gauss integration, was used. Figure 2.34 shows the mesh adopted in the FEM of the 3PBT. To model the crack propagation, the discrete crack model was used by means of an interface element (L8IF) at the notched centre of the beam. The pre-cracking behaviour at the interface element was assumed to be linear elastic, and the elements outside the considered cracked area were modelled to exhibit linear elastic response. The interface post-cracking tensile behaviour was determined by combining the UHPFRC matrix softening curve defined by (Kang and Kim 2011) (see Figure 2.35) and fibrebridging curve also considering fibre orientation. To define the fibre-bridging curve into FEM using user-supplied subroutines, a simplified expression for the stress-crack opening relation was defined by means of an expression based on the model of (Gopalaratnam and Shah 1985) for the ascending branch and a simple linear softening curve suggested by (Kang and Kim 2011) for the descending branch of the fibre-bridging curve. To evaluate the suitability of the simplified stress-crack opening relation defined (modelled curve), a comparison between the micromechanics-based fibre-bridging curve and the modelled fibre-bridging curve was carried out. 
(a)

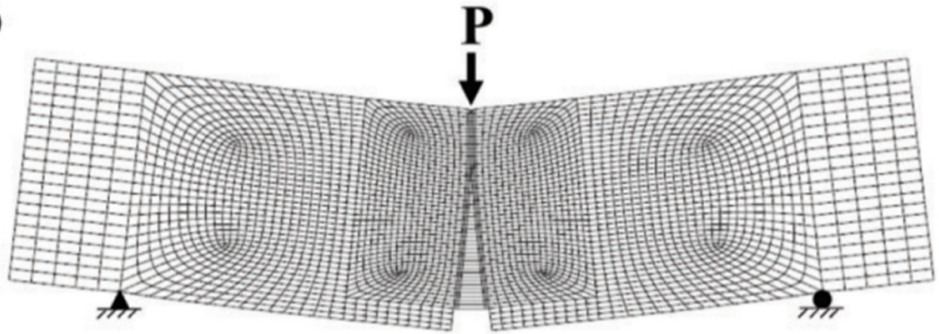

(b)

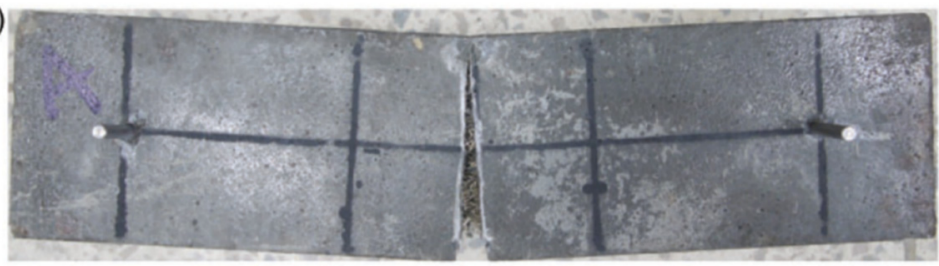

Figure 2.34 (a) Finite Element Mesh used to model the 3PBT and (b) experimental test at failure (Yoo et al. 2017b)

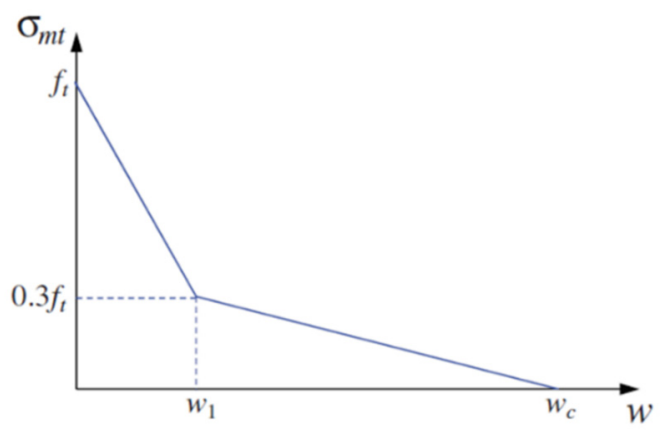

Figure 2.35 UHPFRC matrix softening curve defined by (Kang and Kim 2011)

Moreover, bilinear tension-softening curves obtained as a result of the application of an inverse analysis algorithm defined in (Yoo et al. 2013b) based on the inverse analysis technique of (Uchida and Kurihara 1995), were also considered for comparison. These bilinear tension-softening curves obtained as a result were incorporated in the FEM for the four fibre volume fractions $\left(V_{f}=1 \%, 2 \%, 3 \%\right.$, and $\left.4 \%\right)$ considered in this research.

Flexural behaviour of UHPFRC beams including maximum load, deflection capacity, and post-peak softening were well predicted by the FEM using the tension softening curves from inverse analysis, since these tension-softening curves were obtained as a 
result of the inverse analysis application to the experimental 3PBT results. For the case of the micromechanics-based approach, they showed good or underestimated predictions depending on the assumption of the random fibre orientation: 2D or 3D, respectively.

\subsection{Krahl et al. 2018}

Krahl et al. (Krahl et al. 2018) carried out a research focused on the evaluation of the damage in UHPFRC.

The experimental programme developed in this research consisted on cyclic tension tests with the idea of obtaining additional experimental information from the previous research in this field done by (Paschalis and Lampropoulos 2016), compression and bending tests. The specimens were cast using UHPC and UHPFRC with $1 \%\left(78.5 \mathrm{~kg} / \mathrm{m}^{3}\right)$ and $2 \%\left(157 \mathrm{~kg} / \mathrm{m}^{3}\right)$ in volume of $13 \mathrm{~mm}$ length and $0.2 \mathrm{~mm}$ diameter (13/0.2) of steel fibres. For tension tests, dog-bone shape specimens were used (Figure 2.36(a)); for compression test, cylindrical specimens $(50 \mathrm{~mm}$ of diameter $\times 100 \mathrm{~mm}$ of length) were used (Figure 2.36(b)) and, finally, for bending tests, third-point bending tests, which are a kind of 4PBT where the distance between support roller and load roller is the length of the span divided by 3 (Figure 2.37), were carried out. For the cycles, the loading/unloading process was performed under displacement control in all experimental tests.

(a)

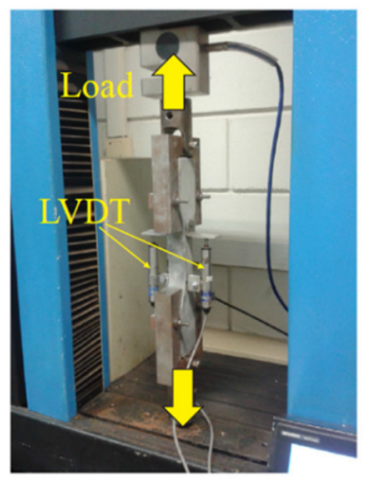

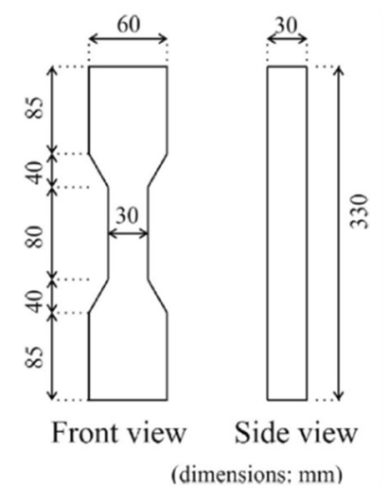

(dimensions: $\mathrm{mm}$ ) (b)

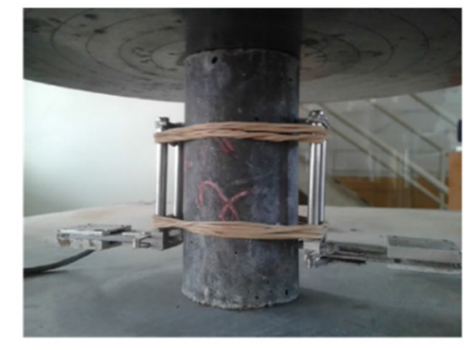

Figure 2.36 (a) Test setup and geometry for direct tensile test and (b) Test setup for compression test in (Krahl et al. 2018) 

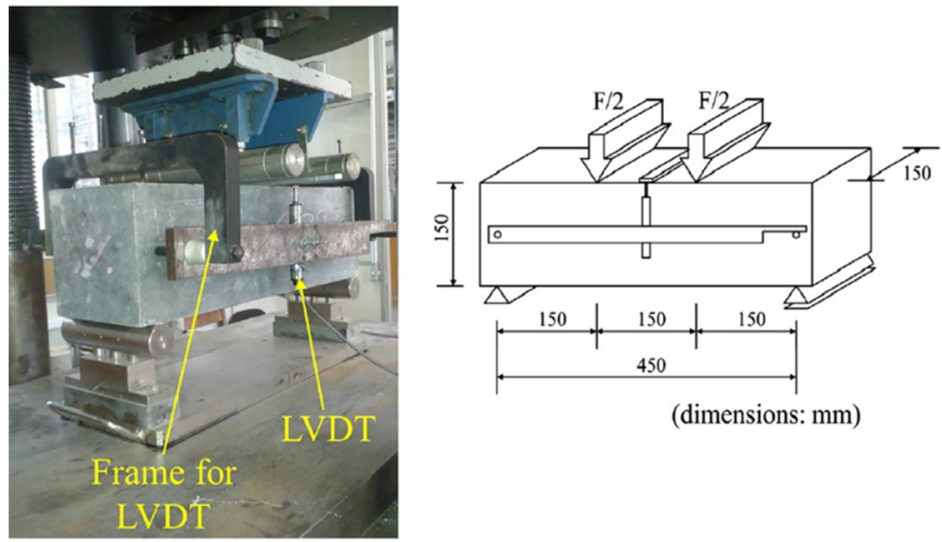

Figure 2.37 Third Point Bending Test setup and geometry in (Krahl et al. 2018)

In this research, uniaxial stress-strain equations were developed to define UHPFRC constitutive behaviour for damage evolution in tension and compression based on plastic-damage model. The evolution of the damage variable was evaluated using the experimental test in tension, compression and bending. To validate these equations, they were adapted and implemented in a FEM to simulate the experimental behaviour of UHPFRC in tension, compression and bending by means of the plastic-damage model implemented in the commercial FE code Abaqus. To simplify, homogeneous and isotropic behaviour was considered until failure in the numerical model. In this case, the equivalent homogenous strain was obtained dividing the experimental displacement until failure by the gauge length.

First, to evaluate the proposed damage laws for UHPFRC, one plane element was modelled. A four-node bilinear plane stress quadrilateral element with reduced integration was used to evaluate the constitutive model at the unique integration point of the element domain (Figure 2.38(a)). The tensile and compressive uniaxial experimental tests were modelled and the results fit the stress-strain experimental envelops with accuracy for both amount of fibres: $1 \%$ and $2 \%$. Then, the FEM to simulate the cyclic 4PBT was developed by means of a mesh using eight-node linear brick element with reduced integration (Figure 2.38(b)). The load was applied by displacement control and Newton-Raphson iterative process was used to solve the nonlinear system of equations.

The numerical plastic-damage model accurately predicted the experimental cyclic curves. Consequently, the proposed damage evolution laws and the stress-strain response for UHPFRC under tension and compression were validated. The model was capable of predicting accurately the load-bearing capacity of the specimens under flexure in the 4PBT. In addition, the numerical model accurately predicted the global damage growth expected in the experimental tests. From these, it was concluded in this research that the proposed models could be applied to any constitutive model based on damage mechanics coupled to the framework of plasticity. 

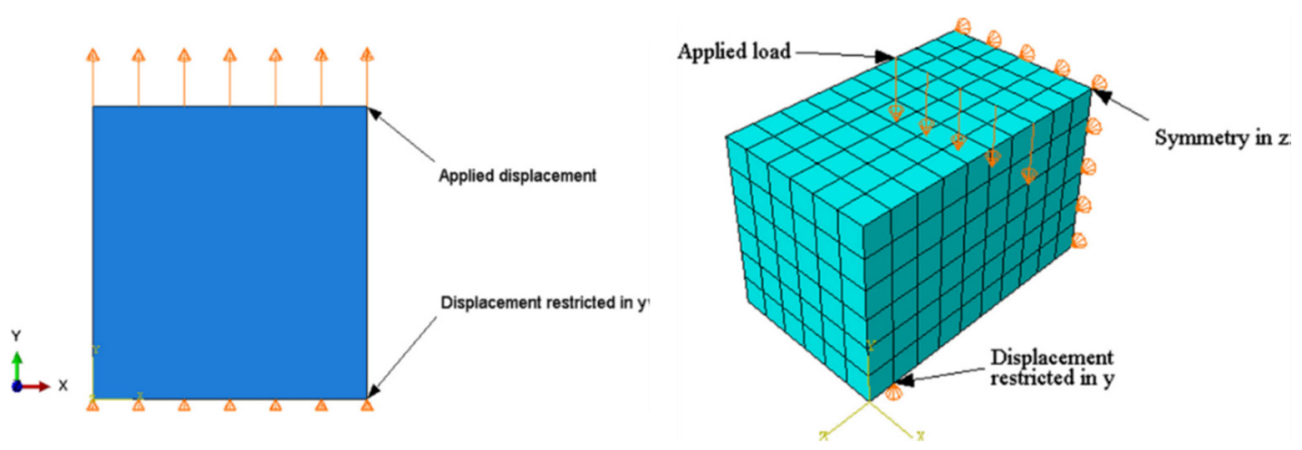

Figure 2.38 (a) FEM to simulate cyclic tension and compression (b) FE discretisation for 4PBT in (Krahl et al. 2018)

\subsection{Rossi et al. 2018}

Rossi et al. (Rossi et al. 2018) verified the validity of a probabilistic explicit cracking model developed for steel fibre reinforced concrete (SFRC) to simulate the behaviour of a reinforced UHPFRC beam subjected to a bending load characterised by a shear failure. In this work, a clear description of the probabilistic explicit cracking model analytical formulation is exposed. As there is said, the model was based on the following physical evidences:

- Concrete was considered a heterogeneous material in which the heterogeneities were modelled with a random spatial distribution of mechanical properties considered decisive in the cracking formation process: the Young's modulus and the tensile strength.

- Scale effects: mechanical properties of the material e.g. the tensile strength were dependent on the size of the mesh elements chosen for the FE analysis. However, this was not the case of the average post-cracking energy.

- Cracking was explicitly treated through the random creation of kinematic discontinuities, this is, cracks were represented by interface elements.

The probabilistic explicit cracking model developed for SFRC was adapted and used to numerically modelling the mechanical behaviour and cracking process of a longitudinally reinforced UHPFRC beam without transverse reinforcement and $2.5 \%$ in volume $\left(\approx 196 \mathrm{~kg} / \mathrm{m}^{3}\right)$ of straight steel fibres with $13 \mathrm{~mm}$ length and $0.2 \mathrm{~mm}$ diameter $(13 / 0.2)$. The beam was tested in a 4PBT (see Figure 2.39) considering the spans between the loading points and the supports 480 and $2000 \mathrm{~mm}$, respectively. 
(a)

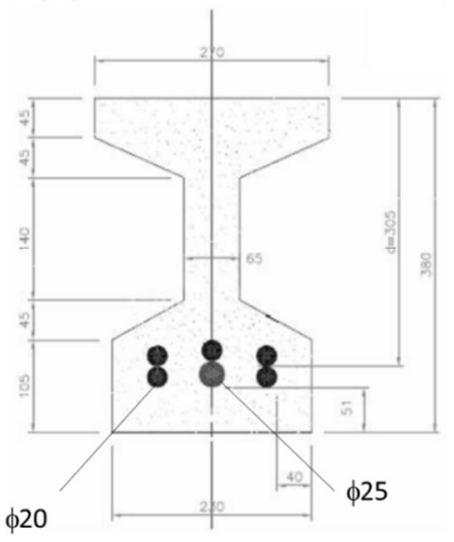

(b)

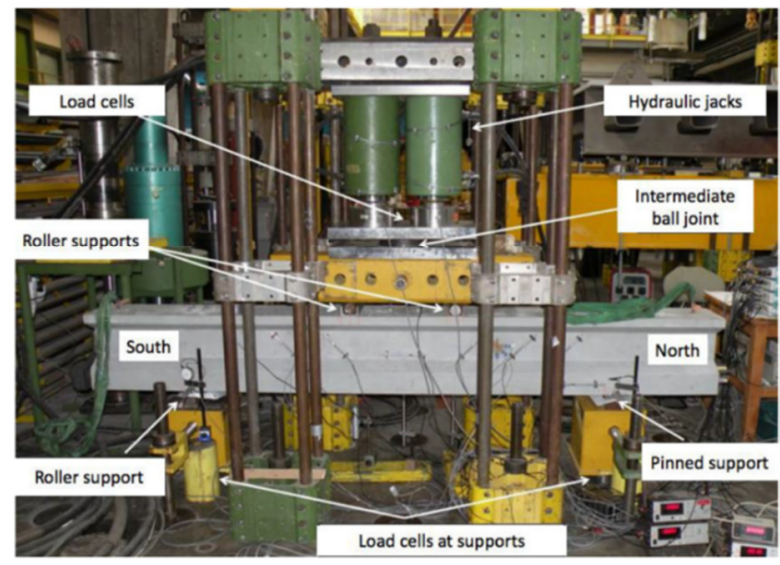

Figure 2.39 (a) cross section (in $\mathrm{mm}$ ) and reinforcement of the beam tested at (b) 4PBT in (Rossi et al. 2018)

After testing the beam, the influence of fibre orientation on the tensile UHPFRC behaviour was considered and evaluated by means of two series of small beams tested at 3PBT. The first series was obtained from sawing it at $45^{\circ}$ angle from the beam tested at 4PBT. The second series was obtained from sawing it parallel to the reinforcement of the beam tested at 4PBT. The dimensions of these small beams were $280 \mathrm{~mm}$ long, $70 \mathrm{~mm}$ high and $60 \mathrm{~mm}$ wide, with a $2 \mathrm{~mm}$ wide and $8 \mathrm{~mm}$ deep notch sawn at mid-span. A support span length of $210 \mathrm{~mm}$ was considered.

To characterise the tensile UHPFRC behaviour, its defining mechanical parameters were determined by inverse analysis. The inverse analysis approach used in this research consisted of modelling by FEM the 3PBT performed on the small notched beams sawn from the reinforced UHPFRC beam to identify those parameters. Figure 2.40 shows the FE mesh used to model the 3PBT of the small beams. As a consequence of the fibre orientation, the small beams sawed parallel to the length of the 4PBT beam presented higher peak load and post-cracking energy than the beams sawed at $45^{\circ}$. 


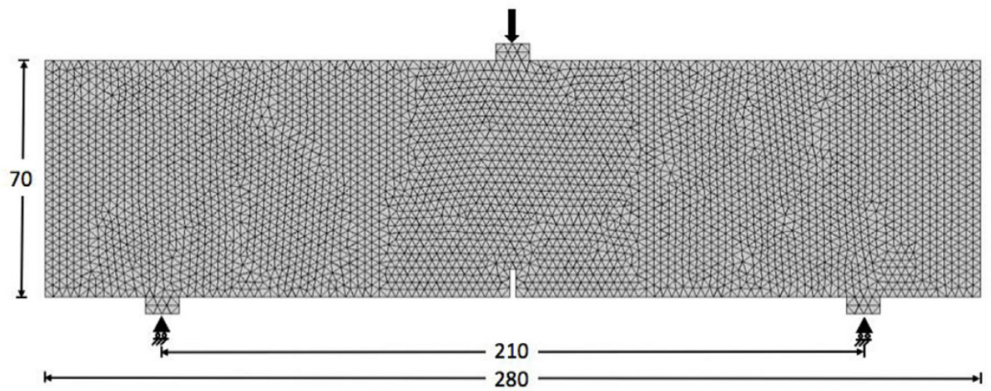

Figure 2.40 FE mesh of the 3PBT notched small beams in (Rossi et al. 2018)

Therefore, the best parameters to model the shear behaviour of the 4PBT beam were those obtained from the characterisation beams sawed at $45^{\circ}$ because they better represented the fibre orientation in diagonal cracks that described the shear failure. To model the beam, plane stress elements were used (see Figure 2.41(a)). The reinforcement bars were modelled with linear volume elements with a height that equals to the rebar's diameter. Linear interface elements were located between all these volume elements to let cracks to cross the rebars. The interface elements ensured the continuity of stresses and displacements before cracking by means of a very high stiffness matrix. After cracking, the rebar's effect on the cracks was modelled linear elastic by setting the normal and tangential components of interface elements' stiffness smaller than before cracking.

(a)

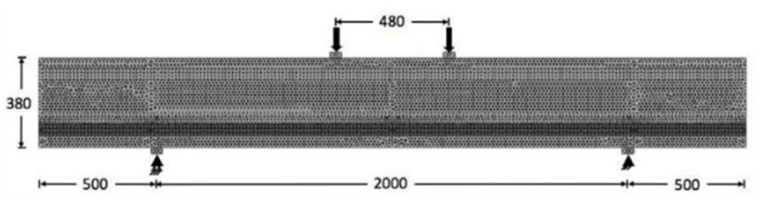

(b)

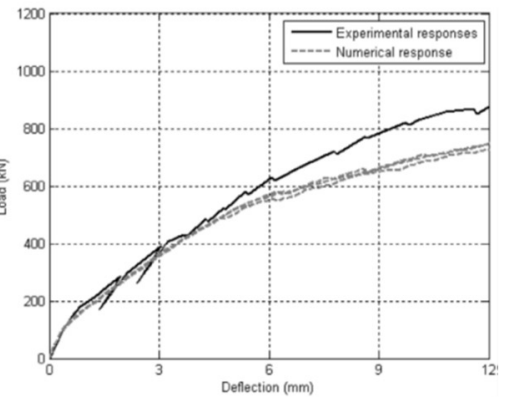

Figure 2.41 (a) FEM of the 4PBT reinforced beam and (b) load-deflection response compared to the experimental results in (Rossi et al. 2018)

The results obtained after the comparison between the experimental load-deflection curve and the numerical simulations response (see Figure 2.41(b)) showed good coherence until a deflection of $5 \mathrm{~mm}$. From this value onwards, the numerical model underestimated the experimental behaviour. This fact was considered due to the underestimation of the post-cracking energy of the tensile behaviour to characterise the UHPFRC obtained from the inverse analysis of 3PBT of the small beams. The notched 3PBT was considered not suitable to represent the volumetric energy from the microcracking stage in the hardening phase of strain-hardening UHPFRC. However, the 
probabilistic explicit cracking model could be considered relevant to analyse the mechanical behaviour of a reinforced UHPFRC beam and provided precise information about the cracking process of this type of material.

\subsection{Yin et al. $2019 a$}

Yin et al. (Yin et al. 2019a) developed a FEM and a modelling technique to study the flexural behaviour of UHPC flexural members under static loads.

In this work an experimental programme of two beams of 1600x300x100 mm were tested at simply supported 3PBT considering the experimental setup shown in Figure 2.42. One of the beams (the so called NR-UHPC), was cast with UHPFRC without longitudinal rebar and, the other beam (so called R-UHPC), was reinforced with five $12 \mathrm{~mm}$ steel bars at the top and bottom as longitudinal rebar. The UHPFRC used contained a $3 \%$ $\left(235.5 \mathrm{~kg} / \mathrm{m}^{3}\right)$ in volume of $13 / 0.2$ smooth steel fibres.

Moreover, in order to increase the specimen variability to characterise the mechanical properties of the UHPFRC used, prismatic UHPFRC specimens of 500x100x100 mm were carried out to be tested at unnotched 3PBT according to the standard (EN 2009a) (see Figure 2.43(a)). They studied the effect of adding 13/0.2 smooth steel fibres at four volume percentages: $0 \%, 1 \%\left(78.5 \mathrm{~kg} / \mathrm{m}^{3}\right), 2 \%\left(157 \mathrm{~kg} / \mathrm{m}^{3}\right)$ and $3 \%\left(235.5 \mathrm{~kg} / \mathrm{m}^{3}\right)$. From this, it was obtained that the flexural strength was linearly dependent on the added volume fraction of steel fibres, as it was stated previously in (Kang et al. 2010). To characterise UHPFRC compressive behaviour, compression tests were carried out using cubic and cylindrical samples (see Figure 2.43(b)). 

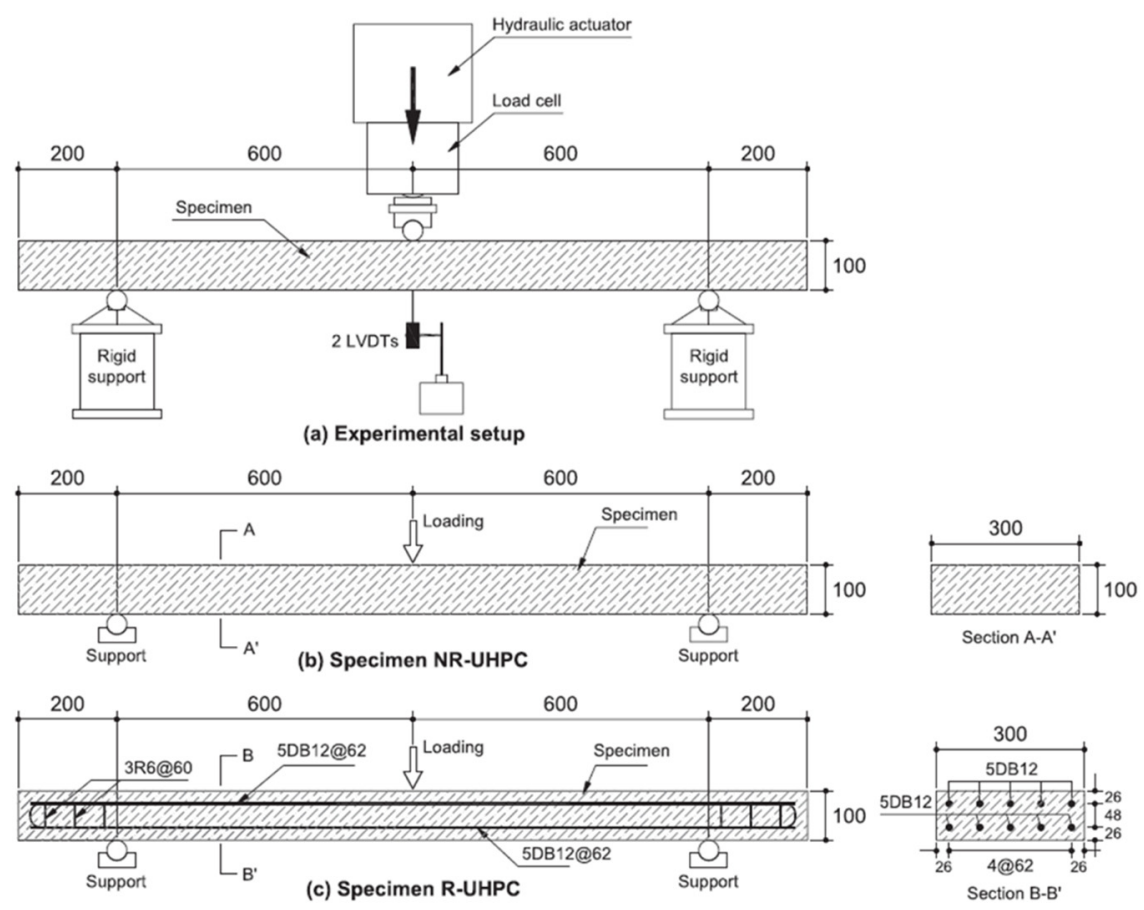

Figure 2.42 Experimental setup and geometry of the flexural beams used in (Yin et al. 2019a)

(a)

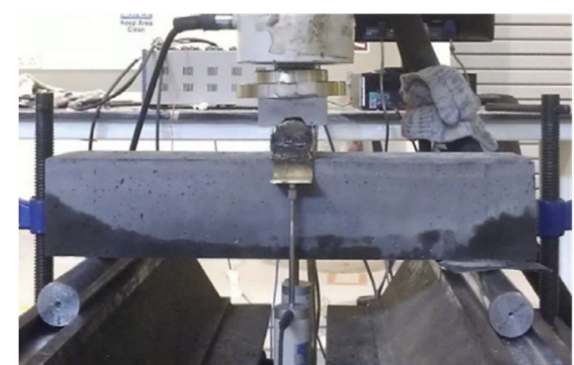

(b)

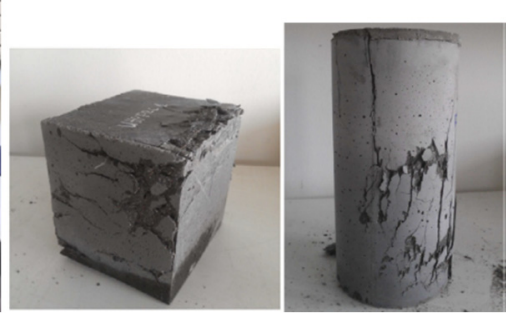

Figure 2.43 UHPFRC characterisation tests: (a) unnotched 3PBT and (b) compression test in (Yin et al. 2019a)

A FEM was built for all flexural specimens developed in the experimental programme using the software LS-DYNA (see Figure 2.44(a)). UHPFRC was modelled by means of eight-node constant-stress solid elements. For the longitudinal reinforcement bars, two- 
node beam elements were employed. Perfect bond behaviour between UHPFRC and rebars was considered. The loading was applied by displacement control. To model the constitutive behaviour of UHPFRC, the concrete damage-plasticity model (CDP) known as the Karagozian \& Case (K\&C) first developed for DYNA3D (Malvar et al. 1997) was used. As this is a continuum model, a calibration of the CDP model considering the mesh sensitivity was carried out in this study. If inappropriate mesh size is used it could lead to convergence problems solving the nonlinear system of equations and, therefore, the FE analysis could terminate prematurely. In this work, compressive and tensile simulations by means of an eight-node cubic element were done varying the element size (see Figure 2.44(b)). They obtained that, for their purpose, the suitable mesh size range was from 5 to $20 \mathrm{~mm}$. Moreover, the initial stiffness of the UHPFRC was adjusted using the pressure and bulk modulus. The rest of the parameters necessary to define the CDP model were obtained calibrating them by the numerical FEM of the 3PBT of all the specimens here developed and from other researchers. It could be considered a kind of inverse analysis process using the FEM to simulate the 3 PBT test varying the parameters and comparing to the experimental load-deflection response to fit the curve. To model the material behaviour of the steel for the rebars, an elastic-plastic model with kinematic and isotropic hardening was adopted.

(a)

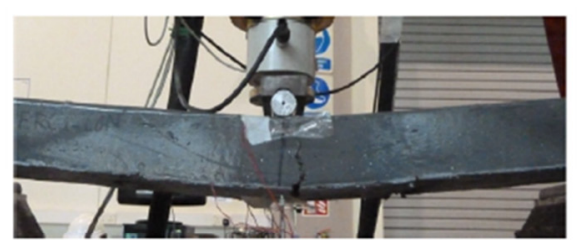

Effective plastic strain

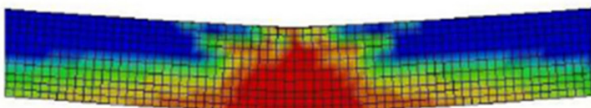

(b)

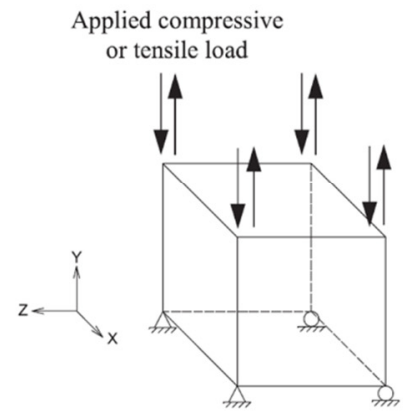

Figure 2.44 (a) Cracking pattern of a 3PBT and Damage model for FEM; (b) Singleelement model for compression and tension in (Yin et al. 2019a)

The simulated load-deflection curves, the ultimate strength, deflection at peak load, stiffness, and hardening and softening behaviours were in good agreement with those of the experimental results. The effective plastic strain patterns obtained using the numerical model were accurately simulated when they were compared to the cracking patterns observed in the experimental tests. The herein developed FEM was appropriate for predicting the flexural behaviour of UHPFRC members using the same steel fibre 
length (13/0.2). For different lengths, the FEM needed a new calibration. These results demonstrate the reliability of the proposed FEM and modelling technique in this work.

\subsubsection{Modelling UHPFRC structural elements}

UHPFRC is being studied experimentally and analytically and numerically modelled as either a constituent material or a strengthening component in more complex elements and under more complex loading states such as impact, blast and seismic loading cases. Currently UHPFRC is mostly used in relatively small applications as non-structural components or structural applications like bridge deck joints and retrofitting of damaged elements.

In the literature it is possible to find several structural applications like shear walls (Hung et al. 2017; Sakr et al. 2019); slabs and plates (Bastien-Masse and Brühwiler 2016; Li et al. 2015, 2016; Wu et al. 2019; Xie et al. 2019; Zhu et al. 2020); columns (Ali Dadvar et al. 2020; Aoude et al. 2015; Astarlioglu and Krauthammer 2014; Fang et al. 2019; Naeimi and Moustafa 2020). With beams, studies have been done about the behaviour of reinforced UHPFRC under shear force in different circumstances (Baby et al. 2013b; Ji and Liu 2020; Kodur et al. 2018): adapting well, proving theories for CC to UHPFRC such as the Modified Compression Field Theory, and developing experimental programmes with UHPFRC and composite beams. Studies on flexural UHPFRC beams (Kodur et al. 2018; Solhmirzaei and Kodur 2017; Yang et al. 2012, 2010; Yoo et al. 2017a; Yoo and Yoon 2015) have dealt with experimental large-scale UHPFRC beams by representing the cracking pattern characterised by multiple microcracking at initial stages, followed by the evolution of a macrocrack in a singular section while load increased.

\subsection{Singh et al. 2017}

Singh et al. (Singh et al. 2017) developed a study with the objective of validating the concrete constitutive model obtained by means of material tests on UHPFRC and to adapt the material model for the analysis of the flexural behaviour of UHPFRC beams. For the UHPFRC mix considered in this work with hooked end steel fibres of $35 \mathrm{~mm}$ in length and aspect ratio of 64 in an amount of $2.25 \%$ by volume $\left(\approx 177 \mathrm{~kg} / \mathrm{m}^{3}\right)$, the material characteristics in both tension and compression by means of stress-strain behaviour under uniaxial tension and compression respectively were obtained. The uniaxial stressstrain response from the tests was used to calibrate the parameters of concrete damagedplasticity (CDP) model founded on a plasticity-based continuum damage model (Lubliner et al. 1989). Then, the calibrated CDP model was adapted for a FEM of fullscale beams. With this, the FEM of the beams developed was validated with the experimental data of the full-scale beam tests carried out in this work. Finally and in 
order to generalise the efficiency of the FEM developed, this was verified with beam tests carried out by other researchers in (Yang et al. 2010).

In this work, four simply supported UHPFRC beams: B25-1, B25-2, B15-1 and B15-2 were cast and tested. Figure 2.45 and Figure 2.46 show the geometry and the flexural tests setup carried out in this work, respectively, for the beams. In order to characterise the UHPFRC mechanical properties and obtain the CDP model parameters, compression and tension specimens were cast together with the beams: 4 standard $100 \mathrm{~mm}$ diameter and $200 \mathrm{~mm}$ height cylinder specimens to be tested in uniaxial compression and $3 \mathrm{dog}$ bone specimens to be tested under direct tension. As a result, the experimental stressstrain relationship for both compression and tension was obtained.

To characterise the UHPFRC material behaviour for the FEM developed for the fullscale beams by means of Abaqus FE software (Figure 2.47), the stress-strain curves obtained from the experimental compressive and tensile tests were used to adapt and calibrate the parameters of the CDP model for UHPFRC. To model the concrete of the four beam specimens carried out in this work, 8 node reduced integration brick elements (C3D8R) were used. The steel reinforcements were modelled by means of 3D truss elements (T3D2) where only their axial deformations were considered. Moreover, the steel reinforcements were considered embedded with a full bond in the solid concrete elements. The support plates and the loading plates were modelled as square prisms of $50 \mathrm{~mm}$ sides by means of 8 node brick elements (C3D8R) considering the material characteristics of the steel. The interface between beam and support was modelled as surface-to-surface standard contact with a hard interaction property and frictional coefficient of 0.1 . The load was modelled by means of an incremental imposed displacement in the loading plates.

As it was demonstrated in this work, the mesh size can produce certain influence in the FEM results as the CDP model used to define the UHPFRC constitutive behaviour in the FEM is a continuum model. In this case, three mesh sizes were analysed: $50 \mathrm{~mm}, 25 \mathrm{~mm}$ and $15 \mathrm{~mm}$. It was observed that a mesh size greater than $50 \mathrm{~mm}$ produced convergence problems solving the equations of the non-linear analysis and, consequently it finished prematurely. By the other side, for 50 and $25 \mathrm{~mm}$, the resulting load-displacement curve showed very similar response but it differed from the yielding point onwards and, the hardening response was better predicted by $25 \mathrm{~mm}$ size than $50 \mathrm{~mm}$. If the element size was reduced, it was observed that the computational time was significantly increased whereas the results were not notoriously improved. For these reasons, the suitable element size considered in this work was $25 \mathrm{~mm}$. Moreover, they considered in the FEM the fibre orientation coefficient $(1 / \mathrm{K})$ reducing by 1.25 the tensile stress-strain response obtained from the dog bone specimen, because they observed that the ultimate load capacity predicted by the model was overestimated by more than $25 \%$ when the fibre orientation coefficient $(1 / \mathrm{K})$ was considered as 1 . 


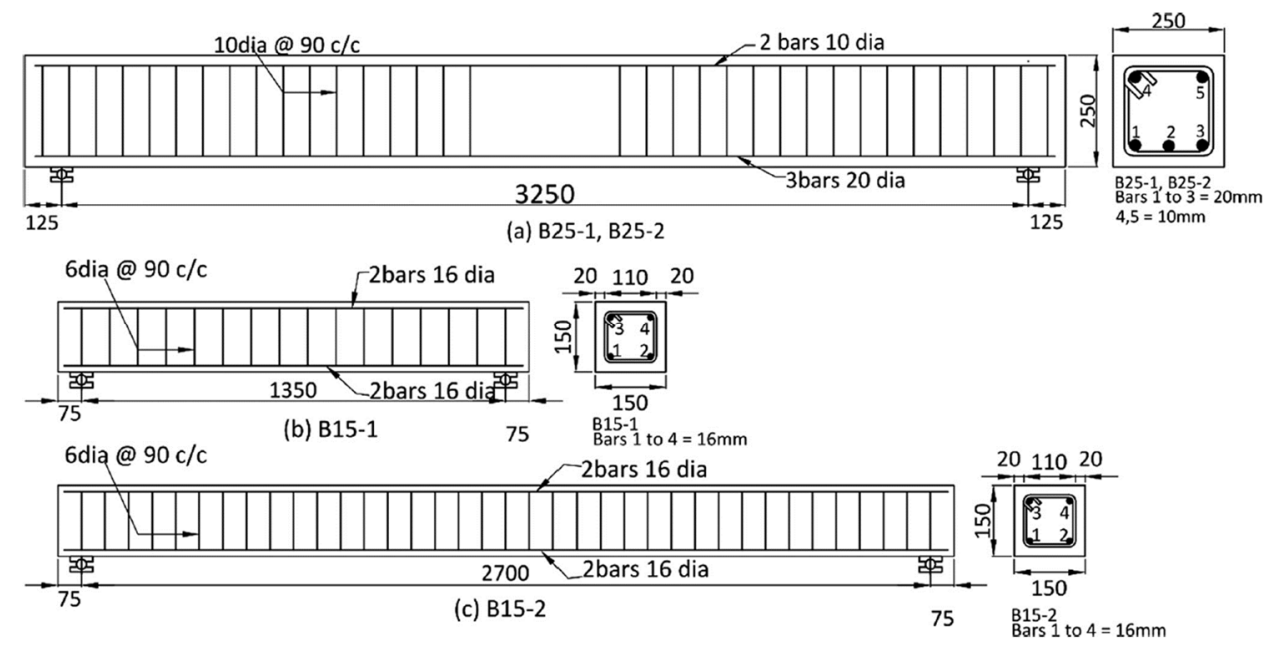

Figure 2.45 Geometry of the full-scale beams cast in (Singh et al. 2017): (a) B25-1 and B25-2, (b) B15-1 and (c) B15-2.

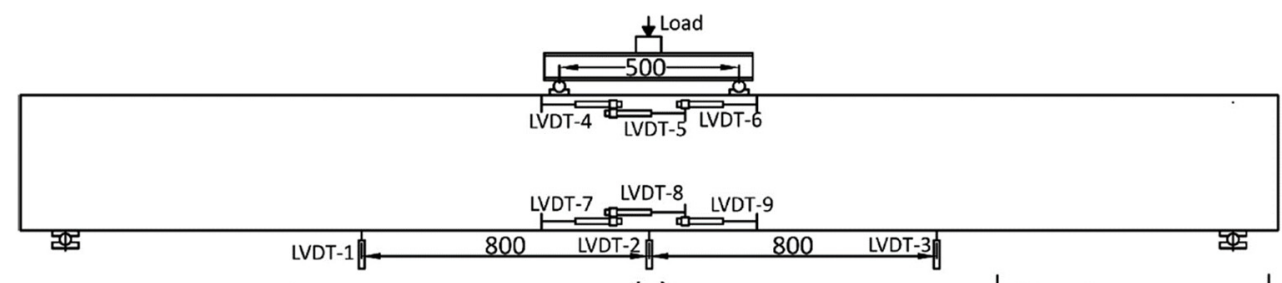

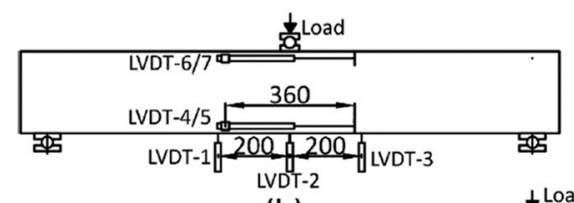

(b)

(a)

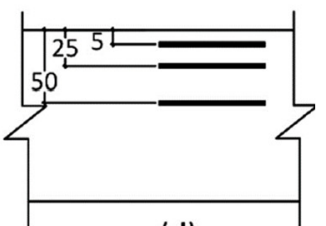

(d)

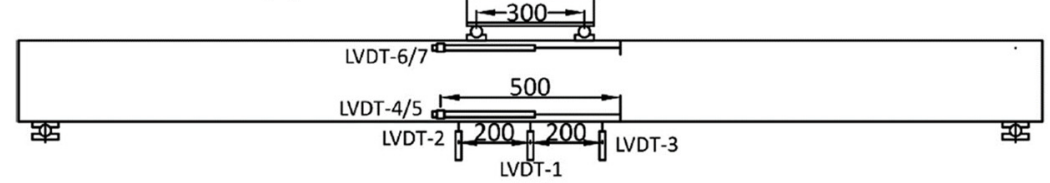

(c)

Figure 2.46 Experimental setup of the full-scale beams carried out in in (Singh et al. 2017): (a) B25-1 and B25-2, (b) B15-1, (c) B15-2 and (d) location of the strain gauges on concrete surface. 
(a)

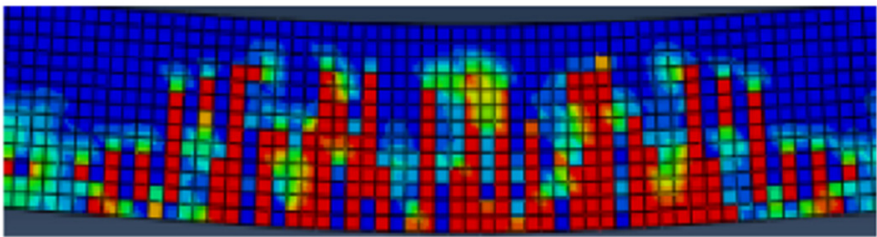

(b)

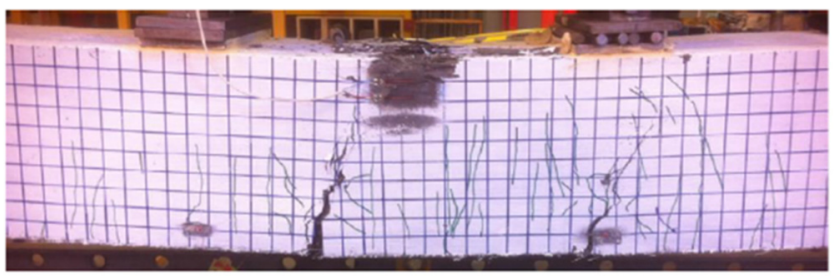

Figure 2.47 (a) Crack damage in the FEM and (b) experimental cracking pattern (Singh et al. 2017)

Taking into account all details above described in the FEM of the full-scale beams, the numerical load-deflection response obtained agreed well with the experimental results for all beams. The variability between the predicted results and the experimental ones in terms of the moment capacities was obtained near $5 \%$. The pre and post peak loaddisplacement response was well captured by the numerical models. These results were confirmed when the FEM developed was used to predict the behaviour of the UHPFRC beams tested by (Yang et al. 2010). From this research, it can be stated that the adapted CDP model for UHPFRC was suitable to predict the load-displacement response of the reinforced UHPFRC beams when the material properties were deduced from material tests.

\subsection{Sadouki et al. 2017}

Sadouki et al. (Sadouki et al. 2017) modelled the structural response of RC cantilever beams retrofitted with a thin layer of UHPFRC. According to these authors, the complex cracking phenomenon of the resulting RC-UHPFRC composite system was carried out by a numerical model after incorporating the real non-linear material laws to accurately predict mechanical behaviour.

In this work, three cantilever beams with a total length of $2000 \mathrm{~mm}$ and $150 \mathrm{~mm}$ wide were analysed by means of non-linear finite element analysis (FEA). MW0 was a monolithic RC beam with a height of $250 \mathrm{~mm}$ used as a reference. Then, its structural capacity was improved by adding a layer of UHPFRC. MW1 was a RC beam with a height of $250 \mathrm{~mm}$ and covered at its top with a $50 \mathrm{~mm}$ thick UHPFRC layer. Finally, MW4 was the same as MW1 but adding 4 equidistant $8 \mathrm{~mm}$ reinforcement bars in the 
middle of the top UHPFRC layer. In the experimental set-up (see Figure 2.48(a)) the values of geometrical parameters $a$ and $l$ were considered 800 and $1600 \mathrm{~mm}$, respectively. Beams were loaded under displacement control mode by means of gradually increasing displacement at point D (Figure 2.48(a)).

A FEM was carried out for the cantilever beams where concrete (plain concrete and UHPFRC) and steel plates were modelled by means of quadrilateral plane stress elements. Figure 2.48(b) shows the mesh used in the FEM of the specimens. In this work, the numerical modelling was developed by means of the FE software DIANA. In this case, a total strain rotating crack model based on a smeared crack model was used to define the constitutive UHPFRC behaviour.

(a)

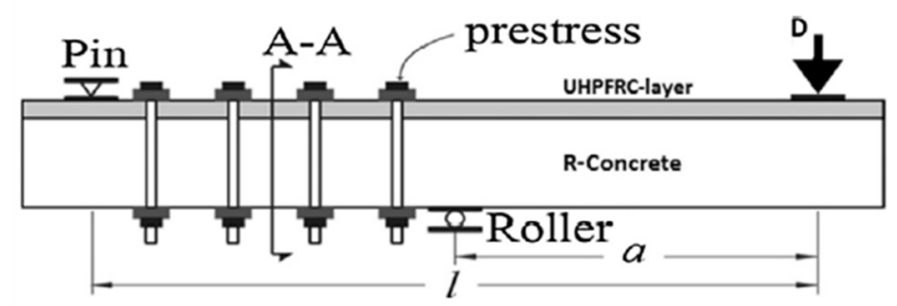

(b)

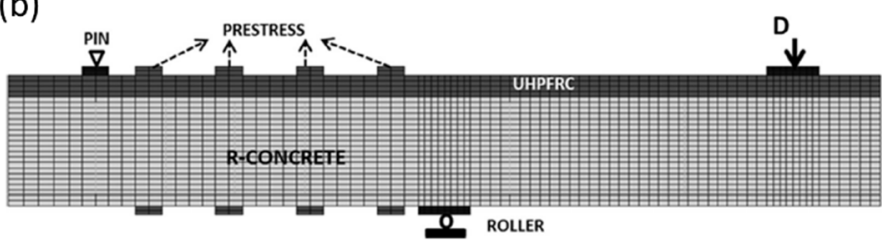

Figure 2.48 (a) Experimental setup and (b) FEM of the cantilever beams in (Sadouki et al. 2017)

A piecewise linear function type was used for defining constitutive tensile behaviour for both plain concrete and UHPFRC (see Figure 2.49 and Figure 2.50). As it can be observed the tensile behaviour in both concretes was defined by two parts: one concerning the elastic and hardening branch by means of stress $(\sigma)$-strain $(\varepsilon)$ relation, and the other concerning the softening part by means of stress $(\sigma)$-crack opening (w) relation. The unloading and reloading assumption was simplified by means of a secant modulus. The compressive behaviour of both concrete and UHPFRC was defined using an ideal elastoplastic curve. 


\section{CONCRETE}

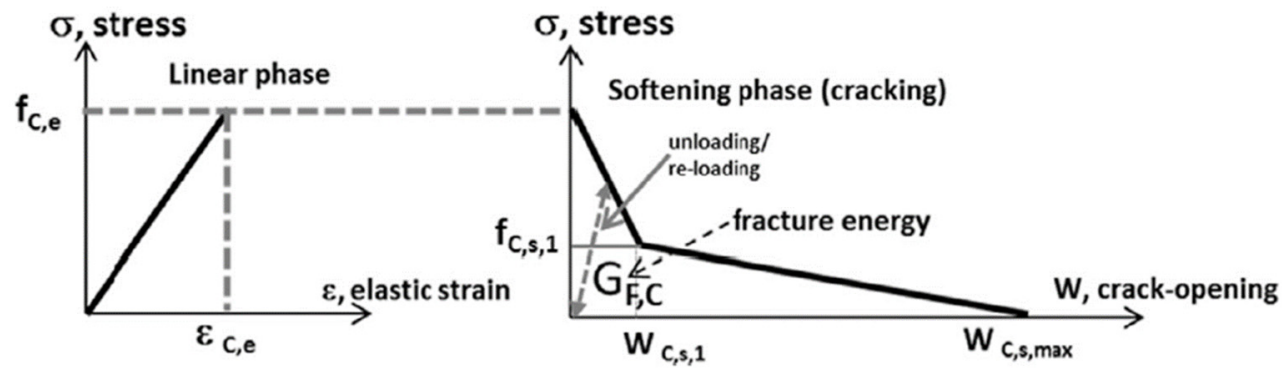

Figure 2.49 Plain concrete constitutive behaviour for the FEM in (Sadouki et al. 2017)

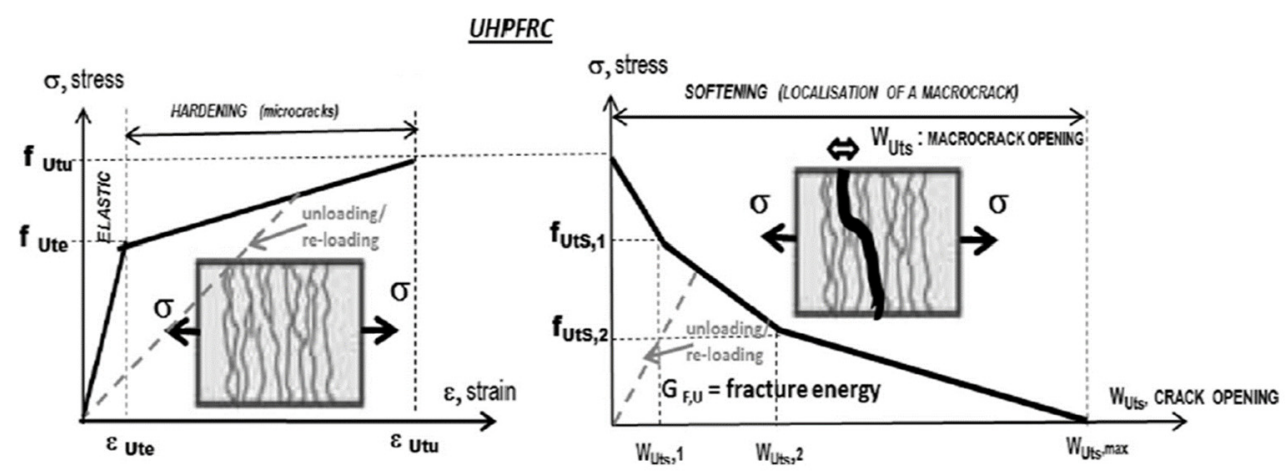

Figure 2.50 UHPFRC constitutive behaviour for the FEM in (Sadouki et al. 2017)

For smeared cracks, the fracture energy is distributed over a crack bandwidth $\left(b_{w}\right)$, which is related to a particular FE size and configuration. As it will be explained in Chapter 3 and evaluated in Chapter 5 of the current thesis, for the smeared crack model the stress $(\sigma)$-crack opening $(\mathrm{w})$ relation is transformed into stress $(\sigma)$-strain $(\varepsilon)$ (strain softening) relation by normalising crack-opening $(\mathrm{w})$ by the crack bandwidth $\left(\mathrm{b}_{\mathrm{w}}\right)$ in order to smear the crack opening into a mean strain in a continuum model. Consequently, the fracture energy is released over this width. For $2 \mathrm{D}$ finite elements, the crack bandwidth $\left(b_{w}\right)$ using the software DIANA is considered as the square root of the area of the cracked element $\left(\mathrm{A}_{\mathrm{ef}}\right)$. This hypothesis, in many cases, gives a good compromise in terms of preserving results independent of the mesh, but not always. In this work carried out by (Sadouki et al. 2017) it seems to be suitable.

Reinforcement bars and stirrups were modelled using embedded 1D line elements. An elastoplastic with hardening constitutive law was used to model the mechanical 
behaviour of the reinforcement steel, with perfect bond between bars and surrounding concrete. The steel for the plates was modelled by means of a linear elastic behaviour.

The parameters necessary to define the tensile constitutive behaviour for UHPFRC were obtained from uniaxial tensile test stress-strain diagrams of 4 UHPFRC dog-bone specimens, with a length of $350 \mathrm{~mm}$, developed in (Oesterlee 2010).

To validate the model, the experimental results obtained from the RC retrofitted with UHPFRC cantilever beams were compared with the numerical findings. The model showed an overestimation of the load $(\mathrm{P})$-deflection $(\delta)$ curve for the case of beams with $\mathrm{RC}$ and the layer of UHPFRC (MW1 and MW4) when the average constitutive parameters from uniaxial tensile dog-bone UHPFRC test were used in the FEM. In the same way, the FEM underestimated the $\mathrm{P}-\delta$ response when the tensile parameters from the weakest dog-bone curve were used in the UHPFRC constitutive behaviour. Finally, accurate results were obtained when adjusted constitutive UHPFRC parameters similar to those obtained from the dog-bone under the average were used in the FEM. Moreover, the UHPFRC layer increased the strength of RC beams (MW0) by near $40 \%$ (MW1). If reinforcement bars were added in the UHPFRC layer (MW4), the maximum load bearing capacity was increased by $53 \%$ compared to MW1.

\subsection{Yin et al. $2019 \mathrm{~b}$}

The same FEM developed in (Yin et al. 2019a) explained above in Section 2.5.3.1.8 was adapted and improved to model the structural behaviour of reinforced concrete members strengthened with UHPFRC in (Yin et al. 2019b). The improvement of the model consisted on simulating the interfacial bond characteristics of composite UHPFRCconcrete members using equivalent beam elements at the interface between UHPFRC and normal strength concrete (NSC) instead of a friction or cohesive element. The nodes of the interface equivalent beam elements and those of the solid elements from the NSC and UHPFRC were intentionally generated to coincide in order to let node sharing at the interface. To avoid perfect bonding and represent a finite bond strength, the equivalent beam elements alternately shared nodes with the solid elements of the two types of concrete. Figure 2.51 extracted from (Yin et al. 2019b) very well synthesises the model described. These beam elements were modelled by means of elastic-plastic constitutive behaviour considering the material characteristics of the weakest NSC. This novel technique using equivalent beam elements was compared to the same FEM but with perfect bond and unbonded interface behaviour, respectively. 
Chapter 2: State of the Art

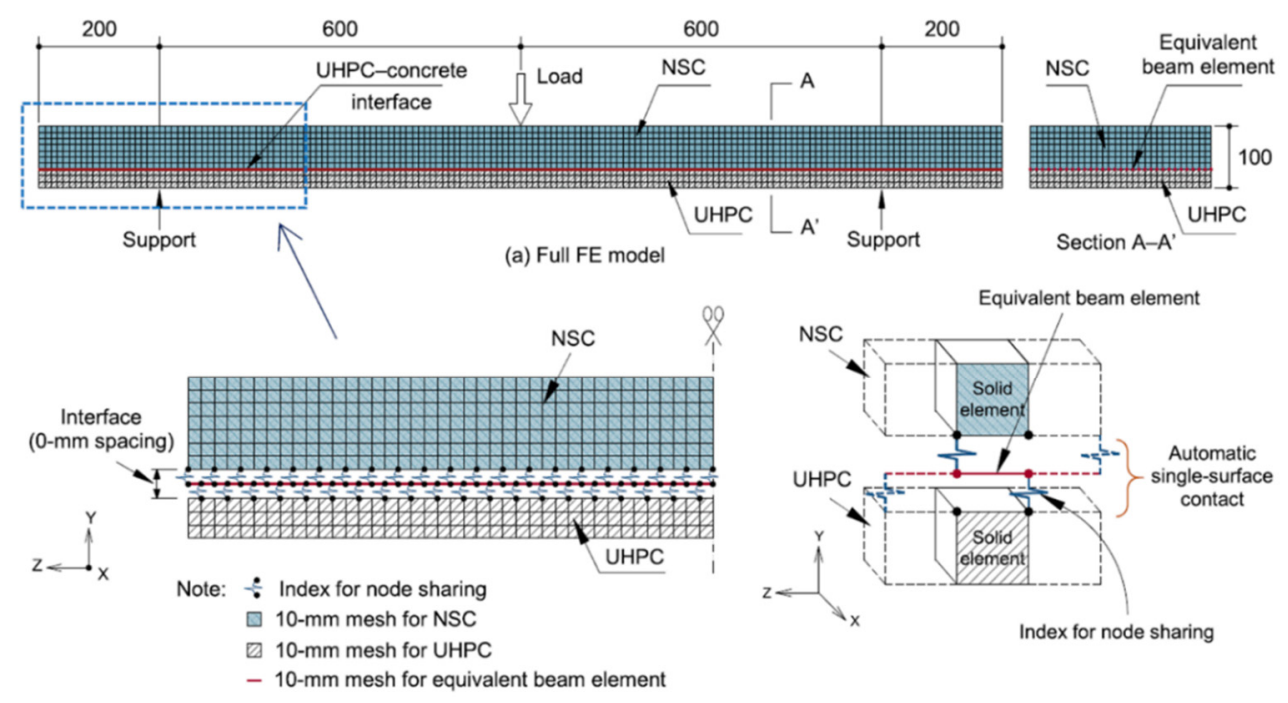

(b) Bond interface using equivalent beam elements

Figure 2.51 Proposed bond interface model by means of equivalent beam elements at the interface in (Yin et al. 2019b)

To validate the FEM, 17 specimens considering non-composite members and various configurations of composite UHPFRC-NSC concrete members were used from several authors in (Yang et al. 2010; Yin et al. 2017; Yoo et al. 2017a). Figure 2.52 shows the experimental 3PBT setup and Figure 2.53 shows some configurations of composite UHPFRC-NSC cross-section beams used in this work.

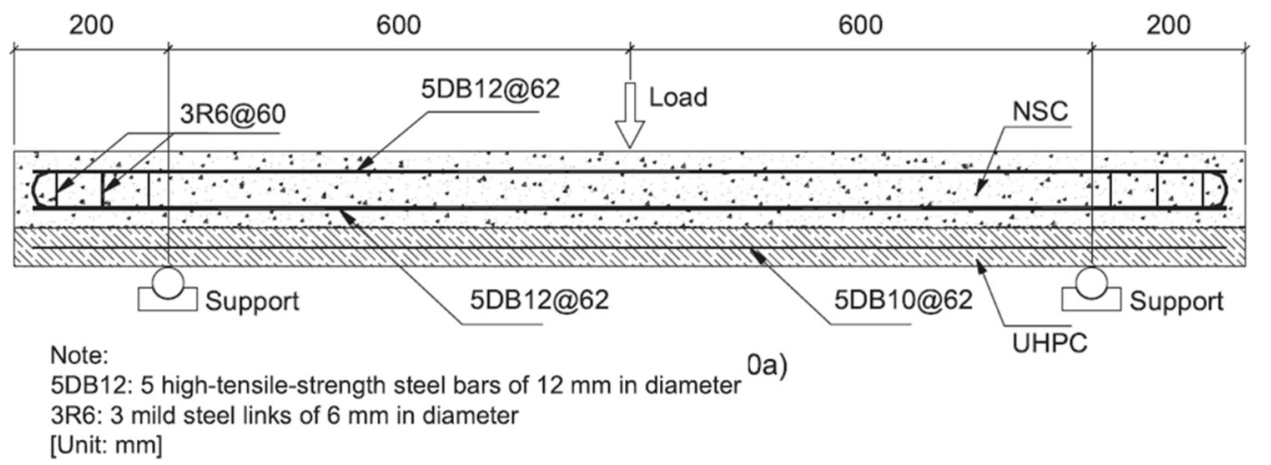

Figure 2.52 Experimental 3PBT setup used in (Yin et al. 2019b) 

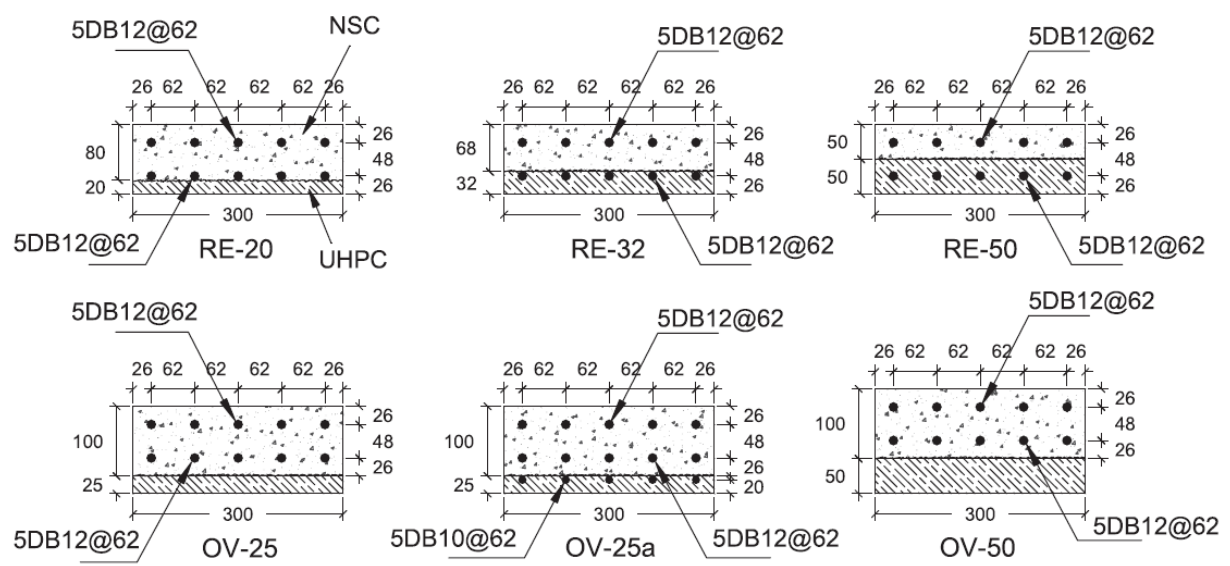

Figure 2.53 Some of the cross section beams used to validate FEM in (Yin et al. 2019b)

The modelling technic consisting in simulating the interfacial behaviour between NSC and UHPFRC composites by means of equivalent beam elements developed in this work brought accurate predictions for the load-deflection curves and good simulations of the crack damage pattern when compared to the experimental results. Moreover, the FEM developed with this technic showed good accuracy of the peak load. Therefore, this research has revealed the importance of considering the bond strength between NSC and UHPFRC when developing FEM of composite elements.

\subsection{Sakr et al. 2019}

Sakr et al. (Sakr et al. 2019) numerically modelled the behaviour of RC shear walls strengthened by UHPFRC and reinforced UHPFRC (R-UHPFRC) jacketing under lateral loading by means of a two dimensional (2D) non-linear FEM incorporating the bond stress-slip effect to the analysis to simulate the interfacial behaviour between the two concretes.

To develop the FEM the software Abaqus was used in this research. To model the concrete, 2D plane stress 4-node bilinear elements with reduced integration were used. To define the concrete material behaviour, the concrete damage-plasticity model (CDP) was adopted. The reinforcement steel bars were modelled by means of 2-node linear truss elements. The steel was considered a bilinear elastic perfectly plastic material both in tension and compression. Perfect bond behaviour between reinforcement steel and concrete was considered. The model used to represent the interface shear strength between both concretes in Abaqus software was the "Cohesive Zone Model" (CZM) (Systèmes 2009) that is defined by means of a traction-separation law to enable the debonding failure mode. In this case, it was necessary to define three parts of the law to simulate the cohesive behaviour: the linear-elastic traction-separation part, the damage 
initiation point, and finally the damage evolution zone (see Figure 2.54). The parameters that described the interfacial law: shear strength, fracture energy, and elastic shear stiffness, could be obtained from experimental tests or in equations such as in the Eurocode 2 (The European Union Per Regulation 305/2011 and Directive 98/34/EC 2004) that relates the shear strength between two concretes cast at different times. The interface zone was modelled by means of non-linear 2D Cartesian connectors elements multiplying by two the stiffness, strength and fracture energy of connectors in order to represent the interface bond on both faces of the shear wall. Finally, the shear wall was modelled with a mesh of $25 \mathrm{~mm}$ size and a displacement control was adopted to apply the load.

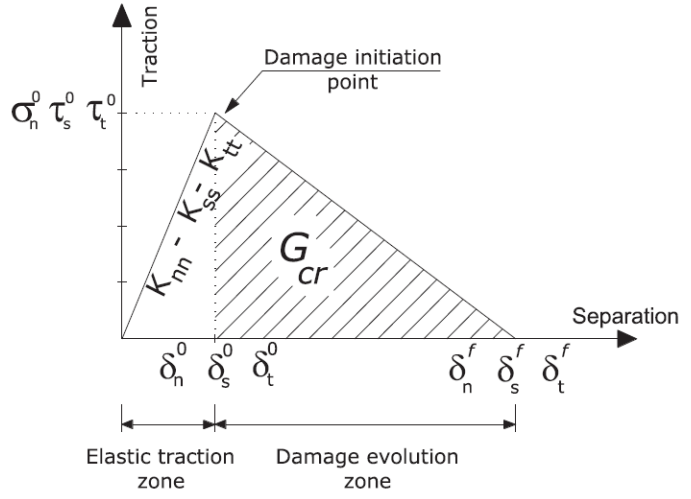

Figure 2.54 Interfacial traction-separation behaviour used in (Sakr et al. 2019)

The geometry of the shear wall modelled in this work was extracted from the experimental programme of Altin et al. (Altin et al. 2013) for reinforced concrete (RC) (see Figure 2.55(a)). Then the FEM developed was validated for this RC wall using the material characteristics of concrete from (Altin et al. 2013). The simulation agreed well with the experimental results, indicating that the FEM was able to predict accurately the behaviour of RC shear wall under lateral loading (see Figure 2.55(c)). The validated 2DFEM was applied to obtain the simulation of the mechanical behaviour of the strengthened RC walls by a UHPFRC and R-UHPFRC jacketing with a thickness of 25 $\mathrm{mm}$ and different configuration of the reinforcement of the UHPFRC jacket (SW-1, SW2, SW-3, SW-4 and SW-5), as shown in Figure 2.55(b), under lateral monotonic loading (see Figure 2.55(c)). In this case, the interfacial modelling between RC and UHPFRC above explained was considered. The material characteristics of UHPFRC for the material modelling were obtained from the uniaxial compression tests on cylindrical specimens and uniaxial tensile tests on dog-bone specimens carried out by Singh et al. (Singh et al. 2017) previously explained in Section 2.5.3.2.1. 


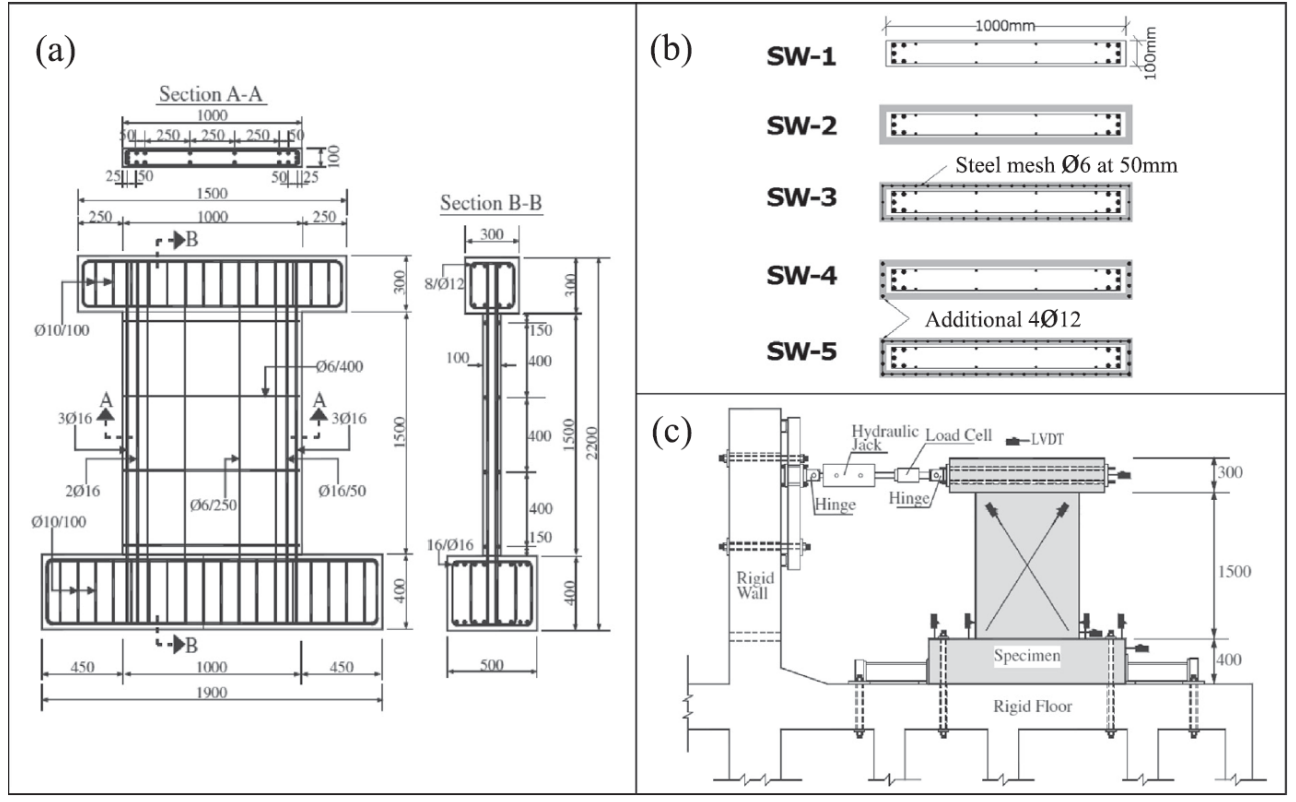

Figure 2.55 (a) Experimental shear wall from (Altin et al. 2013), (b) cross section of the shear wall simulated in (Sakr et al. 2019)and (c) test setup from (Altin et al. 2013)

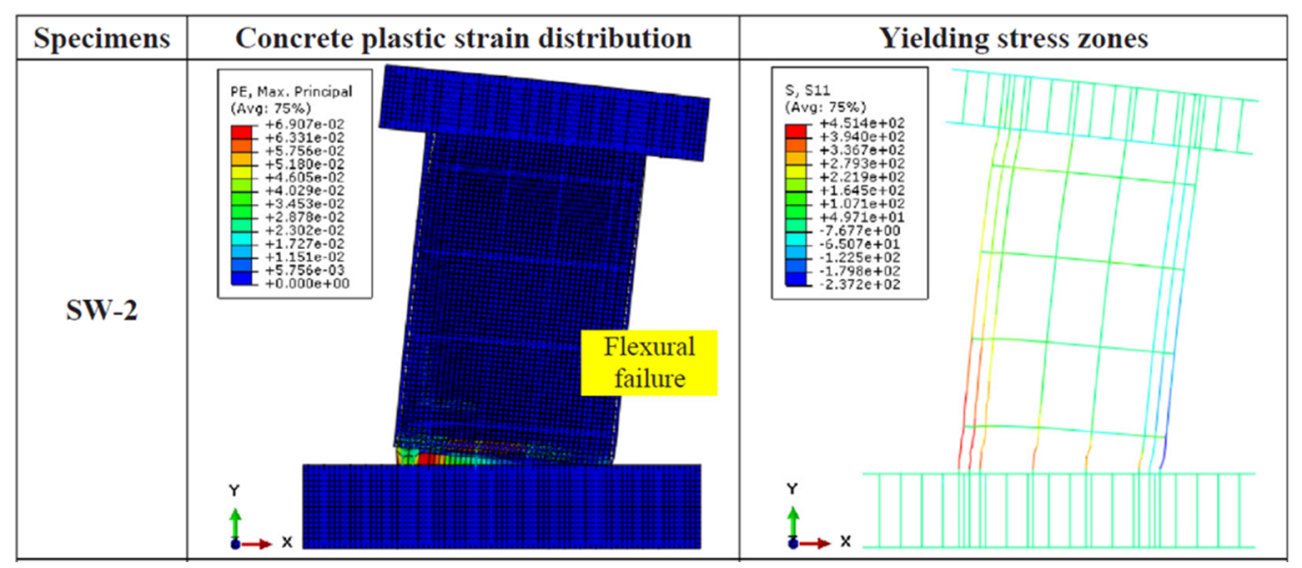

Figure 2.56 FEM results. Plastic strain and yielding zones for $S W$-2 configuration $R C$ shear wall strengthened with UHPFRC and R-UHPFRC in (Sakr et al. 2019)

The results obtained from the simulation done by the non-linear FEM incorporating the bond stress-slip effect to the analysis to simulate the interfacial behaviour between the 
two concretes were reliable (see Figure 2.56) and showed the influence of the different disposition of the R-UHPFRC on the cracking pattern and the failure mode. From the simulation results it was also deducted that, due to its strength in tension, the UHPFRC thin jacket provided confinement on the existing RC shear walls that had a positive effect on both concrete properties: increase in strength and ductility, and steel rebar response. It worked as a system of continuous stirrups. Finally, the ultimate resistance of the RC shear wall strengthened by a UHPFRC and R-UHPFRC jacketing was increased with respect to the ultimate resistance of the original RC shear wall.

\subsection{Zhu et al. 2020}

Zhu et al. (Zhu et al. 2020) developed a 3D-FEM capable of simulating with a good accuracy the flexure behaviour in terms of load-deflection relations, ultimate moment capacity, and failure mode of UHPRC-RC composite slab introducing existing cracks in the considered damaged reinforced concrete (RC) substrate by geometry discontinuous.

The experimental programme carried out in (Zhang et al. 2019) was used to develop the FEM. There, two full-scale damaged normal strength concrete (NSC)-RC slabs strengthened by UHPFRC layer and one non-damaged NSC-RC reference slab were tested. To consider the effect in the flexural response of the strengthened slabs, two load patterns were defined: negative bending moment (NBM) and positive bending moment (PBM). The dimensions of the RC slabs were cross section of $28 \times 200 \mathrm{~cm}$ and $320 \mathrm{~cm}$ of total length. They had two layers of reinforced grid with $16 \mathrm{~mm}$ and $20 \mathrm{~mm}$ diameter of reinforcement bars in each direction and a separation of $150 \mathrm{~mm}$. The layer of UHPFRC had a depth of $50 \mathrm{~mm}$ and was reinforced with a grid of $10 \mathrm{~mm}$ diameter bar with a separation of $37.5 \mathrm{~mm}$. To connect the UHPFRC layer and the RC slab, studs of $150 \mathrm{~mm}$ length were used. Figure 2.57 depicts the geometry and reinforcement of the slabs.

(a)

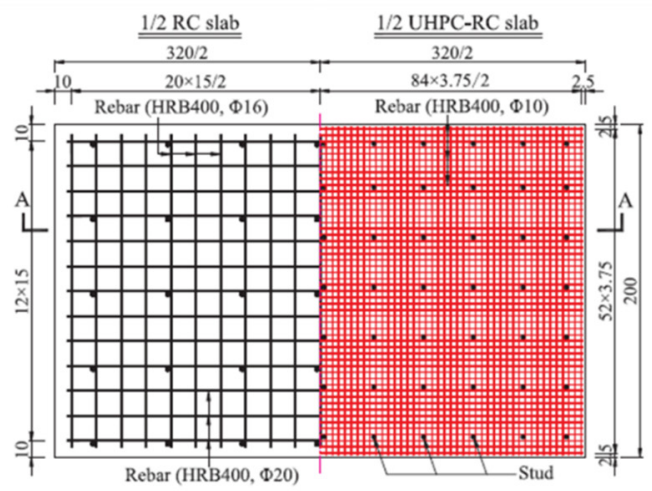

(b)

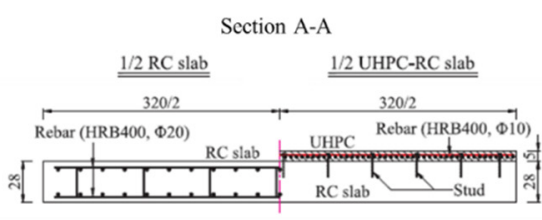

Figure 2.57 (a) Slabs' dimensions and reinforcement, (b) section A-A (dimensions in cm) in (Zhang et al. 2019) 
First, three NSC-RC slabs were cast and two of them were tested at 28 days by flexuretorsion to generate the diagonal cracks that defined their previous damage. After that, these two damaged RC slabs were prepared and the UHPFRC layer was poured on them. From this, after 28 days more, the two UHPFRC strengthened slabs were tested one under NBM and the other under PBM. The three slabs (the RC one and the two strengthened with UHPFRC) were simply supported and tested under 3-point bending (3PBT) (see Figure 2.58).

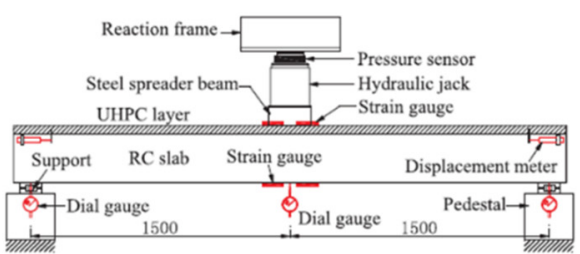

(a)

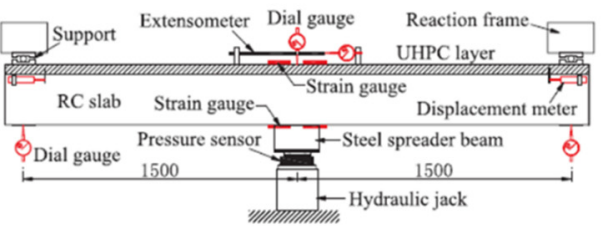

(b)

Figure 2.58 Test setup for (a) PBM loading case and (b) NBM loading case in (Zhang et al. 2019)

To define the FEM the software package Abaqus was applied. To model the nonlinear behaviour of both NSC and UHPFRC, the Concrete Damage Plasticity model (CDP) was used. The uniaxial stress-strain curves to characterise the material behaviour of UHPFRC used (with $3.5 \%$ in volume of steel fibres) were obtained by uniaxial direct tensile tests and compressive tests from (Yang and FANG 2009; Zhang et al. 2015). The uniaxial stress-strain curves derived from the experimental results previously mentioned were converted to stress-inelastic strain relations, which were suitable for analysis using CDP in Abaqus. 3D stress 8-node linear brick elements with reduced integration were used to model both the NSC and UHPFRC components. Elastic-plastic behaviour was used for the reinforcement bars and 2-node linear 3D truss elements were used to model them. The reinforcement grid was considered embedded in concrete elements. To simulate the interface connection between the two concretes, two different interfacial material models: ACI (ACI 2011) and AASHTO (AASHTO 2017) were compared with and without consideration of cohesion/adhesion contribution between UHPFRC and NSC layers. They were modelled in the FEM by means of a traction-separation law considering zero thickness using surface to surface property. To model the steel studs, two possibilities were evaluated: beam elements with a 2-node linear elements in space and solid elements with 8-node linear reduced integration bricks.

To model the total loading process of composite slabs strengthened by UHPFRC, two clear stages were differentiated: the first one was a preloading stage to obtain a damage grade in original NSC-RC slab; the second one concerned the loading phase on the UHPFRC-RC slabs after strengthening by UHPFRC. These two stages could be modelled in Abaqus with a multi-step strategy, where the cracks in NSC- RC from the 
preloading stage were modelled as a geometry entity or geometry discontinues. The crack parameters to define these geometry discontinuities such as the amounts of cracks, crack spacing, crack width, and crack length in RC slabs were assumed from previous experimental research experience. Figure 2.59 shows the FEM for all cases developed in this research: Figure 2.59(a) represents the 3PBT for the non-damaged NSC-RC slab used as the control specimen, Figure 2.59(b) represents the NSC-RC slab for the preloading stage under flexure-torsion loading, Figure 2.59(c) represents the second stage with the preloaded NSC-RC slab assembled with the UHPFRC layer for the case of 3PBT NBM loading and Figure 2.59(d) represents the second stage with the preloaded NSC-RC slab with the assembled UHPFRC layer for the case PBM loading. Figure 2.60 represents the simulations of the same stages of the FEM depicted in Figure 2.59. As it can be observed, very reliable and logical results were obtained from the simulations of the FEM.

(a)

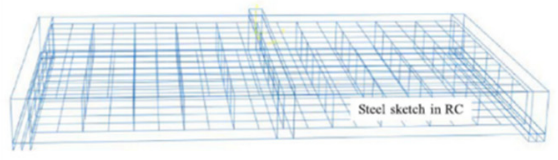

(c)

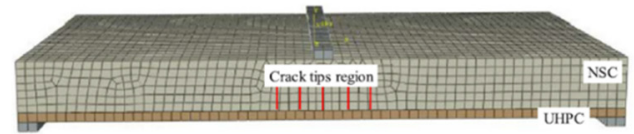

(b)

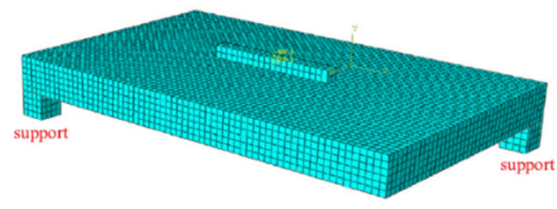

(d)

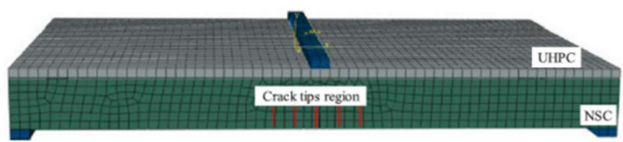

Figure 2.59 FEM mesh of (a) 3PBT for the non-damaged RC slab (b), preloading of the RC slap under flexure-torsion loading; (c) second stage NBM 3PBT for one strengthened slab and (d) second stage PBM 3PBT for the other strengthened slab in (Zhu et al. 2020) 
(a)

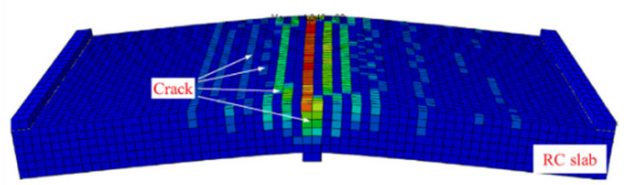

(c)

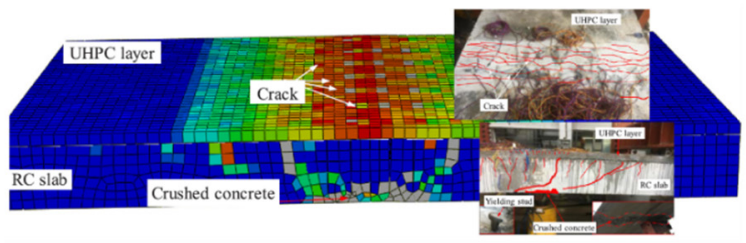

(b)

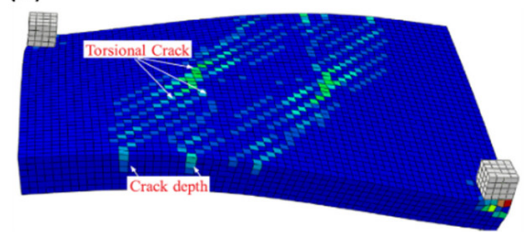

(d)

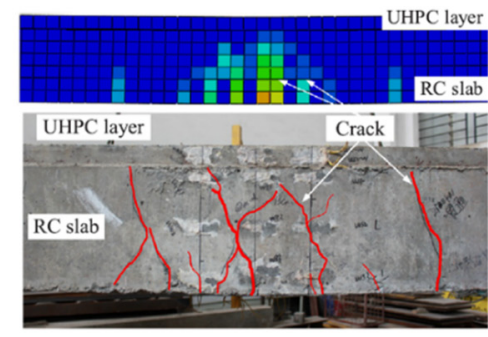

Figure 2.60 FEM simulations of (a) 3PBT for the non-damaged RC slab (b), preloading of the RC slap under flexure-torsion loading; (c) second stage NBM $3 P B T$ for one strengthened slab and (d) second stage PBM 3PBT for the other strengthened slab in (Zhu et al. 2020)

From this research it was concluded that the existing cracks in NSC-RC slab preloaded, simulated by geometry discontinuous, were able to represent roughly the damage grade in reality and the stiffness reduction of RC slab in experiments. Moreover, in some crack configurations, the structural response and ultimate flexure capacity were well captured. In the strengthened slab under PBM, preloaded existing cracks in NSC in RC slab influenced both the initial loading stage and ultimate flexure capacity. In addition, the beam or solid model for the studs influenced the convergence of the analysis of UHPFRC-RC under PBM. In both cases, PBM and NBM, the existing cracks could not be neglected, affecting ultimate flexure capacity.

\subsection{Naemi and Moustafa. 2020}

Naemi and Moustafa (Naeimi and Moustafa 2020) investigated the overall behaviour, failure mechanism, effect of reinforcement and design details of UHPFRC bridge columns by means of 3D finite element modelling. They modelled the push-over response of UHPFRC in a two-column bridge pier and carried out a sensitivity/parametric analysis studying the effect of different steel fibre ratio, longitudinal reinforcement ratio and steel grades of reinforcement bars on the structural response of the columns. 
In this work the material behaviour of UHPFRC was modelled in a FEM developed by means of the multi-linear total strain crack model available in DIANA FEA (DIANA (Software) 2017). The total strain crack model was validated with FE modelling of two experimental UHPFRC material characterisation tests under uniaxial tension and compression. Once they were validated, the material models were implemented into full structural models to investigate the pushover behaviour of UHPC two-column bents.

The total strain based crack models follow a smeared crack approach for the fracture energy and the coaxial stress-strain concept. In this study, the rotating crack approach was used. To validate this model in compression, the experimental data of uniaxial compressive cylinders from $\mathrm{Wu}$ et al. (Wu et al. 2017) was considered. To model UHPFRC, eight-node isoparametric solid brick elements were employed (see Figure 2.61(a)). To validate the model in tension, the experimental data from the uniaxial prismatic tensile tests of Graybeal (Graybeal 2015) was used. To build the mesh, four node, three-side isoparametric solid tetrahedron elements were employed (Figure 2.61(b)). The load was applied in both cases by means of displacement control.

For both models, very reliable results were obtained in terms of stress-strain response when the curves from the experimental tests were implemented in the material model using a multi-linear stress-strain model in the software and compared to the overall response from the numerical simulation. Therefore, the total strain crack model with user-defined input was demonstrated to accurately simulate the elastic, hardening and softening behaviour of UHPFRC under direct tension and compression loading. Consequently, the model was extrapolated to simulate nonlinear behaviour of UHPFRC at structural level.

(a)

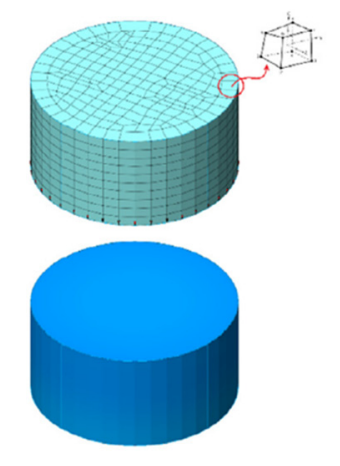

(b)

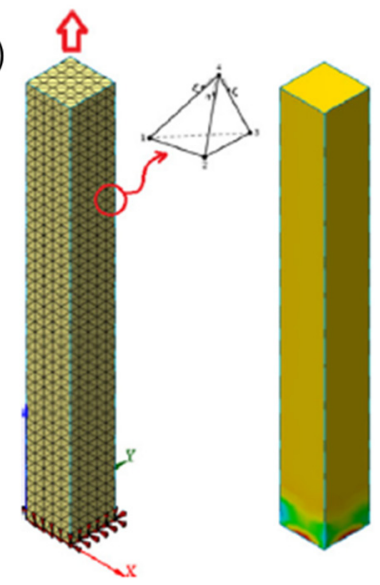

Figure 2.61 FEM of characterisation UHPFRC tests (a) compression and (b) tension in (Naeimi and Moustafa 2020) 
From the validation of the material model used in the FEM for the UHPFRC, a nonlinear analysis of two-column bents from a prototype bridge was carried out. Moreover, the same model was applied using NSC in order to compare the response with both materials. The geometry of a representative California bridge, which is typically used at the Caltrans Design Academy (Caltrans Bridge Design Academy 2006), was used in this study (see Figure 2.62(a)).

For the 3D mesh of the FEM of NSC and UHPC two-column bents in the software Diana, six-node linear isoparametric solid wedge elements were used (Figure 2.62(b)). The reinforcement steel bars were modelled as embedded reinforcement in concrete. In this sense, full bond was assumed between the reinforcement bars and concrete. The crack bandwidth $\left(b_{w}\right)$ for the smeared crack model used in this study was the default value proposed in Diana: $b_{w}=\sqrt[3]{V_{e f}}$ where $V_{e f}$ was the volume of the 3D finite element.

The nonlinear analysis was carried out in two phases. In the first one, the gravity load determined from the prototype bridge influence was applied distributed among all nodes at the top surface of cap beam. A regular Newton-Raphson solver was used for the nonlinear equilibrium equations. For the second phase, a prescribed horizontal top displacement was uniformly applied to the nodes at the left section of the cap beam. In this case, a secant Quasi-Newton method was used to solve the nonlinear equilibrium equations. Displacement, force, energy and residual norms were simultaneously satisfied as the convergence criteria for both phases.

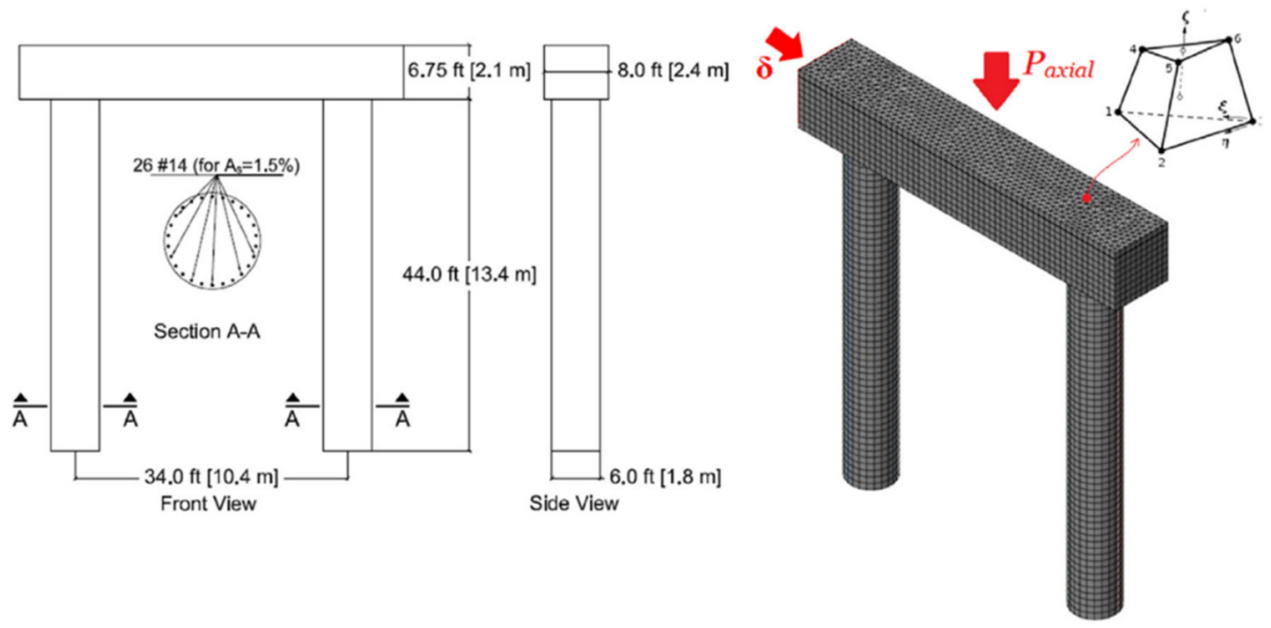

Figure 2.62 (a) geometry and (b) FEM of the bridge bent (Naeimi and Moustafa 2020)

Concerning the constitutive material behaviour modelled in the FEM, a parametric study for the steel reinforcement was carried out. For that, two types of bars were evaluated: Gr60 and Gr100. The constitutive behaviour for the Gr60 was assumed as an elastic perfectly plastic stress-strain relation. For the Gr100 a strain-hardening behaviour for 
steel was used. For both cases, the stress-strain relationship followed the Von-Mises yield criterion. For the case of concrete, the multi-linear stress-strain model to define the Total Crack Model in Diana to implement the stress-strain curves of either concrete or UHPFRC under tension and compression was used. The experimental data to characterise the constitutive behaviour of UHPFRC to define the constitutive multilinear curves in the software were extracted from the average cylindrical compression stress-strain curve obtained in (El Helou 2016) and the average tensile stress-strain obtained in (Duque and Graybeal 2017). Two amounts of steel fibres were considered in UHPFRC: $2 \%\left(157 \mathrm{~kg} / \mathrm{m}^{3}\right)$ and $4 \%\left(314 \mathrm{~kg} / \mathrm{m}^{3}\right)$ in volume.

A total of 48 models of UHPFRC two-column bents were used to carry out the nonlinear pushover analyses to study the effect of the variation of the following parameters: (1) longitudinal reinforcement ratio, (2) reinforcing steel grade, (3) modelling of reinforcing steel hardening effect, (4) UHPFRC steel fibre ratio, (5) stress-strain relationship of UHPFRC, and (6) axial load level. Moreover, the sectional response of one of the types of UHPFRC column was obtained using software SAP2000 and compared to the response of the FEM developed by Diana. To carry out this comparison, the same stressstrain curves that were implemented in Diana to define the mechanical properties of UHPFRC were also implemented in the SAP2000 section analysis through the user defined stress-strain tool.

From this work it could be stated that, when it was compared to NSC, the UHPFRC superior mechanical properties were developed when high reinforcement ratios or high strength steel were used. The flexural capabilities of UHPFRC columns were higher than those from NSC leading to optimised cross sections. The implemented material behaviour reflected confining effects of steel fibres that could lead to reduction in transverse reinforcement. Moreover, higher reinforcement ratios and the use of high strength steel could increase the maximum load capacity. They deduced that the use of high steel fibre ratio such as $4 \%$ could increase the capacity of the UHPFRC but reduced the workability of UHPFRC mixes and also affected the uniform distribution of fibres that could derive in adverse effects. In this work, it was not recommended to consider more than $2 \%$ steel fibres for UHPFRC. Finally, they demonstrated that the ultimate strain value of UHPFRC, especially under tension, had a critical effect on the post-peak behaviour of the UHPFRC two-column bents.

\subsection{Chapter summary and relevant conclusions}

Ultra-high performance fibre-reinforced concrete (UHPFRC) can be considered an advanced modernisation of conventional (CC) and fibre-reinforced (FRC) concretes. However, due to the high cement content and its mix design, UHPFRC can be prone to suffer high shrinkage at early ages. It seems logical to assume as a reference a total shrinkage strain in the range of $0.6-0.9 \mathrm{~mm} / \mathrm{m}$ for UHPFRC with $\mathrm{w} / \mathrm{c}$ ratio $\leq 0.25$ and 
non-heat treatment. Moreover, the presence of steel fibres and the enhanced concrete matrix lead to consider their influence in tension-stiffening behaviour.

When the fracture mechanism of cement based materials with notorious bulk energy dissipation and strain-hardening behaviour such as SH-UHPFRC is represented by means of $\sigma-\varepsilon /$ w diagram, it is possible to differentiate two main parts: the pre-peak part that is composed by the elastic and hardening microcracking phase where the volumetric energy is dissipated, and the post-peak part that contains the softening part where the localised crack and only a surfacic dissipation of energy is developed.

The fracture mechanism of SS-UHPFRC considered in this thesis can be represented also by means of $\sigma-\varepsilon /$ w diagram as for SH-UHPFRC. However, the concept of "peak" in SS-UHPFRC is not the same as for the case of SH-UHPFRC. For the case of SHUHPFRC, the peak in the of $\sigma-\varepsilon / \mathrm{w}$ diagram is represented by the ultimate tensile strength $\left(f_{t u}\right)$ while for the case of SS-UHPFRC the peak is represented by the tensile strength $\left(f_{t}\right)$. Therefore, for SS-UHPFRC, the two main parts of $\sigma-\varepsilon / \mathrm{w}$ diagram are defined as: the pre- $f_{t u}$ part represented by the $\sigma-\varepsilon$ part of the diagram that is composed by the elastic and softening microcracking phase where the volumetric energy is dissipated, and the post- $f_{t u}$ part represented by the $\sigma$-w part of the diagram where the localised crack and only a surfacic dissipation of energy is developed.

Consequently, for UHPFRC a simplification of the uniaxial tensile behaviour following a quadrilinear relationship is assumed. This quadrilinear response can be divided in two main parts: a bilinear behaviour expressed by means of stress-strain behaviour for the part I (elastic) and part II (strain-hardening/softening), and a bilinear behaviour expressed in terms of stress-crack opening for part III (softening).

Currently, the characterisation of UHPFRC tensile behaviour can be assumed a challenge. Due to their simplicity, four-point bending tests (4PBT) are one of the best tests to achieve this purpose. Nevertheless, they require running an inverse analysis methodology to derive tensile properties based on the obtained results. From the design point of view, it can be concluded from the principal standards and recommendations for UHPFRC structural design that they are practically all adaptations from CC design codes.

For modelling, UHPFRC's constitutive model can be defined using continuum models where the model can be described by means of stress-strain laws or by generalised moment-curvature relationships, by discrete models where the relation is stablished between internal forces and relative displacements considered at the edge of sections of finite entities in which the general body is divided, and continuum models with discontinuities that could be considered a midway between continuum and discrete models.

To build the model it is necessary to consider a kinematic description that is directly related to the constitutive law for the cracking material. Therefore, taking into account the regularity of the displacement field, it is possible to set three types of kinematic 
behaviour: strong discontinuities which can be considered jumps in displacements across the discontinuity curve, weak discontinuities where the band between discontinuities is related to a damage process zone with more or less constant density of microdefects, and no discontinuities which use a continuously differentiable displacement field and, therefore, the strain field remains continuous.

The finite element method is one of the existing numerical techniques that let to approximate the behaviour of a structure with an infinite number of degrees of freedom to another with more or less the same physical and geometrical properties but with a finite number of degrees of freedom. With the support of the computer development technology and the increasing complexity of a wide range of fields of the science and engineering, the FE method has become one of the most widespread numerical methods and a powerful technique for the resolution of diverse and complex problems in different engineering fields.

Conclusions extracted from the UHPFRC modelling literature review:

Considering the characteristic tensile behaviour of UHPFRC where an elastic and hardening part are developed until the ultimate strength when the macrocrack appears and the consequent softening branch is developed, it is common to find modelling works where the UHPFRC behaviour is modelled by means of continuum models such as the smeared crack model and the concrete damage plasticity, and also continuum models with discontinuities such as the fictitious crack model and the discrete crack approach where, for the last, the crack is considered discrete and the rest of the material is considered as a continuum.

One of the most important advantages of continuum models and the principal reason of their extended applicability is that it is not necessary to know previously the crack path, as the damage is modelled as a continuum in all body. However, as their constitutive laws are expressed generally in terms of stress-average strain, when they are employed in computational methods in structural analysis such as the finite element method, they may become mesh size dependent if the constitutive law is not adequately scaled or corrected. The smeared crack model constitutes a clear example of continuum models that are mesh size dependent. In their definition, a mean total strain softening behaviour is obtained by means of the crack bandwidth parameter that transforms the crack opening to smeared strain in a considered crack band where the damage is treated in a continuum manner. All the energy dissipated in the cracking process of UHPFRC in all its phases must be correctly represented in the correction or in the crack band parameter used to define the stress-strain constitutive behaviour. As it can be observed in the literature review, in many cases the problem of mesh size dependency for continuum models is addressed calibrating the size of the finite element using different sizes and comparing to the experimental results. This could solve the problem for the particular case modelled but does not constitute a general criteria for continuum models. 
There are some occasions where the localisation of the crack plays an important role and becomes necessary to set the crack position in the model. In other cases, because of the model concept, cracks are modelled discretely and are activated randomly following a stablished activation criteria. These are very good examples where the continuum models with discontinuities are suitable to be employed. When these kind of models are used, there is no mesh dependency as the crack is modelled by an interface behaviour expressed by means of traction-separation law. In this case, the accuracy of the results will depend on the definition and calibration of the traction-separation law that is going to set the interfacial behaviour of the crack and in the definition of an adequate activation criterion.

To model a structural element using UHPFRC it is necessary, first, to characterise the material properties in order to define in the FEM the material behaviour. The compressive parameters such as compressive strength are obtained from cubical or cylindrical compression tests. For the case of tensile parameters, they are mainly obtained from direct tensile tests where the stress-strain response is directly defined, or bending tests which need inverse analysis procedures to obtain the tensile response from the experimental bending curve. It is also important to define and calibrate in the material model special effects that can describe and determine the particular behaviour of UHPFRC such as shrinkage effect, tension stiffening or interfacial behaviour between UHPFRC and other materials. Therefore, it is very frequent to find in the literature works previous tests done to characterise the material model and then the FEM is calibrated by bending tests from experimental beams. Once the FEM is well defined and calibrated, the jump to more complex structural elements considering more complex loading situations could be considered straightforward.

However, not only the adequate definition and calibration of the constitutive behaviour of the UHPFRC will lead to an accurate and reliable model. In this sense, it is important to define and adapt to the model the constitutive behaviour of the reinforcement steel bars and their behaviour in relation to the UHPFRC by means of completely embedded behaviour or a well calibrated bond-slip relationship between steel and concrete by means of interface elements. In the same direction, it is important to consider the influence of the discontinuous reinforcement effect produced by the steel fibres and their random distribution. Both reinforcements must be able to represent the tension stiffening effect of UHPFRC in tension. Moreover, it is necessary to put special attention in the transition zones between the loading and support points with the specimen. They may become a critical font of spurious results and instabilities leading to the use of interface elements to regularise stresses in those zones.

Finally, it is important to set the most appropriate nonlinear structural analysis strategy not only from the point of view of the stability of the analysis but also for the reliability and accuracy of the results. For the case of UHPFRC non-linear analysis, it is common to use an incremental-iterative procedure. The use of one criterion for the step size in the incremental part and the iterative method depends on the expected response of the 
structure analysed and how far the analyst wants to go in the analysis. Frequently, the criteria to choose the correct strategy depends on the experience and ability of the analyst.

From all of the conclusions extracted in this chapter concerning the UHPFRC characterisation and modelling, it seems necessary to set a complete process that involves all the steps to produce a reliable model for UHPFRC structural elements. It is necessary to stablish a direct, simple and reliable procedure to characterise the mechanical tensile constitutive behaviour of UHPFRC from experimental tests. The way of obtaining the constitutive characteristic parameters and their implementation to a numerical model must be evaluated and clearly established. Concerning the numerical models for UHPFRC, it is important to study the suitability of continuum models that represent adequately the UHPFRC constitutive behaviour and its particular cracking process with respect to the mesh size dependency when they are used in finite element modelling. It is also important to study alternatives to continuum models considering the applicability of continuum models with discontinuities such as the discrete cracking approach that make the FEM mesh size independent by means of interface elements with their proper traction-separation law. These kind of models could lead to more accurate results but would need more computational effort. The interaction of UHPFRC with other elements such as the reinforcement must be studied taking into account its bond-slip behaviour and the influence in the tension stiffening effect. It is necessary to incorporate the effect of UHPFRC shrinkage that could generate important internal tensile stresses in the concrete matrix when concrete is in contact to the reinforcement, leading to a decrease in the bearing capacity of the UHPFRC structural element. Moreover, there are aspects concerning the heterogeneity of the mechanical properties of concrete, even increased due to the presence of fibres, which are necessary to be incorporated into the model, for example, by means of random distribution. Therefore, all of these aspects need to be considered to generate a reliable modelling process for UHPFRC elements and they are addressed in the present $\mathrm{PhD}$ document. 


\section{Chapter 3}

\section{Proposed constitutive material models}

\subsection{Introduction.}

The objective of this chapter is to explain the theory of the material characterisation to define the non-linear finite element model (NLFEM) that is herein developed. The aim of the NLFEM is to model Ultra-High Performance Fibre-Reinforced Concrete (UHPFRC) behaviour from the material to the structural level. Hence the model goes from the simple constitutive 1D definition at the material level to complex behaviour when this material works after being integrated into an element with increasing complexity and subjected to boundary conditions, interacts with other materials and elements (e.g. reinforcement), and works in two (2D) and three directions (3D). This generates the basis to integrate it into a general body; that is, when this element works together with other elements to cover a structural objective. Hence the need to establish both how this material will behave in different directions and the theoretical models that define it.

The definition of the NLFEM as its complexity increases leads to different stages being addressed. First of all, it is necessary to model the material's response. This entails defining the constitutive behaviour of the materials to be used: constitutive 1D behaviour, how this 1D behaviour works when it is extrapolated to other directions, 2D and $3 \mathrm{D}$, and how the material's particularities, such as cracking, shrinkage and bonding if reinforced concrete is used, are defined in the model. This constitutes the first step and the core of a model that needs to be correctly defined and controlled to subsequently adapt the element and/or its structural reality by means of: more or less complex 
geometry, boundary and load conditions, suitable finite element types and analysis methods. The material model is linked with its element and structural function, and vice versa. It is necessary to know "for what" we are modelling. Therefore, when someone addresses the model at the material level, it is important to know in which element, structural function and environment it will act because this will condition the different models to be used to define the material.

Therefore in this chapter, this first step is carried out by means of the theoretical definition of materials. For UHPFRC, the constitutive uniaxial (1D) model and the models adopted to be extrapolated to the multiaxial case (2D and 3D) are defined. Afterwards, it examines the way that the parameters defining constitutive UHPFRC behaviour are obtained: the four-point bending tests (4PBT) used as experimental tests and the inverse analysis to derive the tensile parameters from the experimental bending curve. Moreover, the uniaxial reinforcement steel behaviour and the bond between reinforcement and UHPFRC are also defined.

\subsection{The uniaxial UHPFRC material model}

In order to start a model, it is necessary to define it from the simplest constitutive relation. In this case, we move on to define the material's constitutive UHPFRC behaviour in one dimension to establish the basic relation according to its mechanical properties.

\subsubsection{Material behaviour in compression}

For constitutive compressive behaviour, the typical compressive stress-strain curve for fibre-reinforced concrete, such as that from CEB-FIP Model Code 1990 (MC90 1993), was adopted (see Figure 3.1) in this work. This curve can be divided into the following three parts:

- An initial linear elastic part with initial stiffness $E_{c}$, by assuming the same in both tension and compression

- A non-linear hardening part until peak stress or compressive strength $\left(f_{c}\right)$ and its associated strain $\left(\varepsilon_{c}\right)$ where, even though stress still increases with strain, tangential stiffness decreases

- A non-linear softening part where stress decreases, while strain increases, and tangential stiffness becomes negative

Adding steel fibres to the concrete matrix has no notorious effect on the ascending part of the stress-strain curve, and the first cracking strength is influenced more by the concrete matrix strength than the fibre-bridging effect. The properties conferred by fibres affect the descending part of the stress-strain curve depending on the amount of fibres, orientation, geometry, stiffness, and the bond between fibres and the concrete matrix (Fehling et al. 2014; Yoo et al. 2017b). 


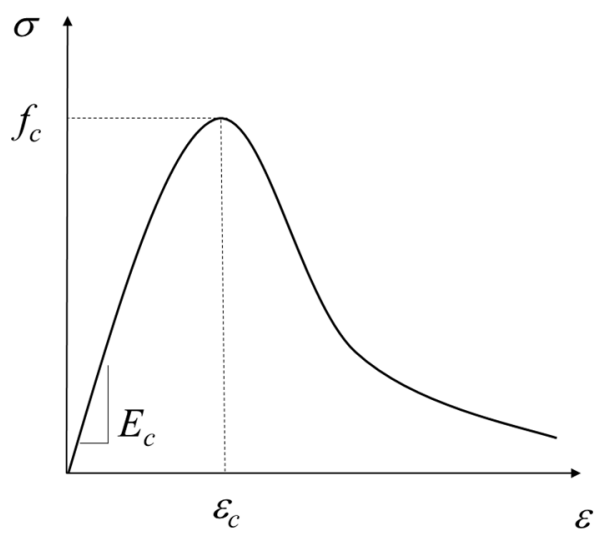

Figure 3.1 Adopted uniaxial compressive stress-strain material UHPFRC behaviour

\subsubsection{Material behaviour in tension}

As deduced in Section 2.3.1 UHPFRC uniaxial tensile response in Chapter 2, tensile constitutive UHPFRC behaviour can be expressed using a quadrilinear response, which is divided into two main blocks: a bilinear relation expressed by means of stress-strain behaviour for part I (elastic) and part II (strain hardening); a bilinear relation expressed in terms of stress-crack opening for part III (softening). Figure 3.2 shows the quadrilinear response proposed by (Wille et al. 2014) and taken from Figure 2.7 of Chapter 2. It is worth noting in this work that two UHPFRC types are characterised and modelled: strainhardening UHPFRC (SH-UHPFRC) and strain-softening UHPFRC (SS-UHPFRC). Therefore in Figure 3.2, both types are differentiated in terms of the stress-strain relation depending on if $f_{t}<f_{t u}$ (SH-UHPFRC) or $f_{t}>f_{t u}$ (SS-UHPFRC). For both cases, uniaxial tensile behaviour is defined by eight parameters: (i) elastic modulus $(E)$ by assuming the same in both tension and compression; (ii) cracking strength or tensile strength $\left(f_{t}\right)$; (iii) ultimate tensile strength $\left(f_{t u}\right)$, defined as the stress where the macrocrack takes place; (iv) its associated ultimate strain $\left(\varepsilon_{t u}\right)$; (v) the unloading modulus $\left(E^{*}\right)$, which is important to clearly differentiate between the energy dissipated in the strain hardening or strain softening block (volumetric energy) and in the crack opening softening block (surface energy); (vi) strength upon the change of slope in the crack opening softening block $\left(f_{t d}\right)$ which, according to the bilinear models developed for concrete, can be defined as a percentage of ultimate strength; (vii) its associated crack opening $\left(w_{d}\right)$; (viii) the crack opening at zero stress, usually known as characteristic crack opening $\left(w_{c}\right)$. Therefore following the criteria in Figure 2.4 in Chapter 2, what is considered to be SS-UHPFRC in this work would be characterised by a behaviour located between level 2 and level 3, and by being mechanically characterised by Figure 3.2(b), whereas what is considered 
SH-UHPFRC would correspond to both levels 3 and 4 and be mechanically characterised by Figure 3.2(a).

$$
\sigma-\varepsilon
$$$$
\sigma-w
$$

(a)
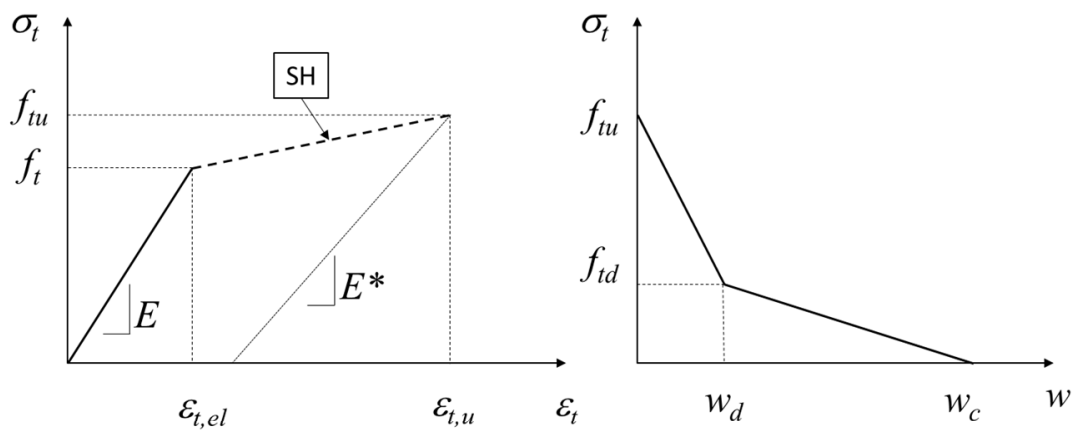

(b)
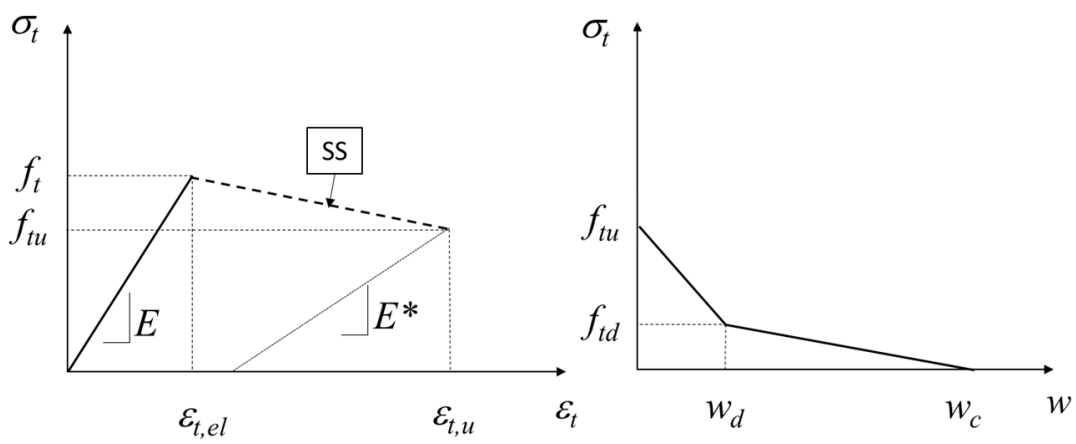

Figure 3.2 Uniaxial tensile material behaviour adopted by (a) SH-UHPFRC and (b) SS-UHPFRC

\subsubsection{Cracking}

Once the material stress-strain/crack opening relation is established, and to complete the uniaxial UHPFRC behaviour definition for modelling, it is necessary to interpret concrete's cracking mechanism. In the physical reality, concrete can be observed on a different scale (like a zoom), when the interpretation of its physical properties to develop the model can change depending on that scale. That is, it is necessary to set the model's scale according to the scale of the physical reality to be modelled. As stated by (HäusslerCombe 2015), it is possible to differentiate three scale levels: the macroscale, which corresponds to spatial dimensions of metres $(\mathrm{m})$ or $\left(\mathrm{m}^{-1}\right)$; the mesoscale, which corresponds to spatial dimensions of millimetres $\left(\mathrm{m}^{-3}\right)$; the microscale, related to spatial 
Chapter 3: Proposed constitutive material models

dimensions of micrometres $\left(\mathrm{m}^{-6}\right)$. By considering all this, concrete can be described as a homogeneous material with more or less isotropic properties (depending on the expected accuracy) if it is contemplated at the macroscale level. Therefore, the material's constitutive relations derive from macroscale specimens. However, if a zoom is performed up to the mesoscale level, it would seem logical to understand that, at this level, concrete cannot be considered homogeneous because of its composition of aggregates and cement, which leads to discontinuities in material properties and, therefore, anisotropic physical and mechanical properties. It is at the mesoscale level where concrete failure can be understood and, consequently, the cracking process and its mechanical consequences depend on their interpretation. Therefore, the UHPFRC material model needs to be expressed by stress-strain/crack opening relation defined at the macroscale level, and completed by a cracking process characterisation model defined at the mesoscale level.

In order to physically understand concrete's cracking mechanism, a uniaxial tensile failure (Mode-I) is represented in Figure 3.3 and Figure 3.4. During the cracking process, three phases were differentiated (Figure 3.3(a)): (1) microcrack formation perpendicularly to the tensile force direction and randomly distributed; (2) microcrack fusion in more general cracks that produced tortuous branches and crack bridges; (3) macrocrack formation due to the fracture of crack bridges and the union of branches. The same process can be followed at the macroscale level by considering a general homogenised stress-strain material relation (Figure 3.3(b)) with its known ascending linear and hardening parts represented by the elastic law in Expression (3.1), and the softening part represented, in this case, by the descending inelastic law in Expression (3.2). In Figure 3.3(b), the cross-section where failure occurred reached point $B$ on the material curve, while the other cross-sections in the hardening part of the curve unloaded at point A. Consequently, strains increased at the failing section to produce strain localisation. At the same time, the strains at the other sections decreased progressively due to unloading (Figure 3.4). The softening effect produced in the failure section extended in a process zone or a crack band with thickness $b_{w}$ (Bazant and Cedolin 1984; Bažant and Oh 1983; Häussler-Combe 2015; Jirásek 2017; Rots and Blaauwendraad $1989 \mathrm{a}$; b) due to the three phases generated as a result of cracking, as shown in Figure 3.3(a) and Figure 3.4. The cracking process finished when the macrocrack had completely set at zero stress in the failing section and the other sections had zero stresses and strains.

$$
\sigma=f_{u n c}\left(\varepsilon_{u n c}\right)
$$

$$
\sigma=f_{c}\left(\varepsilon_{c}\right)
$$


(a)

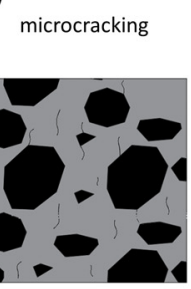

$b_{w}$ crack branches crack bridges

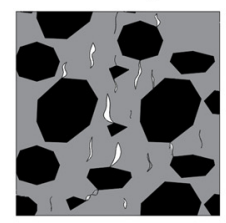

$b_{w}$ macrocracking

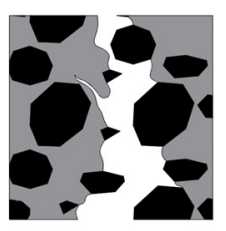

$b_{1}$

(b)

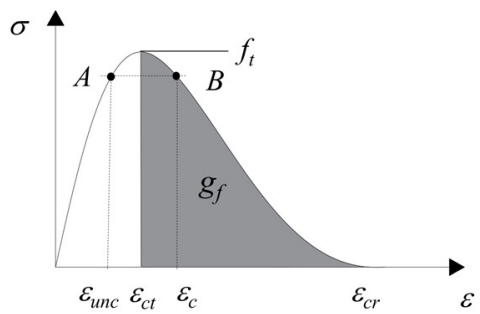

Figure 3.3 (a) Cracking at the mesoscale level and (b) uniaxial stress-strain behaviour at the macroscale level (Häussler-Combe 2015)

$$
\varepsilon
$$
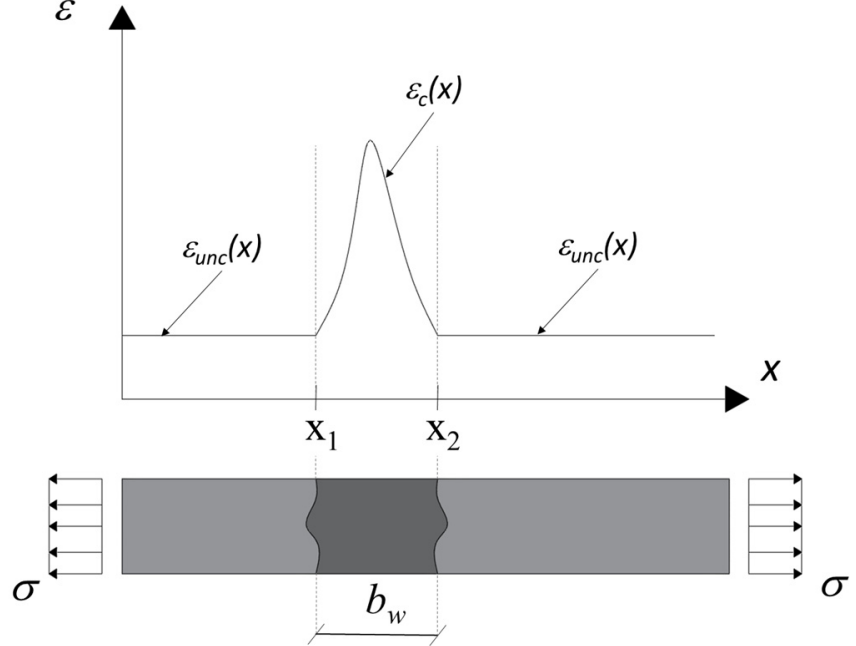

Figure 3.4 Strain localisation on a tension bar (Häussler-Combe 2015)

Figure 3.4 represents how strains can be distributed into the crack band in function $\varepsilon_{c}(x)$. Moreover, crack bandwidth $b_{w}$ can be obtained as Expression (3.3). Consequently, in the crack band a fictitious crack (fictitious macrocrack) can be defined with a crack opening $(w)$ expressed as the area under the curve defined by function $\varepsilon_{c}(x)$, and bounded by $\mathrm{x}_{1}$ and $x_{2}$ in Figure 3.4. This crack opening is found in Expression (3.4). This led to the socalled traction-separation law for the descending branch of the material's constitutive behaviour, as represented in Expression (3.5). This can be considered an objective description of the softening part of the material law. Due to the localised character of the cracking zone, continuum models with discontinuities and discrete crack models (see 
Section 2.5.1.1 Basic types of models in Chapter 2) can be partial or totally defined by traction-separation laws.

$$
\begin{gathered}
b_{w}=x_{2}-x_{1} \\
w=\int_{x_{1}}^{x_{2}} \varepsilon_{c}(x) d x \\
\sigma=f_{w}(w)
\end{gathered}
$$

If a mean strain value $\varepsilon_{c}$ of strain function $\varepsilon_{c}(x)$ in the crack band is assumed, Expression (3.4) used to obtain the fictitious crack opening can be homogenised in Expression (3.6). This assumed mean strain value $\varepsilon_{c}$ corresponded to a strain value represented in the softening part of the stress-strain curve depicted in Figure 3.3(b) and described in Expression (3.2). The $\varepsilon_{c}$ value would fall within the range $\varepsilon_{c t} \leq \varepsilon_{c} \leq \varepsilon_{c r}$, where $\varepsilon_{c t}$ is the strain associated with tensile stress $\left(f_{t}\right)$ and $\varepsilon_{c r}$ is the strain associated with zero stresses from which no stresses were no longer transferred by concrete in the crack band. The material law expressed as the stress-mean strain was used to define the continuum models (see Section 2.5.1.1 Basic types of models in Chapter 2). As this fictitious crack was able to transfer stresses during its formation process, the fictitious crack is also known as the cohesive crack. This led to the cohesive crack model firstly proposed in (Hillerborg et al. 1976) as the fictitious crack model, which is accepted as a realistic simplification of the fracture of brittle or quasi-brittle materials (Cornec et al. 2003; Elices et al. 2002, 2009; Gálvez et al. 2013).

$$
w=b_{w} \varepsilon_{c}
$$

The volume-specific crack energy $\left(g_{f}\right)$ in Mode-I dissipated in the crack band (or process zone) during the fictitious crack (macrocrack) evolution that corresponds to the area under the softening part of the stress-strain curve shadowed in Figure 3.3(b) and defined in Expression (3.7). If this volume-specific crack energy is multiplied by the crack bandwidth $\left(b_{w}\right)$ the surfacic-crack energy or crack energy $\left(G_{F}\right)$ is obtained (Expression (3.8)). This crack energy $\left(G_{F}\right)$ is defined as the energy released in the fictitious crack surface created and, due to the current knowledge status, it is assumed to be a constant material parameter (Bažant and Oh 1983; Häussler-Combe 2015; Rots 1988) as it can be 
related to the area under the $\sigma-w$ curve in Expression (3.8) by considering Expression (3.6).

$$
\begin{gathered}
g_{f}=\int_{\varepsilon_{c t}}^{\varepsilon_{c r}} \sigma_{c}(\varepsilon) d \varepsilon \\
G_{F}=b_{w} g_{f}=\int_{w_{c t} / b_{w}}^{w_{c r} / b_{w}} \sigma_{c}(w) d w
\end{gathered}
$$

\subsubsection{Smeared crack model}

Smeared crack models are included in the continuum models group, previously described in Section 2.5.1.1 Basic types of models in Chapter 2. They separate the total strain into an elastic strain component and an inelastic strain component, herein denoted as cracking strain. This inelastic strain is generated as a result of crack opening and is directly related to the traction transmitted through the crack.

In this case, displacement field regularity is described by means of a kinematic model that is related to the localised bands bounded by two weak discontinuities, where the displacement field remains continuous, while certain components of the strain field display a jump (see Figure 2.20 in Section 2.5.1.2 Kinematic behaviour in Chapter 2). The band between discontinuities is related to the damage process zone with a more or less constant density of microdefects (see Figure 3.3(a)). In these models, it is possible to distribute inelastic effects uniformly through the width of the band with finite thickness $b_{w}$, previously denominated as crack band (denoted as $h$ if Figure 2.21 in Section 2.5.1.2 Kinematic behaviour in Chapter 2 is observed).

Smeared crack models consider the macrocrack phenomenon in a continuous displacement field, which leads to its extended use in the finite element method, where common finite elements need to be applied in a continuum and do not permit discontinuities in the displacement field.

If the same uniaxial tensile bar in Figure 3.4 is considered, a mean total strain for the overall element $\left(\varepsilon_{m}\right)$ can be obtained and could represent the uncracked strain $\left(\varepsilon_{u n c}\right)$ in the uncracked part of the bar and the mean total strain $\left(\varepsilon_{c}\right)$ in the cracked part of the bar (in the crack band) obtained in Section 3.2.3 Cracking. Figure 3.5 illustrates this idea. Expression (3.9) reflects the total displacement or elongation in the element due to the application of tensile load. This total elongation, which can be interpreted as an imposed displacement if load is implemented in displacement terms, is composed of the displacement from both the element's uncracked and cracked parts. The mean total strain $\left(\varepsilon_{m}\right)$ is obtained in Expression (3.10) by dividing Expression (3.9) by the overall element 
length $\left(L_{e}\right)$. That is, a weighted combination of the strain in the uncracked part and the mean total strain in the cracked part. Element length $\left(L_{e}\right)$ resulted from the discretisation chosen, while the crack bandwidth $\left(b_{w}\right)$ was assumed as a characteristic of the material and, therefore, as a material constant.

$$
\begin{gathered}
u=\left(L_{e}-b_{w}\right) \varepsilon_{u n c}+b_{w} \varepsilon_{c} \\
\varepsilon_{m}=\frac{L_{e}-b_{w}}{L_{e}} \varepsilon_{u n c}+\frac{b_{w}}{L_{e}} \varepsilon_{c}=(1-\xi) \varepsilon_{u n c}+\xi \varepsilon_{c}
\end{gathered}
$$

where: $\xi=\frac{b_{w}}{L_{e}}$ is a ratio that remains constant for each element and $0<\xi \leq 1$ can be considered an appropriate restriction in conventional concrete (Bažant and Oh 1983; Häussler-Combe 2015). So for uniaxial behaviour, element length $\left(L_{e}\right)$ equalling or being higher than the crack bandwidth $\left(b_{w}\right)$ would be adequate, as indicated in Expression (3.11).

$$
L_{e} \geq b_{w}
$$

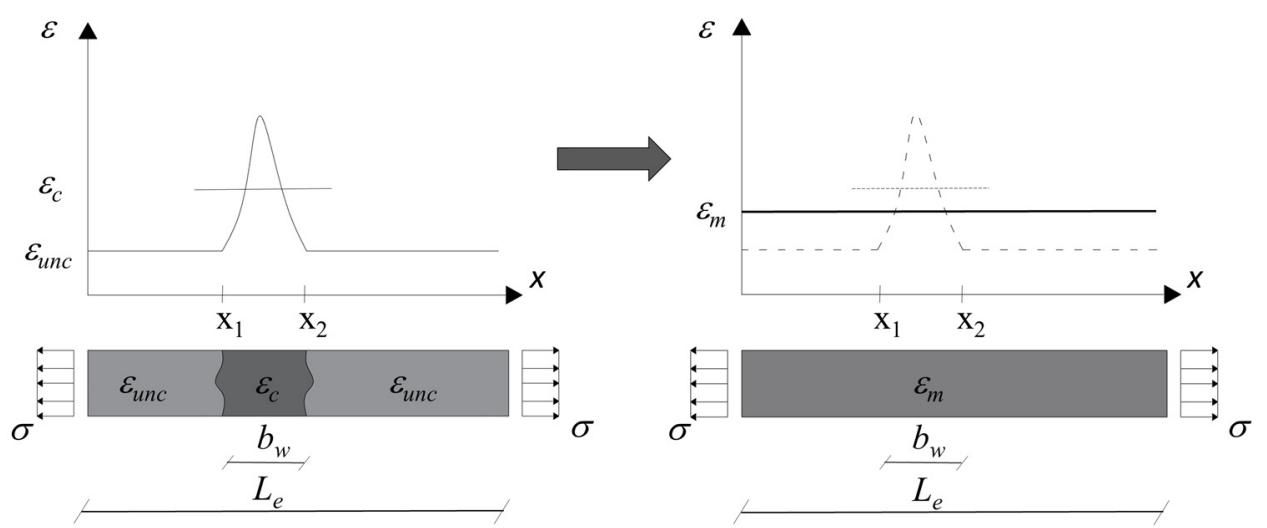

Figure 3.5 The smeared crack model concept

As the crack is smeared and is able to transmit stresses, the cohesive crack concept is applicable to this model. Thus if the typical stress-total strain relation depicted in Figure 3.3(b) is used, the part of the curve corresponding to the mean total strain on the descending branch can be expressed as Expression (3.2). If the mean total strain in the cracked part is what is needed, then Expression (3.2) is inverted as Expression (3.12). 


$$
\varepsilon_{c}=f_{c}^{-1}(\sigma)
$$

At this point, if the part of the curve corresponding to the uncracked strain (the ascending branch until the peak) is addressed, it can be expressed as Expression (3.1) and, as before, if the uncracked strain is needed, then Expression (3.1) is inverted as Expression (3.13).

$$
\varepsilon_{\text {unc }}=f_{\text {unc }}{ }^{-1}(\sigma)
$$

When the element cracks, stress level $\sigma$ must be the same for the uncracked material in the uncracked part and for the cracked material in the crack band due to equilibrium (Figure 3.3(b)). Therefore, by combining Expression (3.10), Expression (3.12) and Expression (3.13), the mean total strain for a cracked element by applying the smeared crack model is obtained in Expression (3.14):

$$
\varepsilon_{m}=(1-\xi) f_{u n c}^{-1}(\sigma)+\xi f_{c}^{-1}(\sigma)=d(\sigma)
$$

where $d$ is a compliance function for the smeared crack model for the cracked element, whose stiffness can be obtained as Expression (3.15):

$$
\sigma=d^{-1}\left(\varepsilon_{m}\right)
$$

It is important to understand in the smeared crack model that the mean total strain $\left(\varepsilon_{m}\right)$ considered for the whole element when it is cracked is obtained from the proportional combination of the strain of the uncracked part $\left(\varepsilon_{u n c}\right)$ and the mean total strain of the cracked part or crack band $\left(\varepsilon_{c}\right)$, as shown in Expression (3.10). Consequently when the element cracks, the overall element is considered under the same unified continuous total strain $\left(\varepsilon_{m}\right)$. Figure 3.5 and Figure 3.6 illustrate the explained process. It is important to realise that although stress $\sigma_{A B}$ is the same in Figure 3.6, the strain is not preserved because the energy of new curve $g_{f m}$ changed in relation to the original one: $\varepsilon_{u n c}<\varepsilon_{m} \leq$ $\varepsilon_{c}$. This fact allows the application of common finite element interpolation, even when the macrocrack takes place, which makes the discontinuity in the displacement field continuous. Therefore, as deduced, the smeared crack model changes the original law for the cracked and uncracked material parts (Expression (3.15)) when the element cracks. In a finite element model, this is reflected at the integration points inside the element, which have a fixed position. Hence an exact crack position was not set in this 
model. Consequently, it is not necessary to know the crack path beforehand to apply the smeared crack model.

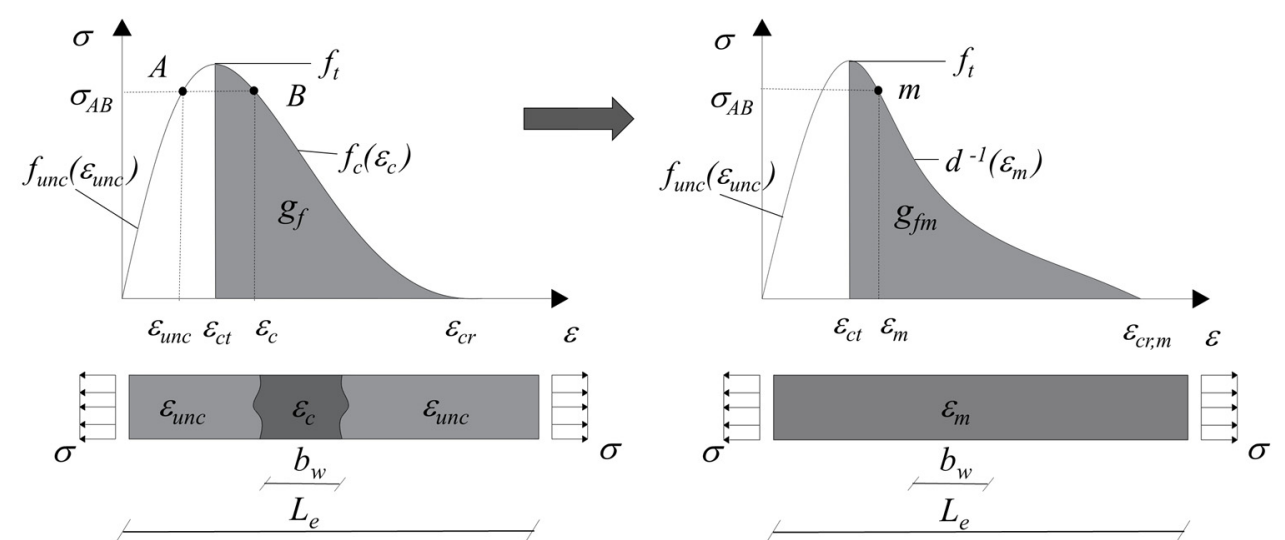

Figure 3.6 The smeared crack model softening stress-total strain material relation

Furthermore, by considering Expression (3.15), the stress-mean total strain relation set by the smeared cracking model when the element cracks (on the descending or softening branch of the material law to the right of Figure 3.6) depends on the element's geometric characteristics $\left(L_{e}\right)$. Therefore, if energy for crack formation $\left(G_{F}\right)$ is obtained by applying Expression (3.7) and Expression (3.8), we observe that its value also depends on the considered element length $\left(L_{e}\right)$. As the crack bandwidth $\left(b_{w}\right)$ and crack energy $\left(G_{F}\right)$ are assumed as the material's characteristics and, therefore, as material constants, they must be preserved no matter what element length is $\left(L_{e}\right)$. The fact that the smeared crack model depends on element size (mesh dependency) provides the idea of regularisation, which is mainly related to its application to finite element modelling.

Figure 3.9 shows the consequences of $L_{e}$ dependence, where the exact element length representing the exact crack energy in crack surface curve formation is set $\left(L e_{\text {exact }}\right)$. As seen in Expression (3.10), Le exact represents the situation in which $L_{e}=b_{w}$. In this case, when the stress level reaches $f_{t}$, the entire element cracks and no uncracked part is preserved. Therefore, the complete displacement obtained by Expression (3.9) when the element cracks is due to the cracking strain, the entire element descends following the softening branch defined in Expression (3.2), and the result of the smeared cracking transformation represented in Figure 3.6 is described in Figure 3.7. Hence $\varepsilon_{m}=\varepsilon_{c}$ and $g_{f m}=g_{f}$; that is, energy is preserved in the smeared transformation. 


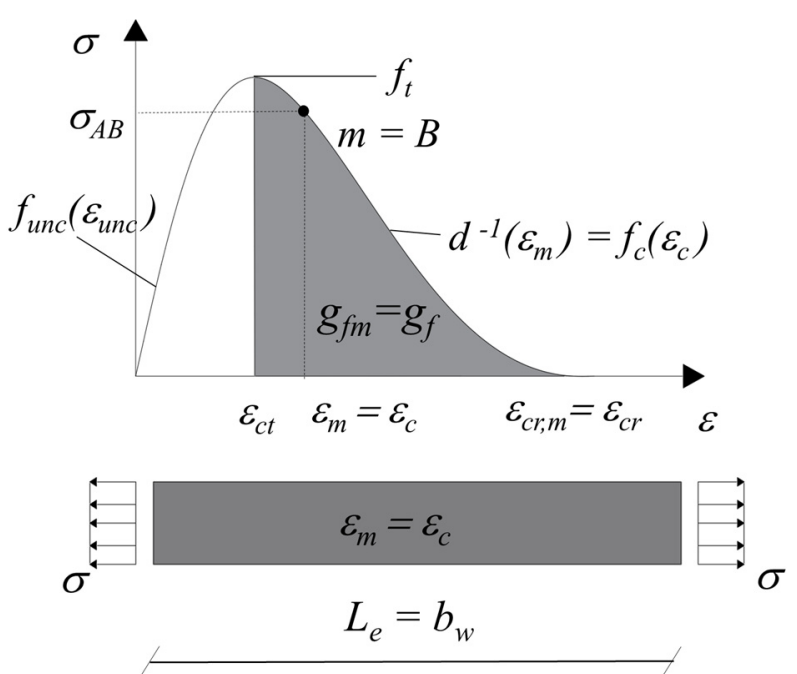

Figure 3.7 Smeared crack model transformation when $L_{e}=b_{w}\left(L e_{\text {exact }}\right)$

If one element length $\left(L_{e}\right)$ is chosen for the discretisation that is higher than $L e_{\text {exact }}\left(L_{e}>\right.$ $b_{w}$ ), then $\varepsilon_{u n c}<\varepsilon_{m}<\varepsilon_{c}$ (see Expression (3.10)) and the smeared $\sigma-\varepsilon_{m}$ curve involves less crack energy $g_{f m}<g_{f}$, as seen in Figure 3.6. In the case, $L_{e}>b_{w}$ represents the majority of situations for quasibrittle materials like concrete as their crack bandwidth $\left(b_{w}\right)$ concentrates on a narrow band that not covers the whole element length. In this case, it is necessary to know that a certain degree of inaccuracy comes into play depending on element length $\left(L_{e}\right)$ when adopting the smeared crack model because the mean total strain $\left(\varepsilon_{m}\right)$ is assumed in both the part where the real strain is the uncracked one $\left(\varepsilon_{u n c}<\varepsilon_{m}\right)$ and that where the real strain is the cracked total strain $\left(\varepsilon_{m}<\varepsilon_{c}\right)$. This is represented in Figure 3.8. If the chosen element length $\left(L_{e}\right)$ is much longer than $L e_{\text {exact }}\left(L_{e}>>>b_{w}\right)$, then crack energy substantially diminishes, and even leads to snap-back material behaviour on the $\sigma-\varepsilon_{m}$ curve $\left(\varepsilon_{u n c}<\varepsilon_{m}<\varepsilon_{c t}<\varepsilon_{c}\right)$, as we can see in Figure 3.6 and Figure 3.9. Moreover, if elongation is considered by means of Expression (3.9), it can also cause a snap-back response of the load-displacement $(P-u)$ curve when $L_{e} \gg \gg b_{w}$, as $u<u_{f t}=L_{e} \cdot \varepsilon_{f t}$. Then the $P-u$ curve takes the same form as the $\sigma-\varepsilon_{m}$ curve represented in Figure 3.9. All of this can pose numerical problems when a non-linear analysis is carried out by a numerical technique, such as the finite element method, depending on the element length $\left(L_{e}\right)$ used for discretisation. 


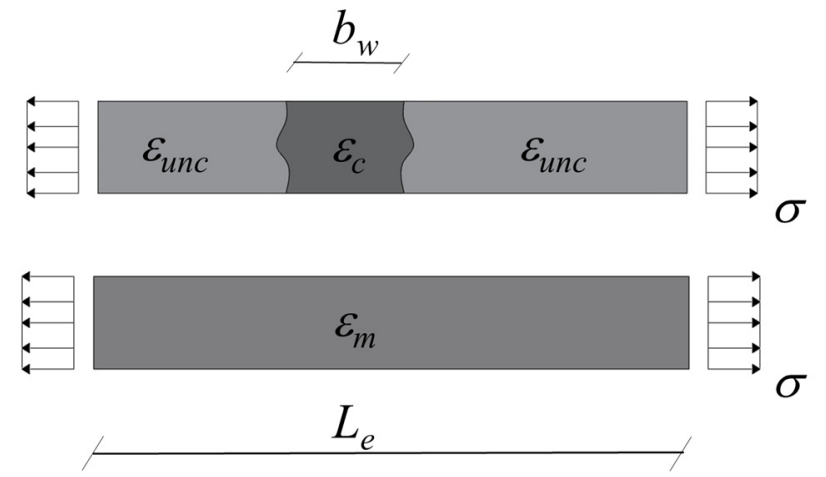

Figure 3.8 Inaccuracy depending on Le when Le $>>>$ bw

If the element length chosen $\left(L_{e}\right)$ is lower than $L e_{\text {exact }}\left(L_{e}<b_{w}\right)$, then $\varepsilon_{m}>\varepsilon_{c}$ (see Expression (3.10)) and the smeared $\sigma-\varepsilon_{m}$ curve involves more crack energy, $g_{f m}>g_{f}$, as observed in Figure 3.9. This situation is not considered because the mean total strain $\left(\varepsilon_{m}\right)$ cannot be higher than the mean total cracked strain $\left(\varepsilon_{c}\right) . \varepsilon_{m}$ must be representative of the cracked and uncracked strain; therefore, $\varepsilon_{u n c}<\varepsilon_{m} \leq \varepsilon_{c}$ (see Figure 3.6). Thus the $L_{e}<b_{w}$ case is considered to fall beyond the range and, as previously indicated in Expression (3.11), element length $\left(L_{e}\right)$ equalling or being higher than crack bandwidth $\left(b_{w}\right)$ would be adequate.

Consequently in the smeared crack model, it is frequent to regularise the strain-softening part of the material law on $\varepsilon_{m}$ to minimise the effect of mesh size dependency. The regularisation idea is applicable to the multiaxial definition of UHPFRC constitutive behaviour and is addressed in more detail in Chapter 4 when the material model is considered in the finite element model. 


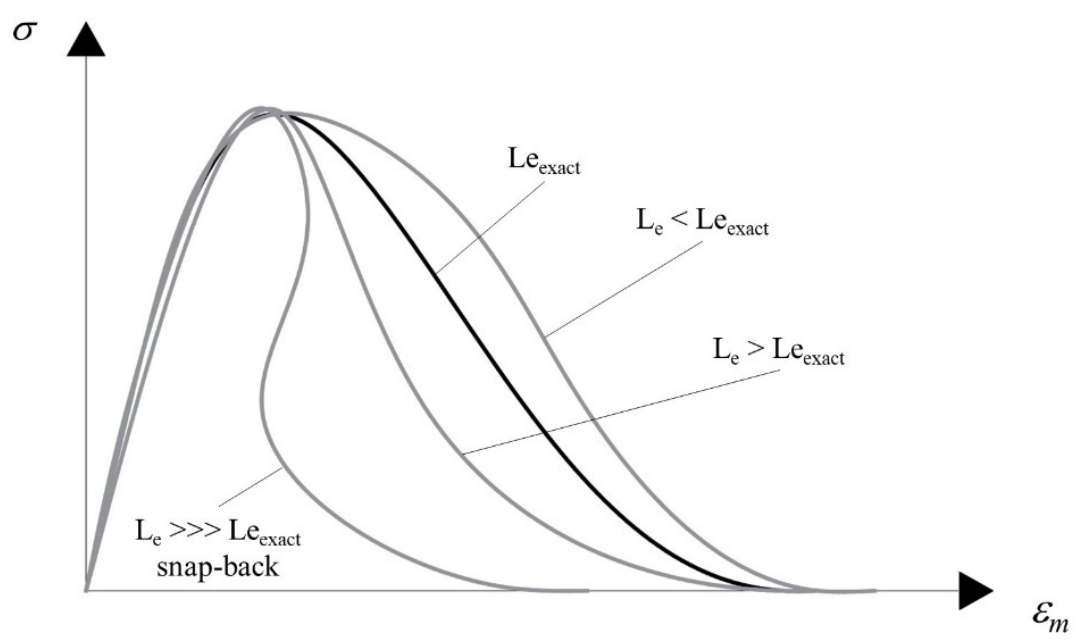

Figure 3.9 Mesh size dependency of the softening part of the material law in the smeared crack model

\subsubsection{Discrete crack approach}

As explained above, the main advantage of the smeared crack model lies in it doing away with having to know the crack pattern of the loaded element beforehand. Moreover, even if a crack appears, the whole specimen is modelled by keeping the displacement field as a continuum. This fact enables the use of common finite element modelling, which therefore renders the geometry definition of the model simpler. However, the main disadvantage of such models is their element size (mesh) dependency because they are conceived by a weighted total strain defined inside the element length used in discretisation. This consequence implies either following a regularisation technique, which can be difficult to implement if a commercial finite element software is applied, or calibrating an element size by comparing simulation results to experimental results. This leads to a kind of inverse analysis that obtains the element size.

If the crack path is clearly known beforehand, or its position seems predictable, applying a continuum model with discontinuities is reasonable (Section 2.5.1.1 Basic types of models in Chapter 2). This kind of models can be considered a hybrid solution that takes into account the advantages of the continuum and discrete models. The idea is to improve the continuum consideration by displacement discontinuities where individual deformation patterns are localised, such as macroscopic cracks (macrocracks). Therefore, the model's continuous part is described using a stress-strain constitutive behaviour, while discrete discontinuity is modelled by bearing in mind initiation and propagation criteria to activate, for example, a traction-separation law. This is why with 
Chapter 3: Proposed constitutive material models

continuum models with discontinuities it is necessary to previously know the crack path. As the crack is modelled discretely by means of, for example, a traction-separation relation, the parameter that defines the crack when it appears and develops at different stress levels is the crack opening instead of a weighted mean total strain that depends on the element length $\left(L_{e}\right)$ considered in discretisation. This leads to a mesh sizeindependent model.

The regularity of the displacement field, in this case, is described by a kinematic model related to strong discontinuities (Figure 2.18 in Section 2.5.1.2 Kinematic behaviour in Chapter 2), which can be taken as jumps in displacements over the discontinuity curve. Consequently, the strain field is represented by a constant or regular part and a singular point where the jump is located. This strong discontinuity represents the crack. This kinematic approach enables continuum models with discontinuities to be developed by considering cohesive crack models. In these models, the cohesive traction in the crack depends on the displacement jump $(\Delta \mathrm{u})$. Consequently in this case, strong discontinuity is defined by its proper constitutive law, set as a traction-separation behaviour that complements the stress-strain constitutive behaviour defined for the continuous part of the body. The area under the traction-separation law is considered the energy required to generate a stress-free crack of a unit area. This energy is defined as Mode-I fracture energy, $G_{F}$. A strong discontinuity case can be addressed in the finite element method using the interface elements situated between the 2D or 3D elements used to divide the general body when the crack path is previously known. If the crack path is not easy to be intuitively known, considering other solutions may be necessary, such as frequent remeshing or using enhanced finite elements with enriched standard shape functions. If the crack path is unknown beforehand, it generally seems simpler to use entirely continuum models, such as the previously defined smeared crack model, and addressing the kinematic model by means of localised bands bounded by two weak discontinuities.

\subsubsection{The UHPFRC material model}

By taking into account all the previously considerations related to the constitutive model adopted for UHPFRC in both compression and tension, as well as the cracking process interpretation, two modelling approaches were defined in this work to model constitutive UHPFRC behaviour. To differentiate one from the other, in this work they are known as the smeared cracking approach and the discrete cracking approach.

\subsubsection{Smeared cracking approach in UHPFRC}

The smeared cracking approach herein defined is based on the smeared crack models included in continuum models, as previously described in Section 3.2.3.1. To define the smeared cracking approach developed in this work, the continuum model with discontinuities defined by the stress-strain/crack opening relation (see Figure 3.2) was transformed into a continuum model by a stress-total strain law. 
In order to sequence the process of applying the smeared crack model in UHPFRC, three phases were defined: Phase 1, in which the constitutive UHPFRC stress-strain/crack opening relation was defined (see Figure 3.2); Phase 2, in which the stress-strain/crack opening relation defined in Phase 1 was transformed into a stress-total strain law that related, from the time the macrocrack appeared henceforth, to the stress transmitted by the localised band to the mean total strain in that band (see Figure 3.10). In addition, its corresponding area defined under the softening curve and the unloading branch, $g_{f}=G_{F}$ $/ b_{w}$, was then translated as the energy spent per unit volume of the localised band (shadowed area in Figure 3.10); Phase 3, in which the smeared crack model was applied to the continuum model and a stress $(\sigma)$-mean total strain $\left(\varepsilon_{m}\right)$ relation was defined by Expression (3.10). In this phase, the energy of the new curve $g_{f m}$ changed in relation to the original one defined in Phase 2: $\varepsilon_{u n c}<\varepsilon_{m} \leq \varepsilon_{c}$.

The parameters that describe the UHPFRC stress-total strain relation in the continuum model in Phase 2 (see Figure 3.10) for the smeared cracking approach herein defined were: (i) elastic modulus $(E)$, by assuming the same in both tension and compression; (ii) cracking strength or tensile strength $\left(f_{t}\right)$; (iii) ultimate tensile strength $\left(f_{t u}\right)$ defined as the stress where the macrocrack took place; (iv) its associated ultimate strain $\left(\varepsilon_{t u}\right)$; (v) the unloading modulus $\left(E^{*}\right)$, which is important to clearly differentiate between the energy dissipated during strain hardening or strain softening block (volumetric energy) and during the crack opening softening block (surface energy); (vi) the strength at the change of slope in the crack opening softening block $\left(f_{t d}\right)$ which, according to the bilinear models developed for concrete, can be defined as a percentage of ultimate strength; (vii) its associate total strain $\left(\varepsilon_{t d}\right)$; (viii) the total strain at zero stress $\left(\varepsilon_{t c}\right)$.

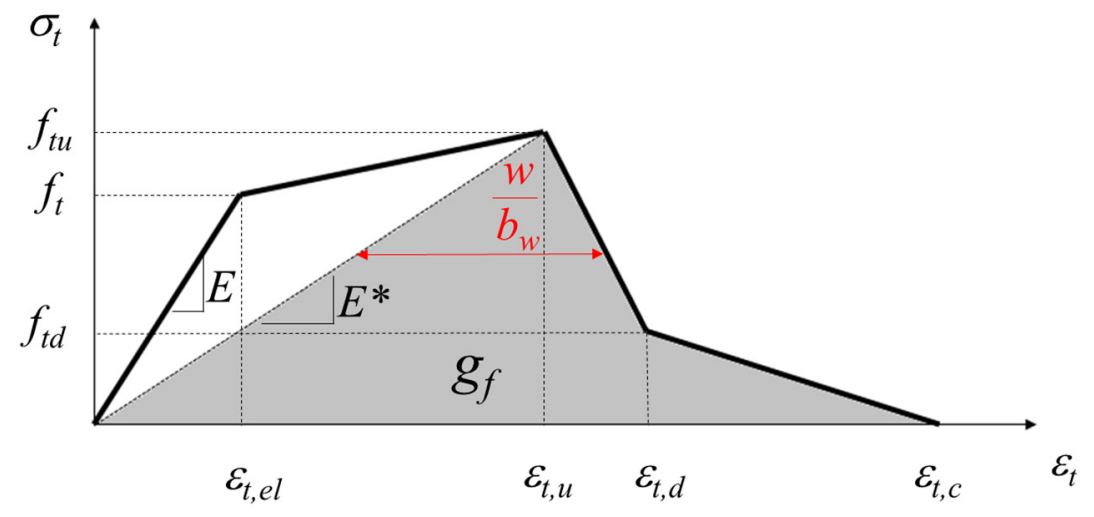

Figure 3.10 The UHPFRC smeared tensile stress-total strain relation assumed by the smeared cracking approach 
In Figure 3.10 we can observe that the part of the curve corresponding to volumetric energy (from 0 to the macrocrack appearing) did not undergo any transformation when the smeared cracking approach was assumed as it coincided with the stress-strain part in Figure 3.2. Elastic unloading was adopted until the macrocrack appeared. Therefore, the total strain generated in the volumetric part was elastic strain (all deformation recovered when unloading occurred following the same path as loading). From the time the macrocrack appeared henceforth, the surfacic part of the curve (the stress-crack opening in Figure 3.2) was transformed (or smeared) into a total strain part. In this part, the total strain was composed of an elastic strain component and an inelastic strain component or cracking strain. This inelastic strain in the smeared cracking approach was assumed to be a consequence of crack opening and was directly related to the traction transmitted through the crack. If a mean strain value was assumed in the crack band, then this inelastic strain could be obtained from Expression (3.6) as $w / b_{w}$. Therefore, the elastic strain could be obtained as the difference between the total strain and the inelastic strain. To do so, it was necessary to set an unloading modulus $\left(E^{*}\right)$ for this part of the curve. This modulus differentiated the area defining crack energy per unit of volume of the localised crack band $\left(g_{f}\right)$. As observed in Figure $3.10, E^{*}$ was herein assumed in Expression (3.16) and, therefore, $g_{f}$ corresponded to the shadowed area. Thus the unloading path in this part of the curve had $E^{*}$ stiffness.

$$
E^{*}=\frac{f_{t u}}{\varepsilon_{t u}}
$$

From the $E^{*}$ considered in this work in Expression (3.16), the total strain at ultimate tensile strength $\left(\varepsilon_{t u}\right)$ became completely elastic (see Figure 3.10 ). Moreover from Expression (3.6), the crack opening ( $\left.w_{f f u}\right)$ and the total strain at ultimate tensile strength $\left(\varepsilon_{t u}\right)$ were related by means of the crack band, as reflected in Expression (3.17). From this point henceforth, the inelastic part of the total strain was obtained as $w / b_{w}$ (see Figure $3.10)$.

$$
\varepsilon_{t u}=\frac{w_{f t u}}{b_{w}}
$$

The total strain at the change of slope $\left(\varepsilon_{t d}\right)$ in the surfacic part of the curve can be geometrically deduced from Figure 3.10, as shown in Expression (3.18). From this expression, the inelastic part of the total strain $\left(\varepsilon_{t d \text {, inelastic }}\right)$, which might remain permanent if the specimen is unloaded, can be separated from the elastic part $\left(\varepsilon_{t d, \text { elastic }}\right)$, which could be recovered if the specimen is unloaded, as shown in Expression (3.19), Expression (3.20) and Expression (3.21). 


$$
\begin{gathered}
\varepsilon_{t d}=\frac{w_{d}}{b_{w}}+\varepsilon_{t u}-\frac{f_{t u}-f_{t d}}{E^{*}} \\
\varepsilon_{t d}=\varepsilon_{t d, \text { inelastic }}+\varepsilon_{t d, \text { elastic }} \\
\varepsilon_{\text {td,inelastic }}=\frac{w_{d}}{b_{w}} \\
\varepsilon_{t d, \text { elastic }}=\varepsilon_{t u}-\frac{f_{t u}-f_{t d}}{E^{*}}
\end{gathered}
$$

The total strain at zero stress $\left(\varepsilon_{t c}\right)$ can also be deduced from Figure 3.10 in Expression (3.22). As we can see, all the strain at this point is the inelastic strain (see Figure 3.10).

$$
\varepsilon_{t c}=\frac{w_{c}}{b_{w}}
$$

Once the UHPFRC continuum model expressed by a stress-total strain relation (see Figure 3.10) was defined in Phase 2, the smeared crack model was applied in Phase 3 by Expression (3.10), which obtained the stress $(\sigma)$-mean total strain $\left(\varepsilon_{m}\right)$ relation. This process is depicted in Figure 3.11 (see the analogy with Figure 3.6). It is important to underline, as stated in Section 3.2.3.1, that the main advantage of the smeared crack model lies in no longer having to know the crack path beforehand. However as depicted in Figure 3.9, this model underwent element size dependency. 


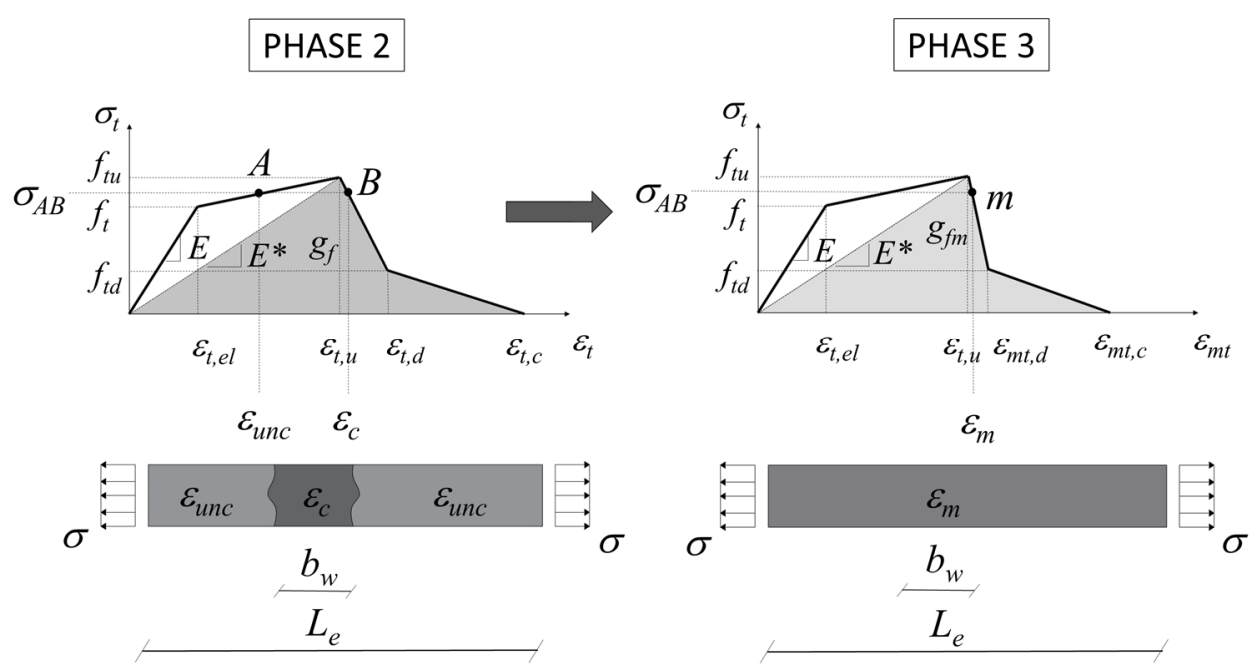

Figure 3.11 The UHPFRC smeared crack model

\subsubsection{Discrete cracking approach in UHPFRC}

The so-called discrete cracking approach for UHPFRC herein developed was used to compare it to the smeared cracking approach following the same philosophy of traditional continuum models with discontinuities developed for the finite element method, such as (Hillerborg et al. 1976; Ngo and Scordelis 1967); that is, discrete cracks represented by its own traction-separation law, where macrocracks will take place, and continuum models represented by a stress-strain relation for the continuous part of the body. Therefore, the discrete crack approach herein developed used the smeared crack approach defined previously in Section 3.2.4.1 to model the constitutive UHPFRC behaviour for the continuum model (continuum part of the body) and a tensile stresscrack opening relation defined as the stress-crack opening part of the $\sigma-\varepsilon / w$ constitutive UHPFRC relation, as depicted in Figure 3.12. To activate the traction-separation law of the macrocrack, the stresses defining the tensile strength and ultimate tensile strength of the constitutive law of UHPFRC for the considered crack were $98 \%$ for $f_{t}$ and $98 \%$ for $f_{t u}$ (see Figure 3.12).

As explained in Section 3.2.3.2, it is important to underline that the advantage of the discrete cracking approach is that it is mesh size-independent because the crack is modelled by a traction-separation law instead of smearing it in a strain localised in a crack band. However, its main disadvantage lies in having to know the crack path beforehand. 


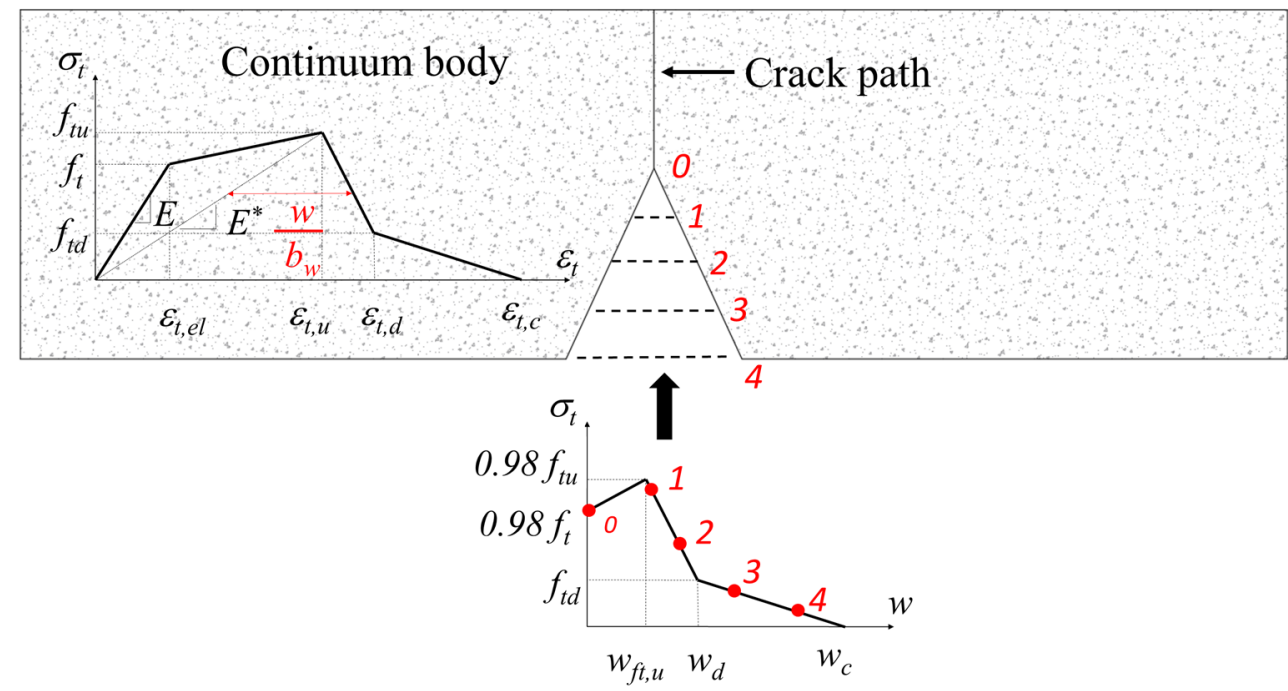

Figure 3.12 The developed discrete cracking approach

\subsubsection{Determining constitutive UHPFRC parameters}

This section indicates the way in which the UHPFRC constitutive parameters are obtained for both compression and tension: experimental tests and the process to derive parameters.

\subsubsection{Compression}

The parameter needed to describe compressive behaviour is compressive strength. In this work, compressive strength is obtained by means of $100-\mathrm{mm}$ cubic compression tests (see Figure 3.13(a)). Load is applied by a MEH-3000 IBERTEST universal testing machine with a bearing capacity of $3000 \mathrm{kN}(60 \mathrm{~mm}$ long) measured by a $350 \mathrm{bar} / 10 \mathrm{~V}$ GROBY-PDCR 4011 Druck (see Figure 3.13(b)). The compression test was performed in compliance with Standard EN 12390-3:2009 (EN 2009b) with a load velocity of $0.6 \pm 0.2 \mathrm{MPa} / \mathrm{s}$. 
(a)

(b)

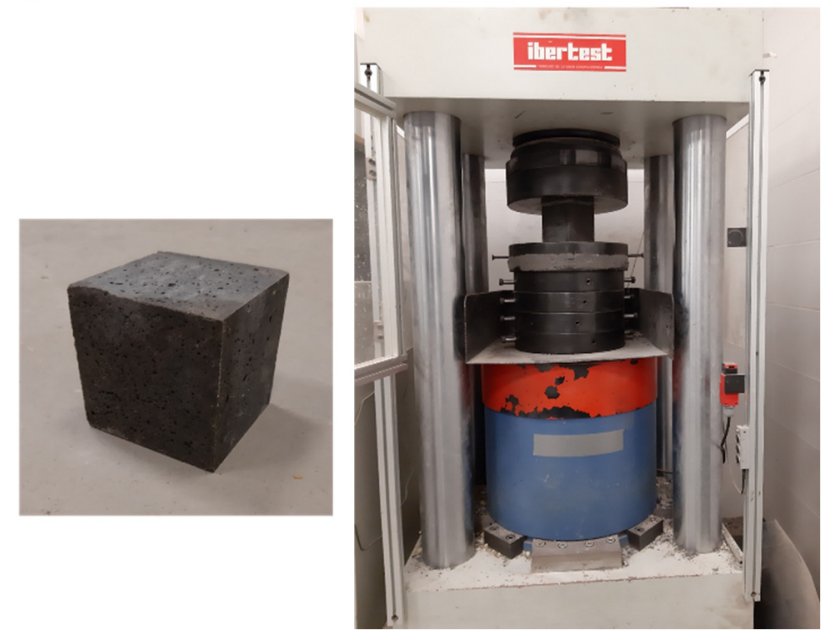

Figure 3.13 (a) Cubic specimen and (b) compression test

\subsubsection{Tension}

In this work, tensile constitutive UHPFRC behaviour was derived from unnotched 4PBT. The reasons for using this kind of test are explained in Section 2.3.2 UHPFRC tensile experimental tests of Chapter 2. They are easy-to-conduct tests that do not need any elaborate setup that can lead to spurious results, such as direct tensile tests. The authors believe that unnotched 4PBT is the most suitable test because it provides a large area with a relatively constant bending moment. Therefore, the microcracking process that characterises this concrete in its hardening part is free to develop. The research group has conducted previous work related to these bending tests (López 2017; López et al. 2017) and this experience leads to consider 4 PBT to be a reliable test for carrying out UHPFRC characterisation in this work.

The total size of the specimens cast for 4PBT was 500x100x100 mm. The length of the span (L) between the roller supports was $450 \mathrm{~mm}$, specimen depth (h) was $100 \mathrm{~mm}$ and specimen width (b) was $100 \mathrm{~mm}$. The distance between load rollers was $\mathrm{L} / 3=150 \mathrm{~mm}$ (see Figure 3.14(a)). Therefore, the specimen's slenderness ratio $(\mathrm{L} / \mathrm{h})$ was 4.5 . Given their characteristic geometry, this $4 \mathrm{PBT}$ is also known as a third-point bending test (ThirdPBT). Tests were carried out at a constant frame displacement rate of $0.05 \mathrm{~mm} / \mathrm{min}$ up to the maximum load. From this point onwards, the frame displacement rate was increased up to $0.2 \mathrm{~mm} / \mathrm{min}$. The test finished when a load that equalled $70 \%$ of the maximum on the unloading branch. To obtain the load-displacement on the mid-span curve, two Penny \& Giles Controls Ltd. displacement transducers were placed: one at 
the front and the other at the back. 4PBT was carried out using a 3382J8440 Instron testing machine with a bearing capacity of $100 \mathrm{kN}$ (see Figure 3.14(b)).

(a)

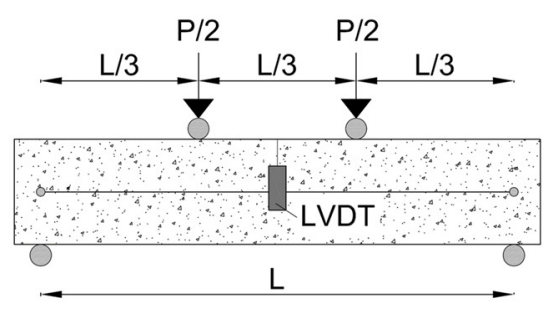

(b)

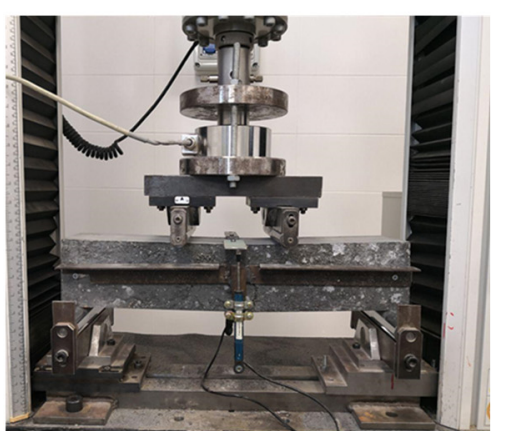

Figure 3.14 4PBT (also known as a ThirdPBT) used to characterise tensile UHPFRC behaviour in this work: (a) geometry and (b) experimental setup

However, 4PBTs require the use of an inverse analysis methodology to derive the tensile properties from the results they obtain. Different inverse analysis methods have been developed to obtain the parameters that define UHPFRC behaviour in tension from 4PBT in (Baby et al. 2012, 2013a; Gröger, Johannes, Viet tue, Nguyen, Wille 2012; Kanakubo 2006; López et al. 2015a; Maalej and Li 1994; Ostergaard et al. 2005; Qian and Li 2007; Rigaud et al. 2012; Soranakom and Mobasher 2007; Tailhan et al. 2004). Any of these methods can be followed to characterise UHPFRC tensile properties from 4PBT experimental results. In this work, an inverse analysis method based on a non-linear hinge model, which was developed properly in the research group for UHPFRC that exhibits SH behaviour (López 2017), was chosen. A schematic explanation of this inverse analysis methodology can be found in Annexe I of this $\mathrm{PhD}$ thesis.

\subsection{Multiaxial constitutive UHPFRC behaviour}

In this section, the multiaxial formation of cracks in concrete and the multiaxial perspective of the smeared crack approach are described to extrapolate the main characteristics of the uniaxial concept to $2 \mathrm{D}$ and $3 \mathrm{D}$ modelling.

\subsubsection{Multiaxial cracking}

As deduced from concrete's uniaxial cracking behaviour, multiaxial cracking modelling can be considered from the fracture mechanics point of view. Indeed cracks are modelled by curves or lines in $2 \mathrm{D}$ and surfaces or planes in $3 \mathrm{D}$ to be able to define the necessary properties to, in turn, define discontinuities in the displacement field. 
Three main fracture modes were distinguished (see Figure 3.15): (i) Mode-I, where crack opening occurred due to normal stresses to the crack plane; (ii) Mode-II, where crack opening took place by the sliding due to the shear stresses that were parallel to the crack surface and normal to the front of that surface; (iii) Mode-III, where a crack was produced due to the shear stresses that were parallel to both the crack surface and the front of that surface. This work considered that the main mechanism which generated the crack addressed the Mode-I fracture mode as the main contemplated forces were flexural and their derived stresses were normal to the crack plane.

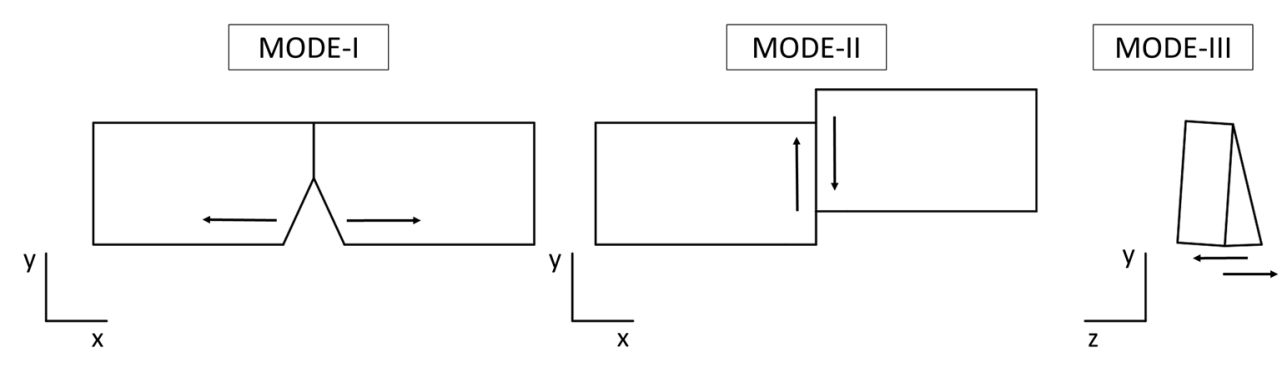

Figure 3.15 Fracture modes

As explained for uniaxial cracking, the idea was to adapt the fracture mechanics cohesive crack model to represent the response of quasi-brittle constitutive UHPFRC behaviour by the smeared cracking approach (continuum model), where the cracking process was developed in the process zone $\left(b_{w}\right)$, and the discrete cracking approach (continuum model with discontinuities). This idea is illustrated in Figure 3.16 for Mode-I. For example, with the discrete cracking approach used to model the specimen as a continuum and the crack as a discontinuity (a jump) of displacements by the cohesive crack model, the cohesive crack law related surface tractions and fictitious crack widths (see Figure 3.12). 

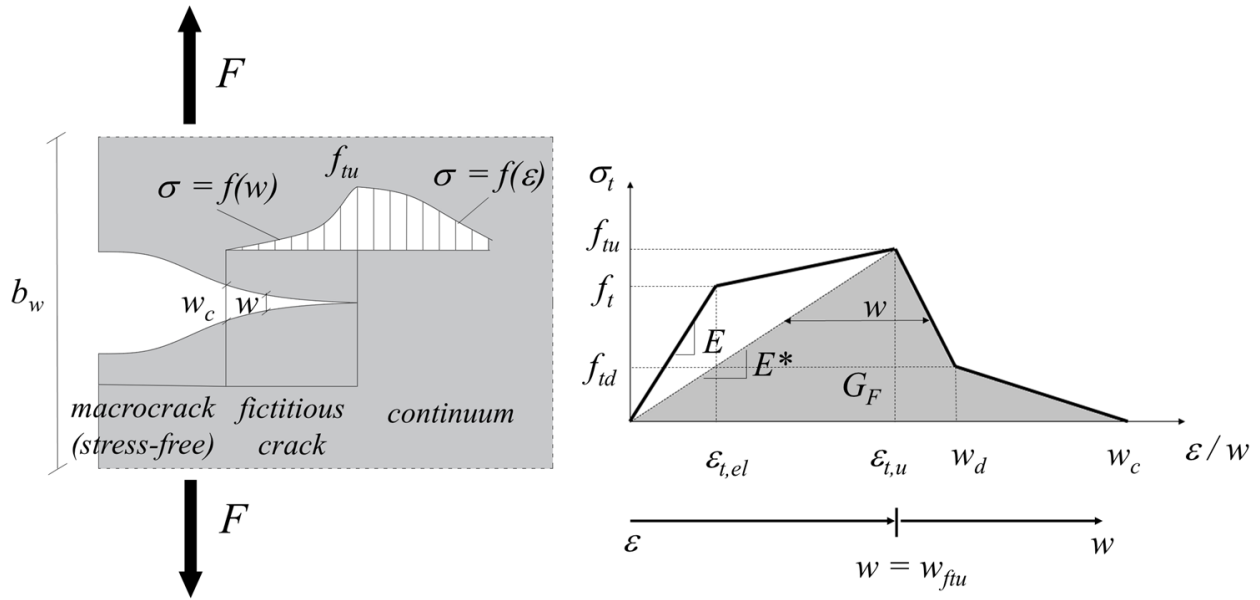

Figure 3.16 Cohesive crack model and assumed $\sigma-\varepsilon / w$ constitutive UHPFRC behaviour

The fictitious crack was bounded by two opposed surfaces that defined the two crack faces. Crack width was defined as the separation of these surfaces during the cracking process. If one of these surfaces was taken as a reference, at any position of the surface, a tangential cracking plane can be set containing a local Cartesian coordinate system with normal vector $\mathbf{n}$. Thus in the local coordinate system, the separation between crack surfaces can be represented by one fictitious crack width normal component, $w_{n}$, and two fictitious crack width sliding components, $w_{s}, w_{t}$. Consequently, the crack width vector $(\boldsymbol{w})$ can be defined by Expression (3.23). Moreover, a surface traction vector (p) was also considered (see Expression (3.24)), expressed in the local coordinate system of the cracking plane. Therefore, crack widths and surface tractions were related by the material law in the crack, as set in Expression (3.25), by considering different relation laws $f_{n}$ for the normal component and $f_{s}$ for the shear or sliding components. Accordingly, it can be deduced that the uniaxial cracking explained in Section 3.2.3 Cracking and represented in Figure 3.3(b) corresponded to the Mode-I $f_{n}$ relation for the normal component. By assuming particular constitutive UHPFRC behaviour, its material law can be expressed by one $\sigma-\varepsilon$ part and one $\sigma-w$ part, as shown in Figure 3.16. The $\sigma-w$ softening part of the curve was obtained by considering Expression (3.18) and Expression (3.22) to preserve the crack energy assumed in Figure 3.10. Consequently, crack UHPFRC behaviour can be modelled using the fracture mechanics as a continuum or quasi-continuum (continuum with certain discontinuities) within the fictitious crack model framework. Therefore, it was applied to the common finite element interpolation with no enhanced property. 


$$
\begin{aligned}
\boldsymbol{w} & =\left(\begin{array}{l}
w_{n} \\
w_{s} \\
w_{t}
\end{array}\right) \\
\boldsymbol{p} & =\left(\begin{array}{c}
p_{n} \\
p_{s} \\
p_{t}
\end{array}\right) \\
p_{n}=f_{n}\left(w_{n}\right) ; \quad p_{s} & =f_{s}\left(w_{s}\right) ; \quad p_{t}=f_{s}\left(w_{t}\right)
\end{aligned}
$$

\subsubsection{Multiaxial smeared crack model}

When modelling a crack as a discontinuity of displacement in a discrete crack approach (continuum model with discontinuities), it could be adapted to multiaxial cracking as a relation of surface tractions and fictitious crack openings. However, when modelling the continuum part of the discrete crack approach, or defining the model entirely as a continuum, it was necessary to extend the uniaxial smeared crack model concept established in Section 3.2.3.1 Smeared crack model to multiaxial material behaviour.

In the uniaxial case, the cracking process started when uniaxial tensile stress reached uniaxial tensile strength $f_{t}$ (see Figure 3.3(b)). For multiaxial stress, the same criterion was extended by considering that cracking started when the highest principal stress reached uniaxial strength $f_{t}$. It was assumed that both uniaxial tensile and multiaxial stresses were similar for concrete, and it could be reasonable to consider the same. Moreover, it was also assumed that crack direction was normal for the principal stress direction that induced this crack. Consequently, this principal direction and normal vector $\mathbf{n}$ of the tangential cracking plane containing the local Cartesian coordinate system $\{\mathbf{n}, \mathbf{s}, \mathbf{t}\}$ were the same.

If stresses were defined by a Cauchy stress tensor in a tetrahedron of base area $\mathrm{d} A$ and normal vector $\mathbf{n}$ to base area $\mathrm{d} A$, one force vector $\mathrm{d} \mathbf{f}$ and one surface traction vector $\mathbf{p}=$ $\mathrm{df} / \mathrm{d} A$ could be set (see Figure 3.17). Then force vector $\mathrm{d} \mathbf{f}$ could be equilibrated by three force vectors $\mathrm{d} \mathbf{f}_{\mathrm{i}}$ on each coordinate plane $\mathrm{i}$. All these forces were related to one surface traction vector $\mathbf{p}_{\mathrm{i}}$ and each surface traction had three stress components $\sigma_{i j}$. Thus nine stress components were given for the Cauchy stress tensor as shown in Expression (3.26). The first index denoted the normal vector to the considered coordinate plane and the second indexed the global direction. Taking the equilibrium of an infinitesimal cube (see Figure 3.18(a)) gave $\sigma_{i j}=\sigma_{j i}$, which led to a symmetrical tensor that can be redefined in the Voigt notation as Expression (3.27). In addition, Expression (3.28) shows the 
components of the symmetric strain tensor and Expression (3.29) was used for the strain tensor in the Voigt and engineering notations.

$$
\begin{gathered}
\boldsymbol{\sigma}_{x y z}=\left[\begin{array}{lll}
\sigma_{x x} & \sigma_{x y} & \sigma_{x z} \\
\sigma_{y x} & \sigma_{y y} & \sigma_{y z} \\
\sigma_{z x} & \sigma_{z y} & \sigma_{z z}
\end{array}\right] \\
\boldsymbol{\sigma}_{x y z}=\left(\begin{array}{l}
\sigma_{x x} \\
\sigma_{y y} \\
\sigma_{z z} \\
\sigma_{y z} \\
\sigma_{x z} \\
\sigma_{x y}
\end{array}\right) \\
\boldsymbol{\varepsilon}_{x y z}=\left(\begin{array}{lll}
\varepsilon_{x x} & \varepsilon_{x y} & \varepsilon_{x z} \\
\varepsilon_{x y} & \varepsilon_{y y} & \varepsilon_{y z} \\
\varepsilon_{x z} & \varepsilon_{y z} & \varepsilon_{z z}
\end{array}\right] \\
\boldsymbol{\varepsilon}_{x y z}=\left(\begin{array}{l}
\varepsilon_{x x} \\
\varepsilon_{y y} \\
\varepsilon_{z z} \\
\gamma_{y z} \\
\gamma_{x z} \\
\gamma_{x y}
\end{array}\right)=\left(\begin{array}{c}
\varepsilon_{x x} \\
\varepsilon_{y y} \\
\varepsilon_{z z} \\
2 \varepsilon_{y z} \\
2 \varepsilon_{x z} \\
2 \varepsilon_{x y}
\end{array}\right)
\end{gathered}
$$




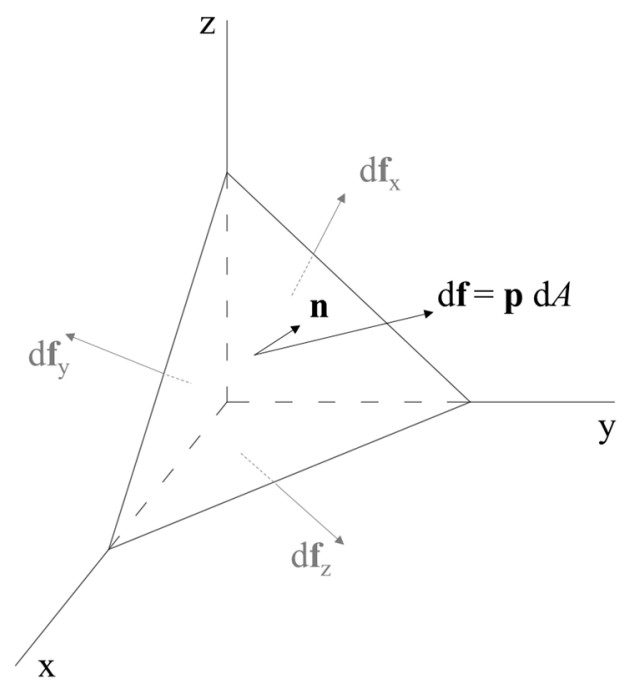

Figure 3.17 Infinitesimal stress tetrahedron

Figure 3.18 represents the stress space for an element coordinate system $\{\mathbf{x}, \mathbf{y}, \mathbf{z}\}$ and the stress space for the crack coordinate system $\{\mathbf{n}, \mathbf{s}, \mathbf{t}\}$, and in Figure 3.19, the face where the normal vector was $\mathbf{n}$ and represented the crack plane. Hence Expression (3.6) for uniaxial cracking can be used for the multiaxial case on the cracking plane as defined in Expression (3.30). In this expression, the mean strain vector $\left(\boldsymbol{\varepsilon}_{c}\right)$ in the crack bandwidth $\left(b_{w}\right)$ expressed in the local (crack) coordinate system in the Voigt notation was related to the crack width vector $(\boldsymbol{w})$ by means of incidence matrix $\boldsymbol{L}$ (Expression (3.31)), which allowed the definition of the local strains in the crack plane in Expression (3.32).

$$
\begin{gathered}
\boldsymbol{\varepsilon}_{c_{n s t}}=\frac{1}{b_{w}} \boldsymbol{L} \cdot \boldsymbol{w} \\
\boldsymbol{L}=\left[\begin{array}{lll}
1 & 0 & 0 \\
0 & 0 & 0 \\
0 & 0 & 0 \\
0 & 0 & 0 \\
0 & 0 & 1 \\
0 & 1 & 0
\end{array}\right]
\end{gathered}
$$




$$
\left(\begin{array}{c}
\varepsilon_{c_{n n}} \\
2 \varepsilon_{c_{n t}} \\
2 \varepsilon_{c_{n s}}
\end{array}\right)=\frac{1}{b_{w}}\left(\begin{array}{l}
w_{n} \\
w_{t} \\
w_{s}
\end{array}\right)
$$

Furthermore, in order to preserve the local equilibrium, crack surface tractions were related to the local Cauchy stresses in the local (crack) coordinate system in the Voigt notation by Expression (3.33), which allowed the local stresses in the crack plane in Expression (3.34) to be defined (see Figure 3.18(b) and Figure 3.19).

$$
\begin{gathered}
\boldsymbol{p}=\boldsymbol{L}^{T} \cdot \boldsymbol{\sigma}_{n s t} \\
\left(\begin{array}{c}
p_{n} \\
p_{s} \\
p_{t}
\end{array}\right)=\left(\begin{array}{c}
\sigma_{n n} \\
\sigma_{n s} \\
\sigma_{n t}
\end{array}\right)
\end{gathered}
$$

(a)

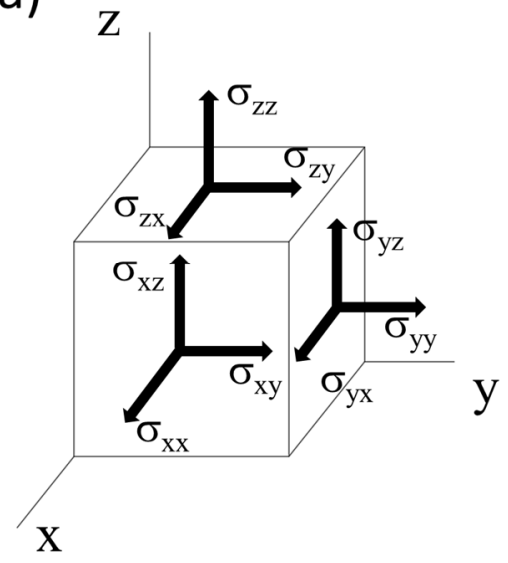

(b)

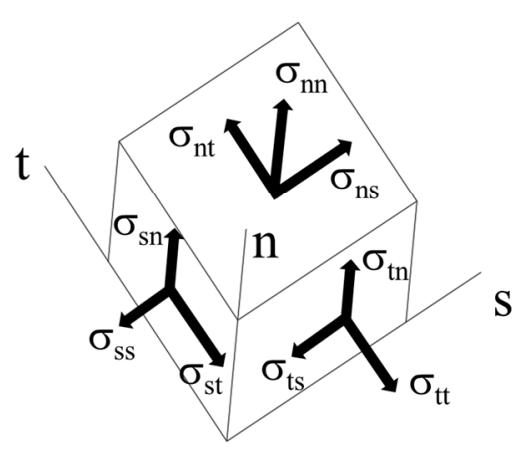

Figure 3.18 (a) Element coordinate system and stress space. (b) Crack coordinate system and stress space 


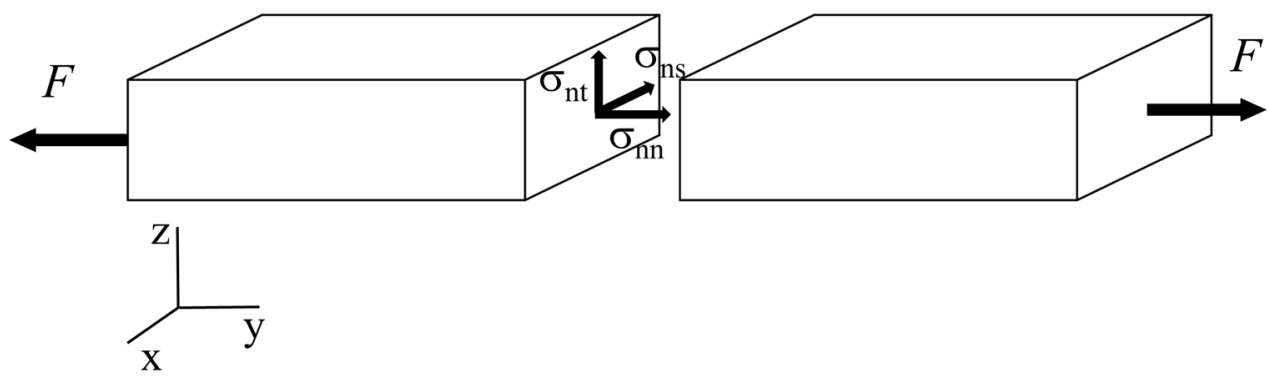

Figure 3.19 Crack plane stresses in the local crack coordinate system and the element coordinate system

In order to obtain the strains and stresses in the element (global) coordinate system $\{\mathbf{x}$, $\mathbf{y}, \mathbf{z}\}$ from the strains and stresses in the crack coordinate system $\{\mathbf{n}, \mathbf{s}, \mathbf{t}\}$, a coordinate transformation matrix $\boldsymbol{Q}$ that depends on the rotation angles between the two coordinate systems can be determined. As matrix $\boldsymbol{Q}$ was orthogonal, then $\boldsymbol{Q}^{-1}=\boldsymbol{Q}^{\mathrm{T}}$, as defined in Expression (3.35) and Expression (3.36).

$$
\begin{gathered}
\boldsymbol{\varepsilon}_{c_{n s t}}=\boldsymbol{Q} \cdot \boldsymbol{\varepsilon}_{\boldsymbol{c}_{x y z}} \\
\boldsymbol{\sigma}_{n s t}=\boldsymbol{Q} \cdot \boldsymbol{\sigma}_{x y z}
\end{gathered}
$$

Therefore, as defined for the smeared crack model in the uniaxial case in Expression (3.10), the mean total strain $\left(\boldsymbol{\varepsilon}_{m}\right)$ was obtained for the smeared crack model in the multiaxial case by taking the same proportion and considering the length covered by both the uncracked and cracked parts to the characteristic element length $\left(L_{c}\right)$, but by using vectors and being expressed in the element coordinate system, as shown in Expression (3.37). That is, a weighted combination of the strain in the uncracked part and the mean total strain in the cracked part. As with the uniaxial case, the characteristic element length $\left(L_{c}\right)$ resulted from the chosen discretisation, while crack bandwidth $\left(b_{w}\right)$ was assumed as a characteristic of the material and, therefore, a material constant. By way of example, if the finite element method is used, the relation proposed in (Häussler-Combe 2015) might be appropriate to obtain the characteristic length of an element $\left(L_{c}\right)$ for plate elements (see Expression (3.38)), where $A$ is the element area and $n_{i}$ is the integration order. This work assumed that the characteristic element length $\left(L_{c}\right)$ was directly the element side length (denoted as $L_{e}$ in the uniaxial case) for the 2D quad element and the 3D solid element; that is $L_{c}=L_{e}$. 


$$
\begin{gathered}
\boldsymbol{\varepsilon}_{m_{x y z}}=(1-\xi) \boldsymbol{\varepsilon}_{u n c_{x y z}}+\xi \boldsymbol{Q}^{T} \cdot \boldsymbol{\varepsilon}_{c_{n s t}} ; \quad \xi=\frac{b_{w}}{L_{c}} \\
L_{c}=\sqrt{\frac{A}{\left(n_{i}+1\right)^{2}}}
\end{gathered}
$$

In order to cover the complete cracking process, it was necessary to consider the combination of the anisotropy generated during crack formation and the isotropic behaviour considered in the material law for the uncracked material. With finite element modelling (FEM), the smeared crack model in the multiaxial case (with occurred the uniaxial one) gave a combination of cracked and uncracked material in a material area (cracking area), represented by a single integration point. This was why the smeared crack model did not need to explicitly set the crack path (the displacement jump). Therefore, multiple cracking can be addressed by extending Expression (3.37), as shown in Expression (3.39). In this case, orientation matrix $\boldsymbol{Q}_{i}$ considers the orientation of crack $i$.

$$
\begin{gathered}
\boldsymbol{\varepsilon}_{m_{x y z}}=(1-\xi) \boldsymbol{\varepsilon}_{u n c_{x y z}}+\xi\left(\boldsymbol{Q}_{1}^{T} \cdot \boldsymbol{\varepsilon}_{c_{n s t, 1}}+\boldsymbol{Q}_{2}^{T} \cdot \boldsymbol{\varepsilon}_{c_{n s t}, 2}+\cdots\right) \\
\xi=\frac{b_{w}}{L_{c}}
\end{gathered}
$$

Another particularity that needs to be taken into account in the smeared crack model is related to the evolution of crack orientations. Principal stress orientations may change in the loading history, which leads to two different concepts about stress orientation in smeared crack models:

- Fixed crack concept: crack orientation remains fixed throughout the process. This is considered fixed after the crack has been produced and during its evolution. So crack orientation does not follow the principal stress direction

- Rotating crack concept: crack orientation follows the principal stress direction during the loading process and crack evolution. This is represented by crack bands and microcracking, where the orientation of the microcracks group changes with a change of principal tensile stress direction. In this concept, cracking is limited to Mode-I (see Figure 3.15) with rotating cracks

In the fixed crack concept, it is necessary to bear some particularities in mind. As crack orientation is fixed, it considers relative crack surface sliding by means of sliding components $w_{s}$ and $w_{t}$ (see Expression (3.23)), which leads to in-plane surface tractions 
on the crack surface: $p_{s}$ and $p_{t}$ (see Expression (3.24)). Therefore, it is necessary to define sliding law $f_{s}$, which relates sliding surface tractions to sliding displacements (see Expression (3.25)). Two important effects are directly related to sliding: (i) dowel action, produced by rebars crossing the crack; (ii) aggregate interlock, as a result of the friction between aggregates on rough crack surfaces. As experimental data were limited, it was difficult to establish a reliable sliding law $f_{s}$. This would lead to the consideration of approximate laws as the shear retention approach (see Expression (3.40)). In this approach, isotropic elastic shear stiffness was reduced by a shear retention factor $(\beta)$, with Young's modulus $E$ and Poisson's ratio $v$.

$$
f_{s}=\beta \frac{E}{2(1+v)}
$$

As tensile UHPFRC behaviour was studied in this work, specimens were loaded mainly at axial and bending forces. Consequently, the main fracture mode that was expected to occur was Mode-I (see Figure 3.15) and, therefore, the results from a fixed crack concept and a rotating crack concept came very close. Given this assumption, the fixed crack concept was adopted in this work.

As explained in the uniaxial definition of the smeared crack model in Section 3.2.3.1, and as observed in Expression (3.37) and Expression (3.39) for the multiaxial case, this model was mesh size-dependent. Consequently, in the smeared crack model it was necessary to regularise the strain-softening part of the material law on $\varepsilon_{m}$ to minimise the mesh size-dependence effect. The regularisation idea is addressed in more detail in Chapter 4, where the material model was considered in the finite element model.

By considering concrete's described uniaxial and multiaxial behaviour, together with the constitutive material law set for the UHPFRC, it is possible to define a material model for UHPFRC to be used in a computational numerical method for structural analyses, such as the finite element method.

\subsection{Reinforcement steel uniaxial constitutive behaviour}

Unlike concrete, steel is considered homogeneous, even at the mesoscale level (millimetres). Moreover, it can be stated that steel manifests the same behaviour in compression as in tension. As explained above in Section 3.2.3 Cracking, given its heterogeneity at the mesoscale level, the uniaxial UHPFRC material model needs to be expressed by a constitutive stress-strain/crack opening relation defined at the macroscale level, completed by a cracking process characterisation model defined at the mesoscale level. For steel, however, its constitutive behaviour can be completely expressed by means of a stress-strain relation due to its homogeneity at the meso- and macroscale level. 
In this work, steel bars were used to discretely model the reinforcement of reinforced UHPFRC specimens. Given its function to resist mainly axial tensile forces, uniaxial stress-strain behaviour was defined to be employed in truss elements, where only axial elongation was considered. The principal characteristic of these elements is that their dimensions that lie perpendicularly to their longitudinal axis are small in relation to element length.

Therefore, the steel for reinforcement bars was characterised by an elastoplastic bilinear stress-total strain constitutive behaviour with strain hardening (see Figure 3.20).

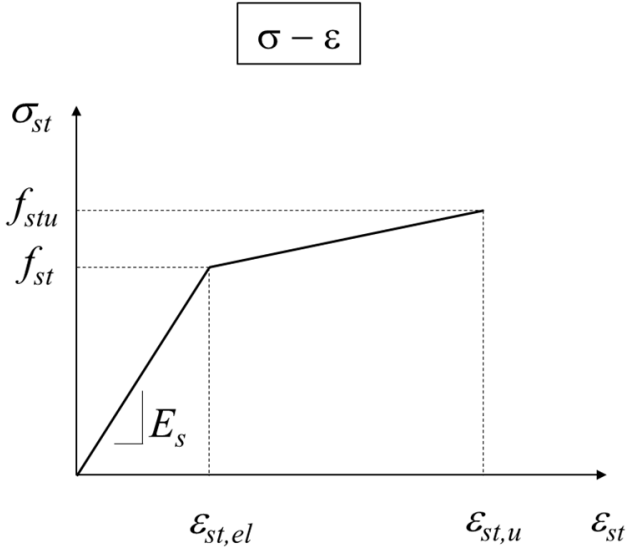

Figure 3.20 Uniaxial stress-strain tensile constitutive behaviour for reinforcement steel

\subsection{Bond between concrete and reinforcement steel bars}

As reinforcement bars were modelled discretely in this work, it was necessary to define an interface behaviour between the steel from the rebars and the UHPFRC surrounding them to contemplate the influence of transition. To completely understand the complex bond-slip mechanism, it is necessary to consider it at the mesoscale level by means of a three dimensional analysis and non-linear material behaviour. Hence it was essential to take a simplified model into account to define bond-slip phenomena from a macroscopic point of view in a special bond-slip constitutive law case.

Recent experimental research into the bond-slip behaviour between UHPFRC and reinforcement bars (Alkaysi and El-Tawil 2017; Chu and Kwan 2019; Lagier et al. 2016; Marchand et al. 2016; Sturm and Visintin 2019; Yoo et al. 2014b; Yuan and Graybeal 2015) provided an idea of the form of constitutive material law that can be modelled with more or less complexity (see Figure 3.21(b)). 
Chapter 3: Proposed constitutive material models

Bond force flow $T$ developed at the interface between the rebar surface and the surrounding concrete (see Figure 3.21(a)) can be defined as Expression (3.41) if the equilibrium is set between rebar force $F_{s}$ and the force in the surrounding concrete body $F_{c}$. As represented in Figure 3.21(a), the relative displacement between the reinforcement bar and concrete was defined as slip $s$. Bond stress $\tau$ can be obtained as shown in Expression (3.42) by assuming a constant perimeter circumference $u$ of the rebar. Therefore, the constitutive shear stress-slip displacement that defines the bond-slip constitutive material behaviour can be formulated as in Expression (3.43), where $f_{T}$ represents the function that relates stress and slip displacement in the interface zone (see Figure 3.21(b)).

$$
\begin{gathered}
T=\frac{d F_{s}}{d x}=\frac{d F_{c}}{d x} \\
\tau=\frac{T}{u} \\
\tau=f_{T}(s)
\end{gathered}
$$

(a)

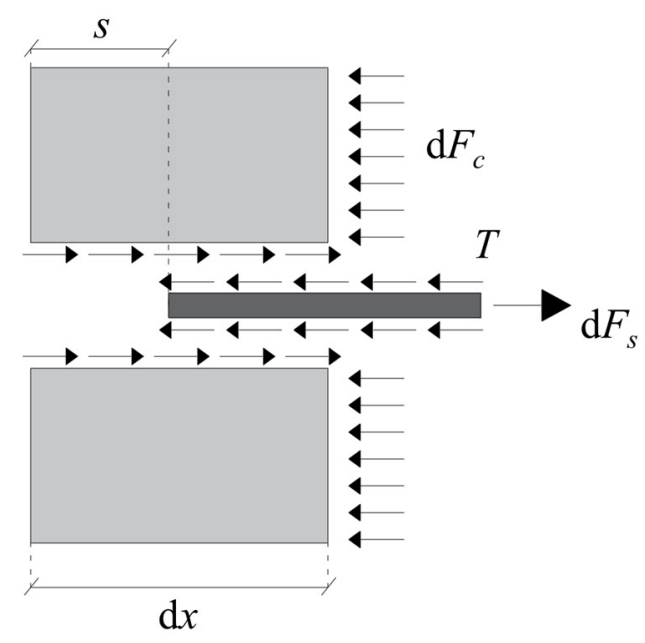

(b)

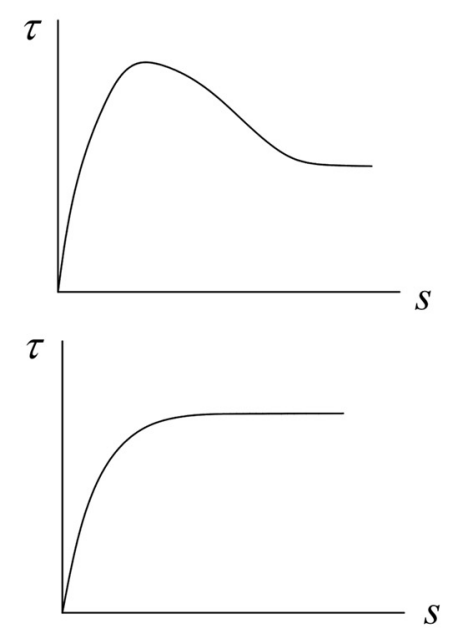

Figure 3.21 (a) Bond-slip mechanism and (b) constitutive material bond-slip behaviour 
In this work, no experimental test was run to evaluate the bond-slip behaviour between the steel rebar and the UHPFRC matrix. Therefore, the modelling of the constitutive material behaviour to represent the bond between steel and UHPFRC was considered by means of the a cubic function in accordance with Dörr (Dorr 1980), as explained in Chapter 4.

\subsection{Chapter summary and relevant conclusions}

In this chapter, the theoretical definition of constitutive material behaviour and the material UHPFRC model that was herein employed to study tensile UHPFRC behaviour from the modelling at the material level to the structural application was achieved. It constitutes the core of the 2D and 3D non-linear finite element models (NLFEM) developed and applied in the UHPFRC experimental tests modelled in the following chapters of this work.

Firstly, the uniaxial UHPFRC material model was set in both compression and tension. Given its particular behaviour, a stress-strain/crack opening relation was adopted to describe the constitutive tensile UHPFRC response. In stress-strain relation terms, this represents the elastic and the hardening or softening parts up to ultimate tensile stress, where the macrocrack appeared, and the softening part that follows by means of stresscrack opening relation. In this work, the both strain-hardening (SH-UHPFRC) and strainsoftening (SS-UHPFRC) responses of UHPFRC were studied.

Given its heterogeneity, to model tensile UHPFRC behaviour it is necessary to not only set its constitutive behaviour at the macroscale level, but to complete its definition by a cracking process characterisation model at the mesoscale level. Therefore, the fracture mechanics approach was considered to model concrete's quasi-brittle cracking process. As tensile UHPFRC behaviour was herein studied, all the carried out and modelled experimental tests were mainly done in fracture Mode-I. Hence two modelling approaches were been defined to model tensile UHPFRC behaviour: the smeared cracking approach and the discrete cracking approach.

The smeared cracking approach is a continuum model in which discontinuity in the displacement field produced by the opening of the cohesive crack is smeared in the process zone or crack bandwidth, which was herein considered to be a constant characteristic of the material. This led to a mean total strain in element length when the element cracked, weighted from the uncracked strain in the uncracked part and the cracked total strain in the crack bandwidth. This fact facilitated the application of common finite element interpolation, even when the macrocrack took place, and made the discontinuity in the displacement field continuous. The principal advantage of the smeared crack model lies in not having to know the crack path beforehand as crack was smeared by a mean strain, which represented the crack along the whole element length. However, this particular cracking treatment leads to mesh-size dependency. This scenario renders the application of a regularisation technique necessary, which can be 
difficult to implement if commercial finite element software is applied, or it would be needed to calibrate adequate element length to obtain reliable results with this model.

The discrete cracking approach is a continuum model with discontinuities, in which the model's continuous part is described by employing stress-strain constitutive behaviour while the discrete discontinuity is modelled taking into account an initiation and propagation criteria to activate a traction-separation law. This is the why it is necessary to previously know the crack path in continuum models with discontinuities. In this work, the model's continuous part was defined by the above-described smeared cracking approach and the discontinuous part by the stress-crack opening relation. This gave a relatively mesh size-independent model. For this reason, the experimental results and the discrete cracking approach results were used to calibrate the appropriate mesh size of the smeared cracking approach and, therefore, the continuum model. All the results were compared in the following chapters of this work for the different modelled experimental tests.

The UHPFRC parameters that described the defined constitutive UHPFRC behaviour were obtained from the experimental tests. With compressive behaviour, compressive strength was obtained by $100-\mathrm{mm}$ cubic compression tests. Tensile constitutive UHPFRC behaviour was herein derived from unnotched 500x100x100 mm 4PBT given its simplicity and suitability, which allowed the microcracking process to characterise UHPFRC behaviour. As it was a bending test, an inverse analysis methodology was followed to obtain the tensile response from the 4PBT experimental results. This inverse analysis methodology was validated in this work with the developed NLFEM.

Both UHPFRC material model approaches, the smeared cracking and the discrete cracking approaches, defined for the uniaxial case, were extrapolated to the multiaxial case for 2D and 3D modelling. The description of the smeared cracking approach in the uniaxial model was extended to the multiaxial one by contemplating crack orientation evolution by means of two possibilities: fixed crack concept or rotating crack concept. As the principal crack mechanism herein considered was developed in Mode-I, the responses of the fixed and rotating concepts was expected to come close and, for this reason, the fixed concept was adopted. The discrete cracking approach of the model in which cracking was modelled as a discontinuity of displacement could be adapted to multiaxial cracking as a relation of surface tractions and fictitious crack openings.

The constitutive behaviour of reinforcement steel can be completely expressed by a stress-strain relation due to its homogeneity at the meso- and macroscale levels. Due to its function of resisting mainly axial tensile forces, uniaxial elastoplastic bilinear stresstotal strain constitutive behaviour with strain hardening was defined to be employed in truss elements where only axial elongation was considered. As reinforcement bars were modelled discretely in this work, it was necessary to define interface behaviour between steel from the rebars and UHPFRC surrounding them to take into account the transition influence. This was carried out by means of a bond-slip constitutive law. 


\section{Chapter 4}

\section{Numerical model: definition and implementation}

\subsection{Introduction.}

The objective of this chapter is to explain the definition and implementation of the nonlinear finite element model (NLFEM) that is defined in this work using as a basis the material model for UHPFRC, reinforcement steel and bond between UHPFRC and reinforcement bars defined in Chapter 3. The development of the model is based on the Finite Element Method, due to its efficiency and its extended use that makes it available to apply to the analysis of the structural response of materials in a continuum. Finally, the finite element model (FEM) is implemented in a commercial software that constitutes a powerful tool to address complex non-linear finite element modelling and analysis.

Once the material models are defined and set, in order to progress in the development of the numerical model it is necessary to use a numerical technique that allows the integration of the differential equations that define the equilibrium of a generic differential element in which a structural element is discretised. The assembly of the comprehensive numerical model is necessary to carry out the structural analysis considering the boundary conditions, the distribution of the mechanical properties of the materials that define the structure, the type of loads, etc.

As it is stated in Chapter 2, the finite element method is one of the existing numerical techniques that let to approximate the behaviour of a structure with an infinite number of degrees of freedom to another with more or less the same physical and geometrical properties but with a finite number of degrees of freedom. The support of the advances in computer technology has led to the development of sophisticated codes and software 
that permit addressing complex non-linear finite element analysis with high level of accuracy and detailed graphical definition of the output results. In this direction, a particular material model can be implemented in the finite element method. To do that, it is necessary to understand the workflow of the method to integrate the material behaviour or, in case of using a finite element package commercial software, to adapt the material model to the capabilities of the software.

Therefore, in this chapter, a general idea of the workflow of the finite element method is presented in order to set the integration of the material models in the method. Then, to carry out the numerical implementation, a finite element software is used. Thus, it is important to know how the software integrates the material models and how they are used in the non-linear analysis to be able to adapt the material models for UHPFRC, the steel reinforcement and the interface behaviour between them defined in Chapter 3 to the particularities of the software. The geometry, boundary conditions, type of finite element and analysis method are described in the following chapters as they are related to the structural element that is addressed there. At this point, it is important to keep in mind what is the mechanical function of the material when it forms part of the structural element.

\subsection{Overview of the finite element method}

In this work, it is assumed that the reader is familiar with the finite element method. Therefore, only the main concepts are set in order to review briefly the basic ideas. For more information about the theory and application of the method the following bibliography can be used (Bathe 2006; Cook 2007; Hughes 2012; Oñate Ibañez de Navarra 1995; Zienkiewicz and Taylor 2005).

\subsubsection{Discretisation}

Starting with a three-dimensional problem of linear elasticity, described by the basic equations valid inside the domain $V$ that represents the body or structure considered as a continuum.

Kinematic (strain-displacement) equations, Expression (4.1):

$$
\varepsilon_{i j}=\frac{1}{2}\left(\frac{\partial u_{i}}{\partial x_{j}}+\frac{\partial u_{j}}{\partial x_{i}}\right)
$$

Constitutive (stress-strain) equations, Expression (4.2):

$$
\sigma_{i j}=D_{i j k l}^{e} \varepsilon_{k l}
$$

Equilibrium (static) equations, Expression (4.3): 


$$
\frac{\partial \sigma_{i j}}{\partial x_{i}}+\bar{b}_{j}=0
$$

where in the above:

$\mathrm{u}$ is the displacement vector inside the domain $V$.

$\varepsilon$ is the column matrix of strain components inside the domain $V$.

$\sigma$ is the column matrix of stress components inside the domain $V$.

$\bar{b}$ is the vector of external body forces.

The continuum is discretised by finite elements that are connected by nodes. Elements adjoin but not overlap and they fill out the space of the body considered (see Figure 4.1).

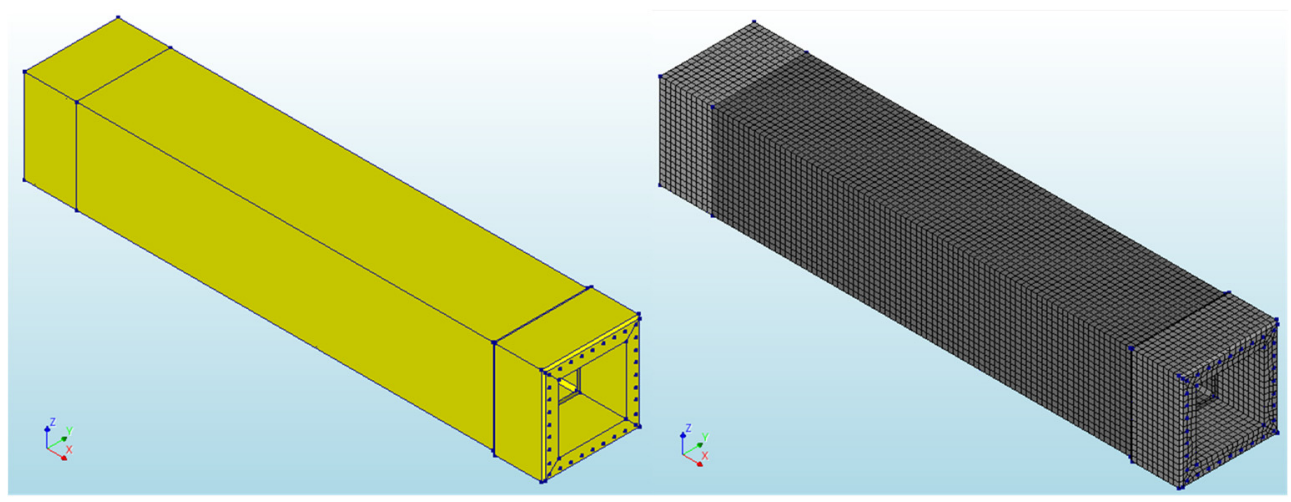

Figure 4.1 Finite element discretisation of the continuum

The displacement components are approximated as linear combinations of convenient chosen interpolation functions from the displacements at the nodes of the finite element. The finite elements are connected between them through the nodes situated in their contour. These functions are known as shape functions. Expression (4.4) shows this relation.

$$
\boldsymbol{u}(x) \approx N(x) d
$$

where:

$\mathbf{u}$ is the displacement vector of a point in the finite element.

$\mathbf{N}$ is the matrix that contains de shape functions.

d is the displacement vector of the nodal displacements of the finite element. 
the argument $x$ marks that those vectors or matrices are position-dependent (it depends on the point that is evaluated)

The kinematic (strain-displacement) relation in Expression (4.1) is discretised resulting in an approximation of the strains by Expression (4.5).

$$
\varepsilon(x) \approx B(x) d
$$

where:

$\varepsilon$ is the vector containing the strain components of a point in the finite element.

$\mathbf{B}$ is the strain-displacement matrix containing the derivatives of the shape functions with respect to the spatial coordinates.

The constitutive (stress-strain) relation in Expression (4.2) is discretised resulting in an approximation of the stresses by Expression (4.6):

$$
\boldsymbol{\sigma}(x) \approx \boldsymbol{D}(x) \boldsymbol{B}(x) \boldsymbol{d}=\boldsymbol{D}(x) \boldsymbol{\varepsilon}(x)
$$

where:

$\sigma$ is the vector containing the stress components of a point in the finite element.

D is the matrix of the material characteristics (constitutive matrix)

Concerning the equilibrium equations in Expression (4.3), as the adopted approximations depend only on a finite number of unknown displacement parameters, the differential equilibrium equations, in general, are not able to be solved exactly at each point of the body (strong form). In this sense, the strong form is substituted by the principle of virtual work (weak form), shown in Expression (4.7), where the left side represents the work done by the internal forces, $f_{\text {int }}$ (integrated in the whole volume of the body $V$ ) and the right side represents the work done by the external forces, $f_{\text {ext }}$ (integrated in the whole surface $S_{t}$ for the external surface forces $\bar{t}$ and the whole volume $V$ of the body for the external volume forces $\bar{b}$ ).

$$
\int_{V} \sigma^{T} \delta \varepsilon d V=\int_{S_{t}} \bar{t}^{T} \delta u d S+\int_{V} \bar{b}^{T} \delta u d V
$$

Following the same idea as the kinematic (Expression (4.1)) and constitutive (Expression (4.2)) equations where the continuum is discretised in finite elements (Expression (4.5) and Expression (4.6), respectively), the continuum weak form equilibrium equation is discretised as shown in Expression (4.8).

$$
\int_{V} \boldsymbol{d}^{T} \boldsymbol{B}^{T}(x) \boldsymbol{D}^{T}(x) \boldsymbol{B}(x) \delta d d V=\int_{S_{t}} \overline{\boldsymbol{t}}^{T} \boldsymbol{N}(x) \delta d d S+\int_{V} \overline{\boldsymbol{b}}^{T} \boldsymbol{N}(x) \delta d d V
$$


And compressed in Expression (4.9) considering that $d$ and $\delta d$ are not function of the spatial coordinates and, therefore, are taken out of the integrals.

$$
\boldsymbol{d}^{T} \boldsymbol{K}^{T} \delta d=\boldsymbol{f}_{\text {ext }}^{T} \delta d
$$

From which the global (as it is integrated in the whole volume $V$ of the body) stiffness matrix $\mathbf{K}$ and the equivalent external force vector $\boldsymbol{f}_{\text {ext }}$ can be deduced as shown in Expression (4.10) and Expression (4.11).

$$
\begin{gathered}
\boldsymbol{K}=\int_{V} \boldsymbol{B}^{T}(x) \boldsymbol{D}(x) \boldsymbol{B}(x) d V \\
\boldsymbol{f}_{\text {ext }}=\int_{S_{t}} \boldsymbol{N}^{T}(x) \overline{\boldsymbol{t}} d S+\int_{V} \boldsymbol{N}^{T}(x) \overline{\boldsymbol{b}} d V
\end{gathered}
$$

Therefore, the internal force vector $\boldsymbol{f}_{\text {int }}$ is represented in Expression (4.12).

$$
\boldsymbol{f}_{\text {int }}=\boldsymbol{K} \boldsymbol{d}
$$

In this numerical implementation the contributions of each finite element to the $\boldsymbol{f}_{\text {int }}$ vector and to the global $\boldsymbol{K}$ are evaluated separately, and the global matrices are assembled from these contributions. Thus, integration over the volume of each element $V_{e}$ that divides the whole body $V$ is performed numerically and, for example, Expression (4.10) is reformulated as Expression (4.13) for the stiffness matrix $\left(\boldsymbol{K}_{e}\right)$ of each element.

$$
\boldsymbol{K}_{e}=\int_{V_{e}} \boldsymbol{B}^{T}(x) \boldsymbol{D}(x) \boldsymbol{B}(x) d V \approx \sum_{k=1}^{N_{i n t}^{e}} \boldsymbol{w}_{k}^{e} \boldsymbol{B}^{T}\left(x_{k}^{e}\right) \boldsymbol{D}\left(x_{k}^{e}\right) \boldsymbol{B}\left(x_{k}^{e}\right)
$$

where $x_{k}^{e}, \mathrm{k}=1,2, \ldots N_{i n t}^{e}$, are the integration points of element number $e$, and $w_{k}^{e}, \mathrm{k}=$ $1,2, \ldots N_{i n t}^{e}$, are the corresponding integration weights.

Therefore, equilibrium equations in Expression (4.3) are discretised as shown in Expression (4.14), where it is possible to solve and obtain the unknown nodal displacements $\mathbf{d}$.

$$
\boldsymbol{f}_{\text {int }}=\boldsymbol{K} \boldsymbol{d}=\boldsymbol{f}_{\text {ext }}
$$


It is important to understand that all the preceding developments can be extended to the situation when the material is not linear elastic. In this case, the difference is that the constitutive equations are now nonlinear (Expression (4.15) and Expression (4.16)).

$$
\begin{gathered}
\boldsymbol{\sigma}=\tilde{\sigma}(\varepsilon) \\
\boldsymbol{\sigma}(x) \approx \tilde{\sigma}(\boldsymbol{B}(x) \boldsymbol{d})
\end{gathered}
$$

\subsubsection{Solution strategies for nonlinear analysis}

The main idea pursued in a nonlinear finite element analysis is to obtain the response of a structural model under the influence of an established loading history. This can be carried out using an incremental-iterative procedure. The load is applied in different incremental steps, and the structural response after the application of each step is solved from the equilibrium equations (Expression (4.14)). Considering that these equations are usually nonlinear, they must be solved by an iterative method.

It becomes necessary to differentiate between the criterion that stablishes the size of each incremental step in the incremental part of the incremental-iterative procedure, and the iterative method that solves the equilibrium equations in each incremental step in the iterative part of the incremental-iterative procedure (see Figure 4.2). Examples of stepsize control techniques can be the load control, direct or indirect displacement control, or various versions of the arc-length control. For the case of iterative methods, some examples could be the standard or modified Newton-Raphson iteration method, initial stiffness method, or quasi-Newton methods. Moreover, additional components of an incremental-iterative solution strategy are the convergence criteria and, optionally, convergence accelerators (for example line-search techniques) and/or step-size adjustment rules. These technics are widely treated in nonlinear finite element analysis bibliography (Batoz and Dhatt 1979; De Borst et al. 2012; Clarke and Hancock 1990; Crisfield 1981, 1983; Hellweg and Crisfield 1998; Matthies and Strang 1979; Riks 1972). 

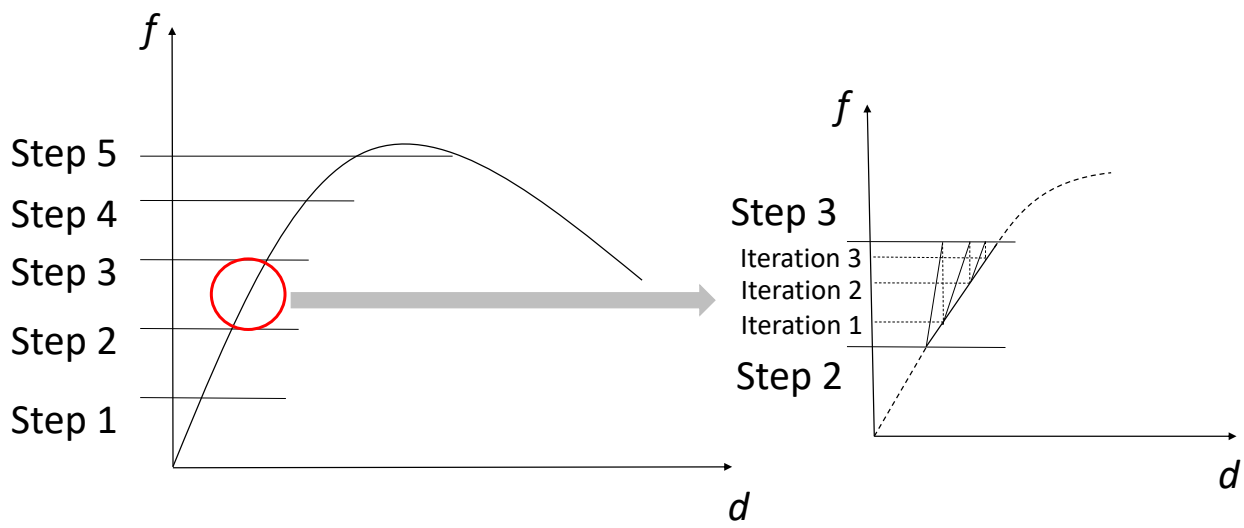

Figure 4.2 Incremental-iterative procedure in a nonlinear FE analysis

The use of a criterion for the step size in the incremental part and the iterative method depends on the expected response of the structure analysed and how far the analyst wants to go in the analysis. It is important to consider this because sometimes, depending of the solution strategy, this could affect to the result. For example, independently of the type of iterative algorithm chosen, a solution strategy based on load control fails if the prescribed loads are not able to be equilibrated by the mobilised strength of the structure. This often occurs when the load is monotonically increased until the load-carrying capacity of the structure is reached. This situation is shown in Figure 4.3(a), where the load-displacement response can be obtained only up to point 5 . After the following increment (point 6), the applied load exceeds the maximum load that is able to be carried by the structure, and the equilibrium equations have no solution. Then, the iteration process diverges, and equilibrium is not possible to be restored. In many engineering situations, it is enough to obtain the collapse load of the structure and the displacements at which collapse takes place. Divergence of the iterative process is often considered as an indicator of structural collapse, and the last converged step has the information of the state before this moment. However, finite element analyses of complex engineering problems can diverge for different reasons as could be, for example, purely numerical reasons and they are not properly the real structural failure.

If the objective of the analysis is to go through the softening branch of the loaddisplacement structural response, it is therefore necessary to use strategies able to continue the load-displacement diagram beyond its peak. This could be the case of the direct displacement control to stablish the incremental step (see Figure 4.3(b)). By way of example of this technique, Figure 4.4(a) represents a simply supported beam loaded by a direct force at mid-span. In the experimental test carried out under load control, the applied load is prescribed, and the resulting deflection is measured. When the applied load is over the collapse load of the structure, sudden failure occurs. In this moment, the 
structure is not in static equilibrium, and the displacements and strains are developed following a dynamic process. If, instead of load control, the experimental test can be controlled by the deflection at the point where the load is applied, the load point can be considered as an additional support with prescribed displacement. Therefore, the force acting on the structure is measured as the reaction generated in this support (see Figure 4.4(b)). In this case, it is possible to maintain the static equilibrium even after the reaction has reached its maximum value and, consequently, the load-displacement response can be obtained from the post-peak onwards.

(a)

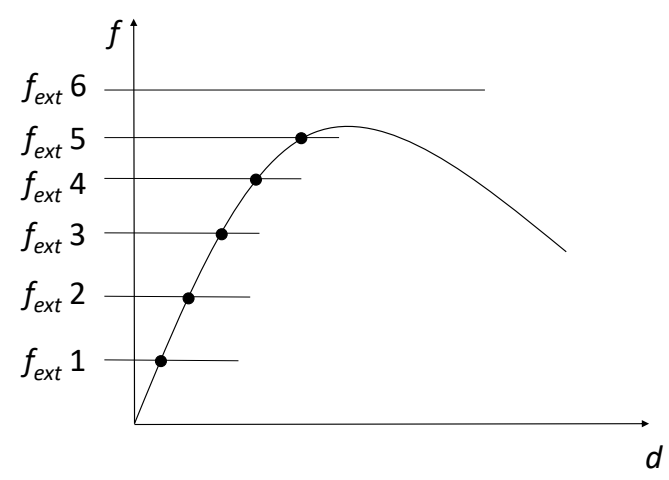

(b)

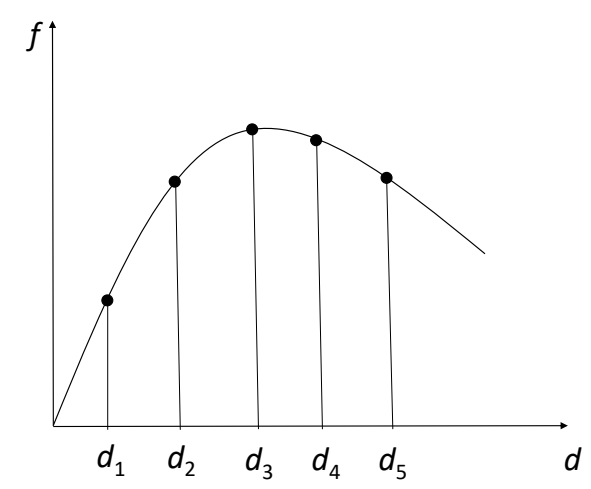

Figure 4.3 Non-linear analysis under (a) load control and (b) direct displacement control 
(a)
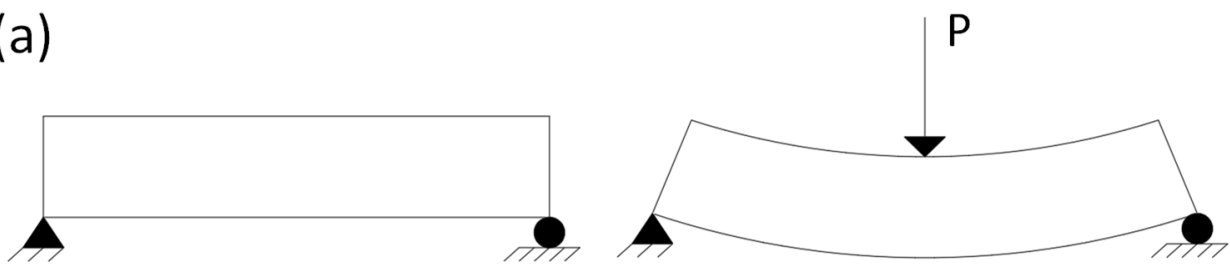

(b)

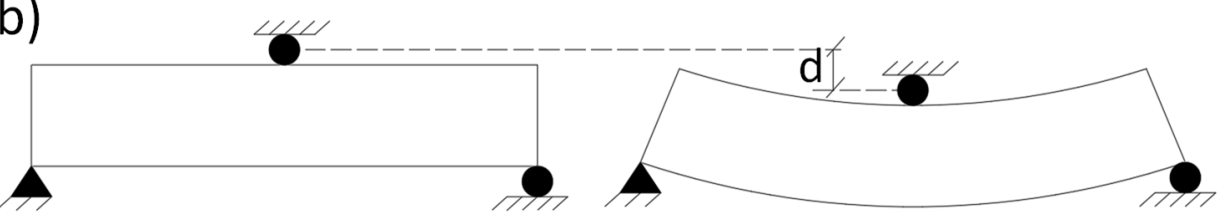

Figure 4.4 Experimental test under (a) load control and (b) displacement control

Consequently, it is important to set the most appropriate nonlinear structural analysis strategy not only from the point of view of the stability of the analysis but also for the reliability and accuracy of the results. Frequently, the criteria to choose the correct strategy depends on the experience and ability of the analyst.

\subsubsection{Workflow}

The workflow of the finite element method for a structural analysis can be set in the following stages when a structure is under the action of external solicitations (see Figure 4.5): 


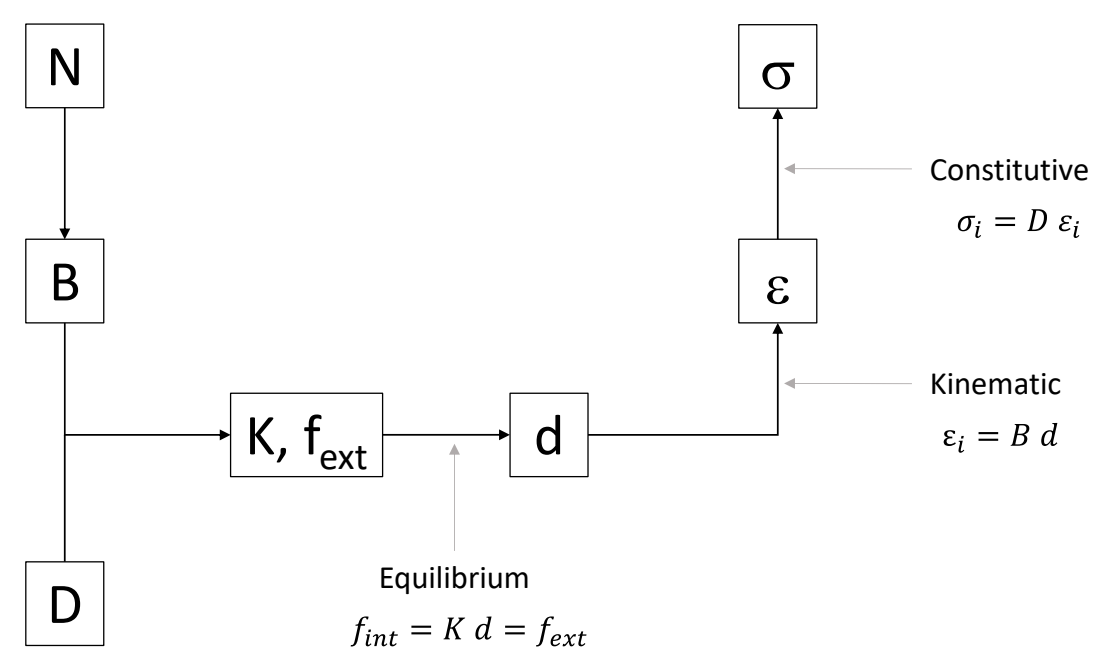

Figure 4.5 Finite element method workflow

Stage 1: From the physical reality of the structure it is necessary to select an appropriated mathematical model able to describe its behaviour, e.g. smeared crack model, damage model, the flow theory of plasticity... Is in this stage where the mechanical properties of the materials that define the structure are set too. This is set in chapter 3 .

Stage 2: Once the mathematical model is defined the structure is discretised using an appropriate type of finite element. From the finite element chosen, the shape function matrix $(\boldsymbol{N})$ is defined that relates the displacement of a point in the finite element to displacements of the nodes of the finite element (see Expression (4.4)).

Stage 3: The strain-displacement matrix $(\boldsymbol{B})$ containing the derivatives of the shape functions with respect to the spatial coordinates is defined. This matrix relates the strain of a point inside the finite element to the nodal displacements of the finite element (see Expression (4.5)). Moreover the constitutive matrix (D) that contains the material properties depending on the mathematical model used is set too. This matrix describes the constitutive relation between the stress and strain in a point in the finite element (see Expression (4.6)).

Stage 4: From the principle of virtual work the stiffness matrix $\left(\boldsymbol{K}_{e}\right)$ and the internal forces $\left(f_{\text {int }, e}\right)$ are obtained for each finite element $e$ (see Expression (4.10) and Expression (4.11)). The contributions of each finite element to the $\boldsymbol{f}_{\text {int }}$ vector and to the global $\boldsymbol{K}$ are evaluated separately, and the global matrices are assembled from these contributions.

Stage 5: From the assembled matrices, the equilibrium equation is set (see Expression (4.14)) and using a method to solve linear equations or a nonlinear strategy in case of 
nonlinear analysis the displacement vector of the nodes of the finite elements (d) that compose the structure is obtained.

Stage 6: From the nodal displacements $(\mathbf{d})$ it is possible to obtain the strain vector $\left(\boldsymbol{\varepsilon}_{\mathrm{i}}\right)$ at each integration point of the finite element that discretises the structure using the kinematic relation (Expression (4.5)).

Stage 7: From the strain vector at the integration points $\left(\varepsilon_{i}\right)$ it is possible to obtain the stress vector $\left(\sigma_{\mathrm{i}}\right)$ at the same integration points of the finite elements that discretises the structure using the constitutive relations (Expression (4.6)).

\subsection{UHPFRC material model in the FEM}

At this point, the material model for UHPFRC to describe its constitutive behaviour and the cracking mechanism defined in chapter 3 is adapted to the application of the finite element method. This has been included in the stage 1 in the workflow of the finite element method set above in section 4.2.3. The idea pursued is to develop a finite element model (FEM) using the material model for UHPFRC described in chapter 3.

\subsubsection{Adaptation of the smeared cracking approach to the FEM}

Figure 4.6 represents the tensile bar used in chapter 3 to explain the cracking procedure of concrete when the entire element is modelled at material level (see Figure 4.6(a)) and when it is modelled considering the FEM (Figure 4.6(b)). In section 3.2.4.1 of chapter 3, the tensile bar $\left(L_{e}\right)$ is modelled using the UHPFRC material model defined by means of the smeared crack model in the so-called smeared cracking approach (Figure 4.6(a)). To do that, three phases are considered. Phase 1, where the UHPFRC constitutive stressstrain/crack opening relationship is defined (see Figure 3.2). Phase 2, where the stressstrain/crack opening relationship defined in phase 1 is transformed into a stress-total strain law that relates, from the macrocrack apparition onwards, the stress transmitted by the localised band to the mean total strain in that band (see Figure 3.10). In addition, its corresponding area defined under the softening curve and the unloading branch, $g_{f}=G_{F}$ $/ b_{w}$, is translated now as the energy spent per unit volume of the localised band (shadowed area in Figure 3.10). Phase 3, where the smeared crack model is applied to the continuum model and a stress $(\sigma)$-mean total strain $\left(\varepsilon_{m}\right)$ relationship is defined by means of Expression (3.10). In this phase, the energy of the new curve $g_{f m}$ has changed with respect to the original one defined in phase 2: $\varepsilon_{u n c}<\varepsilon_{m} \leq \varepsilon_{c}$. Therefore, when the bar cracks, the entire bar is modelled under a mean total strain $\left(\varepsilon_{m}\right)$ that represents the cracked area covered by the crack bandwidth $\left(b_{w}\right)$ and the remaining uncracked area. Figure 3.11 represents the result of the transformation done by the smeared crack model from the continuum model defined in phase 2 .

To define the finite element model (FEM), the tensile bar is discretised in finite elements, as it is shown in Figure 4.6(b). In this sense, the material model for UHPFRC to model 
the entire bar explained above and in sections 3.2.3 and 3.2.4 of chapter 3 is now used to model each of the finite element that discretises the tensile bar. This is, each finite element is made of UHPFRC and, thus, the smeared crack model is applied to obtain stress $(\sigma)$-mean total strain $\left(\varepsilon_{m, e f}\right)$ in each finite element length $\left(L_{e f}\right)$. Therefore Expression (3.10) that represents the mean total strain $\left(\varepsilon_{m}\right)$ of UHPFRC when the tensile bar $\left(L_{e}\right)$ cracks, now is adapted in Expression (4.17) and Expression (4.18) to represent the mean total strain $\left(\varepsilon_{m, e f}\right)$ of the UHPFRC covered by the finite element length $\left(L_{e f}\right)$ when it is cracked, because it is partial or entirely in the crack bandwidth. Here $\xi$ is the ratio that is constant for each finite element and $0<\xi \leq 1$ could be considered an appropriate restriction in conventional concrete (Bažant and Oh 1983; Häussler-Combe 2015). Thus, for uniaxial behaviour, it is adequate that the length of the finite element $\left(L_{e f}\right)$ remains equal or higher than the crack bandwidth $\left(b_{w}\right)$ as indicated in Expression (4.19). It is important to see that the length of the finite element $\left(L_{e f}\right)$ is a result of the discretisation chosen while the crack bandwidth $\left(b_{w}\right)$ is assumed as a characteristic of the material and, therefore, a material constant.

$$
\begin{gathered}
u_{e f}=\left(L_{e f}-b_{w}\right) \varepsilon_{u n c}+b_{w} \varepsilon_{c} \\
\varepsilon_{m, e f}=\frac{L_{e f}-b_{w}}{L_{e f}} \varepsilon_{u n c}+\frac{b_{w}}{L_{e f}} \varepsilon_{c}=(1-\xi) \varepsilon_{u n c}+\xi \varepsilon_{c} \\
\xi=\frac{b_{w}}{L_{e f}} \\
L_{e f} \geq b_{w}
\end{gathered}
$$

Therefore, the same three phases that describe the smeared crack model application for UHPFRC for the entire bar $\left(L_{e}\right)$ in section 3.2.4.1 of chapter 3 can be used for each finite element $\left(L_{e f}\right)$ that composes the tensile bar. The general response of the entire bar is represented by the individual contribution of each finite element when the finite element method described in section 4.2 is applied. 
(a)

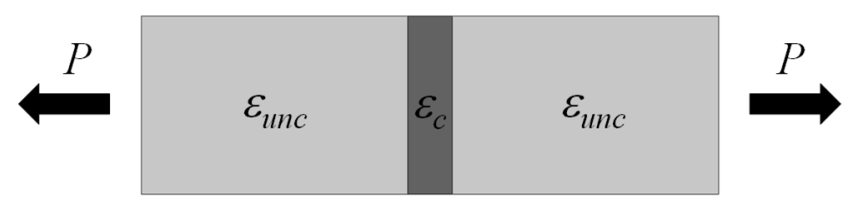

(b)

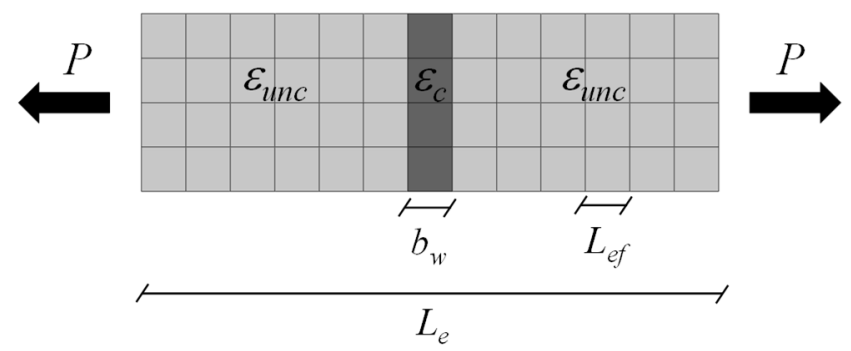

Figure 4.6 Tensile bar: (a) material model, (b) FEM

\section{PHASE 3}

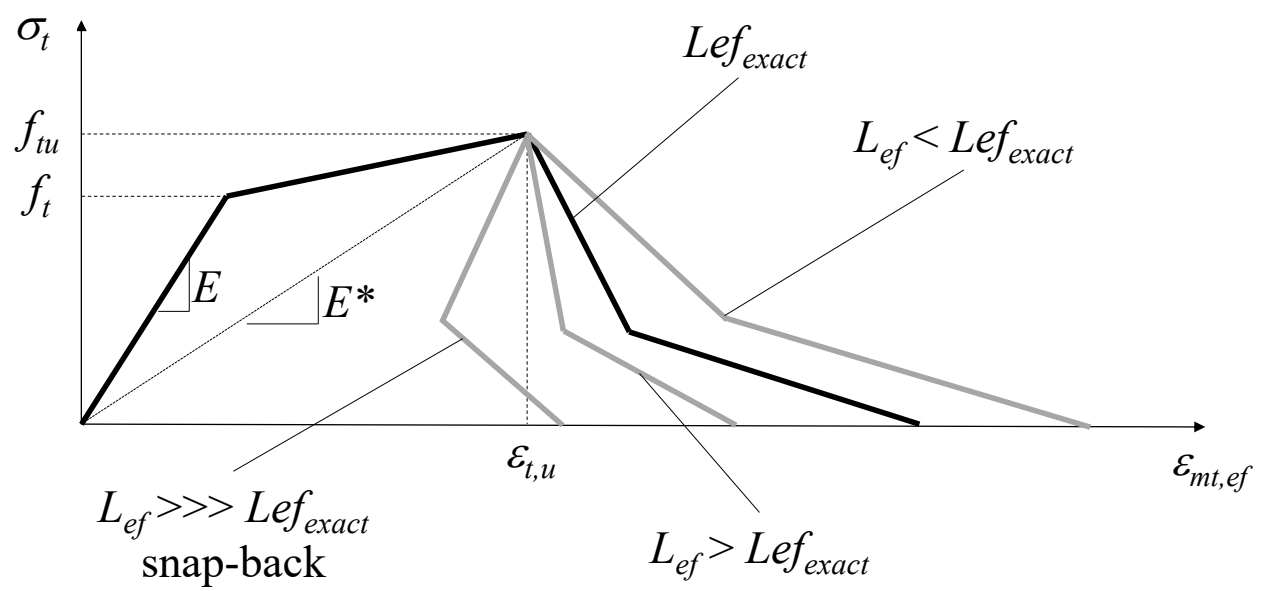

Figure 4.7 Mesh size dependency of the softening part of the material law in the smeared crack model obtained in phase 3 in the FEM 
As it happens in chapter 3 for the total length of the bar $\left(L_{e}\right)$ in this case, the smeared crack model is dependent on the finite element size $\left(L_{e f}\right)$. Figure 4.7 shows the consequences of the $L_{e f}$ dependency in the constitutive $\sigma-\varepsilon_{m, e f}$ smeared crack model for UHPFRC obtained in phase 3 applying Expression (4.18) depending on the element length chosen $\left(L_{e f}\right)$. There, the exact finite element length that represents the exact crack energy in the formation of the crack surface curve is set $($ Lef exact $)$. As it can be observed in Expression (4.18) the Lefexact represents the situation when the length of the finite element chosen fits exactly the crack bandwidth, i.e., $L_{e f}=b_{w}$ (see Figure 4.8). In this case, when the stress level reaches the $f_{t u}$, the entire finite element is cracked and no uncracked part is preserved. Therefore, all the displacement obtained by Expression (4.17) when UHPFRC in the finite element cracks is due to the cracking strain, the entire finite element is descending following the softening branch defined in Expression (3.2) and the result of the smeared cracking transformation is represented in Figure 4.9. In this sense, $\varepsilon_{m, e f}=\varepsilon_{c}$ and $g_{f m, e f}=g_{f}$, this is, the crack energy is preserved in the smeared transformation in the finite element.
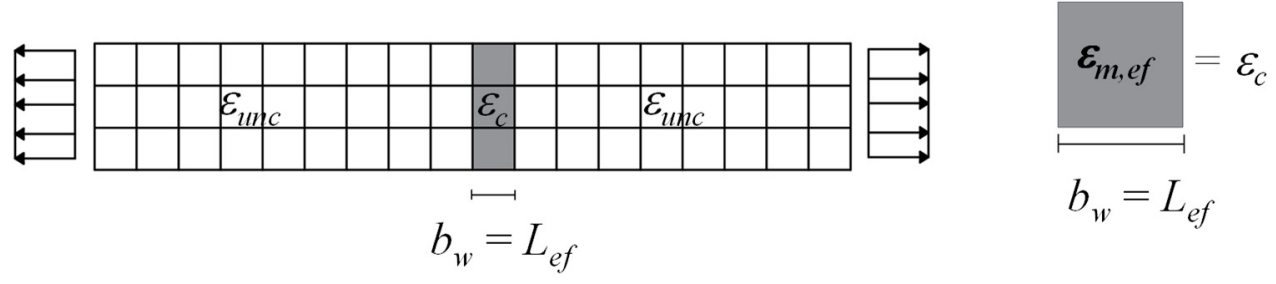

Figure 4.8 FEM when $b_{w}=L_{e f}$

PHASE 2

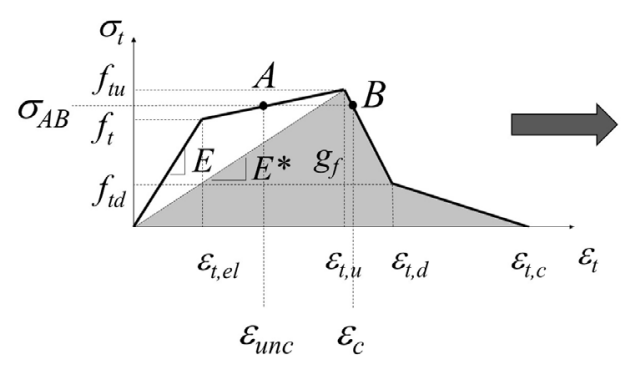

PHASE 3

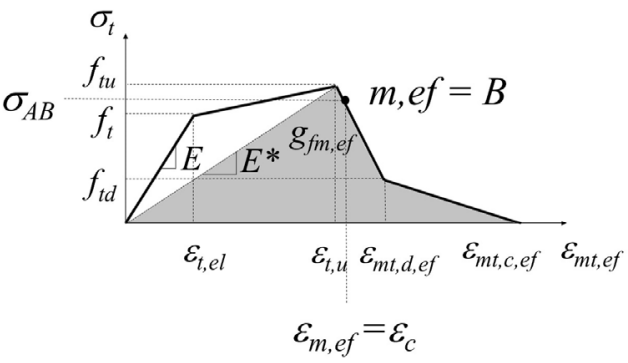

Figure 4.9 UHPFRC smeared crack model when $b_{w}=L_{e f}$ 
If the finite element length $\left(L_{e f}\right)$ chosen for the discretisation is higher than $L e f_{\text {exact }}\left(L_{e f}>\right.$ $b_{w}$ ), then $\varepsilon_{u n c}<\varepsilon_{m, e f}<\varepsilon_{c}$ (see Expression (4.18)) and the smeared $\sigma-\varepsilon_{m, e f}$ curve for the finite element length chosen $\left(L_{e f}\right)$ involves less crack energy $g_{f m, e f}<g_{f}$, as it can be observed in Figure 4.7. It is necessary to know that, in this case, a certain grade of inaccuracy is generated depending on the finite element length chosen $\left(L_{e f}\right)$ when the smeared crack model is adopted, because the mean total strain in the finite element $\left(\varepsilon_{m, e f}\right)$ is assumed in the length of the finite element $\left(L_{e f}-b_{w}\right)$ where the real strain is the uncracked one $\left(\varepsilon_{u n c}<\varepsilon_{m, e f}\right)$ and also in the length of the finite element $\left(b_{w}\right)$ where the real strain is the cracked total strain $\left(\varepsilon_{m, e f}<\varepsilon_{c}\right)$, as it is represented in Figure 4.10. If the finite element length chosen $\left(L_{e f}\right)$ is very higher compared to the Lefexact $\left(L_{e f}>\gg b_{w}\right)$, then the crack energy $\left(g_{f m, e f}\right)$ becomes very small even leading to a snap-back material behaviour in the $\sigma-\varepsilon_{m, e f}$ curve $\left(\varepsilon_{u n c}<\varepsilon_{m, e f}<\varepsilon_{t u}<\varepsilon_{c}\right)$, as it can be seen in Figure 4.7 and Figure 4.11. Moreover, if the elongation of the finite element $\left(u_{e f}\right)$ is considered by means of Expression (4.17), it can be observed that it could cause also a snap-back response of the load-displacement $\left(P-u_{e f}\right)$ curve when $L_{e f} \gg \gg>b_{w}$, as $u_{e f}<u_{f t, e f}=L_{e f} \varepsilon_{t u}$. In this sense, the $P-u_{e f}$ curve has the same form as the $\sigma-\varepsilon_{m, e f}$ curve represented in Figure 4.7. All of these could derive in numerical problems depending on the finite element length $\left(L_{e}\right)$ used for the discretisation.

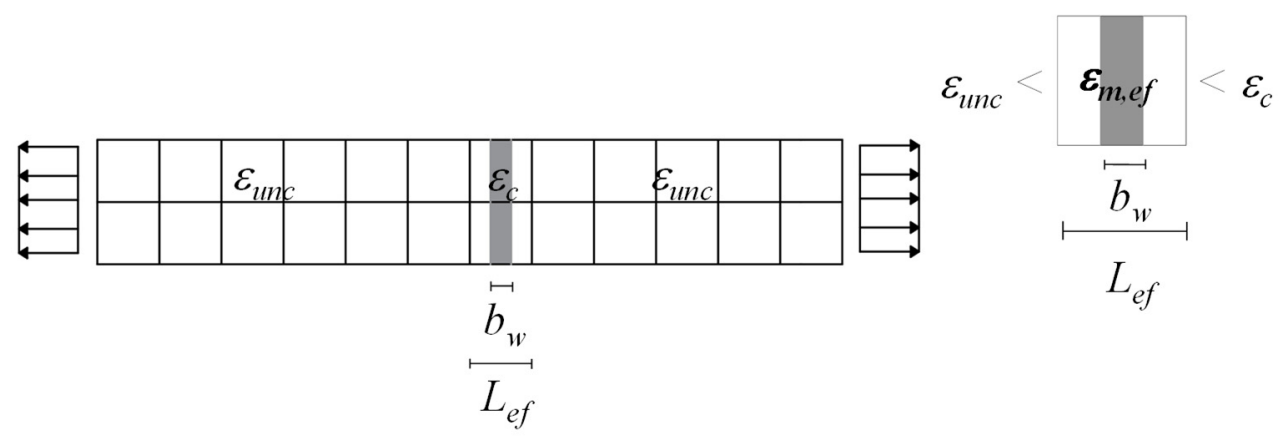

Figure 4.10 FEM when $b_{w}<L_{e f}$ 
PHASE 2

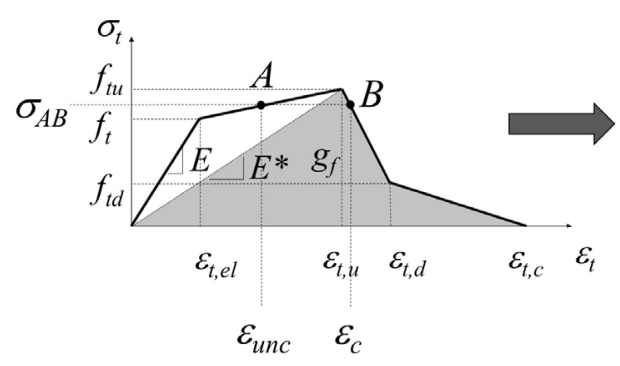

PHASE 3

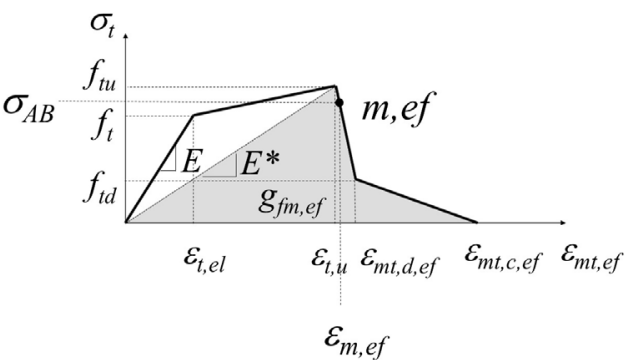

Figure 4.11 UHPFRC smeared crack model when $b_{w}<L_{e f}$

If the finite element length chosen $\left(L_{e f}\right)$ is lower than $L e f_{e x a c t}\left(L_{e f}<b_{w}\right)$, then $\varepsilon_{m, e f}>\varepsilon_{c}$ (see Expression (4.18)) and the smeared $\sigma-\varepsilon_{m, e f}$ curve for the finite element length chosen $\left(L_{e f}\right)$ involves more crack energy, $g_{f m, e f}>g_{f}$, as it can be observed in Figure 4.7. This situation is not considered as the mean total strain in the finite element $\left(\varepsilon_{m, e f}\right)$ cannot be higher than the mean total cracked strain $\left(\varepsilon_{c}\right)$. $\varepsilon_{m, e f}$ must be representative of the cracked and uncracked strain in the finite element length chosen $\left(L_{e f}\right)$ and therefore, $\varepsilon_{u n c}<\varepsilon_{m, e f} \leq$ $\varepsilon_{c}$. Thus, the case $L_{e f}<b_{w}$ is considered out of range and, as it is indicated previously in Expression (4.19), it is adequate that the length of the finite element $\left(L_{e f}\right)$ has been chosen equal or higher than the crack bandwidth $\left(b_{w}\right)$.

All the analysis done in this section for the adaptation of the smeared crack model to the finite element method in the uniaxial case is completely applicable for the multiaxial case treated in section 3.3 of chapter 3 . However, all the analysis is developed considering that the crack bandwidth $\left(b_{w}\right)$ of the material (in this case the UHPFRC) is known. Even though $b_{w}$ is assumed as a material parameter and, thus, a material constant, it is frequent that its value is unknown. This is the case for the crack bandwidth of the UHPFRC in this work. Therefore, the idea is to assume that the crack bandwidth $\left(b_{w}\right)$ equals the finite element length chosen $\left(L_{e f}\right)$ for the smeared cracking approach of the FEM and compare the results obtained to the results from the discrete cracking approach of the FEM and the experimental programme. In this sense, an inverse analysis is developed where the parameter to be adjusted is the $b_{w}$ varying at each iteration the length of the finite element $\left(L_{e f}\right)$ for the smeared cracking approach and comparing to the discrete cracking approach and the experimental programme. When the results adjust, then, the $L_{e f}$ used in the last iteration will be the crack bandwidth $\left(b_{w}\right)$ of UHPFRC.

\subsubsection{Inobjectivity of the strain-softening continuum material models}

An important property to consider from the mathematical point of view when the finite element method is applied for the continuum material models where the stress-crack opening law is transformed into a stress-strain law and the crack opening is divided by 
the process zone or crack bandwidth $\left(b_{w}\right)$, is related to the loss of ellipticity of the governing differential equation. From the numerical point of view, it derives in a situation where the boundary value problem becomes ill-posed leading to a pathological sensitivity of the results to the size of the finite elements. To avoid this problem and the numerical algorithm properly captures the most localised solution, the softening region produced by the strain localisation when the crack is developing should be extended over the length of a finite element $\left(L_{e f}\right)$. In this sense, a numerically resolved band of localised strain $h_{b}$ is defined. This parameter $h_{b}$ can be considered as a numerical crack band. This band $h_{b}$ refers to the fully localised band obtained in numerical simulations and it is related to the size, shape and orientation of finite elements (Bazant and Cedolin 1979; Bažant and Oh 1983; Cedolin and Bažant 1980; Jirásek 2017; Rots 1988). In this direction, it can be deduced that the numerical strain localisation is produced where physically it takes place, this is, more or less the length of the crack band $\left(b_{w}\right)$. Therefore, it can be stated that the optimum application of the finite element method in a smeared crack model where the strain localisation is modelled in a narrow band is produced when $h_{b} \approx L_{e f} \approx b_{w}$.

In this sense, the constitutive law from a continuum material model is considered mesh size dependent. This is because the continuum material model is defined by a stressstrain law from the transformation of the stress-crack opening law considering a crack band $\left(b_{w}\right)$ equal to the width of the numerical localisation band $\left(h_{b}\right)$, which is in simple cases equal to the width of the band of finite elements $\left(L_{e f}\right)$ where the cracking process localises. Figure 4.12 shows the dependency of the continuum models to the size of the finite element $\left(L_{e f}\right)$ that delimitates the process zone. For the case of the smeared cracking approach used in this work for UHPFRC, this affects to the phase 2 where the stressstrain/crack opening UHPFRC constitutive behaviour defined in phase 1 is transformed into a continuum stress-strain model dividing the crack opening $(w)$ of the softening branch by the crack bandwidth $\left(b_{w}\right)$ considered equal to the length of the finite element $\left(L_{e f}\right)$. As it can be observed in Figure 4.12, if the finite element size is increased $\left(L_{e f} \uparrow \uparrow \uparrow\right)$ or the number of finite elements is decreased, this is, if the material crack bandwidth is increased $\left(b_{w} \uparrow \uparrow \uparrow\right)$, the constitutive $\sigma-\varepsilon_{t}$ softening curve for the continuum model becomes stiffer, even leading to a possible snap back behaviour. Furthermore, if the element size is decreased $\left(L_{e f} \downarrow \downarrow \downarrow\right)$ ) or the number of finite elements is increased, this is, if the material crack bandwidth is decreased $\left(b_{w} \downarrow \downarrow \downarrow\right)$ ) the constitutive $\sigma-\varepsilon_{t}$ softening curve for the continuum model becomes softer. 


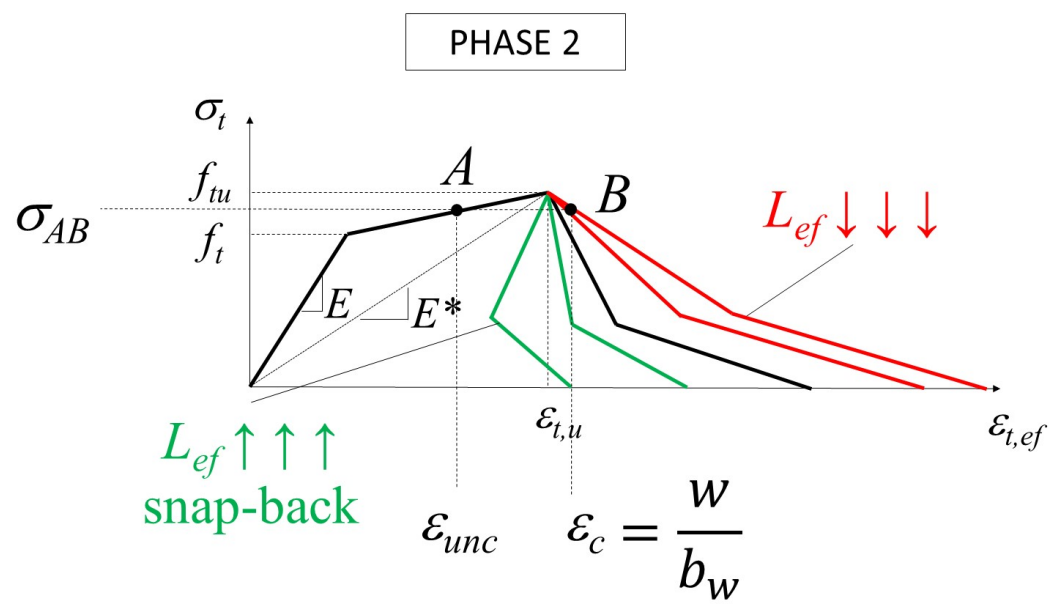

Figure 4.12 Constitutive continuum $\sigma-\varepsilon_{t}$ model for UHPFRC in phase 2 depending on the Lef chosen

Moreover, if the cracked tensile bar with a total length $L_{e}$ and a section $S_{e}$ depicted in Figure 4.6 is considered, it can be observed from Expression (4.17) how the load $(P)$ elongation $(u)$ relationship (where $P=\sigma_{A B} \cdot S_{e}$ ) suffers the opposite effect as the $\sigma-\varepsilon_{t}$ constitutive curve shown in Figure 4.12. Seeing Figure 4.13(a), if the element size is decreased $\left(L_{e f} \downarrow \downarrow \downarrow\right)$ ) or the number of finite elements is increased, this is, if the material crack bandwidth is decreased $\left(b_{w} \downarrow \downarrow \downarrow\right)$ ) the constitutive $P$ - $u$ curve from the continuum model for a bar length of $L_{e}$ becomes stiffer, even leading to a possible snap back behaviour. In addition, Figure 4.13(b) represents the strain profiles along the cracked tensile bar length $\left(L_{e}\right)$ for a stress level $\sigma_{A B}$, where part of the bar is unloaded with a strain $\varepsilon_{u n c}$ in point $A$ and the cracked part of the bar in the crack bandwidth $\left(b_{w}\right)$ is unloaded with a cracked strain $\varepsilon_{c}$ in point $B$ (see also Figure 4.6 and Figure 4.12). As it is considered, if the numerical localisation band $\left(h_{b}\right)$ is associated to the crack bandwidth $\left(b_{w}\right)$ and to the finite element length $\left(L_{e}\right)$, in Figure 4.13(b) it can be observed how if the element size is decreased $\left(L_{e f} \downarrow \downarrow \downarrow\right)$ ) or the number of finite elements is increased, the cracked strain $\left(\varepsilon_{c}\right)$ becomes higher and more concentrated in a narrow band. The opposite effect is done if the finite element size is increased $\left(L_{e f} \uparrow \uparrow \uparrow\right)$ or the number of finite elements is decreased. 
(a)

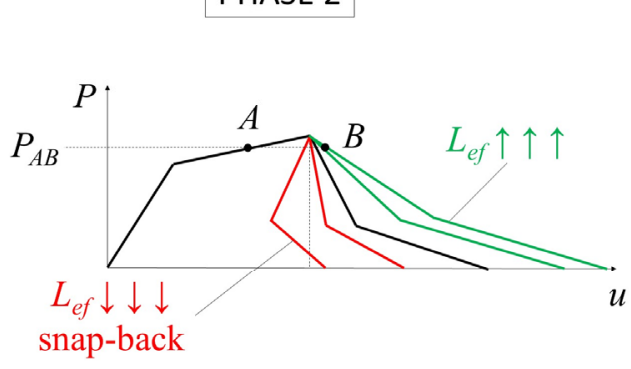

(b)

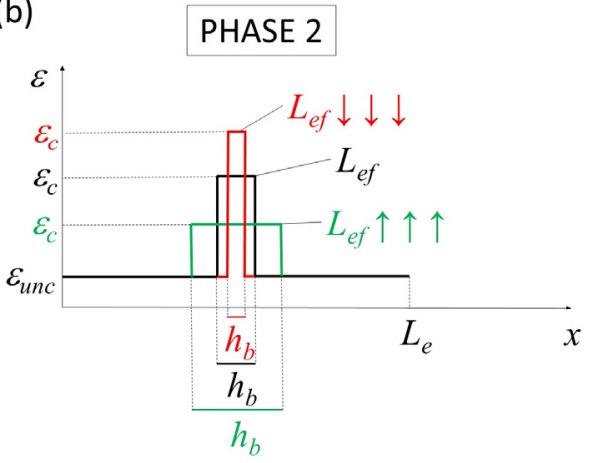

Figure 4.13 Tensile bar (a) $P$-u response and (b) $\varepsilon$-x response along the bar for the continuum model in phase 2 depending on the $L_{\text {ef }}$ chosen.

Therefore, as it can be deduced from this section and the previous section 4.3.1, the smeared cracking approach of the model used for UHPFRC is pathologically mesh size dependent at two levels. In phase 2, the continuum model is obtained by the $\sigma-w$ softening constitutive curve transformation to $\sigma-\varepsilon_{c}$ for the softening part of the UHPFRC constitutive curve, and this transformation involves the crack bandwidth $\left(b_{w}\right)$ consideration (see Figure 4.12). In addition, in phase 3 the cracked strain $\left(\varepsilon_{c}\right)$ from the continuum model in phase 2 is smeared in the finite element length $\left(L_{e f}\right)$ considering Expression (4.18) and, therefore, obtaining a smeared $\sigma-\varepsilon_{m, e f}$ UHPFRC constitutive behaviour (see Figure 4.9 and Figure 4.11). Both of them lead to the conclusion that the optimum application of the finite element method in a smeared crack model where the strain localisation is modelled in a narrow band is produced when $h_{b} \approx L_{e f} \approx b_{w}$. Finite element sizes $\left(L_{e f}\right)$ greater that the crack bandwidth $\left(b_{w} \approx h_{b}\right)$ can be used but it must be controlled as they can lead to snap-back $\sigma-\varepsilon$ behaviour associated to numerical stability problems and inaccuracy of the results obtained in the finite element analysis.

Consequently, when the smeared crack model is used for the finite element modelling, it is necessary to regularise the strain-softening part of the material law concerning to phase 2 (in the continuum model) and phase 3 (in the smeared model) to minimise the effect of the mesh size dependency. The idea of regularisation has been addressed by means of several techniques with their particularities and their more or less accuracy in plain concrete. Some of them are related to the scaling of the softening part of the stressstrain with different treatments of the crack bandwidth-element length ratio ( $\overline{\text { ) }}$ (Häussler-Combe 2015; Jirásek 2017; Rots and Blaauwendraad 1989a; b; Switek 2008). A different consideration to control the fracture propagation based on the fracture energy instead of a stress criteria was carried out by (Bazant and Cedolin 1979; Cedolin and Bažant 1980) to avoid the mesh dependency. Fracture mechanics approach was adopted in order to eliminate spurious dependence in the element size when the fracture is modelled as bands of parallel cracks smeared in the whole finite element. In the fracture 
mechanics approach, the crack propagation is associated to the fact that the work consumed as the crack or the crack band is extended by a unit length is considered a constant. In (Bazant and Cedolin 1979; Cedolin and Bažant 1980), the energy-release rate for the extension of the crack band was calculated from the strain energy change within the element into which the crack band spreads and the work of nodal forces that are released at the nodes of this element, for constant and linear strain triangles. Therefore, they stablished that it is necessary to consider the energy released over the crack bandwidth during the crack formation to obtain results independent of the mesh. This idea leads to the spreading of extended theories like the crack band theory for fracture of concrete developed in (Bazant and Cedolin 1984; Bažant and Oh 1983), or nonlocal methods able to solve the local crack-band behaviour additionally to regularisation (Bazant and Planas 1997; Jirasek 1998; Pijaudier-Cabot and Bažant 1987).

For the case of UHPFRC, the crack bandwidth and crack energy are not completely calibrated and, therefore, many regularisation techniques for plain concrete could be not directly applicable. Moreover, the use of commercial finite element software packages could difficult the adaptation of a regularisation technique in the case of new materials due to their limited availability of material models and their restricted capacity for new implementations. Therefore, the problem of mesh size dependency for continuum models is frequently addressed calibrating the size of the finite element using different sizes and comparing to the experimental results, as it can be observed in (Singh et al. 2017; Yin et al. 2019a) in the literature survey in section 2.5.3 Modelling UHPFRC in the literature in chapter 2. In this work, following the idea from (Rots 1988), the experimental results and the results from the discrete cracking approach (that is mesh size independent) are used to calibrate the appropriate mesh size of the smeared cracking approach and, therefore, the continuum model.

\subsubsection{Adaptation of the discrete cracking approach to the FEM}

If the crack path is clearly known beforehand or its position seems to be predictable, it could be reasonable to apply a continuum model with discontinuities (section 2.5.1.1 Basic types of models in chapter 2). As it is described in section 3.2.4.2 in chapter 3 in the discrete cracking approach for UHPFRC developed in this work, the continuous part of the model is described using a stress-strain constitutive behaviour by means of the smeared cracking approach while the discrete discontinuity is modelled taken into account an initiation and propagation criteria to activate a traction-separation law. To activate the traction separation law of the macrocrack, the stresses that defines the tensile strength and the ultimate tensile stress of the constitutive law of the UHPFRC for the crack considered are $98 \%$ of $f_{t}$ and $98 \%$ of $f_{t u}$. This is the reason why in the continuum models with discontinuities it is necessary to know, previously, the crack path. In this sense, as the crack is modelled discretely by means of a traction-separation relationship, the parameter that defines the crack when it appears and develops at different stress levels is the crack opening instead of a weighted mean total strain depending on the finite 
element length $\left(L_{e f}\right)$ considered in the discretisation. This leads to a mesh size independent model.

Figure 4.14 shows an example of the adaptation of the discrete cracking approach of the material UHPFRC constitutive model to the finite element modelling of the tensile bar. Figure 4.14(a) represents the tensile bar when the load $P_{1}$ generates a tensile state $\left(P_{1}=\right.$ $\sigma_{l} \cdot S_{e}$ ) in the elastic branch of the $\sigma-\varepsilon$ UHPFRC constitutive behaviour, as it is shown in Figure 4.15. The crack is modelled by means of interface elements that are constituted by discrete nodes and governed by a stress (or traction)-separation law from the beginning. This is, the discontinuity is set from the beginning and it is activated when the stress reaches the tensile stress $\left(f_{t}\right)$ at the nodes where the interface is located. As it can be observed in Figure 4.15 the stress is under the tensile stress $\left(f_{t}\right)$ and, consequently no crack opening or displacement $(w)$ is generated. Therefore, all the continuum defined by the smeared crack approach is under an uncracked strain $\left(\varepsilon_{\text {uncl }}\right)$ and the interfaces remain close.

(a)

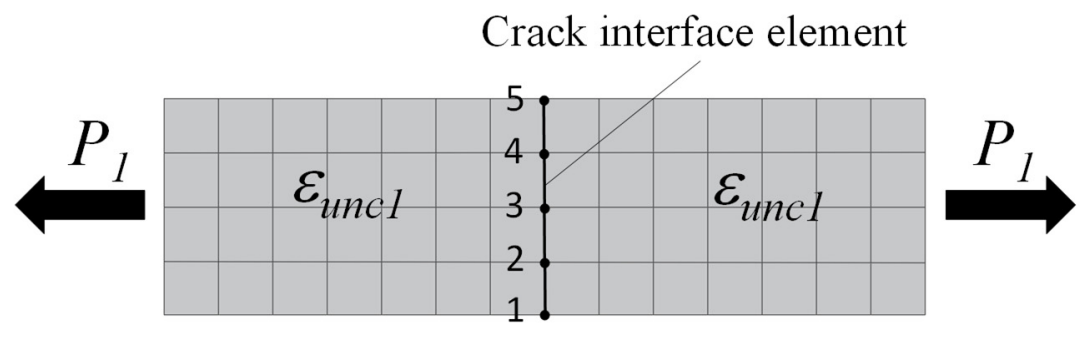

(b)

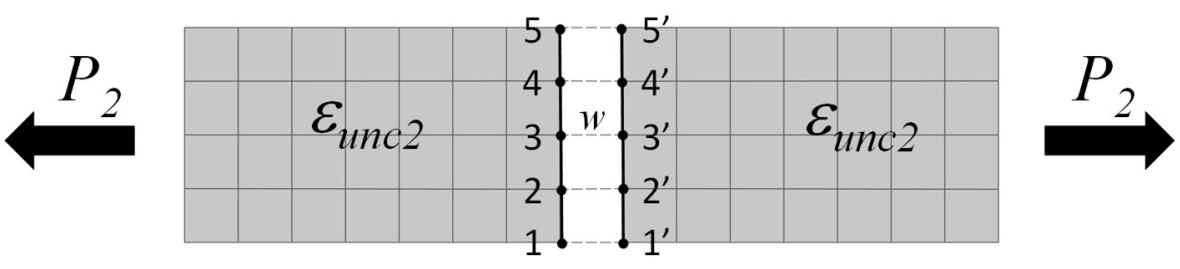

Figure 4.14 Discrete cracking approach in tensile bar (a) loading stage 1 and (b) loading stage 2.

Figure 4.14(b) represents a loading stage where the load $P_{2}$ generates a tensile state $\left(P_{2}\right.$ $=\sigma_{2} \cdot S_{e}$ ) in the softening branch of the $\sigma-w$ UHPFRC constitutive behaviour as it is shown in Figure 4.16. This is, the section in the mid-span has reached $0.98 f_{t}$ and the crack opening has initiated in the nodes that constitute the interface elements in the discrete crack. As the crack opening is progressing in the discrete elements, each node of the interface is split into two and represent the separation $(w)$ between them (see Figure 4.14(b)). The ultimate tensile stress $\left(f_{t u}\right)$ is reached and the descending branch of the 
softening $\sigma-w$ curve is followed. From the $f_{t u}$ onwards, the stress in the interface is decreasing and the crack opening is increasing $\left(w_{2}\right)$ as the process in the discrete crack is following the softening $\sigma-w$ branch (see Figure 4.16). At the same time, the rest of the tensile bar that constitutes the continuum represented by the smeared cracking approach is following the elastic unloading generating an uncracked strain $\left(\varepsilon_{\text {unc } 2}\right)$, as it can be observed in Figure 4.16.
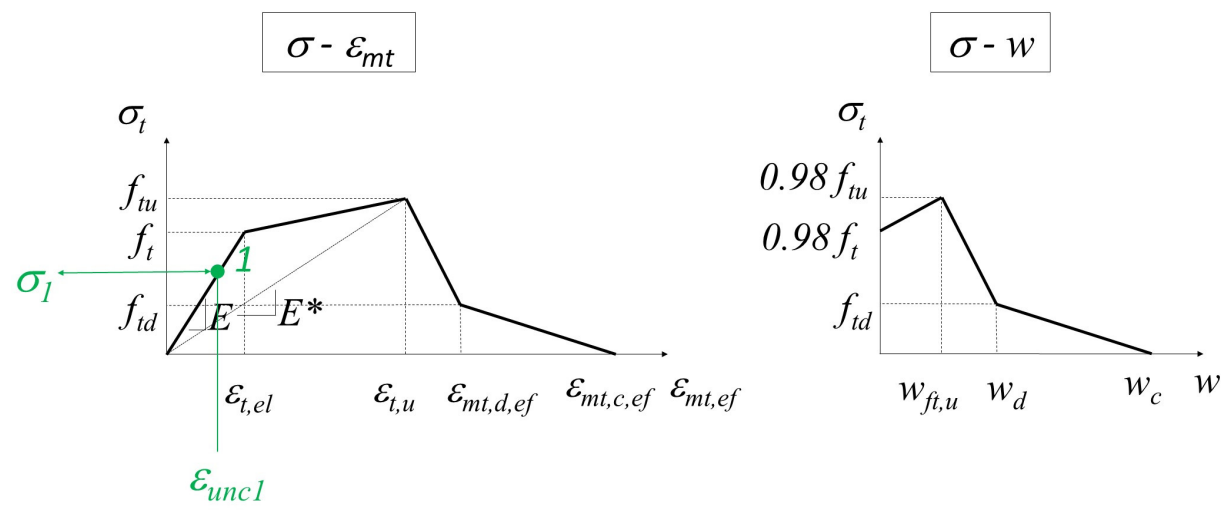

Figure $4.15 \sigma-\varepsilon_{m t}$ curve for the smeared cracking approach in the continuum and $\sigma-w$ curve for the crack interface in loading stage 1.

As it can be observed in Figure 4.16, the cracking process follows the $\sigma-w$ law that describes the discrete crack interface element behaviour. Moreover, no softening mean strain is smeared in any crack bandwidth as the crack is directly described by its opening $(w)$. The softening branch of the smeared cracking approach that describes the continuum is not activated as the crack follows the path set by the interface. Therefore, the discrete cracking approach is mesh-size independent and it is able to represent the localised damage where it appears as it is described by a proper stress (or traction)-separation law. In this sense, the material behaviour simulated by the FEM with the discrete cracking approach in the overall tensile bar is very close to the so-called phase 1 defined in section 4.3.1 that describes the exact stress-strain/crack opening material UHPFRC constitutive behaviour set in Figure 3.2 in section 3.2.2 of chapter 3. 


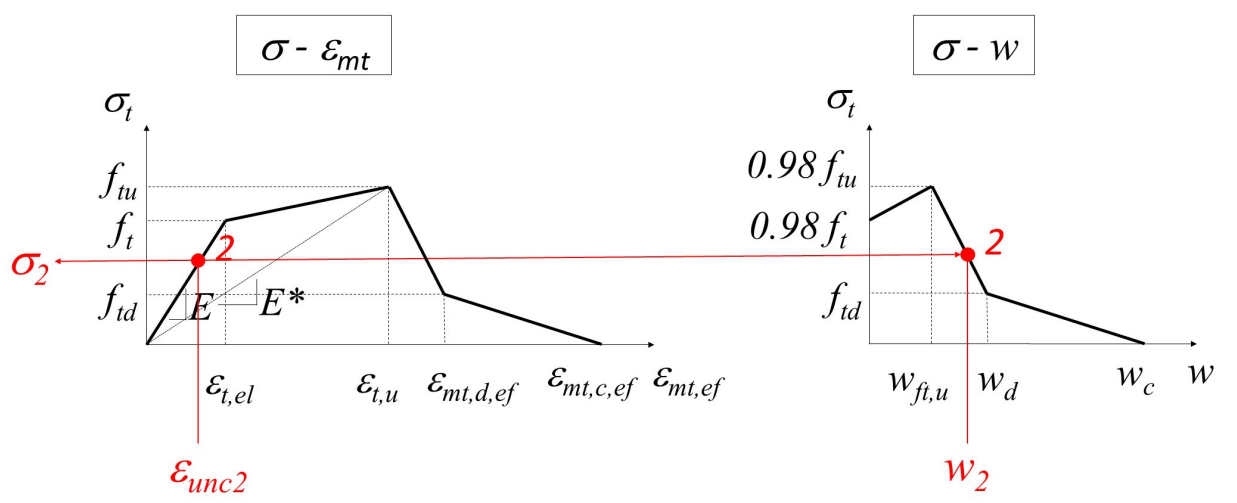

Figure $4.16 \sigma-\varepsilon_{m t}$ curve for the smeared cracking approach in the continuum and $\sigma-w$ curve for the crack interface in loading stage 2.

Consequently, it is expected that when the location of the crack is known and it is set by interface elements following the discrete cracking approach, the result of the analysis is going to be very accurate when it is compared to the experimental results, as the crack is accurately represented by its proper traction-separation law. Moreover, the microcracking stage that characterises the UHPFRC behaviour before reaching the ultimate tensile stress $\left(f_{t u}\right)$ and, therefore, the macrocrack apparition, is expected to be modelled with reliability with the smeared cracking approach in the continuum part of the specimen. The elastic and microcracracking stages are related to the volumetric energy that involves all the specimen and, thus, represented by the smeared cracking approach in the continuum and, when the macrocrack appears following the interface path, all the energy is released in the macrocrack apparition (surfacic energy) that involves the crack surface. Therefore, all the cracking process of the specimen during the experimental test is expected to be accurately modelled by means of the discrete cracking approach.

\subsection{Numerical implementation}

In this work, the software DIANA FEA (DIANA (Software) 2017) has been used to develop the numerical finite element model (FEM) for the non-linear analysis of UHPFRC elements. UHPFRC is not previously established by default in the software so it is necessary to adapt the material model and particular characteristics of UHPFRC defined in the previous sections to the capabilities of the software. In this sense, the model implemented needs to be able to represent all the particular characteristics of UHPFRC. Therefore, to build a FEM it becomes necessary to define the constitutive model of the material, but it is also important to implement it adequately in the software platform chosen. 
In this section it is studied how are the material models set in the software and the way of implementing the UHPFRC constitutive behaviour and the hypotheses considered in previous sections to build the FEM.

\subsubsection{Smeared cracking implementation}

The multiaxial formulation of the smeared cracking approach is expressed by means of the total strain concept. The constitutive model based on total strain is developed following the idea of the Modified Compression Field Theory (MCFT), defined by Vecchio \& Collins (Vecchio and Collins 1986). The definition of the multiaxial smeared cracking approach is based on the extension to the three dimensions of the MCFT formulation proposed by (Selby and Vecchio 1993). The total strain based crack models follow a smeared approach for the fracture energy. The smeared crack models consider cracking as a distributed effect in which directionality and cracked material is simulated as a continuous medium with anisotropic characteristics.

While in the Rotating crack model the stress-strain relations are evaluated in the principal directions of the strain vector, in the fixed stress-strain concept, that is used here, the stress-strain relations are evaluated in a fixed coordinate system which is fixed after cracking.

In the Total Strain Crack models the stress is evaluated in the directions given by the crack directions. The strain vector $\varepsilon_{x y z}$ in the element coordinate system $x y z$ is updated with the strain increment $\Delta \varepsilon_{x y z}$ by Expression (4.20).

$$
{ }_{i+1}^{t+\Delta t} \varepsilon_{x y z}={ }^{t} \varepsilon_{x y z}+{ }_{i+1}^{t+\Delta t} \Delta \varepsilon_{x y z}
$$

that is converted to the strain vector in the crack directions using the strain transformation matrix $\boldsymbol{T}$ in Expression (4.21),

$$
{ }_{i+1}^{t+\Delta t} \varepsilon_{n s t}=\mathbf{T} \quad{ }_{i+1}^{t+\Delta t} \varepsilon_{x y z}
$$

In the rotating concept the strain transformation matrix $\boldsymbol{T}$ depends on the current strain vector, as it is shown in Expression (4.22),

$$
\mathbf{T}=\mathbf{T}\left({ }_{i+1}^{t+\Delta t} \varepsilon_{x y z}\right)
$$


whereas in a fixed concept the $\boldsymbol{T}$ matrix is fixed upon cracking. The behaviour in compression is evaluated in a rotating coordinate system when the material is not cracked, where in case of a fixed concept the compressive behaviour is evaluated in the fixed coordinate system determined by the crack directions.

The $\boldsymbol{T}$ matrix is determined calculating the eigenvectors of the strain tensor using, for example, the Jacobi method. The strain tensor is expressed as Expression (4.23):

$$
E=\left[\begin{array}{lll}
\varepsilon_{x x} & \varepsilon_{x y} & \varepsilon_{x z} \\
\varepsilon_{y x} & \varepsilon_{y y} & \varepsilon_{y z} \\
\varepsilon_{z x} & \varepsilon_{z y} & \varepsilon_{z z}
\end{array}\right]
$$

The eigenvectors are set in the rotation matrix $\boldsymbol{R}$ as shown in Expression (4.24):

$$
\mathbf{R}=\left[\begin{array}{lll}
\mathbf{n} & \mathbf{s} & \mathbf{t}
\end{array}\right]=\left[\begin{array}{lll}
c_{x n} & c_{x s} & c_{x t} \\
c_{y n} & c_{y s} & c_{y t} \\
c_{z n} & c_{z s} & c_{z t}
\end{array}\right]
$$

with $c_{x n}=\cos \phi_{i j}$ the cosine between the $i$ axis and the $j$ axis. Then, the strain transformation matrix $\boldsymbol{T}$ is obtained by substituting the corresponding values,

$$
\mathbf{T}=\left[\begin{array}{cccccc}
c_{x n}^{2} & c_{y n}^{2} & c_{z n}^{2} & c_{x n} c_{y n} & c_{y n} c_{z n} & c_{z n} c_{x n} \\
c_{x s}^{2} & c_{y s}^{2} & c_{z s}^{2} & c_{x s} c_{y s} & c_{y s} c_{z s} & c_{z s} c_{x s} \\
c_{x t}^{2} & c_{y t}^{2} & c_{z t}^{2} & c_{x t} c_{y t} & c_{y t} c_{z t} & c_{z t} c_{x t} \\
2 c_{x n} c_{x s} & 2 c_{y n} c_{y s} & 2 c_{z n} c_{z s} & c_{x n} c_{y s}+c_{y n} c_{x s} & c_{y n} c_{z s}+c_{z n} c_{y s} & c_{z n} c_{x s}+c_{x n} c_{z s} \\
2 c_{x s} c_{x t} & 2 c_{y s} c_{y t} & 2 c_{z s} c_{z t} & c_{x s} c_{y t}+c_{y s} c_{x t} & c_{y s} c_{z t}+c_{z s} c_{y t} & c_{z s} c_{x t}+c_{x s} c_{z t} \\
2 c_{x t} c_{x n} & 2 c_{y t} c_{y n} & 2 c_{z t} c_{z n} & c_{x t} c_{y n}+c_{y t} c_{x n} & c_{y t} c_{z n}+c_{z t} c_{y n} & c_{z t} c_{x n}+c_{x t} c_{z n}
\end{array}\right]
$$

in a general three-dimensional stress situation. For the other stress situations, the appropriate sub-matrix should be taken. Then, the constitutive model is formulated in the crack coordinate system expressed as: 


$$
{ }_{i+1}^{t+\Delta t} \sigma_{n s t}=\sigma\left(\begin{array}{l}
t+\Delta t \\
{ }_{i+1}
\end{array} \varepsilon_{n s t}\right)
$$

The updated stress vector in the element coordinate system is finally given by:

$$
{ }_{i+1}^{t+\Delta t} \sigma_{x y z}=\mathbf{T}^{\mathrm{T}} \quad{ }_{i+1}^{t+\Delta t} \sigma_{n s t}
$$

The strain transformation matrix $\boldsymbol{T}$ is given by the current strain transformation matrix $\left.\boldsymbol{T}^{T}{ }^{t+\Delta t}{ }_{i+1} \varepsilon_{x y z}\right)$ in the rotating approach. In the fixed approach, which used in this work, the strain transformation matrix $\boldsymbol{T}$ is given by the transformation matrix at the beginning of cracking.

\subsubsection{Loading and Unloading Determination}

The behaviour in loading and unloading is modelled differently with secant unloading. During loading process, concrete is subjected to both tensile and compressive stress which can lead to cracking and crushing of the material. In a fixed stress-strain approach the shear behaviour is modelled explicitly considering a relation between the shear stress and the shear strain. The deterioration of the material due to cracking and crushing is monitored with six internal damage variables $\alpha_{k}$, set in the vector $\boldsymbol{\alpha}$. Internal variables $k$ $=1, \ldots, n s t r$ monitoring the maximum strain, hence greater or equal zero, and variables $k$ $=n s t r+1, \ldots, 2 \times n s t r$ monitoring minimum strain and hence smaller or equal zero (see Figure 4.17). It is considered that damage recovery is not possible which implies that the absolute values of the internal damage variables are increasing. 


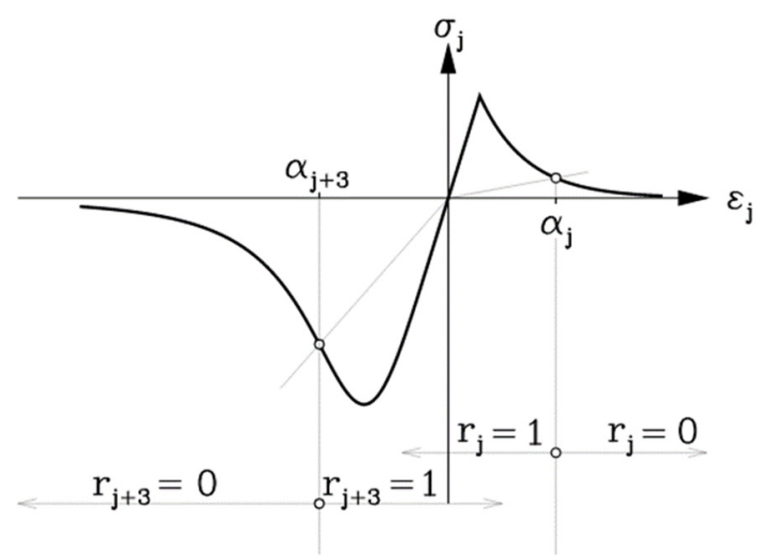

Figure 4.17 Loading-unloading-reloading conditions, damage variables and unloading constrains.

The loading-unloading-reloading condition is registered with the additional unloading constraints $r_{k}$ (see Figure 4.17) which are determined for both tension and compression to model the stiffness degradation in tension and compression in a separate way. In tension, the unloading constraints are obtained using Expression (4.28):

$$
r_{k}=\left\{\begin{array}{lll}
0 & \text { if } \quad{ }_{i+1}^{t+\Delta t} \varepsilon_{k}>\alpha_{k} \\
1 & \text { if } \quad{ }_{i+1}^{t+\Delta t} \varepsilon_{k} \leq \alpha_{k}
\end{array} \quad k=1, \ldots,\right. \text { nstr }
$$

and in compression using Expression (4.29):

$$
r_{k}=\left\{\begin{array}{lll}
0 & \text { if } & { }_{i+1}^{t+\Delta t} \varepsilon_{k-3}<\alpha_{k} \\
1 & \text { if } & { }_{i+1}^{t+\Delta t} \varepsilon_{k-3} \geq \alpha_{k}
\end{array} \quad k=\mathrm{nstr}+1, \ldots, 2 \times \mathrm{nstr}\right.
$$

The update of the internal variables are expressed by Expression (4.30):

$$
{ }_{i+1}^{t+\Delta t} \alpha={ }^{t} \alpha+\mathbf{W} \Delta \varepsilon
$$


where the matrix $\boldsymbol{W}$ is defined as Expression (4.31):

$$
\mathbf{W}=\left\{\begin{array}{lll}
W_{k, k} & =1-r_{k} & k=1, \ldots, \text { nstr } \\
W_{k, k-\text { nstr }} & =1-r_{k} & k=\text { nstr }+1, \ldots, 2 \times \text { nstr }
\end{array}\right.
$$

Taking into account the assumption of no damage recovery, the stress in direction $j$ is expressed as shown in Expression (4.32):

$$
\sigma_{j}=f_{j}\left(\alpha, \varepsilon_{n s t}\right) \cdot g_{j}\left(\alpha, \varepsilon_{n s t}\right)
$$

The uniaxial stress-strain relation, $f_{j}$, depends not only on the internal variable $\alpha_{j}$, but also on the internal variables and strain both in the other directions, therefore $f_{j}(\alpha, \varepsilon)$. If unloading and reloading is modelled considering a secant approach, defined by the maximum and minimum strain in each crack direction, the loading-unloading function, considered as $g$ with $0 \leq g \leq 1$, is expressed as Expression (4.33):

$$
g_{j}= \begin{cases}1-\frac{\alpha_{j}-\varepsilon_{j}}{\alpha_{j}} & \text { if } \varepsilon_{j}>0 \\ 1-\frac{\alpha_{j+\mathrm{nstr}}-\varepsilon_{j}}{\alpha_{j+\mathrm{nstr}}} & \text { if } \varepsilon_{j}<0\end{cases}
$$

The uniaxial stress-strain relation set in Expression (4.32) is based on the basic strength in the crack directions $f$, multiplied by the loading-unloading function $g$. Therefore, in the material model, the effect of confinement and the effect of lateral cracking are considered in the basic strength because the maximum strength and, in general, the shape of the stress-strain curve are influenced.

\subsubsection{Stiffness Matrix}

Considering an incremental-iterative solution scheme, which is the analytical procedure carried out in this work, equilibrium between the internal force vector and the external load vector is reached using, for example, a Newton-Raphson iterative process. To get this objective, the constitutive model should also define the stiffness matrix that is used to get the equilibrium.

Two approaches to the stiffness matrix can be used: a secant stiffness matrix and a tangent stiffness matrix. The first approach is considered robust and stable in case of 
reinforced concrete structures with extensive cracking. The second shows better results in case of analysis where localised cracking and crack propagation are the most important effects.

\section{Tangent Stiffness Matrix:}

The tangent stiffness matrix in the element coordinate system $x y z$ is set as Expression (4.34):

$$
\mathbf{D}=\mathbf{T}^{\mathrm{T}} \mathbf{D}_{\text {tangent }} \mathbf{T}
$$

where $\boldsymbol{T}$ is the strain transformation matrix, and $\boldsymbol{D}_{\text {tangent }}$ is the tangent stiffness matrix in the crack coordinate system nst. The tangent stiffness matrix is composed by four submatrices as set in Expression (4.35):

$$
\mathbf{D}_{\text {tangent }}=\left[\begin{array}{ll}
\mathbf{D}_{n n} & \mathbf{D}_{n \theta} \\
\mathbf{D}_{\theta n} & \mathbf{D}_{\theta \theta}
\end{array}\right]
$$

where $\boldsymbol{D}_{\boldsymbol{n} \boldsymbol{n}}$ is the tangent stiffness sub-matrix of the normal components of the local (crack) strain, $\boldsymbol{D}_{\boldsymbol{\theta} \theta}$ is the tangent stiffness sub-matrix of the shear components of the local strain, and $\boldsymbol{D}_{\boldsymbol{n} \theta}$ and $\boldsymbol{D}_{\boldsymbol{\theta} \boldsymbol{n}}$ are the tangent stiffness sub-matrices representing the coupling terms between the normal and the shear strain.

In the rotating approach the coupling sub-matrices are equal to zero and the sub-matrix $\boldsymbol{D}_{\boldsymbol{\theta} \theta}$ is dependent on the principal stress components. The sub-matrix $\boldsymbol{D}_{\boldsymbol{\theta} \theta}$ is defined as Expression (4.36):

$$
\mathbf{D}_{\theta \theta}=\left[\begin{array}{ccc}
\frac{\sigma_{1}-\sigma_{2}}{2\left(\varepsilon_{1}-\varepsilon_{2}\right)} & 0 & 0 \\
0 & \frac{\sigma_{2}-\sigma_{3}}{2\left(\varepsilon_{2}-\varepsilon_{3}\right)} & 0 \\
0 & 0 & \frac{\sigma_{3}-\sigma_{1}}{2\left(\varepsilon_{3}-\varepsilon_{1}\right)}
\end{array}\right]
$$

The shear stiffness terms are dependent on the stresses in the principal directions. This is a direct result of the spin of the principal coordinate system.

In the fixed approach the coupling sub-matrices are not necessarily zero but depend on the specific relation between the shear retention and the normal strain components. Generally, the sub-matrix $\boldsymbol{D}_{\boldsymbol{n} \theta}$ is equal to zero because the normal stress components are 
independent on the shear components of the strain vector. Moreover, the sub-matrix $\boldsymbol{D}_{\boldsymbol{\theta} \boldsymbol{n}}$ is defined as Expression (4.37):

$$
\mathbf{D}_{\theta n}=\left[\begin{array}{lll}
\frac{\partial \sigma_{n s}}{\partial \varepsilon_{n n}} & \frac{\partial \sigma_{n s}}{\partial \varepsilon_{s s}} & \frac{\partial \sigma_{n s}}{\partial \varepsilon_{t t}} \\
\frac{\partial \sigma_{s t}}{\partial \varepsilon_{n n}} & \frac{\partial \sigma_{s t}}{\partial \varepsilon_{s s}} & \frac{\partial \sigma_{s t}}{\partial \varepsilon_{t t}} \\
\frac{\partial \sigma_{t n}}{\partial \varepsilon_{n n}} & \frac{\partial \sigma_{t n}}{\partial \varepsilon_{s s}} & \frac{\partial \sigma_{t n}}{\partial \varepsilon_{t t}}
\end{array}\right]
$$

which is equal to zero when the shear retention is independent upon the normal (crack) strain. The shear components of the tangent stiffness matrix are set by Expression (4.38):

$$
\mathbf{D}_{\theta \theta}=\left[\begin{array}{ccc}
\frac{\partial \sigma_{n s}}{\partial \gamma_{n s}} & 0 & 0 \\
0 & \frac{\partial \sigma_{s t}}{\partial \gamma_{s t}} & 0 \\
0 & 0 & \frac{\partial \sigma_{t n}}{\partial \gamma_{t n}}
\end{array}\right]
$$

The normal stiffness terms, $\boldsymbol{D}_{\boldsymbol{n} \boldsymbol{n}}$, are partial derivatives. As coupling due to lateral strain effects is included in the calculation of the principal stresses, the off-diagonal terms are different to zero, and the resulting matrix is non-symmetric (Expression (4.39)).

$$
\mathbf{D}_{n n}=\left[\begin{array}{lll}
\frac{\partial \sigma_{n n}}{\partial \varepsilon_{n n}} & \frac{\partial \sigma_{n n}}{\partial \varepsilon_{s s}} & \frac{\partial \sigma_{n n}}{\partial \varepsilon_{t t}} \\
\frac{\partial \sigma_{s s}}{\partial \varepsilon_{n n}} & \frac{\partial \sigma_{s s}}{\partial \varepsilon_{s s}} & \frac{\partial \sigma_{s s}}{\partial \varepsilon_{t t}} \\
\frac{\partial \sigma_{t t}}{\partial \varepsilon_{n n}} & \frac{\partial \sigma_{t t}}{\partial \varepsilon_{s s}} & \frac{\partial \sigma_{t t}}{\partial \varepsilon_{t t}}
\end{array}\right]
$$

The first step for the derivation of the stiffness terms $\boldsymbol{D}_{\boldsymbol{n} \mathbf{}}$ is the stress-strain relation defined in Expression (4.32),

$$
\sigma_{i}=f_{i}\left(\alpha, \varepsilon_{n s t}\right) \cdot g_{i}\left(\alpha, \varepsilon_{n s t}\right)
$$


The derivative with respect to the principal strain vector, $\varepsilon_{n s t}$, is defined by Expression (4.40):

$$
\begin{aligned}
\frac{\partial \sigma_{i}}{\partial \varepsilon_{n s t}}=g_{i}\left(\alpha, \varepsilon_{n s t}\right) & \left\{\frac{\partial \alpha^{\mathrm{T}}}{\partial \varepsilon_{n s t}} \frac{\partial f_{i}}{\partial \alpha}+\frac{\partial f_{i}}{\partial \varepsilon_{n s t}}\right\}+ \\
& f_{i}\left(\alpha, \varepsilon_{n s t}\right)\left\{\frac{\partial \alpha^{\mathrm{T}}}{\partial \varepsilon_{n s t}} \frac{\partial g_{i}}{\partial \alpha}+\frac{\partial g_{i}}{\partial \varepsilon_{n s t}}\right\}
\end{aligned}
$$

with the derivative of the internal variables with respect to the strain vector $\partial \alpha / \partial \varepsilon_{n s t}$, defined in the matrix $\boldsymbol{W}$ in Expression (4.31), resulting in Expression (4.41).

$$
\begin{aligned}
\frac{\partial \sigma_{i}}{\partial \varepsilon_{n s t}}=g_{i}\left(\alpha, \varepsilon_{n s t}\right) \quad & \left.\mathbf{W}^{\mathrm{T}} \frac{\partial f_{i}}{\partial \alpha}+\frac{\partial f_{i}}{\partial \varepsilon_{n s t}}\right\}+ \\
& f_{i}\left(\alpha, \varepsilon_{n s t}\right)\left\{\mathbf{W}^{\mathrm{T}} \frac{\partial g_{i}}{\partial \alpha}+\frac{\partial g_{i}}{\partial \varepsilon_{n s t}}\right\}
\end{aligned}
$$

that is developed as Expression (4.42).

$$
\begin{aligned}
& \mathbf{D}_{n s t}=\left[\begin{array}{ccc}
\left(m_{1} r_{1}+\left(1-m_{1}\right) r_{4}\right) \bar{E}_{1} & 0 & 0 \\
0 & \left(m_{2} r_{2}+\left(1-m_{2}\right) r_{5}\right) \bar{E}_{2} & 0 \\
0 & 0 & \left(m_{3} r_{3}+\left(1-m_{3}\right) r_{6}\right) \bar{E}_{3}
\end{array}\right]+ \\
& {\left[\begin{array}{ccc}
g_{1} & 0 & 0 \\
0 & g_{2} & 0 \\
0 & 0 & g_{3}
\end{array}\right]\left[\begin{array}{lll}
\frac{\partial f_{1}}{\partial \varepsilon_{1}} & \frac{\partial f_{1}}{\partial \varepsilon_{2}} & \frac{\partial f_{1}}{\partial \varepsilon_{3}} \\
\frac{\partial f_{2}}{\partial \varepsilon_{1}} & \frac{\partial f_{2}}{\partial \varepsilon_{2}} & \frac{\partial f_{2}}{\partial \varepsilon_{3}} \\
\frac{\partial f_{3}}{\partial \varepsilon_{1}} & \frac{\partial f_{3}}{\partial \varepsilon_{2}} & \frac{\partial f_{3}}{\partial \varepsilon_{3}}
\end{array}\right]+} \\
& {\left[\begin{array}{ccc}
g_{1} & 0 & 0 \\
0 & g_{2} & 0 \\
0 & 0 & g_{3}
\end{array}\right]\left[\begin{array}{llll}
\frac{\partial f_{1}}{\partial \alpha_{1}} & \frac{\partial f_{1}}{\partial \alpha_{2}} & \cdots & \frac{\partial f_{1}}{\partial \alpha_{6}} \\
\frac{\partial f_{2}}{\partial \alpha_{1}} & \frac{\partial f_{2}}{\partial \alpha_{2}} & \cdots & \frac{\partial f_{2}}{\partial \alpha_{6}} \\
\frac{\partial f_{3}}{\partial \alpha_{1}} & \frac{\partial f_{3}}{\partial \alpha_{2}} & \cdots & \frac{\partial f_{3}}{\partial \alpha_{6}}
\end{array}\right]\left[\begin{array}{ccc}
1-r_{1} & 0 & 0 \\
0 & 1-r_{2} & 0 \\
0 & 0 & 1-r_{3} \\
1-r_{4} & 0 & 0 \\
0 & 1-r_{5} & 0 \\
0 & 0 & 1-r_{6}
\end{array}\right]}
\end{aligned}
$$

In Expression (4.41) an additional status indicator $m_{i}$ is introduced which is obtained by the state of strain set in Expression (4.43). 


$$
m_{i}= \begin{cases}1 & \text { if } \varepsilon_{i}>0 \\ 0 & \text { if } \varepsilon_{i} \leq 0\end{cases}
$$

The secant stiffness terms set in Expression (4.44):

$$
\bar{E}_{j}=\frac{f_{j}\left(\alpha, \varepsilon_{n s t}\right)}{\alpha_{j}}
$$

and Expression (4.45):

$$
\bar{E}_{j}=\frac{f_{j}\left(\alpha, \varepsilon_{n s t}\right)}{\alpha_{j+\mathrm{nstr}}}
$$

respectively in the tensile and compressive regime. The tangent stiffness terms are obtained with a forward-difference approach in which the $j$-th component is disturbed with a small quantity $h$ in accordance to Expression (4.46):

$$
\frac{\partial f_{i}}{\partial \varepsilon_{j}}=\frac{f_{i}\left(\alpha, \varepsilon_{n s t}+h \mathbf{e}_{j}\right)-f_{i}\left(\alpha, \varepsilon_{n s t}\right)}{h}
$$

and Expression (4.47):

$$
\frac{\partial f_{i}}{\partial \alpha_{j}}=\frac{f_{i}\left(\alpha+h \mathbf{a}_{j}, \varepsilon_{n s t}\right)-f_{i}\left(\alpha, \varepsilon_{n s t}\right)}{h}
$$

with the components of the vector $\boldsymbol{e}_{j}$ equal to zero except for the $j$-th component. This holds also for the vector $\boldsymbol{a}_{j}$. The step length $h$ for the forward-difference approximation is taken equal to tol $\varepsilon_{j}$, respectively tol $\cdot \alpha_{j}$, with tol the square-root of the machine precision which is assumed equal to $1 \times 10^{-16}$.

The diagonal stiffness terms of the stiffness matrix $\boldsymbol{D}_{\text {nst }}$ defined in Expression (4.41) are developed by writing the stiffness terms as Expression (4.48). 


$$
\begin{aligned}
\frac{\partial \sigma_{i}}{\partial \varepsilon_{i}}= & \left(m_{i} r_{i}+\left(1-m_{i}\right) r_{i+\mathrm{nstr}}\right) \bar{E}_{i}+ \\
& g_{i}\left(\left(1-r_{i}\right) \frac{\partial f_{i}}{\partial \alpha_{i}}+\left(1-r_{i+\mathrm{nstr}}\right) \frac{\partial f_{i}}{\partial \alpha_{i+\mathrm{nstr}}}\right)
\end{aligned}
$$

If a tensile strain state is active, i.e., $m_{i}=1$ and $r_{i+n s t r}=1$, the stiffness term further reduces to Expression (4.49):

$$
\frac{\partial \sigma_{i}}{\partial \varepsilon_{i}}=r_{i} \bar{E}_{i}+g_{i}\left(1-r_{i}\right) \frac{\partial f_{i}}{\partial \alpha_{i}}
$$

which results in a more convenient format as set in Expression (4.50):

$$
\frac{\partial \sigma_{i}}{\partial \varepsilon_{i}}= \begin{cases}\bar{E}_{i} & \text { if unloading, i.e., } r_{i}=1, g_{i} \leq 1 \\ \frac{\partial f_{i}}{\partial \alpha_{i}} & \text { if loading, i.e., } r_{i}=0, g_{i}=1\end{cases}
$$

In a compressive strain state, i.e., $m_{i}=0$ and $r_{i}=1$, the stiffness term reduces to Expression (4.51):

$$
\frac{\partial \sigma_{i}}{\partial \varepsilon_{i}}=r_{i+\mathrm{nstr}} \bar{E}_{i}+g_{i}\left(1-r_{i+\mathrm{nstr}}\right) \frac{\partial f_{i}}{\partial \alpha_{i+\mathrm{nstr}}}
$$

which results in Expression (4.52):

$$
\frac{\partial \sigma_{i}}{\partial \varepsilon_{i}}= \begin{cases}\bar{E}_{i} & \text { if unloading, i.e., } r_{i+\text { nstr }}=1, g_{i} \leq 1 \\ \frac{\partial f_{i}}{\partial \alpha_{i+\text { nstr }}} & \text { if loading, i.e., } r_{i+\text { nstr }}=0, g_{i}=1\end{cases}
$$

\section{Secant Stiffness Matrix:}

The secant approach is defined according to the stiffness of an orthotropic material with zero Poisson's ratio in all directions. This results in the secant stiffness matrix in the principal coordinate system as set in Expression (4.53). 


$$
\mathbf{D}_{\text {secant }}=\left[\begin{array}{cccccc}
\bar{E}_{1} & 0 & 0 & 0 & 0 & 0 \\
0 & \bar{E}_{2} & 0 & 0 & 0 & 0 \\
0 & 0 & \bar{E}_{3} & 0 & 0 & 0 \\
0 & 0 & 0 & \bar{G}_{12} & 0 & 0 \\
0 & 0 & 0 & 0 & \bar{G}_{23} & 0 \\
0 & 0 & 0 & 0 & 0 & \bar{G}_{31}
\end{array}\right]
$$

\subsubsection{Lateral Expansion Effects due to Poisson's Ratio}

As it is known, the Poisson effect of a material determines the lateral displacement of a specimen subjected to a uniaxial tensile or compressive loading. If these displacements are constrained a passive lateral confinement will act on the specimen. This effect is considered important in a three-dimensional modelling of reinforced concrete structures. In the work of Selby \& Vecchio (Selby and Vecchio 1993) this effect is modelled through a pre-strain concept in which the lateral expansion effects are accounted for with an additional external loading on the structure. This implies that the computational flow of the finite element engine is adapted to this method.

The Poisson effect is taken into account via the equivalent uniaxial strain concept. In case of linear-elastic behaviour the constitutive relation in a three-dimensional stressstrain situation is expressed following Expression (4.54):

$$
\sigma_{n s t}=\frac{E}{(1+\nu)(1-2 \nu)}\left[\begin{array}{ccc}
1-\nu & \nu & \nu \\
\nu & 1-\nu & \nu \\
\nu & \nu & 1-\nu
\end{array}\right] \varepsilon_{n s t}
$$

which can be developed as Expression (4.55):

$$
\begin{aligned}
\sigma_{n s t}= & {\left[\begin{array}{ccc}
E & 0 & 0 \\
0 & E & 0 \\
0 & 0 & E
\end{array}\right] \times } \\
& {\left[\begin{array}{ccc}
\frac{1-\nu}{(1+\nu)(1-2 \nu)} & \frac{\nu}{(1+\nu)(1-2 \nu)} & \frac{\nu}{(1+\nu)(1-2 \nu)} \\
\frac{\nu}{(1+\nu)(1-2 \nu)} & \frac{1-\nu}{(1+\nu)(1-2 \nu)} & \frac{\nu}{(1+\nu)(1-2 \nu)} \\
\frac{\nu}{(1+\nu)(1-2 \nu)} & \frac{\nu}{(1+\nu)(1-2 \nu)} & \frac{1-\nu}{(1+\nu)(1-2 \nu)}
\end{array}\right] \varepsilon_{n s t} }
\end{aligned}
$$


This relation is now defined in terms of equivalent uniaxial strains as Expression (4.56):

$$
\sigma_{n s t}=\left[\begin{array}{ccc}
E & 0 & 0 \\
0 & E & 0 \\
0 & 0 & E
\end{array}\right] \tilde{\varepsilon}_{n s t}
$$

with the equivalent uniaxial strain vector $\tilde{\varepsilon}_{n s t}$ defined as Expression (4.57):

$$
\left\{\begin{array}{c}
\tilde{\varepsilon}_{1} \\
\tilde{\varepsilon}_{2} \\
\tilde{\varepsilon}_{3}
\end{array}\right\}=\left[\begin{array}{ccc}
\frac{1-\nu}{(1+\nu)(1-2 \nu)} & \frac{\nu}{(1+\nu)(1-2 \nu)} & \frac{\nu}{(1+\nu)(1-2 \nu)} \\
\frac{\nu}{(1+\nu)(1-2 \nu)} & \frac{1-\nu}{(1+\nu)(1-2 \nu)} & \frac{\nu}{(1+\nu)(1-2 \nu)} \\
\frac{\nu}{(1+\nu)(1-2 \nu)} & \frac{\nu}{(1+\nu)(1-2 \nu)} & \frac{1-\nu}{(1+\nu)(1-2 \nu)}
\end{array}\right]\left\{\begin{array}{l}
\varepsilon_{1} \\
\varepsilon_{2} \\
\varepsilon_{3}
\end{array}\right\}
$$

or Expression (4.58):

$$
\tilde{\varepsilon}_{n s t}=\mathscr{P} \varepsilon_{n s t}
$$

The stress vector in the principal coordinate system, Expression (4.26), is evaluated in terms of the equivalent uniaxial strain vector, $\tilde{\varepsilon}_{123}$, and not in terms of the principal strain vector, $\varepsilon_{n s t}$. The equivalent uniaxial strain vector is simply determined when the principal strain vector and the (constant) Poisson's ratio are known.

The tangent stiffness sub-matrix $\boldsymbol{D}_{\text {nst }}$ is slightly modified due to the equivalent uniaxial strain concept. The matrix is obtained by Expression (4.59):

$$
\mathbf{D}_{n s t}=\frac{\partial \sigma_{n s t}}{\partial \varepsilon_{n s t}}=\frac{\partial \sigma_{n s t}}{\partial \tilde{\varepsilon}_{n s t}} \mathscr{P}
$$

with the matrix $\partial \sigma_{n s t} / \partial \tilde{\varepsilon}_{n s t}$ given by Expression (4.41) with $\tilde{\varepsilon}_{n s t}$ substituted for $\varepsilon_{n s t}$. 


\section{Poisson Effect and Shear Modulus in Cracked State:}

In a cracked state, the Poisson effect of a material does not exist anymore. Stretching of a cracked direction does no longer lead to contraction of the perpendicular directions. To model this phenomenon, an orthotropic formulation is adapted for Poisson's ratios. Similar to a damage formulation where the secant modulus reduces after cracking, the Poisson's ratios reduce at the same pace. Assuming that:

$$
\nu_{\mathrm{yz}}=\nu_{\mathrm{zy}}, \nu_{\mathrm{zx}}=\nu_{\mathrm{xz}}, \nu_{\mathrm{xy}}=\nu_{\mathrm{yx}}
$$

the matrix $\mathcal{P}$ of Expression (4.58) is written as shown in Expression (4.61):

$$
\mathscr{P}=\left[\begin{array}{ccc}
\frac{1-\nu_{y z}^{2}}{\Delta^{\prime}} & \frac{\nu_{y x}+\nu_{z x} \nu_{y z}}{\Delta^{\prime}} & \frac{\nu_{z x}+\nu_{y x} \nu_{z y}}{\Delta^{\prime}} \\
\frac{\nu_{x y}+\nu_{x z} \nu_{z y}}{\Delta^{\prime}} & \frac{1-\nu_{z x}^{2}}{\Delta^{\prime}} & \frac{\nu_{z y}+\nu_{z x} \nu_{x y}}{\Delta^{\prime}} \\
\frac{\nu_{x z}+\nu_{x y} \nu_{y z}}{\Delta^{\prime}} & \frac{\nu_{y z}+\nu_{x z} \nu_{y x}}{\Delta^{\prime}} & \frac{1-\nu_{x y}^{2}}{\Delta^{\prime}}
\end{array}\right]
$$

Where:

$$
\Delta^{\prime}=1-\nu_{\mathrm{xy}}^{2}-\nu_{\mathrm{yz}}^{2}-\nu_{\mathrm{zx}}^{2}-2 \nu_{\mathrm{xy}} \nu_{\mathrm{yz}} \nu_{\mathrm{zx}}
$$

For recomputation of the shear moduli both stiffnesses and Poisson's ratios are reduced:

$$
G=\frac{E}{2(1+\nu)}
$$

\subsubsection{Tensile behaviour}

For introducing the uniaxial behaviour of concrete to define the total strain smeared crack model in Diana, the software offers different implemented tensile models based on fracture energy $\left(G_{F}\right)$ that are all related to a crack bandwidth $\left(b_{w}\right)$ as shown in Expression (3.8) in chapter 3. In this work, both parameters are assumed as constant material characteristics. Some of these models are the nonlinear softening curve according to Hordijk (Hordijk 1991), according to Model Code for Concrete Structures 2010 ((fib) 2013), according to Japan Society of Civil Engineers (JSCE) ((JSCE) 2007), etc. 
Moreover, it can be also defined models that are not directly related to the fracture energy such as a multilinear general behaviour, a general brittle behaviour, the softening curve of the fédération internationale du béton/International Federation for Structural Concrete (fib) working groups, etc. More information of the available tensile curves for the total strain smeared crack model in Diana can be consulted in (DIANA (Software) 2017).

For implementing the uniaxial tensile behaviour of UHPFRC defined in section 3.2 for the smeared cracking approach in Diana, a fixed total strain crack model expressed according to the crack-opening curve is chosen. As bending and direct tensile tests are used to study the tensile behaviour of UHPFRC, in this work it is mainly developed the fracture mode-I (see Figure 3.15 in chapter 3) and, therefore, the results from a fixed crack concept and rotating crack concept are expected to be very close. As it is explained in section 3.2.4.1 and section 3.3.2 in chapter 3 where the smeared cracking approach is exposed for both uniaxial and multiaxial cases, once the tensile constitutive UHPFRC behaviour is set in terms of stress-strain/crack opening (see Figure 3.2 in section 3.2.2) defined as phase 1, this behaviour is transformed in a continuum model stress-total strain relationship using the crack bandwidth parameter $\left(b_{w}\right)$, as it is shown in Figure 3.10 in section 3.2.4.1 in the so-called phase 2 .

For the smeared crack model definition, the software needs as an input the uniaxial constitutive behaviour. It can be implemented directly as a stress-total strain $\left(\sigma-\varepsilon_{c}\right)$ defined in phase 2, transforming manually the softening $\sigma$ - $w$ relationship from phase 1 by means of the crack bandwidth $\left(b_{w}\right)$ and introducing manually the $\sigma-\varepsilon_{c}$ curve, or implementing the $b_{w}$ value for the fracture energy models using any available constitutive model. The constitutive behaviour can be also implemented by means of stress-crack opening directly from phase 1 in which Diana will, internally, transform it in a stress-total strain relationship to use it in the smeared crack model (Diana makes internally the transformation to phase 2 from the implemented phase 1).

Actually, the only possibility in Diana to define the constitutive curve in terms of stresscrack opening is by means of the tensile failure model for fibre reinforced concrete as defined by the fédération internationale du béton/International Federation for Structural Concrete (fib) working groups stress-crack opening curve. As it can be seen in Figure 4.18, the model can be specified according to either the total strain or the crack opening. These two functions are related by the proper crack bandwidth parameter defined by Diana $\left(b_{w, D I A N A}\right)$. This is, using this available material model for the smeared crack model, it is possible to implement the constitutive UHPFRC parameters by means of stress-crack opening curve ((n) option in Figure 4.18) and, therefore, Diana will transform it internally into stress-total strain relationship ((m) option in Figure 4.18) by means of its proper definition of the crack bandwidth $\left(b_{w, D I A N A}\right)$, substituting $b_{w}$ by $b_{w, D I A N A}$ in Expression (3.6), or directly implement the constitutive UHPFRC parameters by means of stress-total strain relationship ((m) option in Figure 4.18). Once the stresstotal strain law defined in phase 2 is stablished, the smeared crack model is ready to be applied. 

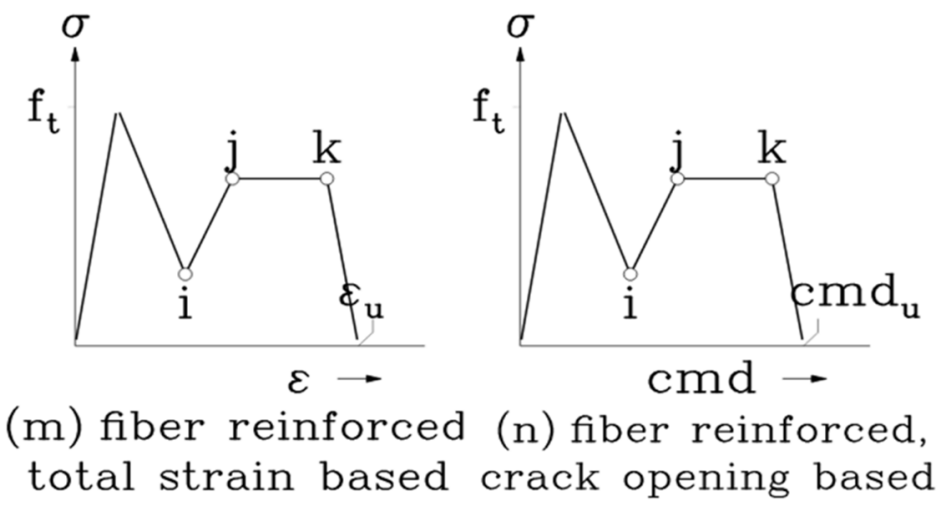

Figure 4.18 Predefined fédération internationale du béton/International Federation for Structural Concrete (fib) working groups tension softening curve for Total Strain

Crack model (DIANA (Software) 2017)

4.4.1.4.1. Analysis of the implications of the crack bandwidth and the mesh size dependency in the implementation of the UHPFRC tensile behaviour smeared crack model

Other important question to study when implementing the constitutive UHPFRC behaviour to define the smeared crack model in a software is the consideration of the crack bandwidth $\left(b_{w}\right)$ parameter. It is important to understand how the software interprets this parameter and how it is used internally to be coherent with the concept of crack bandwidth defined in section 3.2.4.1 and section 3.3.2 where the smeared cracking approach is exposed for both uniaxial and multiaxial cases. If the constitutive behaviour is implemented by means of the available stress-total strain tensile models based on fracture energy $\left(G_{F}\right)$ to define the phase 2, the software needs this parameter as an input to define the softening part of the tensile model (as it is explained in section 3.2.3). In these cases, Diana lets the possibility to enter the crack bandwidth parameter manually, by means of the Rots' element based method (Feenstra 1993; Rots 1988) or by means of Govindjee's projection method (Govindjee et al. 1995). It is important to say that, in these cases, if nothing is implemented with respect to the crack bandwidth, the software will use, by default, the Rots' element based method.

If the constitutive behaviour is implemented by means of stress-crack opening curve using the fédération internationale du béton/International Federation for Structural Concrete (fib) working groups stress-crack opening curve ((n) option in Figure 4.18), Diana will transform it internally into stress-total strain relationship ((m) option in Figure $4.18)$ to define the phase 2 by means of its proper crack bandwidth $\left(b_{w, D I A N A}\right)$. In this 
case, the software always use the Rots' element based method to define the crack bandwidth $\left(b_{w, D I A N A}\right)$ to transform the crack opening (phase 1$)$ into total strain (phase 2 ) with no other option.

In (Rots 1988) it was studied the problem of crack propagation through the mesh in a zig-zag path in a Crack-Line-Wedge-Loaded Double-Cantilever-Beam (CLWL-DCB) tested by (Kobayashi et al. 1985) (see Figure 4.19(a)). Here, as the smeared formulation of softening material model relationship involved the crack bandwidth, it was related to the finite element configuration in order to adjust the more accurate response of the smeared crack model. They estimated the optimal crack bandwidth to be used in the smeared crack model as a function of the finite element type and size. These estimations were carried out calibrating by "trial-and-error" fitting, comparing to the results from a discrete crack approach model, considered as an objective reference since it released the fracture energy exactly with independence of the mesh (see Figure 4.19(b)). It was obtained that the best relation between the crack bandwidth parameter and the finite element configuration was set by Expression (4.64) for the case of linear twodimensional finite elements, Expression (4.65) for the case of higher order twodimensional finite elements and Expression (4.66) for solid finite elements. Where $A_{e f}$ is the total area of the finite element. If the quadrilateral finite elements are used: $A_{e f}=L_{e f}$ x $L_{e f}$, where $L_{e f}$ is the finite element length. $V_{e f}$ is the volume of the finite element. For cubic tetrahedrons: $V_{e f}=L_{e f} \times L_{e f} \times L_{e f}$. These expressions constitute the so-called Rots' element based method in Diana. The crack bandwidth defined by these expressions is what it is considered in this work as Diana's crack bandwidth $b_{w, D I A N A}$ in order to differentiate it from the crack bandwidth $\left(b_{w}\right)$ considered as a material constant and used to define the UHPFRC material model in section 3.2.4.1 and section 3.3.2 in chapter 3.

$$
\begin{gathered}
b_{w, \text { DIANA }}=\sqrt{2 A_{e f}} \\
b_{w, \text { DIANA }}=\sqrt{A_{e f}} \\
b_{w, \text { DIANA }}=\sqrt[3]{V_{e f}}
\end{gathered}
$$


(a)

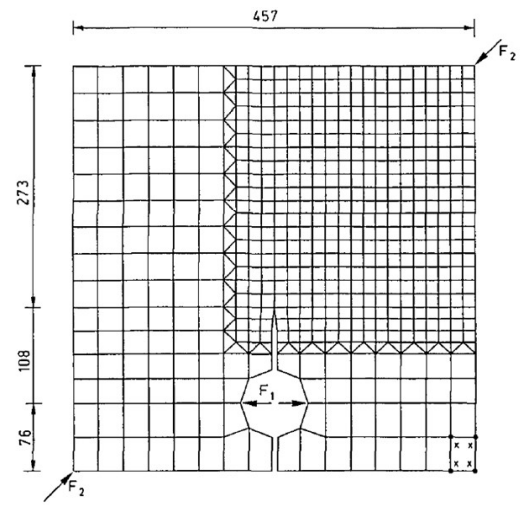

(b)

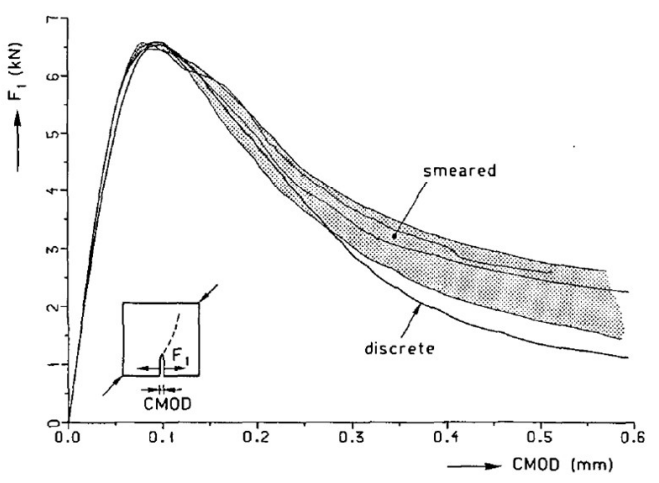

Figure 4.19 (a) Finite element mesh (dimensions in mm) and (b) Load-CMOD model responses of the CLWL-DCB specimen in (Rots 1988).

It is important to understand that $b_{w, D I A N A}$ is what Diana considers its crack bandwidth when the Rots' element based method is used by default in tensile models based on fracture energy $\left(G_{F}\right)$, and the crack bandwidth used to transform the stress-crack opening relationship into stress-total strain law when the fédération internationale du béton/International Federation for Structural Concrete (fib) working groups stress-crack opening curve is used. This fact represents an important aspect concerning the accuracy of the model in relation to the finite element mesh and the real crack bandwidth $\left(b_{w}\right)$ that can affect the results if its influence is not taken into account. In this work, higher order two-dimensional (for the 2D model) and solid (for the 3D model) finite elements are considered to define the FEM for UHPFRC. Therefore, if Expression (4.65) and Expression (4.66) are used as a consequence of Rots' element based method, the $b_{w, \text { DIANA }}$ considered by Diana equals the finite element length $\left(L_{e f}\right)$, as it is shown in Expression (4.67). Moreover, the crack bandwidth $\left(b_{w}\right)$ in section 3.2.3 is defined as the process zone with a thickness $b_{w}$ where the softening effect produced in the failure section is extended and, therefore, where the fictitious crack (fictitious macrocrack) is defined (see Figure 3.3(a) and Figure 3.4 in chapter 3 ). This crack bandwidth $\left(b_{w}\right)$ is considered in this work as a material constant.

$$
b_{W, D I A N A}=L_{e}
$$

The Rots' element based method is used in the fédération internationale du béton/International Federation for Structural Concrete (fib) working groups stress-crack 
opening curve to transform the stress-crack opening relationship (phase 1) into stresstotal strain law (phase 2$)$. In this case, the crack bandwidth for Diana $\left(b_{w, D I A N A}\right)$ equals the finite element length $\left(L_{e f}\right)$ by means of Expression (4.67). Therefore, it is expected that the mean total strain obtained from the smeared crack model using $b_{w, \text { DIANA }}$ $\left(\varepsilon_{m, e f, D I A N A}\right)$ inside the length of the finite element $\left(L_{e f}\right)$ in phase 3 equals the mean cracked strain using $b_{w, D I A N A}\left(\varepsilon_{c, D I A N A}\right)$ defined in phase 2 , as it can be deduced from Expression (4.18) and shown in Expression (4.68).

$$
\varepsilon_{m, e f, D I A N A}=\varepsilon_{c, D I A N A}
$$

If this idea is true, it represents the Lefexact solution in Figure 4.7 when $b_{w, D I A N A}$ is used $\left(L e f_{\text {exact,DIANA }}\right)$. Moreover, using the Rots' element based method in this way, for the model, the numerical crack bandwidth $\left(h_{b}\right)$ equals the finite element length $\left(L_{e f}\right)$, as Diana equals its $b_{w, D I A N A}$ to the finite element length $\left(L_{e f}\right)$. Thus, in this situation, no problems related to the numerical strain localisation are expected and different scenarios depending on the size of the finite element length $\left(L_{e f}\right)$ chosen for the FEM could be established:

Scenario 1: if $L_{e f}=b_{w}$. In this case, the finite element length $\left(L_{e f}\right)$ represents the width of the real crack band $\left(b_{w}\right)$, as shown in Figure 4.20. Therefore, the mean total strain obtained from the smeared crack model $\left(\varepsilon_{m, e f}\right)$ in phase 3 equals the mean cracked total strain $\left(\varepsilon_{c}\right)$ in phase 2 by means of Expression (4.18) and it is represented in the correct extension in the FEM as the length of the element $\left(L_{e f}\right)$ is exactly the real crack bandwidth $\left(b_{w}\right)$, as shown Figure 4.20. This scenario represents the Lefexact solution in Figure 4.7 and the situation described in Figure 4.8 and Figure 4.9 in section 4.3.1.
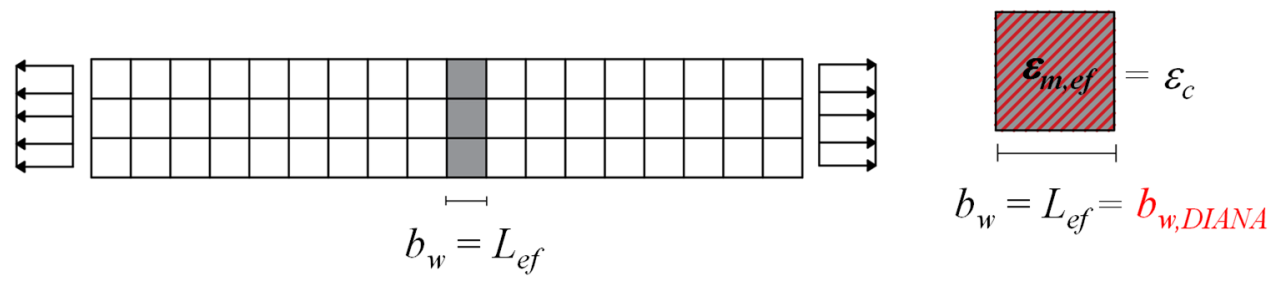

Figure 4.20 Scenario 1

Scenario 2: if $L_{e f}>b_{w}$. In this case, the finite element length $\left(L_{e f}\right)$ represents a width wider than the real crack bandwidth $\left(b_{w}\right)$, as shown in Figure 4.21. Therefore, the mean total strain obtained from the smeared crack model using $b_{w, D I A N A}\left(\varepsilon_{m, e f, D I A N A}\right)$ in phase 3 equals the mean cracked total strain using $b_{w, D I A N A}\left(\varepsilon_{c, D I A N A}\right)$ defined in phase 2 by means of Expression (4.18). However, the values of $\varepsilon_{c, D I A N A}$ and $\varepsilon_{m, e f, D I A N A}$ are lower than those from scenario $1\left(\varepsilon_{c}\right.$ and $\left.\varepsilon_{m, e f}\right)$ that represents the exact solution considering the material crack bandwidth $\left(b_{w}\right)$, as it is shown in Figure 4.22. The energy under the curves in phase 
2 and phase 3 are lower for scenario 2 compared to scenario $1: g_{f}>g_{f, D I A N A}$ (in phase 2) and $g_{f f n, e f}>g_{f m, e f, D I A N A}$ (in phase 3 ). Moreover, it is not represented in the correct extension in the FEM as the length of the finite element $\left(L_{e f}\right)$ is higher than the real crack bandwidth $\left(b_{w}\right)$. This is, the mean total strain obtained in the model when $L_{e f}>b_{w}$ is lower than the real mean total strain and its extension in the model is higher than in the reality as the crack bandwidth in the model $\left(b_{w, D I A N A}\right)$ represented by the finite element length $\left(L_{e f}\right)$ (Expression (4.67)) is higher than the crack bandwidth considered in the reality $\left(b_{w}\right)$, as shown in Figure 4.21. As it is observed in Figure 4.22 it is necessary to keep in mind that it may appear numerical convergence problems related to the possibility of snap-back constitutive response in both cases: phase 2 and phase 3, if the length of the finite element is too much higher than the real crack bandwidth $\left(L_{e f}>>>b_{w}\right)$.

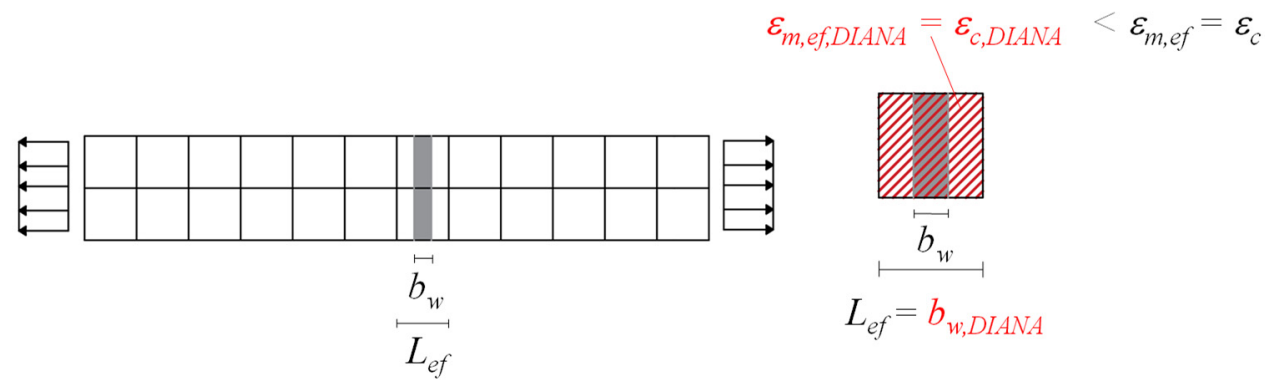

Figure 4.21 Scenario 2

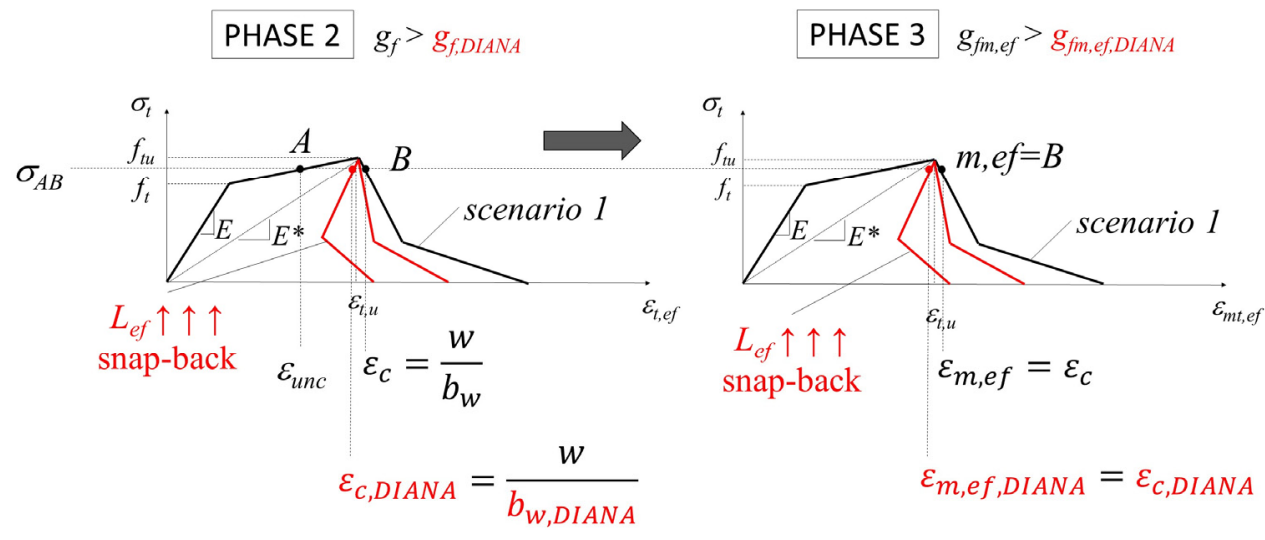

Figure 4.22 Phase 2 and Phase 3 for scenario 2. 
Scenario 3: if $L_{e f}<b_{w}$. This scenario constitutes the opposite situation than that described in scenario 2 . In this case, the finite element length $\left(L_{e f}\right)$ represents a width narrower than the real crack band $\left(b_{w}\right)$, as shown in Figure 4.23. Therefore, the mean total strain obtained from the smeared crack model using $b_{w, D I A N A}\left(\varepsilon_{m, e f, D I A N A}\right)$ in phase 3 equals the mean cracked total strain using $b_{w, D I A N A}\left(\varepsilon_{c, D I A N A}\right)$ defined in phase 2 by means of Expression (4.18). However, the values of $\varepsilon_{c, D I A N A}$ and $\varepsilon_{m, e f, D I A N A}$ are higher than those from scenario 1 ( $\varepsilon_{c}$ and $\varepsilon_{m, e f}$ ) that represents the exact solution considering the material crack bandwidth $\left(b_{w}\right)$, as it is shown in Figure 4.24. The energy under the curves in phase 2 and phase 3 are higher for scenario 3 compared to scenario 1: $g_{f}<g_{f, D I A N A}$ (in phase 2) and $g_{f m, e f}<g_{f m, e f, D I A N A}$ (in phase 3). Moreover, it is not represented in the correct extension in the FEM as the length of the finite element $\left(L_{e f}\right)$ is lower than the real crack bandwidth $\left(b_{w}\right)$. This is, the mean total strain obtained in the model when $L_{e f}<b_{w}$ is higher than the real mean total strain and its extension in the model is lower than in the reality as the crack bandwidth in the model $\left(b_{w, D I A N A}\right)$ represented by the finite element length $\left(L_{e f}\right)$ (Expression (4.67)) is lower than the crack bandwidth considered in the reality $\left(b_{w}\right)$, as shown in Figure 4.23.

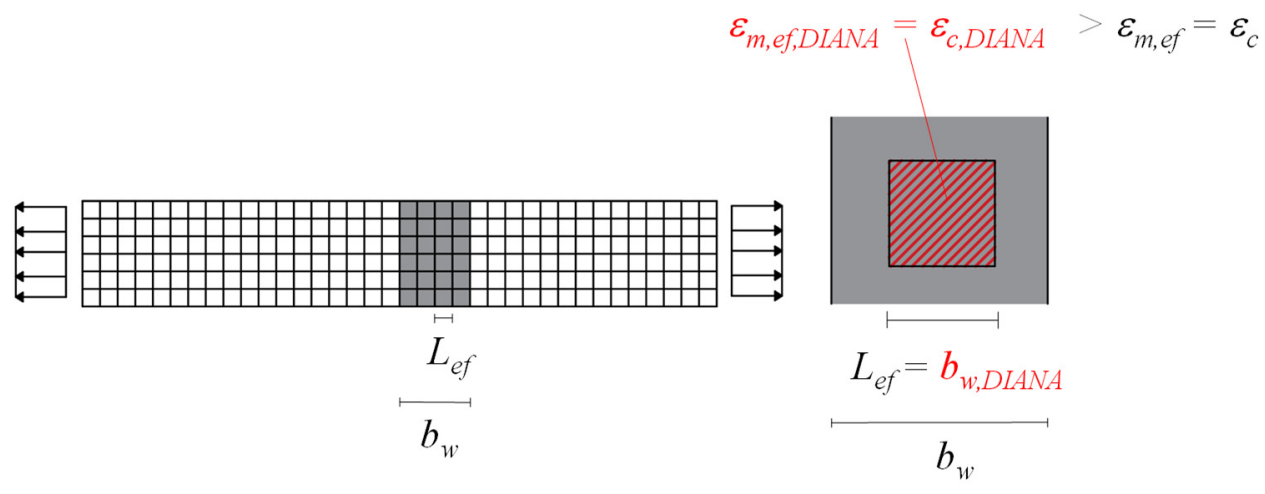

Figure 4.23 Scenario 3. 


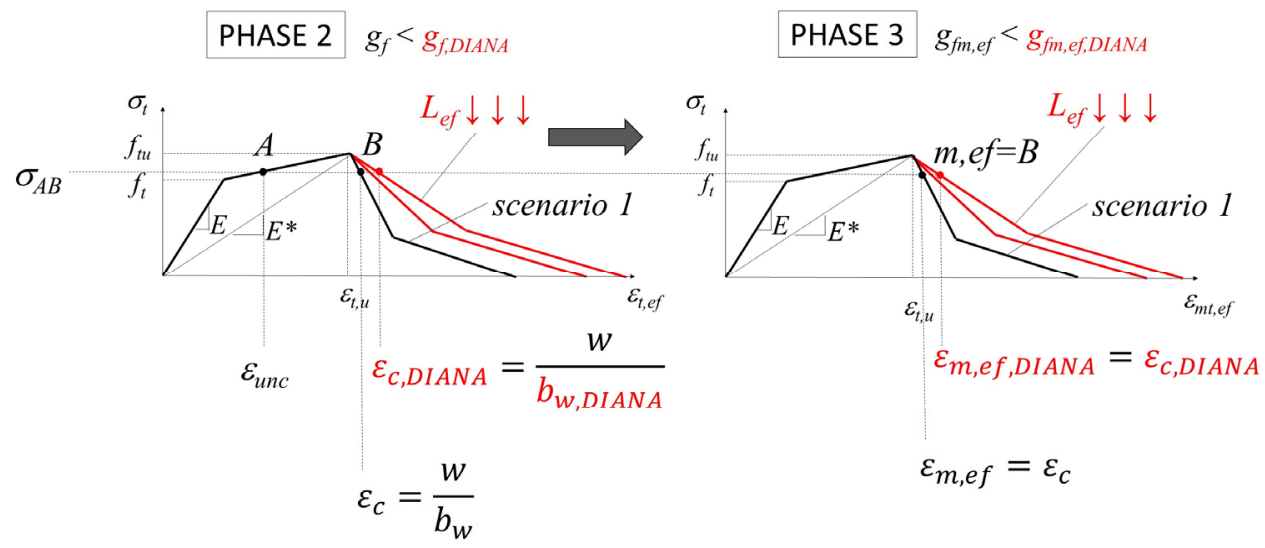

Figure 4.24 Phase 2 and Phase 3 for scenario 3.

In this sense, it becomes necessary to know the real crack bandwidth $\left(b_{w}\right)$ of the UHPFRC in order to choose the finite element length $\left(L_{e f}\right)$ to model the specimen. It is important to know that the element length $\left(L_{e f}\right)$ has a direct influence on the computational time. Therefore, it is necessary to know that as the element length chosen becomes closer to the real crack bandwidth, the solution will be more accurate. However, it is also important to be aware of the element size in comparison to the specimen size from the computational point of view.

From experimental results, it is common to assume a crack bandwidth for plain concrete of two to three times the largest aggregate size. As it is said by (Cedolin and Bažant 1980), this could be the reason why satisfactory results are obtained in many practical calculations of reinforced concrete beams, slabs and panels without considering the effect of the mesh dependency in smeared crack models, since the element size frequently used for doing so has been about the smallest admissible one in relation to material inhomogeneities, i.e., the aggregate size. This is not directly applicable to the case of UHPFRC as its material composition and, therefore, its mechanical behaviour, is different to plain concrete. Moreover, for the case of UHPFRC, the crack bandwidth and crack energy are not completely calibrated and, therefore, many regularisation technics for plain concrete used to address the mesh size dependency of the smeared crack model could be not directly applicable. In addition, the use of commercial finite element software packages could difficult the adaptation of a regulariaation technic in the case of new materials.

In this work, no regularisation technique has been applied. To calibrate the real crack bandwidth $\left(b_{w}\right)$ of the UHPFRC and, therefore the exact finite element length $\left(L_{e f}\right)$, the same idea followed by (Rots 1988) and explained above has been carried out. This is, using the experimental results and the discrete cracking approach of the FEM developed, as this is considered mesh size independent, the calibration of the adequate crack bandwidth $\left(b_{w}\right)$ of UHPFRC and, thus, the adequate finite element length $\left(\right.$ Lef $\left._{\text {exact }}\right)$ has 
been carried out by "trial-and-error" for the smeared cracking approach of the FEM. This calibration process is applied for the modelling of the 4PBT in chapter 5.

\subsection{Adaptation of the UHPFRC tensile behaviour}

To implement in Diana the UHPFRC stress-total strain constitutive tensile behaviour defined in Figure 3.10 for the continuum model in phase 2, to be used for the smeared cracking approach in phase 3, the fédération internationale du béton/International Federation for Structural Concrete (fib) working groups stress-crack opening curve is used ((n) option in Figure 4.18).

To be coherent to the constitutive parameters obtained from the inverse analysis application explained in chapter 3 and Annexe I by means of the I-IA and 5P-IA, the stress at the change of the slope in the softening part $\left(f_{t d}\right)$ has been assumed as one third of the ultimate tensile stress $\left(f_{t u}\right)$, as shown in Expression (4.69). With this consideration, Figure 3.10 in section 3.2.4.1 is actualised as Figure 4.25.

$$
f_{t d}=\frac{f_{t u}}{3}
$$

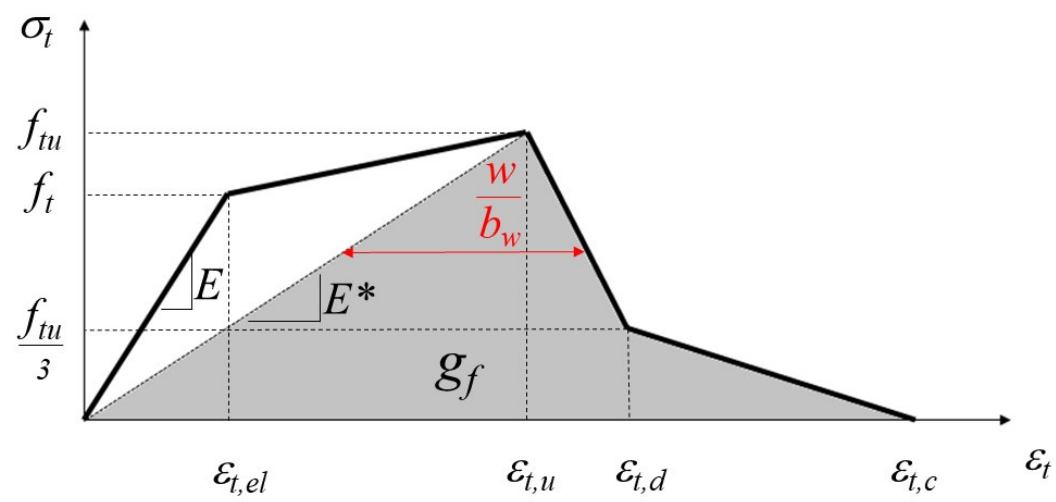

Figure 4.25 Stress-strain relationship adopted for Diana implementation.

The parameters are expressed as follows for the smeared stress-strain behaviour in Diana:

From Expression (3.16), Expression (3.18) and Expression (4.69), the total strain at the change of the slope in the softening part $\left(\varepsilon_{t d}\right)$ in phase 2 for the UHPFRC material model can be deduced as Expression (4.70):

$$
\varepsilon_{t d}=\frac{w_{d}}{b_{w}}+\frac{\varepsilon_{t u}}{3}
$$


Diana makes the internal transformation mean cracked total strain $\left(\varepsilon_{c}\right)$-crack opening $(w)$ to transform the stress-crack opening curve ((n) option in Figure 4.18) in phase 1 into the stress-total strain relationship ((m) option in Figure 4.18) in phase 2, for the smeared crack model by means of its proper definition of the crack bandwidth $\left(b_{w, D I A N A}\right)$ using the Rots' element based method. Therefore, the mean cracked total strain at the change of slope in phase 2 for Diana $\left(\varepsilon_{t d, D I A N A}\right)$ is defined as Expression (4.71):

$$
\varepsilon_{t d, D I A N A}=\frac{w_{d, D I A N A}}{b_{w, D I A N A}}=\frac{w_{d, D I A N A}}{L_{e f}}
$$

To define the constitutive continuum model in phase 2 it is necessary that Expression $(4.70)=$ Expression (4.71). Therefore, the crack opening that must be implemented in phase 1 in Diana is defined as Expression (4.72):

$$
w_{d, D I A N A}=\varepsilon_{t d} \cdot L_{e f}
$$

The same deduction can be done for the crack opening at zero stress $w_{c}$ for the case of the parameters obtained from the I-IA and the 5P-IA and $w_{o}$ for the case of the parameters obtained from 4P-IA (see Figure A-I.3, Figure A-I.6 and Figure A-I.7 in Annexe I). Expression (3.22) here denoted as Expression (4.73) and Figure 4.25 for I-IA and 5P-IA and Expression (4.74) for 4P-IA define the material total cracked strains for the constitutive continuum material model of UHPFRC in phase 2 defined in chapter 3 . They are equalled to the Diana's total strains from the Rots' element based method to define the phase 2 from the $\sigma-w$ curve implemented in Diana in phase 1, in Expression (4.75) and Expression (4.76).

$$
\begin{gathered}
\varepsilon_{t c}=\frac{w_{c}}{b_{w}} \\
\varepsilon_{t 0}=\frac{w_{0}}{b_{w}} \\
\varepsilon_{t c, \text { DIANA }}=\frac{w_{c, \text { DIANA }}}{b_{w, \text { DIANA }}}=\frac{w_{c, \text { DIANA }}}{L_{e f}}
\end{gathered}
$$




$$
\varepsilon_{t 0, D I A N A}=\frac{w_{0, D I A N A}}{b_{w, D I A N A}}=\frac{w_{0, D I A N A}}{L_{e f}}
$$

Thus, the crack opening at zero stress that must be implemented in phase 1 in Diana in the stress-crack opening curve ((n) option in Figure 4.18) is defined as Expression (4.77) and Expression (4.78), respectively.

$$
\begin{aligned}
& w_{c, \text { DIANA }}=\varepsilon_{t c} \cdot L_{e f} \\
& w_{0, \text { DIANA }}=\varepsilon_{t 0} \cdot L_{e f}
\end{aligned}
$$

For strain at ultimate tensile stress $\varepsilon_{t u}$, the same deduction can be done if $\varepsilon_{t u}$ from phase 2 of the continuum material model of UHPFRC defined in chapter 3 equals the $\varepsilon_{t u, D I A N A}$ in Expression (4.79).

$$
\varepsilon_{t u, D I A N A}=\frac{w_{f t u, D I A N A}}{b_{w, D I A N A}}=\frac{w_{f t u, D I A N A}}{L_{e f}}
$$

Thus, the crack opening at ultimate tensile stress that must be implemented in phase 1 in Diana in the stress-crack opening curve ((n) option in Figure 4.18) is defined as Expression (4.80).

$$
w_{f t u, D I A N A}=\varepsilon_{t u} \cdot L_{e f}
$$

Therefore, when the constitutive behaviour is implemented in phase 1 by means of stresscrack opening curve using the fédération internationale du béton/International Federation for Structural Concrete (fib) working groups stress-crack opening curve ((n) option in Figure 4.18), Diana will transform it internally into stress-total strain relationship ((m) option in Figure 4.18) to obtain the phase 2 by means of its proper crack bandwidth $\left(b_{w, D I A N A}\right)$ defined by the Rots' element based method. As it can be observed in Figure 4.26 for the case of I-IA and 5P-IA and in Figure 4.27 for the case of 4P-IA, when the stress-crack opening curve (phase 1 for Diana) is implemented by means of Expression (4.72), Expression (4.77) and Expression (4.80), the stress-total strain curve obtained as a result of the Rots' element based method to define the phase 2 in Diana will be exactly the stress-total strain curve of the UHPFRC material behaviour for phase 2 defined in section 3.2.4.1 in chapter 3 and depicted in Figure 4.25. This is completely equivalent to directly implement the stress-total strain relationship ((m) option in Figure 4.18) to directly define the phase 2 in Diana using the UHPFRC material behaviour for phase 2 defined in section 3.2.4.1 in chapter 3 and depicted in Figure 4.25 by means of 
Expression (4.70), Expression (4.73) for I-IA and 5P-IA and Expression (4.74) for 4PIA.

$$
\text { I-IA and 5P-IA }
$$
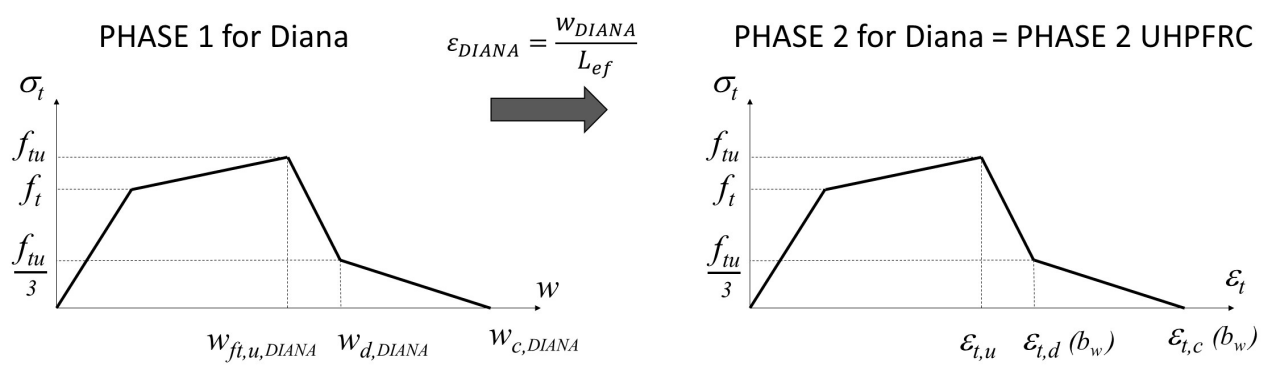

Figure 4.26 UHPFRC constitutive model implementation for I-IA and 5P-IA.

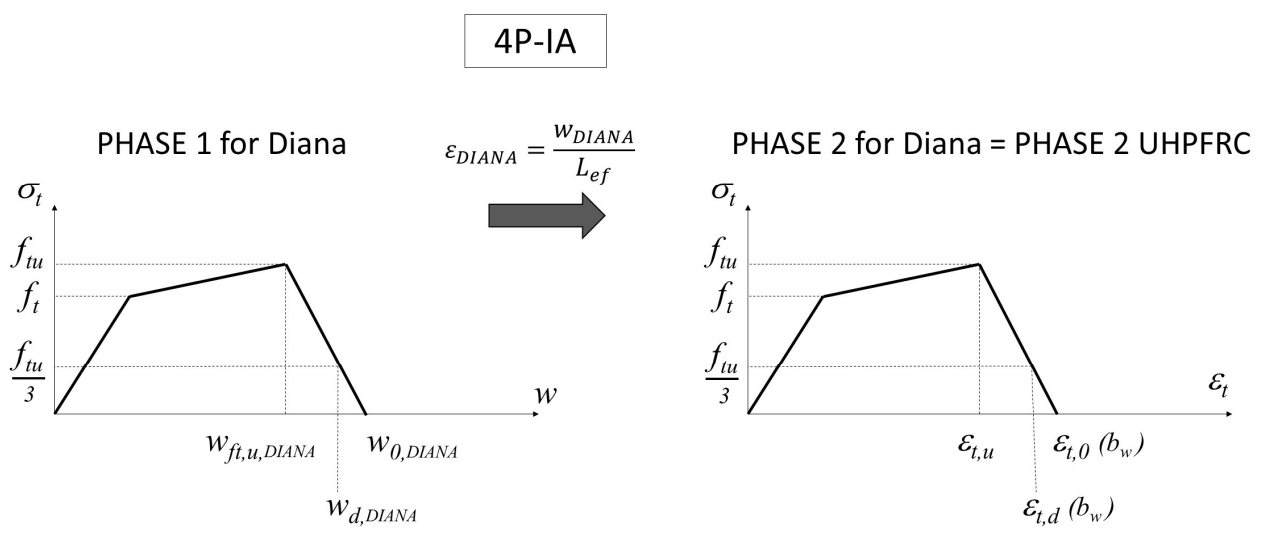

Figure 4.27 UHPFRC constitutive model implementation for 4P-IA.

As the UHPFRC material crack bandwidth $\left(b_{w}\right)$ is unknown, to calibrate its value using the smeared cracking approach, it is assumed the case explained in scenario 1 if the curve is implemented by means of stress-crack opening curve using the fédération internationale du béton/International Federation for Structural Concrete (fib) working groups stress-crack opening curve ((n) option in Figure 4.18) in phase 1 of Diana. In this sense, $L_{e f}=b_{w}$, this is, the real crack bandwidth $\left(b_{w}\right)$ equals the Diana's crack bandwidth $\left(b_{w, D I A N A}\right)$ that would lead to the Lefexact solution in Figure 4.7 and the situation described in Figure 4.8 and Figure 4.9 in section 4.3.1. Therefore, Expression (4.70) and 
Expression (4.73) for I-IA and 5P-IA and Expression (4.74) for 4P-IA are redefined as Expression (4.81), Expression (4.82) and Expression (4.83), respectively and then, they are used in Figure 4.26 for the case of I-IA and 5P-IA and in and Figure 4.27 for the case of 4P-IA.

$$
\begin{gathered}
\varepsilon_{t d}=\frac{w_{d}}{L_{e f}}+\frac{\varepsilon_{t u}}{3} \\
\varepsilon_{t c}=\frac{w_{c}}{L_{e f}} \\
\varepsilon_{t 0}=\frac{w_{0}}{L_{e f}}
\end{gathered}
$$

\subsubsection{Compressive behaviour}

Concrete subjected to compressive stresses shows a pressure dependent behaviour, i.e., the strength and ductility increase with increasing isotropic stress. Due to the lateral confinement, the compressive stress-strain relation is modified to incorporate the effects of the increased isotropic stress. Furthermore, it is assumed that the compressive behaviour is influenced by lateral cracking. To model the lateral confinement effect, the parameters of the compressive stress-strain function, $f_{c f}$ and $\varepsilon_{p}$, are determined with a failure function which gives the compressive stress which causes failure as a function of the confining stresses in the lateral directions.

If the material is cracked in the lateral direction, the parameters are reduced with the factor $\beta_{\varepsilon c r}$ for the peak strain, and with the factor $\beta_{\sigma c r}$ for the peak stress. It is assumed that the base curve in compression is determined by the peak stress value $f_{p}$ and the corresponding peak strain value $\alpha_{p}$ as defined in Expression (4.84) and Expression (4.85), respectively.

$$
\begin{gathered}
f_{\mathrm{p}}=\beta_{\sigma_{\mathrm{cr}}} \cdot f_{\mathrm{cf}} \\
\alpha_{\mathrm{p}}=\beta_{\varepsilon_{\mathrm{cr}}} \cdot \varepsilon_{\mathrm{p}}
\end{gathered}
$$


For modelling the compressive behaviour of UHPFRC in the smeared cracking approach in Diana, the CEB-FIP Model Code 1990 is used (see Figure 4.28).

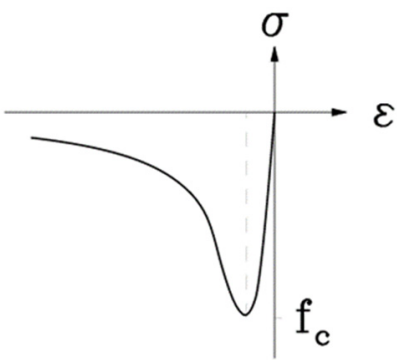

\section{(k) CEB-FIP 1990}

Figure 4.28 CEB-FIP Model Code 1990 compressive curve (DIANA (Software) 2017)

In this case, no reduction due to lateral cracking and no increase due to stress confinement has taken into account.

\subsubsection{Shear behaviour}

The modelling of the shear behaviour is necessary in the fixed crack concept, which is the model used in this work. In Diana, only a constant shear stiffness reduction is modelled, as shown in Expression (4.86).

$$
G^{\mathrm{cr}}=\beta G
$$

with $\beta$ the shear retention factor, $0 \leq \beta \leq 1$. This is in accordance with the proposed shear retention factor in section 3.3.2 in chapter 3, where the multiaxial UHPFRC crack model is set (see Expression (3.40)).

In this case, a constant shear retention factor of $\beta=0.01$ is used (see Figure 4.29). 


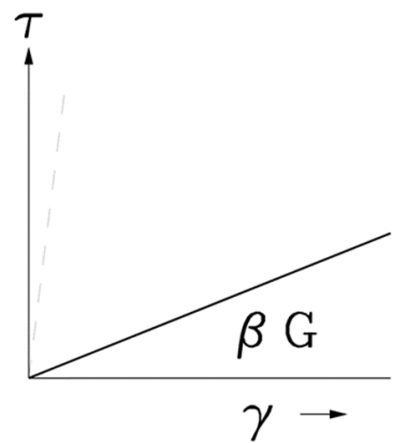

Figure 4.29 Constant shear retention for Total Strain Crack models (DIANA

(Software) 2017)

\subsubsection{Discrete cracking implementation}

In the discrete cracking approach, the crack is directly modelled by a discontinuity that separates two elements. To simulate the cracking in a discrete cracking model in Diana, interface elements are used. The constitutive behaviour of the discrete model approach using interface elements is explained in the following section 4.4.3. of this document.

\subsubsection{Constitutive behaviour for interface elements implementation.}

To model geometric discontinuities, such as discrete cracks in concrete and bond-slip layers in reinforced concrete, Diana's multipurpose structural interface elements are used. These elements relate the forces acting on the interface to the relative displacement of the two sides of the interface as depicted in Figure 4.30 for the case of the twodimensional configuration.

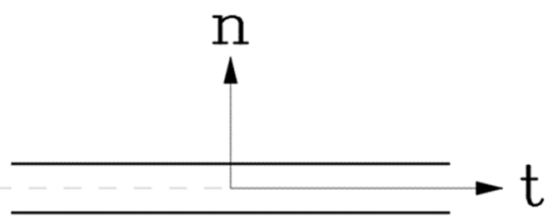

Figure 4.30 Two-dimensional interface element

The material models for interface elements set a linear or nonlinear relation between tractions, i.e., stresses, and relative displacements across the interface. The tractions are normal traction $t_{n}$ and shear tractions $t_{s} t_{t}$. The relative displacements are a normal relative displacement $\Delta u_{n}$ and a shear relative displacement $\Delta u_{t}$. 
The nonlinear relations are described here for the two-dimensional configuration, i.e., the line interface elements, but in general the relations are also valid for the threedimensional case. The traction vector $t$ is defined for the two-dimensional case as shown in Expression (4.87),

$$
\mathbf{t}=\left\{\begin{array}{l}
t_{n} \\
t_{t}
\end{array}\right\}
$$

and the vector composed by the relative displacements as shown in Expression (4.88).

$$
\Delta \mathbf{u}=\left\{\begin{array}{l}
\Delta u_{n} \\
\Delta u_{t}
\end{array}\right\}
$$

The linear constitutive relation between the traction vector and the relative displacement vector is defined in Expression (4.89).

$$
\left\{\begin{array}{l}
t_{n} \\
t_{t}
\end{array}\right\}=\left[\begin{array}{cc}
k_{n} & 0 \\
0 & k_{t}
\end{array}\right]\left\{\begin{array}{l}
\Delta u_{n} \\
\Delta u_{t}
\end{array}\right\}
$$

with $k_{n}$ and $k_{t}$ that usually assigns large penalty values to model the initial continuous geometry. Application of a Gaussian integration scheme to interface elements can lead to spurious kinematic element performance under certain conditions, as it is set in (Rots 1988). It is therefore recommended to use a lumped integration scheme for interface elements with large dummy stiffnesses.

The general constitutive relation is assumed to be incrementally linear, as it is defined in Expression (4.90).

$$
\dot{\mathbf{t}}=\mathbf{D} \Delta \dot{\mathbf{u}}
$$

Where $\mathbf{t}$ is the traction vector, $\Delta \mathbf{u}$ the vector with the relative displacements, and $\mathbf{D}$ the tangential stiffness matrix defined in Expression (4.91).

$$
\mathbf{D}=\left[\begin{array}{ll}
D_{11} & D_{12} \\
D_{21} & D_{22}
\end{array}\right]
$$

In which the stiffness coefficients generally depend on $\Delta u_{n}, \Delta u_{t}, t_{n}, t_{t}$ and maybe on other state parameters. 


\subsubsection{Discrete cracking constitutive behaviour of UHPFRC}

The constitutive law for discrete cracking in Diana is based on a total deformation theory, which expresses the tractions as a function of the total relative displacements, the crack width $\Delta u_{n}$ and the crack slip $\Delta u_{t}$ (see Figure 4.31).

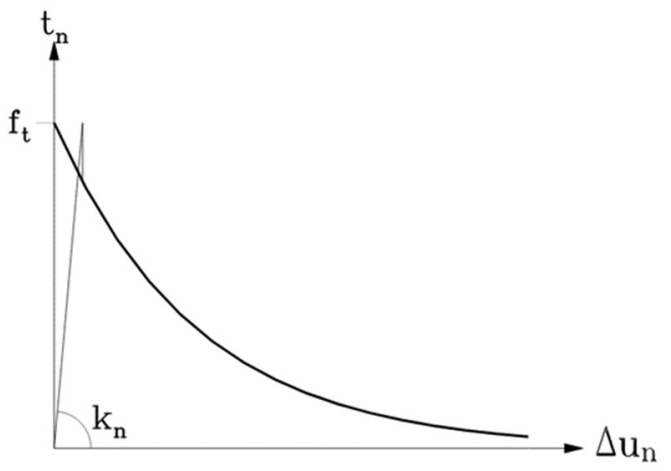

Figure 4.31 Discrete cracking interface constitutive behaviour

In Diana, both the relations between normal traction and crack width and between shear traction and slip are assumed as a nonlinear function, as it is defined in Expression (4.92).

$$
\left\{\begin{array}{c}
t_{n}=f_{n}\left(\Delta u_{n}\right) \\
t_{t}=f_{t}\left(\Delta u_{t}\right)
\end{array}\right.
$$

Differentiating Expression (4.92) results in expressions for the tangential stiffness coefficients shown in Expression (4.93).

$$
\left\{\begin{array}{c}
D_{11}=\frac{\partial f_{n}}{\partial \Delta u_{n}} \\
D_{12}=0 \\
D_{21}=0 \\
D_{22}=\frac{\partial f_{t}}{\partial \Delta u_{t}}
\end{array}\right.
$$

Generally, the normal traction $t_{n}$ is defined by a tension softening relation. For structural interface elements, Diana offers predefined curves. In this case, a multilinear tension softening law has been introduced (see Figure 4.32). Unloading and reloading is following a secant model to be consistent with the smeared crack model explained in 
section 3.2.4.1. As it can be seen in Figure 4.32, the diagram also contains an ascending part (hardening).
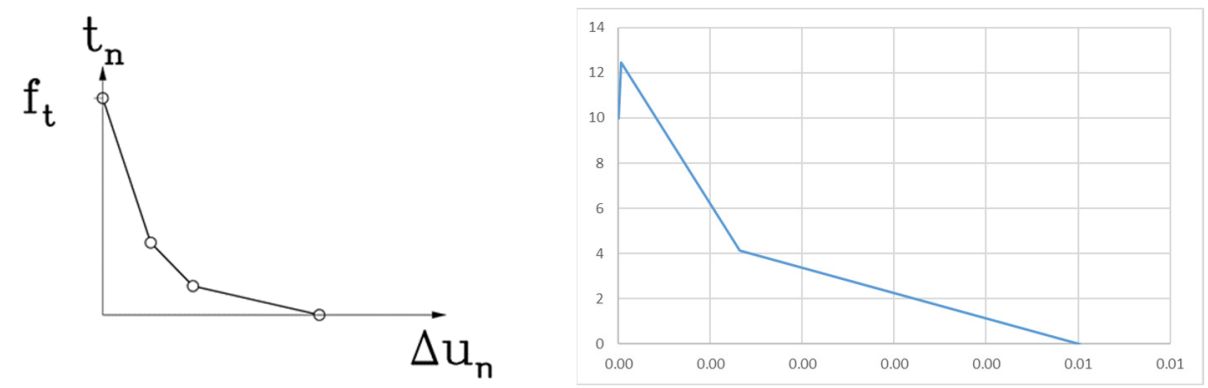

Figure 4.32 Multilinear stress-crack opening law for discrete crack interface

\subsubsection{Bond-slip constitutive behaviour between reinforcement and UHPFRC}

In reinforced concrete the interaction between the reinforcement and the concrete is very complex. This interaction is governed by secondary transverse and longitudinal cracks in the vicinity of the reinforcement. This behaviour can be modelled with a bond-slip mechanism where the relative slip of the reinforcement and the concrete is described in a phenomenological sense. The mechanical behaviour of the slip zone is then described by the interface element with a zero thickness.

The constitutive law for bond-slip that has been proposed is mostly based on a total deformation theory, which expresses the tractions as a function of the total relative displacements. In Diana, the relation between the normal traction and the normal relative displacement is considered to be linear elastic, whereas the relation between the shear traction and the slip is considered as a nonlinear function, as it is defined in Expression (4.94).

$$
\left\{\begin{array}{l}
t_{n}=k_{n} \Delta u_{n} \\
t_{t}=f_{t}\left(\Delta u_{t}\right)
\end{array}\right.
$$

Differentiating Expression (4.94) results in expressions for the tangential stiffness coefficients shown in Expression (4.95).

$$
\left\{\begin{array}{c}
D_{11}=k_{n} \\
D_{12}=0 \\
D_{21}=0 \\
D_{22}=\frac{\partial f_{t}}{\partial \Delta u_{t}}
\end{array}\right.
$$


Diana offers predefined curves for the relations between shear traction and slip. In this case a Cubic function according to Dörr (Dorr 1980) has been used. As it is shown in Figure 4.33, Dörr described a polynomial relation between shear traction and slip that exhibits a limit if the slip is higher than a certain value $\Delta u_{t}^{0}$.

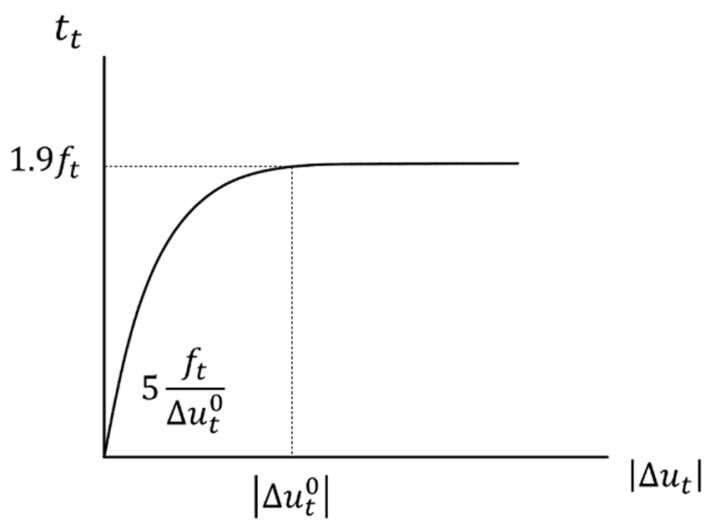

Figure 4.33 Cubic function for bond-slip (Dorr 1980)

This relation is defined by a cubic function shown in Expression (4.96).

$$
\begin{array}{cc}
t_{t}=f_{t}\left(5\left(\frac{\Delta u_{t}}{\Delta u_{t}^{0}}\right)-4.5\left(\frac{\Delta u_{t}}{\Delta u_{t}^{0}}\right)^{2}+1.4\left(\frac{\Delta u_{t}}{\Delta u_{t}^{0}}\right)^{3}\right) & \text { if } 0 \leq \Delta u_{t}<\Delta u_{t}^{0} \\
t_{t}=1.9 f_{t} & \text { if } \Delta u_{t} \geq \Delta u_{t}^{0}
\end{array}
$$

Unloading and reloading follow the elastic stiffness. In this case, the elastic unloading/reloading curve is followed until the inverse maximum traction value is reached, and from there the bond-slip curve is followed from the point where the bondslip curve was left, in the opposite direction. In case the reloading is initiated from a point of the elastic unloading curve, the bond-slip curve is recaptured at the point where it was left.

\subsubsection{Implementation of the constitutive behaviour in tension for reinforcement steel.}

For the implementation of the constitutive behaviour in tension for the reinforcement steel in Diana, the flow theory of plasticity to describe the steel for the reinforcement as an elastoplastic material behaviour has been used. For modelling the behaviour of the steel in tension for the reinforcement, a bilinear stress-total strain constitutive behaviour 
with strain hardening has been used (see Figure 4.34), based on the yield condition of Von Mises.

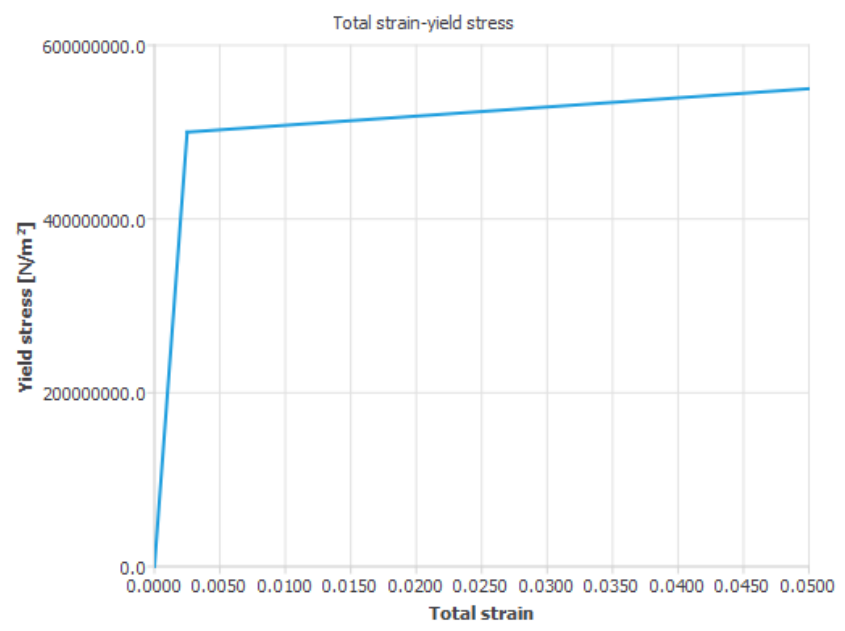

Figure 4.34 Stress-total strain constitutive behaviour in tension of steel for the reinforcement

Taking into account the hypothesis of small strains, the consideration of an additive strain decomposition into an elastic and a plastic or irreversible part is made as defined in Expression (4.97).

$$
\varepsilon=\varepsilon^{\mathrm{e}}+\varepsilon^{\mathrm{p}}
$$

By means of the approach of the flow theory of plasticity, to describe the elastoplastic material behaviour, the total stress $\sigma$ at time $t$ can be modelled as a function of the total strain $\varepsilon$ at time $t$ and, also, as a function of the stress and strain history.

The stress and strain history of the material is considered implicitly by introducing an internal parameter, known as $\kappa$, that is defined by a specific evolution law. Consequently, the elastoplastic material behaviour can be described considering the following points:

- The elastic stress-strain relation, that defines the relation between the total stress and the elastic strain. This can be defined as Expression (4.98).

$$
\sigma=\mathbf{D} \varepsilon^{\mathrm{e}}
$$


where $\mathbf{D}$ is the material stiffness matrix.

- The yield condition, that defines the state of stress at which the plastic flow is initiated. This condition can be expressed as a function of the stress vector and the internal state parameter as Expression (4.99).

$$
f(\sigma, \kappa)=0
$$

If the value of the yield function is less than zero, the state is considered to be elastic and no plastic flow will occur. By other side, a value of the yield function higher than zero is not admissible for rate-independent plasticity.

- The flow rule that defines the inelastic or plastic strain rate vector as a function of the state of stress. Considering the flow theory of plasticity and assuming Koiter's rule (Koiter 1953), the plastic strain rate vector is defined as Expression (4.100).

$$
\dot{\varepsilon}^{\mathrm{p}}=\sum_{j=1}^{n} \dot{\lambda}_{j} \frac{\partial g_{j}}{\partial \sigma}
$$

with the $n$ plastic potential functions $g_{j}$ which can also be considered as a function of the stress vector and the internal state parameter, i.e., $g_{j}(\sigma, \kappa)$. The plastic multipliers $\lambda_{j}$ are restricted by the standard Kuhn-Tucker conditions defined in Expression (4.101).

$$
f \leq 0 \quad ; \quad \dot{\lambda}_{j} \geq 0 \quad ; \quad \dot{\lambda}_{j} f=0
$$

These conditions are actually a reformulation of the admissible states at plastic flow, i.e., no plastic flow will occur $\left(\lambda_{j}=0\right)$ if the yield function is less than zero.

- The hardening hypothesis that defines the evolution of the internal state parameter. Normally, the evolution is expressed as a function of the stress vector and the plastic strain rate vector, i.e., $\kappa^{*}=h(\sigma, \varepsilon p)$.

Considering this, the yield condition of Von Mises is a smooth approximation of the Tresca yield condition: a circular cylinder in the principal stress space (Figure 4.35). 


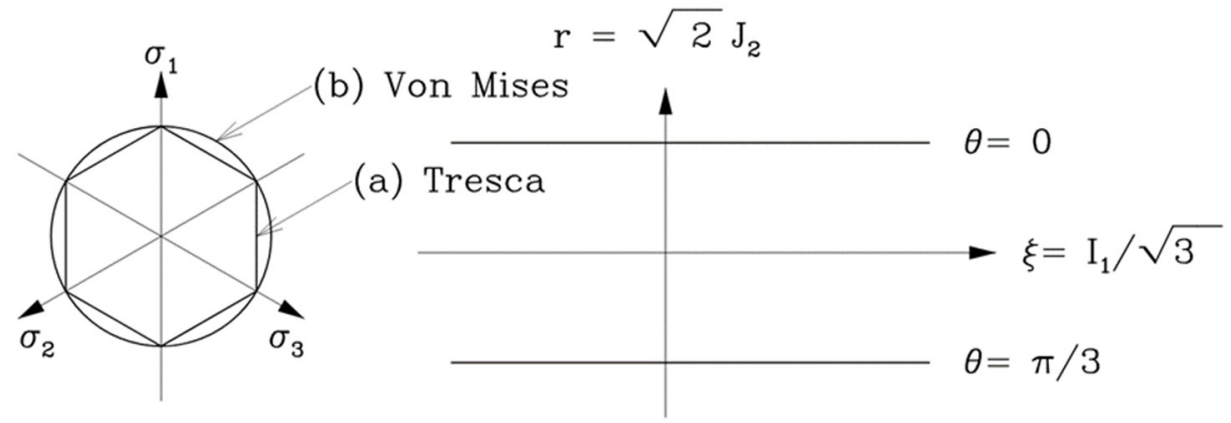

Figure 4.35 Tresca and Von Mises yield condition (in $\pi$ and rendulic plane)

The yield function of Von Mises is defined as Expression (4.102).

$$
f(\sigma, \eta, \kappa)=\sqrt{3 J_{2}}-\bar{\sigma}(\kappa)=\sqrt{\frac{1}{2}(\sigma-\eta)^{\mathrm{T}} \mathbf{P}(\sigma-\eta)}-\bar{\sigma}(\kappa)
$$

Where $\sigma(\kappa)$ is the uniaxial yield strength expressed as a function of the internal state variable $\kappa$ and $\eta$ is the back stress or the centre of the yield circle on the $\pi$ plane (see Figure 4.35), which moves in the direction of the plastic flow if kinematic hardening effect is considered. The projection matrix $\boldsymbol{P}$ is defined as Expression (4.103).

$$
\mathbf{P}=\left[\begin{array}{cccccc}
2 & -1 & -1 & 0 & 0 & 0 \\
-1 & 2 & -1 & 0 & 0 & 0 \\
-1 & -1 & 2 & 0 & 0 & 0 \\
0 & 0 & 0 & 6 & 0 & 0 \\
0 & 0 & 0 & 0 & 6 & 0 \\
0 & 0 & 0 & 0 & 0 & 6
\end{array}\right]
$$

The flow rule is expressed by the associated flow rule $g \equiv f$, which results for the plastic strain rate vector in Expression (4.104).

$$
\dot{\varepsilon}^{\mathrm{p}}=\dot{\lambda} \frac{\mathbf{P}(\sigma-\eta)}{2 \bar{\sigma}}
$$


The evolution of back stress $\eta$ is given as Expression (4.105).

$$
\dot{\eta}=\frac{2}{3}(1-\gamma) \frac{\partial \bar{\sigma}}{\partial \kappa} \dot{\lambda} \frac{\mathbf{P}(\sigma-\eta)}{2 \bar{\sigma}}
$$

Where $\gamma$ is a scalar parameter $(0 \leq \gamma \leq 1)$. The parameter $\gamma$ controls the contribution of the isotropic and kinematic hardening effect. If $\gamma=1$, only the isotropic hardening effect is considered i.e. $\eta^{*}=0$. If $\gamma=0$, only the kinematic hardening effect is considered. For intermediate value of $\gamma$, e.g. $\gamma=0.5$, mixed isotropic and kinematic hardening effects are taken into account.

The hardening hypothesis defines the relation between the internal state variable $\kappa$ and the plastic process. In this case, the strain hardening hypothesis is considered for the Von Mises yield condition, which is defined in the principal space by Expression (4.106).

$$
\dot{\kappa}=\sqrt{\frac{2}{3}\left(\dot{\varepsilon}_{1}^{\mathrm{p}} \dot{\varepsilon}_{1}^{\mathrm{p}}+\dot{\varepsilon}_{2}^{\mathrm{p}} \dot{\varepsilon}_{2}^{\mathrm{p}}+\dot{\varepsilon}_{3}^{\mathrm{p}} \dot{\varepsilon}_{3}^{\mathrm{p}}\right)}
$$

Which can be easily expressed as defined in Expression (4.107).

$$
\dot{\kappa}=\dot{\lambda}
$$

\subsection{Chapter summary and relevant conclusions}

In this chapter, the definition and the implementation of the numerical non-linear finite element model (NLFEM) that is going to be used in this work for the study of the tensile behaviour of UHPFRC from the modelling at material level to the structural application is carried out. This constitutes the adaptation and application of the material model developed in chapter 3 to the finite element modelling technique, leading to the numerical definition of the 2D and 3D model developed and applied in the UHPFRC experimental tests modelled in the following chapters of this work.

To develop the model, the finite element method is employed. This method is a numerical technique that allows the integration of the differential equations that define the equilibrium of a generic differential element in which a structural element is discretised. With this technique, an incremental-iterative structural non-linear analysis 
can be developed considering the boundary conditions, the distribution of the mechanical properties of the materials that define the structure, the type of loads, etc.

The material model for UHPFRC defined in chapter 3 to describe its constitutive behaviour and the cracking mechanism is adapted to the application of the finite element method. To define the finite element model (FEM), the structural element $\left(L_{e}\right)$ is discretizsd in finite elements $\left(L_{e f}\right)$. In this sense, the material model for UHPFRC explained in chapter 3 to model the entire structural element is now used to model each of the finite element that discretises the entire element.

For the smeared cracking approach adaptation, the smeared crack model is applied to obtain the stress $(\sigma)$-mean total strain $\left(\varepsilon_{m, e f}\right)$ in each finite element length $\left(L_{e f}\right)$. Therefore, in the FEM the smeared crack model is dependent on the finite element size $\left(L_{e f}\right)$. The exact finite element length that represents the exact crack energy in the formation of the crack surface curve is set when the length of the finite element chosen fits exactly the crack bandwidth, i.e., $L_{e f}=b_{w}$. In this case, all the displacement obtained when UHPFRC in the finite element cracks is due to the cracking strain and the crack energy is preserved in the smeared transformation in the finite element.

In addition, from the numerical point of view, the continuum models manifest a pathological sensitivity of the results to the size of the finite elements. To avoid this problem and the numerical algorithm properly captures the most localised solution, the softening region produced by the strain localisation when the crack is developing $\left(h_{b}\right)$ should be extended over the length of a finite element $\left(L_{e f}\right)$. Therefore, it can be stated that the optimum application of the finite element method in a smeared crack model where the strain localisation is modelled in a narrow band is produced when $h_{b} \approx L_{e f} \approx$ $b_{w}$.

For the case of UHPFRC, the crack bandwidth and crack energy are not completely calibrated and, therefore, many regularisation techniques for plain concrete could be not directly applicable. Moreover, the use of commercial finite element software packages could difficult the adaptation of a regularisation technic in the case of new materials due to their limited availability of material models and their restricted capacity for new implementations. Therefore, the problem of mesh size dependency for continuum models is frequently addressed calibrating the size of the finite element using different sizes and comparing to the experimental results.

If the crack path is clearly known beforehand or its position seems to be predictable, it could be reasonable to apply a continuum model with discontinuities. In the discrete cracking approach for UHPFRC developed in this work, the continuous part of the model is described using a stress-strain constitutive behaviour by means of the smeared cracking approach while the discrete discontinuity is modelled taken into account an initiation and propagation criteria to activate a traction-separation law in interface elements located along the crack path. The material behaviour simulated by the FEM with the discrete cracking approach in the overall specimen is very close to the exact 
stress-strain/crack opening material UHPFRC constitutive behaviour. Consequently, when the location of the crack is known and it is set by interface elements following the discrete cracking approach, it is expected that the results of the finite element analysis are going to be very accurate when they are compared to the experimental results, as the crack is accurately represented by its proper traction-separation law leading to a mesh size independent model.

In this work, to carry out the numerical implementation, a finite element software is used. Thus, it is important to know how the software integrates the material models and how they are used in the non-linear analysis to be able to adapt to the particularities of the software the material models theoretically defined for UHPFRC, the steel reinforcement and the interface behaviour between them. Special attention must be paid in the smeared cracking model treatment when a finite element software package is employed. It is important to know which hypotheses are used in the software to transform the stresscrack opening relation into stress-mean total strain and how the material models need to be implemented in the software to be coherent with its theoretical definition. In this direction, it is important to control the definition and implementation of the two main parameters that define the smeared crack model: the crack bandwidth and the fracture energy. 


\section{Chapter 5}

\section{Direct procedure to characterise the UHPFRC tensile constitutive behaviour}

\subsection{Introduction.}

Once the numerical model of UHPFRC has been defined and the way of implementing it in the software considering its particular behaviour by means of stress-strain/crack opening at macroscale and the cracking process at mesoscale level, it is necessary to start with its application and evolution depending on the particularities of the specimen and the experimental process that are modelled. It is important to keep in mind the main objective stablished in this work that is the definition and modelling of the tensile behaviour of UHPFRC. Therefore, all the experimental tests that are employed and modelled are focused to cover this objective. This implies, as it is stated in chapter 3 , that the main fracture mechanism that is going to develop is the fracture mode I. It is also important to emphasise that the non-linear finite element model (NLFEM) defined in this work is based on two approaches: a smeared cracking approach and a discrete cracking approach, each one with its advantages and disadvantages when they are compared.

As it is explained in chapter 3 and chapter 4, the smeared cracking approach does no need to define a crack path, however it is based on a mean total strain $\left(\varepsilon_{m, e l}\right)$ considering all the finite element length $\left(L_{e f}\right)$ that represents the uncracked strain $\left(\varepsilon_{u n c}\right)$ in the uncracked part of the finite element and the mean total strain $\left(\varepsilon_{c}\right)$ in the cracked part of 
the finite element (in the crack bandwidth, $b_{w}$ ). The exact finite element length that represents the exact crack energy in the formation of the crack surface curve is set when the length of the finite element chosen fits exactly the crack bandwidth. This leads to the main disadvantage of the smeared cracking approach: its mesh size dependency.

In this work, no regularisation technique has been used for the smeared cracking approach. However, the experimental results and the results from the discrete cracking approach are used to calibrate the finite element size that may represent the UHPFRC crack bandwidth and, therefore, the exact element length $\left(L e_{\text {exact }}\right)$ that can generate the most accurate results for the smeared cracking approach. In this sense, the discrete cracking approach can be considered mesh size independent as the crack is modelled by means of an interface behaviour represented by a stress-crack opening law and, consequently, no average strain is set depending on the finite element length $\left(L_{e f}\right)$. As the main disadvantage of the discrete cracking approach is the need to know the crack path beforehand, it could be minimised if this path is really known more or less due to the particular experimental test modelled. This is the main reason why the discrete cracking approach can be used as an objective approach to calibrate the UHPFRC crack bandwidth in this chapter and, therefore, adjust the smeared cracking approach of the model.

As it is explained in chapter 3 , to obtain the characteristic parameters that define the UHPFRC tensile behaviour, the four point bending test (4PBT) is employed due to its simplicity and its suitability to represent the microcracking stage that characterises the UHPFRC tensile response. As this is a bending test, to obtain the tensile behaviour it is necessary to use an inverse analysis. In this work, an inverse analysis methodology based on a non-linear hinge model defined for UHPFRC that exhibits strain-hardening behaviour has been used.

To study all the range of UHPFRC, an experimental programme of 4PBT specimens is carried out covering the UHPFRC behaviour from SH to SS at different levels. The main idea pursued in this chapter is that the process to characterise the UHPFRC tensile behaviour should be simple and easy to apply so that its application is direct. Therefore, this chapter presents the development of a complete process to obtain the tensile constitutive parameters of UHPFRC and a numerical NLFEM able to model the tensile UHPFRC behaviour without reinforcement supported by an extensive 4PBT experimental programme carried out specifically to get this purpose.

Considering that the 4PBT specimens employed to characterise the tensile behaviour of UHPFRC does not have reinforcement bars, the model with its smeared cracking approach and the discrete cracking approach does not take into account the steel and the interface behaviour between UHPFRC and reinforcement steel explained in chapter 3 . This fact is going to take an important influence in the results concerning these two approaches.

As one of the main objectives of this work is to establish a complete process to characterise the UHPFRC tensile behaviour in both cases: when exhibits strain- 
hardening tensile behaviour (SH-UHPFRC) and also when exhibits strain-softening tensile behaviour (SS-UHPFRC), the main subject of this chapter is to model the 4PBT, to validate numerically the inverse analysis for the case of SH-UHPFRC and to adapt it defining, if it is necessary, any improvement to use it for the case of SS-UHPFRC. Finally, taking into account the database obtained from the experimental 4PBT programme carried out here, a predicting application is developed in order to avoid the variability in the application of the simplified inverse analysis. This application can be considered a good starting point in order to improve the robustness of the direct process to characterise the UHPFRC tensile behaviour here developed.

\subsection{Four point bending test}

As it is stated in chapters 2 and 3, to obtain the tensile behaviour of UHPFRC, the unnotched Four Point Bending Test (4PBT) is considered in this work the most suitable test because it generates a large area with a relatively constant bending moment. Therefore, the micro-cracking process that characterises this concrete in its hardening/softening part is free to develop. Figure 5.1 shows the scheme of the 4PBT (Figure 5.1(a)) and the development of the microcracking phase between the load rollers where the moment is expected to be relatively constant up to the macrocrack apparition (Figure 5.1(b)).

(a)

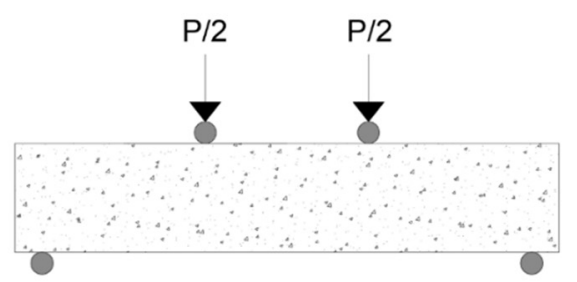

(b)

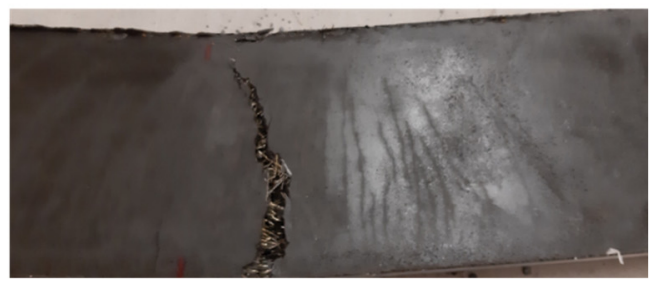

Figure 5.1 (a) Four-Point Bending Test and (b) micro-cracking process and macrocrack localisation of UHPFRC

Figure 5.2 summarises schematically the set up and the geometry of the 4PBT used in this work. The total size of the specimens cast for the 4 PBT is $500 \times 100 \times 100 \mathrm{~mm}$. The length of the span (L) between roller supports is $450 \mathrm{~mm}$, the specimen depth $(\mathrm{h})$ is $100 \mathrm{~mm}$ and the specimen width (b) is $100 \mathrm{~mm}$. The distance between load rollers is $\mathrm{L} / 3$ $=150 \mathrm{~mm}$. Therefore, the slenderness ratio $(\mathrm{L} / \mathrm{h})$ of the specimen is 4.5 . Because of their characteristic geometry, this 4PBT is also known as third-point bending test (ThirdPBT). 


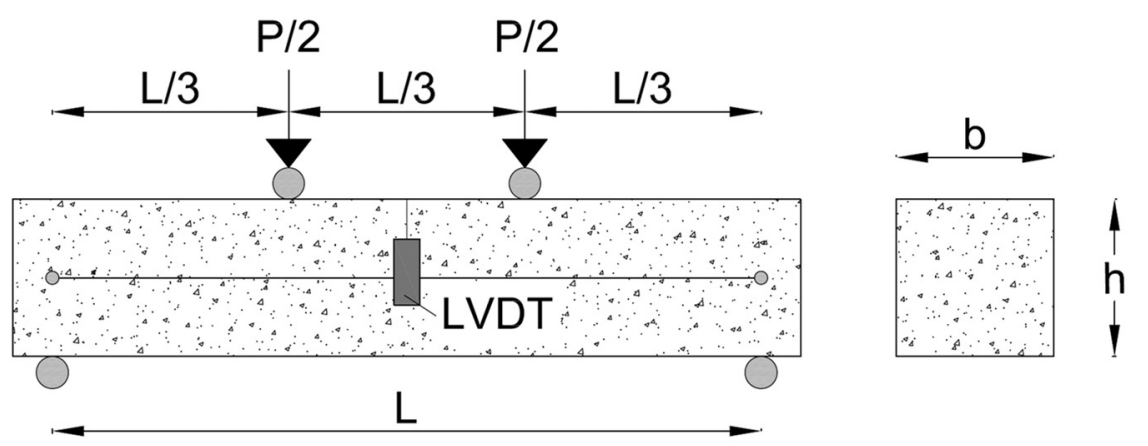

Figure 5.2 Specimen size and degrees of freedom for the 4PBT

Tests are carried out at a constant frame displacement rate of $0.05 \mathrm{~mm} / \mathrm{min}$ up to maximum load. From this point onwards, the frame displacement rate is increased up to $0.2 \mathrm{~mm} / \mathrm{min}$. The test finishes when a load equal to $70 \%$ of the maximum is reached in the unloading branch.

To obtain the load (P)-displacement $(\delta)$ at mid span curve, two Penny \& Giles Controls Ltd displacement transducers are placed one in the front side and the other in the back side, shown in Figure 5.3(left). The 4PBT is carried out by means of a 3382J8440 Instron testing machine with a bearing capacity of $100 \mathrm{kN}$. As a result, P- $\delta$ at mid span curves from each displacement transducer (DT1 and DT2) and the average curve are obtained (Figure 5.3(right)). Together with the displacement at mid-span, the distance of the crack tip to the mid-span section measured at the top face (d) has been obtained as this parameter is needed for the 4P-IA application. The equivalent bending stress is obtained following Expression (5.1).

$$
\sigma=\frac{P \cdot L}{b \cdot h^{2}}
$$



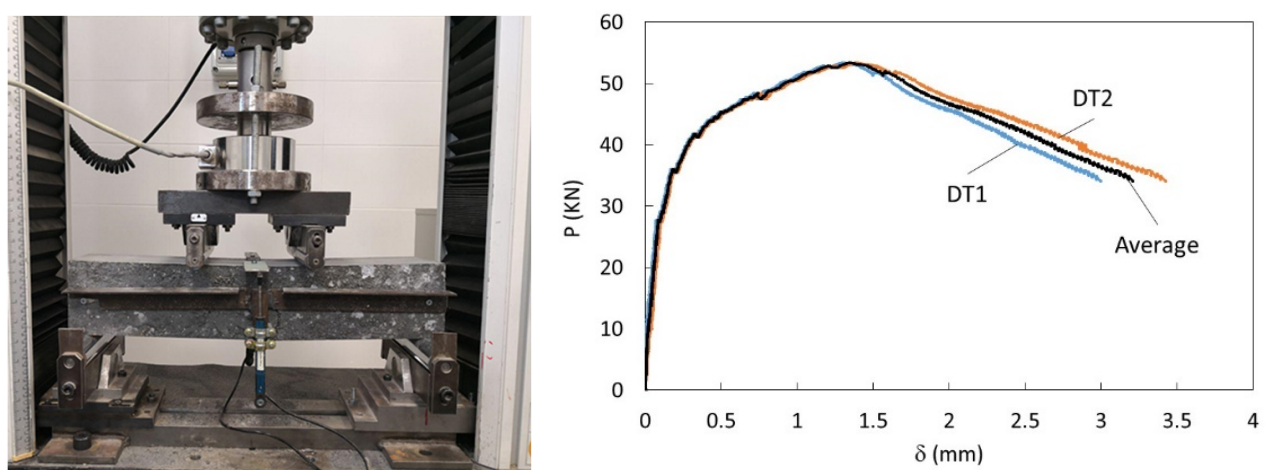

Figure 5.3 4PBT set up (left) and resulting P- $\delta$ curves (right)

\subsection{Strain-hardening UHPFRC and material validation}

Currently, the characterisation of UHPFRC tensile behaviour can be assumed a challenge. Due to their simplicity, 4PBTs are one of the best tests to achieve this purpose. Nevertheless, they require running an inverse analysis methodology to derive tensile properties based on the obtained results.

In this work, an inverse analysis method that was developed properly in the research group for UHPFRC that exhibits SH behaviour is chosen. As it is set in chapter 3 and Annexe I, the Simplified Four-Point Inverse Analysis Method (4P-IA) developed in (López 2017; López et al. 2017), is a simplified methodology based on the closed-form nonlinear hinge model developed in (López 2017; López et al. 2016). It entails having to select four specific key points extracted from the experimental 4PBT equivalent bending stress-displacement on the mid-span curve (see Figure 5.4). Using these points, the parameters defining the assumed simplified trilinear $\sigma-\varepsilon / w$ law inside the hinge can be determined by a back-of-the-envelope calculation. This law is used to determine the constitutive tensile behaviour of SH-UHPFRC.

The proposed UHPFRC constitutive model for the 4P-IA defined in this work (see Figure 4.27 in chapter 4$)$ is depicted in Figure 5.4 according to the following parameters: elastic modulus $(E)$; the unloading modulus $\left(E^{*}\right)$; tensile strength $\left(f_{t}\right)$; ultimate tensile strength $\left(f_{t u}\right)$ and its associated strain $\left(\varepsilon_{t u}\right)$; crack opening at the intersection of the line that defines the initial slope to the $w$ axis $\left(w_{0}\right)$. Therefore a simplified trilinear $\sigma-\varepsilon / w$ constitutive behaviour is proposed. 


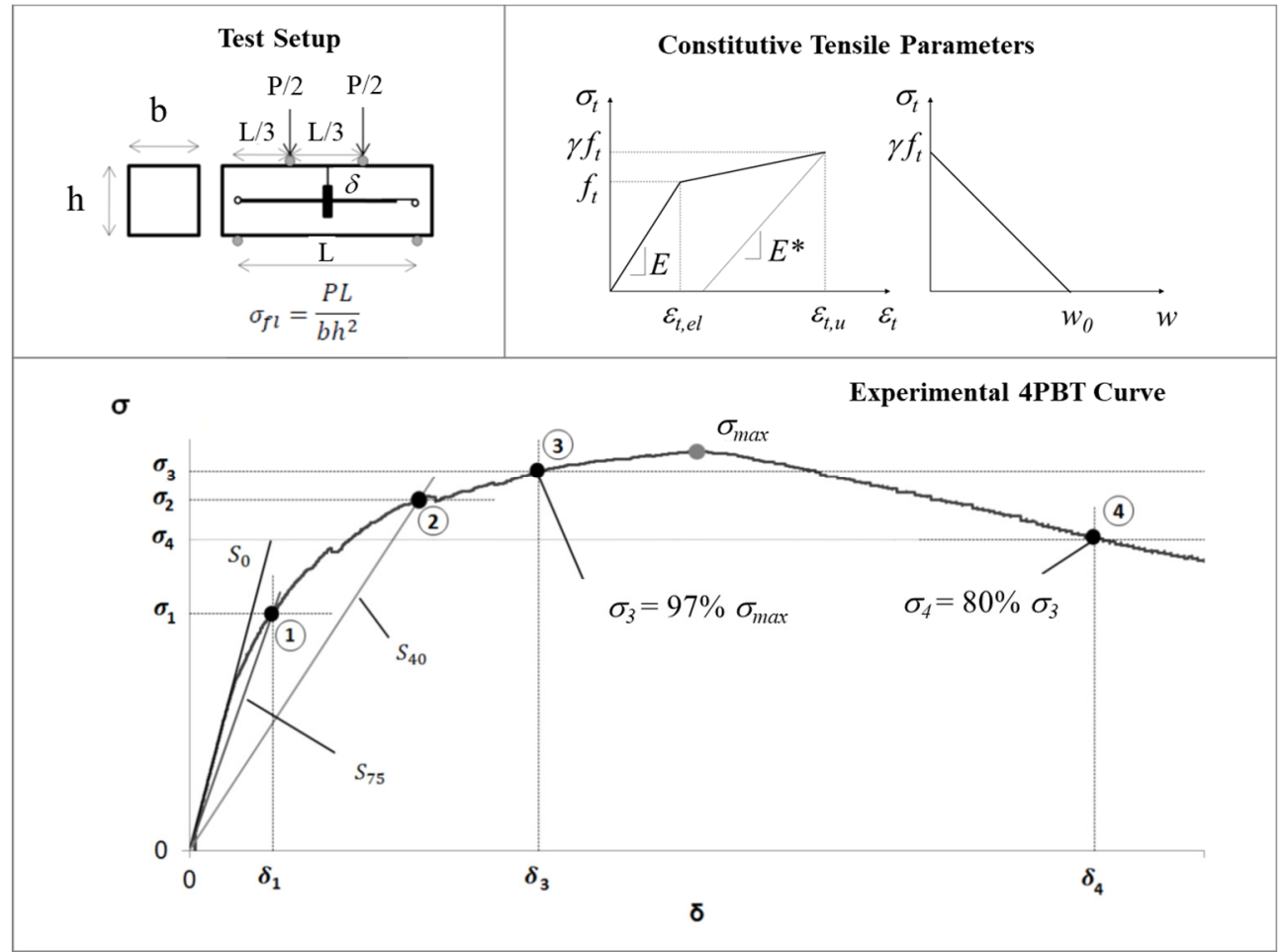

Figure 5.4 Simplified 4P-IA

The objective now is to validate numerically the inverse analysis methodology developed in (López 2017) to obtain the simplified 4P-IA for SH-UHPFRC using the NLFEM. As the simplified 4P-IA is a resulting simplification of the closed form iterative inverse analysis and the simplified 5P-IA developed in (López 2017) and explained in chapter 3 and Annexe I, this entails having to consider them in the numerical validation. Therefore, the numerical validation proposed in the following consists on the definition of the tensile material behaviour of the SH-UHPFRC in the NLFEM from the obtained tensile constitutive parameters using these two methods, model the 4PBT and compare the results obtained to the experimental ones. The NLFEM follows the theoretical and numerical background presented in chapter 3 and chapter 4 . To do this, the results from the experimental programme carried out in (López 2017) concerning to the tensile parameters and experimental $\sigma-\delta$ curves for SH-UHPFRC are used. The setup and the results of this experimental programme are detailed in Annexe I.

\subsubsection{Numerical non-linear finite element modelling (NLFEM)}

Crack formation and propagation can be a very important non-linear process in concrete structures. Nowadays, FE-codes based on non-linear material models are capable of very 
accurately predicting the mechanical behaviour of concrete structures subjected to loads with different grades of complexity. With the evolution of new materials such as UHPFRC, it is necessary to both review and adapt concrete material models (Tysmans et al. 2015).

Two different approaches are frequently used in FE-codes for computational simulations of crack propagation in RC structures: the smeared and discrete crack approaches (Rots 2002; Rots and Blaauwendraad 1989b). The discrete crack approach models a crack as a geometrical discontinuity. Such models are used mainly in structures in which the crack path is known beforehand (Sadouki et al. 2017). In the smeared crack approach, cracks are assumed to be smeared over continuum finite elements and no predefined position of cracks is needed. A cracked material is then treated as a continuum, but with modified material properties to account for cracking (Sadouki et al. 2017).

If the classification stablished in chapter 2 is attended, the smeared crack models are included in the continuum models group and the discrete crack approach in the continuum models with discontinuities. As it is stated in chapter 3 concerning the modelling at material level, the idea behind the smeared crack model is to treat the discontinuity in the displacement field generated by the macrocrack as a continuum by means of a stress-mean total strain smeared in the overall length of the element. This mean total strain $\left(\varepsilon_{m}\right)$ is obtained considering all the element length $\left(L_{e}\right)$ that represents the uncracked strain $\left(\varepsilon_{u n c}\right)$ in the uncracked part of the element and the mean total strain $\left(\varepsilon_{c}\right)$ in the cracked part of the element defined as the process zone or crack band $\left(b_{w}\right)$. As it is explained in chapter 4, when the material smeared crack model is adapted to the finite element method to develop the numerical model, the exact finite element length that represents the exact crack energy in the formation of the crack surface is set when the length of the finite element $\left(L_{e f}\right)$ chosen fits exactly the crack bandwidth $\left(b_{w}\right)$. This fact generates the mesh size dependence of the smeared cracking approach developed.

In this work, no regularisation technique has been used to make mesh size independent the smeared cracking approach. Instead of this, a discrete cracking approach is developed to calibrate the UHPFRC crack bandwidth $\left(b_{w}\right)$, here assumed as a material characteristic, that leads to define the adequate mesh size to obtain reliable results in the smeared cracking approach. In the discrete cracking approach, the macrocrack is modelled considering interface elements along the crack path in which their constitutive law is defined by means of UHPFRC stress-crack opening relationship. Thus, it is expected mesh size independent. Even though in the case of the discrete cracking approach it is necessary to know the crack path beforehand, in the case of the 4PBT it could be more or less predictable. If an ideal situation is set, it could be expected that the macrocrack will appear in the centre of the specimen. This could be a good starting point for the discrete cracking approach.

In this work, numerical modelling is developed using the FE software Diana (see section 4.4 of chapter 4). As a commercial FE software package is used, it is very important to know how the mean total strain in the smeared cracking approach is addressed to 
correctly adapt the theoretical definition of the smeared crack model and its relation with the crack bandwidth. It becomes necessary to correctly introduce the crack bandwidth in order to represent adequately the real fracture energy $\left(G_{F}\right)$ to define the crack formation in the crack bandwidth $\left(b_{w}\right)$. This is detailed in section 4.4.1.4 in chapter 4 , where the adaptation of the uniaxial constitutive model for the smeared crack model and the implications of the crack bandwidth definition by means of the Rots' element based method is addressed for the software Diana.

As it is explained in section 4.4.1.4 in chapter 4 , as the real crack bandwidth $\left(b_{w}\right)$ for the UHPFRC is unknown, the idea is to calibrate using the experimental results and the discrete cracking approach of the FEM developed, as this is considered mesh size independent, the adequate crack bandwidth $\left(b_{w}\right)$ of UHPFRC and, thus, the adequate element length $\left(L e_{\text {exact }}\right)$ by "trial-and-error" for the smeared cracking approach of the FEM. To model the UHPFRC constitutive behaviour in the smeared cracking approach, the fédération internationale du béton/International Federation for Structural Concrete (fib) working groups stress-crack opening curve is used. In this sense, scenario 1 (see section 4.4.1.4.1 in chapter 4) is set, assuming that the real crack band $\left(b_{w}\right)$ equals Diana's proper definition of the crack bandwidth $\left(b_{w, D I A N A}\right)$ and, by means of the Rots' element based method, equals the finite element length $\left(L_{e f}\right)$. Therefore, a finite element length $\left(L_{e f}\right)$ is assumed and, after the FE analysis, the results in terms of stress-deflection at mid-span of the 4PBT modelled are compared to the experimental results and the discrete cracking approach. If the results do not fit, another finite element length $\left(L_{e f}\right)$ is set and the FE analysis of the 4PBT model are compared again until the assumed fitting. In this sense, an inverse analysis procedure considering the length of the finite element $\left(L_{e f}\right)$ is, in a way, established. As a result, the exact finite element length $\left(L e f_{\text {exact }}\right)$ is obtained and, by means of the Rots' element based method, the real crack bandwidth $\left(b_{w}\right)$ of UHPFRC.

Therefore, to model the 4PBT by means of a finite element model (FEM) using Diana, the particularities of the material models adapted to this kind of experimental test and the FEM definition are explained in this section. Moreover a 2D FEM is developed leading to the definition of the finite element mesh used to discretise the UHPFRC specimen. As the 4PBT used to characterise the UHPFRC tensile behaviour is unreinforced, the finite element mesh is set to model the UHPFRC for the smeared and discrete cracking approach and the interface element for the macrocrack modelling in the discrete cracking approach. The definition of the load and the boundary conditions are also represented and finally, the incremental-iterative analysis procedure is set.

\subsubsection{Constitutive behaviour}

As it is explained in chapter 3 and chapter 4 , to model the tensile UHPFRC constitutive behaviour, two different approaches are used: a smeared cracking approach and a discrete cracking approach. 


\section{Smeared cracking approach}

As it is set in section 4.4.1.4 in chapter 4, in this approach, the constitutive model for UHPFRC is based on a fixed total strain crack model expressed according to the crackopening curve. As the general fracture mode developed in the 4PBT is mode-I, it is expected that the fixed crack concept and the rotating one generate quite similar results. In the smeared cracking approach, to model UHPFRC tensile behaviour in the software Diana, the "fibre-reinforced concrete model (FRCCON)" from the Fédération Internationale du Béton/International Federation for Structural Concrete (fib) working groups is used as a constitutive model (see Figure 4.18). The model can be specified according to either the total strain or the crack opening. These two functions are related with the software proper definition of the crack bandwidth parameter $\left(b_{w, D I A N A}\right)$. The crack-opening is transformed into a strain by normalising the crack-opening $(w)$ by the crack bandwidth $\left(b_{w, D I A N A}\right)$.

The crack bandwidth used is obtained from the "Rots' element-based method" (Feenstra 1993; Rots 1988) implemented into Diana, in which $b_{w, D I A N A}$ depends on the size, shape and interpolation function of the finite element used.

For linear two-dimensional elements:

$$
b_{w, D I A N A}=\sqrt{2 A_{e f}}
$$

For higher order two-dimensional elements:

$$
b_{w, D I A N A}=\sqrt{A_{e f}}
$$

where $A_{e f}$ is the total area of the finite element.

\section{Discrete cracking approach}

As it is set in sections 4.4.2 and 4.4.3 in chapter 4, in this approach the constitutive model for UHPFRC is founded on the discrete cracking model as interface behaviour. The constitutive law for discrete cracking in Diana is based on a total deformation theory, which expresses tractions according to the total relative displacements, crack width and crack slip. In this case, to model UHPFRC constitutive tensile behaviour in Diana, a multi-linear function relating the relative displacements $\Delta u_{n}$ normal to the interface and the tensile tractions $t_{n}$ normal to the interface is used (see Figure 4.31).

This behaviour is forced only on the central beam section (see Figure 5.6). To fulfil this objective tensile strength $\left(f_{t}\right)$ and ultimate tensile strength $\left(f_{t, u}\right)$ are reduced by $2 \%$. The rest of the beam is modelled using the model described in the smeared cracking approach. 
To model compression UHPFRC constitutive behaviour, the MC-1990 curve is used in both cases, as it is explained in section 4.4.1.5 in chapter 4 .

\subsubsection{Finite element mesh}

In order to define the finite element model (FEM) once the material constitutive behaviour is adapted, it is necessary to define the geometry of the specimen that is modelled and the finite element mesh that is used to discretise the continuum and to be filled with the material information. As it is stated in section 4.2 in chapter 4 , the size, the shape and interpolation function of the finite element used have direct influence on the solution of the differential equations that define the equilibrium, the discretisation of the results obtained depending on the nodes and the shape functions and the accuracy of the solution by means of the integration points. All of these also have a direct relation to the computational effort to run the analysis and process the results.

The 4PBT has been modelled by means of 2D FEM with a 2D quadratic plane stress eight-node quadrilateral element $(\mathrm{CQ} 16 \mathrm{M})$ when the smeared and discrete cracking approaches are used (see Figure 5.5(left)). Besides, when the discrete cracking approach is used, a quadratic 2D 3+3 nodes line interface element (CL12I) is placed on the central beam section (see Figure 5.5(right)). Figure 5.6 shows the mesh defined for the finite element model. A $10-\mathrm{mm}$ element length is considered in the model as a first attempt to find the exact finite element length $\left(\right.$ Lef $\left.f_{\text {exact }}\right)$ and, considering the Rots' element-based method and scenario 1 , the real crack bandwidth $\left(b_{w}\right)$. Using interface elements, it is possible to model the discrete behaviour of the crack at the mid-span cross-section (Figure 5.6). Steel plates have been defined to model the support and loading plates. These are discretised by means of the same 2D quadratic plane stress CQ16M element used for the UHPFRC. The specimen is simply supported for the boundary conditions and the load is applied to the steel load plates by gradual increasing displacement.
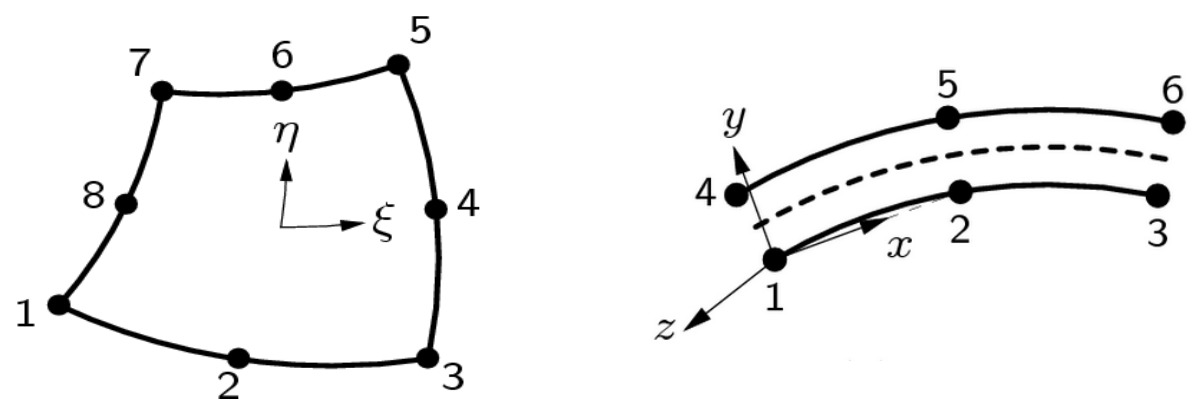

Figure 5.5 CQ16M (left) and CL12I (right) (DIANA (Software) 2017) 


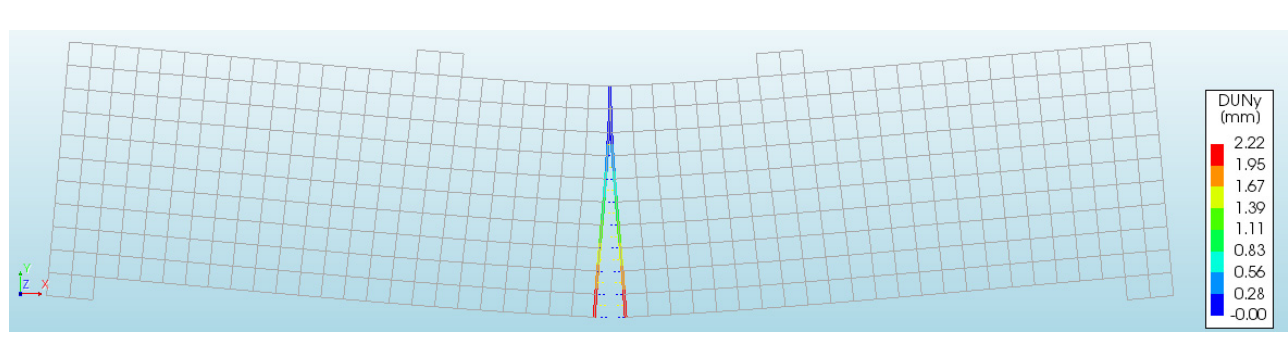

Figure 5.6 Interface-relative displacements for the Discrete Cracking Approach

\subsubsection{Analysis procedure}

As it is explained in section 4.2.2 in chapter 4, in non-linear finite element analysis it is frequently used an incremental-iterative solution procedure to obtain the response of a structural model under the influence of an established loading history. This is the type of analysis used to define the 4PBT structural model here. In this sense, it becomes necessary to differentiate between the criterion that stablish the size of each incremental step in the incremental part of the incremental-iterative procedure, and the iterative method that solves the equilibrium equations in each incremental step in the iterative part of the incremental-iterative procedure (see Figure 4.2). It is important to set the most appropriate nonlinear structural analysis strategy not only from the point of view of the stability of the analysis but also for the reliability and accuracy of the results.

For the load steps application (the incremental part), an adaptive loading iteration-based method is used. The size of increments is limited by the convergence characteristics of the selected iteration process. The allowable step size depends on the amount of the nonlinearity in the increment, which is used in combination with the Arc-length method. As the objective of the analysis is to go through the softening branch of the loaddisplacement structural response, it is therefore necessary to use strategies able to continue the load-displacement diagram beyond its peak. This is the reason why the direct displacement control to stablish the incremental step is used by means of the definition of the load as an imposed displacement, as it is detailed in section 4.2.2 in chapter 4 .

For the iterative part, the Modified Newton-Raphson method is carried out because, in situations where Regular Newton-Raphson does not converge any more, the Modified Newton-Raphson process can sometimes still converge. Moreover, a Line Search algorithm is also used because, in structures with strong nonlinearities, for instance cracking, Line Search algorithms can increase the convergence rate and are especially useful if the ordinary iteration process fails. To check the convergence of the iteration process, the energy norm is used. 
When the objective of the analysis is to study the structural response from the peak of the load-displacement diagram onwards through the softening branch of the material constitutive behaviour, it is important to understand that the analysis becomes very unstable leading to a great effort to find the adequate analysis strategy that ensures an adequate equilibrium between convergence, accuracy of the results and computational effort. The analysis strategy designed to get this purpose has an important influence in the results, especially for the case of the smeared cracking approach.

\subsubsection{NLFEM application}

The tensile material properties obtained as result of the application of I-IA and 5P-IA from experimental programme described in Annexe I are implemented into the numerical 2D-NLFEM developed for the 4PBT described in section 5.3.1 and compared to the experimental programme results. In the following, the most important particularities of the results are described after the application of the two approaches for the UHPFRC material model applied to the finite element method developed in this work: the smeared cracking approach and the discrete cracking approach.

\subsubsection{Smeared cracking approach}

To calibrate the real crack bandwidth $\left(b_{w}\right)$ of the UHPFRC and, therefore the exact finite element length $\left(L_{e f}\right)$, the same idea followed by (Rots 1988) and explained in section 4.4.1.4 of chapter 4 has been carried out. This is, using the experimental results and the discrete cracking approach of the FEM developed, as this is considered mesh size independent, the calibration of the adequate crack bandwidth $\left(b_{w}\right)$ of UHPFRC and, thus, the adequate finite element length $\left(\right.$ Lef $_{\text {exact }}$ ) has been carried out by "trial-and-error" for the smeared cracking approach of the FEM.

As the UHPFRC material crack bandwidth $\left(b_{w}\right)$ is unknown, to calibrate its value using the smeared cracking approach, it is assumed the case explained in scenario 1 and the curve is implemented by means of stress-crack opening curve using the fédération internationale du béton/International Federation for Structural Concrete (fib) working groups stress-crack opening curve ((n) option in Figure 4.18) in phase 1 of Diana. In this sense, it is assumed that $L_{e f}=b_{w}$, this is, the real crack bandwidth $\left(b_{w}\right)$ equals the Diana's crack bandwidth $\left(b_{w, D I A N A}\right)$ that leads to the Lefexact solution in Figure 4.7 and the situation described in Figure 4.8 and Figure 4.9 in section 4.3.1 in chapter 4.

Figure 5.7 shows the four elements sizes $\left(L_{e f}\right)$ used to calibrate the smeared cracking approach: 5, 10, 20 and $50 \mathrm{~mm}$. Therefore, each time as the element size $\left(L_{e f}\right)$ is changed and the smeared cracking approach is run, the model considers that its material crack bandwidth $\left(b_{w}\right)$ is the element size $\left(L_{e f}\right)$ used. An iterative process is developed trying with an element size $\left(L_{e f}\right)$, running the smeared cracking approach and comparing the stress $(\sigma)$-deflection at mid span $(\delta)$ curve obtained as a result of the NLFEM and the experimental $\sigma-\delta$ curve. 
Figure 5.8 shows the equivalent bending stress $(\sigma)$-deflection at mid span $(\delta)$ curve obtained as a result of the 2D-NLFEM when the smeared cracking approach is used for element sizes $\left(L_{e f}\right): 10,20$ and $50 \mathrm{~mm}$, when the constitutive parameters resulting from IIA for specimen number 6 with $h=100 \mathrm{~mm}$ (see Table A-I.1 in Annexe I) are implemented into the numerical model. As it can be observed, the smeared cracking approach is completely mesh size dependent as it is based on a continuum $\sigma-\varepsilon$ constitutive model in phase 2 . Therefore, as the $L_{e f}$ is increased, the softening part of the continuum $\sigma-\varepsilon$ constitutive model in phase 2 becomes stiffer, as it is explained in section 4.3.2 in chapter 4 where the inobjectivity of the stress-strain continuum models is addressed (see Figure 4.12). This fact results in a stiffer softening part of the $(\sigma)$ deflection at mid span $(\delta)$ numerical curve as the $L_{e f}$ is increased in the flexural 4PBT, as it can be observed in Figure 5.8 (on the contrary that is expected with the load $(P$ )elongation $(u)$ for the tensile bar in Figure 4.13 in section 4.3.2 in chapter 4). If the $L_{e f}$ chosen is very high, it is important to consider that it could derive in snap-back continuum $\sigma-\varepsilon$ constitutive model in phase 2 and this could lead to numerical problems in the analysis of the NLFEM.

As it can be seen in Figure 5.8, the ascending branch and even the hardening branch of the equivalent bending stress $(\sigma)$-deflection at mid span $(\delta)$ numerical curves when the smeared cracking approach is used for 10, 20 and $50 \mathrm{~mm}$ element size (or crack bandwidth) fit accurately the experimental one. This result is expectable as the ascending branch of the continuum model is exactly the stress-strain part of the material constitutive behaviour of the UHPFRC defined in phase 1 and represented in Figure 3.2 in chapter 3. However, the maximum stress and the softening part of each element size used in the smeared cracking approach do not fit with relevant accuracy the experimental $\sigma-\delta$ curve. Moreover, the maximum stress for the $L_{e f}=50 \mathrm{~mm}$ numerical response seems to be successfully obtained but its softening part is not accurate enough. It seems that the smeared cracking approach of the NLFEM does not preserve the UHPFRC crack energy with reliability. The transformation done for the softening $\sigma-w$ part of the curve defined in phase 1 to the $\sigma-\varepsilon$ softening curve for the continuum model in phase 2 by means of the $b_{w}$ seems not reliable. 

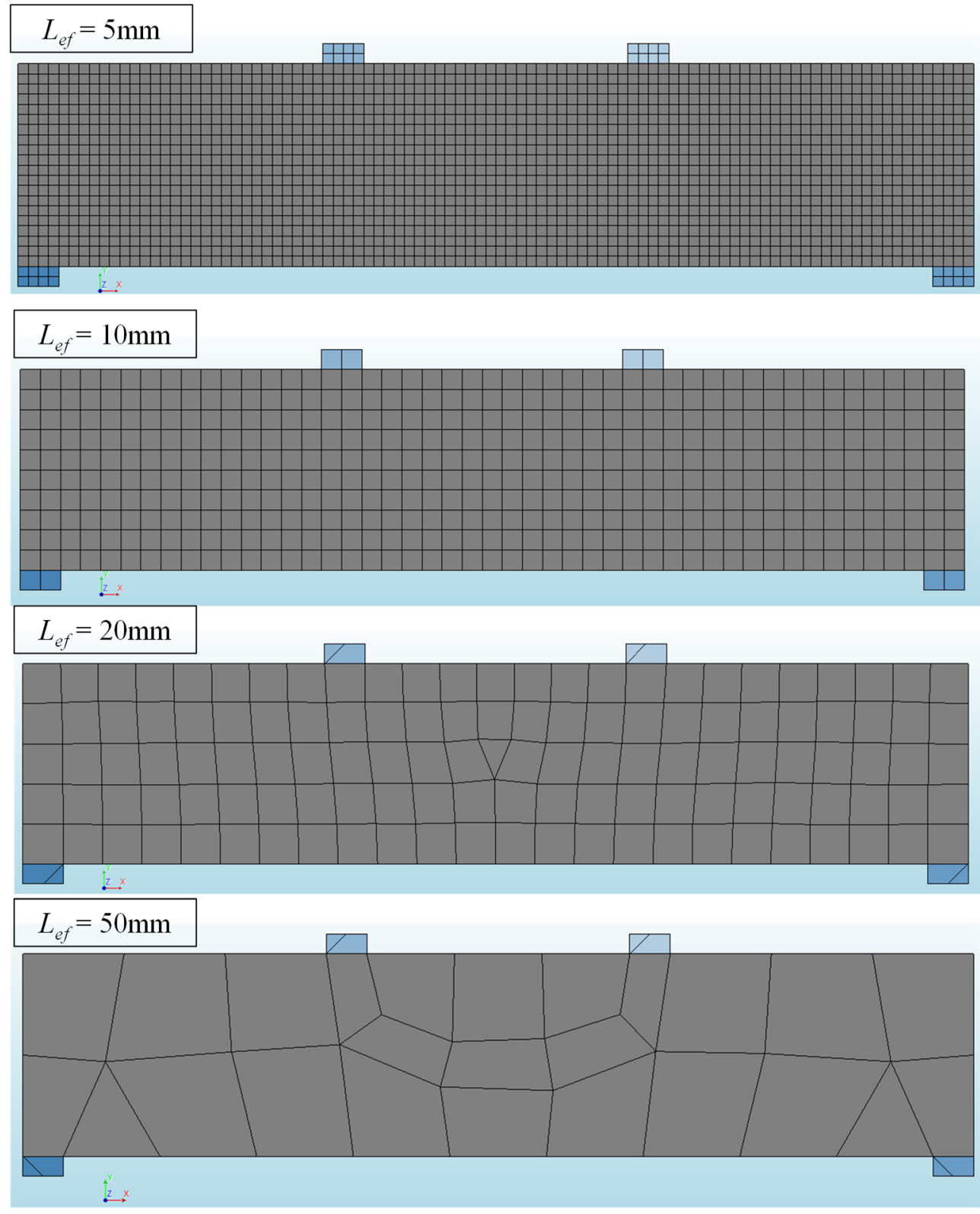

Figure 5.7 Element sizes $\left(L_{e f}\right)$ used in the NLFEM for the smeared cracking approach 


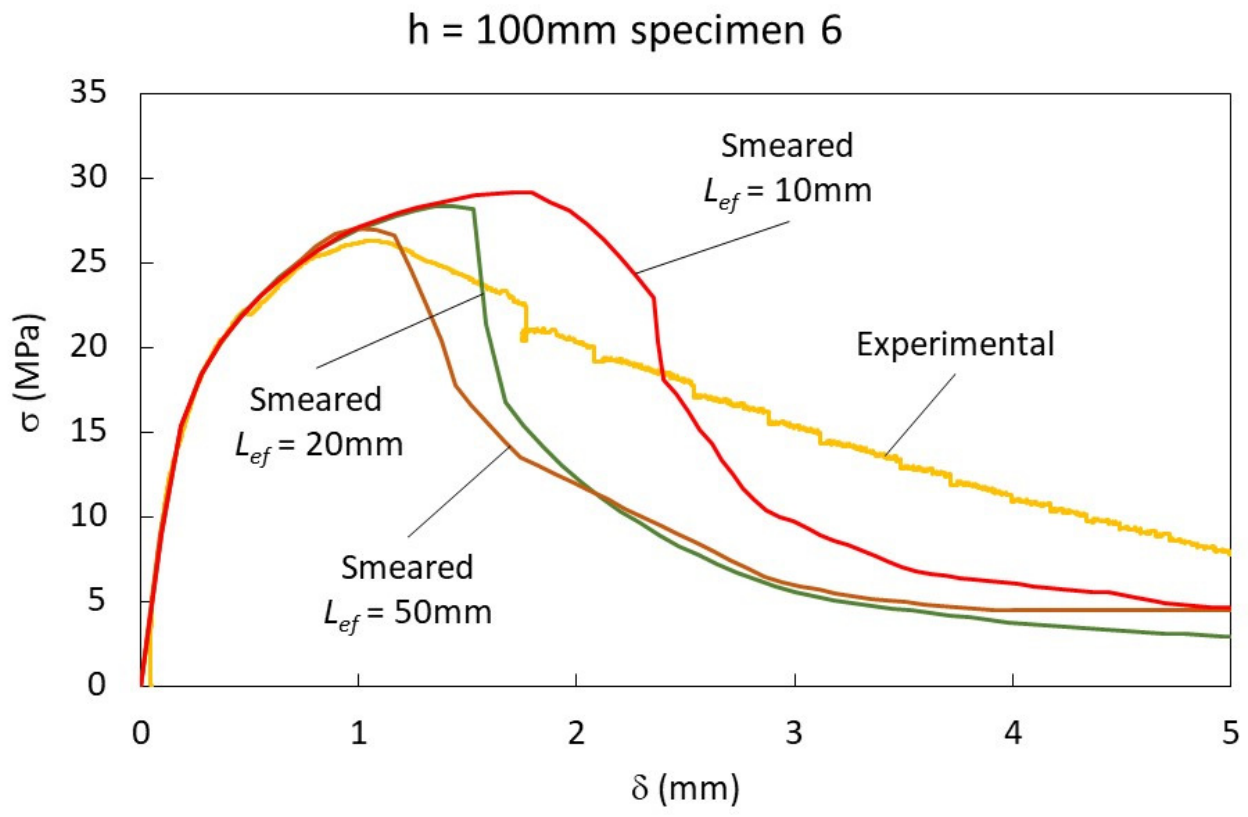

Figure 5.8 NLFEM smeared cracking approach $\sigma$ - $\delta$ curves vs experimental $\sigma$ - $\delta$ curve for $h=100 \mathrm{~mm}$ specimen 6 .

Moreover, it is important to control the type of analysis that is used. Figure 5.9 represents the equivalent bending stress $(\sigma)$-deflection at mid span $(\delta)$ curve obtained as a result of the 2D-NLFEM when the smeared cracking approach is used for $10 \mathrm{~mm}$ element size $\left(L_{e f}\right)$, when the constitutive parameters resulting from I-IA for specimen number 6 with $h=100 \mathrm{~mm}$ (see Table A-I.1 in Annexe I) are implemented into the numerical model. If the type of analysis procedure is changed, a variation of the maximum bending stress and softening branch of the $\sigma-\delta$ curve can be observed too. Therefore, as it can be seen in Figure 5.9 for the smeared cracking approach of the NLFEM, these parts of the model are sensitive to the type of analysis procedure. Consequently, as it is said in section 4.2.2 in chapter 4 , it is important to set the most appropriate nonlinear structural analysis strategy not only from the point of view of the stability of the analysis but also for the reliability and accuracy of the results. Frequently, the criteria to choose the correct strategy depends on the experience and ability of the analyst. 


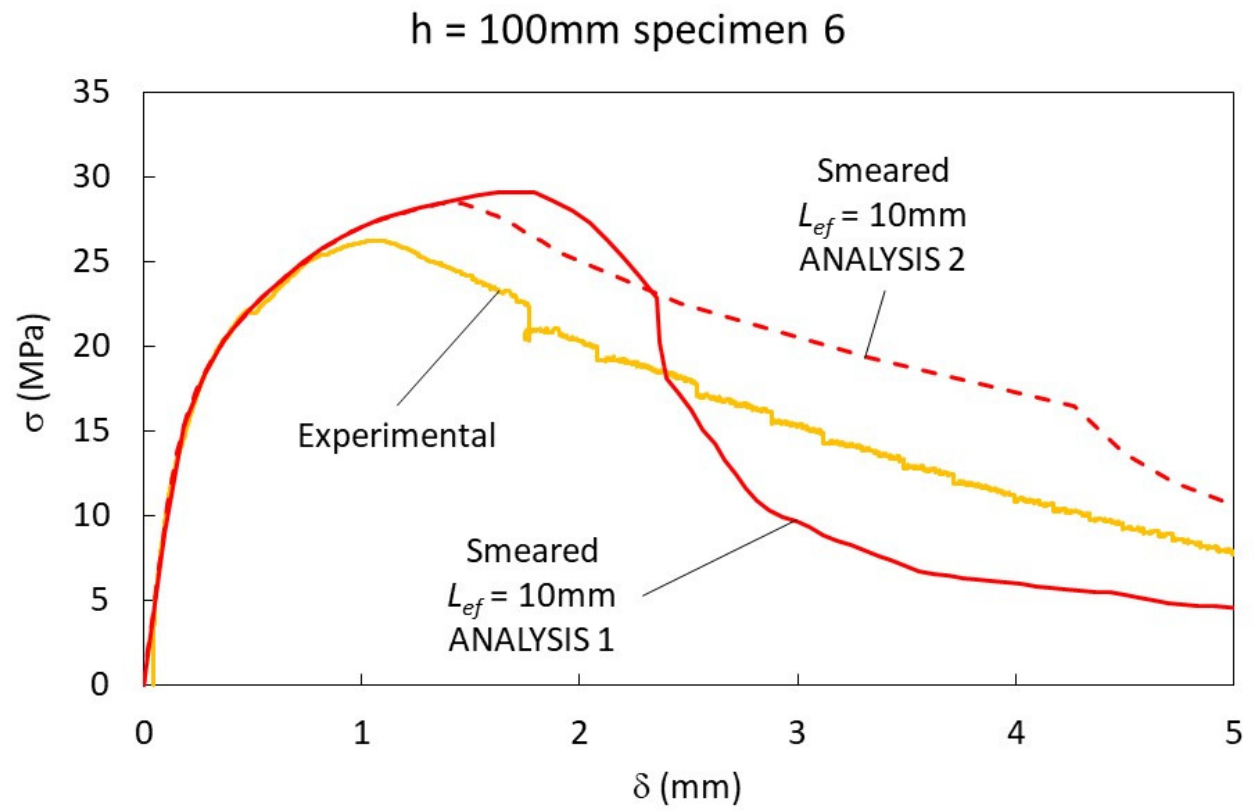

Figure 5.9 NLFEM smeared cracking approach $\sigma$ - $\delta$ curves for $L_{e f}=10 \mathrm{~mm}$ and different analysis vs experimental $\sigma-\delta$ curve for $h=100 \mathrm{~mm}$ specimen 6

In order to improve the smeared cracking approach response, a random variation of the FRCFAC factor that multiplies the values of the UHPFRC tensile stress in the constitutive behaviour has been added in the analysis definition of the 2D-NLFEM to better model the heterogeneity of concrete. In this way, different behaviours can be expected from different runs of the same algorithm. The random field to vary the FRCFAC factor used is based on a Cholesky covariance matrix decomposition using a log-normal distribution.

Table 5.1 shows the values of the correlation length (corlen) and the standard deviation (stddev) of the FRCFAC for the random field used to generate the different runs of the 2D-NLFEM for each element length $L_{e f}$ chosen. The number of grid lines used in the Cholesky decomposition for the random field generation are also detailed: $\mathrm{Nx}$ in $\mathrm{x}$ direction and $\mathrm{Ny}$ in y direction. Therefore, in this way different distribution of the tensile stresses can be obtained to represent a simulation of a real distribution. Figure 5.10 shows the distribution of the FRCFAC factor that multiplies the tensile stress for the three runs (R1, R2 and R3) done for the model of specimen number 6 with $h=100 \mathrm{~mm}$ (see Table A-I.1 in Annexe I) with an element length of $10 \mathrm{~mm}$. As a consequence of this distribution, different random positions of the macro-crack can be generated, as it is 
Chapter 5: Direct procedure to characterise the UHPFRC tensile constitutive behaviour

observed in Figure 5.11 for the three runs done for the 2D-NLFEM with an element length of $10 \mathrm{~mm}$.

Table 5.1 FRCFAC random field generation in the smeared 2D-NLFEM

\begin{tabular}{|c|c|c|c|}
\hline corlen & stddev & $\mathrm{Nx}$ & $\mathrm{Ny}$ \\
\hline 25 & 0.10 & 50 & 5 \\
\hline
\end{tabular}
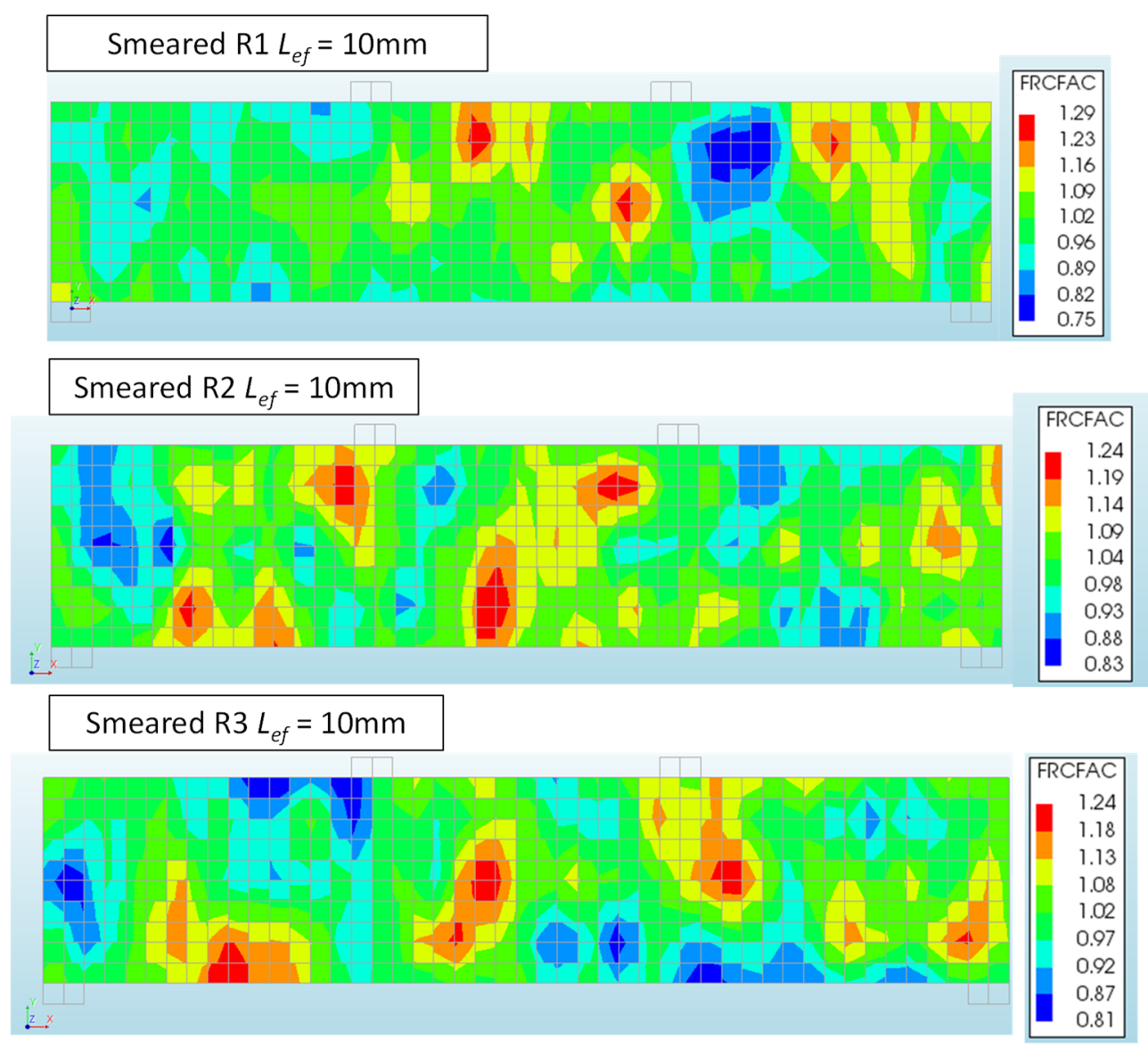

Figure 5.10 Variation of the FRFAC factor 


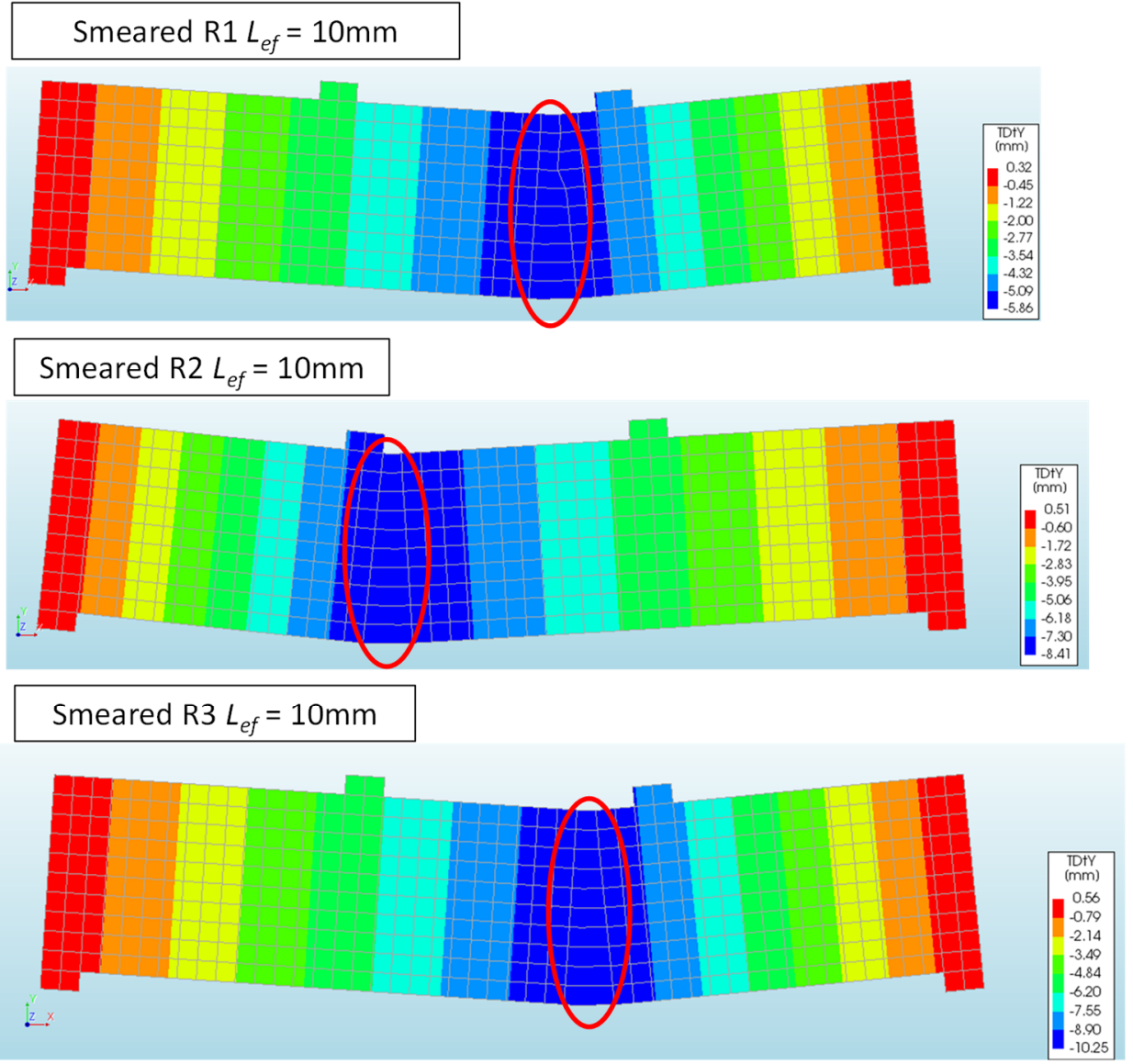

Figure 5.11 Positions of the crack in the random 2D-NLFEM for $L_{e f}=10 \mathrm{~mm}$

Figure 5.12 shows the three equivalent bending stress $(\sigma)$-deflection at mid span $(\delta)$ numerical curves obtained as a result of the smeared cracking approach with the three runs of the random analysis of the 2D-NLFEM of specimen number 6 with $h=100 \mathrm{~mm}$ (see Table A-I.1 in Annexe I) depicted in Figure 5.10 and Figure 5.11. In Figure 5.12, these three curves are also compared with the numerical result without applying the random analysis from Figure 5.8 and with the experimental curve. As it can be observed in Figure 5.12, the application of the 2D-NLFEM with random analysis also models with accuracy the ascending and the hardening part of the $\sigma-\delta$ curve, as it happens with the 2D-NLFEM without the random analysis. Moreover, the 2D-NLFEM with the random analysis also improves the simulation of the maximum bending stress for the case of $L_{e f}$ $=10 \mathrm{~mm}$, especially for the random distribution obtained in run $1(\mathrm{R} 1)$ and run $2(\mathrm{R} 2)$ of 
the analysis. It constitutes and improvement with respect to the 2D-NLFEM without the random application. However, as it can be observed in Figure 5.12, the softening part of all the simulated curves for $L_{e f}=10 \mathrm{~mm}$ with and without the random analysis of the 2DNLFEM do not fit the experimental $\sigma-\delta$ curve. Again, it seems that the smeared cracking approach of the NLFEM does not preserve the UHPFRC crack energy with reliability. The transformation done for the softening $\sigma-w$ part of the curve defined in phase 1 to the $\sigma-\varepsilon$ softening curve for the continuum model in phase 2 by means of the $b_{w}$ seems not reliable for the case of UHPFRC.

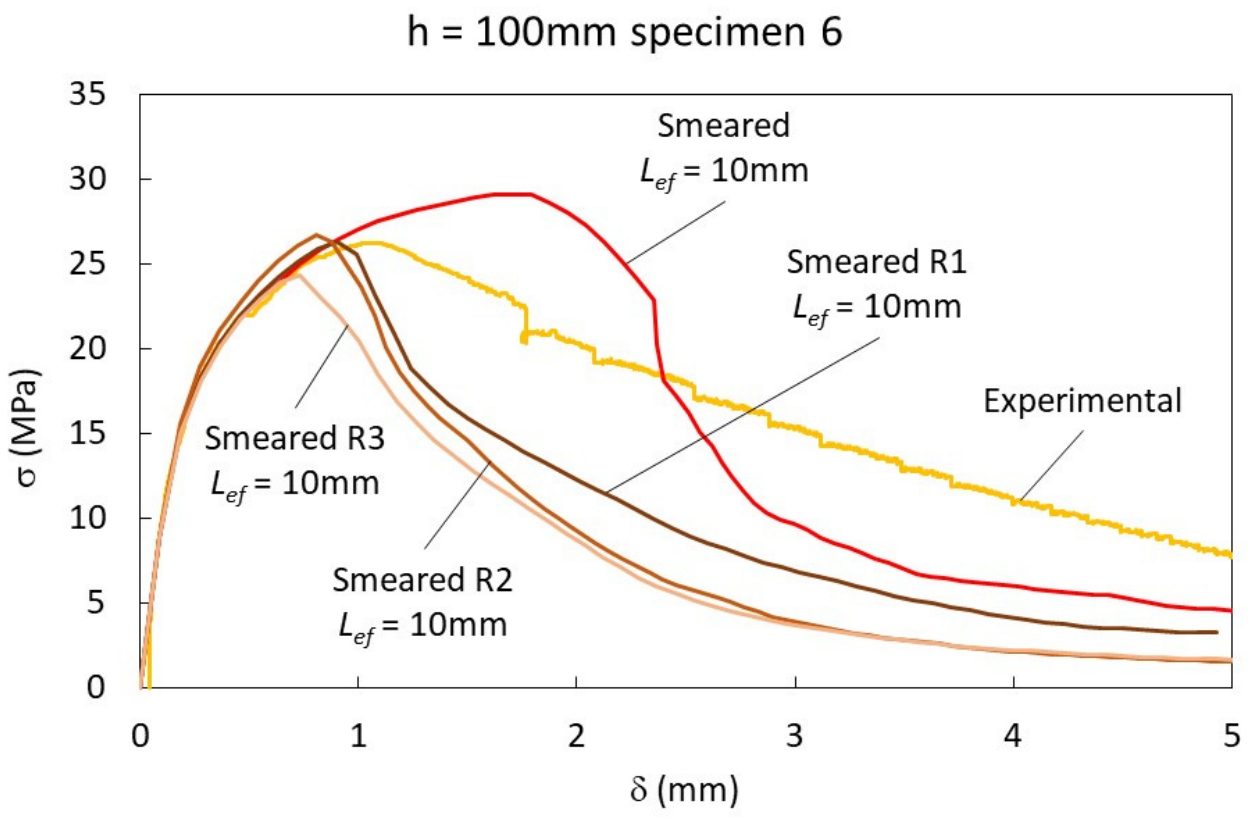

Figure 5.12 2D-NLFEM $\sigma$ - $\delta$ curves with $L_{e f}=10 \mathrm{~mm} v$ s experimental $\sigma$ - $\delta$ curve for $h$ $=100 \mathrm{~mm}$ specimen 6

The same result is obtained when different finite element length $\left(L_{e f}\right)$ are used. Figure 5.13 shows the equivalent bending stress $(\sigma)$-deflection at mid span $(\delta)$ numerical curves obtained as a result of the smeared cracking approach with runs of the random analysis of the 2D-NLFEM of specimen number 6 with $h=100 \mathrm{~mm}$ (see Table A-I.1 in Annexe I) considering mesh sizes of 5,10 and $20 \mathrm{~mm}$. For element lengths of 5 and $20 \mathrm{~mm}$ two runs (R1 and R2) have been done for the random analysis of the 2D-NLFEM considering the same values of the random parameters defined in Table 5.1 and used for obtaining the three runs (R1, R2 and R3) of the $10 \mathrm{~mm}$ element length, also represented in Figure 5.13. When the model results are compared to the experimental curve of specimen 
number 6 with $h=100 \mathrm{~mm}$, it can be observed how the model curves fit accurately the ascending branch of the experimental curve even the maximum bending stress, especially for the cases of $L_{e f}=5 \mathrm{~mm}$ and $10 \mathrm{~mm}$. However, the softening branch of the experimental curve is not represented with enough accuracy with the smeared cracking approach.

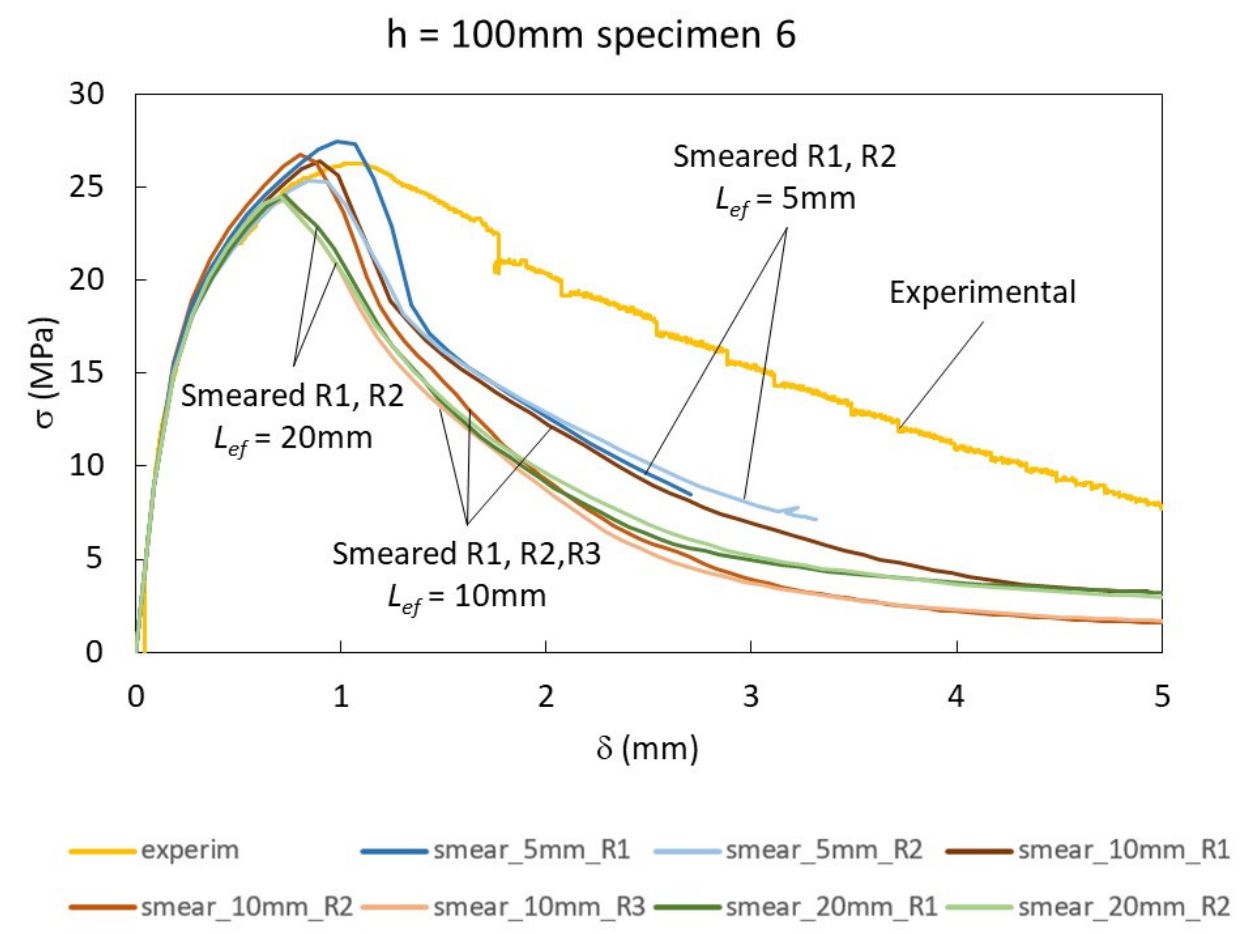

Figure $5.132 D$-NLFEM $\sigma$ - $\delta$ curves with $L_{e f}=5,10$ and $20 \mathrm{~mm}$ vs experimental $\sigma-\delta$ curve for $h=100 \mathrm{~mm}$ specimen 6

As it can be seen in Figure 5.8 and Figure 5.13, the smeared approach shows very accurate results for the equivalent-bending stress-displacement at mid-span curve for the elastic branch and part of the inelastic ascending branch of the curve. It represents very well the initial elastic stiffness and the first part of the following hardening deflection stiffness. From this onwards, the accuracy varies not fitting very well the maximum bending stress but even more in the descending part of the curve. This variability could be related to the mesh sensitivity of the smeared cracking approach. The adaptation of this model, which works well with plain and conventional fibre-reinforced concrete, maybe is not reliable enough when implemented into materials with significant bulk energy dissipation, such as UHPFRC. 
Therefore, the smeared cracking approach of the model works very well and reaches a great level of accuracy up to service level but it is not reliable from this onward due to the mesh size dependence. Even though the main advantage of the smeared cracking approach is that it is not necessary to know beforehand the crack pattern, it is important to take into account this dependence especially after the macrocrack takes place in specimens without reinforcement like the 4PBT used in this work to characterise the UHPFRC tensile constitutive behaviour.

A possibility of improving the smeared approach response could be related to the scaling of the stress-strain softening constitutive law to guarantee fracture energy preservation according to the mesh size (Jirásek 2017; Sadouki et al. 2017; Switek 2008). However, it implies to calibrate the models and the scaling formulas to UHPFRC considering its characteristic amount of bulk energy. Thus, its adaptation could not be straightforward.

Moreover, as it is shown in Figure 5.9, it is important to control the type of analysis that is defined in the NLFEM. The smeared cracking approach of the 2D-NLFEM is sensitive to the type of analysis procedure. Therefore, it is important to set the most appropriate nonlinear structural analysis strategy from the point of view of the stability, the reliability and accuracy of the results.

In Figure 5.14, the crack bandwidth $\left(b_{w}\right)$ is represented for the run 3 (R3) of the smeared cracking approach using the random analysis of the 2D-NLFEM with an element length $\left(L_{e f}\right)$ of $10 \mathrm{~mm}$ for specimen number 6 with $h=100 \mathrm{~mm}$. Therefore, the crack bandwidth there represented equals to $10 \mathrm{~mm}$. As it can be observed, the entire damage represented by the crack opening is concentrated in a crack bandwidth of $10 \mathrm{~mm}$. The response of this kind of model is not accurate in the softening branch as it is demonstrated in Figure 5.8 and Figure 5.13 for different element lengths. The reason of this could be that the fracture mechanics of materials with significant bulk energy is not extremely concentrated in a narrow crack band. As it is observed experimentally for the UHPFRC unreinforced 4PBT specimens, the fracture process involves all the specimen length during the microcracking phase up to the macrocracking formation. However, when the macrocrack takes place, this is not a thin crack crossing the section. It seems to be a coalescence of microcracks covering a wide length and dissipating more crack energy than a typical concrete macrocrack concentrated in a narrow band. Consequently, theories for continuum models such as the blunt crack propagation, the crack band theory and the smeared crack model (Bazant and Cedolin 1979; Bažant and Oh 1983; De Borst and Nauta 1985; Cope et al. 1980; Gupta and Akbar 1984; Rashid 1968; Rots 1988; Rots and Blaauwendraad 1989b; Suidan and Schnobrich 1973) thought for plain concrete are not completely applicable to these advanced composites and should be adapted. 


\section{Smeared $\mathrm{R} 3 \mathrm{~L}_{\text {ef }}=10 \mathrm{~mm}$}

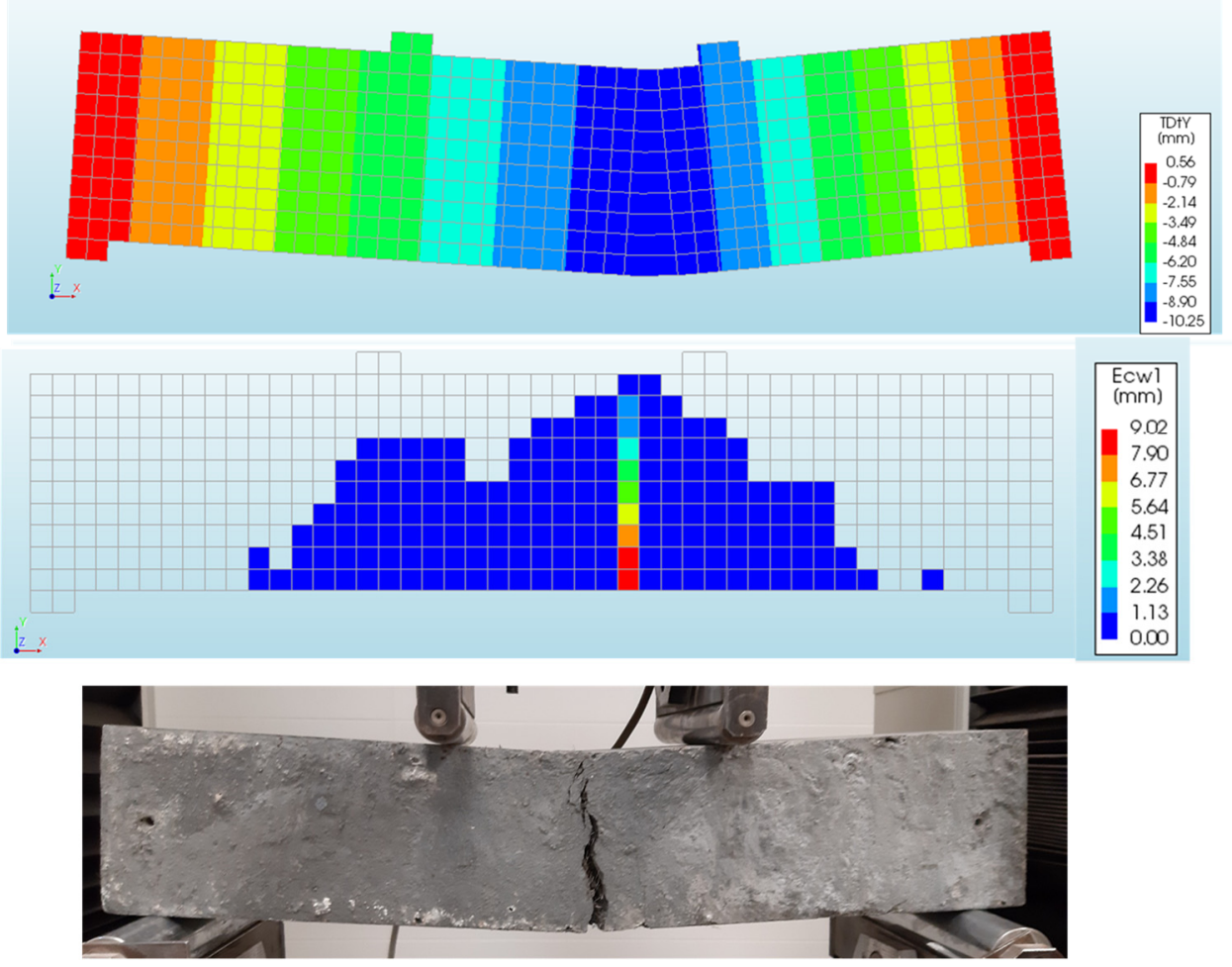

Figure $5.1410 \mathrm{~mm}$ crack bandwidth for the random analysis (R3) smeared cracking approach of $h=100 \mathrm{~mm}$ specimen 6

\subsubsection{Discrete cracking approach}

Figure 5.15 represents the application of the discrete cracking approach of the FEM defined in this work. The discontinuity produced by the macrocrack is modelled using interface elements placed at the mid-span section of the 4PBT specimen. For the continuum part, the smeared cracking approach has been used with a finite element length $\left(L_{e f}\right)$ of $10 \mathrm{~mm}$. As it can be observed in the Figure 5.15, when the crack is initiated following the criteria described in section 5.3.1, the specimen is separated in two blocks and the constitutive behaviour of the crack is governed by a traction-separation law independently of the mesh size as no crack opening is smeared in any crack bandwidth. 

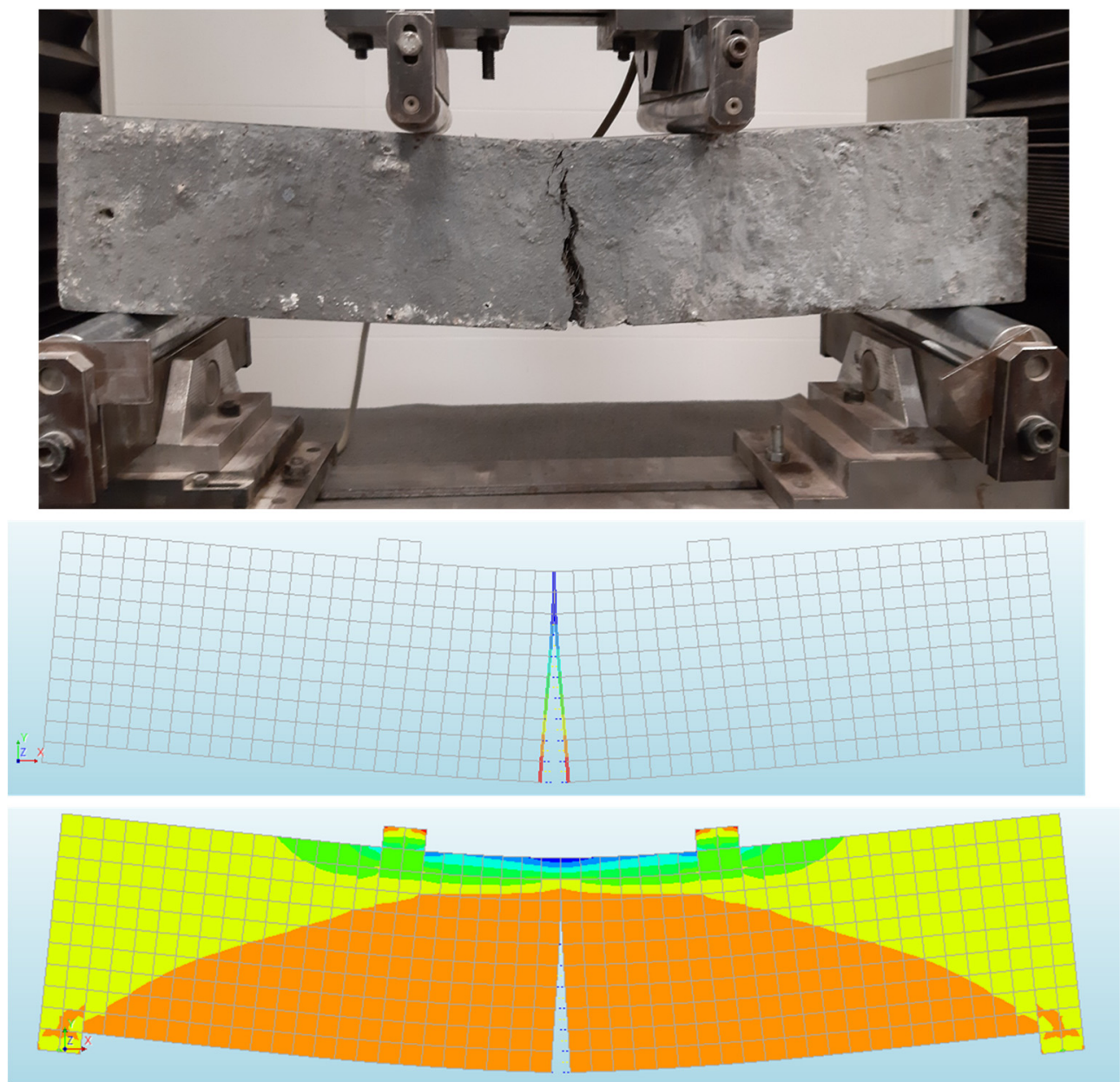

Figure 5.15 4PBT discrete cracking approach 2D-NLFEM representation.

Figure 5.16 shows the equivalent bending stress $(\sigma)$-deflection at mid span $(\delta)$ numerical curve obtained as a result of the discrete cracking approach of the 2D-NLFEM of specimen number 6 with $h=100 \mathrm{~mm}$ (see Table A-I.1 in Annexe I) compared to the experimental response and the smeared cracking approach of the 2D-NLFEM using the random analysis considering mesh sizes of 5,10 and 20mm, represented in Figure 5.13. As it can be observed in Figure 5.16, excellent accuracy is achieved for the discrete cracking approach response when it is compared to the experimental one. Therefore, as it is said in section 4.3 .3 of chapter 4 , the material behaviour simulated by the FEM with the discrete cracking approach in the overall specimen is very close to the so-called phase 
1 defined in section 4.3 .1 of chapter 4 , that describes the exact stress-strain/crack opening material UHPFRC constitutive behaviour set in Figure 3.2 in section 3.2.2 of chapter 3.

\section{$\mathrm{h}=100 \mathrm{~mm}$ specimen 6}

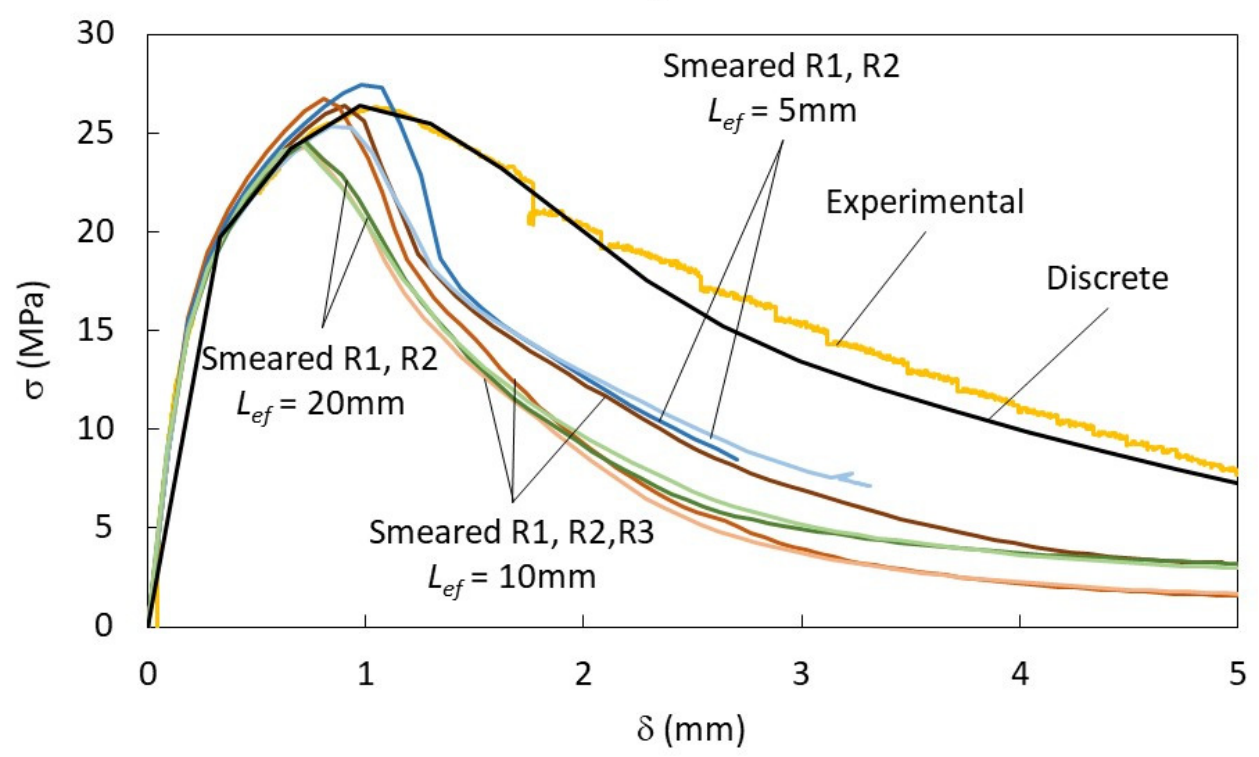

Figure 5.16 Discrete and smeared cracking approaches $2 D$-NLFEM $\sigma$ - $\delta$ curves vs experimental $\sigma$ - $\delta$ curve for $h=100 \mathrm{~mm}$ specimen 6

The experimental equivalent bending stress $(\sigma)$-deflection at mid span $(\delta)$ shown in Figure 5.17 is the result from a $100 \times 100 \times 500 \mathrm{~mm} 4 \mathrm{PBT}$ specimen (HB3C-1) developed in the softening experimental programme in section 5.4. In order to check the mesh size independence of the discrete cracking approach, if the size of the finite element mesh in the continuum part is varied using 10,20 and $50 \mathrm{~mm}$, the equivalent bending stressdisplacement at mid-span numerical curves obtained are very close and very accurate if they are compared to the experimental one, as it can be seen in Figure 5.17. Therefore, the size of the finite element mesh is not affecting the results in the discrete cracking approach. The principal reason is that no softening crack opening branch of the constitutive curve is smeared in a mean total strain in any crack bandwidth as the crack is directly described by its opening $(w)$. The softening branch of the smeared cracking approach that describes the continuum is not activated as the crack follows the path set by the interface. Therefore, the discrete cracking approach is mesh-size independent and it is able to represent the localised damage where it appears as it is described by a proper stress (or traction)-separation law. 


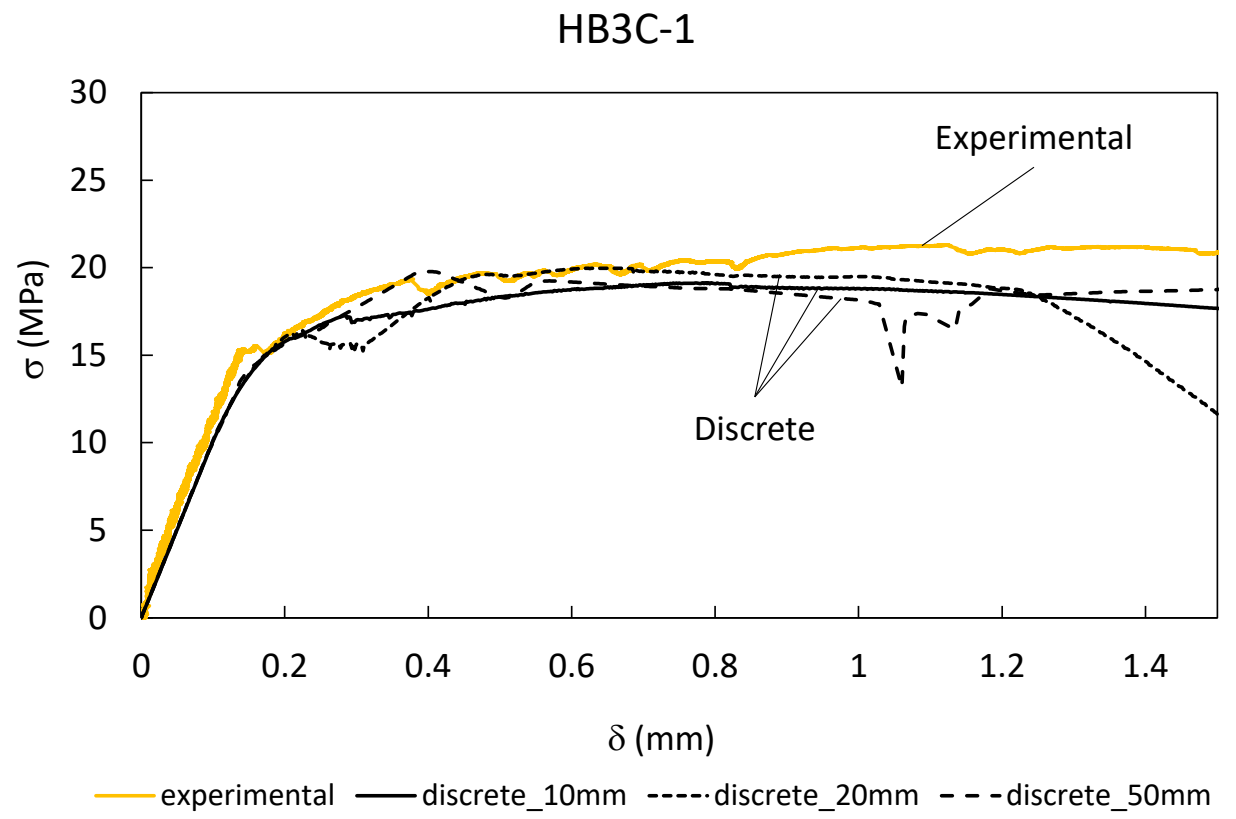

Figure 5.17 Equivalent bending stress-displacement at mid-span curves using different mesh sizes in the discrete cracking approach

Therefore, as it is observed from the results shown in Figure 5.16 and Figure 5.17, the discrete cracking approach of the 2D-NLFEM generates the most accurate results and thus it becomes a more reliable model than the smeared cracking approach for unreinforced UHPFRC specimens considering the reasons above exposed. Even though the discrete cracking needs to know the crack path beforehand in order to place the discrete finite elements there, as the 4PBT is a symmetric test it could be predictable that the crack will appear, more or less, in the mid-span section of the specimen. Consequently, the discrete cracking approach considering the discrete crack in the midspan section is used to model the unreinforced 4PBT UHPFRC specimens in this section for the numerical validation of the I-IA and the 5P-IA from the experimental programme described in Annexe I for SH-UHPFRC and to study the adaptation of the 4P-IA for the case of SS-UHPFRC in the 4PBT experimental programme developed in this work in section 5.4 .

In Figure 5.18, Figure 5.19 and Figure 5.20 the experimental equivalent bending stress $(\sigma)$-deflection at mid span $(\delta)$ curves and the numerical model with the discrete cracking approach curves are compared for the specimens considered in Table A-I.1 in Annexe I. The tensile constitutive parameters obtained by the application of the I-IA to the 
experimental $\sigma-\delta$ curve of the 4PBT specimens with SH-UHPFRC described in Table A-I.1 in Annexe I are implemented in the discrete cracking approach of the 2D-NLFEM as it is explained in section 4.4 in chapter 4 .
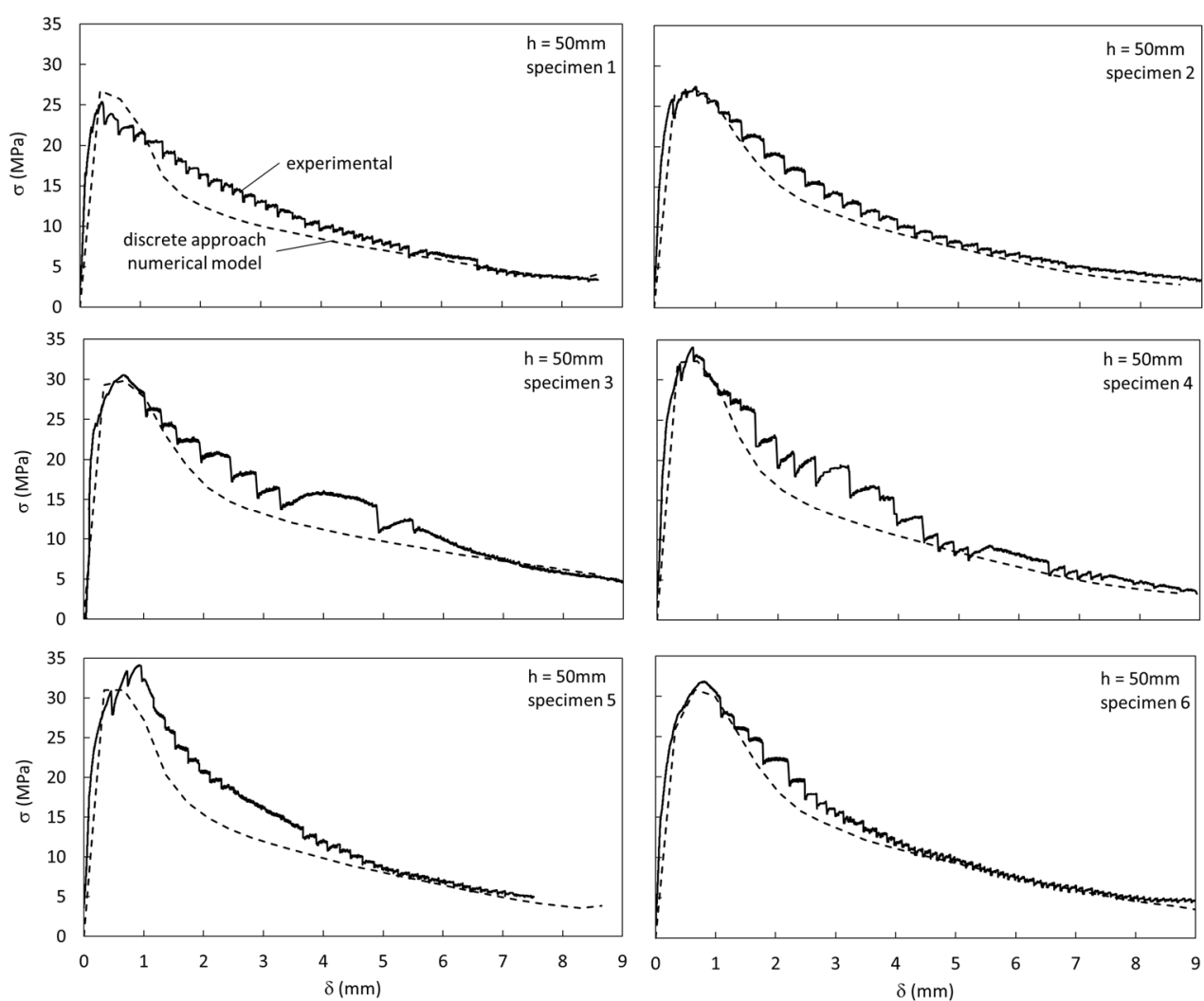

Figure $5.18 \sigma$ - $\delta$ at the mid-span curves for the $h=50 \mathrm{~mm}$ specimens from Table A-I.1 in Annexe I 
Chapter 5: Direct procedure to characterise the UHPFRC tensile constitutive behaviour
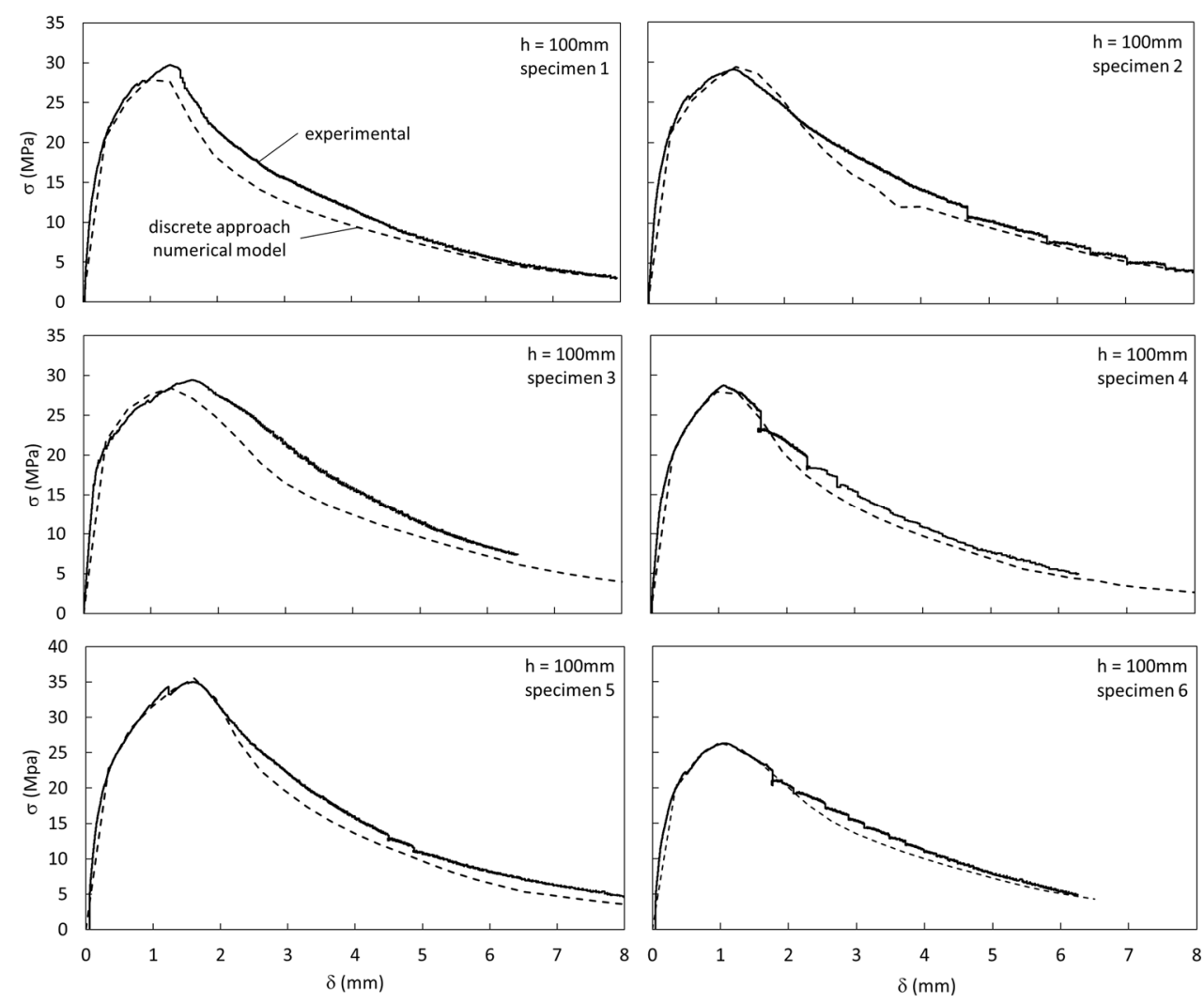

Figure $5.19 \sigma$ - $\delta$ at the mid-span curves for the $h=100 \mathrm{~mm}$ specimens from Table A-I.1 in Annexe I.

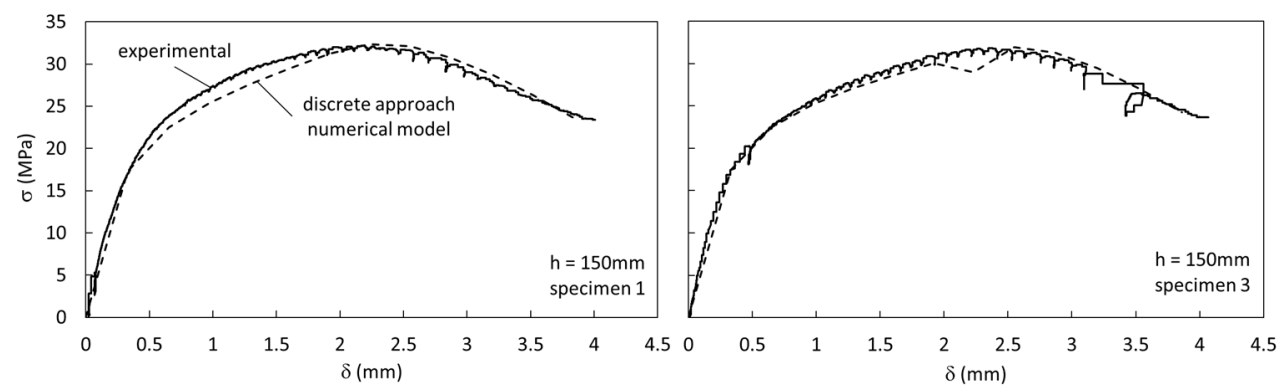

Figure $5.20 \sigma$ - $\delta$ at the mid-span curves for the $h=150 \mathrm{~mm}$ specimens from Table A-I.1 in Annexe I 
It is observed in Figure 5.18, Figure 5.19 and Figure 5.20 that the 2D-NLFEM using the discrete cracking approach seems to fit the experimental $\sigma-\delta$ response of the unreinforced 4PBT specimens when the constitutive UHPFRC parameters obtained from the application of the I-IA to the experimental $\sigma-\delta$ are implemented in the numerical model. This implies that the hinge model developed to obtain the tensile constitutive behaviour of SH-UHPFRC is consistent and reliable. The tensile SH-UHPFRC constitutive behaviour can be obtained from an easy to conduct flexural test (the 4PBT) with a reliable inverse analysis method. Therefore, it can be concluded that the 2DNLFEM with the discrete cracking approach is reliable enough and, consequently, the closed-form non-linear hinge model is a suitable method to derive the tensile UHPFRC's properties from the load-deflection response obtained from the 4PBT experimental tests.

However, some numerical curves do not completely fit the experimental ones in terms of maximum bending stress (for example, $h=50 \mathrm{~mm}$, specimen 5 in Figure 5.18). The reason for this inaccuracy might be due to the incremental-iterative process carried out in the analysis procedure of the NLFEM. To improve this fitting, a particular treatment is developed in the analysis procedure of the numerical model taking into account, as it is said in Figure 5.9, that the type of analysis can influence in the maximum bending stress and in the softening branch of the $\sigma-\delta$ curve. This improvement consists in developing an analysis continuation approach.

\subsection{Analysis continuation approach}

There are some situations in which non-linear analysis solutions may be hard to obtain for all the steps using only one single incremental-iterative solution procedure. For this reason, it is better to split the load increment process into more than one part. Therefore, different solution methods can be applied. Diana software offers this possibility. The new analysis that follows the preceding one starts using the last converged results obtained from the previous one. Each analysed specimen has its particular analysis process. That is, the analysis process used for one specimen is not general for the others because each specimen has converged in its own particular way.

By way of example, Figure 5.21 shows improved accuracy with the analysis continuation approach applied for the $h=50 \mathrm{~mm}$ specimen 5 from Table A-I.1 in Annexe I and Figure 5.18. In this case, the nonlinear analysis based on an incremental-iterative solution procedure is split in eight nonlinear analyses one following the other from its last converged results. Each analysis has its properly incremental and iterative processes (see Figure 5.22). 
$h=50 \mathrm{~mm}$ specimen 5

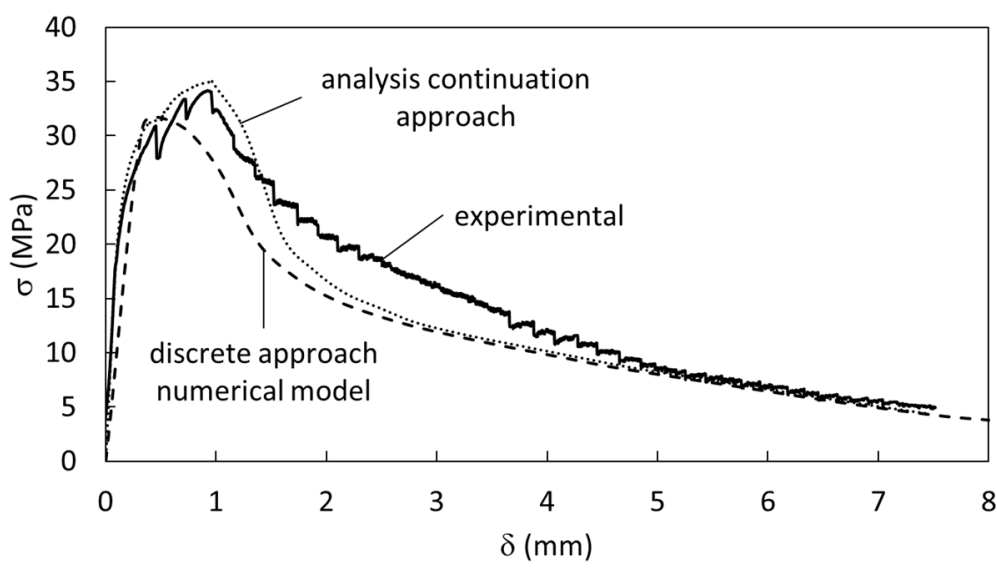

Figure $5.21 \sigma$ - $\delta$ at the mid-span curves for the $h=50 \mathrm{~mm}$ specimen 5 from Table A-I.1.

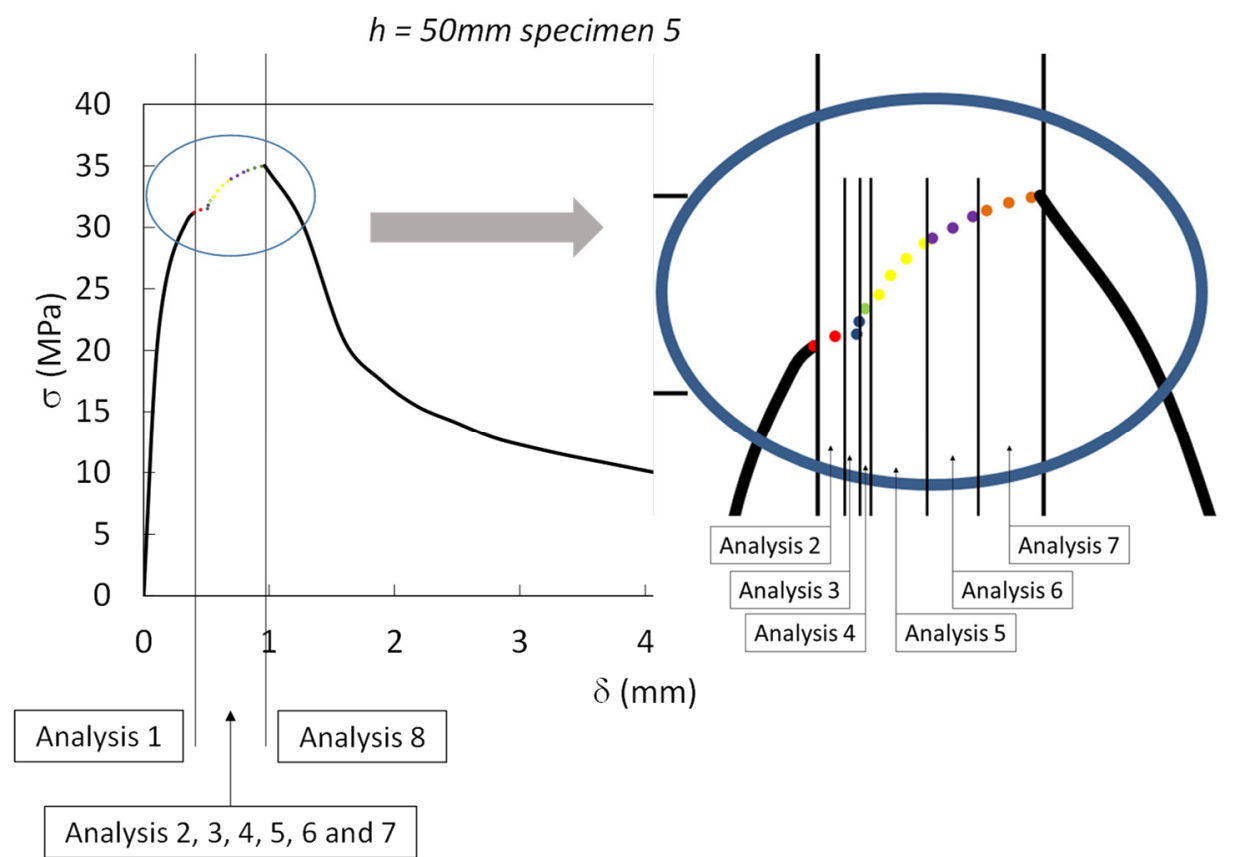

Figure 5.22 a) analysis continuation approach equivalent bending stress-displacement at mid-span curve for $h=50 \mathrm{~mm}$ specimen 5 ; b) detail of a) 
Table 5.2 summarises the main characteristics of the different analyses carried out to develop the analysis continuation approach for $\mathrm{h}=50 \mathrm{~mm}$ specimen 5 shown in Figure 5.22 .

Table 5.2 Analyses' properties for $h=50 \mathrm{~mm}$ specimen 5

\begin{tabular}{|c|c|c|c|c|}
\hline Analysis & Incremental process & Iterative method & $\begin{array}{c}\text { Converge } \\
\text { norm }\end{array}$ & $\begin{array}{c}\text { Number of } \\
\text { converged steps }\end{array}$ \\
\hline Analysis 1 & $\begin{array}{l}\text { Adaptive loading } \\
\text { iteration based }\end{array}$ & $\begin{array}{c}\text { Modified } \\
\text { Newton-Raphson }\end{array}$ & Energy & 11 \\
\hline Analysis 2 & Automatic size & $\begin{array}{l}\text { Constant } \\
\text { Stiffness }\end{array}$ & $\begin{array}{c}\text { Force } \\
\text { Displacement }\end{array}$ & 4 \\
\hline Analysis 3 & Specified size & $\begin{array}{c}\text { Modified } \\
\text { Newton-Raphson }\end{array}$ & $\begin{array}{c}\text { Force } \\
\text { Displacement }\end{array}$ & 600 \\
\hline Analysis 4 & Specified size & $\begin{array}{c}\text { Modified } \\
\text { Newton-Raphson }\end{array}$ & $\begin{array}{c}\text { Force } \\
\text { Displacement }\end{array}$ & 1000 \\
\hline Analysis 5 & Specified size & $\begin{array}{c}\text { Modified } \\
\text { Newton-Raphson }\end{array}$ & $\begin{array}{c}\text { Force } \\
\text { Displacement }\end{array}$ & 40 \\
\hline Analysis 6 & Specified size & $\begin{array}{c}\text { Modified } \\
\text { Newton-Raphson }\end{array}$ & $\begin{array}{c}\text { Force } \\
\text { Displacement }\end{array}$ & 40 \\
\hline Analysis 7 & Specified size & $\begin{array}{c}\text { Modified } \\
\text { Newton-Raphson }\end{array}$ & $\begin{array}{c}\text { Force } \\
\text { Displacement }\end{array}$ & 40 \\
\hline Analysis 8 & Automatic size & $\begin{array}{c}\text { Modified } \\
\text { Newton-Raphson }\end{array}$ & $\begin{array}{c}\text { Force } \\
\text { Displacement }\end{array}$ & 30 \\
\hline
\end{tabular}

To avoid very large predictions for the displacements, an indirect displacement control by means of Arc-length control with a linearized constraint has been implemented in all analyses described in Table 5.2. Moreover, a Line Search algorithm is also used because it can increase the convergence rate and are especially useful if the ordinary iteration process fails. 
After seeing Figure 5.22 and Table 5.2, it can be observed that, sometimes, the process of convergence to the solution can be very hard in terms of calculation and analysis. From this, it can be concluded that the result is very dependent on the analysis strategy followed.

\subsection{Equivalent bending stress versus displacement at mid-span} curves for different hinge lengths

Figure 5.23 and Figure 5.24 show the results when the 5P-IA parameters from Table AI.2, Table A-I.3 and Table A-I.4 in Annexe I are used in the discrete cracking approach of the NLFEM. The material properties obtained from the simplified 5P-IA are implemented in the numerical model and compared to the experimental results from specimen number 1 and 3 with a slenderness ratio $(\mathrm{L} / \mathrm{h})$ of 4.5 and 3 respectively, using different hinge lengths $\left(l_{c}=1.5 \mathrm{~h}, \mathrm{~h}\right.$ and $\left.\mathrm{h} / 2\right)$. Stress-displacement at mid-span curves are compared in Figure 5.23 and Figure 5.24. As it can be seen, the discrete cracking approach of the numerical 2D-NLFEM shows an excellent accuracy.

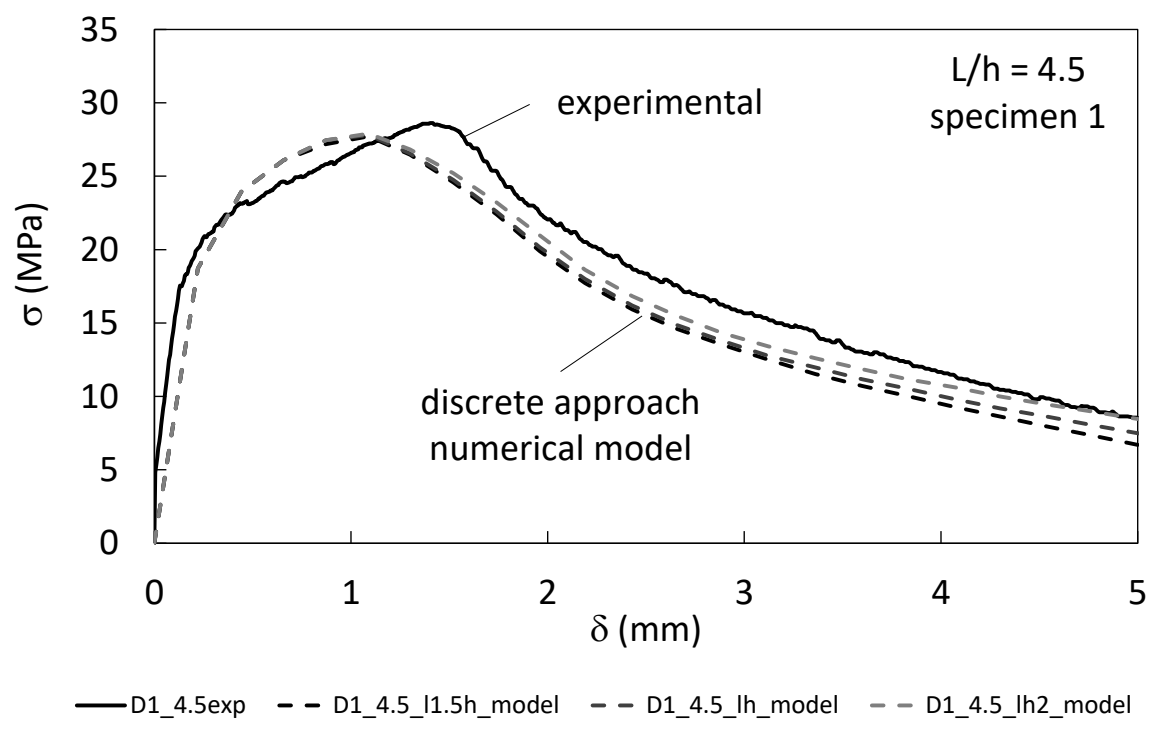

Figure 5.23 Equivalent $\sigma$ - $\delta$ at mid-span curves for $L / h=4.5$ (specimen 1) with hinge length of $1.5 h, h$ and $h / 2(h 2)$. 


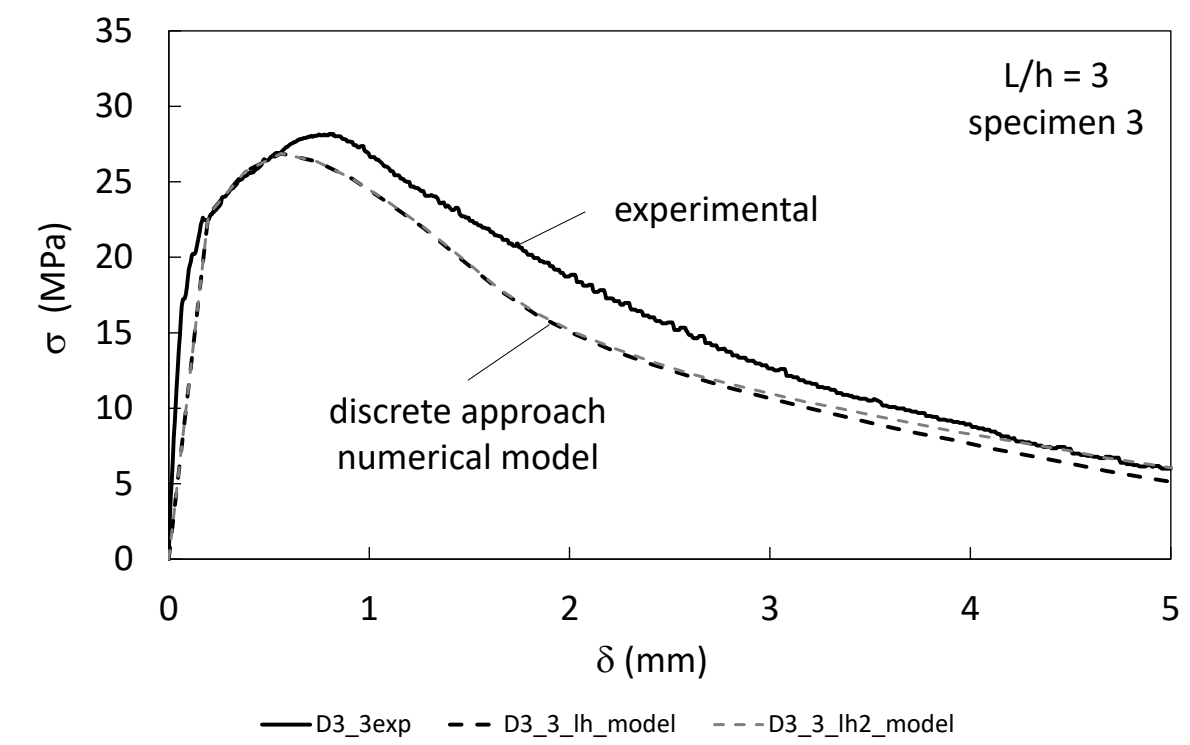

Figure 5.24 Equivalent $\sigma$ - $\delta$ at mid-span curves for $L / h=3$ (specimens 3 ) with hinge length of $h$ and $h / 2$ (h2)

\subsection{Equivalent bending stress versus curvature}

The equivalent bending stress $(\sigma)$ versus curvature on the boundaries of the non-linear hinge $(\phi)$ relationship is obtained from two different sources: (i) the experimental data from the displacement transducer on the back side of the specimen (see Figure A-I.8 in Annexe I); (ii) using the stress-strain sectional behaviour law that derives from I-IA and the non-linear hinge model.

In case (i), the experimental curvature is obtained by the linear regression of the strain measurements of three displacement transducers, $\delta_{c}, \delta_{m}$, and $\delta_{t}$ (see Figure A-I.8 in Annexe I), placed on the back side of the $100-\mathrm{mm}$ and $150-\mathrm{mm}$ specimens. The experimental curvature in the 50-mm specimens is obtained following Expression (5.4), where $d_{\phi}$ is the distance between the displacement transducers, and $s$ is gage length or hinge length.

$$
\emptyset_{50 m m}=\frac{\left|\delta_{t}-\delta_{c}\right| / s}{d_{\emptyset}}
$$


The I-IA results, from Table A-I.1 in Annexe I, are implemented into the discrete cracking approach numerical 2D-NLFEM. The $\sigma-\phi$ curve from the numerical model can be obtained following the displacements of the finite element nodes situated in the same position of the displacement transducers.

Figure 5.25 shows the three different $\sigma$ versus the normalised average curvature ( $\phi_{n}=$ $\phi h)$ obtained for three different specimens from the three different specimen depths used in Figure A-I. 8 and Table A-I. 1 in Annexe $\mathrm{I}: \mathrm{h}=50 \mathrm{~mm}, \mathrm{~h}=100 \mathrm{~mm}$ and $\mathrm{h}=150 \mathrm{~mm}$. Both, the experimental and I-IA hinge model curves are compared to the one of the discrete cracking approach 2D-NLFEM.
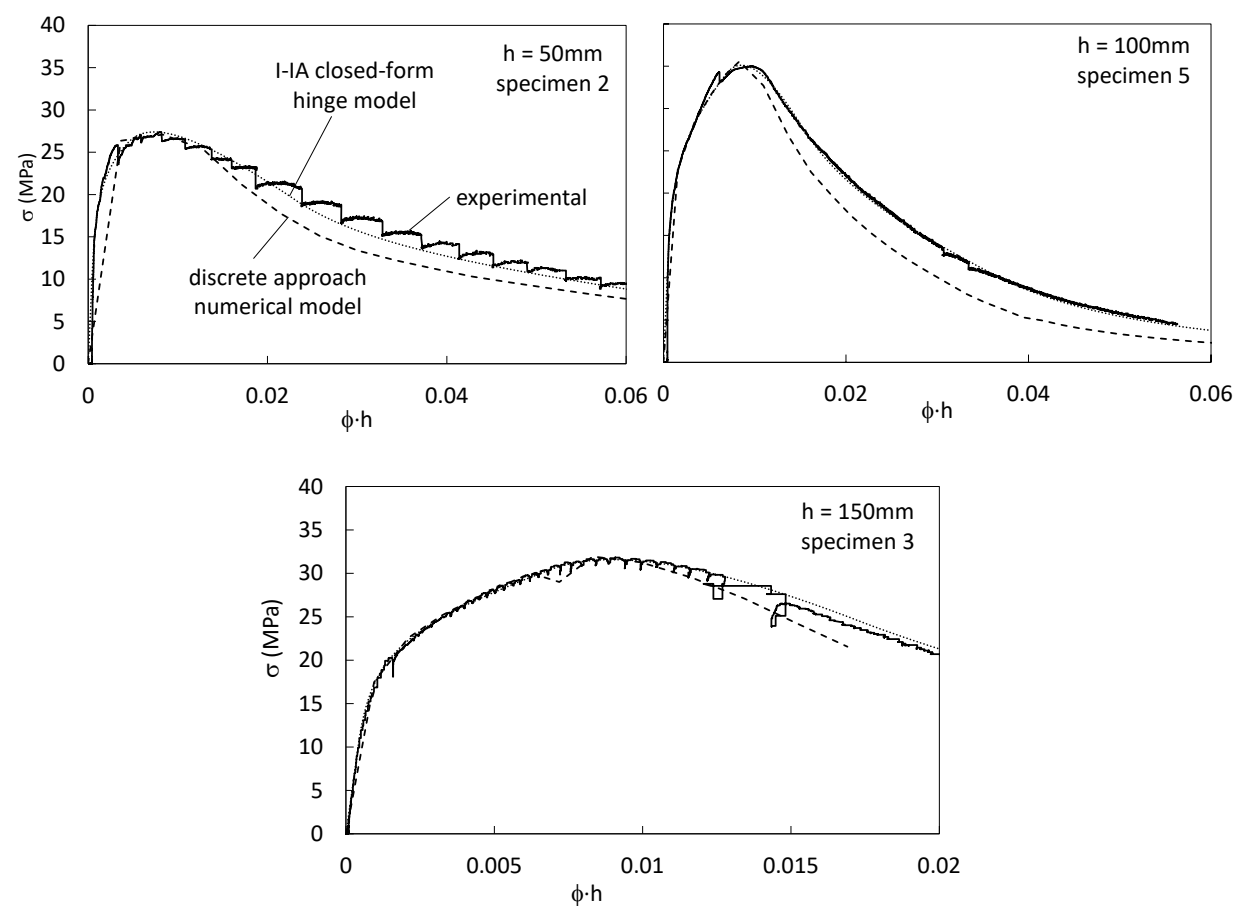

Figure $5.25 \sigma-\phi \cdot h$ curves for the $h=50 \mathrm{~mm}$ specimen 2 , the $h=100 \mathrm{~mm}$ specimen 5 and the $h=150 \mathrm{~mm}$ specimen 3 .

The discrete cracking approach numerical model accurately represents the equivalent bending strength versus the normalised average curvature, as shown in Figure 5.25. It proves that the non-linear hinge model used to define the I-IA and the 5P-IA is reliable enough.

\subsection{Average strain profile inside the hinge}

Experimental equivalent flexural stress versus the average strain on the non-linear hinge on the different depth position curves are obtained using the displacement transducers 
placed on the back and bottom sides of the tested specimens (see Figure A-I.8 in Annexe I). The average strain values $\varepsilon_{c}, \varepsilon_{m}$, and $\varepsilon_{t}$, represented in Figure 5.26, Figure 5.27 and Figure 5.28 are obtained by dividing the $\delta_{c}, \delta_{m}$, and $\delta_{t}$ displacement transducer measurements by their gage length, which corresponded to the constant bending moment area. Then, the average strain values at the different depth positions obtained from the experimental tests are compared to the values that derived from the constitutive law obtained by I-IA.

The I-IA results, from Table A-I.1 in Annexe I, are implemented into the discrete cracking approach 2D-NLFEM. The equivalent flexural stress versus the average strain at the different depth positions curve from the numerical model can be obtained following the displacements of the finite element nodes situated in the same position of the displacement transducers.

Figure 5.26, Figure 5.27 and Figure 5.28 show the equivalent flexural stress $(\sigma)$ versus the average strain at different depth positions curves $\left(\varepsilon_{c}, \varepsilon_{m}\right.$, and $\left.\varepsilon_{t}\right)$ obtained for three different specimens from the three different specimen depths used: $\mathrm{h}=50 \mathrm{~mm}, \mathrm{~h}=100 \mathrm{~mm}$ and $\mathrm{h}=150 \mathrm{~mm}$ (see Figure A-I.8 in Annexe I). Both the experimental and I-IA hinge model curves are compared to the one of the discrete cracking approach 2D-NLFEM.

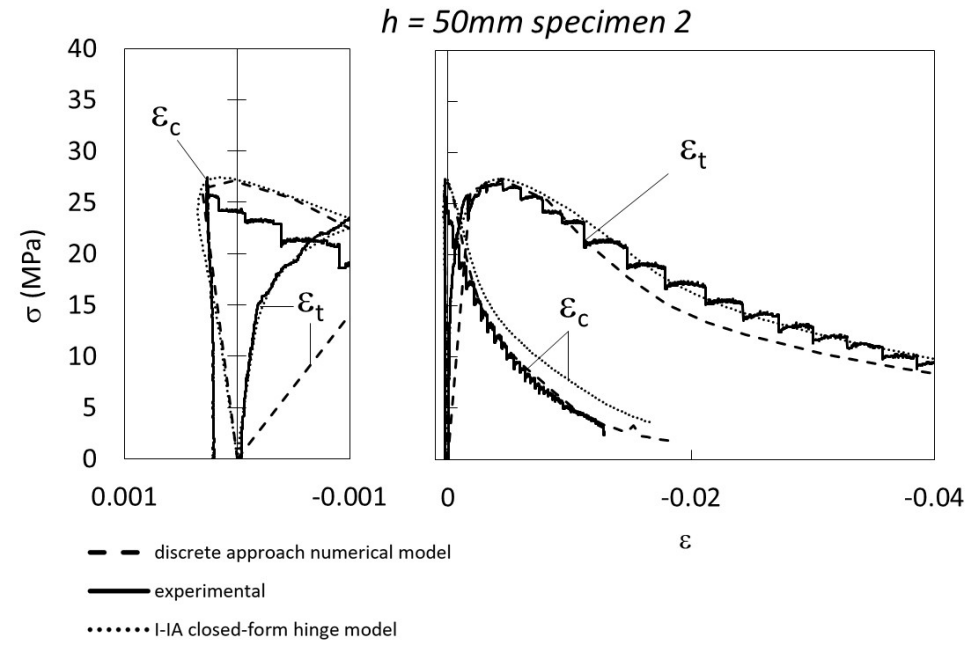

Figure 5.26 Equivalent bending stress $(\sigma)$ versus the average strain at different depth positions $\left(\varepsilon_{c}\right.$, and $\left.\varepsilon_{t}\right)$ for the $h=50 \mathrm{~mm}$ specimen 2 


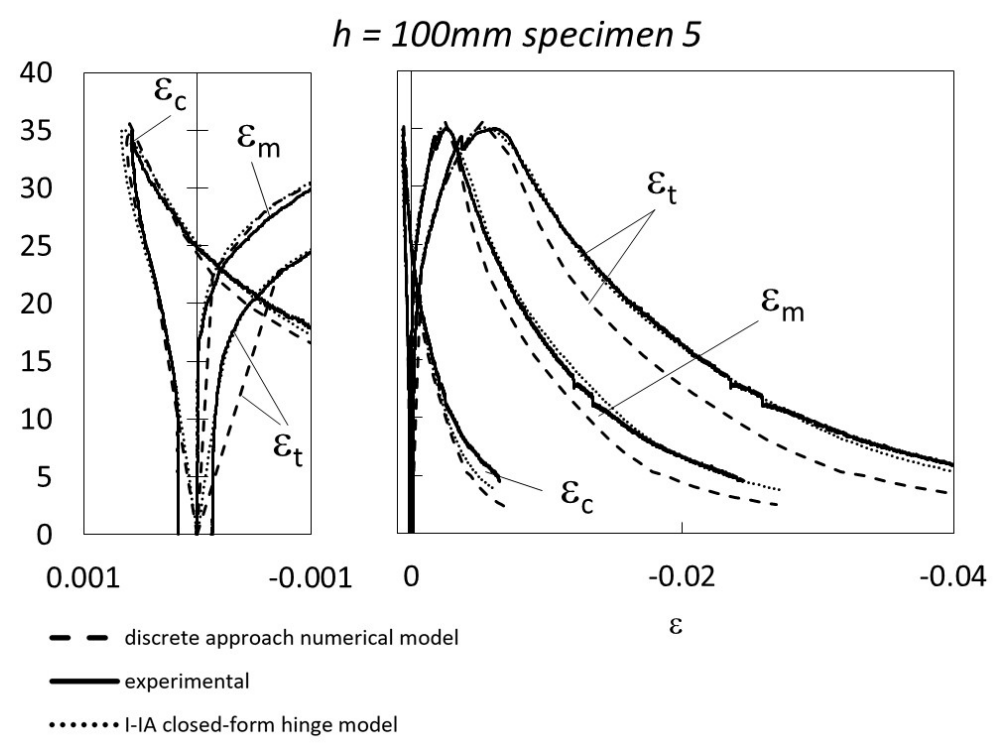

Figure 5.27 Equivalent bending stress $(\sigma)$ versus the average strain at different depth positions $\left(\varepsilon_{c}, \varepsilon_{m}\right.$, and $\left.\varepsilon_{t}\right)$ for the $h=100 \mathrm{~mm}$ specimen 5 .

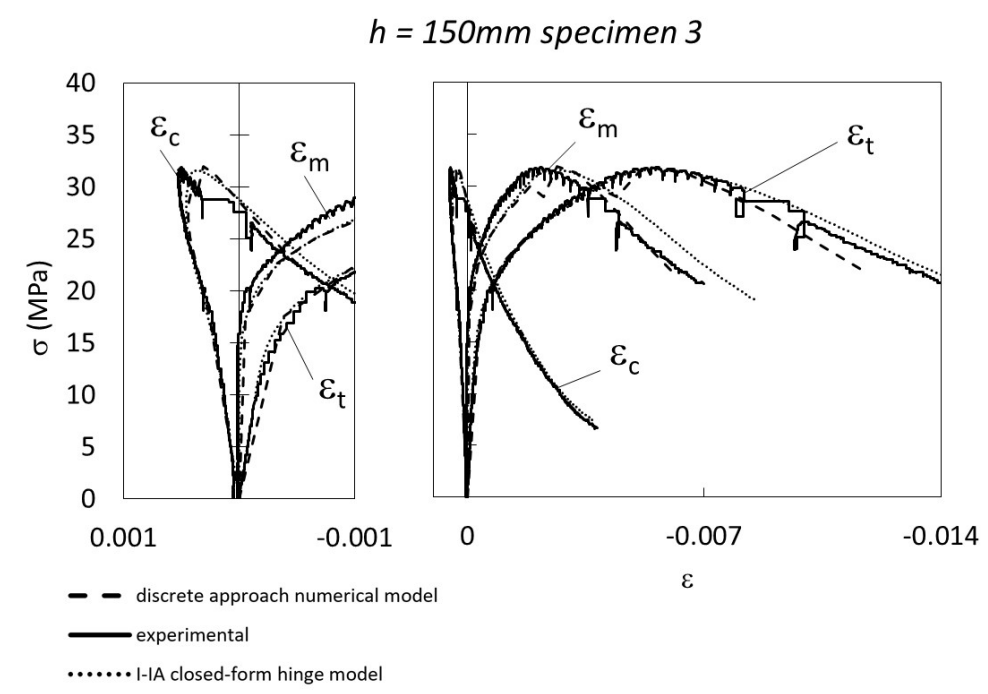

Figure 5.28 Equivalent bending stress $(\sigma)$ versus the average strain at different depth positions $\left(\varepsilon_{c}, \varepsilon_{m}\right.$, and $\left.\varepsilon_{t}\right)$ for the $h=150$ specimen 3 
The discrete cracking approach 2D-NLFEM accurately represents the equivalent bending strength versus the average strain at the different depth positions, as seen in Figure 5.26, Figure 5.27 and Figure 5.28. The two models offer similar results and fit the experimental results. Both are valid to determine the tensile properties of UHPFRC in a 4PBT.

\subsection{Representation of the stress and strain evolution}

Finally, by way of example Figure 5.29 shows the evolution of stresses and crack strains of the specimen 4 with $\mathrm{L} / \mathrm{h}=4.5$ and hinge length of $l_{c}=1.5 \mathrm{~h}$ from Table A-I. 2 and Table A-I.4 in Annexe I at four different load steps, when the discrete cracking approach 2DNLFEM is applied. It can be seen how the model represents the propagation of the smeared crack pattern when concrete is at its hardening level (between $f_{t}=10.7 \mathrm{MPa}$ and $f_{t u}=11.6 \mathrm{MPa}$ ) and the apparition of the macro-crack when $f_{t u}$ is reached. It demonstrates that the model can reproduce with a great level of accuracy the behaviour of UHPFRC in a 4 PBT.
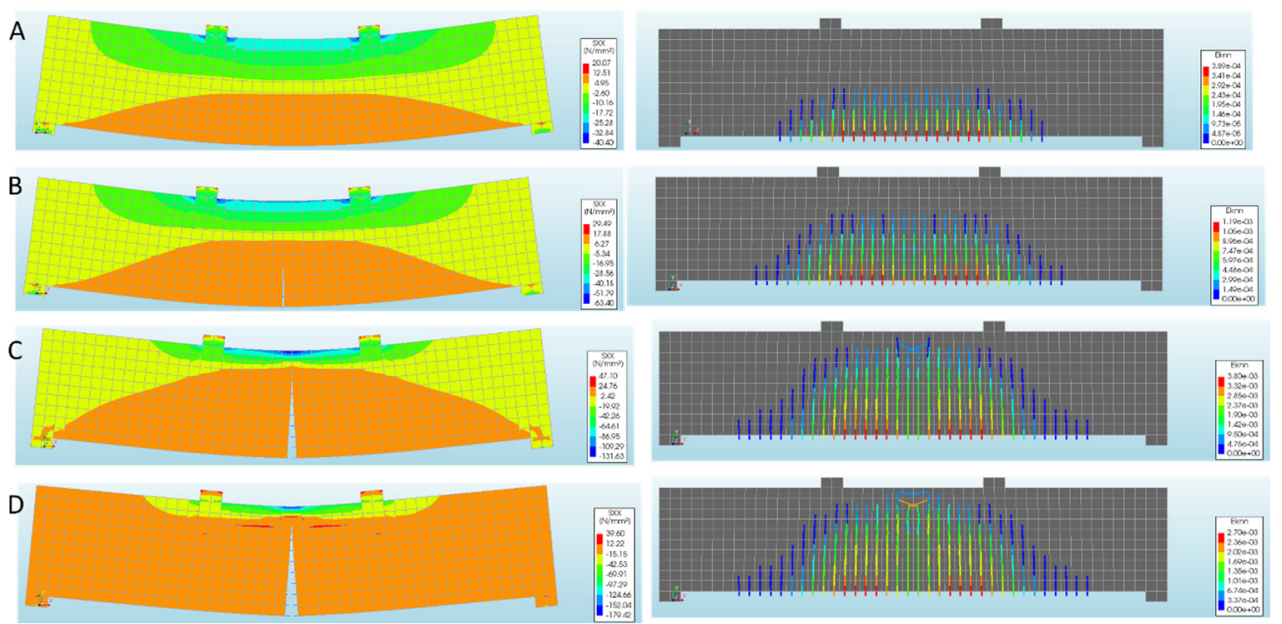

Figure 5.29 Normal stresses and crack strains: specimen $4, L / h=4.5, l_{c}=1.5 h$.

Therefore, from the application of the smeared cracking approach 2D-NLFEM, it can be concluded that the inverse analysis methodology developed in (López 2017) is reliable to characterise the tensile behaviour of UHPFRC that exhibits strain-hardening behaviour in tension (SH-UHPFRC) from 4PBT. Moreover, the simplified 4P-IA could be a direct and easy to apply method to carry out this objective in a reliable way. 


\subsection{Strain-softening UHPFRC: characterisation of the tensile constitutive behaviour}

In previous section 5.3, the inverse analysis methodology adopted in this work to characterise the tensile behaviour of strain-hardening UHPFRC from 4PBT is demonstrated and numerically validated by means of a discrete cracking approach 2DNLFEM. Therefore, the inverse analysis methodology adopted is considered reliable enough for the characterisation of UHPFRC that exhibits strain-hardening tensile constitutive behaviour.

However, this methodology can be questionable in some situations. As it is stated, the inverse analysis is defined for UHPFRC that exhibits strain-hardening behaviour in tension (SH-UHPFRC). What happens if this is not the case? The application of the inverse analysis is not tested in UHPFRC that exhibits strain-softening behaviour in tension (SS-UHPFRC). Is the simplified 4P-IA accurate enough for the strain-softening case? Other important question could be related to the reliability of simplified inverse analyses. The idea of developing these simplified methods lies in their direct application to structural design or quality control so they are "easy to conduct". Even though these methods seem easy to apply, they are not completely accurate and objective, and are subjected to variations depending on the type of application. In this section and in the following one, these questions are addressed.

To distinguish between the UHPFRCs that exhibit SH behaviour from those exhibiting SS behaviour in tension, a hardening ratio ( $\gamma$ ) is defined in Expression (5.5). If $\gamma \geq 1$, then UHPFRC would exhibit SH. If $\gamma<1$, then UHPFRC would exhibit SS. Figure 5.30 illustrates this interpretation.

$$
\gamma=\frac{f_{t u}}{f_{t}}
$$



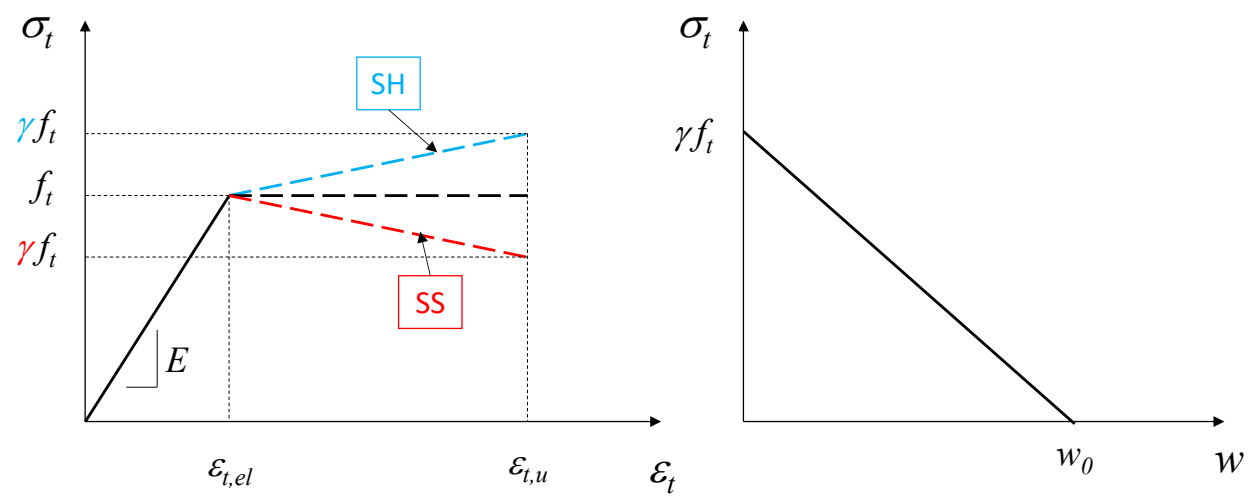

Figure 5.30 Constitutive behaviour of UHPFRC with SH and SS

4P-IA is used for the UHPFRC exhibiting SH tensile constitutive behaviour $(\gamma \geq 1)$ (López 2017). In order to extend its application to the SS range $(\gamma<1)$, it is necessary to use the two dimensional nonlinear finite element model (2D-NLFEM) to simulate the $4 \mathrm{PBT}$ to test and calibrate the inverse analysis. Moreover, an experimental programme of 4PBT covering all the range from SH to SS-UHPFRC becomes necessary to calibrate the 4P-IA and apply the 2D-NLFEM.

In this section, the 2D-NLFEM used for validating the inverse analysis methodology for SH-UHPFRC in previous section is employed. The discrete cracking approach is followed to model tensile UHPFRC constitutive behaviour. In this approach, the constitutive model for UHPFRC is based on the discrete cracking model as an interface behaviour. The constitutive law for discrete cracking is based on a total deformation theory. This behaviour is forced only on the central beam section (Figure 5.6). To fulfil this objective, both tensile strength $\left(f_{t}\right)$ and ultimate tensile strength $\left(f_{t u}\right)$ are reduced by $2 \%$. The rest of the beam is modelled by the smeared cracking approach based on a fixed total strain crack model expressed according to the crack opening curve, as it is explained in chapter 3 and chapter 4 .

4PBT is modelled with 2D quadratic plane stress eight-node quadrilateral elements. Quadratic 2D 3+3 nodes line interface elements are placed on the central beam section (see Figure 5.5). The load is applied to the steel load plates by gradual increasing displacement. A nonlinear analysis is carried out by following an incremental-iterative solution procedure.

\subsubsection{Experimental programme}

In order to generate a database of the tensile constitutive parameters obtained from 4PIA, an experimental programme of 227 UHPFRC specimens $(100 \times 100 \times 500 \mathrm{~mm})$ is cast 
and tested in 4PBT (see Figure 5.31). Sixty-nine of them are cast using 1.53-1.66\% (120$\left.130 \mathrm{~kg} / \mathrm{m}^{3}\right)$ in volumes of smooth-straight (13/0.20) steel fibres, and 158 with $2.00 \%$ $\left(160 \mathrm{~kg} / \mathrm{m}^{3}\right) .4$ PBTs are carried out by means of the experimental setup detailed in section 5.2. As a result, the load (P)-displacement at the mid-span $(\delta)$ curves is obtained. By using Expression (5.1), it is possible to represent the equivalent bending stress $(\sigma)$ displacement at the mid-span ( $\delta$ ) (see Figure 5.32).
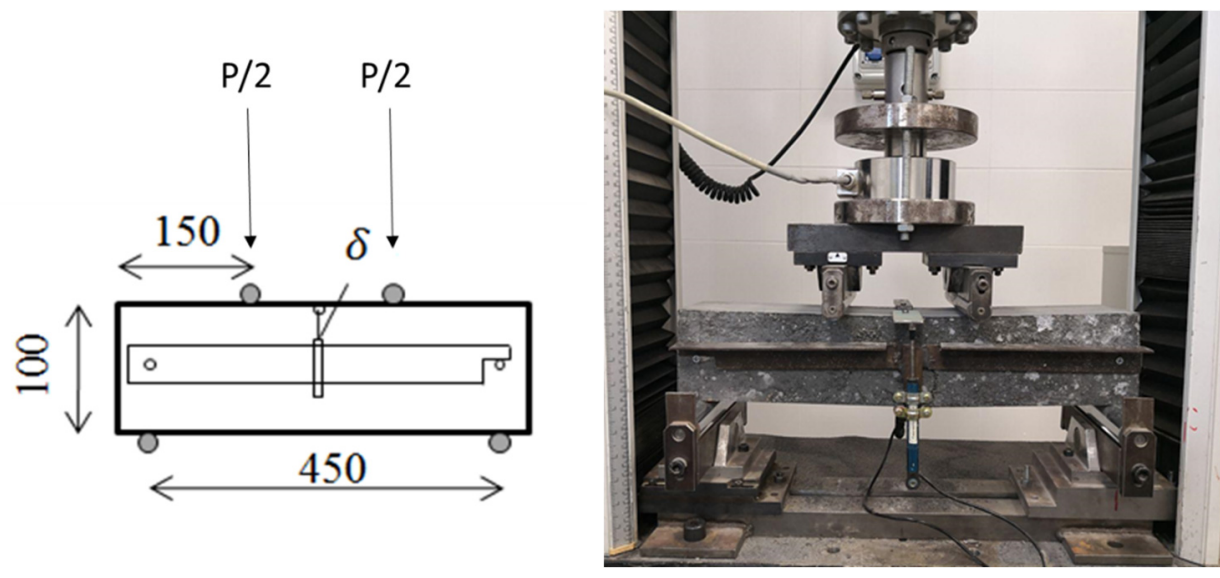

Figure 5.31 Four-Point Bending Test (4PBT)

Compressive strength is obtained from 100-mm cubes within a range of [99.88, 148.18] MPa for the case of $120-130 \mathrm{~kg} / \mathrm{m}^{3}$ and $[114.23,172.08] \mathrm{MPa}$ for the case of $160 \mathrm{~kg} / \mathrm{m}^{3}$. The tensile parameters obtained from the 227 specimens fall within the following ranges:

For the case of the $69120-130 \mathrm{~kg} / \mathrm{m}^{3}$ specimens:

$$
\begin{aligned}
& f_{t} \in[5.77,10.64] \mathrm{MPa} \\
& f_{t u} \in[4.19,11.34] \mathrm{MPa} \\
& \varepsilon_{t u} \in[1.09,8.71] \% \\
& E \in[39100,56200] \mathrm{MPa} \\
& w_{0} \in[1.86,5.60] \mathrm{mm} \\
& \gamma \in[0.51,1.51]
\end{aligned}
$$

For the case of the $158160 \mathrm{~kg} / \mathrm{m}^{3}$ specimens:

$$
f_{t} \in[4.12,12.70] \mathrm{MPa}
$$




$$
\begin{aligned}
& f_{t u} \in[4.77,13.75] \mathrm{MPa} \\
& \varepsilon_{t u} \in[0.96,8.75] \% \\
& E \in[42300,56500] \mathrm{MPa} \\
& w_{0} \in[1.23,4.85] \mathrm{mm} \\
& \gamma \in[0.54,1.68]
\end{aligned}
$$

Figure 5.32 depicts the experimental equivalent bending stress $(\sigma)$-displacement on the mid-span $(\delta)$ curves for the 158 specimens of $160 \mathrm{~kg} / \mathrm{m}^{3}$ and the 69 specimens of 120 $130 \mathrm{~kg} / \mathrm{m}^{3}$ of fibres.
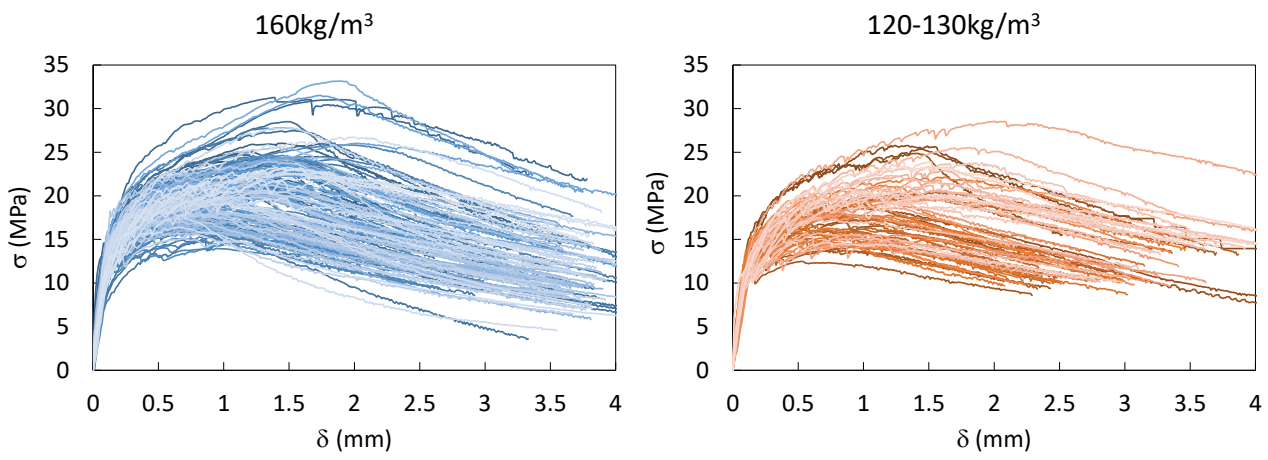

Figure $5.32 \sigma$ - $\delta$ curves for the specimens with $160 \mathrm{~kg} / \mathrm{m}^{3}$ (left) and $120-130 \mathrm{k} / \mathrm{m}^{3}$ of fibres (right)

Using the $\sigma-\delta$ curves shown in Figure 5.32, 4P-IA is applied to each curve to obtain each specimen's tensile constitutive behaviour. Figure 5.33 and Figure 5.34 depict the tensile constitutive behaviour for the specimens with $160 \mathrm{~kg} / \mathrm{m}^{3}$ and $120-130 \mathrm{~kg} / \mathrm{m}^{3}$. 

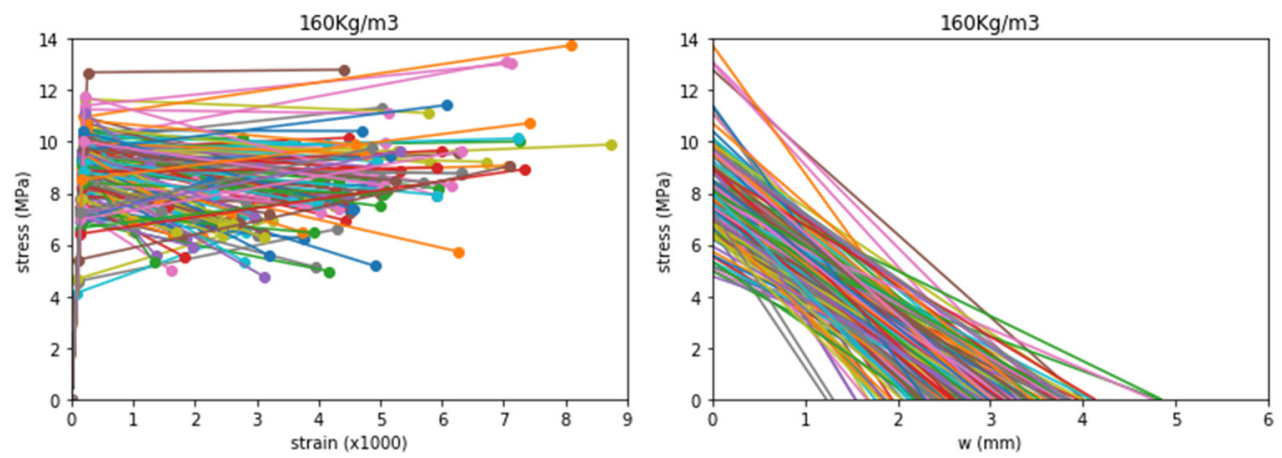

Figure 5.33 Constitutive behaviour for UHPFRC specimens with $160 \mathrm{~kg} / \mathrm{m}^{3}$ of fibres
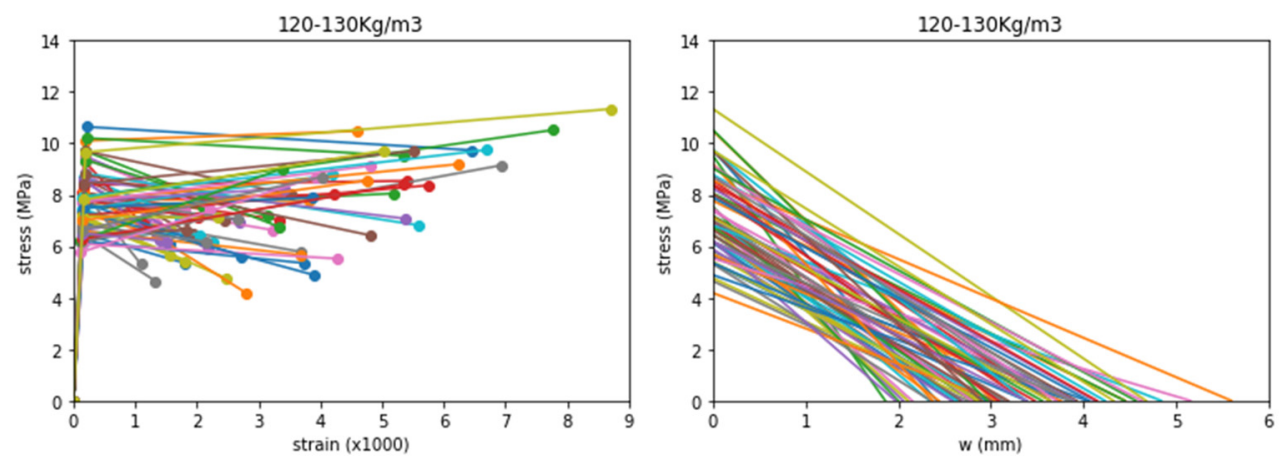

Figure 5.34 Constitutive behaviour for UHPFRC specimens with $120-130 \mathrm{~kg} / \mathrm{m}^{3}$ of fibres

We may wonder about the need to use UHPFRC with SS. According to UHPFRC standards (AFGC 2013; Swiss Society of Engineers and Architects SIA 2016), it would seem that the concretes displaying SH behaviour provide desirable behaviour and guarantee good concrete. This may be right, but is sometimes questionable. In line with this, an analysis is done using the specimens from the experimental programme. Figure 5.35 represents the $\mathrm{P}-\delta$ curves for some specimens with similar $f_{t}$ for both amounts of fibres: $160 \mathrm{~kg}$ and $130 \mathrm{~kg}$. Table 5.3 shows the tensile constitutive parameters for these specimens. We observe that for an $f_{t}$ value of around $9.5 \mathrm{MPa}$ for the $130 \mathrm{~kg} / \mathrm{m}^{3}$ specimens and an $f_{t}$ value of about $8.5 \mathrm{MPa}$ for $160 \mathrm{~kg} / \mathrm{m}^{3}$, the P- $\delta$ response for the specimens that exhibited SH $(\gamma \geq 1)$ accumulated more energy (in terms of area under the P- $\delta$ curve, Figure 5.35) than those exhibiting SS $(\gamma<1)$ with both amount of fibres. So in these cases, the SH response would appear to be more resistant than for the same $f_{t}$ value. 

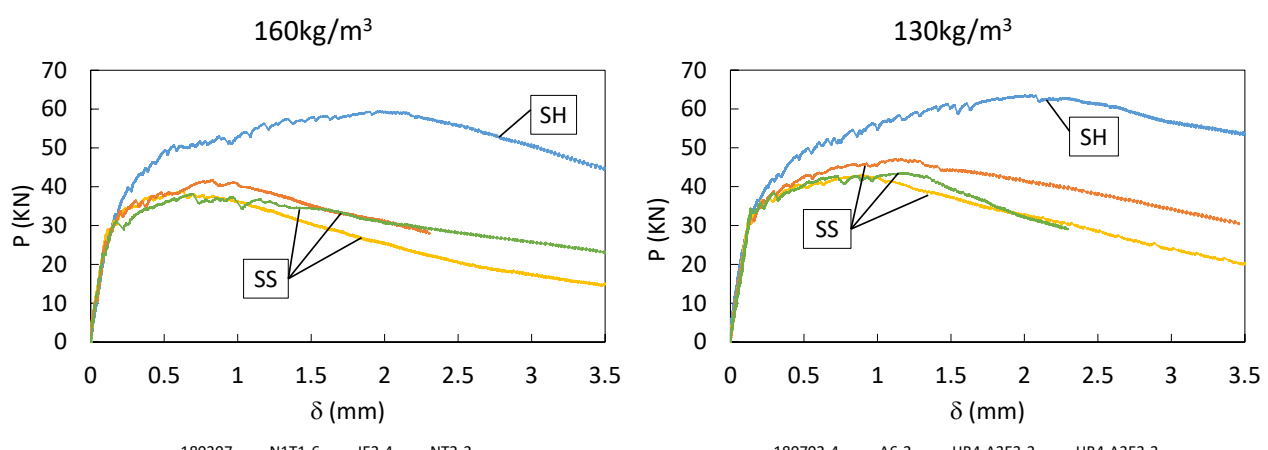

Figure $5.35 P$ - $\delta$ curves for the specimens with similar $f_{t}$ values.

Table 5.3 Tensile constitutive parameters for the specimens with similar $f_{t}$ values

\begin{tabular}{|c|c|c|c|c|c|c|c|}
\hline \multicolumn{7}{|c|}{$130 \mathrm{~kg} / \mathrm{m}^{3}$ of steel fibres } \\
\hline Id. & $f_{t}$ (MPa) & $f_{t u}(\mathrm{MPa})$ & $\varepsilon_{t u}(\%)$ & $E(\mathrm{MPa})$ & $w_{o}(\mathrm{~mm})$ & $\gamma$ \\
\hline $180702-4$ & 9.66 & 11.34 & 8.71 & 50000 & 4.68 & 1.17 \\
\hline A6-2 & 9.50 & 6.93 & 2.68 & 50100 & 2.69 & 0.73 \\
\hline HB4-A3E3-2 & 9.70 & 8.01 & 3.52 & 49400 & 3.93 & 0.83 \\
\hline HB4-A3E3-3 & 9.42 & 7.48 & 2.20 & 50400 & 2.80 & 0.79 \\
\hline \multicolumn{7}{|c|}{$160 \mathrm{~kg} / \mathrm{m}^{3}$ of steel fibres } \\
\hline Id. & $f_{t}(\mathrm{MPa})$ & $f_{t u}(\mathrm{MPa})$ & $\varepsilon_{t u}(\%)$ & $E(\mathrm{MPa})$ & $w_{o}(\mathrm{~mm})$ & $\gamma$ \\
\hline 180307 & 8.54 & 10.73 & 7.42 & 50300 & 3.44 & 1.26 \\
\hline N1T1-6 & 8.47 & 6.66 & 1.65 & 50900 & 2.16 & 0.79 \\
\hline JE2-4 & 8.61 & 7.23 & 2.81 & 47800 & 2.48 & 0.84 \\
\hline NT2-2 & 8.25 & 6.34 & 2.46 & 53200 & 3.48 & 0.77 \\
\hline
\end{tabular}

A comparison is made in energy terms. In Figure 5.36, the P- $\delta$ curves for some specimens with similar energy (similar area under the P- $\delta$ curve) are represented for both amounts of fibres: $160 \mathrm{~kg}$ and $130 \mathrm{~kg}$. Table 5.4 shows the tensile constitutive parameters. In both cases (160 and 130), when the energy accumulated on the P- $\delta$ curve is similar for the specimens exhibiting SH and SS, the $f_{t u}$ for the SH specimens come very close to the $f_{t}$ for the SS specimens. A difference in stiffness appears when the curve loses its linearity, which could explain SH/SS behaviour. When comparing the specimens with 
Chapter 5: Direct procedure to characterise the UHPFRC tensile constitutive behaviour

SS to one another for both amounts of fibres, they show different load levels at the loss of linearity point and at the maximum flexural load, which are represented in Figure 5.36 and, consequently, at the $f_{t}$ and $f_{t u}$ values (Table 5.4). They all have more or less the same stiffness up to loss of linearity. However, when comparing them to the specimen displaying SH behaviour (Table 5.4), the change in stiffness become more evident (Figure 5.36).
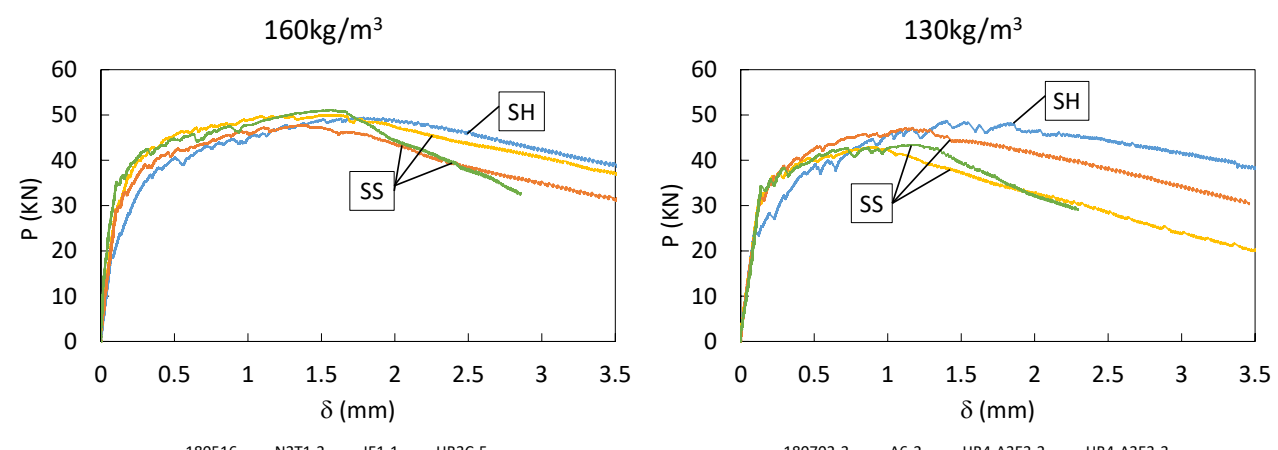

Figure 5.36 P- $\delta$ curves for the specimens with similar energy.

Table 5.4 Tensile constitutive parameters for the specimens with similar energy

\begin{tabular}{|c|c|c|c|c|c|c|}
\hline \multicolumn{7}{|c|}{$130 \mathrm{~kg} / \mathrm{m}^{3}$ of Steel fibres } \\
\hline Id. & $f_{t}(\mathrm{MPa})$ & $f_{t u}(\mathrm{MPa})$ & $\varepsilon_{t u}(\%)$ & $E(\mathrm{MPa})$ & $w_{o}(\mathrm{~mm})$ & $\gamma$ \\
\hline $180702-3$ & 6.17 & 9.15 & 6.93 & 52400 & 3.64 & 1.48 \\
\hline A6-2 & 9.50 & 6.93 & 2.68 & 50100 & 2.69 & 0.73 \\
\hline HB4-A3E3-2 & 9.70 & 8.01 & 3.52 & 49400 & 3.93 & 0.83 \\
\hline HB4-A3E3-3 & 9.42 & 7.48 & 2.20 & 50400 & 2.80 & 0.79 \\
\hline \multicolumn{7}{|c|}{$160 \mathrm{~kg} / \mathrm{m}^{3}$ of steel fibres } \\
\hline Id. & $f_{t}(\mathrm{MPa})$ & $f_{t u}(\mathrm{MPa})$ & $\varepsilon_{t u}(\%)$ & $E(\mathrm{MPa})$ & $w_{o}(\mathrm{~mm})$ & $\gamma$ \\
\hline 180516 & 5.41 & 9.06 & 7.11 & 56200 & 3.20 & 1.68 \\
\hline N2T1-2 & 9.42 & 8.49 & 4.32 & 53700 & 4.85 & 0.90 \\
\hline JE1-1 & 8.94 & 8.11 & 4.69 & 52100 & 3.70 & 0.91 \\
\hline HB3C-5 & 9.91 & 8.32 & 6.15 & 50200 & 3.16 & 0.84 \\
\hline
\end{tabular}


It can be deduced for the UHPFRC specimens exhibiting SS behaviour versus those showing SH in Table 5.4 and Figure 5.36 that the concrete matrix could be more resistant for UHPFRC with SS and, therefore, the $f_{t}$ value could be higher. The UHPFRC cases exhibiting SH behaviour could be cast with a concrete matrix capable of reaching less strength and, consequently, the $f_{t}$ parameter would lower. In this case, the steel fibre effect would make the $f_{t u}$ value increase. This would mean that the concrete with SH would not necessarily be better than the concrete exhibiting SS. Consequently, if it were possible to ensure a high-resistant concrete matrix with the same amount of fibres, then concrete would display SS tensile behaviour $(\gamma<1)$. However, the energy obtained in its $\mathrm{P}-\delta$ experimental response come close to a concrete with $\mathrm{SH}$ tensile behaviour $(\gamma \cdot \geq 1)$, with an $f_{t u}$ value of the SH concrete coming close to the $f_{t}$ value of the SS concrete.

\subsubsection{Numerical model application}

The material constitutive parameters obtained from applying the simplified 4P-IA for 65 specimens from the experimental programme are implemented into the discrete cracking approach 2D-NLFEM (see Section 4.4 in chapter 4) and compared to the experimental programme results.

Figure 5.37 illustrates the comparison made between the experimental and numerical stress-deflection $(\sigma-\delta)$ curves for an SH specimen (Figure 5.37, left) and an SS specimen (Figure 5.37, right).
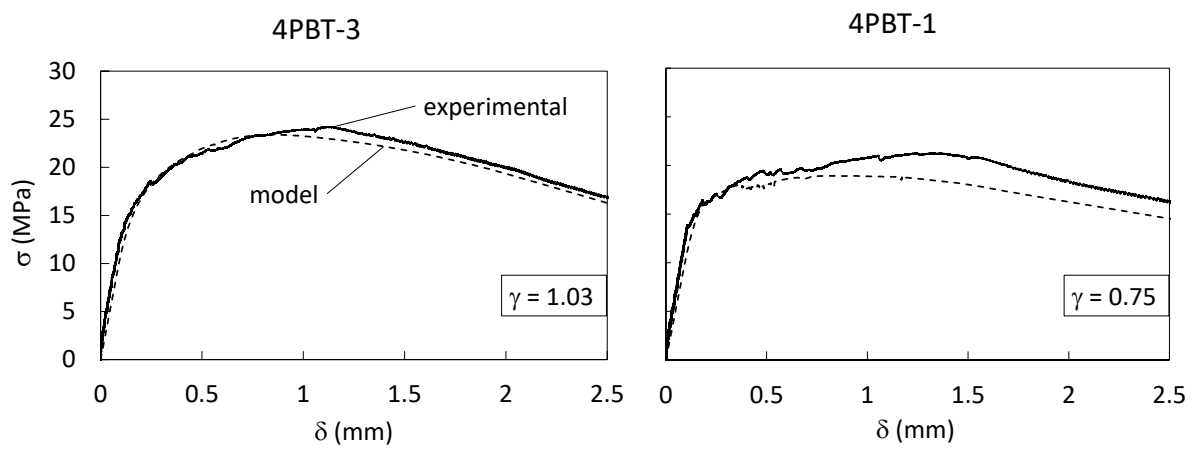

Figure 5.37 Specimen with SH (left); specimen with SS (right)

As seen in Figure 5.37, the $\sigma-\delta$ curve from NLFEM for the specimens displaying SH ( $\gamma$ $\geq 1)$ is more accurate than for those exhibiting SS $(\gamma<1)$. Notwithstanding, the inaccuracy observed in the model's curve for the specimens showing SS is conservative.

To quantify the accuracy of the NLFEM response, a coefficient of accuracy (CS) is defined as the ratio between the experimental stress and the stress obtained from the model (see Expression (5.6)). This CS is obtained at four levels of the experimental

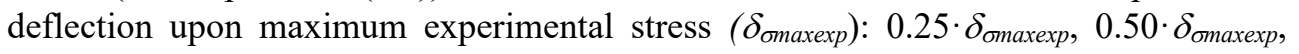


$\delta_{\text {omaxexp }}$ and $1.25 \cdot \delta_{\text {omaxexp }}$ (see Figure 5.38 ). The energy of the curve delimited by both the $\delta_{\text {omaxexp }}(\mathrm{A} 1)$ and $1.25 \cdot \delta_{\text {omaxexp }}$ levels (A2) for the experimental and model curves is obtained.

$$
C S=\frac{\sigma_{\text {exp }}}{\sigma_{\text {model }}}
$$

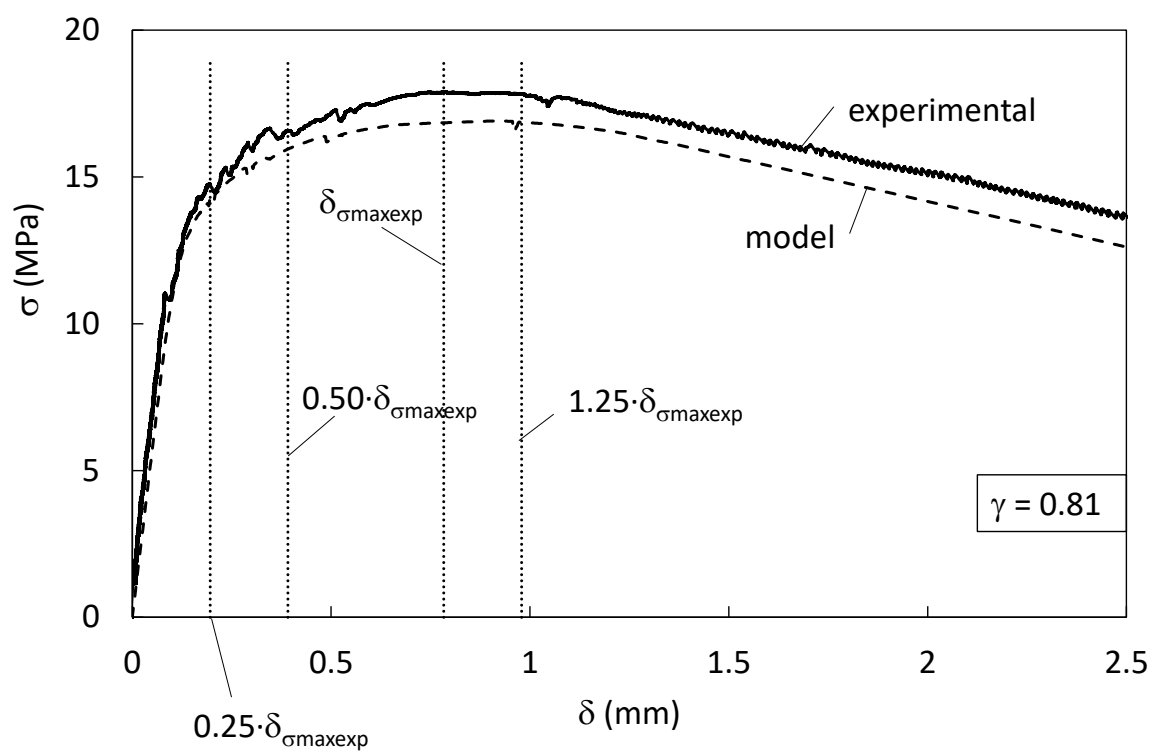

Figure 5.38 Coefficient of accuracy levels.

Figure 5.39 shows the relation between the hardening ratio $(\gamma)$ and the CS at the four experimental deflection levels upon maximum experimental stress ( $\left.\delta_{\text {omaxexp }}\right)$ : $0.25 \cdot \delta_{\text {omaxexp }}, 0.50 \cdot \delta_{\text {omaxexp }}, \delta_{\text {omaxexp }}$ and $1.25 \cdot \delta_{\text {omaxexp }}$ for the analysed 65 specimens: 54 specimens of $160 \mathrm{~kg} / \mathrm{m}^{3}$ of fibres and 11 of $130 \mathrm{~kg} / \mathrm{m}^{3}$. 

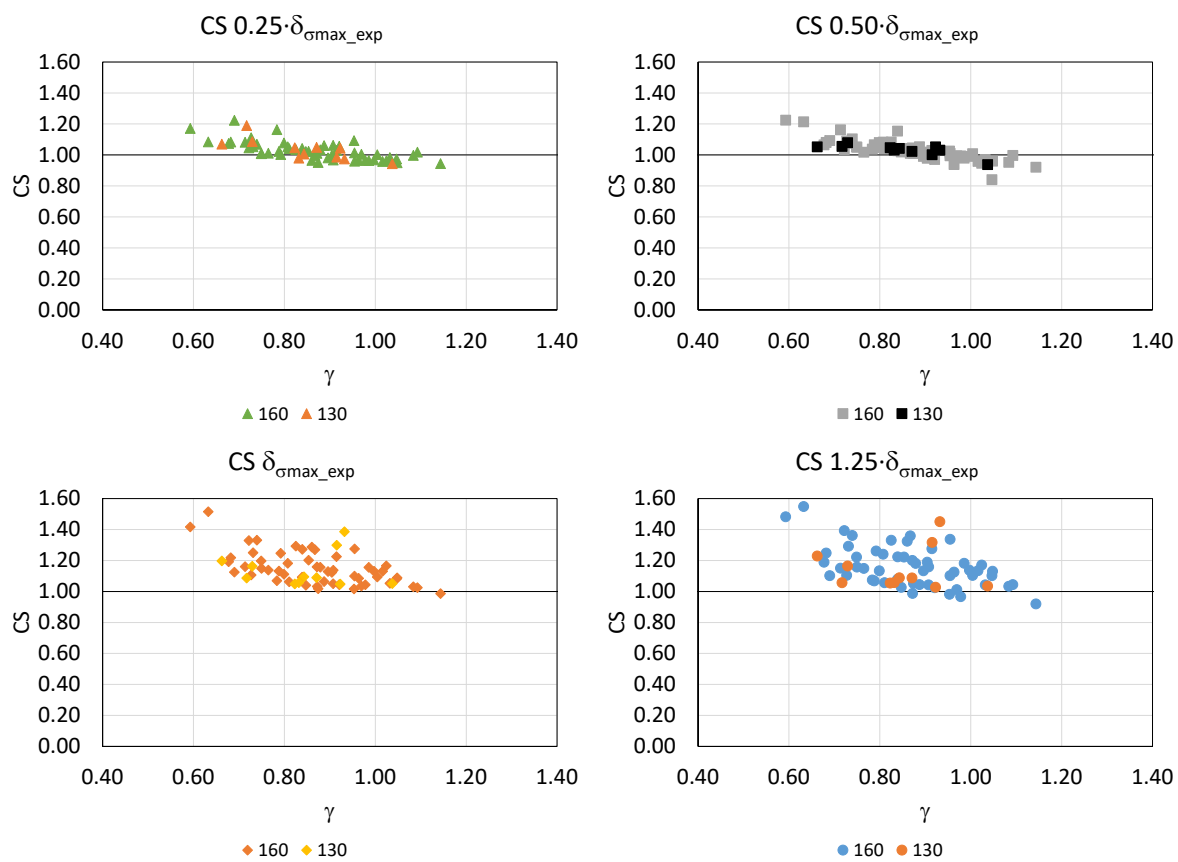

Figure 5.39 CS vs. rat four Slevels

As observed in Figure 5.39, the CS comes close to 1 in the early stages of the $\sigma-\delta$ curve

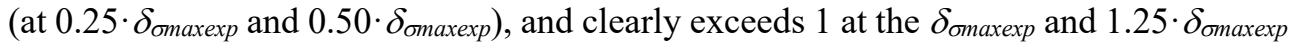
levels. This means that in the first stages, the model accurately predicts the experimental curve. When the highest level of the curve is reached and the descending branch takes part, the model's accuracy is not as good as on the elastic branch, but is conservative. Therefore, the model is reliable enough. According to Figure 5.39, certain inaccuracy appears at the first two levels, $0.25 \cdot \delta_{\text {omaxexp }}$ and $0.50 \cdot \delta_{\text {omaxexp }}$ (elastic branch of the $\sigma-\delta$ curve) on the non conservative side with the specimens made of UHPFRC exhibiting SH $(\gamma \geq 1)$. Nevertheless, this inaccuracy is negligible. At the last levels, and despite them being conservative, the stress experimental values are higher than the numerical ones, especially for SS $(\gamma<1)$. The model appears more accurate in these stages for the UHPFRC specimens displaying SH behaviour.

Figure 5.40 shows the relation between the energy calculated for the experimental ( $\left.\mathrm{A} 1_{\text {exp }}\right)$ and numerical ( $\left.\mathrm{A} 1_{\text {model }}\right)$ curves at the $\delta_{\text {бraxexp }}$ level and the energy calculated for the experimental $\left(\mathrm{A} 2_{\exp }\right)$ and numerical $\left(\mathrm{A} 2_{\text {model }}\right)$ curves at the $1.25 \cdot \delta_{\text {omaxexp }}$ level for the same 65 specimens. 
A1

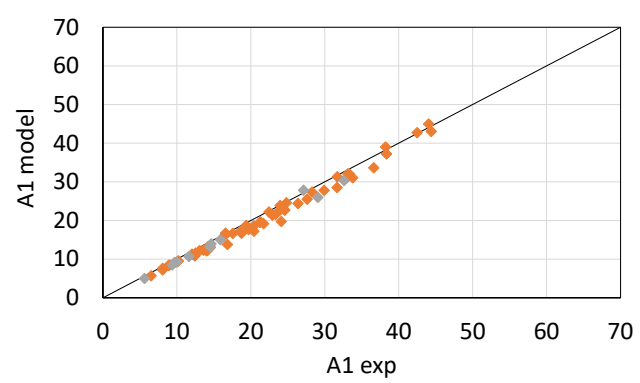

$\diamond 160 \diamond 130$
A2

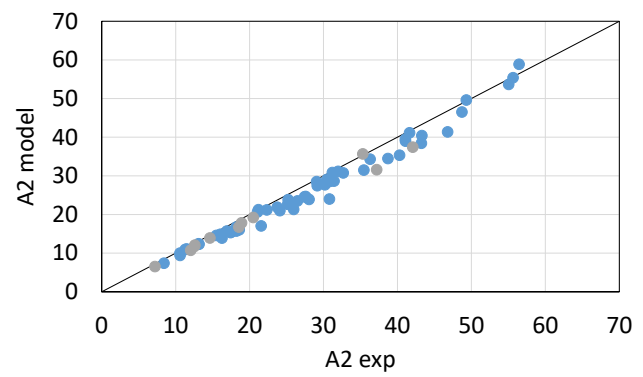

$-160 \bullet 130$

Figure 5.40 Alexp vs. Almodel, A2exp vs. A2model

As Figure 5.40 illustrates, the energy obtained in the experimental test is slightly higher than that obtained in the model. The same trend is observed for the other specimens in relation to the energy limited by $\delta_{\text {бmaxexp }}(\mathrm{A} 1)$ and $1.25 \cdot \delta_{\text {бmaxexp }}(\mathrm{A} 2)$. So the model is slightly conservative.

Figure 5.41 shows the relation between the experimental and numerical $\sigma_{\max }$ for the same 65 specimens.

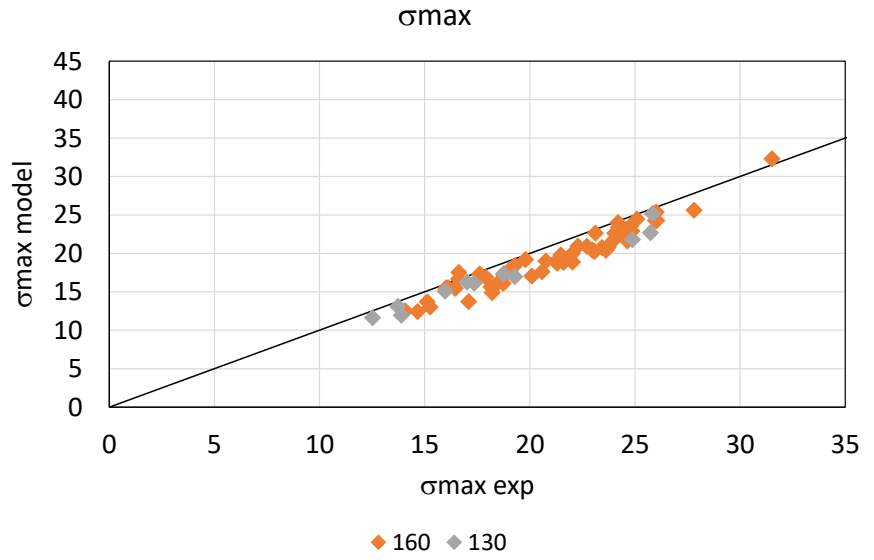

Figure 5.41 Experimental vs. model omax.

As shown in Figure 5.41, the experimental $\sigma_{\max }$ value is higher than the numerical one for each specimen. So as with energy, this value means that the model is conservative compared to the experimental results, and the level of accuracy is acceptable (see Figure 5.39, Figure 5.40 and Figure 5.41). 
It is important to understand that the 4P-IA procedure is developed for UHPFRC manifesting SH behaviour $(\gamma \geq 1)$. The results in Figure 5.39, Figure 5.40 and Figure 5.41 demonstrate that the simplified inverse analysis method is applicable for SS, but can be considered too conservative. Therefore, a study of the adjustment of 4P-IA is run to obtain more accurate results and to reduce the conservative response in the UHPFRC exhibiting SS behaviour $(\gamma<1)$. The idea is to adapt 4P-IA to cover all those cases that could appear when working with optimised UHPFRC; that is, $\mathrm{SH}$ behaviour, but also SS.

The adjustment procedure consists in calibrating the $\varepsilon_{t u}$ and $f_{t u}$ parameters to better fit the NLFEM $\sigma-\delta$ curve in 4PBT. A parametrical study focussing on the $\varepsilon_{t u}$ and $f_{t u}$ parameters is done to study their influence on the $\sigma-\delta$ response. By way of example, Figure 5.42 shows the experimental $\sigma-\delta$ at the mid-span of an SS specimen with $130 \mathrm{~kg} / \mathrm{m}^{3}$. If 4P-IA is applied and the resulting tensile parameters are used in NLFEM, the obtained $\sigma-\delta$ response would be conservative, as seen in Figure 5.42(left). Therefore, $f_{t u}$ is incremented by a percentage to study its influence on the $\sigma-\delta$ response. As shown in Figure 5.42(right), the $\sigma-\delta$ response very accurately adjusted the experimental one when $f_{t u}$ is incremented by $7 \%$ of the original value. Table 5.5 shows the tensile constitutive parameters after applying 4P-IA, which are used in NLFEM (see Figure 5.42(left)) and the same parameters with the $7 \% f_{t u}$ increment employed in NLFEM (see Figure 5.42(right)).

Therefore, the $f_{t u}$ parameter directly influences the model's response and, as we can see, 4P-IA underestimates the $f_{t u}$ value, which gives a conservative result in the $\sigma-\delta$ response and, consequently, in the energy that takes part in the flexural response of UHPFRC with SS behaviour.
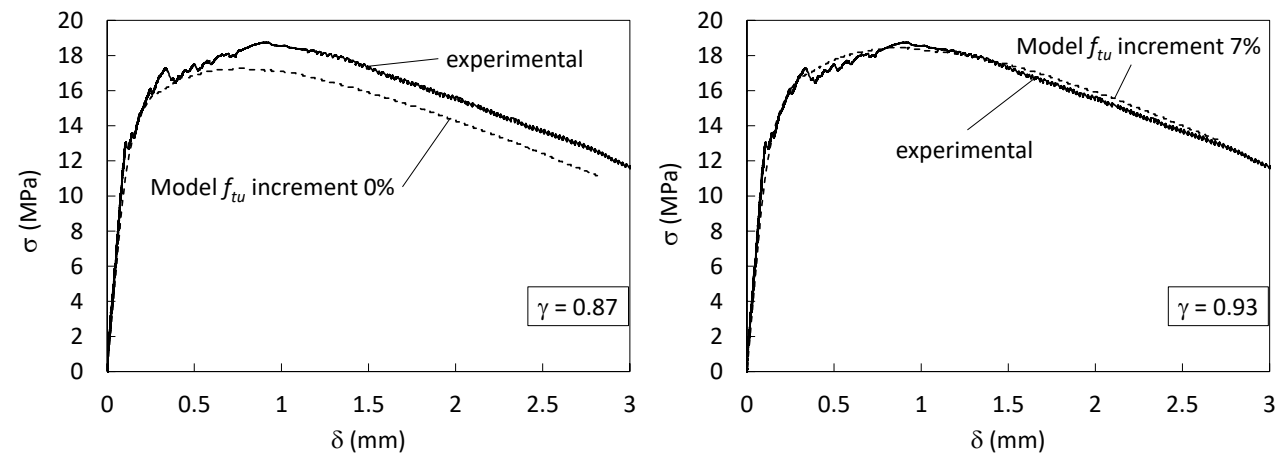

Figure $5.42 \sigma$ - $\delta$ response of the $f_{t u}$ variation in a strain-softening behaviours specimen. 
Chapter 5: Direct procedure to characterise the UHPFRC tensile constitutive behaviour

Table 5.5 Constitutive tensile parameters from applying $4 P-I A$ and $f_{\text {tu }}$ variation

\begin{tabular}{|c|c|c|c|c|c|c|}
\hline & \multicolumn{6}{|c|}{ constitutive tensile law } \\
\cline { 2 - 7 } & $f_{t}(\mathrm{MPa})$ & $f_{t u}(\mathrm{MPa})$ & $\varepsilon_{t u}(\%)$ & $E(\mathrm{MPa})$ & $w_{o}(\mathrm{~mm})$ & $\gamma$ \\
\hline 4P-IA & 8.08 & 7.03 & 3.35 & 54400 & 3.11 & 0.87 \\
\hline$f_{t u} 7 \%$ inc. & 8.08 & 7.52 & 3.35 & 54400 & 3.11 & 0.93 \\
\hline
\end{tabular}

The parametric study then focuses on the $\varepsilon_{t u}$ parameter. By way of example, the experimental $\sigma-\delta$ on the mid-span curve for the same specimen as in Figure 5.42 is depicted in Figure 5.43. In this case, the $f_{t u}$ value remains because the value obtained from the simplified 4P-IA and the parameter that varies is $\varepsilon_{t u}$. Figure 5.43(left) shows the $\sigma-\delta$ response of NLFEM when $\varepsilon_{t u}$ is incremented by $100 \%$ of the $\varepsilon_{t u}$ value obtained with 4P-IA. In Figure 5.43(right), the $\sigma-\delta$ curve from NLFEM when $\varepsilon_{t u}$ is incremented by $200 \%$ is found. Table 5.6 shows the tensile constitutive parameters after applying the simplified 4P-IA, which are the same parameters with the $100 \% \varepsilon_{t u}$ increment and the same parameters with the $200 \% \varepsilon_{t u}$ increment employed in NLFEM in Figure 5.43. Therefore, as shown in Figure 5.43 and Table 5.6, the variation in the $\varepsilon_{t u}$ parameter needs to be very wide to have some effect on the model's $\sigma-\delta$ response. Consequently, the influence of the variation in $\varepsilon_{t u}$ is considered negligible.
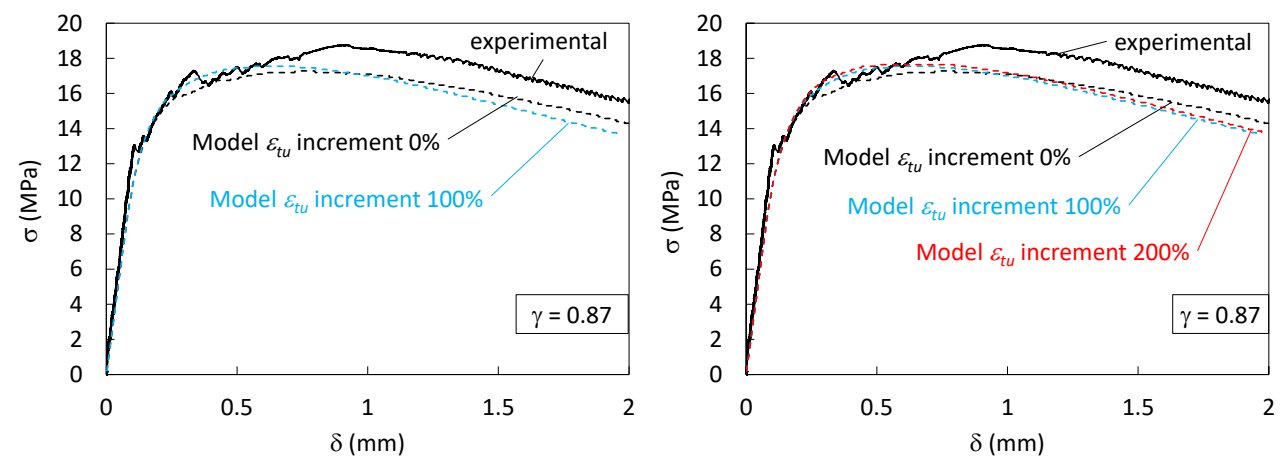

Figure $5.43 \sigma$ - $\delta$ response of the $\varepsilon_{t u}$ variation in a strain-softening behaviour specimen. 
Table 5.6 Constitutive tensile parameters from applying 4P-IA and $\varepsilon_{t u}$ variation

\begin{tabular}{|c|c|c|c|c|c|c|}
\hline \multirow{2}{*}{} & \multicolumn{6}{|c|}{ constitutive tensile law } \\
\cline { 2 - 7 } & $f_{t}(\mathrm{MPa})$ & $f_{t u}(\mathrm{MPa})$ & $\varepsilon_{t u}(\%)$ & $E(\mathrm{MPa})$ & $w_{o}(\mathrm{~mm})$ & $\gamma$ \\
\hline 4P-IA & 8.08 & 7.03 & 3.35 & 54400 & 3.11 & 0.87 \\
\hline$\varepsilon_{t u} 100 \%$ inc. & 8.08 & 7.03 & 6.70 & 54400 & 3.11 & 0.87 \\
\hline$\varepsilon_{t u} 200 \%$ inc. & 8.08 & 7.03 & 10.05 & 54400 & 3.11 & 0.87 \\
\hline
\end{tabular}

Parameter $f_{t u}$, which is obtained from applying 4P-IA, is calibrated using NLFEM as shown in Figure 5.42 for 64 specimens with different $\gamma$ values; 32 specimens with $160 \mathrm{~kg} / \mathrm{m}^{3}$ and 32 with $130 \mathrm{~kg} / \mathrm{m}^{3}$. For each specimen, the increment in $f_{\text {tu }}$, denoted by variable var, required to fit the NLFEM $\sigma-\delta$ curve is obtained for the specimens with $130 \mathrm{~kg} / \mathrm{m}^{3}$ and $160 \mathrm{~kg} / \mathrm{m}^{3}$ of fibres for the different hardening coefficient $(\gamma)$ values, as shown in Figure 5.44(left). Therefore, a bilinear expression that relates the increment in the $f_{t u}$ (var) percentage with the hardening coefficient $(\gamma)$ can be deduced from Figure 5.44(right).
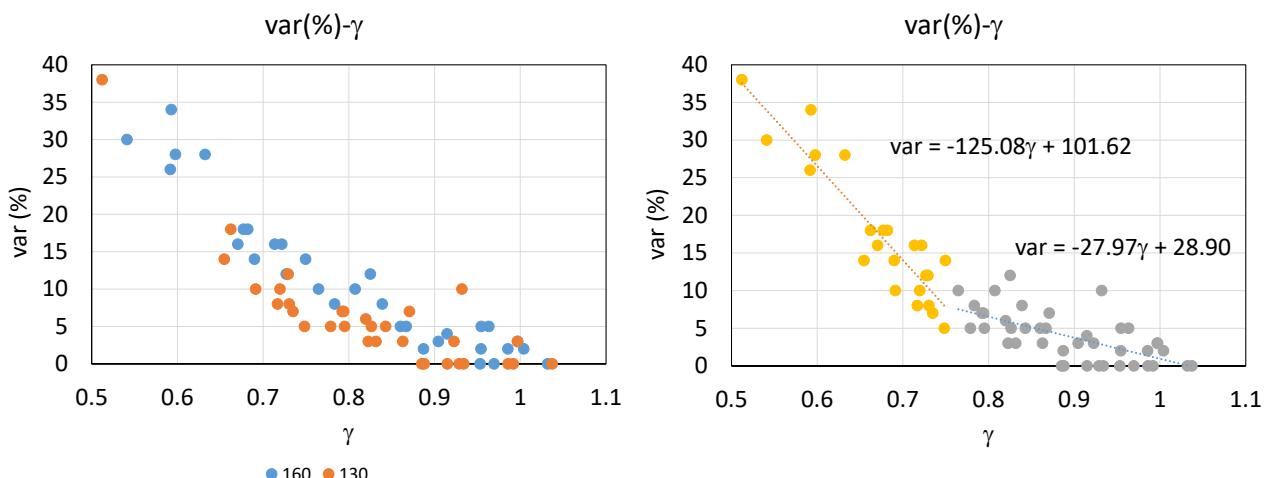

Figure 5.44 Relation var (\%) $-\gamma: 160 \mathrm{~kg} / \mathrm{m}^{3}$ and $130 \mathrm{~kg} / \mathrm{m}^{3}$ of fibres (left) and bilinear expression (right)

From Figure 5.44, Expression (5.7) can be deduced to relate the increment in the $f_{t u}$ (var) percentage with the hardening coefficient $(\gamma)$. Consequently for the UHPFRCs that exhibits SS $(\gamma<1)$ after applying 4P-IA, a correction of the $f_{t u}$ parameter using Expression (5.8) can be made to fit the model response to the experimental one. 


$$
\begin{array}{cc}
\text { var }=0 & \gamma \geq 1 \\
\operatorname{var}=-27.97 \cdot \gamma+28.90 & 1>\gamma>0.75 \\
\operatorname{var}=-125.08 \cdot \gamma+101.62 & 0.75 \geq \gamma
\end{array}
$$

$$
f_{t u c}=\left(1+\frac{v a r}{100}\right) \cdot f_{t u}
$$

Next, the correction of $f_{t u}\left(f_{t u c}\right)$ from Expression (5.8) is done for the same 65 specimens as in Figure 5.39, Figure 5.40 and Figure 5.41. The $f_{\text {tuc }}$ parameter and the other constitutive parameters obtained from the simplified 4P-IA are implemented into NLFEM and compared to the experimental results. By considering the same previously defined criteria for CS (see Figure 5.38), the new relations between the hardening ratio $(\gamma)$ and the CS at the four experimental deflection levels upon maximum experimental stress $\left(\delta_{\text {omaxexp }}\right): 0.25 \cdot \delta_{\text {omaxexp }}, 0.50 \cdot \delta_{\text {omaxexp }}, \delta_{\text {omaxexp }}$ and $1.25 \cdot \delta_{\text {omaxexp }}$ for the 65 analysed specimens including 54 specimens of $160 \mathrm{~kg} / \mathrm{m}^{3}$ of fibres and $11 \mathrm{of} 130 \mathrm{~kg} / \mathrm{m}^{3}$ (see Figure 5.45).
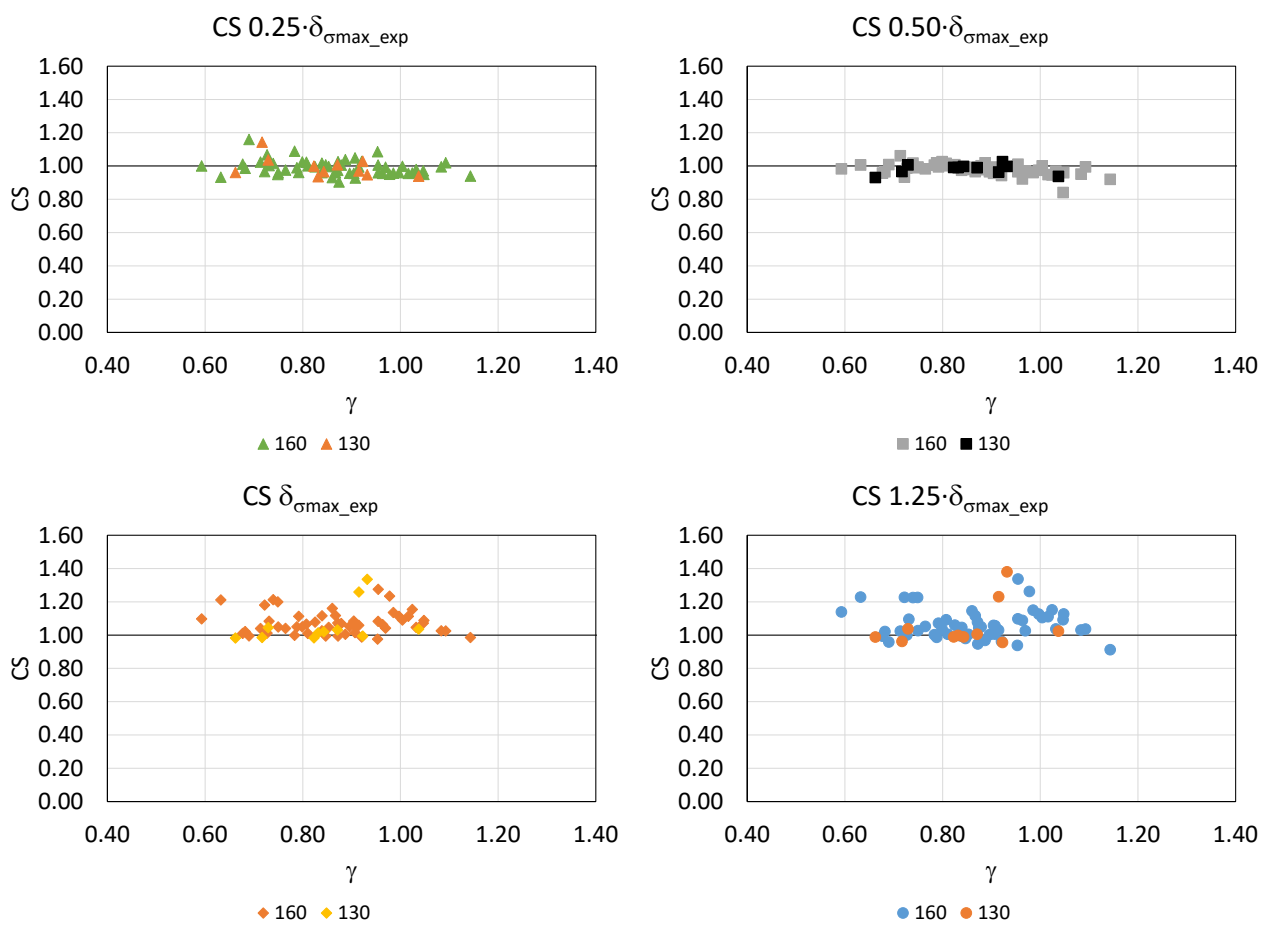

Figure 5.45 CS vs. rat four $\delta$ levels when correcting $f_{t u}$ 
When comparing Figure 5.45 to Figure 5.39, the cloud of the CS- $\gamma$ points in all the graphs are more aligned near 1.00 in Figure 5.45. In the early stages of the $\sigma-\delta$ curve, these take place at $0.25 \cdot \delta_{\text {omaxexp }}$ and $0.50 \cdot \delta_{\text {omaxx }}$, Figure 5.45 shows very accurate results, which means that the model improves for SS, especially in $\gamma<0.8$ in both cases. At the $\delta_{\text {onaxexp }}$ and $1.25 \cdot \delta_{\text {onaxexp }}$ levels, not only are the values more aligned, but the scatter of the results also reduced in the SS part $(\gamma<1)$. Therefore thanks to the $f_{t u}$ correction, the results improve for SS and, consequently, the model becomes more accurate.

Figure 5.46 shows the relation between the energy calculated for the experimental $\left(\mathrm{A} 1_{\text {exp }}\right)$ and numerical $\left(\mathrm{A} 1_{\text {model }}\right)$ curves at the $\delta_{\text {omaxexp }}$ level and the energy calculated for the experimental $\left(\mathrm{A} 2_{\mathrm{exp}}\right)$ and numerical $\left(\mathrm{A} 2_{\text {model }}\right)$ curves at the $1.25 \cdot \delta_{\text {omaxexp }}$ level for the same 65 specimens when making the $f_{t u}$ correction in Expression (5.8).

A1

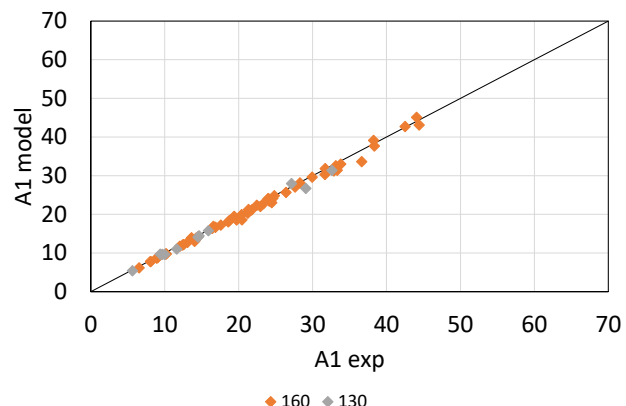

$\mathrm{A} 2$

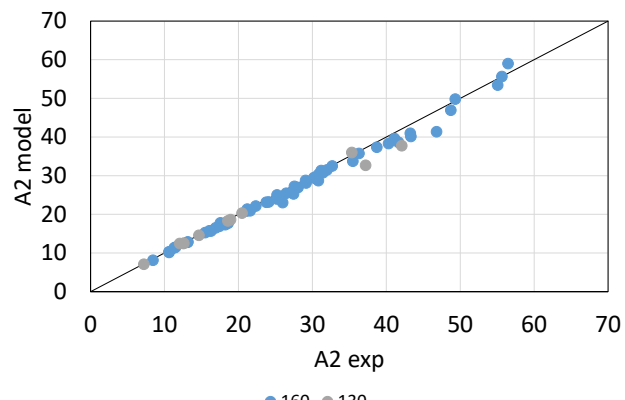

Figure 5.46 Alexp vs. A1model, A2exp vs. A2model when correcting $f_{t u}$

When comparing Figure 5.46 and Figure 5.40, the energy obtained in the experimental test comes very close to that obtained in the model for the same specimen when the $f_{t u}$ correction from Expression (5.8) is applied. The same trend is observed for the other specimens as the energy limited by $\delta_{\text {omaxx }}(\mathrm{A} 1)$ and that limited by $1.25 \cdot \delta_{\text {omaxexp }}(\mathrm{A} 2)$. What this demonstrates is that the model which employs the $f_{t u}$ correction for SS is more accurate and the obtained energy is similar to that obtained in the experimental test.

Figure 5.47 shows the relation between the experimental and numerical $\sigma_{\max }$ for the same 65 specimens when making the $f_{t u}$ correction in Expression (5.8). 


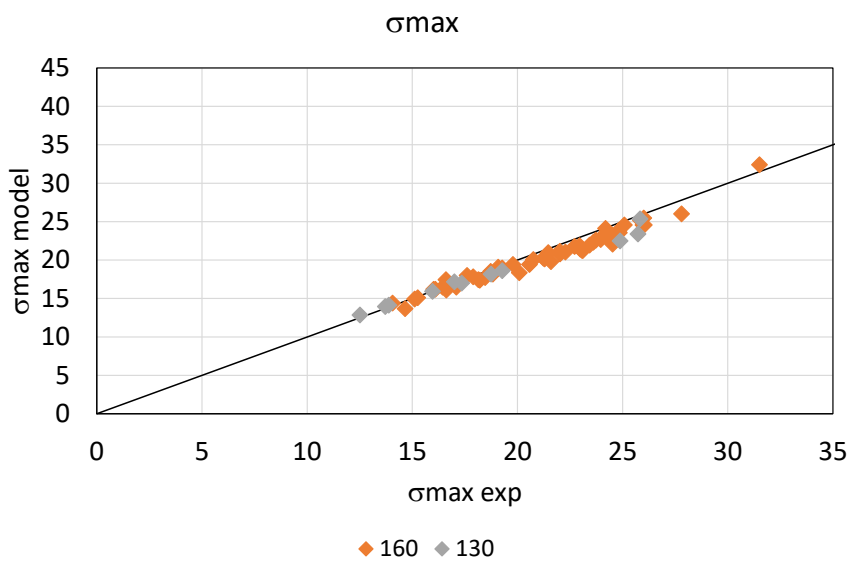

Figure 5.47 Experimental vs. model $\sigma_{\max }$ when correcting $f_{t u}$

When comparing Figure 5.47 and Figure 5.41, we see how, as in Figure 5.41, that the experimental $\sigma_{\max }$ value is higher than the numerical one for each specimen. Therefore and as previously mentioned, this value demonstrated that the model is conservative in relation to the experimental results. According to Figure 5.47, the model more accurately fits the experimental results when correcting the $f_{t u}$ value following Expression (5.7) and Expression (5.8) for SS behaviour $(\gamma<1)$.

Therefore, as demonstrated above, the correction of the $f_{\text {tu }}$ parameter for SS behaviour $(\gamma<1)$ using Expression (5.7) and Expression (5.8), and its application to the discrete cracking approach 2D-NLFEM, lead to an improved model response and make the prediction more accurate and reliable. The softening correction $\left(f_{t u c}\right)$ applied to SSUHPFRC reduces the scatter of the model results at four levels of the of the CS- $\gamma$ curve:

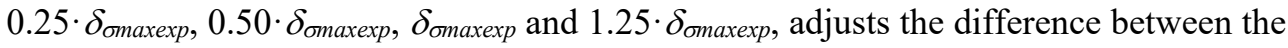
energy obtained in the experimental test to that obtained in the model and fits accurately the $\sigma_{\max }$ value. Consequently, it can be concluded that the 4P-IA is directly applicable when the UHPFRC manifests SH tensile behaviour $(\gamma \geq 1)$ and applicable with the softening correction $\left(f_{\text {tuc }}\right)$ when the UHPFRC manifests SS tensile behaviour $(\gamma<1)$, leading to a reliable inverse analysis methodology to be used to obtain the UHPFRC tensile constitutive behaviour from SH to SS range in simple flexural tests such as the 4PBT.

\subsection{Direct procedure: UHPFRC tensile constitutive behaviour.}

From the above-described work, it can be stated that anyone who proposes characterising the tensile behaviour of UHPFRC could do so no matter if it exhibited SH or SS. A direct, reliable and simple inverse analysis methodology has been set to be applied in 
simple and easy to conduct 4PBT. At this point, the characteristic $\sigma-\delta$ curve of UHPFRC herein used is obtained to set the characteristic tensile parameters, which could be a reference for such concretes. The procedure herein described is applied step-by-step to the characteristic $\sigma-\delta$ to exemplify the direct procedure here developed.

Moreover, bearing in mind the extensive experimental database that we present here in 5.4.1 section, namely 227 UHPFRC 4PBT specimens, a predicting application is developed to avoid variability in the application of a simplified inverse analysis. With this application, it is possible to obtain the constitutive tensile parameters of UHPFRC by introducing only the $\sigma-\delta$ curve obtained from $4 \mathrm{PBT}$ without having to apply 4P-IA and the correction for SS because this is already considered in the predicting application.

\subsubsection{Characteristic UHPFRC tensile constitutive behaviour.}

The idea of this section is to show the application of the direct method to obtain the UHPFRC tensile constitutive behaviour set in the consecutive sections of this chapter. Moreover, the characteristic $\sigma-\delta$ curve of UHPFRC of all the range of UHPFRC considered in the experimental programme in section 5.4.1 is obtained to establish a reference of the $\sigma-\delta$ curve expectable when the experimental 4PBT is applied in the range of UHPFRC treated in this work. Therefore, the direct procedure is used to obtain the characteristic UHPFRC $\sigma-\delta$ curve establishing a reference for the $\sigma-\delta$ curve of the optimised UHPFRC range addressed in this work and for its tensile constitutive behaviour parameters.

Of the $227 \sigma-\delta$ curves obtained from the experimental programme carried out in 5.4.1 section, the characteristic $\sigma-\delta$ curve of the 158 specimens of $160 \mathrm{~kg} / \mathrm{m}^{3}$ and the 69 of 120 $130 \mathrm{~kg} / \mathrm{m}^{3}$ of steel fibres are obtained. In Figure 5.48, the characteristic $\sigma-\delta$ curve for each amount of fibres is depicted.
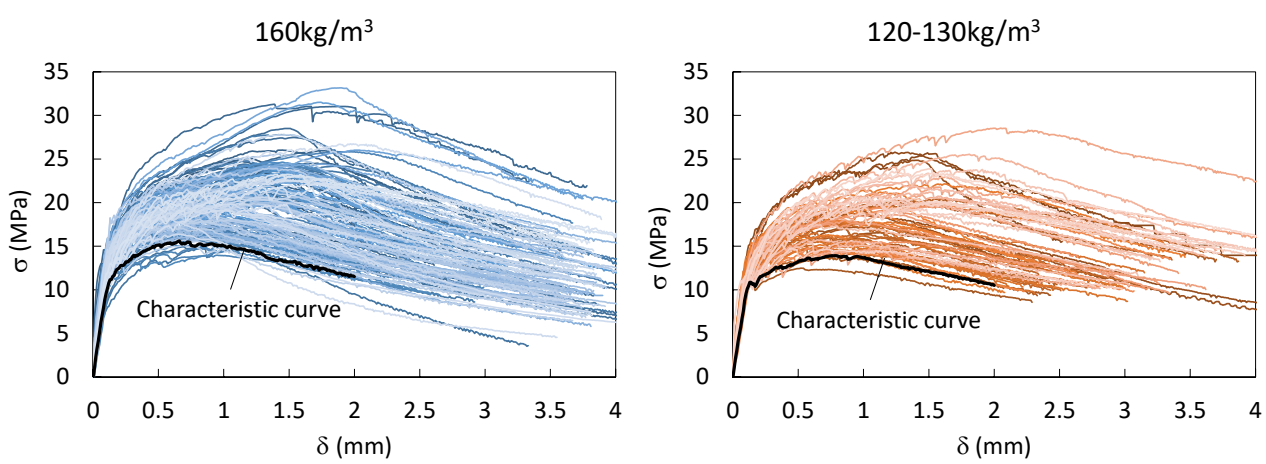

Figure 5.48 Characteristic $\sigma-\delta$ curve for the $160 \mathrm{~kg} / \mathrm{m}^{3}$ and $120-130 \mathrm{~kg} / \mathrm{m}^{3}$ steel fibre specimens 
When the test ends, the equivalent flexural stress is obtained from the experimental load following Expression (5.1). Using the $\sigma-\delta$ curve, 4P-IA is applied to obtain the tensile parameters (see Figure 5.4) following (López 2017). The method is explained in detail for the characteristic $\sigma-\delta$ curve of the $160 \mathrm{~kg} / \mathrm{m}^{3}$ specimens.

If the extension of the linear elastic slope of the $\sigma-\delta$ curve intersects the $\delta$ axis at a different point $\delta_{c}$ to 0 , all the measured $\delta$ values have to be corrected following Expression (5.9). In this case, $\delta_{c}$ equals $-0.003 \mathrm{~mm}$ (see Figure 5.49)

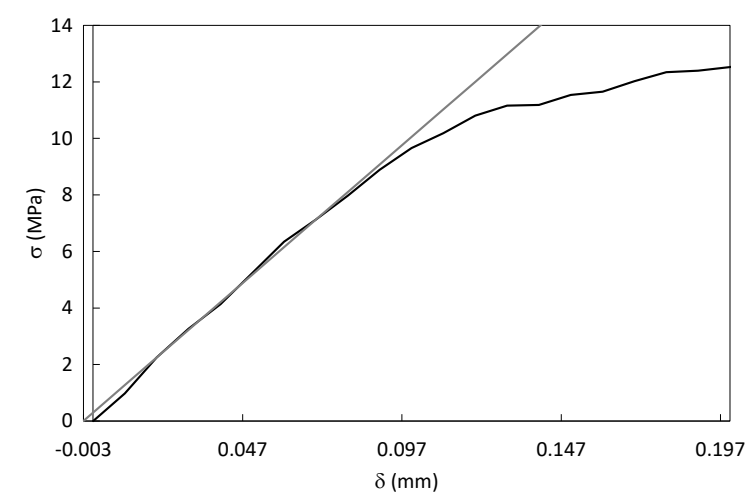

Figure 5.49 Intersection between elastic slope and the $\delta$ axis

$$
\delta_{\text {corr }}=\delta-\delta_{c}
$$

The corrected curve is shown in Figure 5.50(left), where the line defining the linear elastic behaviour passes through the origin. The determination of the initial slope $(m)$ is defined using two points in the linear part of the curve (see Figure 5.50(left)). After obtaining the slope, line $\mathrm{S}_{0}$ could be easily drawn and then lines $\mathrm{S}_{75}$ and $\mathrm{S}_{40}$ are drawn. Their slope is $0.75 \cdot \mathrm{m}$ and $0.40 \cdot \mathrm{m}$, respectively (see Figure 5.50 (right)). 

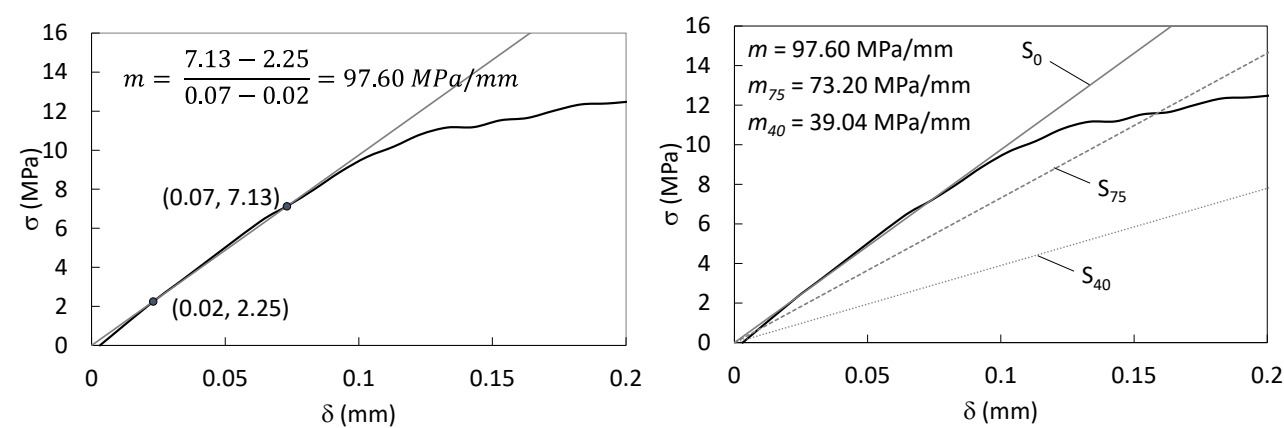

Figure 5.50 Elastic slope corrected (left) and the slopes of $S_{0,} S_{75}$ and $S_{40}$ (right)

Then these lines are drawn and the four key points are obtained, as shown in Figure 5.51.
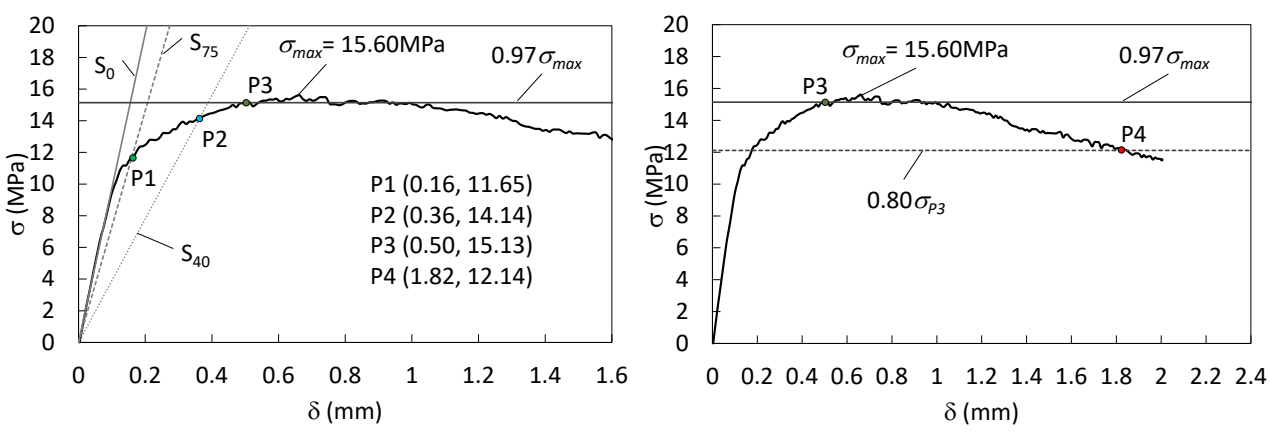

Figure 5.51 Determination of the four key points.

Using the values obtained as described above and applying the 4P-IA formulation detailed in Table 5.7, the parameters that define the characteristic tensile behaviour of UHPFRC with $160 \mathrm{~kg} / \mathrm{m}^{3}$ of steel fibres are calculated and are shown in Table 5.8.

Table 5.7 4P-IA formulation

\begin{tabular}{|c|c|c|}
\hline $\begin{array}{c}\text { Tensile } \\
\text { constitutive } \\
\text { parameters }\end{array}$ & $\frac{L}{h}=4.5$ & Auxiliary parameters \\
\hline$E$ & $4.79 \mathrm{hm}$ & \\
\hline$f_{t}$ & $\frac{\sigma_{1}}{1.59}\left(\frac{\sigma_{1}}{\sigma_{2}}\right)^{0.21}$ & \\
\hline
\end{tabular}


Chapter 5: Direct procedure to characterise the UHPFRC tensile constitutive behaviour

\begin{tabular}{|c|c|c|}
\hline$\varepsilon_{t, u}$ & $\frac{f_{t}}{E}\left(6.65 \frac{\delta_{3}}{\delta_{1}}-9.40\right)$ & \\
\hline$\gamma$ & $\alpha^{-0.17}\left(2.24 \frac{\sigma_{3}}{\sigma_{1}}-1.55\right)$ & $\alpha=\varepsilon_{t, u} \frac{E}{f_{t}}$ \\
\hline$\varepsilon_{t, d}$ & $\gamma^{-0.38} \alpha^{0.89}\left(2.82 \frac{\delta_{4}^{*}}{\delta_{3}}-1.68\right) \frac{f_{t}}{E}$ & $\delta_{4}^{*}=\delta_{4}\left(1+\frac{9 d}{20(L-2 d)}\right)$ \\
\hline$w_{0}$ & $\left(\varepsilon_{t, d}-\varepsilon_{t, u}+\frac{10 \gamma f_{t}}{3 E}\right) \frac{9 h}{4}$ & \\
\hline
\end{tabular}

where:

$d$ is the distance from the macrocrack to the mid-span measured on the top face. In this case, it is considered 0 .

$L$ is the length of the span between supports. In this case: $L=450 \mathrm{~mm}$ (Figure 5.31)

$h$ is specimen depth. In this case: $h=100 \mathrm{~mm}$

Table 5.8 Characteristic constitutive tensile parameters for $120-130$ and $160 \mathrm{~kg} / \mathrm{m}^{3}$ of fibre UHPFRC

\begin{tabular}{|c|c|c|c|c|c|c|}
\hline \multirow{2}{*}{$\begin{array}{c}\text { Steel fibres } \\
\left(\mathrm{kg} / \mathrm{m}^{3}\right)\end{array}$} & \multicolumn{6}{|c|}{ UHPFRC characteristic constitutive tensile law } \\
\cline { 2 - 7 } & $f_{t}(\mathrm{MPa})$ & $f_{t u}(\mathrm{MPa})$ & $\varepsilon_{t u}(\%)$ & $E(\mathrm{MPa})$ & $w_{o}(\mathrm{~mm})$ & $\gamma$ \\
\hline $120-130$ & 6.51 & 5.12 & 2.62 & 42500 & 2.65 & 0.79 \\
\hline 160 & 7.03 & 6.32 & 1.71 & 46750 & 2.35 & 0.90 \\
\hline
\end{tabular}

As seen in Table 5.8, the obtained characteristic tensile law for UHPFRC of $160 \mathrm{~kg} / \mathrm{m}^{3}$ exhibits SS, which is $\gamma<1$. Therefore, it is necessary to correct the $f_{t u}$ value following Expression (5.7) and Expression (5.8). The corrected tensile parameters $f_{\text {tuc }}$ and $\gamma_{\mathrm{c}}$ are detailed in Table 5.9. In addition, if the same process is repeated for UHPFRC with 120$130 \mathrm{~kg}$ of fibres, the characteristic curve of UHPFRC with $120-130 \mathrm{~kg}$ of steel fibres could be obtained. The results are found in Table 5.8 and Table 5.9. Table 5.9 provides details of the characteristic tensile constitutive parameters for UHPFRC with $120-130 \mathrm{~kg} / \mathrm{m}^{3}$ and $160 \mathrm{~kg} / \mathrm{m}^{3}$ of steel fibres. In Figure 5.52, the comparison made between the characteristic experimental $\sigma-\delta$ curve and the 2D-NLFEM $\sigma-\delta$ curve, when the characteristic corrected tensile parameters from Table 5.9 are used in the model, is depicted for the UHPFRC 
with both amounts of fibres. Hence, the comparison in Figure 5.52 demonstrates the employed method's reliability to obtain the constitutive tensile parameters of UHPFRC in Table 5.9.

Table 5.9 Corrected characteristic constitutive parameters for $120-130$ and $160 \mathrm{~kg} / \mathrm{m}^{3}$ of fibre UHPFRC

\begin{tabular}{|c|c|c|c|c|c|c|}
\hline \multirow{2}{*}{$\begin{array}{c}\text { Steel fibres } \\
\left(\mathrm{kg} / \mathrm{m}^{3}\right)\end{array}$} & \multicolumn{5}{|c|}{ UHPFRC characteristic corrected constitutive tensile law } \\
\cline { 2 - 7 } & $f_{t}(\mathrm{MPa})$ & $f_{t u c}(\mathrm{MPa})$ & $\varepsilon_{t u}(\%)$ & $E(\mathrm{MPa})$ & $w_{o}(\mathrm{~mm})$ & $\gamma_{c}$ \\
\hline $120-130$ & 6.51 & 5.47 & 2.62 & 42500 & 2.65 & 0.84 \\
\hline 160 & 7.03 & 6.56 & 1.71 & 46750 & 2.35 & 0.93 \\
\hline
\end{tabular}
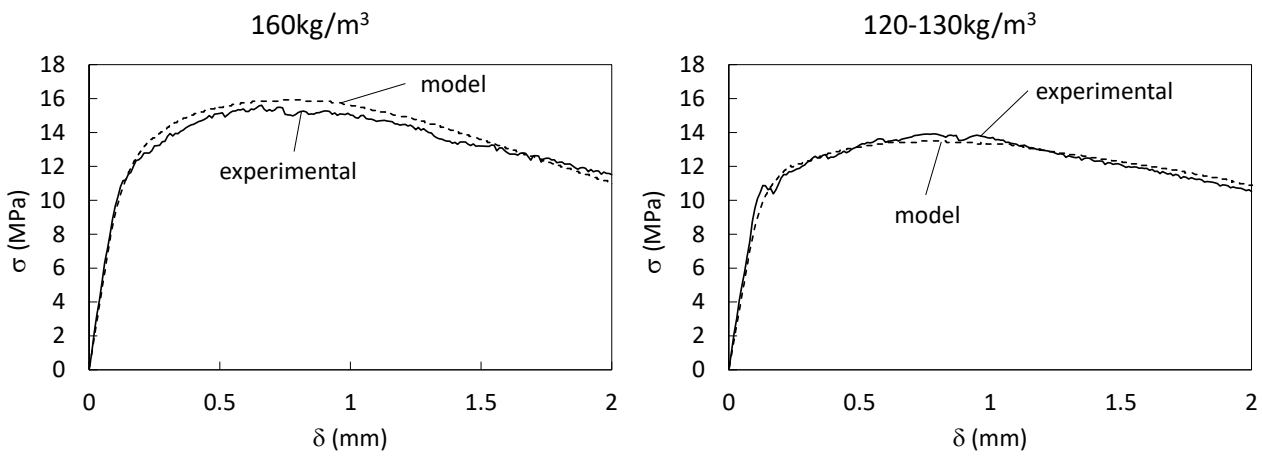

Figure 5.52 Characteristic $\sigma$ - $\delta$ curves: $2 D$-NLFEM using corrected tensile parameters $v$ s. experimental response.

\subsubsection{Predicting application to obtain UHPFRC tensile constitutive behaviour}

As it is described in section 5.4.1 an extensive experimental programme of 4PBT UHPFRC specimens has been carried out in this work to cover all the range from $\mathrm{SH}$ to SS-UHPFRC for both amounts of steel fibres considered: $160 \mathrm{~kg} / \mathrm{m}^{3}$ and $120-130 \mathrm{~kg} / \mathrm{m}^{3}$. For the 227 specimens that constitute the overall programme, the experimental 4PBT $\sigma$ $\delta$ curves are obtained and the direct procedure to characterise the UHPFRC tensile constitutive behaviour here developed is applied to obtain the tensile parameters. Therefore, each experimental 4PBT $\sigma-\delta$ curve of each specimen is linked to its set of UHPFRC tensile parameters, as it can be seen in previous section 5.5.1. In this sense, a database that relates $\sigma-\delta$ curves to tensile parameters is set. Moreover, all of the experimental 4PBT tests and the tensile parameters are carried out and calculated by the 
author of this work, so they are obtained by the same way and following the same pattern. Thus, the possible variability of the results due to "human factor" is controlled.

Therefore, the objective of this section is, by obtaining the experimental $\sigma-\delta$ from 4PBT as input and the tensile constitutive parameters as output, to generate an application which, by introducing the experimental $\sigma-\delta$ curve, directly returned the tensile constitutive parameters. With this application, it is possible to avoid the variability due to the interpretation and application of the simplified 4P-IA because the whole database is produced in the same way.

The application is developed using a kriging predictor adaptation from the DACE (Design and Analysis of Computer Experiments) software package. This is a Matlab toolbox developed by (H. B. Nielsen 2002) to work with kriging approximations with computer models. In this application, the addressed computer models are deterministic.

The required inputs to build the model are:

- S: a matrix containing all the $\sigma-\delta$ experimental curves. Each column of the matrix is a $\sigma-\delta$ curve. In this case, 200 curves are used: 139 with $160 \mathrm{~kg} / \mathrm{m}^{3}$ of steel fibres and 61 with $120-130 \mathrm{~kg} / \mathrm{m}^{3}$. That is, the model "learns" by using these curves as a database. Therefore, the matrix would contain 200 columns. The number of rows is the number of points of the $\sigma-\delta$ curve.

- $\quad \mathbf{Y}$ : a matrix containing the responses of each curve (column) of $\mathbf{S}$. These are the tensile constitutive parameters: $f_{t}, f_{\text {tuc }}\left(f_{t u}\right.$ corrected by the softening function using Expression (5.7) and Expression (5.8)), $\varepsilon_{t u}, E$ and $w_{o}$. Each column of the matrix corresponds to each parameter, and the number of rows is determined by the number of used curves, which is 200 in this case. Each row of matrix $\mathbf{Y}$ is the response of each column of matrix $\mathbf{S}$.

- The regression model used here is a zero-order polynomial.

- The correlation model used here is the exponential one.

The model is built using this information. This can be considered the information which the model "learns" with and, accordingly, it would be able to predict.

To calibrate the model, 27 specimens are used: 19 of $160 \mathrm{~kg} / \mathrm{m}^{3}$ of steel fibres and 8 with $120-130 \mathrm{~kg} / \mathrm{m}^{3}$. Therefore, the 27 experimental $\sigma-\delta$ curves are introduced into the model using a matrix with 27 columns (one column for each curve). With these, the model predicts the tensile constitutive parameters for each curve. Figure 5.53 depicts a comparison made between the prediction response and the result if 4P-IA is applied (the "real" response) for the 27 evaluated specimens. 

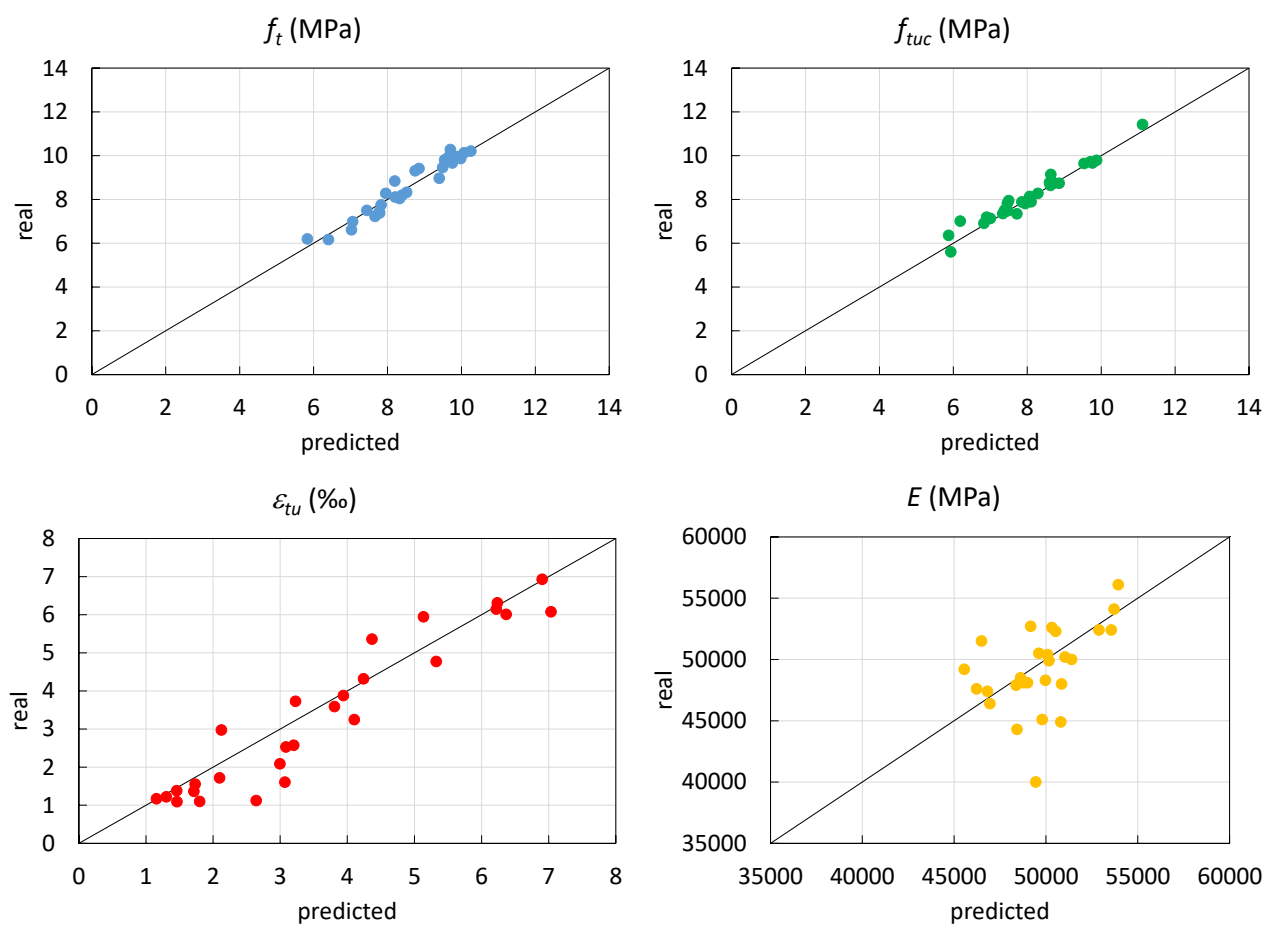

$w_{o}(\mathrm{~mm})$

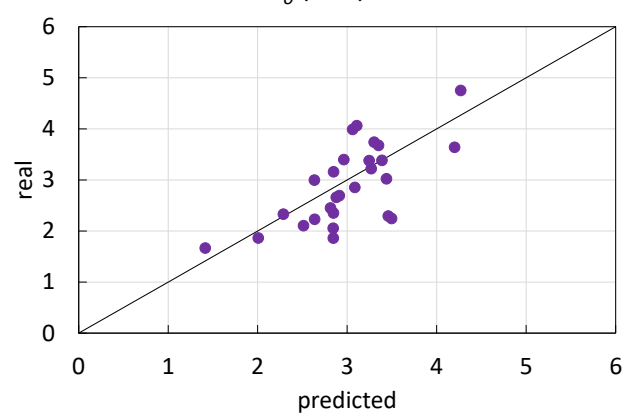

Figure 5.53 UHPFRC Tensile constitutive parameters: predicted values vs. real values.

As observed in Figure 5.53, the predicted $f_{t}$ and $f_{t u c}$ values are very accurate. The $\varepsilon_{t u}$ and $w_{o}$ values are reliable and, even though the $E$ values seem to show some point with slight deviation, it could be generally considered a good prediction.

Moreover, in Table 5.10 a prediction is made of the characteristic constitutive tensile parameters from the characteristic 4PBT curves treated in section 5.5.1 and depicted in 
Chapter 5: Direct procedure to characterise the UHPFRC tensile constitutive behaviour

Figure 5.48. When the values predicted in Table 5.10 are compared to those in Table 5.9, the prediction is quite good.

Table 5.10 The predicted characteristic constitutive tensile parameters for 120-130 and $160 \mathrm{~kg} / \mathrm{m}^{3}$ of fibre UHPFRC

\begin{tabular}{|c|c|c|c|c|c|}
\hline \multirow{2}{*}{$\begin{array}{c}\text { Steel fibres } \\
\left(\mathrm{kg} / \mathrm{m}^{3}\right)\end{array}$} & \multicolumn{5}{|c|}{ UHPFRC predicted characteristic constitutive tensile law } \\
\cline { 2 - 6 } & $f_{t}(\mathrm{MPa})$ & $f_{\text {tuc }}(\mathrm{MPa})$ & $\varepsilon_{t u}(\%)$ & $E(\mathrm{MPa})$ & $w_{o}(\mathrm{~mm})$ \\
\hline $120-130$ & 6.18 & 5.74 & 2.63 & 46296 & 3.07 \\
\hline 160 & 6.78 & 6.60 & 2.00 & 45974 & 2.25 \\
\hline
\end{tabular}

Therefore by using 200 UHPFRC 4PBT specimens (139 with $160 \mathrm{~kg} / \mathrm{m}^{3}$ of steel fibres and 61 with $120-130 \mathrm{~kg} / \mathrm{m}^{3}$ ), a prediction model is developed that is able to make an accurate prediction of the UHPFRC tensile constitutive parameters, $f_{t}, f_{t u c}, \varepsilon_{t u}, E$ and $w_{o}$, from the 4PBT experimental $\sigma-\delta$ curve. This application is simple, direct and avoids variability in the simplified 4P-IA due to the interpretation and application of the inverse analysis. This application can become a good starting point in this direction.

\subsection{Chapter summary and relevant conclusions}

In this chapter a complete process to characterise Ultra-High-Performance FibreReinforced Concrete (UHPFRC) in both strain-hardening (SH) and strain-softening (SS) tensile behaviour is developed. This process is composed by the following phases: an experimental test based on a Four Point Bending Test (4PBT) and the use of an inverse analysis method to obtain the tensile constitutive behaviour from the 4PBT experimental stress-deflection curve. Moreover, a predictive application is presented that integrates the process. The only input needed is the experimental stress-deflection curve and, as a result, the constitutive tensile behaviour is obtained.

To get this objective, an inverse analysis (IA) method developed by (López 2017) to obtain the tensile behaviour of UHPFRC that exhibits SH behaviour in tension from 4PBT is set and validated by means of a discrete cracking approach two dimensional non-linear finite element model (2D-NLFEM). The 2D-NLFEM is defined in this work and reproduces the 4PBT using, as UHPFRC material definition, the tensile behaviour obtained from the application of the IA. After the successful validation, the simplified IA (4P-IA) is calibrated and corrected using the 2D-NLFEM in order to be applicable in the case of SS-UHPFRC. To get this, an extensive experimental programme of 2274 PBT specimens composed by UHPFRC that exhibits different grades of SH and SS behaviour using two amounts of fibres: $120-130$ and $160 \mathrm{~kg} / \mathrm{m}^{3}$ is carried out. Taking into account 
the experimental database generated, the characteristic constitutive tensile behaviour of the UHPFRC used in this work can be stablished which could be a reference for such concretes. Finally, using the database, a predictive application is developed in order to obtain the tensile behaviour only using, as an input, the experimental 4PBT stressdeflection at mid span curve. The application is able to obtain reliable predictions of the tensile constitutive parameters avoiding the possible variability due to the application of the simplified inverse analysis.

Therefore, the numerical findings presented in the present chapter allows to draw the main concluding remarks listed in the following.

The non-linear closed-form hinge model and its derived simplified inverse analysis methods (5P-IA and 4P-IA), defined to obtain the tensile constitutive behaviour for UHPFRC that exhibits strain hardening in tension, have been validated resorting to a robust non-linear finite element modelling (2D-NLFEM) and a set of four-point bending tests with variable depth, slenderness and hinge length.

The discrete cracking approach of the numerical model is more adequate for modelling the tensile behaviour of UHPFRC in a four point bending test without reinforcement. Even though the smeared cracking approach gives good results, it is sensitive to the mesh size. Moreover, it is important to keep in mind, as it is demonstrated in this chapter, that the 2D-NLFEM is influenced by the non-linear analysis strategy defined.

When using the tensile parameters resulting from an iterative inverse analysis method using the closed-form non-linear hinge model presented and its derived simplified inverse analysis methods, the discrete cracking approach describes accurately: (a) the load deflection response, (b) the bending curvatures, and (c) the average longitudinal strains measured in the bending tests.

The discrete cracking approach numerical model can reproduce with a great level of accuracy the behaviour of UHPFRC in a 4PBT.

As a result, inverse analysis methodologies based on the closed-form non-linear hinge model and the derived simplified inverse analysis methods proposed can be recommended to derive UHPFRC's tensile properties in four-point bending tests in case of UHPFRC that exhibits strain-hardening constitutive stress-strain behaviour in tension.

There is a need to establish a complete process to characterise UHPFRC tensile behaviour in either SH or in SS behaviour. This process starts with the experimental test which, in this work, is the 4PBT given its simplicity.

To move from the experimental $\sigma-\delta$ response in bending to tensile behaviour, the simplified 4P-IA, developed by the research group, is used. As it is developed for the UHPFRC exhibiting the SH tensile response, its application to UHPFRC with SS needs to be adapted. Consequently, an experimental programme of 227 4PBT that goes from the SH behaviour to the SS behaviour is carried out using UHPFRC with $120-130 \mathrm{~kg} / \mathrm{m}^{3}$ and $160 \mathrm{~kg} / \mathrm{m}^{3}$ of steel fibres. As demonstrated by means of the 2D-NLFEM developed 
for modelling the 4PBT, 4P-IA works well for UHPFRC with $\mathrm{SH}$, but is still too conservative for SS. Therefore, a parametrical study that focuses on the $\varepsilon_{t u}$ and $f_{t u}$ parameters is performed to study their influence on the $\sigma-\delta$ response using the 2DNLFEM developed. The $f_{t u}$ parameter has a direct influence on the model's response and 4P-IA underestimates the $f_{t u}$ value, which leads to a conservative result. However, the influence of the variation in $\varepsilon_{t u}$ is considered negligible.

A correction of 4P-IA for SS UHPFRC is made in $f_{t u}$ terms after analysing 65 specimens from the experimental programme with different hardening ratio $(\gamma)$ values, and after the calibration of $f_{t u}$ from 64 specimens from the experimental programme. This correction leads to a more accurate response in stress and energy terms at different levels. Consequently, UHPFRC is characterised in tensile behaviour terms by following a reliable process.

Having set up a reliable method to characterise UHPFRC tensile behaviour, the characteristic $\sigma$ - $\delta$ curve of UHPFRC from the experimental data is extracted. Therefore, the characteristic tensile behaviour parameters could be obtained for UHPFRC with 120$130 \mathrm{~kg}$ and $160 \mathrm{~kg} / \mathrm{m}^{3}$ of steel fibres. These values could act as a reference for UHPFRC with these amounts of fibres.

Using the extensive experimental programme herein employed, a predictive application for predicting the tensile UHPFRC parameters from the $\sigma-\delta$ curve from 4PBT is developed. The prediction gives reliable results. The application is simple, direct and avoids not only variability in the simplified 4P-IA due to misinterpretations, but also applying the inverse analysis. 


\section{Chapter 6}

\section{UHPFRC: reinforced elements}

\subsection{Introduction}

From the work carried out until this point, it can be stated that we are able to characterise the UHPFRC constitutive tensile behaviour both in strain-softening (SS) and strainhardening ( $\mathrm{SH}$ ) cases with demonstrated reliability and accuracy using the developed non-linear finite element model (NLFEM). Therefore, from the simple and easy to apply complete process to characterise UHPFRC tensile behaviour developed in chapter 5, the modelling of UHPFRC at material level in the NLFEM is completely set and controlled. In the next step, it is required to add the reinforcement in order to analyse the behaviour of reinforced UHPFRC elements. Accordingly, the NLFEM developed in chapter 3 and chapter 4 and used for unreinforced 4PBT in chapter 5 is enhanced taking into account the influence of the reinforcement and the interaction between reinforcement and UHPFRC matrix.

In the first part of this chapter, a complete study on the tensile behaviour of flexural reinforced UHPFRC is presented in order to contribute to define UHPFRC mechanical characterisation and structural design. An experimental programme with two different sized flexural reinforced UHPFRC beams is carried out. Beams are cast and tested in a four-point bending test scheme (4PBT) using UHPFRC with different amounts of fibres: 130 and $160 \mathrm{~kg} / \mathrm{m}^{3}$. The NLFEM developed for unreinforced UHPFRC elements developed is improved to validate the mechanical tensile characterisation of UHPFRC when applied to flexural reinforced elements. Two important effects are considered in order to improve the model: shrinkage and tension stiffening influence on reinforcement. 
After the NLFEM simulation, very reliable results are observed at the service and ultimate load levels compared to the experimental ones. Finally, some aspects about the design of reinforced UHPFRC cross-sections under bending forces are addressed and compared to the experimental results satisfactorily.

In the second part of the chapter, a numerical modelling study on the uniaxial tensile behaviour of reinforced UHPFRC ties by means of the NLFEM is carried out, and the results are compared to the results from an experimental programme developed in a work carried out by other researchers in the research group. These tensile bars (ties) modelled in this work are cast using UHPFRC with $160 \mathrm{~kg} / \mathrm{m}^{3}$ of steel fibres and tested in a direct tensile test. The NLFEM developed for the reinforced flexural beams used in the first part of the chapter is applied in order to validate the mechanical tensile characterisation of UHPFRC when direct tensile reinforced elements are considered. As it happens with the flexural elements, in this case the shrinkage and tension stiffening effects are essential in the model to simulate the reality of the tensile test. After the NLFEM simulation, very accurate results are obtained that lead to consider the reliability of the NLFEM model developed not only for flexural reinforced elements, but also for direct tensile ones. Consequently, we have developed a NLFEM and a tensile constitutive behaviour characterisation procedure that is able to represent both the unreinforced and reinforced UHPFRC elements.

\subsection{Flexural reinforced elements}

The aim of this section is to study the influence of the reinforcement bars in UHPFRC elements subjected to bending forces, considering mechanisms like the shrinkage and tension stiffening. In addition, it is intended to validate the accuracy of traditional design methods for the case of reinforced UHPFRC sections under failure and serviceability conditions. Therefore, in the section an experimental programme composed of UHPFRC reinforced short and long beams to be tested in bending and the specimens to characterise the material properties is carried out. At the same time, the NLFEM proposed in chapter 3 and chapter 4 and implemented for unreinforced 4PBT specimens in chapter 5 is enhanced to be able to model the behaviour of reinforced UHPFRC elements in bending to validate the experimental programme. Consequently, the results from the model's application are presented and discussed. Moreover, in addition, some aspects that deal with designing reinforced UHPFRC cross-sections under bending forces are examined and compared to the experimental results.

\subsubsection{Experimental programme}

To move toward the structure reality and to model and design reinforced UHPFRC elements, an experimental programme including reinforced concrete beams on different scales is carried out. A set of thirty-six short beams and two large-scale beams are cast. At the same time, prismatic and cubic specimens are cast and tested to characterise the 
tensile and compressive behaviour of the UHPFRC used, respectively. All reinforced concrete beams and specimens are tested at 49 days after casting.

\subsubsection{Short beams}

To study the behaviour of UHPFRC in reinforced specimens, a campaign of short beams is carried out (see Figure 6.1). This will constitute a first step toward applying the model herein developed at a structural level.

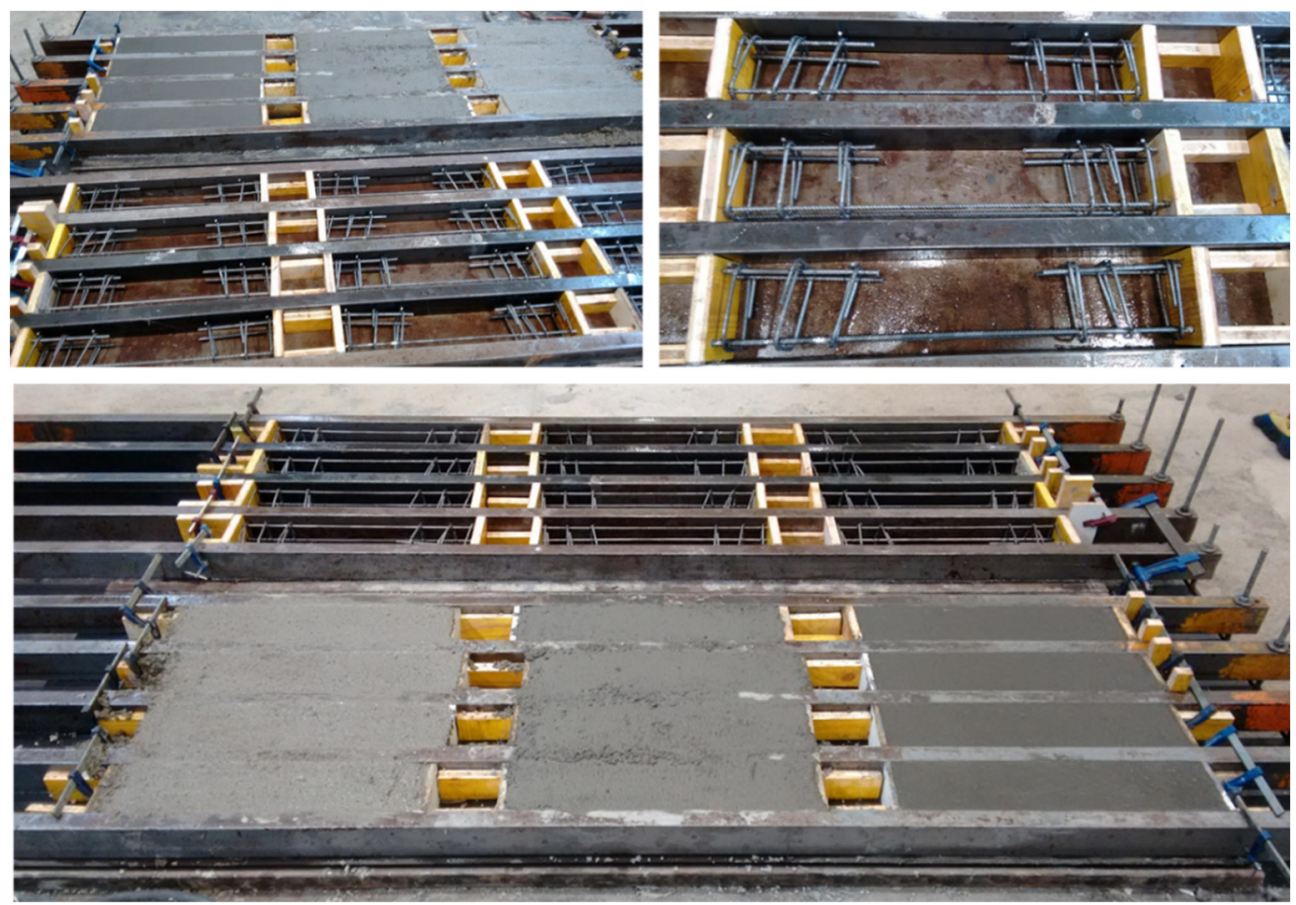

Figure 6.1 UHPFRC short beams campaign

These specimens are cast at the two different UHPFRC dosages studied in this doctoral thesis, by varying the amount of smooth-straight (13/0.20) steel fibres between 130 $\mathrm{kg} / \mathrm{m}^{3}\left(1.66 \%\right.$ in vol.) and $160 \mathrm{~kg} / \mathrm{m}^{3}(2.00 \%$ in vol.), also used in chapter 5 for the unreinforced 4PBT. The dimensions of the beams are 750x150x100 mm.

At the beginning, they were cast using two $\phi 10 \mathrm{~mm}$ as longitudinal reinforcement situated at the bottom (see Figure 6.2). 

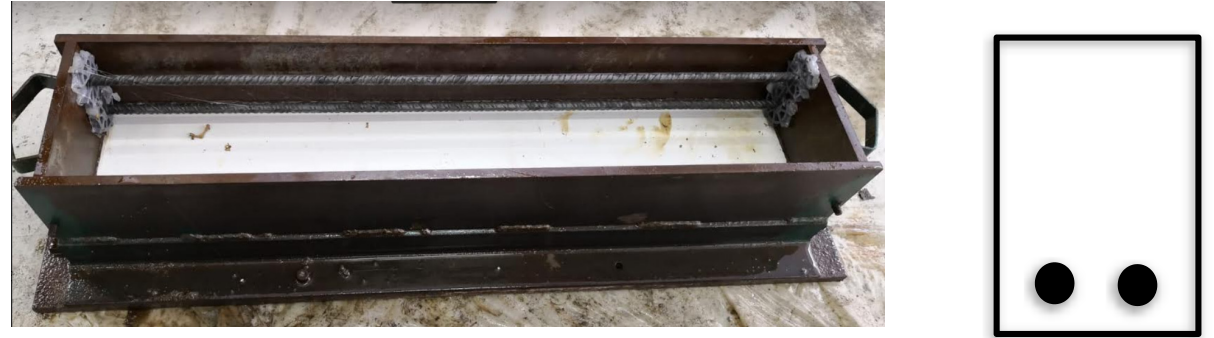

Figure 6.2 First reinforcement setting for short beams

When the specimens reached their resistance (after been stored for more than 28 days), they were tested in the 4PBT and they had a shear failure instead of a bending failure that was the objective (see Figure 6.3).

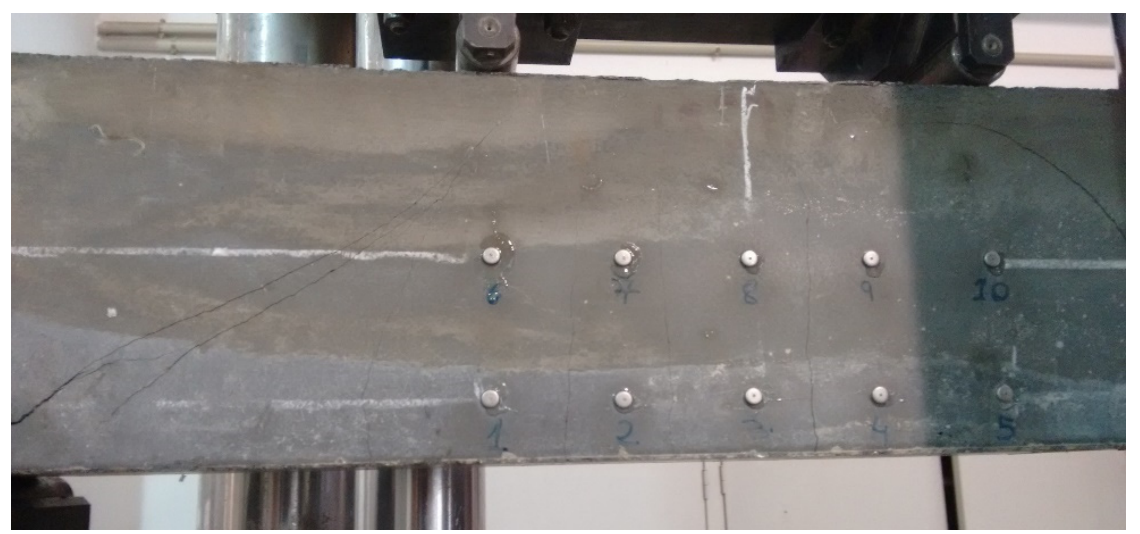

Figure 6.3 Short beam shear failure

Therefore, Figure 6.4 shows the final geometry and arrangement of the reinforcement of the developed short beams. That is, beam dimensions are 750x150x100 mm. Six $\phi 6 \mathrm{~mm}$ stirrups, three on each side positioned symmetrically to avoid shear failure; two couples of $\phi 8 \mathrm{~mm}$ longitudinal reinforcement bars placed at the top of the section, one on each side and symmetrically positioned; two $\phi 8 \mathrm{~mm}$ longitudinal reinforcement bars situated at the bottom of the section. 

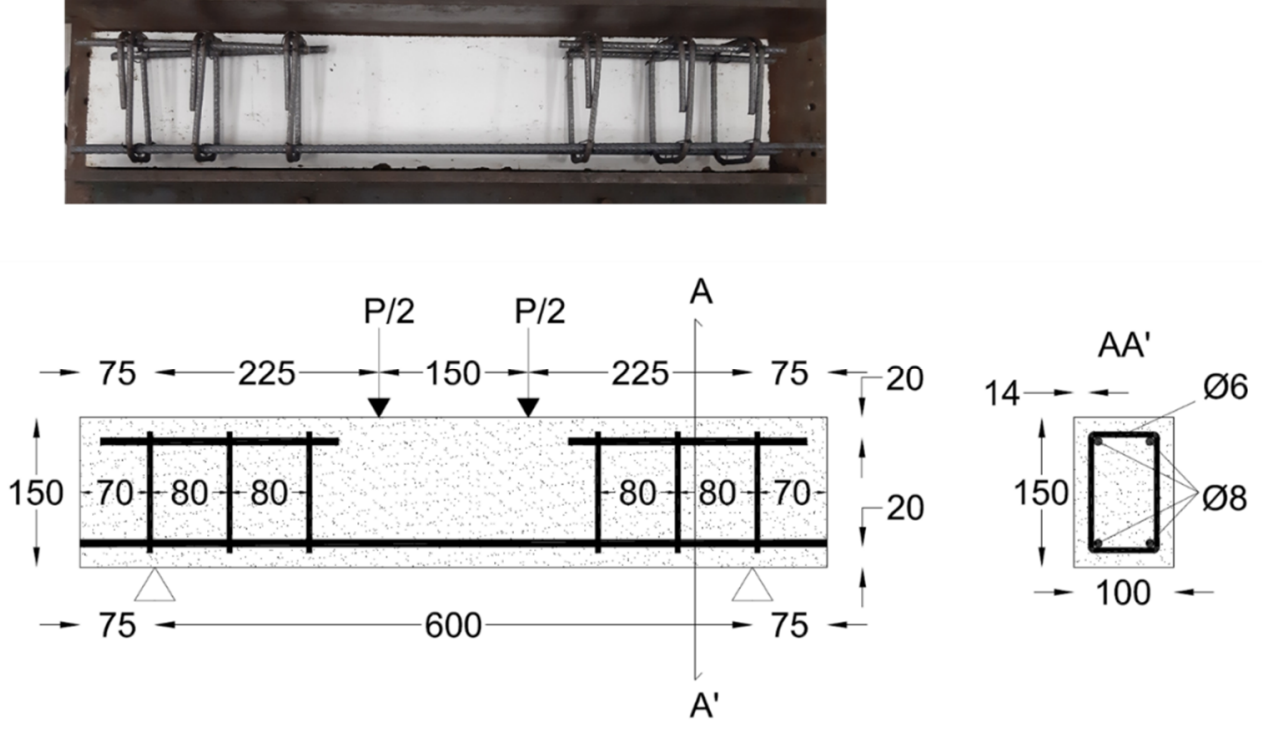

Figure 6.4 Reinforced UHPFRC short beam. Final geometry details (units in mm).

Thirty-six UHPFRC reinforced short beams are cast and tested using the 4PBT: 13 specimens with $130 \mathrm{~kg} / \mathrm{m}^{3}$ of fibres and 23 with $160 \mathrm{~kg} / \mathrm{m}^{3}$. The position of the load and support rollers is depicted in Figure 6.4. That is, the length of the span between the support rollers is $600 \mathrm{~mm}$, the length between the load rollers is $150 \mathrm{~mm}$ and, consequently, the shear span between the support and the load roller is $225 \mathrm{~mm}$. One Penny \& Giles Controls Ltd Linear displacement transducer is placed to obtain the loaddeflection at the mid-span curve. The load is applied by means of an IBERTEST universal testing machine with $1500 \mathrm{kN}$ of bearing capacity and measured by means of a $350 \mathrm{bar} / 10 \mathrm{~V}$ GROBY-PDCR 4011 Druck. Figure 6.5 shows the 4PBT setup for these short beams. 

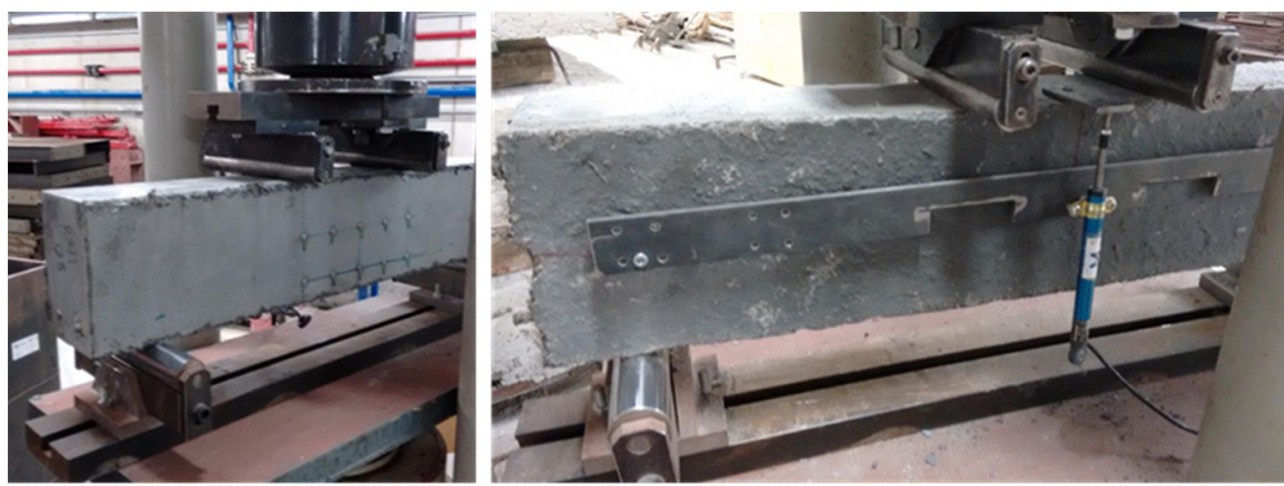

Figure 6.5 4PBT set up of reinforced short beams

According to Expression (6.1) where the experimental load (P) is transformed into equivalent flexural stress at mid-span $(\sigma)$, Figure 6.6 depicts the stress $(\sigma)$-deflection at the mid-span $(\delta)$ curves obtained as a result of the 4 PBT carried out for the 13 reinforced specimens of $130 \mathrm{~kg} / \mathrm{m}^{3}$ of fibres (left) and the 23 of $160 \mathrm{~kg} / \mathrm{m}^{3}$ (right).

$$
\sigma=\frac{675 \cdot P}{b \cdot h^{2}} \quad\left(\mathrm{~N} / \mathrm{mm}^{2}\right)
$$
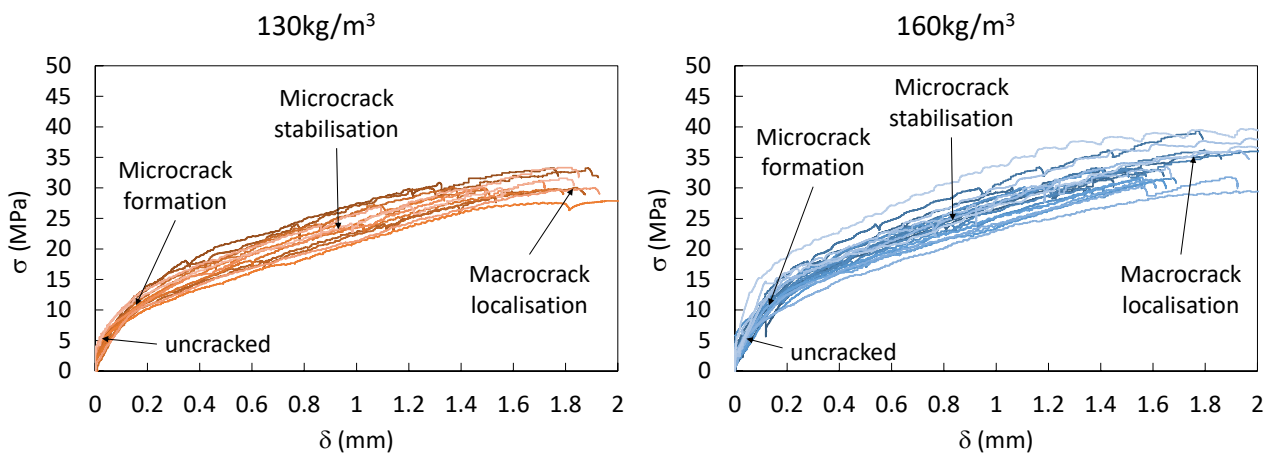

Figure 6.6 Experimental 4PBT $\sigma$ - $\delta$ curves for specimens with 130 (left) and 160 (right) $\mathrm{kg} / \mathrm{m}^{3}$ of fibres 
According to the results after the experimental test, in Figure 6.6 and regardless of fibre content, curves depict two different stages: a first stage with greater stiffness, where uncracked concrete and reinforcement work together; a second stage with lesser stiffness, where a microcracking process takes place and the tension stiffening phenomenon develops. In the second stage, microcracks grow in a smeared way by covering part of the span between supports (the so-called process zone) as load increases. When this stage ends, the concentration in one macrocrack takes place. Collapse is imminent at this point. This is a characteristic flexural behaviour of UHPFRC (Fehling et al. 2014). Figure 6.7 shows one of these short beams after collapse, where we can see the development of microcrack stabilisation phase and the subsequent concentration in a macrocrack, also known as crack localisation according to ((fib) 2013) in its section 5.6.1, along with the crush in the compression at the top of the section, which generated a very narrow and concentrated compression head.

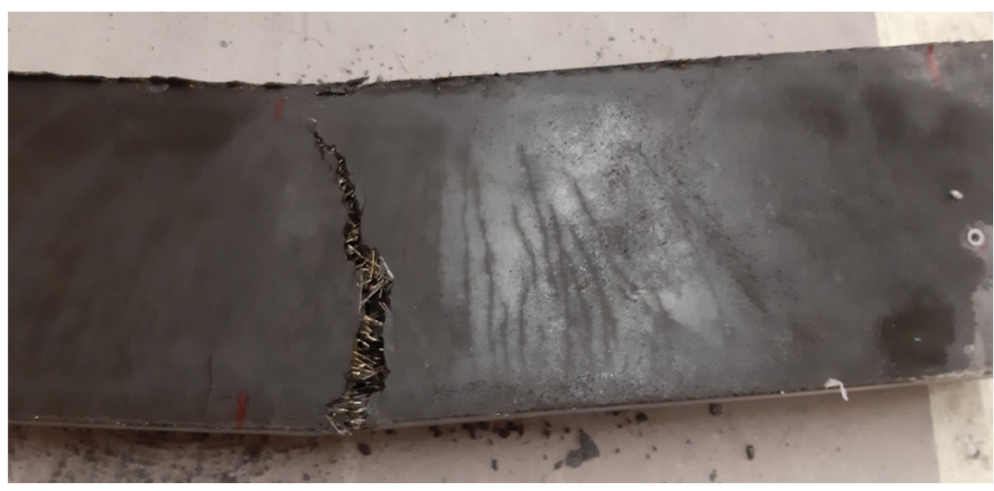

Figure 6.7 Collapsed short beam

\subsubsection{Long beams}

To study large-scale specimens, two long reinforced beams are included in the experimental programme. The two beams are cast using UHPFRC with $160 \mathrm{~kg} / \mathrm{m}^{3}$ $(2.00 \%$ in vol.) of smooth-straight (13/0.20) steel fibres. Figure 6.8 shows the geometry, the arrangement of the reinforcement and the displacement transducer's position of the

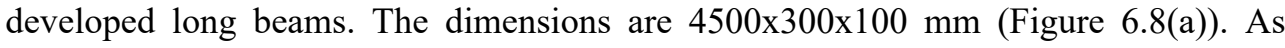
shown in Figure 6.8(b), reinforcement consists of two longitudinal B500S bars of $\phi 20$ or $\phi 16$ ( $\phi 20$ for one beam (JE-1) and $\phi 16$ for the other (JE-2)) on the bottom face, with a concrete cover of $20 \mathrm{~mm}$ in both cases. Regarding displacement transducer's position (Figure 6.8(c)): two displacement transducers are placed at the mid-span to measure the deflection, one on the front face and the other on the back face; two displacement transducers are placed at the support level to register the possibility of vertical displacement there; and four displacement transducers (two on the front and two on the 
back face) in horizontal position are located at the mid-span at two levels: $25 \mathrm{~mm}$ from the top, to measure average compressive strains, and 28 and $30 \mathrm{~mm}$ from the bottom (at the reinforcement level), to measure average tensile strains.
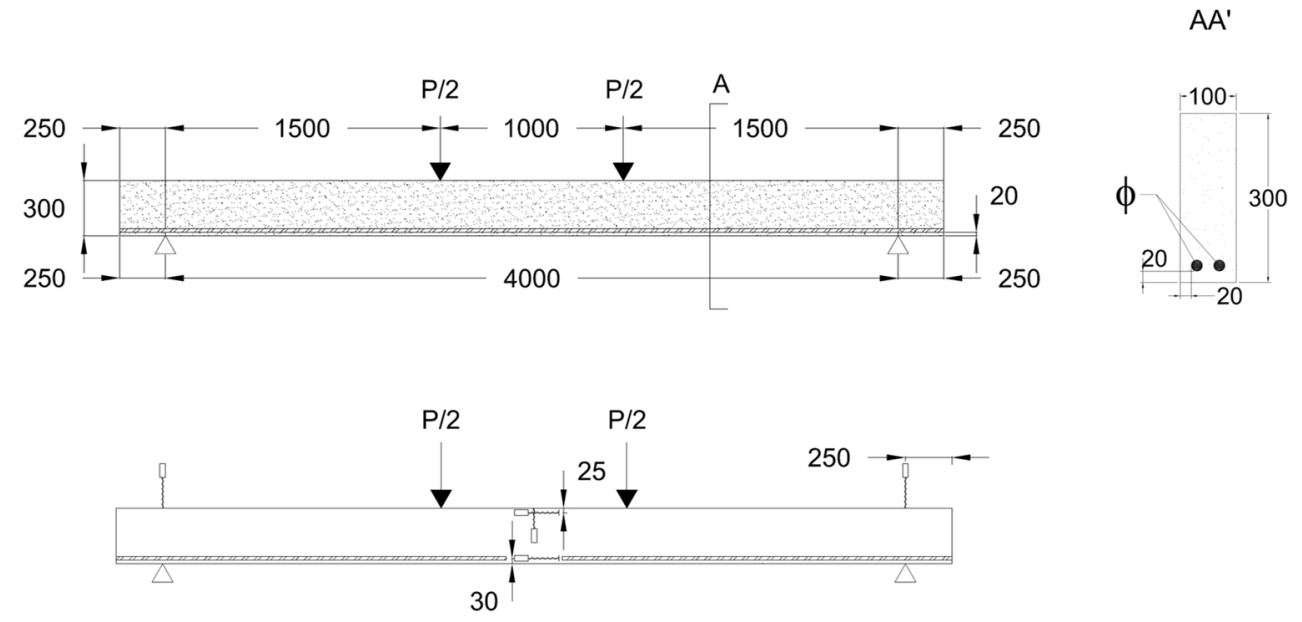

Figure 6.8 Long beams: (a) geometry (in $\mathrm{mm}$ ), (b) reinforcement details and (c) displacement transducer's position

Figure 6.9(a) shows a general view of the casting zone, and Figure 6.9(b) shows the testing setup for the long beams. As observed in Figure 6.9(b), the testing load is applied by using a hydraulic jack on an intermediate beam which, in turn, distributes loads on two loading plates situated each at $1.5 \mathrm{~m}$ from the supports, as set out in Figure 6.8(a). Figure 6.10 shows in detail the intermediate beam and loading plates (Figure 6.10(a)), and also details of the supports materialisation: a sliding support (Figure 6.10(b)) and a fixed one (Figure 6.10(c)), both including a hinged platform, are used (Figure 6.10(d)). Load is applied under displacement control by means of a servo-hydraulic HINE actuator, which has a bearing capacity of $1240 \mathrm{kN}$ and $250 \mathrm{~mm}$ long. Between the intermediate beam and the actuator a $500 \mathrm{kN} \mathrm{HBM-C6A} \mathrm{load} \mathrm{cell} \mathrm{is} \mathrm{attached} \mathrm{to} \mathrm{measure}$ the total load transmitted by the jack (Figure 6.10(a)). 

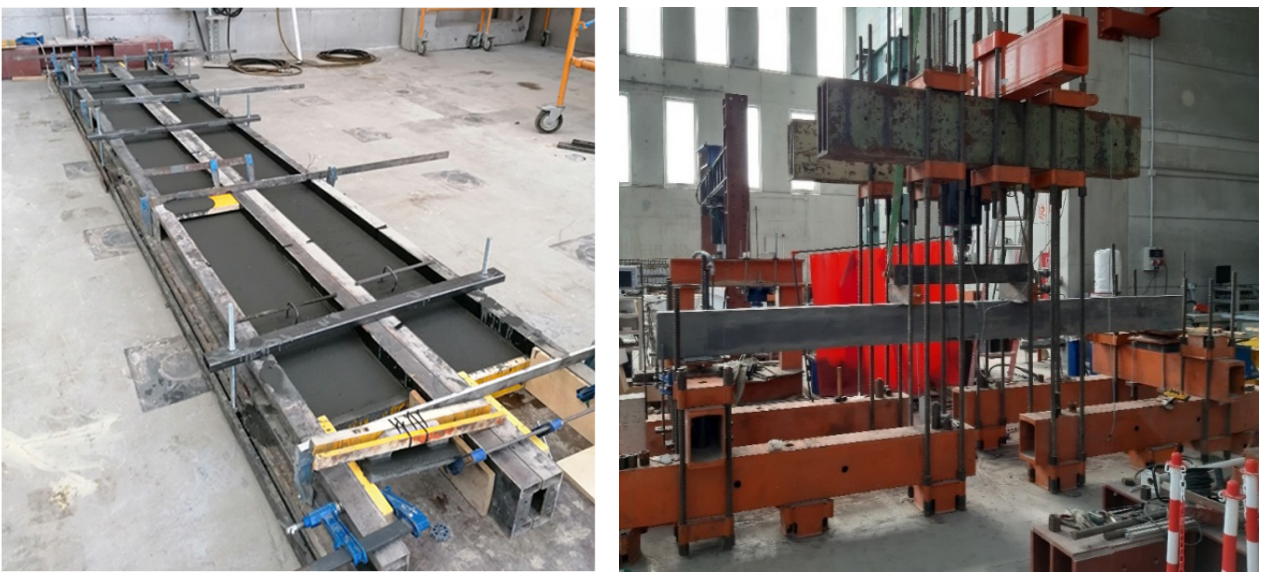

Figure 6.9 UHPFRC long beams: (a) general view of casting zone and (b) testing setup
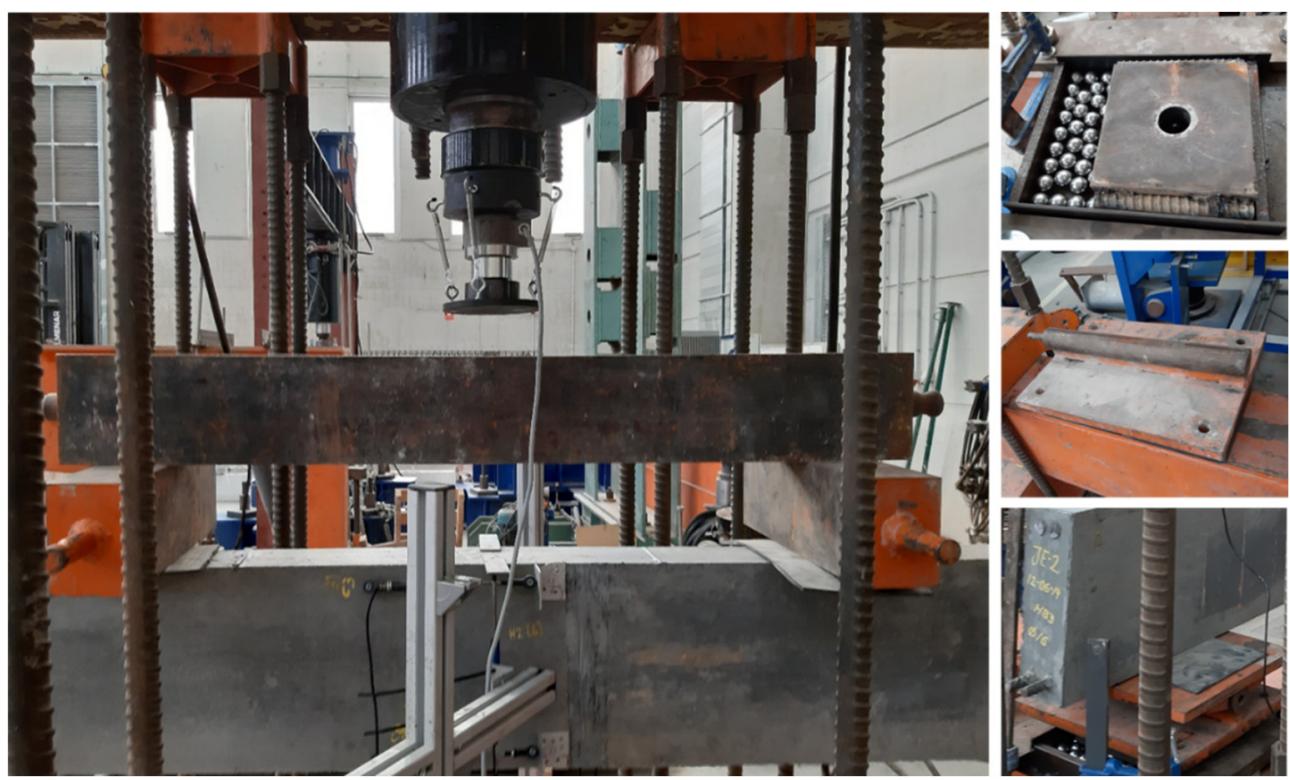

Figure 6.10 Testing frame details: (a) intermediate beam and loading plates, (b) sliding support, (c) fixed support and (d) hinged platform

For the JE-1 and JE-2 beams, Figure 6.11(left) shows the curves obtained from the experimental measurements taken of the vertical displacement transducers at the mid- 
span, corrected by the measurements of the supports' displacement transducers. Moreover, Figure 6.11(right) depicts the experimental moment (M) -curvature $(\phi)$ obtained from the horizontal displacement transducers at the mid-span section for the two beams (see Figure 6.8(c)). The moment at the mid-span section is obtained considering the moment's law for the 4PBT geometry depicted in Figure 6.8(a), by means of Expression (6.2). The curvature is obtained as the inverse of the inclination of the strain plane defined by de horizontal displacement transducers at the mid-span section, by means of Expression (6.3).
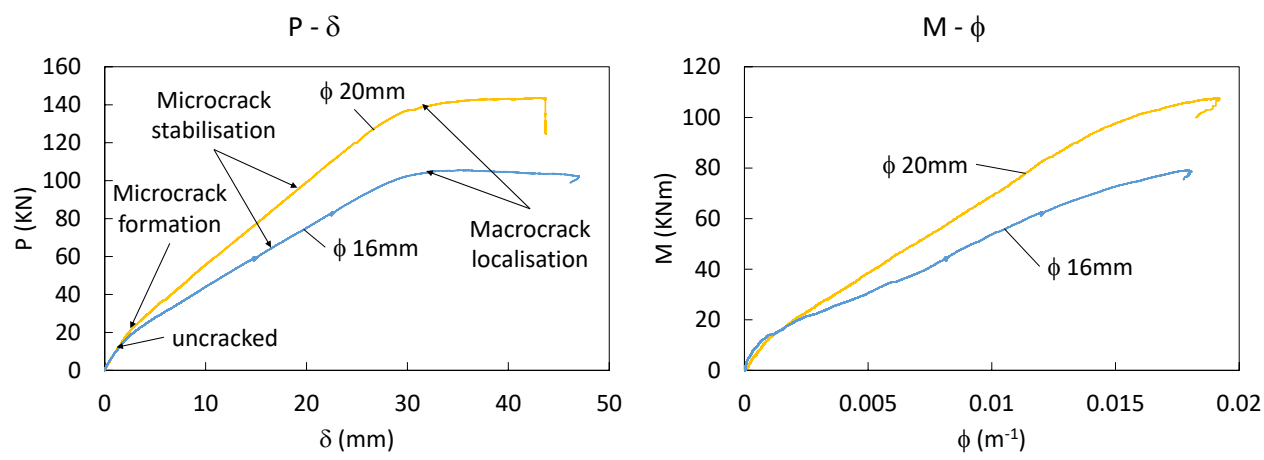

Figure 6.11 Load-deflection curve at the mid-span section (left) and load-curvature (right) for the $\phi 16 \mathrm{~mm}$ and $\phi 20 \mathrm{~mm}$ beams

$$
\begin{gathered}
M=1.5 \cdot \frac{P}{2} \quad(\mathrm{KN} \cdot \mathrm{m}) \\
\phi=\frac{\left|\Delta u_{c}-\Delta u_{t}\right| / l_{g}}{l_{d t}}
\end{gathered}
$$

Where $\Delta \mathrm{u}_{\mathrm{c}}$ and $\Delta \mathrm{u}_{\mathrm{t}}$ are the displacements from the compression and tension horizontal displacement transducers, respectively (see Figure 6.12), $l_{g}$ represents the gage length of the displacement transducers initially (here $l_{g}=160 \mathrm{~mm}$ ) and $l_{d t}$ the separation between both displacement transducers $\left(l_{d t}=245 \mathrm{~mm}\right.$ for the case of JE1 and $l_{d t}=247 \mathrm{~mm}$ for the case of JE2).

Figure 6.12 shows the average load $(\mathrm{P})$ - displacement in compression $\left(\Delta \mathrm{u}_{\mathrm{c}}\right)$ from the horizontal displacement transducers positioned at the top of the mid span section (Figure 6.12(left)) and the average load $(\mathrm{P})$ - displacement in tension $\left(\Delta \mathrm{u}_{\mathrm{t}}\right)$ from the horizontal 
displacement transducers positioned at the bottom of the mid span section (Figure 6.12(right)) for the $\phi 20 \mathrm{~mm}$ (JE-1) and $\phi 16 \mathrm{~mm}$ (JE-2) beams, see Figure 6.8(c).
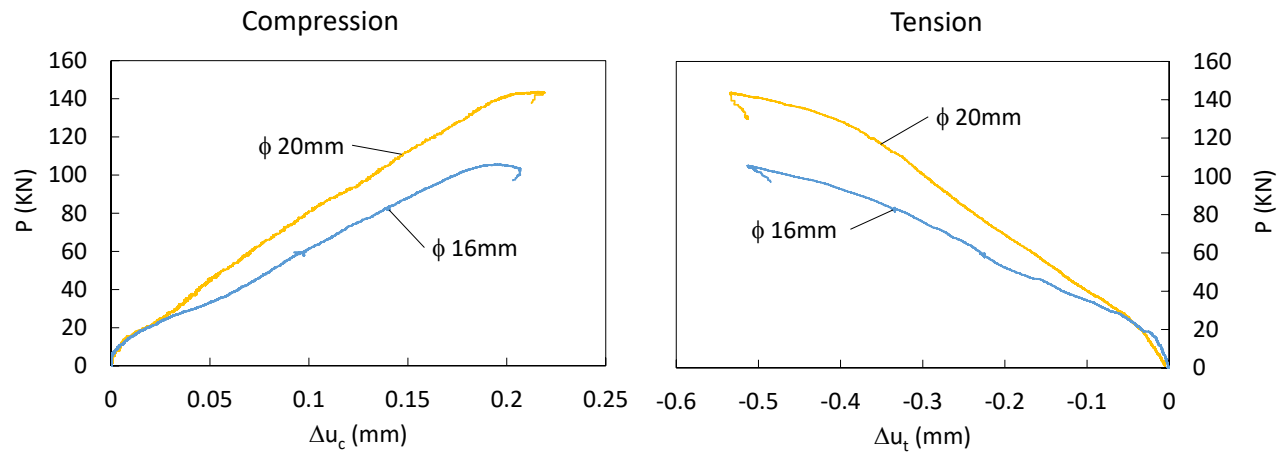

Figure $6.12 P-\Delta u_{c}$ curve (left), $P-\Delta u_{t}$ curve (right)

In addition, Figure 6.13 depicts the equivalent bending stress $(\sigma)$ - average strain at the mid-span section at the compression displacement transducer's height $\left(\varepsilon_{c o m p}\right)$ and at the tension displacement transducer's height $\left(\varepsilon_{\text {tens }}\right)$. The equivalent bending stress is obtained following Expression (6.4) and the average strains for compression and tension are obtained dividing the respective horizontal displacements in Figure 6.12 by the gage length $\left(l_{g}\right)$.
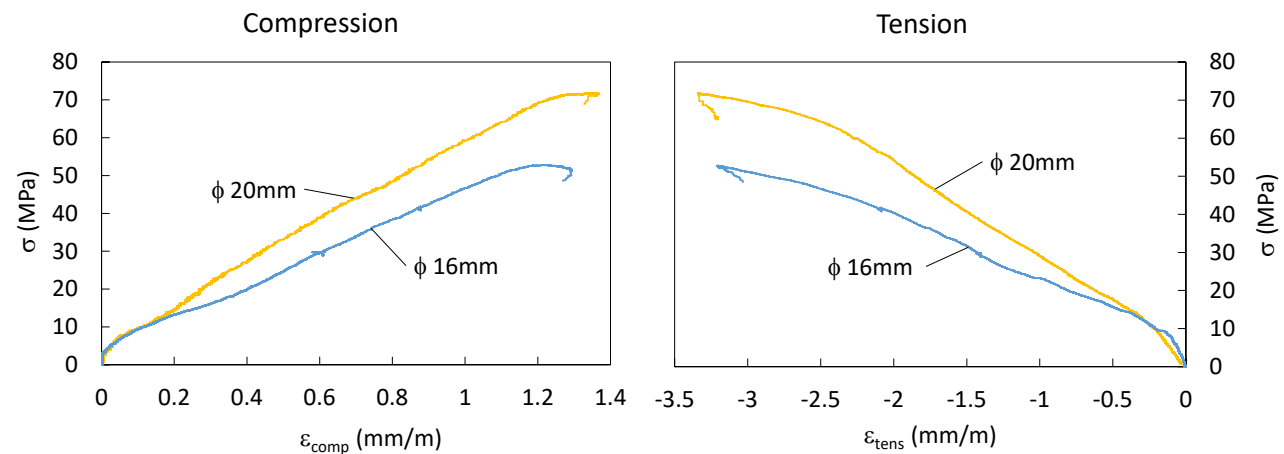

Figure $6.13 \sigma-\varepsilon_{\text {comp }}$ curve (left), $\sigma-\varepsilon_{\text {tens }}$ curve (right)

$$
\sigma=\frac{4500 \cdot P}{b \cdot h^{2}} \quad\left(\mathrm{~N} / \mathrm{mm}^{2}\right)
$$


As with the short beams, the same pattern developed while testing for the long beams characterised by a first stage with greater stiffness, where uncracked concrete and reinforcement work together; a second stage with lesser stiffness, where a microcracking process takes place and the tension stiffening phenomenon develops (see Figure 6.11(left)). When concrete reaches its tensile strength, the microcrack stabilisation phase takes place (see Figure 6.14(left)). A macrocrack appears as load increases and the beam collapses. Figure 6.14(right) depicts the macrocrack and the crushed compression head of the long beam.
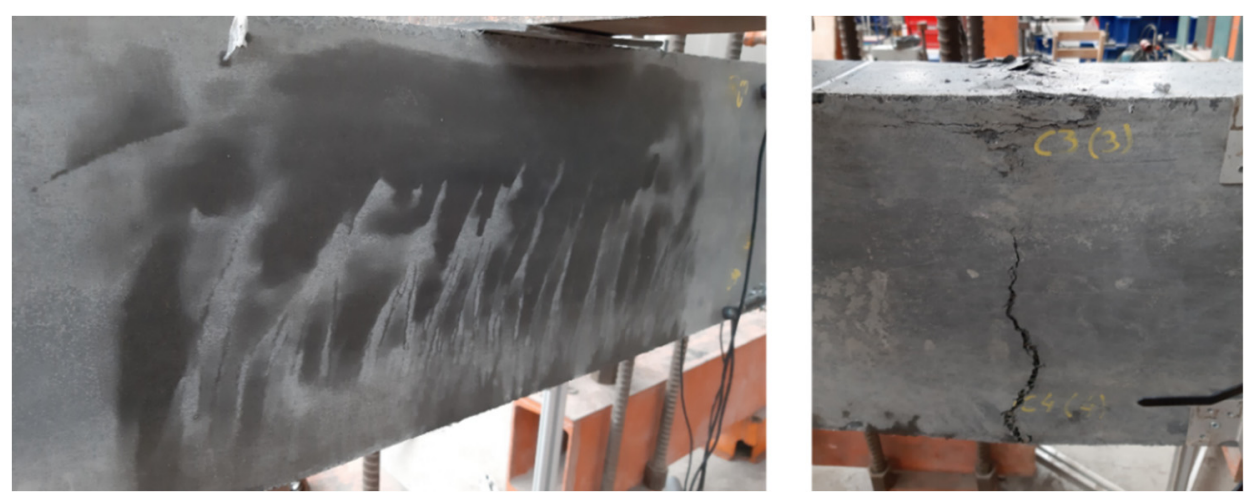

Figure 6.14 Microcracking (left) and collapse (right) of a long beam

\subsubsection{Material characterisation}

In order to characterise the mechanical behaviour of the UHPFRC used in each mix, a set of $100 \mathrm{~mm}$ cubic specimens for the compression test and 100x100x500 mm unreinforced specimens for the 4PBT are cast together with beams (Figure 6.15). A total of 22 UHPFRC batches are done in the experimental programme: 8 batches for UHPFRC with $130 \mathrm{~kg} / \mathrm{m}^{3}$ (32 cubic specimens and 25 unreinforced 4PBT specimens) and 14 batches for UHPFRC with $160 \mathrm{~kg} / \mathrm{m}^{3}$ (61 cubic specimens and 38 unreinforced 4PBT specimens).
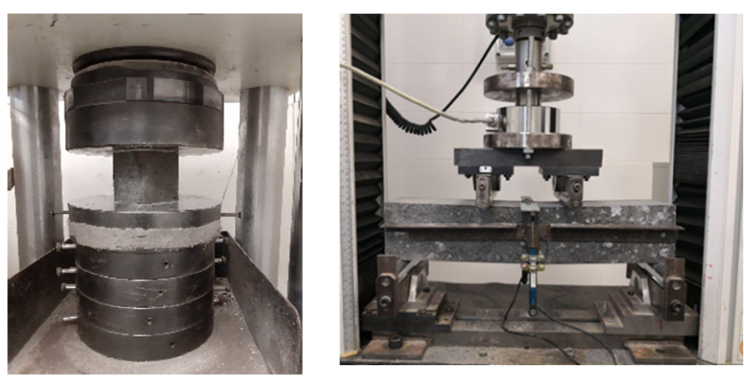

Figure 6.15 Compression test (left) and 4PBT (right) 
To use bending tests to obtain tensile behaviour, it is necessary to apply inverse analyses. For this purpose, it is chosen an inverse analysis method that was properly developed by the research group for UHPFRC which exhibits strain-hardening behaviour: a simplified Four-Point Inverse Analysis method (4P-IA) that is developed in (López 2017; López et al. 2017) and summarised in chapter 3 of this doctoral thesis. This method has also been calibrated and adapted for UHPFRC exhibiting strain-softening in chapter 5 of this work and in (Mezquida-Alcaraz et al. 2019b, 2021) establishing a softening correction for $f_{t u}$ $\left(f_{t u c}\right)$. According to 4P-IA, to define the tensile behaviour, it is necessary to select four specific key points from the experimental $4 \mathrm{PBT}$ equivalent bending stress-displacement at the mid-span curve. Using these points, the parameters defining the assumed simplified trilinear $\sigma-\varepsilon / w$ law can be determined by back-of-the-envelope calculations (Figure 6.16).

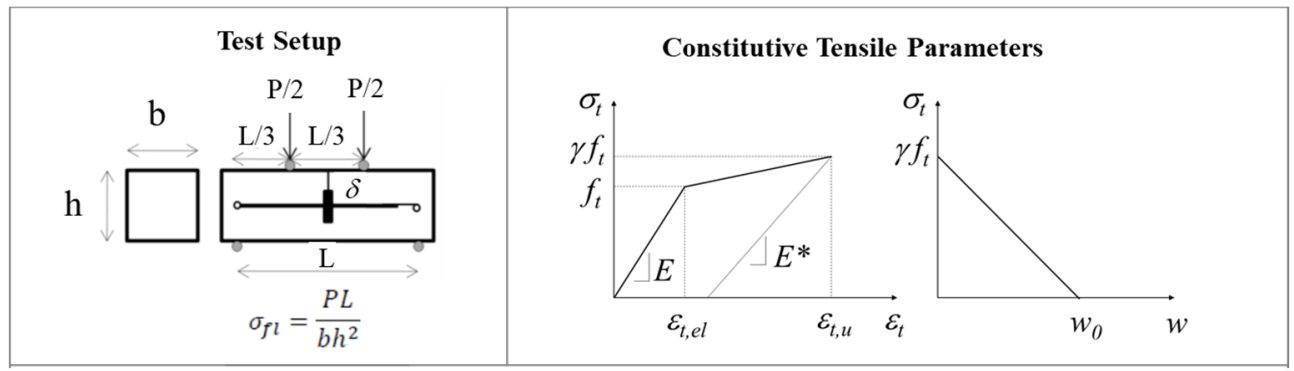

Figure 6.16 (a) 4PBT and (b) constitutive tensile law from the 4P-IA application

Figure 6.17 and Figure 6.18 depict the 4PBT $\sigma-\delta$ experimental curves and the tensile constitutive law after the application of the 4P-IA obtained for 25 specimens of 130 $\mathrm{kg} / \mathrm{m}^{3}$ and 38 of $160 \mathrm{~kg} / \mathrm{m}^{3}$ of fibre. Figure 6.17 emphasises the $\sigma-\delta$ experimental curves of the characteristic $5 \%, 50 \%$ and $95 \%$ for the 130 and $160 \mathrm{~kg} / \mathrm{m}^{3}$ specimens.
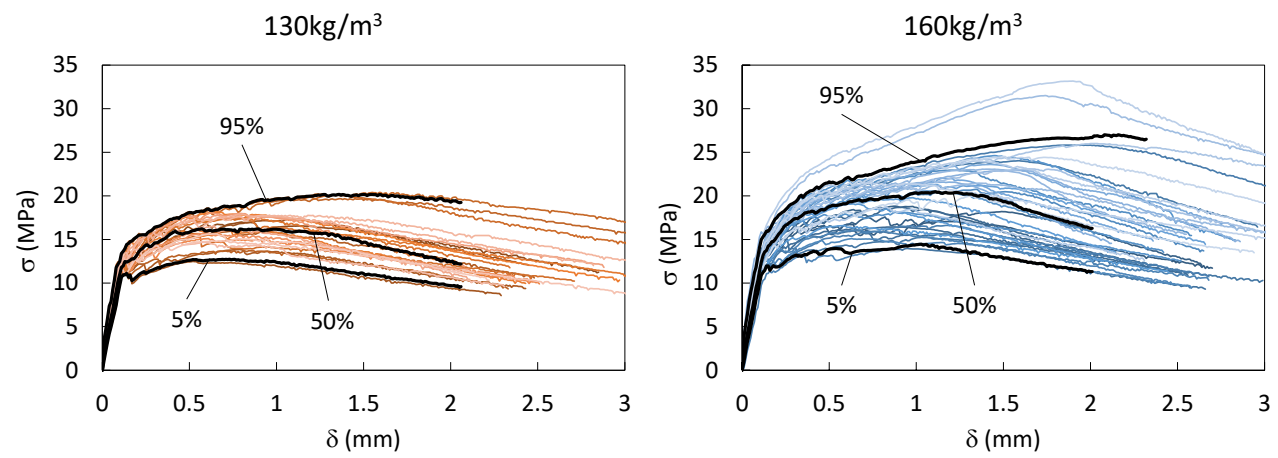

Figure $6.17 \sigma$ - $\delta$ curve from $4 P B T$ of the (a) $130 \mathrm{~kg} / \mathrm{m}^{3}$ and (b) $160 \mathrm{~kg} / \mathrm{m}^{3}$ specimens 

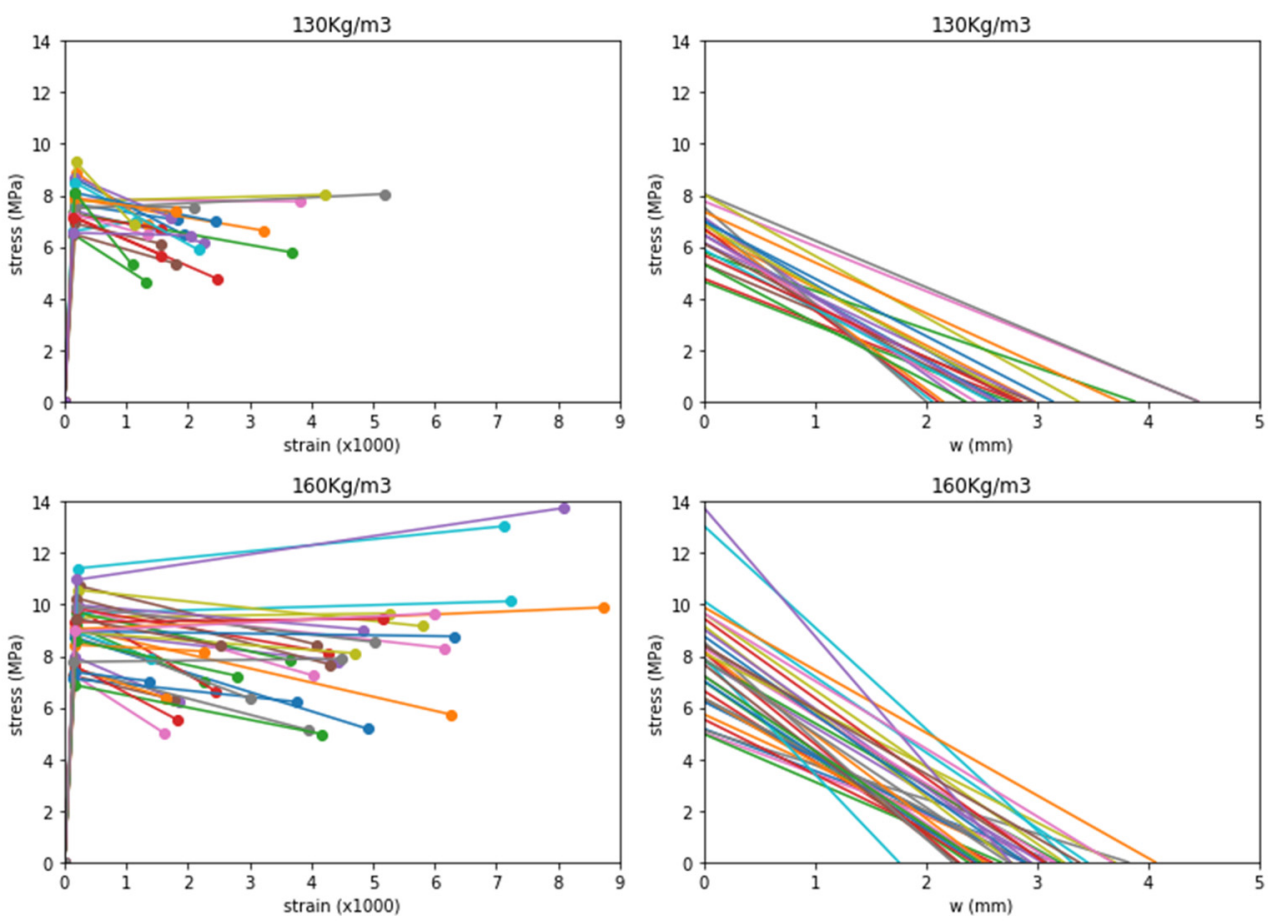

Figure 6.18 Tensile constitutive law from the 4P-IA application

The compressive strength obtained from the $93100 \mathrm{~mm}$ cubes, 32 for $130 \mathrm{~kg} / \mathrm{m}^{3}$ and 61 for $160 \mathrm{~kg} / \mathrm{m}^{3}$, fall within a range of [99.88, 130.56] $\mathrm{MPa}$ and [114.23, 172.08] $\mathrm{MPa}$, respectively. The tensile parameters obtained from the $63100 \times 100 \times 500 \mathrm{~mm}$ specimens are included within the following ranges:

For the 25 specimens of $130 \mathrm{~kg} / \mathrm{m}^{3}$ of fibres:

$$
\begin{aligned}
& f_{t} \in[6.48,9.31] \mathrm{MPa} \\
& f_{t u} \in[4.65,8.06] \mathrm{MPa} \\
& \varepsilon_{t u} \in[1.09,5.20] \% \\
& E \in[39100,53800] \mathrm{MPa} \\
& w_{0} \in[2.00,4.45] \mathrm{mm} \\
& \gamma \in[0.65,1.08]
\end{aligned}
$$

For the 38 specimens of $160 \mathrm{~kg} / \mathrm{m}^{3}$ of fibres:

$$
f_{t} \in[6.88,11.41] \mathrm{MPa}
$$




$$
\begin{aligned}
& f_{t u} \in[4.97,13.75] \mathrm{MPa} \\
& \varepsilon_{t u} \in[1.37,8.75] \% \\
& E \in[44100,55100] \mathrm{MPa} \\
& w_{0} \in[1.75,4.06] \mathrm{mm} \\
& \gamma \in[0.59,1.25]
\end{aligned}
$$

In Table 6.1, the tensile constitutive parameters of the characteristic curves are obtained after applying 4P-IA and the softening correction.

Table 6.1 Characteristic constitutive tensile parameters and softening-correction

\begin{tabular}{|c|c|c|c|c|c|}
\hline \multicolumn{7}{|c|}{$130 \mathrm{~kg} / \mathrm{m}^{3}$ of steel fibres } \\
\hline Charact. $\sigma-\delta$ & $f_{t}(\mathrm{MPa})$ & $f_{\text {tuc }}(\mathrm{MPa})$ & $\varepsilon_{t u}(\%)$ & $E(\mathrm{MPa})$ & $w_{o}(\mathrm{~mm})$ \\
\hline $5 \%$ & 6.59 & 5.27 & 1.43 & 44700 & 2.81 \\
\hline $50 \%$ & 7.56 & 7.05 & 1.18 & 49000 & 2.43 \\
\hline $95 \%$ & 8.88 & 7.85 & 4.38 & 53600 & 4.45 \\
\hline \multicolumn{7}{|c|}{$160 \mathrm{~kg} / \mathrm{m}^{3}$ of steel fibres } \\
\hline Charact. $\sigma-\delta$ & $f_{t}(\mathrm{MPa})$ & $f_{\text {tuc }}(\mathrm{MPa})$ & $\varepsilon_{t u}(\%)$ & $E(\mathrm{MPa})$ & $w_{o}(\mathrm{~mm})$ \\
\hline $5 \%$ & 7.01 & 5.57 & 4.09 & 46300 & 2.55 \\
\hline $50 \%$ & 8.89 & 8.14 & 3.69 & 48700 & 2.42 \\
\hline $95 \%$ & 10.22 & 10.23 & 7.56 & 51800 & 3.31 \\
\hline
\end{tabular}

Steel for the reinforcement bars has been characterised by a bilinear stress-total strain constitutive behaviour with strain hardening (see Figure 6.19) considering: tensile strength $\left(f_{s t}\right)$ of $500 \mathrm{MPa}$, ultimate tensile strength $\left(f_{\text {stu }}\right)$ of $550 \mathrm{MPa}$, elastic strain $\left(\varepsilon_{s t, e l}\right)$ of 0.0025 , ultimate tensile strain $\left(\varepsilon_{s t, u}\right)$ of 0.05 and elastic modulus $\left(E_{s}\right)$ of $200000 \mathrm{MPa}$. 

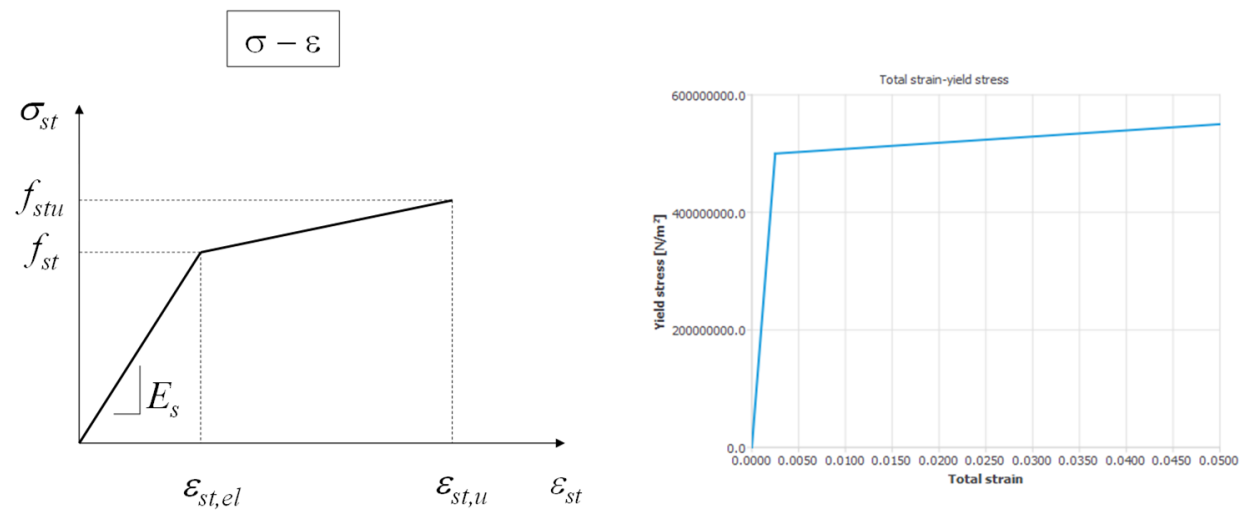

Figure 6.19 Stress-strain diagram to characterise reinforcement steel in tension

\subsubsection{Numerical validation}

Non-linear 2D and 3D finite element models (NLFEM) are developed to model the reinforced UHPFRC specimens using the Finite Element software DIANA FEA (DIANA (Software) 2017). These models start from a NLFEM defined in this work in chapter 3, chapter 4 and chapter 5 and in (Mezquida-Alcaraz et al. 2018, 2019a; b, 2021). In this case, the objective is to adapt the capabilities of NLFEM, even with reinforced concrete beams.

To model tensile UHPFRC constitutive behaviour, two different approaches are used: a smeared cracking approach and a discrete cracking approach. In the smeared cracking approach, the constitutive model for UHPFRC is based on a fixed total strain crack model expressed according to the crack-opening curve. For the discrete cracking approach, the constitutive model for UHPFRC is based on the discrete cracking model as the interface behaviour. This behaviour is forced only at the central specimen section. To force it, tensile strength $\left(f_{t}\right)$ and ultimate tensile strength $\left(f_{t u}\right)$ are reduced by $2 \%$. The rest of the specimen is modelled by the smeared cracking approach.

Reinforcement is modelled using Von Mises strain-hardening elasto-plastic behaviour for the steel with a bond-slip behaviour between reinforcement and the UHPFRC matrix by the Dorr constitutive model for the interface bond-slip elements.

The results of the UHPFRC characterisation obtained by the 4P-IA with softening correction are implemented into the constitutive behaviour of the described NLFEM. Therefore, the effect of fibres on constitutive tensile behaviour is considered with these parameters. Another important effect that is contemplated is concrete shrinkage and its consequences for concrete and reinforcement. In this case, it is taken into account as a material function when the UHPFRC model is defined in NLFEM using the total strain 
crack model. Accordingly, the shrinkage function from EN 1992-1-1 Eurocode 2 (The European Union Per Regulation 305/2011 and Directive 98/34/EC 2004) is used. From it, the obtained values are incremented as a percentage to be adapted to the UHPFRC response. That is, the total shrinkage strain of UHPFRC $\left(\varepsilon_{C S U H P F R C}\right)$ is defined as Expression (6.5), in which the value obtained on the testing day using Eurocode $2\left(\varepsilon_{c s}\right)$ is incremented by different percentages $\left(s h_{i n c}\right)$ of this value to take into account the influence of shrinkage on UHPFRC.

$$
\varepsilon_{C S U H P F R C}=\varepsilon_{C S} \cdot\left(1+s h_{\text {inc }} / 100\right)
$$

Both the reinforced short beams and long beams are modelled with 2D quadratic plane stress elements (with the 2D model) and 3D quadratic structural isoparametric solid brick elements (with the 3D model) when the smeared and discrete cracking approaches are used. Besides, for the discrete cracking approach, a quadratic 2D line interface element (with the 2D model) and a quadratic plane 3D interface element (with 3D) is placed at the mid-span section to model macrocrack behaviour (see Figure 6.20 and Figure 6.21). Reinforcement is modelled discretely using truss bond-slip elements.

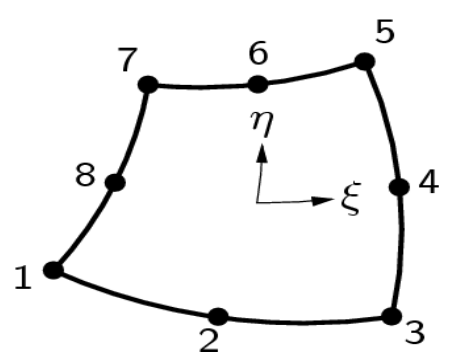

Figure 6.20 Finite elements for 2D model: (a) CQ16M and (b) CL12I (DIANA

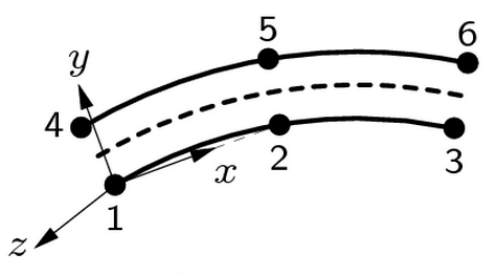

(Software) 2017) 

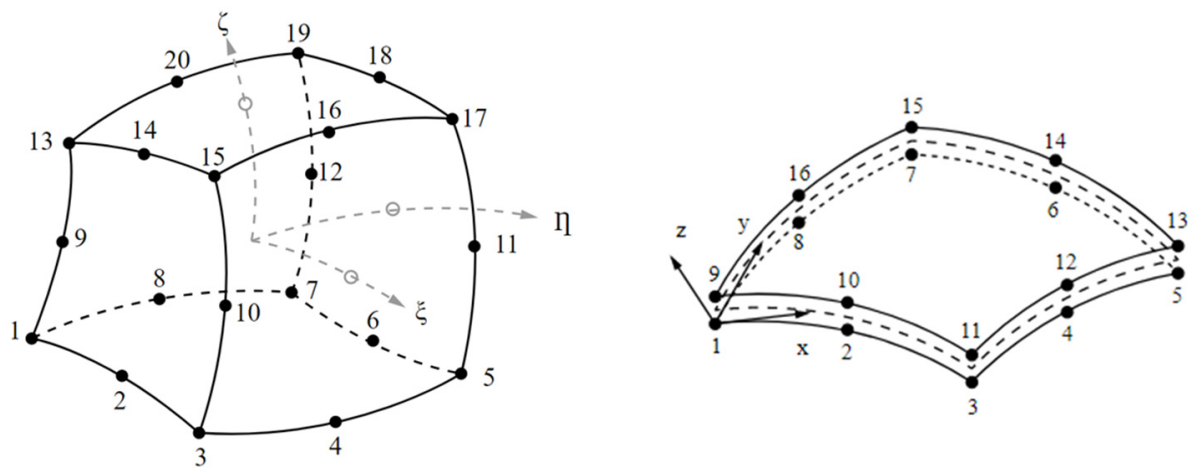

Figure 6.21 Finite elements for 3D model: (a) CX60 and (b) CQ48I (DIANA

(Software) 2017)

Figure 6.22, Figure 6.23 and Figure 6.24 show the mesh used for NLFEM with short beams and long beams in 2D and 3D. Load is applied to the steel loading plates by gradually increasing displacement (displacement control). A non-linear analysis is carried out by an incremental-iterative solution procedure. In Figure 6.22 two element sizes $\left(L_{e f}\right)$ are represented for the case where the discrete cracking approach of the 2DNLFEM of the short beams is used: $10 \mathrm{~mm}$ and $20 \mathrm{~mm}$. For the 3D-NLFEM of the short beams (Figure 6.24), an element size of $20 \mathrm{~mm}$ is used and for the 2D-NLFEM of the long beams an element size of $50 \mathrm{~mm}$ is considered (Figure 6.23). As the discrete cracking approach is not mesh size dependent, we are able to optimise the time and calculation resources with the mesh size. 

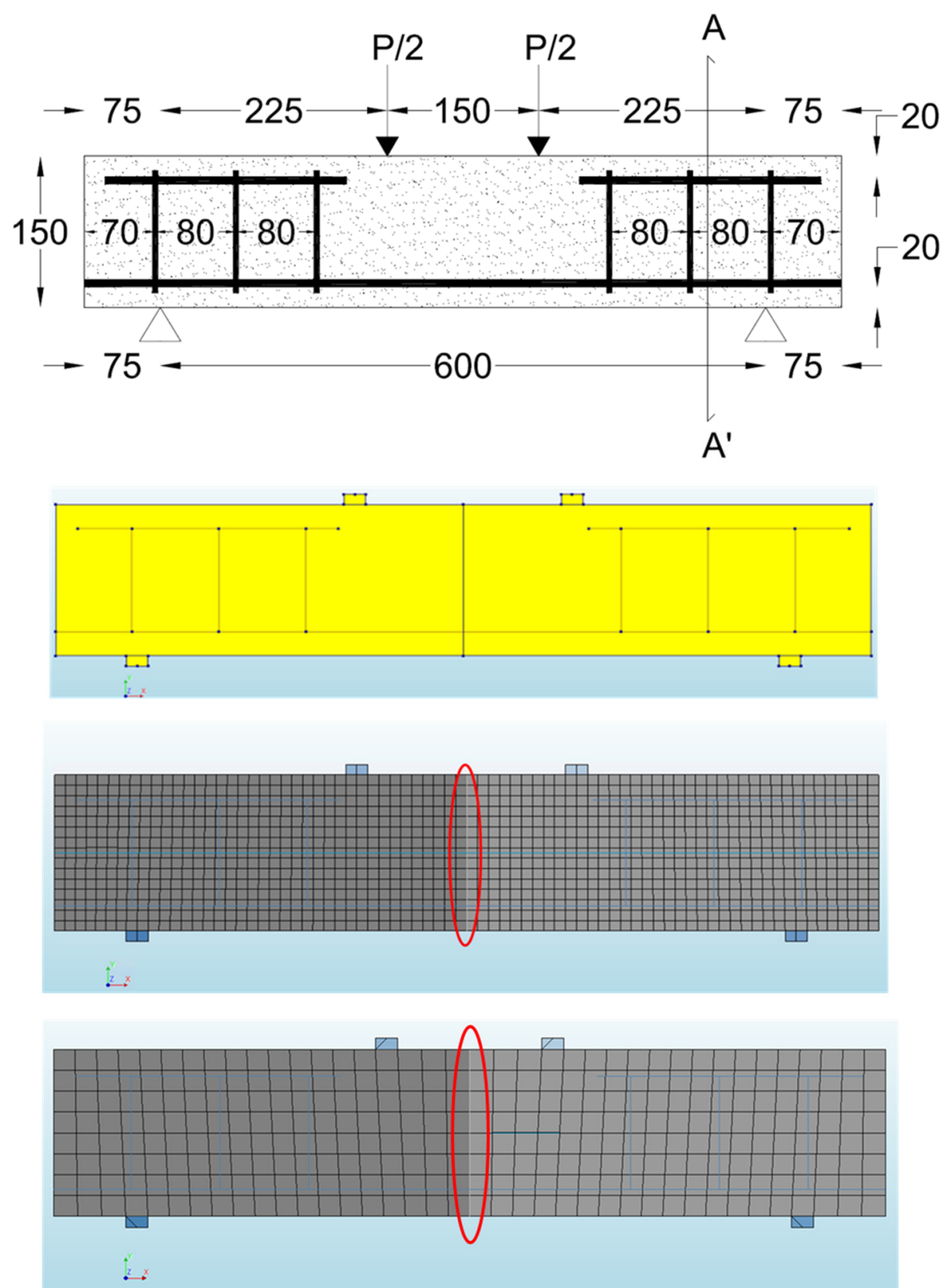

Figure 6.22 2D mesh for reinforced short beams $4 P B T$ 

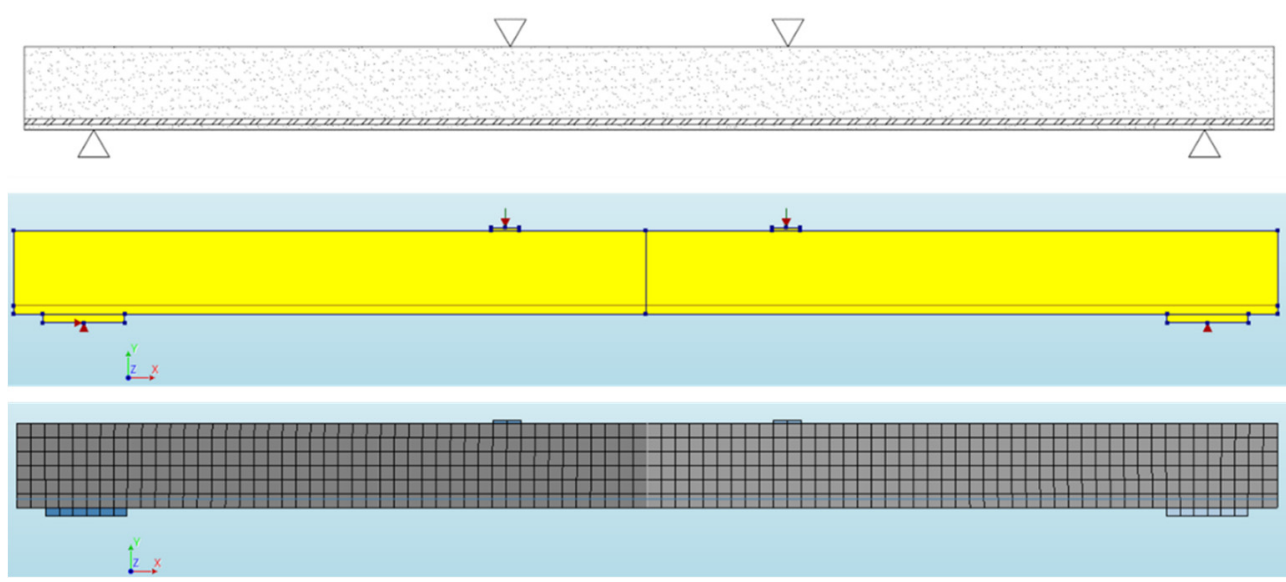

Figure 6.23 2D mesh for reinforced long beams 4PBT
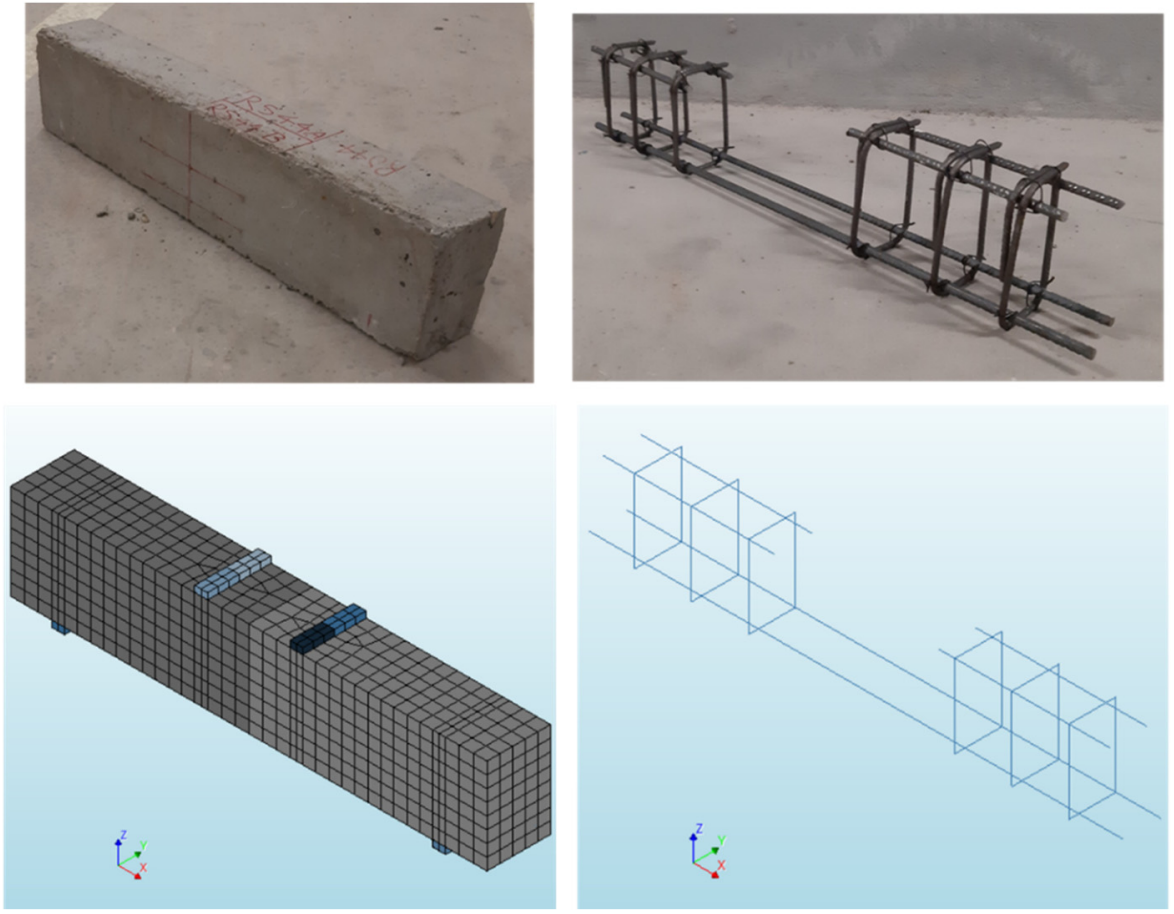

Figure $6.243 D$ mesh for reinforced short beams $4 P B T$ 


\subsubsection{Results and Discussion}

The objective of this section is to evaluate the reliability of using the constitutive parameters obtained from the characterisation test to describe the mechanical response in UHPFRC-reinforced elements. Moreover, the two material models developed in this thesis: the smeared crack approach and the discrete cracking approach are used in the 2D and 3D NLFEM to study how they work when the reinforcement bars are considered. The idea is to check if the differences between them are relevant as it happens with the unreinforced specimens used to characterise the UHPFRC tensile behaviour modelled in chapter 5. Considering the reinforcement, is still the smeared cracking approach mesh size dependent or the reinforcement is able to absorb the problem? Is the discrete cracking approach accurate enough? Is reasonable to model the UHPFRC towards the idea of a general $\sigma-\varepsilon / w$ behaviour (the so-called phase 1 in chapter 3 ) when it is simulated with the discrete cracking approach? To get this objective, the results from the experimental programme are compared to the response of the NLFEM developed.

\subsubsection{Short beams}

With short beams, the characteristic tensile parameters in Table 6.1, obtained by applying 4P-IA and its softening correction to the characteristic 4PBT $\sigma-\delta$ curves of the $500 \times 100 \times 100 \mathrm{~mm}$ specimens, are implemented into NLFEM. The numerical response of the obtained reinforced short beams are compared to the experimental response depicted in Figure 6.6.

Figure 6.25 shows the characteristic experimental $4 \mathrm{PBT} \sigma-\delta$ curves for $5 \%, 50 \%$ and $95 \%$ of the reinforced short beams tested for the experimental programme (the continuous black lines) compared to the characteristic response of the 2D-NLFEM when the discrete cracking approach is used (discontinuous ones). As observed, the model curves accurately fit the experimental ones for each level. This demonstrates not only the reliability of the developed NLFEM, but also the coherence of the process. That is, if the characteristic tensile constitutive parameters used to mechanically characterise UHPFRC were implemented into the NLFEM of the reinforced beams, then the numerical response would accurately fit the experimental one at the 5\%, 50\% and $95 \%$ percentile levels. 

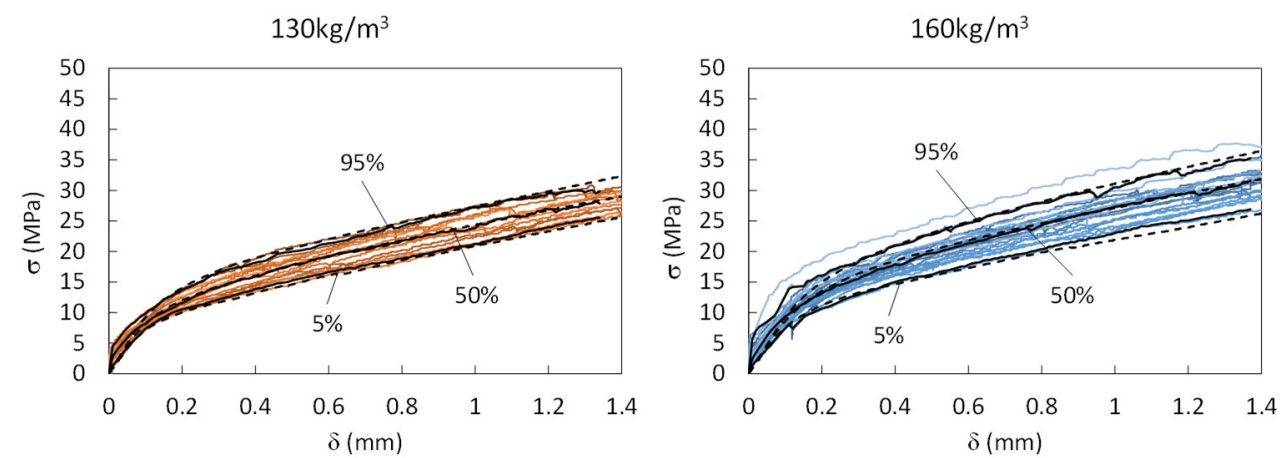

$\begin{array}{ll}\text { - percentile_5\% } & \text { - percentile_50\% } \\ - \text { - model_5\%_shinc_120\% } & - \text { model_50\%_shinc_120\% - - model_95\%_shinc_120\% }\end{array}$

Figure 6.25 Experimental $v$ s. numerical $\sigma$ - $\delta$ charact. response for $5 \%, 50 \%$ and $95 \%$

In addition, in Figure 6.26 the behaviour of the discrete cracking approach of the model applied to a short beam at failure moment is represented for a case in which the failure mechanism is developed completely along the discrete crack. It can be observed how the discrete crack behaves in this particular situation. Sometimes, the failure in the discrete cracking approach can be produced for a combination between the discrete crack and the smeared part as it can be seen in Figure 6.33.

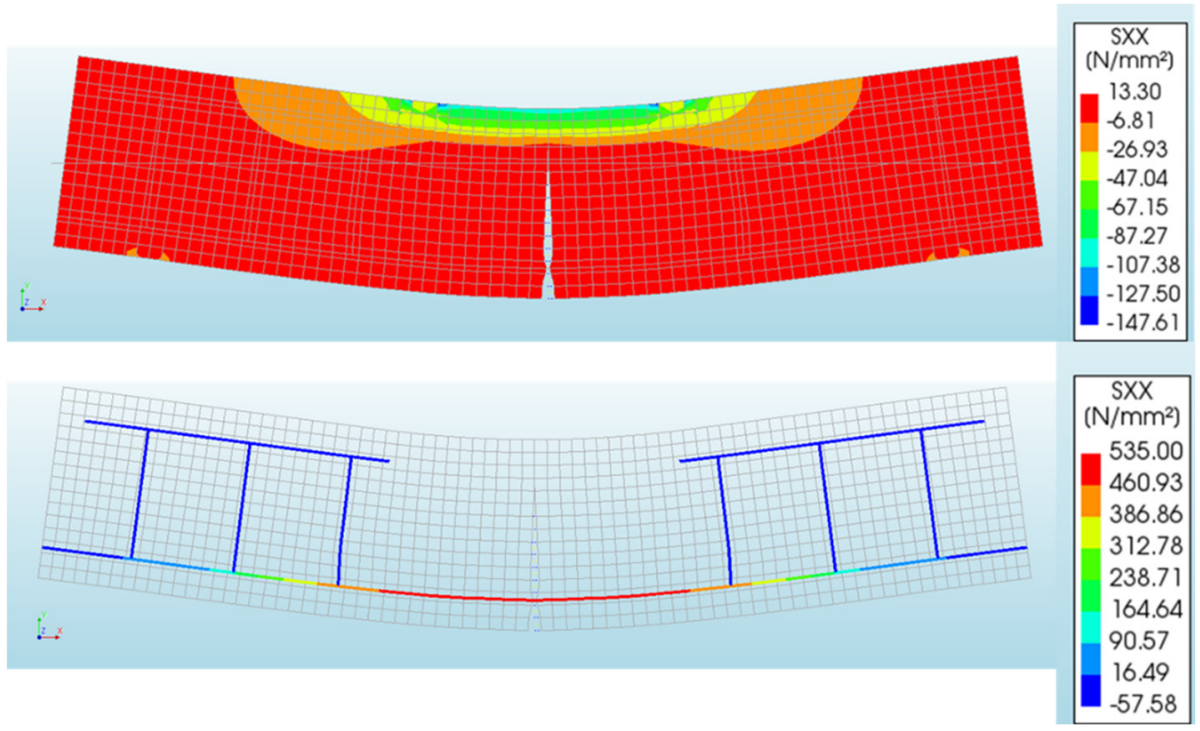

Figure 6.26 Behaviour of discrete cracking approach at failure for short beams 
It is important to pay attention to the shrinkage value used to calibrate the model. To fit the results with this accuracy, a $120 \%$ increment in the shrinkage value calculated from EN 1992-1-1 Eurocode 2 (The European Union Per Regulation 305/2011 and Directive 98/34/EC 2004) is needed in NLFEM. In Table 6.2, the shrinkage values $\left(\varepsilon_{c s}\right)$ for each characteristic level and the $120 \%$ increment $\left(\mathrm{sh}_{\text {inc }}\right)$ needed to fit the accurately results are provided. The total shrinkage strain of UHPFRC $\left(\varepsilon_{C S U H P F R C}\right)$ is calculated using Expression (6.5). The calculated UHPFRC shrinkage strain $\left(\varepsilon_{C S U H P F R C}\right)$ falls within the range of $[0.75,0.84] \mathrm{mm} / \mathrm{m}$. Figure 6.27 visually depicts the stress consequences that the shrinkage effect on the UHPFRC beam with $160 \mathrm{~kg} / \mathrm{m}^{3}$ of steel generates by taking into account the $50 \%$ characteristic tensile parameters in 3D-NLFEM in both reinforcement (Figure 6.27(a)) and the UHPFRC body (Figure 6.27(b)). In Figure 6.27(b) only the tensile stress range is illustrated to emphasise the stresses due to the shrinkage effect on UHPFRC. This effect follows the reinforcement path.

Table 6.2 Shrinkage values for UHPFRC of short beams

\begin{tabular}{|c|c|c|c|c|}
\hline \multicolumn{5}{|c|}{$130 \mathrm{~kg} / \mathrm{m}^{3}$ of steel fibres } \\
\hline Charact. & Testing day & $\varepsilon_{C S}(\mathrm{~mm} / \mathrm{m})$ & sh inc $(\%)$ & $\begin{array}{c}\varepsilon_{\text {CSUHPFRC }} \\
(\mathrm{mm} / \mathrm{m})\end{array}$ \\
\hline $5 \%$ & 49 & 0.34 & 120 & 0.75 \\
\hline $50 \%$ & 49 & 0.34 & 120 & 0.75 \\
\hline $95 \%$ & 49 & 0.35 & 120 & 0.77 \\
\hline \multicolumn{7}{|c|}{$160 \mathrm{~kg} / \mathrm{m}^{3}$ of steel fibres } \\
\hline Charact. & Testing day & $\varepsilon_{C S}(\mathrm{~mm} / \mathrm{m})$ & $\mathrm{sh}_{\text {inc }}(\%)$ & $\begin{array}{c}\varepsilon_{\text {cSUHPFR }} \\
(\mathrm{mm} / \mathrm{m})\end{array}$ \\
\hline $5 \%$ & 49 & 0.34 & 120 & 0.75 \\
\hline $50 \%$ & 49 & 0.35 & 120 & 0.77 \\
\hline $95 \%$ & 49 & 0.38 & 120 & 0.84 \\
\hline
\end{tabular}




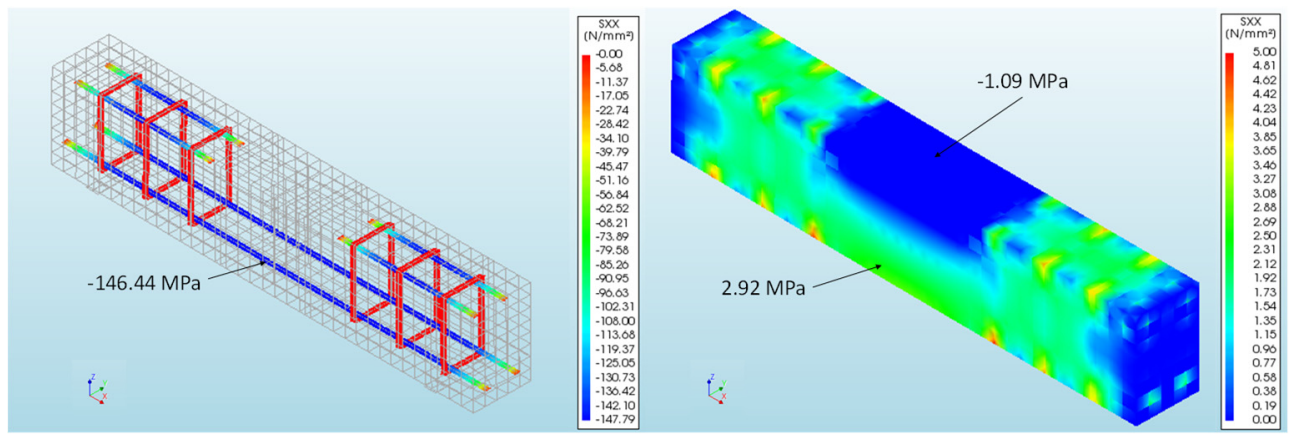

Figure 6.27 Shrinkage stress 3D NLFEM: (a) reinforcement and (b) UHPFRC

In Figure 6.28, both NLFEM cracking approaches (smeared and discrete) are compared to the experimental $\sigma-\delta$ response for the characteristic $50 \%$ level. The tensile constitutive parameters for $50 \%$ in Table 6.1 are implemented in both NLFEM approaches and compared. As we can see, the numerical model fits the experimental response very well. The elastic and multicrack stages are accurately represented. Unlike the behaviour obtained with the unreinforced specimens in the 4PBT in chapter 5 (see Figure 5.16), we can see that the differences between both the NLFEM approaches are not significant. This means that the presence of reinforcement has a notorious influence on specimens' mechanical behaviour when the macrocrack appears. At that time, UHPFRC loses its bearing capacity and stress is transmitted progressively to reinforcement through the "tension stiffening" mechanism. This effect gives a close response between the smeared and discrete NLFEM cracking approaches. We can also observe how the differences between the 2D and 3D NLFEM are negligible. The model's accuracy is good and both the models with the smeared and discrete cracking approaches prove to be completely reliable. This fact justifies that, for long beams, only the $2 \mathrm{D}$ model is used to avoid the amount of calculation time and sources spent for the 3D one. In any case, the 3D model is used to observe such important $3 \mathrm{D}$ effects like shrinkage (Figure 6.27). In this figure, it is very interesting to observe how the longitudinal and transverse reinforcement do not let the concrete shorten freely, and therefore inducing concentration of concrete tensile stresses in the vicinity of the reinforcement. 


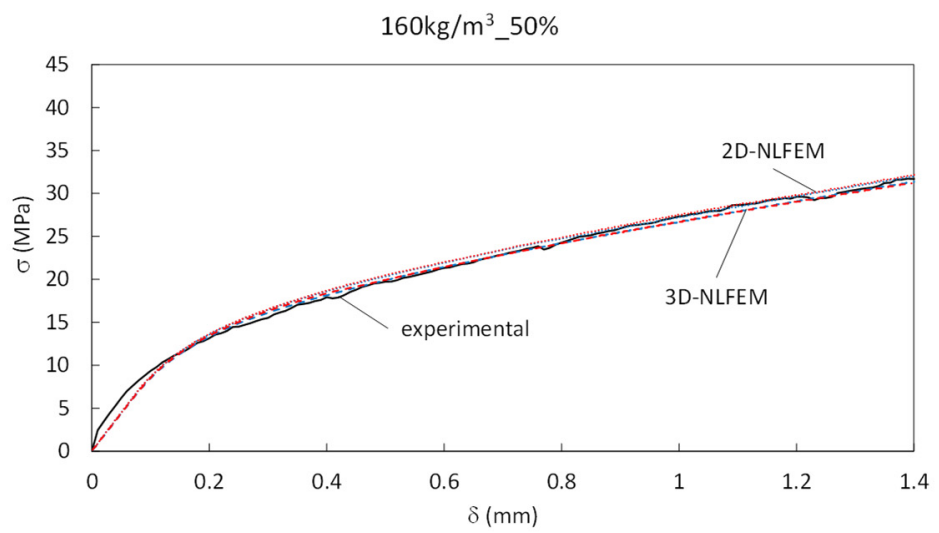

— exp_50\% -....... model2Ddisc_sh120_50\% …… model2Dsm_120sh_50\%---model3Ddisc_sh120_50\% - - model3Dsm_sh120_50\%

Figure 6.28 Comparison between the NLFEM approaches for $160 \mathrm{~kg} / \mathrm{m}^{3}$ of steel fibres

\subsection{Evaluation of NLFEM through different stress levels}

In order to evaluate how the NLFEM represents the characteristic phases of reinforced UHPFRC behaviour in a 4PBT described in Figure 6.6 for $130 \mathrm{~kg} / \mathrm{m}^{3}$ and $160 \mathrm{~kg} / \mathrm{m}^{3}$ of steel fibres, the model has been studied at different stress levels for both amount of fibres. In Figure 6.29, the $\sigma-\delta$ curve of the discrete cracking approach of NLFEM is depicted for both amount of fibres, when the characteristic 50\% (percentile of 50\%) UHPFRC tensile constitutive parameters (Table 6.1) are applied. As we know from Figure 6.28 the smeared and the discrete cracking approach for 2D and 3D of the NLFEM in reinforced UHPFRC have exactly the same response so, in Figure 6.29 , for the $130 \mathrm{~kg} / \mathrm{m}^{3}$ curve the discrete cracking approach of the 2D-NLFEM is used and for the $160 \mathrm{~kg} / \mathrm{m}^{3}$ the discrete cracking approach of the 3D-NLFEM is used.

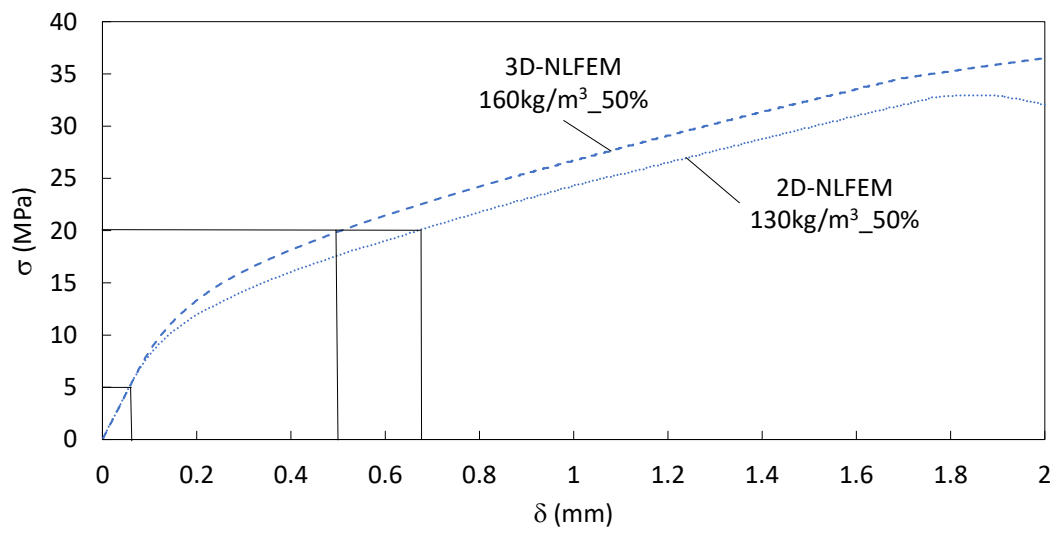

Figure $6.29 \sigma$ - $\delta$ curves for discrete NLFEM 2D for $130 \mathrm{~kg} / \mathrm{m}^{3}$ and $3 D$ for $160 \mathrm{~kg} / \mathrm{m}^{3}$ 
Figure 6.30, Figure 6.31, Figure 6.32 and Figure 6.33 represent the stresses for the reinforced short beams at different stress levels (see Figure 6.29) when the discrete cracking approach of the 2D-NLFEM developed is applied for the case of $130 \mathrm{~kg} / \mathrm{m}^{3}$ of fibres and the characteristic 50\% constitutive parameters (Table 6.1) are used. The stress levels represented are: previous the test starting at 49 days (Figure 6.30), at $5 \mathrm{MPa}$ stress level during the 4PBT (Figure 6.31) at the elastic branch, at $20 \mathrm{MPa}$ stress level (Figure 6.32) during the $4 \mathrm{PBT}$ at the microcrack stabilisation phase and at collapse (Figure 6.33) where microcracks are concentrated in one macrocrack.

As it can be observed at Figure 6.30 the shrinkage produces a very important influence, as it has been also demonstrated in Figure 6.27 with the discrete cracking approach of the 3D-NLFEM with $160 \mathrm{~kg} / \mathrm{m}^{3}$ and when the characteristic $50 \%$ percentile constitutive parameters are used. As it can be observed, in the case represented using the 2D model with $130 \mathrm{~kg} / \mathrm{m}^{3}$ and the $50 \%$ percentile constitutive parameters (Figure 6.30), the stress in the UHPFRC is near 2.50 MPa in tension and $1.40 \mathrm{MPa}$ in compression. In addition, in the reinforcement, the longitudinal bars are compressed at $130 \mathrm{MPa}$ and the stress at the bottom of the interface element is near $2.50 \mathrm{MPa}$ in tension. Therefore, the beam is pre-stressed due to the shrinkage effect before the 4PBT starts. These results are in the same line that in the case of $160 \mathrm{~kg} / \mathrm{m}^{3}$ in Figure 6.27.

At day 49 the 4PBT starts and during the elastic phase represented in Figure 6.31 the tensile stress in UHPFRC is under the $f_{t}$ value $\left(f_{t}=7.50 \mathrm{MPa}\right.$, see Table 6.1). As it can be observed, the reinforcement longitudinal bars at the bottom are still compressed due to the influence of the shrinkage. The tensile stress in the interface crack element is almost at the level of cracking because it will happen when the stress reaches at the bottom the $98 \%$ of $f_{t}$.

The microcrack stabilisation phase is represented in Figure 6.32. The tensile stress in the UHPFRC situated at the bottom of the beam is between the $f_{t}=7.56 \mathrm{MPa}$ and $f_{t u}=7.05$ $\mathrm{MPa}$, because the characteristic $50 \%$ constitutive behaviour of $130 \mathrm{~kg} / \mathrm{m}^{3}$ UHPFRC has strain-softening (SS) behaviour (see Table 6.1). The longitudinal bars now have tensile stresses and the interface crack is opening from the bottom because it is reaching its tensile strength progressively from the bottom to the top. In this figure, the crack widths are also represented in order to observe how concrete is microcraked along the bottom part of the beam where is modelled using the smeared cracking approach.

Figure 6.33 represents the moment when the beam collapses. As it is observed in the model for this case, the collapse is not only produced in the UHPFRC for the mid span section where the discrete crack interface element is located, but also in the smeared cracking part as it is marked in the "UHPFRC stresses x direction" figure from Figure 6.33. The longitudinal bars of the reinforcement are yielded near the collapse and crack interface element is opened in all its profile except at the compression head level. Moreover, at this level, the crack width is represented in order to show how the macrocrack is located at the mid span section. This moment is represented in Figure 6.7. 


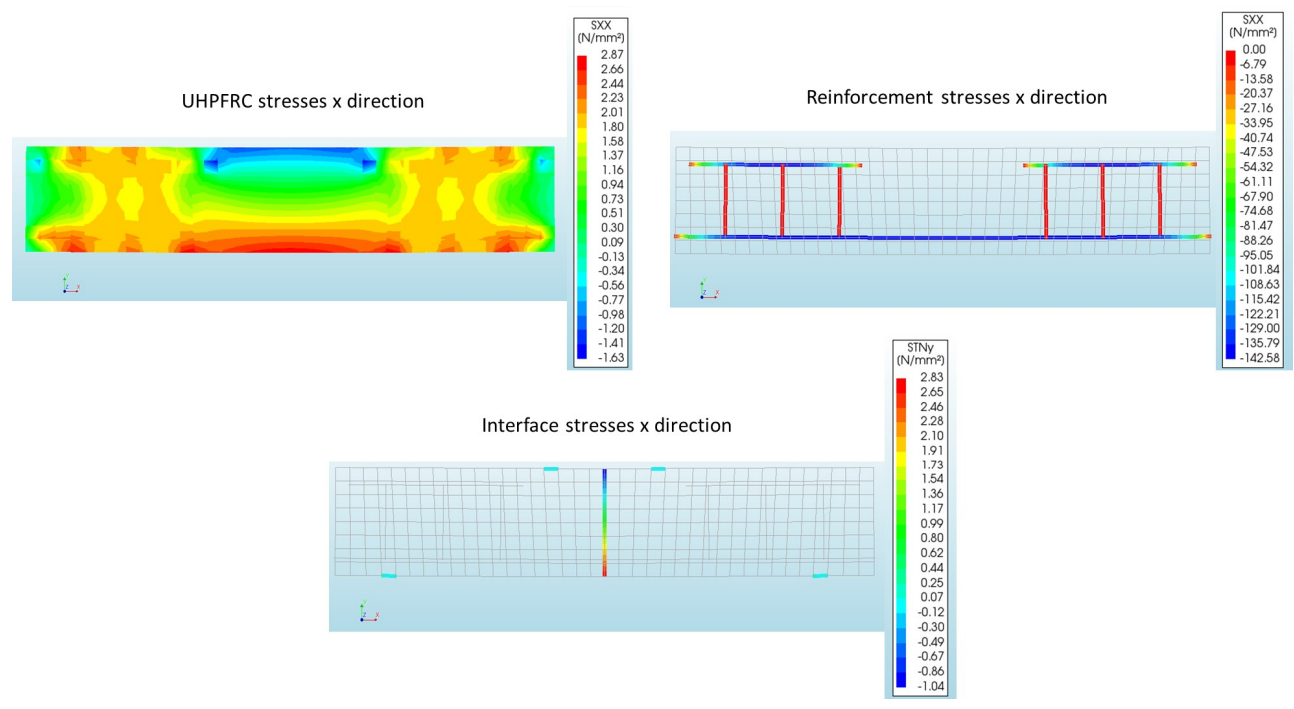

Figure 6.30 2D-NLFEM_130kg_50\%, shrinkage stresses at 49 days

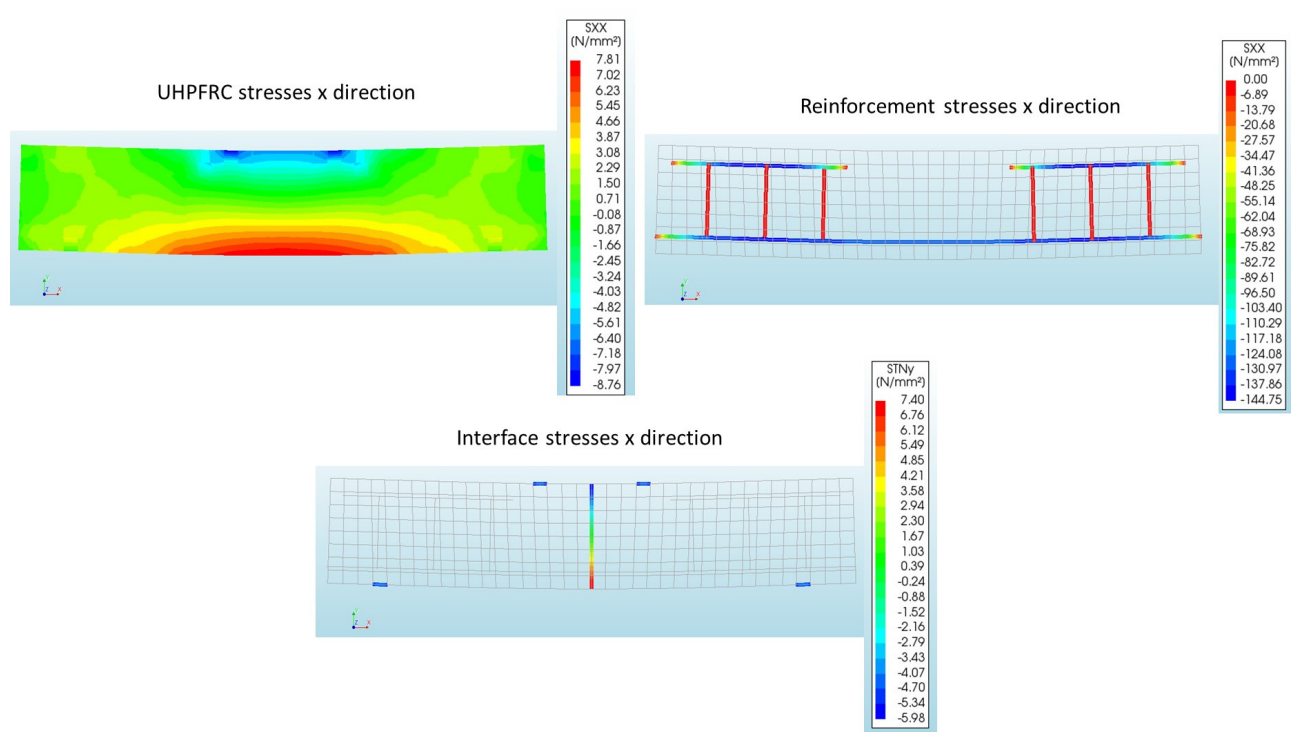

Figure 6.31 2D-NLFEM_130kg_50\%, stresses in the elastic branch $(\sigma=5 \mathrm{MPa})$ 


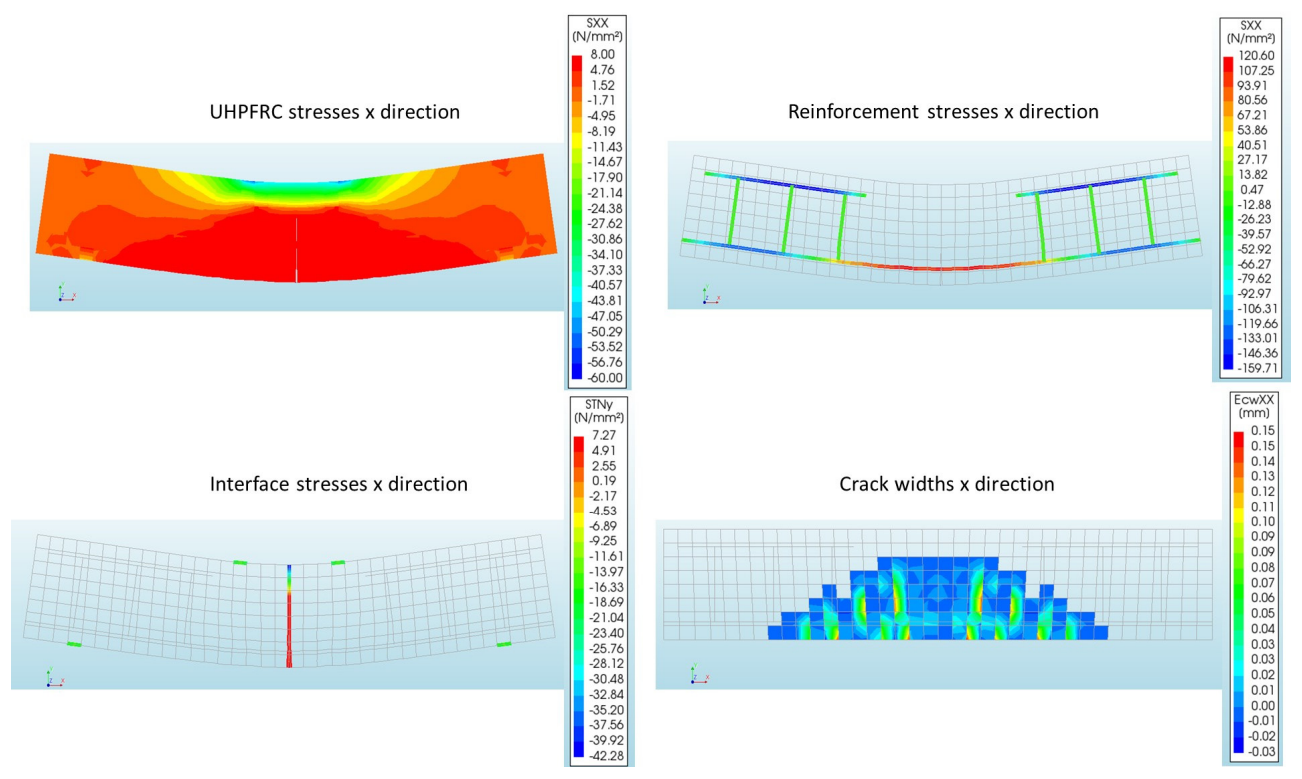

Figure 6.32 2D-NLFEM_130kg_50\%, stress and crack width for $\sigma=20 \mathrm{MPa}$

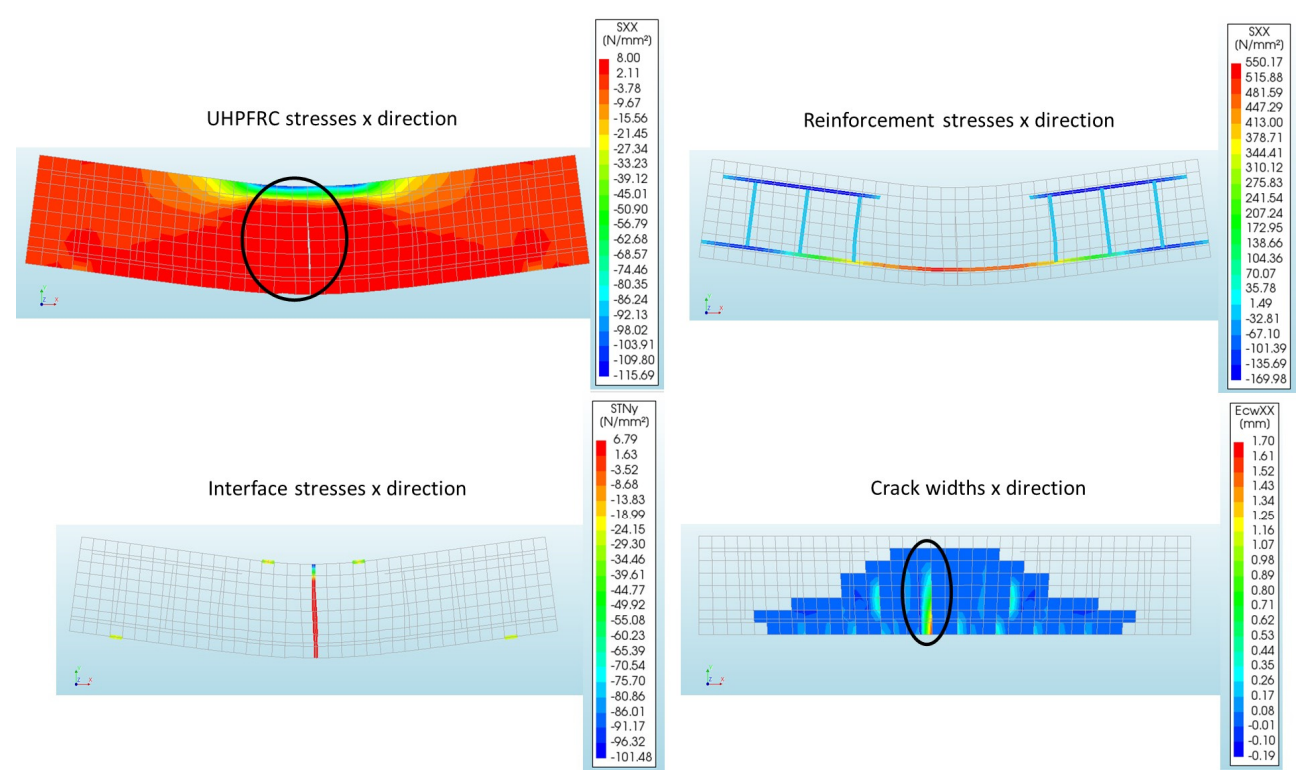

Figure 6.33 2D-NLFEM_130kg_50\%, stresses and crack widths at the collapse level 
Now, for the case of $160 \mathrm{~kg} / \mathrm{m}^{3}$ of steel fibres using the characteristic $50 \%$ percentile constitutive UHPFRC tensile parameters (Table 6.1), the discrete cracking approach of the 3D-NLFEM is represented in Figure 6.34, Figure 6.35, Figure 6.36 and Figure 6.37, for the stress levels depicted at Figure 6.29 and also used for the 2D-NFEM in the case of $130 \mathrm{~kg} / \mathrm{m}^{3}$.

In Figure 6.34 the shrinkage effect has been registered just before the test starts, at 49 days. This figure is the same as Figure 6.27 considering all the stress range from compression to tension. As it happens at Figure 6.30 with the case of $130 \mathrm{~kg} / \mathrm{m}^{3}$, the shrinkage produces a very important influence. As it can be observed, in the case represented using the $3 \mathrm{D}$ model with $160 \mathrm{~kg} / \mathrm{m}^{3}$ and the $50 \%$ percentile constitutive parameters (Figure 6.34), the stress in the UHPFRC is near 2.92 MPa in tension and 1.09 $\mathrm{MPa}$ in compression. In addition, in the reinforcement, the longitudinal bars are compressed at $146.44 \mathrm{MPa}$ and the stress at the bottom of the interface element is near $2.90 \mathrm{MPa}$ in tension. Therefore, the beam is pre-stressed due to the shrinkage effect before the 4PBT starts. These results are in the same line that in the case of $130 \mathrm{~kg} / \mathrm{m}^{3}$ in Figure 6.30, even though these values are slightly higher in tension and slightly lower in compression for the case of $160 \mathrm{~kg} / \mathrm{m}^{3}$, maybe due to the amount of fibres considered that leads to a higher UHPFRC constitutive parameters. Consequently, the shrinkage effect is slightly higher in the case of $160 \mathrm{~kg} / \mathrm{m}^{3}$.

At day 49 the $4 \mathrm{PBT}$ starts and during the elastic phase represented in Figure 6.35 the tensile stress in UHPFRC is under the $f_{t}$ value $\left(f_{t}=8.89 \mathrm{MPa}\right.$, see Table 6.1). As it can be observed, the reinforcement longitudinal bars at the bottom are still compressed due to the influence of the shrinkage. The tensile stress in the interface crack element is almost at the level of cracking because it will happen when the stress reaches at the bottom the $98 \%$ of $f_{t}$. If the stresses at Figure 6.35 for the $160 \mathrm{~kg} / \mathrm{m}^{3}$ are compared to those at Figure 6.31 for $130 \mathrm{~kg} / \mathrm{m}^{3}$, the values are slightly higher for the case of 160 $\mathrm{kg} / \mathrm{m}^{3}$ due to the amount of fibres and the influence of the previous shrinkage phase but still close to those for the case of $130 \mathrm{~kg} / \mathrm{m}^{3}$, as it is represented in Figure 6.29 .

The microcrack stabilisation phase is represented in Figure 6.36. The tensile stress in the UHPFRC situated at the bottom of the beam is between the $f_{t}=8.89 \mathrm{MPa}$ and $f_{t u}=8.14$ $\mathrm{MPa}$, because the characteristic $50 \%$ constitutive behaviour of $160 \mathrm{~kg} / \mathrm{m}^{3}$ UHPFRC has strain-softening (SS) behaviour (see Table 6.1). The longitudinal bars now have tensile stresses and the interface crack is opening from the bottom because it is reaching its tensile strength progressively from the bottom to the top. In this figure, the crack widths are represented too in order to observe how concrete is microcraked along the bottom part of the beam where is modelled using the smeared cracking approach. If Figure 6.36 is compared to Figure 6.32 it could be observed how the stress in the reinforcement is lower for the case of $160 \mathrm{~kg} / \mathrm{m}^{3}$ than for the case of $130 \mathrm{~kg} / \mathrm{m}^{3}$. This is, due to the amount of fibres, the UHPFRC matrix reaches more strength in tension for the case of $160 \mathrm{~kg} / \mathrm{m}^{3}$ and, moreover, its deflection-hardening behaviour in flexion is also higher leading to a greater influence of tension stiffening effect. This is, as the amount of fibres increases, 
the combination of fibres and reinforcement leads to higher strength and a more progressive softening behaviour when UHPFRC microcracks.

Figure 6.37 represents the moment when the beam collapses. As it is observed in the model for this case, the collapse is not only produced in the UHPFRC for the mid span section where the discrete crack interface element is located, but also in the smeared cracking part as it is marked in the "UHPFRC stresses x direction" figure from Figure 6.37. The longitudinal bars of the reinforcement are yielded near the collapse and crack interface element is opened in all its profile except at the compression head level. Moreover, at this level, the crack width is represented in order to show how the macrocrack is located at the mid span section. This moment is also represented in Figure 6.7. The behaviour when the beam collapses is very similar to that represented in Figure 6.33 for the 2D model for the case of $130 \mathrm{~kg} / \mathrm{m}^{3}$.
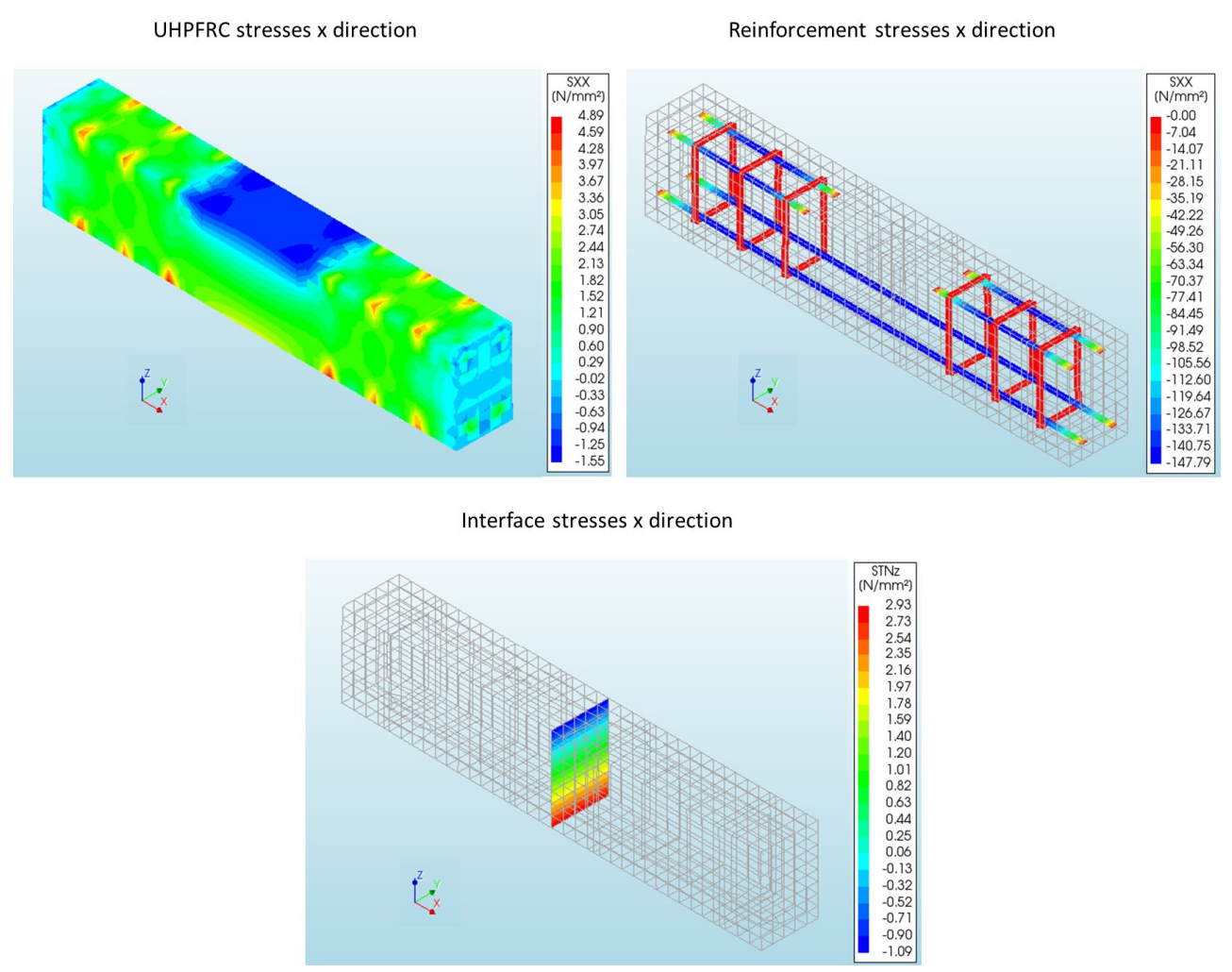

Figure 6.34 3D-NLFEM_160kg_50\%, shrinkage stresses at 49 days 


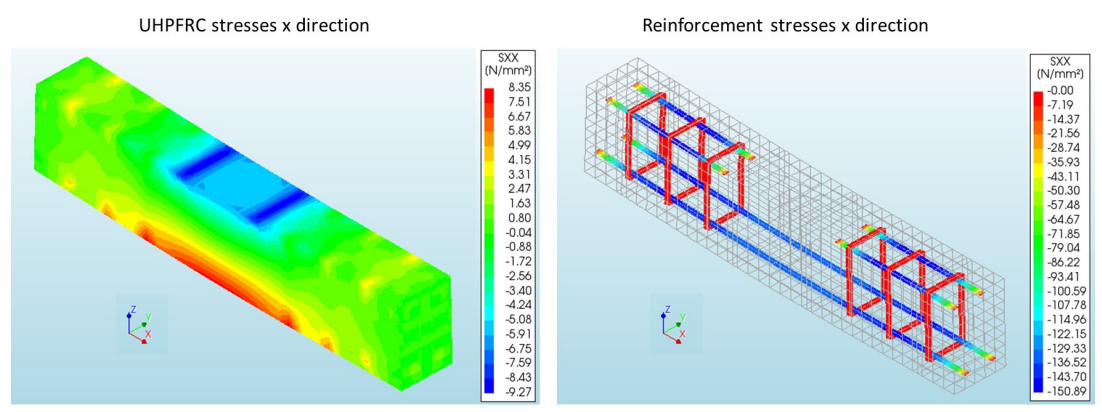

Interface stresses $x$ direction

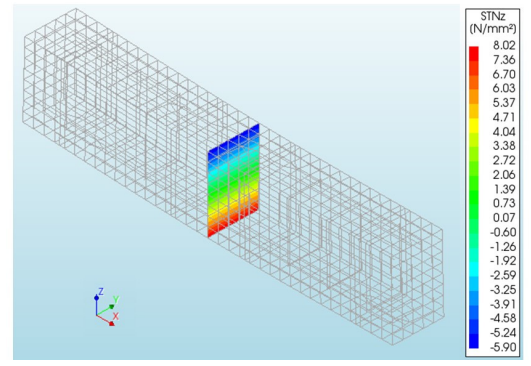

Figure 6.35 3D-NLFEM_160kg_50\%, stresses in the elastic branch $(\sigma=5 \mathrm{MPa})$

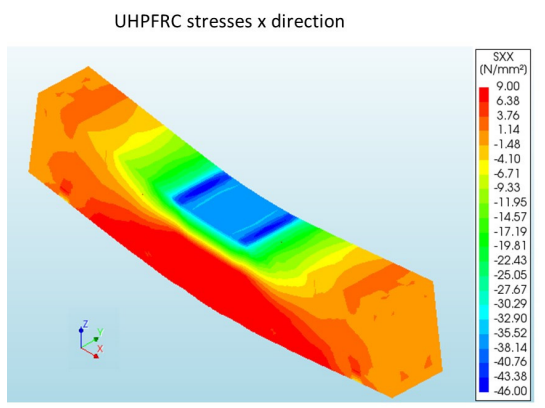

Interface stresses $\mathrm{x}$ direction

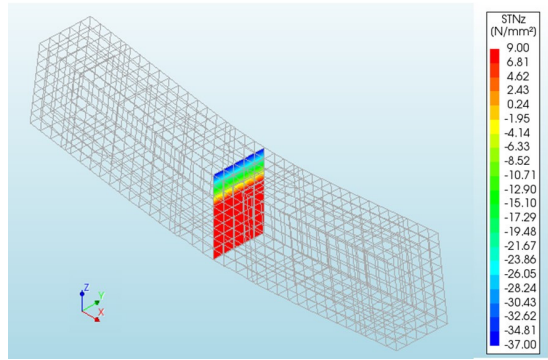

Reinforcement stresses $\mathrm{x}$ direction

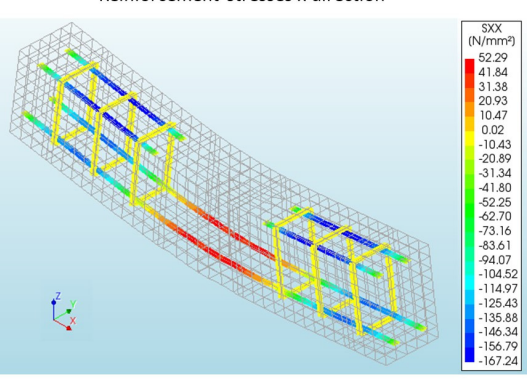

Crack widths $x$ direction

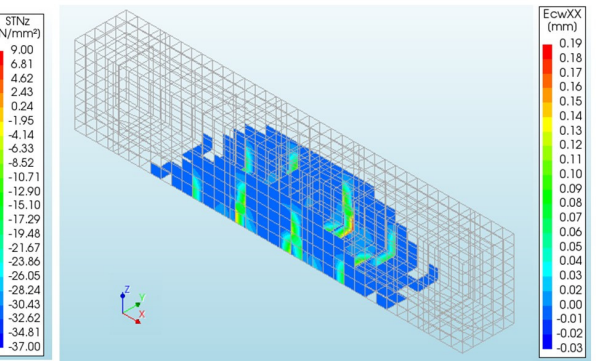

Figure 6.36 3D-NLFEM_160kg_50\%, stress and crack width for $\sigma=20 \mathrm{MPa}$ 


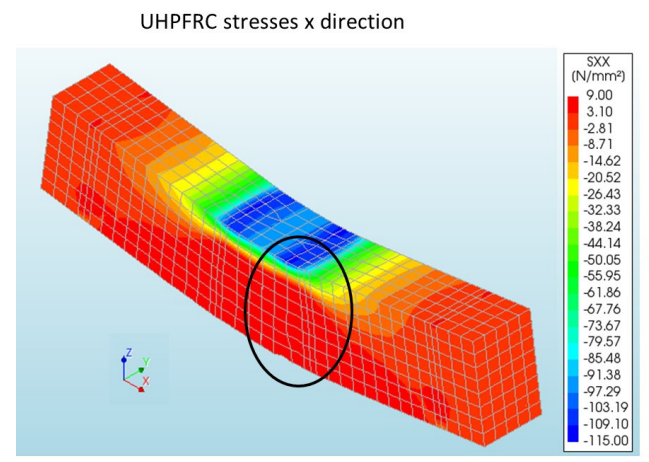

Interface stresses $\mathrm{x}$ direction

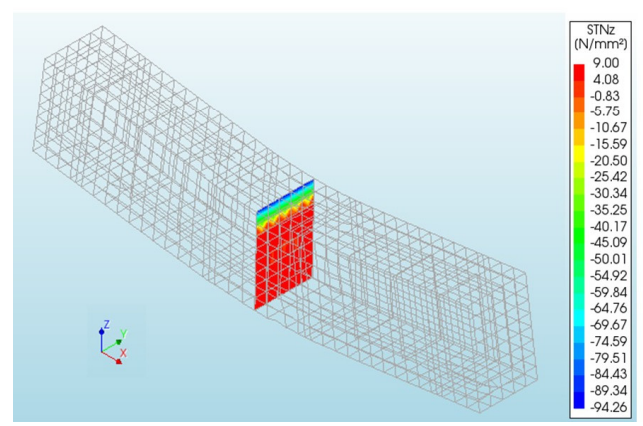

Reinforcement stresses $\mathrm{x}$ direction

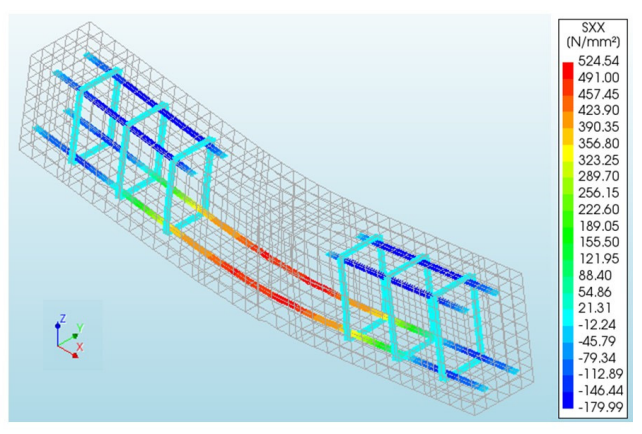

Crack widths $\mathrm{x}$ direction

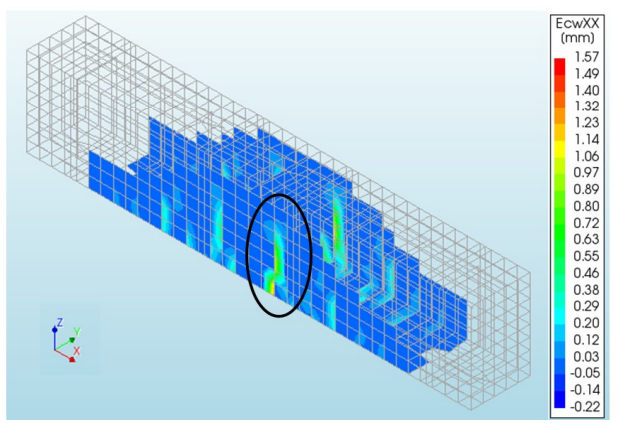

Figure 6.37 3D-NLFEM_160kg_50\%, stresses and crack widths at the collapse level

It is important to understand that the crack widths obtained in this section are a result from the smeared cracking approach application on the continuous part of the discrete cracking approach NLFEM. Therefore, the crack widths values are linked to the finite element size $\left(L_{e f}\right)$ or crack bandwidth $\left(b_{w}\right)$ considered. In this case, for the reinforced short flexural beams for both models the $2 \mathrm{D}$ and the $3 \mathrm{D}$, an element size of $20 \mathrm{~mm}$ is used. Thus, assuming scenario 1 (see chapter 4$)$, the element size $\left(L_{e f}\right)$ equals the crack bandwidth $\left(b_{w}\right)$ when the UHPFRC cracks. For the author of the this thesis a crack bandwidth $\left(b_{w}\right)$ between $10-50 \mathrm{~mm}$ assumed when the UHPFRC cracks can be considered a valid approximation of the real crack bandwidth expected for the UHPFRC as the NLFEM response fits the experimental one for this range.

\subsection{Cracking Pattern representation}

At this point, the representation of the cracking pattern obtained from the application of the discrete cracking approach of the 2D-NLFEM for UHPFRC that exhibits different 
corrected hardening ratio $\left(\gamma_{c}\right)$ in its constitutive tensile behaviour has been carried out. The idea is to evaluate how the evolution of cracking depending on the UHPFRC constitutive tensile behaviour is developed. To do that, four different UHPFRC tensile behaviours at different grades of the $\gamma_{c}$ as defined in Expression (6.6) have been used in the 2D-NLFEM from the material characterisation at Figure 6.17 and Figure 6.18.

$$
\gamma_{c}=\frac{f_{t u c}}{f_{t}}
$$

In Table 6.3 the constitutive parameters used are set for UHPFRC with $160 \mathrm{~kg} / \mathrm{m}^{3}$ of fibres. The table represents four sets of constitutive parameters obtained after the application of the 4P-IA and the softening correction developed in chapter 5 for four unreinforced specimens used to characterise the tensile behaviour of UHPFRC in a 4PBT, in Figure 6.17 and Figure 6.18. As it can be observed, the hardening ratio $(\gamma)$ goes from SH $(\gamma>1)$ to $\mathrm{SS}(\gamma<1)$.

Table 6.3 Constitutive parameters for UHPFRC with $160 \mathrm{~kg} / \mathrm{m}^{3}$

\begin{tabular}{|c|c|c|c|c|c|c|c|c|c|c|}
\hline \multicolumn{10}{|c|}{$160 \mathrm{~kg} / \mathrm{m}^{3}$ of steel fibres } \\
\hline \multirow{2}{*}{ Id. } & \multicolumn{9}{|c|}{ constitutive tensile law (4P-IA) } & \multicolumn{3}{c|}{ softening correction } & Comp. \\
\cline { 2 - 13 } & $\begin{array}{c}f_{t} \\
(\mathrm{MPa})\end{array}$ & $\begin{array}{c}f_{t u} \\
(\mathrm{MPa})\end{array}$ & $\begin{array}{c}\varepsilon_{\text {tu }} \\
(\%)\end{array}$ & $\begin{array}{c}\mathrm{E} \\
(\mathrm{MPa})\end{array}$ & $\begin{array}{c}w_{d} \\
(\mathrm{~mm})\end{array}$ & $\gamma$ & $\begin{array}{c}\text { var } \\
(\%)\end{array}$ & $\begin{array}{c}f_{\text {tuc }} \\
(\mathrm{MPa})\end{array}$ & $\gamma_{\mathrm{c}}$ & $\begin{array}{c}f_{\mathrm{c}} \\
(\mathrm{MPa})\end{array}$ \\
\hline CP1 & 10.97 & 13.75 & 8.09 & 55100 & 1.84 & 1.25 & 0.00 & 13.75 & 1.25 & 149.78 \\
\hline CP2 & 9.05 & 9.89 & 8.75 & 51700 & 2.71 & 1.09 & 0.00 & 9.89 & 1.09 & 172.08 \\
\hline CP3 & 10.57 & 9.16 & 5.80 & 48000 & 1.84 & 0.87 & 4.66 & 9.59 & 0.91 & 129.30 \\
\hline CP4 & 9.90 & 7.24 & 4.05 & 47464 & 1.68 & 0.73 & 10.18 & 7.97 & 0.81 & 137.99 \\
\hline
\end{tabular}

The parameters of Table 6.3 are applied in the material behaviour of the discrete cracking approach of the 2D-NLFEM for the numerical simulation of the 4PBT for the reinforced short beams obtaining, as a result, the $\sigma-\delta$ at mid span curves for each set of constitutive parameters, as it is depicted in Figure 6.38. As it can be observed, the set CP3 has better $\sigma-\delta$ response than CP2 because the first one has higher value of $f_{t}$ so the UHPFRC matrix has more strength for this set of constitutive parameters. 


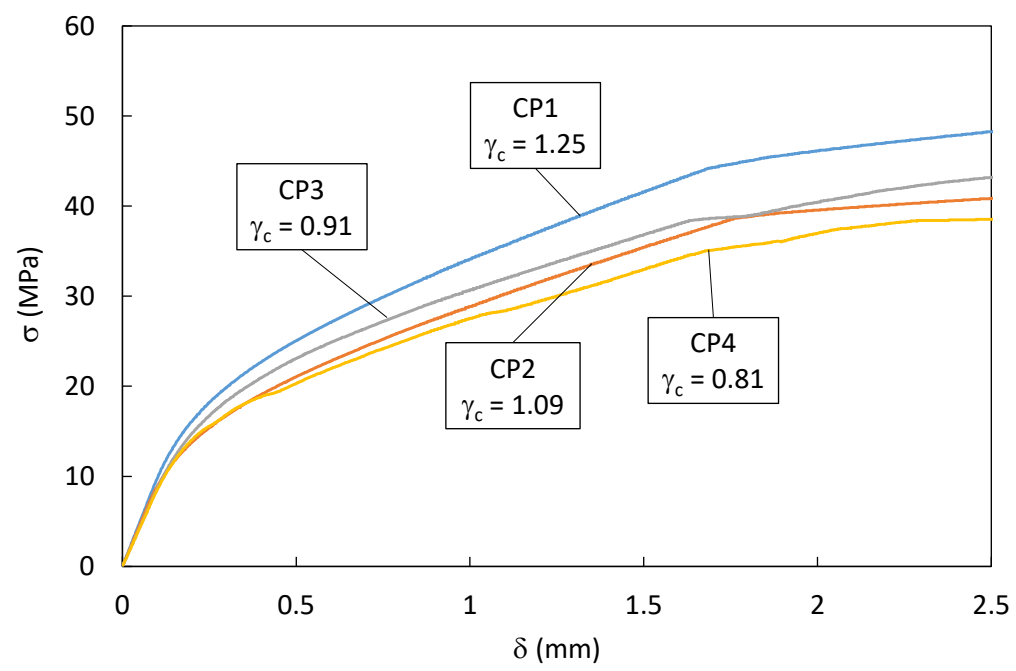

Figure 6.38 2D-NLFEM $\sigma$ - $\delta$ curves for different values of $\gamma$

Figure 6.39, Figure 6.40, Figure 6.41 and Figure 6.42 depict the cracking pattern of the reinforced short beams obtained from de 2D-NLFEM application considering the four set of constitutive parameters shown in Figure 6.38, at $\sigma=30 \mathrm{MPa}$ (microcrack stabilisation phase) and at collapse level (where the macrocrack takes place). As it is observed in these figures the cracking pattern at microcrack stabilisation phase $(\sigma=30$ $\mathrm{MPa}$ ) is more smeared and the crack widths are more reduced as the corrected hardening ratio $\left(\gamma_{c}\right)$ increases. The same tendency can be observed at collapse level. It seems that, when UHPFRC exhibits SH behaviour (CP1 and $\mathrm{CP} 2)$, the microcrack stabilisation phase is more extended and distributed as a mapped fine pattern. Then, at collapse level, the wider cracks are concentrated in an area near the mid-span section. It seems that there is not a clear macrocrack but a concentrated area where cracks are more developed. On the other hand, when UHPFRC exhibits SS behaviour (CP3 and CP4), the cracks at the microcrack stabilisation phase are more concentrated than in case of SH. In this phase, for SS, it seems that cracking pattern is smeared but it can be differentiated clear zones where cracks are more concentrated. Then, when the specimen reaches the collapse moment, a clear macrocrack is developed from a previous zone developed in the microcrack stabilisation phase. Therefore, there is a great difference in the cracking pattern depending on the hardening ratio of UHPFRC considered. As the hardening ratio increases going from SS to SH behaviour, the cracking pattern goes from a more concentrated to a more smeared crack distribution. This is a very important effect that is described clearly using the NLFEM and generates an important difference between UHPFRC that exhibits SS and that with SH. 


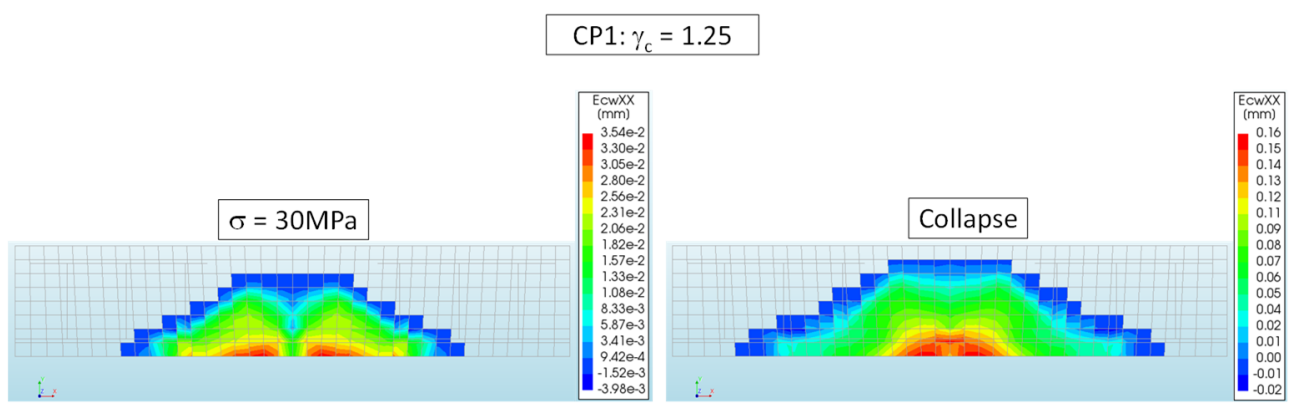

Figure 6.39 Crack pattern for CP1 constitutive parameters with $\gamma_{c}=1.25$

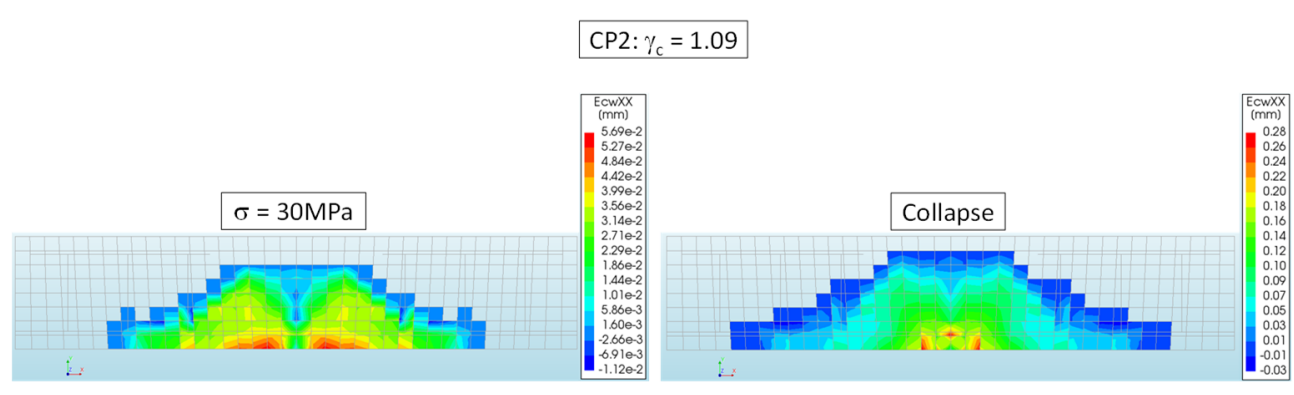

Figure 6.40 Crack pattern for CP2 constitutive parameters with $\gamma_{c}=1.09$

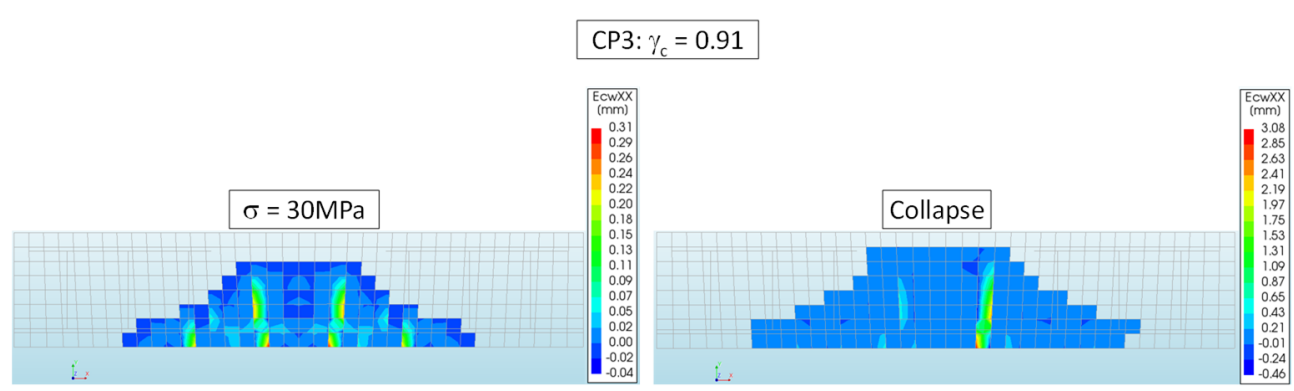

Figure 6.41 Crack pattern for CP3 constitutive parameters with $\gamma_{c}=0.91$ 


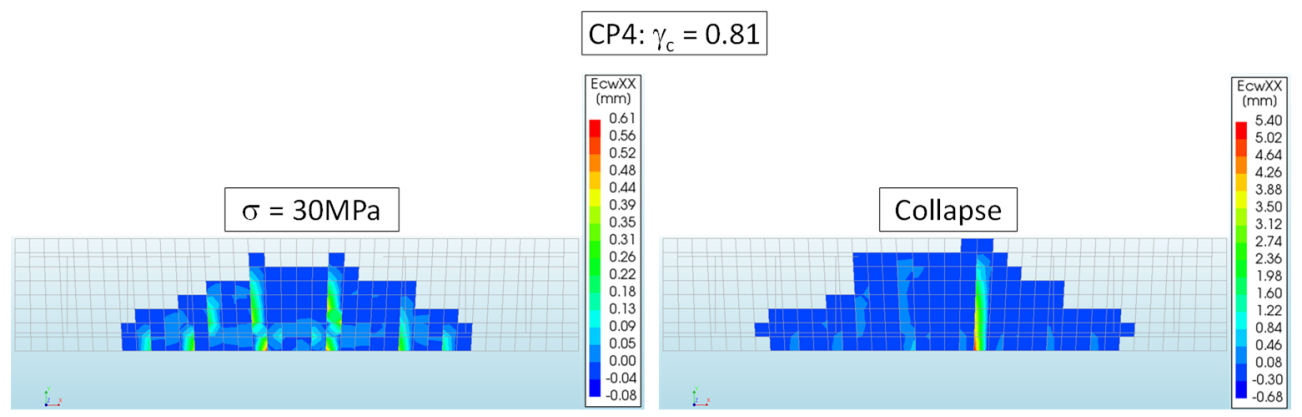

Figure 6.42 Crack pattern for CP4 constitutive parameters with $\gamma_{c}=0.81$

\subsubsection{Long beams}

Table 6.4 contains the average tensile parameters for the $500 \times 100 \times 100 \mathrm{~mm}$ unreinforced specimens cast together with the beams for the UHPFRC mechanical characterisation. Specimens are tested in a 4PBT and the $\sigma-\delta$ average curves are obtained for the specimens cast with JE-1 $(\phi 20 \mathrm{~mm})$ and JE-2 $(\phi 16 \mathrm{~mm})$, respectively. These $\sigma-\delta$ curves are located near the 95\% percentile curve in Figure 6.17(b). Therefore, a good tensile response of these UHPFRC batches can be expected. Then the 4P-IA analysis and softening correction are applied to obtain the average tensile constitutive behaviour for each beam. In Table 6.4, the average compressive strength from the $100-\mathrm{mm}$ cubic specimens is reported. The obtained UHPFRC mechanical parameters are implemented into the discrete cracking approach of 2D-NLFEM. After running the model for long beams, several results are analysed.

Table 6.4 Mechanical UHPFRC properties for long beams

\begin{tabular}{|c|c|c|c|c|c|c|}
\hline \multicolumn{7}{|c|}{$160 \mathrm{~kg} / \mathrm{m}^{3}$ of steel fibres } \\
\hline Beam & $f_{t}(\mathrm{MPa})$ & $f_{\text {tuc }}(\mathrm{MPa})$ & $\varepsilon_{t u}(\%)$ & $E(\mathrm{MPa})$ & $w_{o}(\mathrm{~mm})$ & $f_{c}(\mathrm{MPa})$ \\
\hline $\mathrm{JE}-1(\phi 20 \mathrm{~mm})$ & 9.43 & 10.44 & 6.25 & 54500 & 3.13 & 165.77 \\
\hline $\mathrm{JE}-2(\phi 16 \mathrm{~mm})$ & 8.95 & 8.48 & 3.74 & 50000 & 3.14 & 172.08 \\
\hline
\end{tabular}

Figure 6.43 shows the equivalent bending stress $(\sigma)$-displacement at the mid-span $(\delta)$ curves for the experimental test, obtained after applying Expression (6.4) to the experimental load (P)-displacement at the mid-span curves (Figure 6.11(left)), compared to the response of the different model characteristics: when the model is applied without taking shrinkage into account ("model no sh"), the model taking into account the shrinkage calculated as EN 1992-1-1 Eurocode 2 (The European Union Per Regulation 
305/2011 and Directive 98/34/EC 2004) ("model 0\%sh-inc") and the model with a 90\% incremented shrinkage value ("model 90\%sh-inc") in JE-1 and 120\% ("model 120\%shinc") in JE-2.

As observed in Figure 6.43, the model very well fits the experimental curve when a $90 \%$ shrinkage increment is applied at 49 days for JE- 1 and one of $120 \%$ for JE-2. Table 6.5 shows these values for the tested two beams. The total shrinkage strain of UHPFRC $\left(\varepsilon_{C S U H P F R C}\right)$ is calculated by Expression (6.5). Therefore, the UHPFRC shrinkage strain $\left(\varepsilon_{C S U H P F R C}\right)$ calculated for these two beams falls within the range of $[0.70,0.81] \mathrm{mm} / \mathrm{m}$.
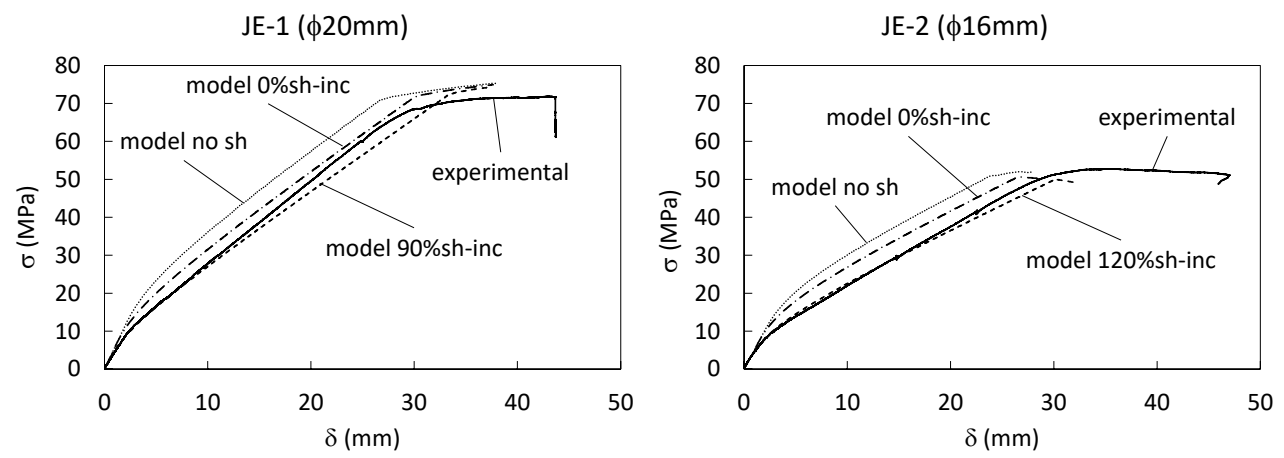

Figure $6.43 \sigma$ - $\delta$ curves for JE-1 (left) and JE-2 (right)

Table 6.5 Shrinkage values at 49 days for long beams

\begin{tabular}{|c|c|c|c|c|}
\hline \multicolumn{5}{|c|}{$160 \mathrm{~kg} / \mathrm{m}^{3}$ of steel fibres } \\
\hline Beam & $\begin{array}{c}\text { Testing } \\
\text { day }\end{array}$ & $\begin{array}{c}\varepsilon_{c s} \\
(\mathrm{~mm} / \mathrm{m})\end{array}$ & $\operatorname{sh}_{\text {inc }}(\%)$ & $\begin{array}{c}\varepsilon_{c s U H P F R C} \\
(\mathrm{~mm} / \mathrm{m})\end{array}$ \\
\hline $\mathrm{JE}-1(\phi 20 \mathrm{~mm})$ & 49 & 0.37 & 90 & 0.70 \\
\hline $\mathrm{JE}-2(\phi 16 \mathrm{~mm})$ & 49 & 0.37 & 120 & 0.81 \\
\hline
\end{tabular}

If shrinkage range obtained for short beams in Table 6.2 and the long beams' range in Table 6.5 are considered, the shrinkage strain of UHPFRC ( $\left.\varepsilon_{C S U H P F R C}\right)$ with $130 \mathrm{~kg} / \mathrm{m}^{3}$ and $160 \mathrm{~kg} / \mathrm{m}^{3}$ of steel fibres herein used to cast the reinforced specimens would fall within the range of $[0.70,0.84] \mathrm{mm} / \mathrm{m}$. This is consistent with the range of $[0.60,0.90]$ $\mathrm{mm} / \mathrm{m}$ for UHPC with a non heat treatment and a water/cement ratio of $\leq 0.25$ that other researchers considered in (Fang et al. 2020; Fehling et al. 2014; Xie et al. 2018; Yoo et al. 2015a). 
Figure 6.44 and Figure 6.45 show the stresses at UHPFRC and at the reinforcement due to the shrinkage effect at 49 days (just before the test starts) for the JE1 and JE2 beams respectively.

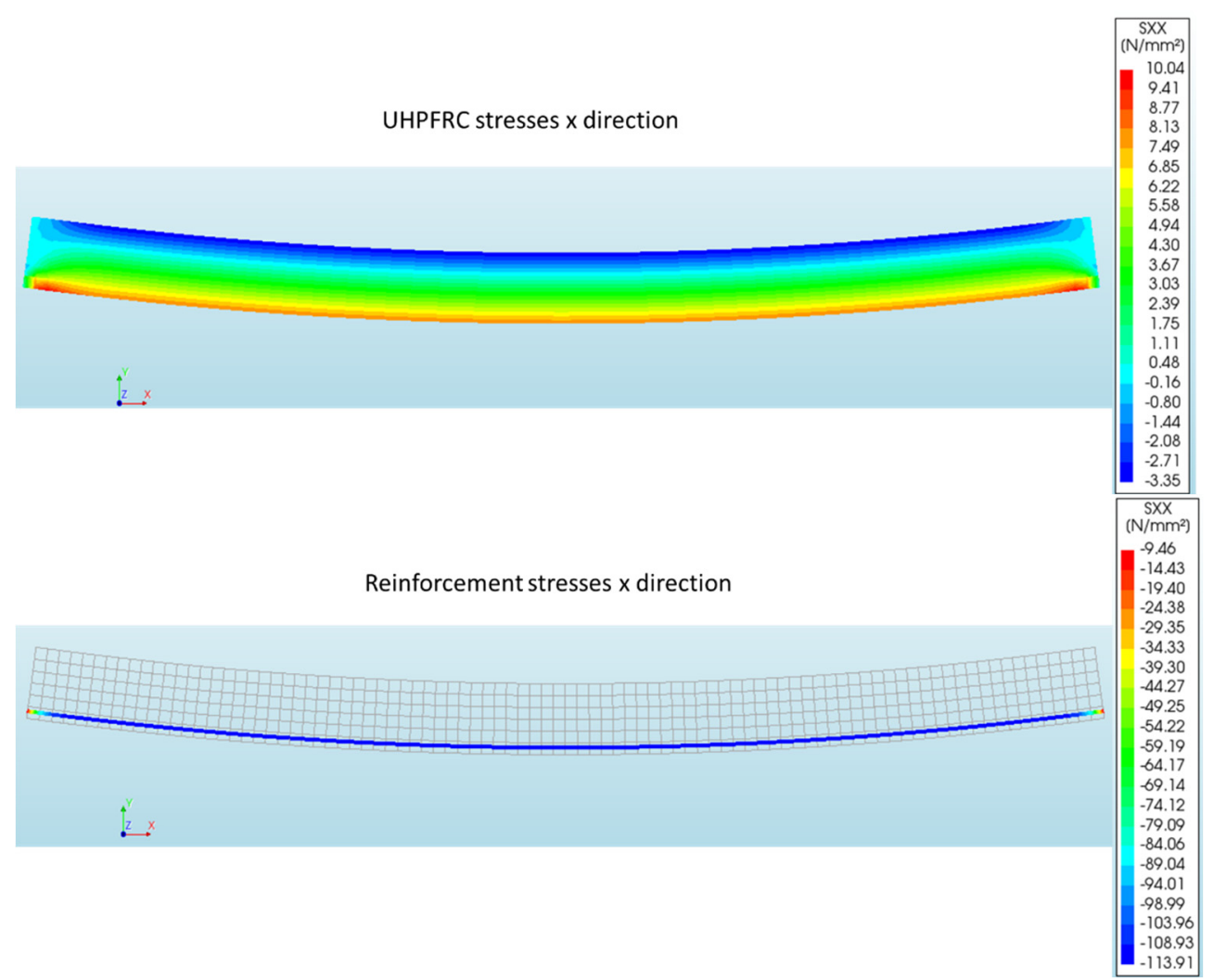

Figure 6.44 Shrinkage stresses for JE-1 at UHPFRC (top) and reinforcement (bottom) at 49 days. 


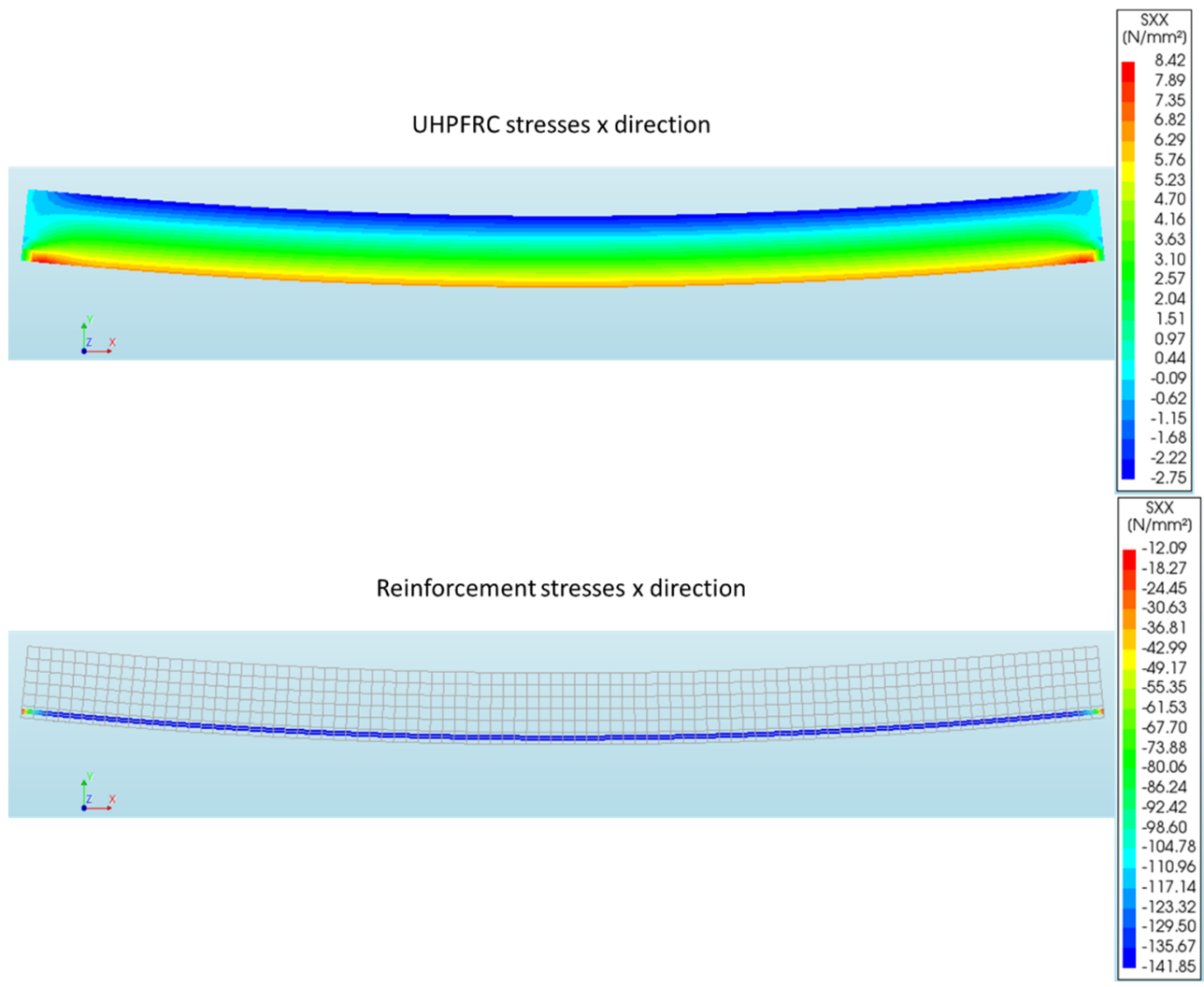

Figure 6.45 Shrinkage stresses for JE-2 at UHPFRC (top) and reinforcement (bottom) at 49 days.

For more detail, Figure 6.46 offers the stress profile at the mid-span section of the two beams due to UHPFRC shrinkage $\left(\varepsilon_{C S U H P F R C}\right)$ at 49 days from them being cast before starting the experimental test. As we can see, the generated stress is very important given the influence of the reinforcement bars embedded in the UHPFRC matrix. So it can be deduced that the UHPFRC in the vicinity of reinforcement is highly stressed in tension, and even comes close to the $f_{t}$ value before the test started. This means that the concrete there is "negatively" pre-stressed near cracking and, consequently, its bearing capacity reduced. The effect on reinforcement is the opposite. The longitudinal bars are compressed and, as a result, they display pre-compression before the test that leads to a higher bearing capacity for the bending test. When comparing both graphs, we can observe that the JE-1 beam achieves more stress in both compression $(\mathrm{h}=300 \mathrm{~mm})$ and tension $(\mathrm{h}=0 \mathrm{~mm})$ than the JE-2 beam. Furthermore, reinforcement is less compressed in JE-1 than in JE-2. These results are absolutely logical if the different amounts of reinforcement between JE-1 $(2 \phi 20 \mathrm{~mm})$ and JE-2 $(2 \phi 16 \mathrm{~mm})$ are considered. Therefore, 
after analysing these results, we can conclude that the shrinkage effect is very strong on UHPFRC and, consequently, its influence on the beam's structural response is not at all negligible.
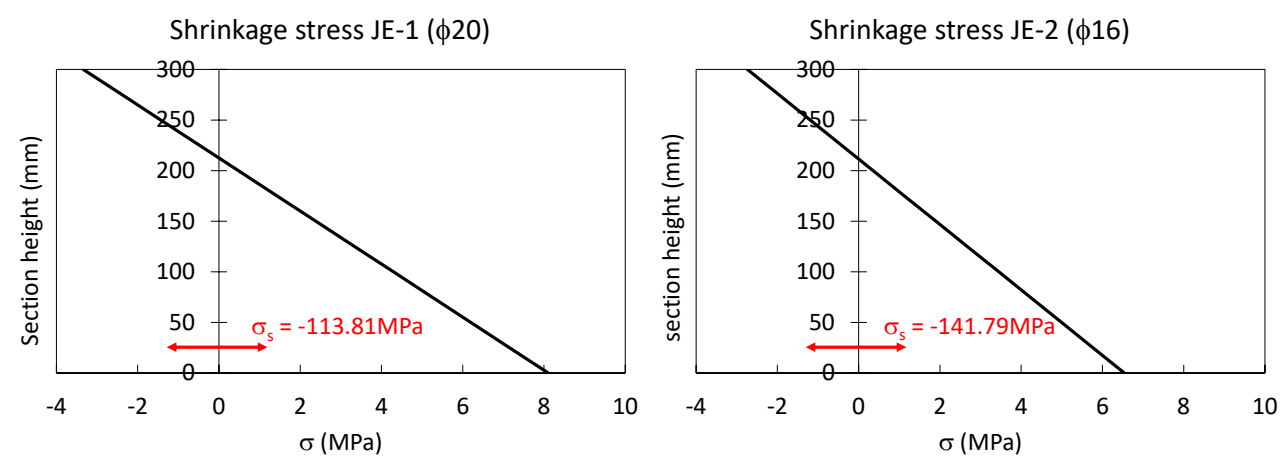

Figure 6.46 Shrinkage stresses at the mid-span section for JE-1 (left) and JE-2 (right) at 49 days.

\subsection{Cracking Pattern and stresses in the reinforcement}

Figure 6.47 and Figure 6.48 show that, when using NLFEM, the cracking process of the UHPFRC beams is described like in the experimental programme. These figures represent the crack opening and stress in reinforcement at two stress levels in the central part of the JE-1 and JE-2 beam (see Figure 6.43): in the microcrack stabilisation phase $(\sigma=30 \mathrm{MPa}$ for JE-1 and $\sigma=20 \mathrm{MPa}$ for JE-2) and upon collapse. These figures very well describe the appearance of microcracking and how this stress is transmitted to reinforcement, while concrete loses its resistance capacity. Upon collapse, the cracking process concentrates on one macrocrack and, consequently, the tensile stress of reinforcement increases at this point until its plasticity level is reached. As it happens with the short beams, the cracking pattern is different depending on the hardening ratio $(\gamma)$ of the UHPFRC constitutive behaviour developed. For the case of the long beams, in Table 6.4 the average constitutive parameters are obtained from the application of the $4 \mathrm{P}-\mathrm{IA}$ and the softening correction to the average $\sigma-\delta$ experimental curves from the unreinforced specimens cast to characterise the UHPFRC used for the casting of the long breams. For the case of JE-1, the corrected hardening ratio is $\gamma_{\mathrm{c}}=1.11$, so the UHPFRC used exhibits SH. For the case of JE-2, the corrected hardening ratio is $\gamma_{\mathrm{c}}=0.95$, so the UHPFRC in this case exhibits SS. As is observed in Figure 6.47 for the case of JE-1, the cracking pattern is smeared with a mapped cracking in the microcrack stabilisation phase and it progress to a more concentrated area with higher crack width as the macrocrack appears. For the case of JE-2 (see Figure 6.48), the cracking pattern is smeared too in the microcrack stabilisation phase, but a bit different from JE-1. For JE-2, as its UHPFRC exhibits SS, the microcrack stabilisation phase has cracks concentrated in clear zones 
and the macrocrack is developed from one of these zones. The effect is very similar as it happens with the cracking pattern of the short beams Therefore, the cracking process simulated by NLFEM is coherent, very reliable and very well represents reality in both cases: at the service and ultimate load levels.

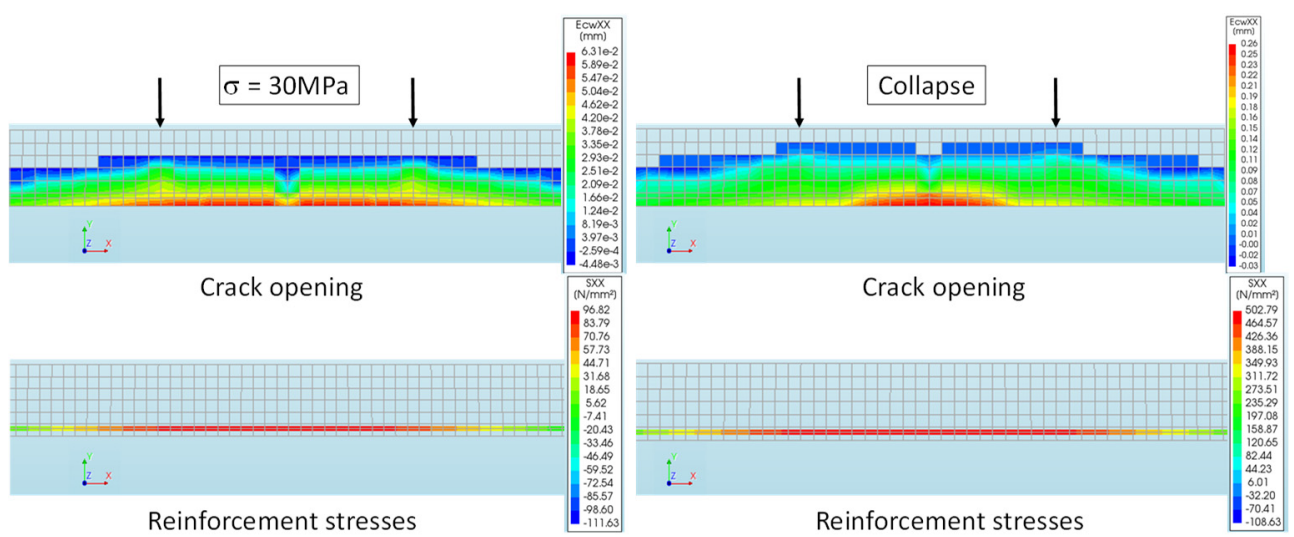

Figure 6.47 Crack opening and reinforcement stresses at $30 \mathrm{MPa}$ and at collapse for the JE-1 beam

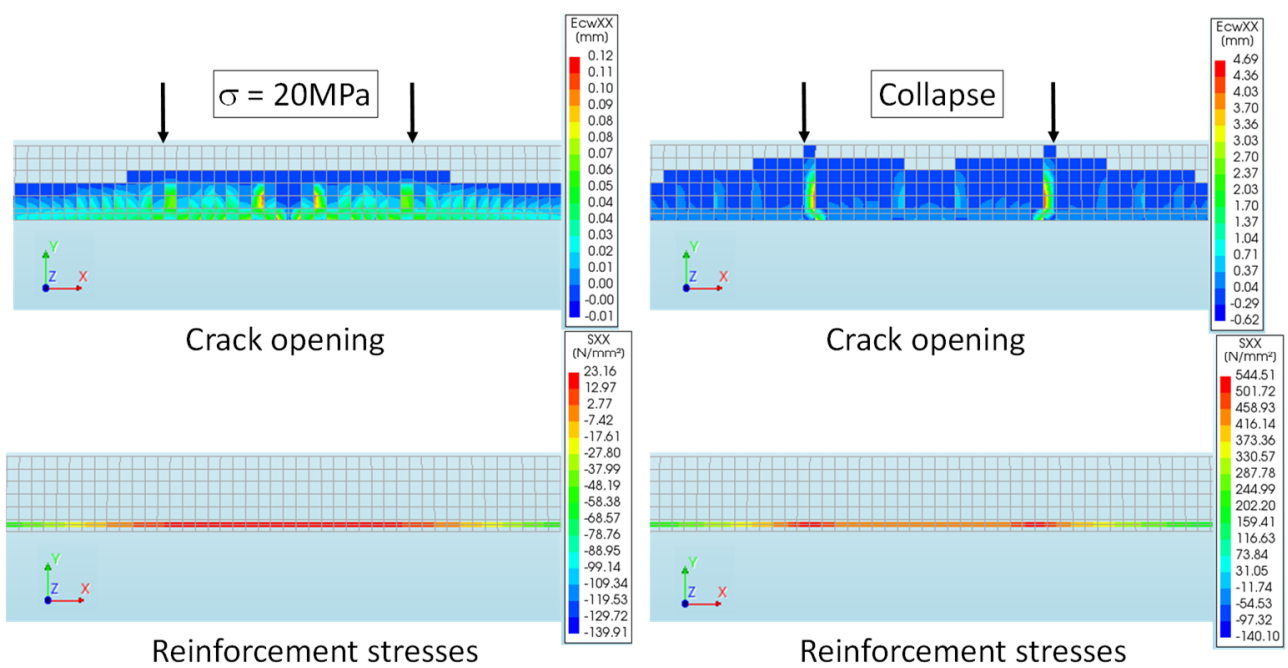

Figure 6.48 Crack opening and reinforcement stresses at 20 MPa and at collapse for the JE-2 beam 


\subsection{Results from the horizontal displacements at mid-span section}

Figure 6.49 represents the comparison between the moment $(\mathrm{M})$-curvature $(\phi)$ curves obtained from the experimental (see Figure 6.11(right)) and numerical horizontal displacement transducers at the mid-span section for the two beams. The moment at the mid-span section is obtained considering Expression (6.2). The curvature is obtained as the inverse of the inclination of the strain plane defined by de horizontal displacement transducers at the mid-span section, by means of Expression (6.3). To compare the results from the model, the displacements of the nodes of the finite elements situated at the same position as the experimental displacement transducers have been registered for each load step of the non-linear analysis. It can be observed in Figure 6.49 that the model fits with a good accuracy the experimental response. The response of the model can be considered a bit conservative.
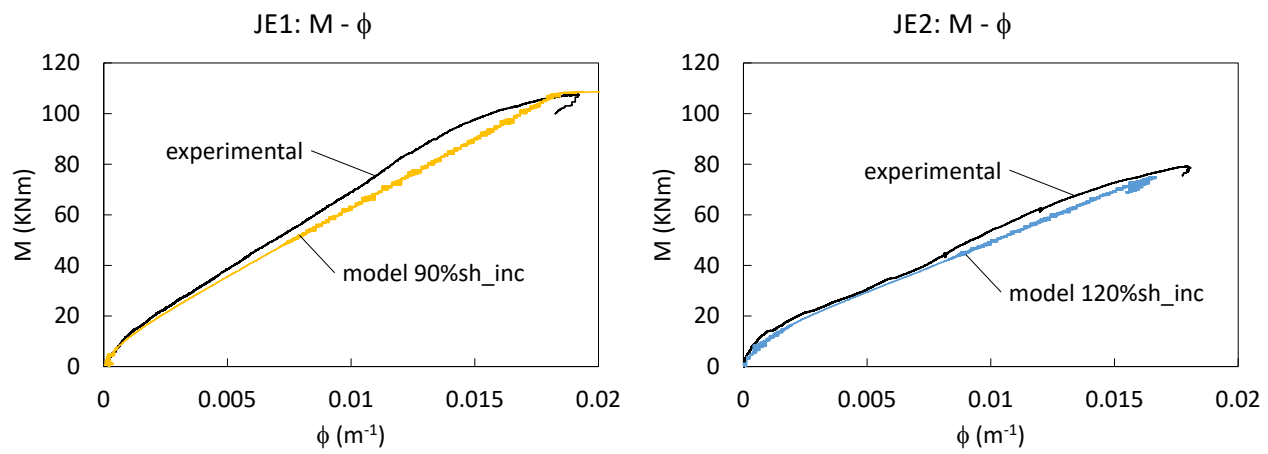

Figure 6.49 Moment-curvature diagram for JE1 and JE2

In addition, Figure 6.50 and Figure 6.51 show the equivalent bending stress $(\sigma)$ - average strain at the mid-span section at the horizontal compression displacement transducer's height $\left(\varepsilon_{\text {comp }}\right)$ and at the tension displacement transducer's height $\left(\varepsilon_{\text {tens }}\right)$, when the experimental curves from Figure 6.13 are compared to the average strain at the mid-span section obtained from the 2D-NLFEM for both beams: JE1 and JE2. The equivalent bending stress is obtained following Expression (6.4) and the average strains for compression and tension are obtained dividing the respective horizontal displacements in Figure 6.12 by the gage length $\left(l_{g}\right)$ of both beams. As it is said before, to compare the results from the model, the displacements of the nodes of the finite elements situated at the same position as the experimental displacement transducers have been registered for each load step of the non-linear analysis. As it can be observed, the NLFEM response represents with a certain level of accuracy the average strains at both levels: at the top (compression) and at the bottom (tension), when it is compared to the experimental response of both beams: JE-1 and JE-2. As it happens with the curvatures, for the case of the average strains, the response of the model can be considered a bit conservative. 

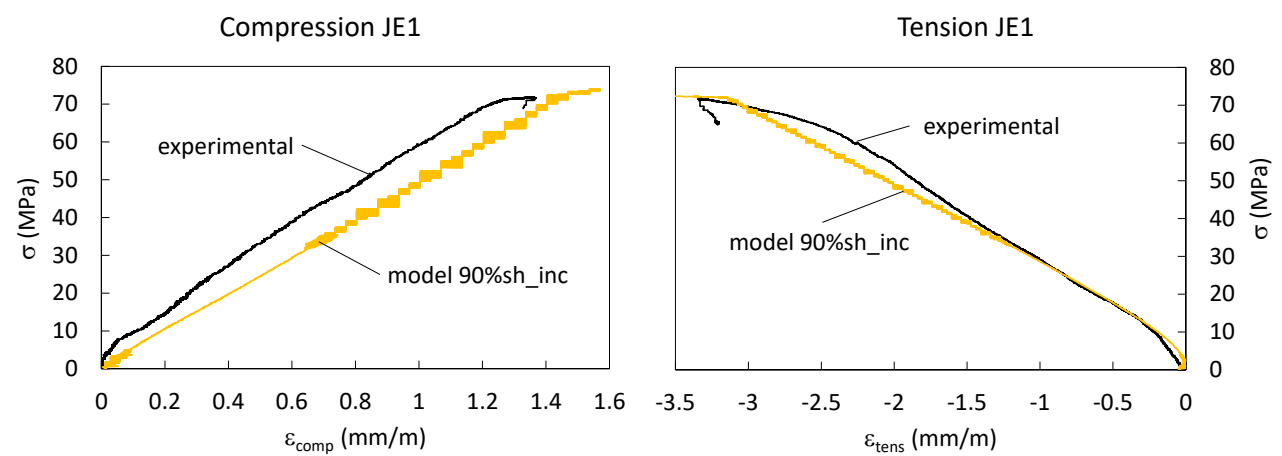

Figure $6.50 \sigma-\varepsilon$ at mid span section at the top (left) and at the bottom (right) of JE-1
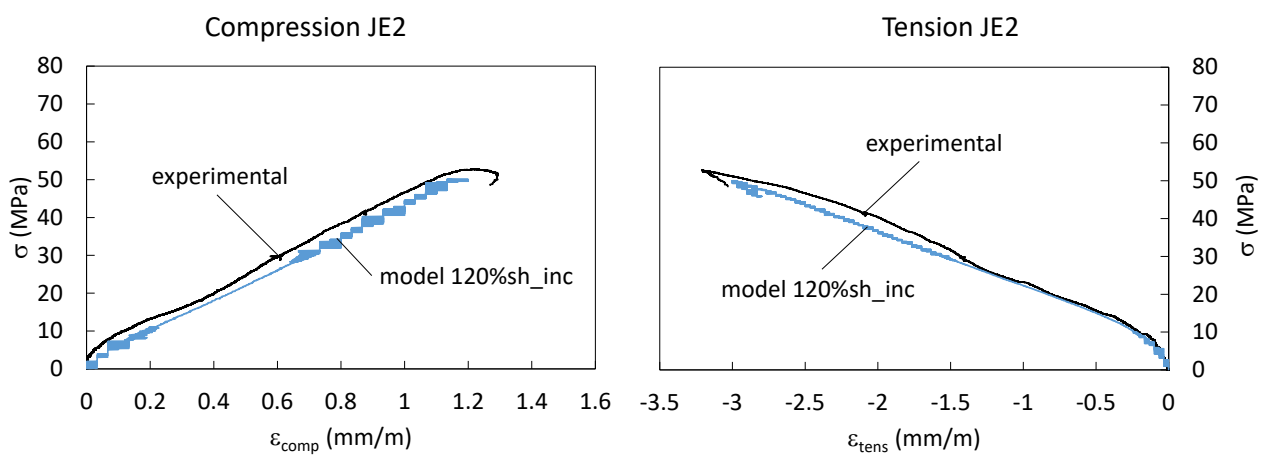

Figure $6.51 \sigma$-Eat mid span section at the top (left) and at the bottom (right) of JE-2

\subsubsection{Design considerations for UHPFRC}

Some design aspects of the bending section under serviceability and ultimate conditions are considered. This is done to know if the traditional design under bending and normal forces would be accurate enough for the reinforced UHPFRC cross-sections, and also intended to evaluate how fibres actually contributed to flexure strength.

\subsubsection{Serviceability level}

In cracking behaviour terms, it is worth mentioning that no clear formation of macrocracks up to the failure conditions is observed on either short beams or long ones. Under service conditions, the following three stages are observed instead for both beam 
types: (1) uncracked; (2) microcrack formation; (3) stabilised microcracking (see Figure 6.25 and Figure 6.43).

In load-deflection response terms, flexural stiffness remains relatively constant in the stabilised microcracking stage. The experimental flexural stiffness $\left(\mathrm{EI}_{\mathrm{exp}}\right)$ is determined in all the tested beams and the obtained values are shown in Table 6.6. Moreover, the flexural stiffness $\left(\mathrm{EI}_{\mathrm{cr}}\right)$ calculated when considering the contribution of only the uncracked concrete part and the longitudinal reinforcement is also obtained. This simplified way to calculate flexural stiffness follows the traditional approach, which considers the cracked section, as several codes suggest to estimate RC member deflections, as in EN 1992-1-1:2004 (The European Union Per Regulation 305/2011 and Directive 98/34/EC 2004).

Table 6.6 Cross-section flexural stiffness under serviceability conditions

\begin{tabular}{|c|c|c|c|}
\hline Beam & $\begin{array}{c}\mathrm{EI}_{\text {exp }} \\
{\left[\mathrm{kN} \cdot \mathrm{m}^{2}\right]}\end{array}$ & $\begin{array}{c}\mathrm{EI}_{c r} \\
{\left[\mathrm{kN} \cdot \mathrm{m}^{2}\right]}\end{array}$ & $\begin{array}{c}\mathrm{EI}_{\text {exp }} / \\
\mathrm{EI}_{c r}\end{array}$ \\
\hline Short $130 \mathrm{~kg} / \mathrm{m}^{3}$ & 182.8 & 228.9 & 0.799 \\
\hline Short $160 \mathrm{~kg} / \mathrm{m}^{3}$ & 208.3 & 228.7 & 0.911 \\
\hline JE-1 $(\phi 20 \mathrm{~mm})$ & 5349.6 & 5395.4 & 0.992 \\
\hline JE-2 $(\phi 16 \mathrm{~mm})$ & 3843.0 & 3817.5 & 1.007 \\
\hline
\end{tabular}

It can be outlined that the flexural stiffness of long beams under serviceability conditions come very close to the fully cracked cross-section stiffness. However in short beams, the calculated stiffness is lower than the experimental one. In any case, the poorest reinforced beam (the short beam with $130 \mathrm{~kg} / \mathrm{m}^{3}$ ) reaches nearly $80 \%$ of total flexural stiffness.

According to Bischoff (Bischoff 2008), a tension-stiffening factor $\beta$ can be obtained to define the element's member response. Setting $\beta$ equal to 1 gives a bilinear response with constant tension stiffening that represents an upper bound on member stiffness, as shown in Figure 6.52 for the long beams, while a $\beta$ value of 0 gives a lower bound with no tension stiffening that essentially gives the $\mathrm{I}_{\mathrm{cr}}$ response. Both long beams show a nearly full-tension stiffening response since an experimental $\beta$ value close to 1 is obtained under serviceability conditions (Figure 6.52). Therefore, the control of deflections in those beams exhibiting full-tension stiffening may be carried out in the whole service stage (stabilised microcracking) by assuming an effective moment of inertia $\mathrm{I}_{\mathrm{e}}$ given by Bischoff's proposed expression (Bischoff 2008) and considering ( $\beta=1$ ): 


$$
I_{e}=\frac{I_{c r}}{1-\eta \cdot \beta \cdot\left(M_{c r} / M_{a}\right)} \leq I_{g} \text { where } \eta=1-I_{c r} / I_{g}
$$
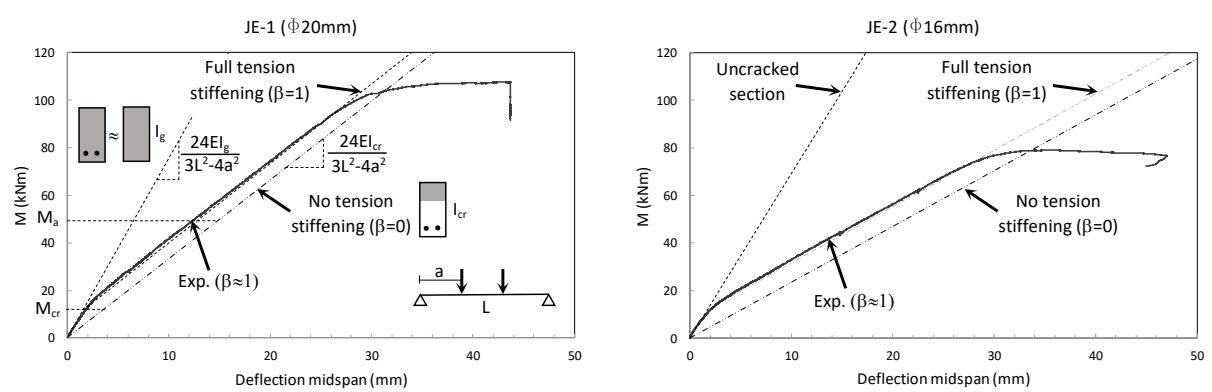

Figure 6.52 Deflection comparison of long beams with tension-stiffening factors $\beta$

\subsubsection{Ultimate level}

The constitutive equation to be used in the axial and bending analysis at ultimate limit state requires converting the stress-crack branch of the tensile properties obtained in Table 6.4 into a continuous stress-strain diagram. To do so, a characteristic length that equalled $2 \mathrm{~h} / 3=200 \mathrm{~mm}$ is assumed according to NF P18-470 (Association Francaise de Normalisation 2016a), along with a coefficient of orientation $\mathrm{K}=1.25$ to module the tensile properties of UHPFRC (Association Francaise de Normalisation 2016a). Finally, the concrete compressive strength is assumed as that obtained in a cylinder $\left(\mathrm{f}_{\mathrm{c}, \mathrm{cyl}}\right)$, which can be related to cubic strength with a difference of $-15 \mathrm{MPa}$ (Association Francaise de Normalisation 2016a). By way of example, Figure 6.53(a) presents the constitutive equation assumed in the design analysis under bending for the JE-2 beam. The crosssection's possible plain strain distributions in the ultimate limit states are limited by a peak strain in the most compressed fibre that equals $\mathrm{f}_{\mathrm{c}, \mathrm{cyl}} / \mathrm{E}$, or a maximum tensile strain in the longitudinal reinforcement of $10 \%$. So by applying the axial equilibrium equation, the location of the neutral axis $\left(\mathrm{x}_{0}\right)$ is obtained, and the momentum equilibrium equation allows an evaluation of the maximum bending moment $\left(\mathrm{M}_{\mathrm{u}, \mathrm{cal}}\right)$ that the reinforced UHPFRC cross-section can resist (Figure 6.53(b)). In the presented calculations, no safety coefficients are taken into account to be compared to the maximum bending moment achieved in the test $\left(\mathrm{M}_{\mathrm{u}, \mathrm{exp}}\right)$. 


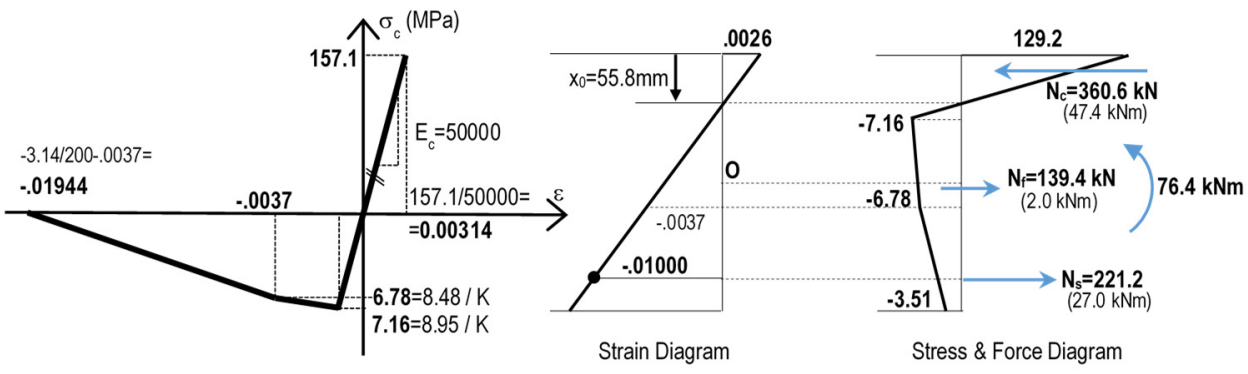

Figure 6.53 Flexure strength estimation of the JE-2 beam: (a) constitutive law assumed, (b) strain diagram, and (c) stress and force diagram

The calculations for both long beams (JE-1 and JE-2), and the comparison to the obtained experimental results, are summarised in Table 6.7. It is worth mentioning that predictions are relatively accurate, but very much depend on not only the axial tensile force that fibres in tension can carry, but also on the tensile force on the longitudinal bars, which reach their yielding stress on both beams. Fibres carry a tension of $34.1 \%$ in JE-1 and one of $38.7 \%$ in JE-2 of the total tensile force required in the section equilibrium. Therefore, fibres play a significant role in the beam's flexure strength despite them not collaborating directly with the resisted bending moment. For instance, only $2.0 \mathrm{kN} \cdot \mathrm{m}$ is resisted by the fibres in the JE-2 beam (Figure 6.53(c)). It should be noted that predictions are based on the tensile properties affected by a K coefficient of 1.25 , which would result in a lower flexure strength estimation. In the studied cases, $\mathrm{K}=1.25$ can be considered a reasonable orientation factor given the obtained $\mathrm{M}_{\mathrm{u}, \exp } / \mathrm{M}_{\mathrm{u}, \text { cal }}$ ratios.

Table 6.7 Comparison between the predicted and experimental values at failure

\begin{tabular}{|c|c|c|c|c|c|c|c|}
\hline Beam & $\begin{array}{c}\mathrm{M}_{u, \exp } \\
{[\mathrm{kN} \cdot \mathrm{m}]}\end{array}$ & $\begin{array}{c}\mathrm{M}_{u, \text { cal }} \\
{[\mathrm{kN} \cdot \mathrm{m}]}\end{array}$ & $\begin{array}{c}\mathrm{M}_{u, \exp } / \\
\mathrm{M}_{u, \text { cal }}\end{array}$ & $\begin{array}{c}\mathrm{x}_{0} \\
{[\mathrm{~mm}]}\end{array}$ & $\begin{array}{c}\mathrm{N}_{\mathrm{c}} \\
{[\mathrm{kN}]}\end{array}$ & $\begin{array}{c}\mathrm{N}_{\mathrm{f}} \\
{[\mathrm{kN}]}\end{array}$ & $\begin{array}{c}\mathrm{N}_{\mathrm{s}} \\
{[\mathrm{kN}]}\end{array}$ \\
\hline JE-1 $(\phi 20 \mathrm{~mm})$ & 107.4 & 114.2 & 0.94 & 69.6 & 524.5 & 178.9 & 345.6 \\
\hline JE-2 $(\phi 16 \mathrm{~mm})$ & 79.1 & 76.4 & 1.04 & 55.8 & 360.6 & 139.4 & 221.2 \\
\hline
\end{tabular}




\subsection{Tensile bars}

The aim of this section is to model the influence of the reinforcement bars in UHPFRC elements working in direct tension, considering mechanisms like the shrinkage and tension stiffening. Therefore, the results of an experimental programme composed of UHPFRC reinforced ties tested in direct tensile test and the specimens to characterise the material properties are adopted from research developed concurrently by other researchers in the group to compare to the results obtained from the NLFEM herein developed for the tensile bars. Consequently, the results from the model's application are presented and discussed.

\subsubsection{Experimental programme}

An experimental programme of UHPFRC reinforced tensile bars was developed in (Khorami et al. 2019, 2020; Navarro Laguarda 2018). In order to progress with the evolution of the NLFEM and the validation of the characterisation of the tensile behaviour of UHPFRC, the experimental results of the tested tensile bars and the unreinforced 4PBT to characterise the tensile behaviour of UHPFRC cast with $160 \mathrm{~kg} / \mathrm{m}^{3}$ of steel fibres have been adopted. They are compared to the simulated response of the NLFEM developed from the one in section 6.2.2. All reinforced concrete tensile bars and 4 PBT specimens are tested at 30 days after casting.

\subsubsection{Reinforced tensile bars}

In Figure 6.54 and Figure 6.55 the geometry and setup of the direct tensile test carried out in (Khorami et al. 2019, 2020; Navarro Laguarda 2018) are depicted. The idea is to consider in the NLFEM the same geometry, load and boundary conditions carried out experimentally. The tensile UHPFRC bar is $1 \mathrm{~m}$ length and it has a squared section of $60 \times 60,80 \times 80$ and 100x $100 \mathrm{~mm}$. It has a reinforcement disposition that can be described in three parts: the beginning and the last $250 \mathrm{~mm}$ composed by three reinforcement bars vertically aligned and the central $500 \mathrm{~mm}$ where the central reinforcement bar is continued. The diameters of the reinforcement bars considered are $\phi 10, \phi 12$ and $\phi 16 \mathrm{~mm}$ (see Figure 6.54).

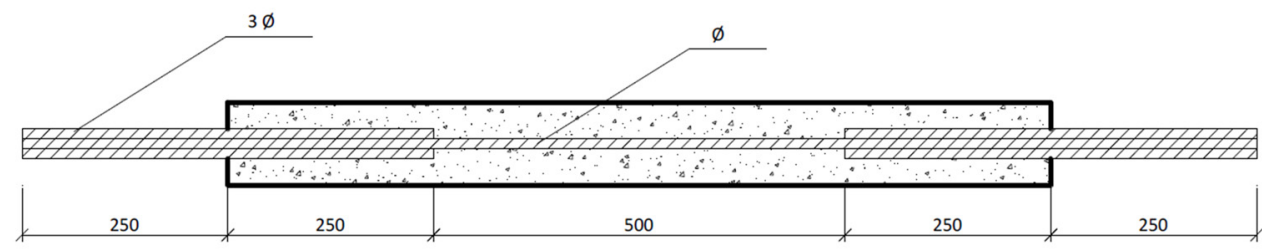

Figure 6.54 Geometry of the tensile bar specimen (Navarro Laguarda 2018) 
The tensile bar is set in a frame that takes it from the reinforcement in both sides. One side is fixed, that constitutes the reactive side. The other side, considered the active part, is connected to a hydraulic jack that will apply the tensile force to the reinforcement (see Figure 6.55). The tensile stress in the rebar is transmitted to the UHPFRC by bond mechanism. Figure 6.56 shows the position of the displacement transducers. The same scheme is repeated at the four faces of the bar in order to compensate undesired local rotations in the element.

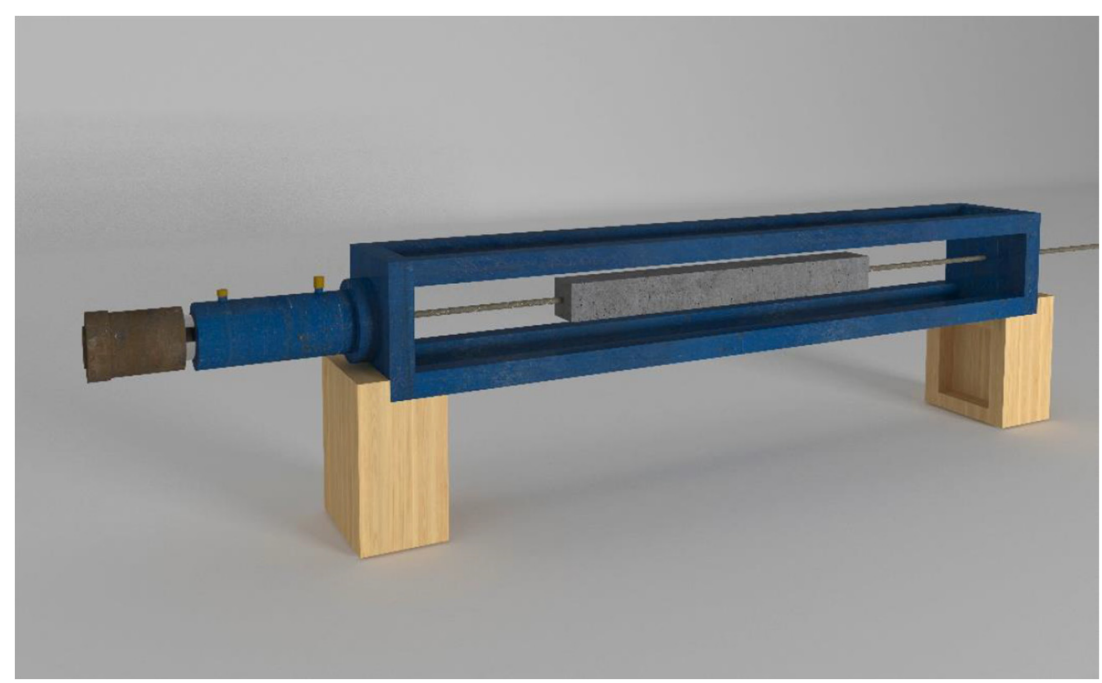

Figure 6.55 Tensile bar test setup (Navarro Laguarda 2018)

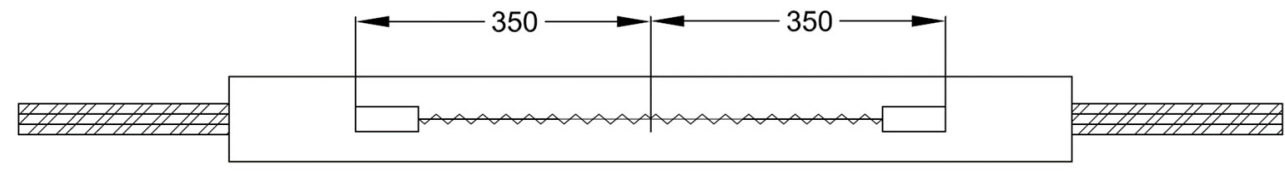

Figure 6.56 Displacement transducers distribution at each of the four faces of the bar (units in $\mathrm{mm}$ )

In Table 6.8, the geometric characteristics and the number of tensile test specimens adopted from the experimental programme of (Khorami et al. 2019, 2020) cast with UHPFRC with $160 \mathrm{~kg} / \mathrm{m}^{3}$ of steel fibres to be modelled using the NLFEM developed in this chapter are summarised. 
Table 6.8 Tensile test specimens from experimental programme from (Khorami et al. 2019, 2020)

\begin{tabular}{|c|c|c|}
\hline UHPFRC section $(\mathrm{mm})$ & Rebars $\phi(\mathrm{mm})$ & Num. of specimens \\
\hline \multirow{2}{*}{$60 \times 60$} & 10 & 5 \\
\cline { 2 - 3 } & 12 & 3 \\
\hline \multirow{3}{*}{$80 \times 80$} & 10 & 3 \\
\cline { 2 - 3 } & 12 & 3 \\
\cline { 2 - 3 } & 16 & 3 \\
\hline \multirow{3}{*}{$100 \times 100$} & 10 & 1 \\
\cline { 2 - 3 } & 12 & 3 \\
\cline { 2 - 3 } & 16 & 3 \\
\hline
\end{tabular}

\subsubsection{Material characterisation}

In order to characterise the mechanical behaviour of the UHPFRC of $160 \mathrm{~kg} / \mathrm{m}^{3}$ used in the tensile bar's batches, a set of $100 \mathrm{~mm}$ cubic specimens for the compression test and $100 \times 100 \times 500 \mathrm{~mm}$ unreinforced specimens for the 4PBT are cast together with tensile bars (see Figure 6.15). Figure 6.57 depicts the $\sigma-\delta$ experimental curves of the characteristic 5\% and 50\% (average) from the 4PBT of the unreinforced 100x100x500 $\mathrm{mm}$ specimens. 


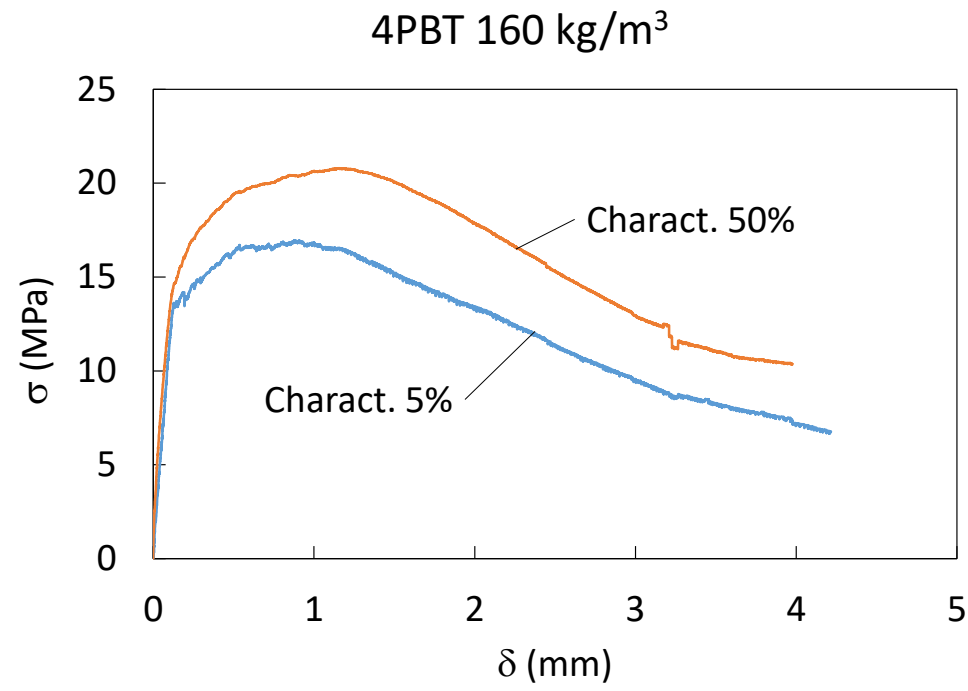

Figure $6.574 P B T$ characteristic 5 and $50 \% \sigma-\delta$ curves

To obtain the UHPFRC tensile constitutive behaviour from the 4PBT experimental $\sigma-\delta$ at mid span curves, the Simplified Four-Point Inverse Analysis method (4P-IA) summarised in chapter 3 of this work and the softening correction for $f_{t u}\left(f_{t u c}\right)$ developed in chapter 5 is used. Table 6.9 shows the characteristic tensile parameters and the compressive strength for the $5 \%$ percentile and for the $50 \%$ (average). As it can be observed, the UHPFRC used for casting the tensile bars exhibits SS.

Table 6.9 Mechanical characterisation for UHPFRC tensile bars

\begin{tabular}{|c|c|c|c|c|c|c|}
\hline \multicolumn{7}{|c|}{$160 \mathrm{~kg} / \mathrm{m}^{3}$ of steel fibres } \\
\hline Charact. $\sigma-\delta$ & $f_{t}(\mathrm{MPa})$ & $f_{\text {tuc }}(\mathrm{MPa})$ & $\varepsilon_{t u}(\%)$ & $E(\mathrm{MPa})$ & $w_{o}(\mathrm{~mm})$ & $f_{c}(\mathrm{MPa})$ \\
\hline $5 \%$ & 8.74 & 7.05 & 1.80 & 51400 & 2.92 & 148.86 \\
\hline $50 \%$ & 9.62 & 8.44 & 3.31 & 50700 & 3.24 & 153.99 \\
\hline
\end{tabular}

For the characterisation of the steel for the reinforcement bars, the same stress-strain constitutive behaviour described for the reinforcement of the flexural beams at section 6.2.1.3 of this chapter has been used. 


\subsubsection{Numerical validation}

The same 2D-NLFEM and 3D-NLFEM defined for the reinforced beams explained in section 6.2.2 has been used to model the tensile bars. In this particular case, the discrete cracking approach of the model is used as it is demonstrated for the unreinforced 4PBT in chapter 4 more reliable than the smeared cracking approach. With the discrete cracking approach, the general behaviour of the specimen obtained from the NLFEM is expected to be more similar to the $\sigma-\varepsilon / w$ UHPFRC material behaviour defined in chapter 3 (the real phase 1). Therefore, for this approach, the constitutive model for UHPFRC is based on the discrete cracking model as the interface behaviour. This behaviour is forced only at the central specimen section. To force it, tensile strength $\left(f_{t}\right)$ and ultimate tensile strength $\left(f_{t u}\right)$ are reduced by $2 \%$. The rest of the specimen is modelled by the smeared cracking approach. The effect of shrinkage in concrete is considered as a material function when the UHPFRC model is defined in NLFEM using the total strain crack model, by means of Expression (6.5). Reinforcement is modelled using Von Mises strain-hardening elasto-plastic behaviour for the steel with a bond-slip behaviour. The results of the UHPFRC characterisation obtained by the 4P-IA with softening correction are implemented into the constitutive behaviour of the described NLFEM.

Figure 6.58 and Figure 6.59 show the mesh used for NLFEM of tensile bars in 2D and 3D. For the 2D model, a $10 \mathrm{~mm}$ element size has been used and for the 3D a $20 \mathrm{~mm}$ element size. 2D quadratic plane stress elements (for the 2D model) and 3D quadratic structural isoparametric solid brick elements (for the 3D model) are used for the continuum part. Besides, for the discrete cracking interface, quadratic 2D line interface elements (for the 2D model) and quadratic plane 3D interface elements (for 3D) are placed at the mid-span section to model macrocrack behaviour (see Figure 6.20 and Figure 6.21). Reinforcement is modelled discretely using truss bond-slip elements.

For the case of the tensile bars, the load is applied punctually to one extreme of the reinforcement bars by gradually increasing the load (load control) to simulate the action of the hydraulic jack. Fixed supports are defined at the other extreme of the reinforced bars to simulate the reactive side. A non-linear analysis is carried out by an incrementaliterative solution procedure.

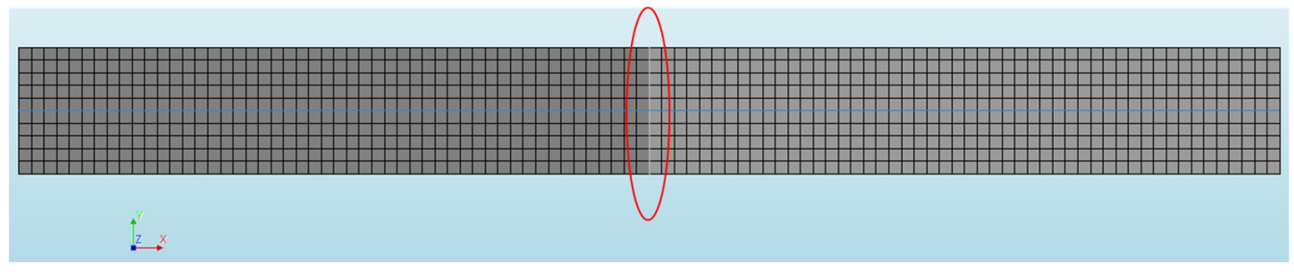

Figure 6.58 Mesh for the discrete 2D-NLFEM of tensile bars 


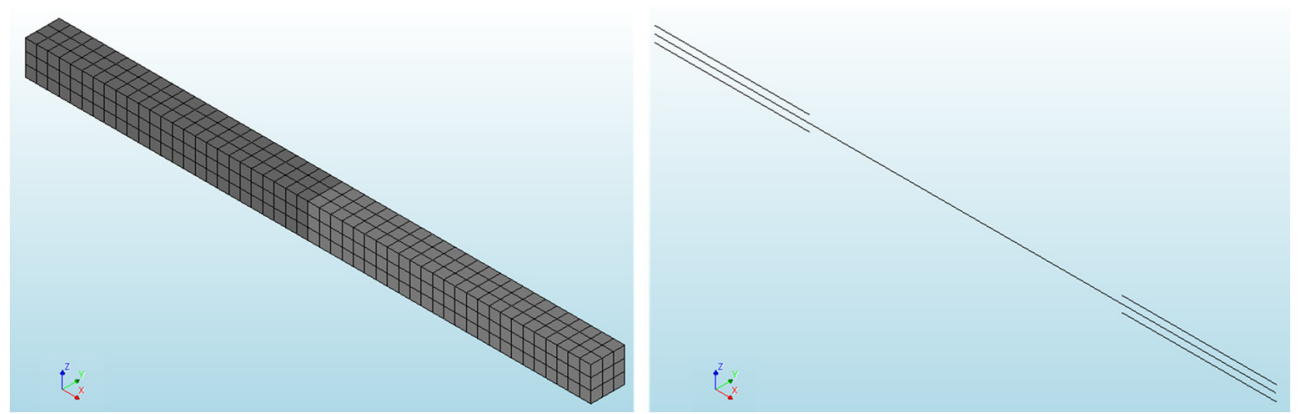

Figure 6.59 Mesh for the discrete 3D-NLFEM of UHPFRC tensile bars.

As in can be observed in Figure 6.60 where the deformed shape of the discrete cracking approach of the 2D-NLFEM is represented at collapse level, there are sometimes where the deformations representing the macrocrack are not only concentrated in the predefined interface discrete crack, but also in the smeared part. To improve this situation, the discrete cracking approach of the 3D model has been developed in a more complex way (3D-NLFEM-multicrack) with the objective of improving, also, the behaviour when the microcracking phase appears and the consequent cracking formation branch.

This improved 3D-NLFEM-multicrack consists on the definition of interface behaviour not only at the mid span section but also between all the 3D solid elements in the same vertical, as it is depicted in Figure 6.61. They are defined by means of quadratic plane 3D interface elements as shown in Figure 6.21(right), with their stress (traction)separation law and the activation criteria of all interface cracks, which is the same as defined for the simple crack interface behaviour: tensile strength $\left(f_{t}\right)$ and ultimate tensile strength $\left(f_{t u}\right)$ are reduced by $2 \%$. With this, each finite element is bounded vertically by an interface element. The solid 3D element is defined by the UHPFRC smeared cracking approach and the boundary interface elements by the stress-crack opening law.

Therefore in the 3D-NLFEM-multicrack, the body of the UHPFRC 3D solid element behaves absorbing the bulk energy that implies all the element volume, related to the $\sigma$ $\varepsilon$ part of the constitutive law of phase 1 (see Figure 3.2). Then, when the macrocrack is going to appear, the interface element in the solid element vertical boundary is activated representing the $\sigma-\mathrm{w}$ softening part of the constitutive law of phase 1. In this sense, a composed finite element defined by a 3D solid element bounded vertically by two interface elements at each side able to represent the real UHPFRC $\sigma-\varepsilon / w$ constitutive law defined in phase 1 (see Figure 3.2) is generated. The idea behind this improved discrete cracking approach 3D multicrack model (3D-NLFEM-multicrack) is to be closer to the $\sigma-\varepsilon / w$ UHPFRC material behaviour defined in chapter 3 (the real phase 1) by means of defined composed finite elements. 
Moreover, in the analysis definition of the 3D-NLFEM-multicrack, a random variation of the FRCFAC factor that multiplies the values of the UHPFRC tension stress in the constitutive behaviour of the NLFEM has been added to better model the heterogeneity of concrete. A similar idea is developed in (Rossi et al. 2018). In this way, different behaviours can be expected from different runs of the same algorithm (see Figure 6.62). The random field to vary the FRCFAC factor used is based on a Cholesky covariance matrix decomposition using a log-normal distribution.

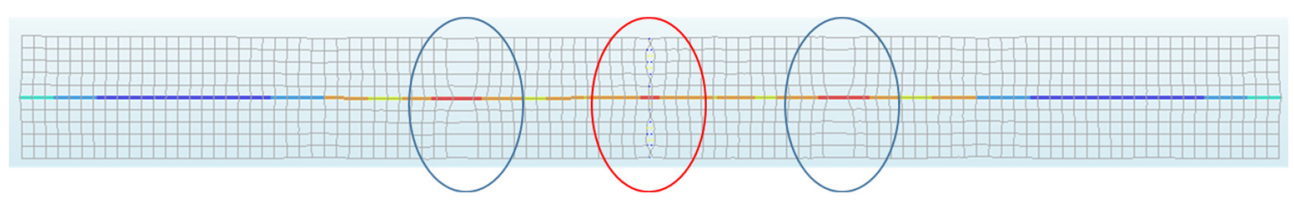

Figure 6.60 Secondary macrocracks appearing in the smeared part of the discrete 2DNLFEM
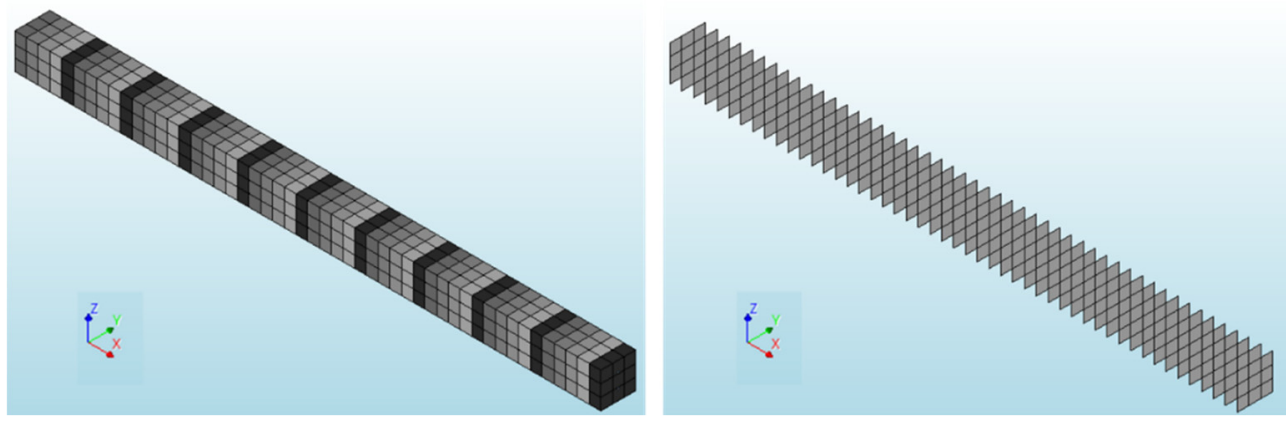

Figure 6.61 FEM mesh for the 3D model with interfaces

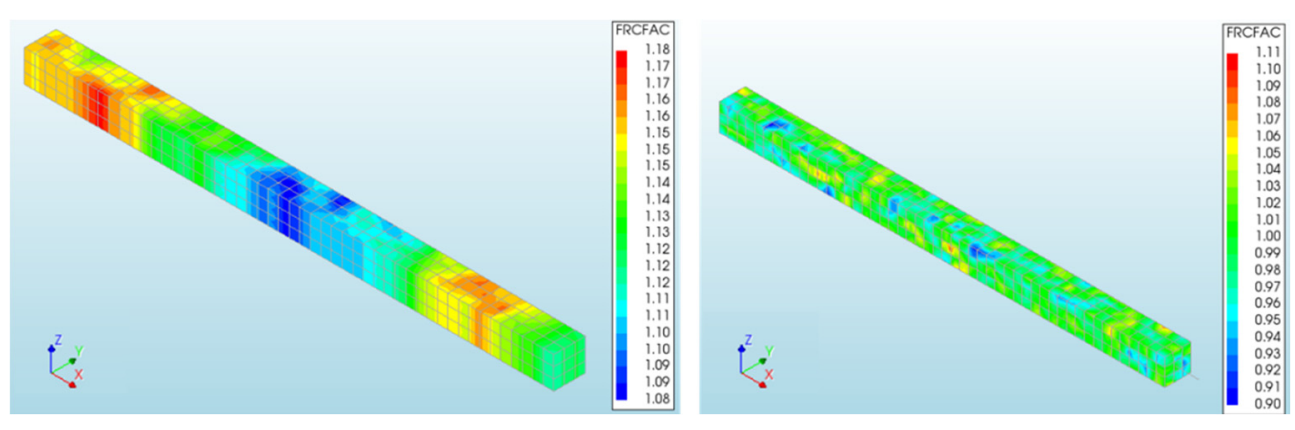

Figure 6.62 Random distribution of tensile properties (FRCFAC) 


\subsubsection{Results and Discussion}

The objective of this section is to evaluate the reliability of using the constitutive parameters obtained from the characterisation test to describe the mechanical response in UHPFRC-reinforced elements. To get this objective, the results from the tensile bar experimental programme are compared to the response of the NLFEM developed.

Figure 6.63, Figure 6.64 and Figure 6.65 show the experimental tensile test load (P)displacement $(\Delta \mathrm{u})$ average $(50 \%)$ curve of the reinforced tensile bars tested for the experimental programme (the continuous black lines) considered in Table 6.8, compared to the characteristic 5 and $50 \%$ response of the 2D-NLFEM when the discrete cracking approach is used (discontinuous ones). As observed, the model curves accurately fit the experimental ones for $50 \%$ level. This demonstrates not only the reliability of the developed NLFEM, but also the coherence of the process. That is, if the characteristic tensile constitutive parameters used to mechanically characterise UHPFRC in Table 6.9 were implemented into the NLFEM of the reinforced bars, then the numerical response would accurately fit the experimental one at $50 \%$ percentile level. Moreover, the 2DNLFEM response when the characteristic 5\% tensile parameters are used is also represented to see the difference between using $5 \%$ or $50 \%$ parameters in the model. As it can be observed, the characteristic 5\% response is conservative in all cases. The model very well represents the linear branch of the P- $\Delta \mathrm{u}$ curve, the microcrack formation and the microcrack stabilisation phase, as it happens with the flexural beams.

As it happens with the flexural reinforced beams, it is important to pay attention to the shrinkage value used to calibrate the model for the reinforced tensile bars in Figure 6.63, Figure 6.64 and Figure 6.65. To fit the results with this accuracy, it is necessary to increment the shrinkage value $\left(\varepsilon_{c s}\right)$ calculated from EN 1992-1-1 Eurocode 2 (The European Union Per Regulation 305/2011 and Directive 98/34/EC 2004) to be used in NLFEM. In Table 6.10, the shrinkage values $\left(\varepsilon_{c s}\right)$ for each section and reinforcement diameter of the tensile bar and the increment (shinc) needed to fit accurately the results when the 2D-NLFEM is used are provided. The total shrinkage strain of UHPFRC $\left(\varepsilon_{C S U H P F R C}\right)$ is calculated using Expression (6.5). The calculated UHPFRC shrinkage strain $\left(\varepsilon_{C S U H P F R C}\right)$ falls within the range of $[0.51,0.96] \mathrm{mm} / \mathrm{m}$. 

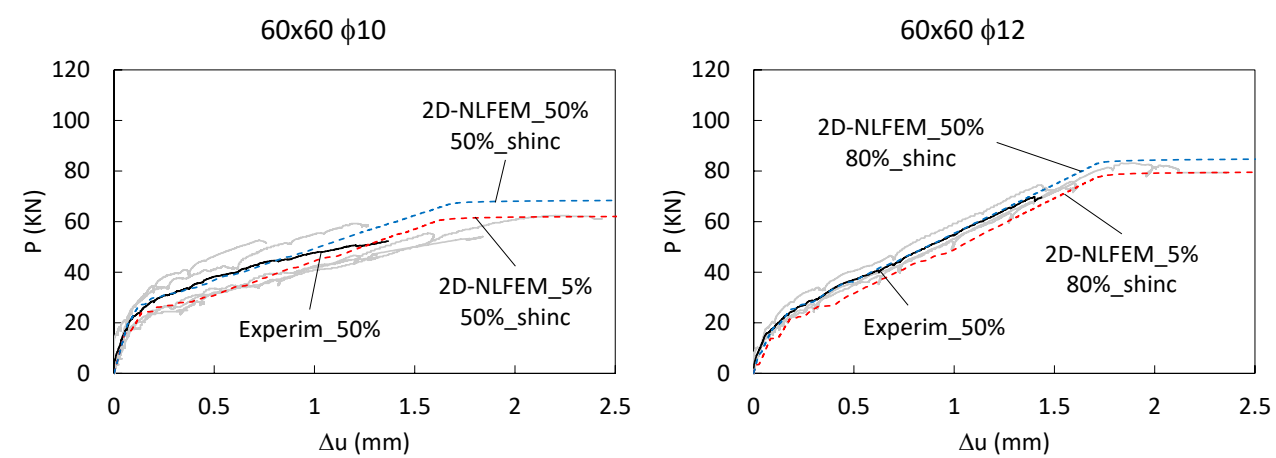

Figure 6.63 Experimental and numerical $P$ - $\Delta u$ response for $60 x 60$ tensile bars
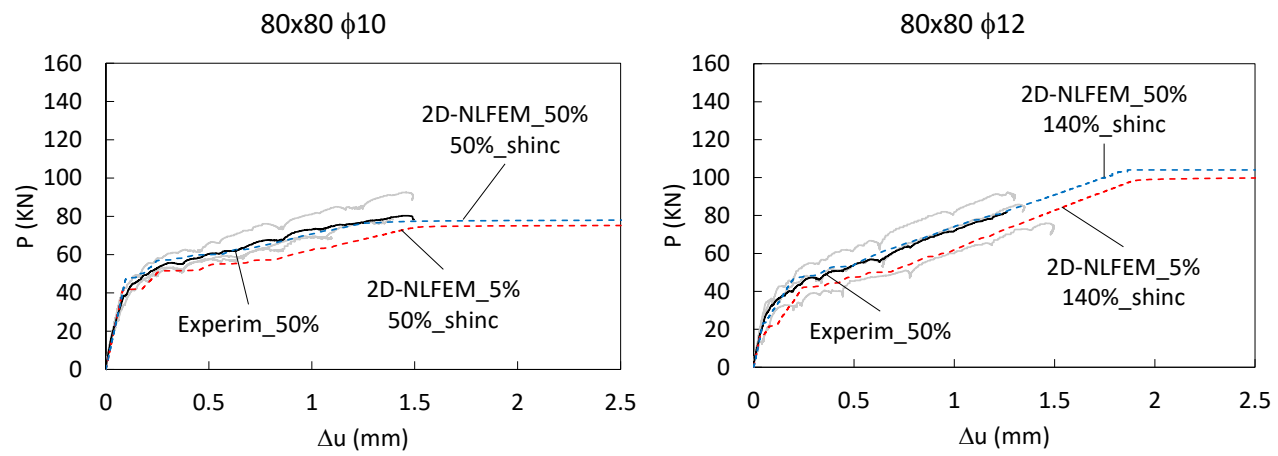

$80 \times 80 \phi 16$

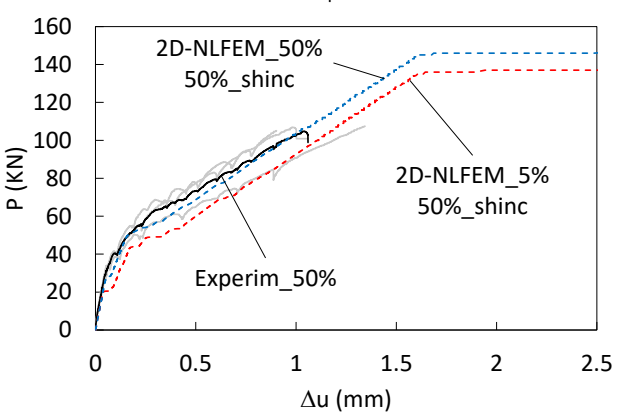

Figure 6.64 Experimental and numerical $P$ - $\Delta u$ response for $80 x 80$ tensile bars 

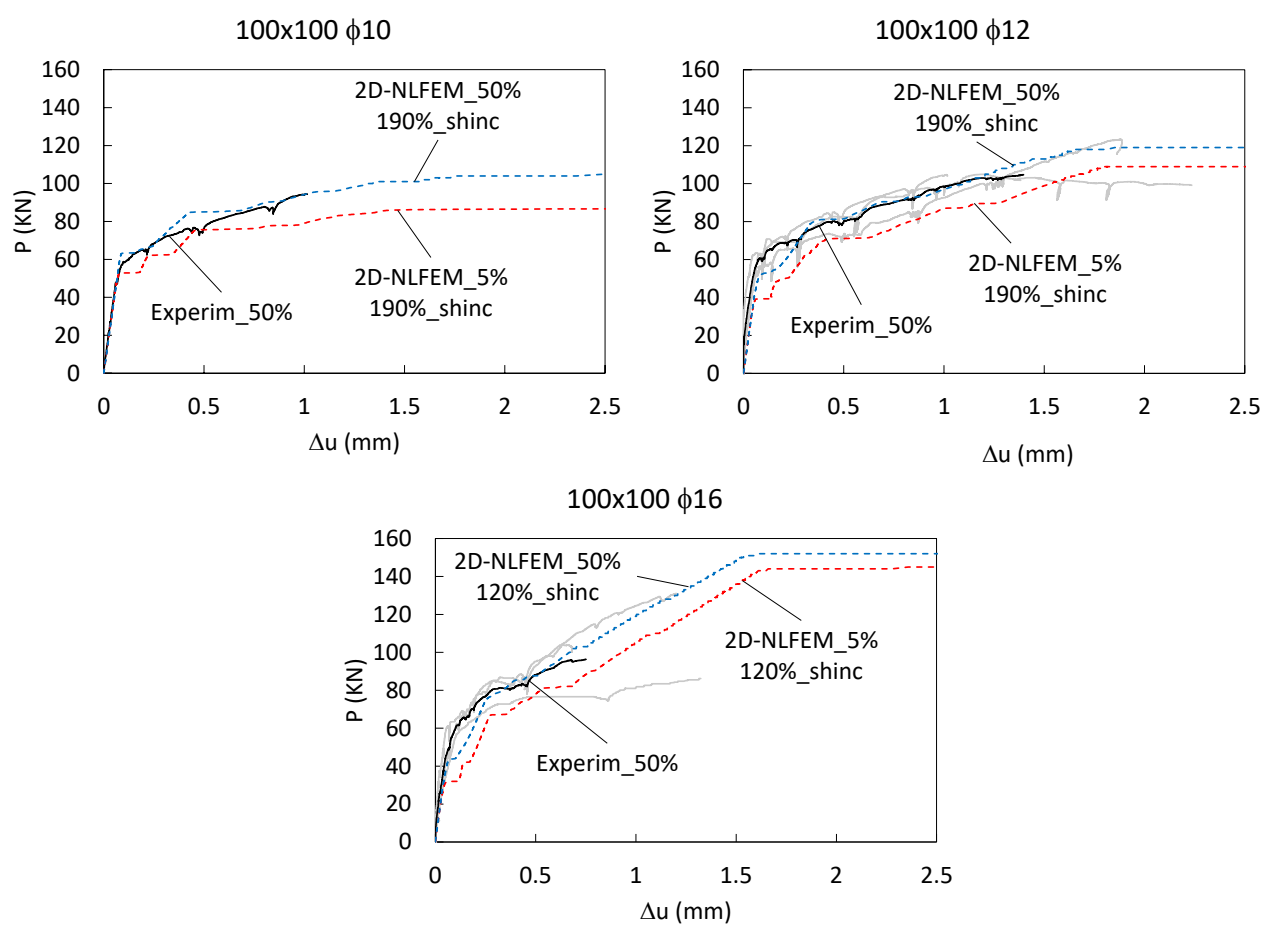

Figure 6.65 Experimental and numerical $P$ - $\Delta u$ response for $100 \times 100$ tensile bars

Table 6.10 Shrinkage values for UHPFRC with the 50\% characteristic behaviour of tensile bars using the 2D-NLFEM

\begin{tabular}{|c|c|c|c|c|}
\hline \multicolumn{5}{|c|}{ 60x60 characteristic of 50\% } \\
\hline$\phi(\mathrm{mm})$ & Testing day & $\varepsilon_{c S}(\mathrm{~mm} / \mathrm{m})$ & $\mathrm{sh}_{\text {inc }}(\%)$ & $\varepsilon_{\text {CSUHPFRC }}(\mathrm{mm} / \mathrm{m})$ \\
\hline 10 & 30 & 0.34 & 50 & 0.51 \\
\hline 12 & 30 & 0.34 & 80 & 0.61 \\
\hline \multicolumn{5}{|c|}{$80 \times 80$ characteristic of $50 \%$} \\
\hline$\phi(\mathrm{mm})$ & Testing day & $\varepsilon_{c S}(\mathrm{~mm} / \mathrm{m})$ & $\mathrm{sh}_{\text {inc }}(\%)$ & $\varepsilon_{\text {cSUHPFRC }}(\mathrm{mm} / \mathrm{m})$ \\
\hline 10 & 30 & 0.34 & 50 & 0.51 \\
\hline 12 & 30 & 0.34 & 140 & 0.82 \\
\hline 16 & 30 & 0.34 & 50 & 0.51 \\
\hline
\end{tabular}




\begin{tabular}{|c|c|c|c|c|}
\hline \multicolumn{5}{|c|}{$100 \mathrm{x} 100$ characteristic of $50 \%$} \\
\hline$\phi(\mathrm{mm})$ & Testing day & $\varepsilon_{c s}(\mathrm{~mm} / \mathrm{m})$ & $\mathrm{sh}_{\text {inc }}(\%)$ & $\varepsilon_{\text {csUHPFRC }}(\mathrm{mm} / \mathrm{m})$ \\
\hline 10 & 30 & 0.33 & 190 & 0.96 \\
\hline 12 & 30 & 0.33 & 190 & 0.96 \\
\hline 16 & 30 & 0.33 & 120 & 0.73 \\
\hline
\end{tabular}

As it can be observed in Table 6.10, the shrinkage value of UHPFRC ( $\left.\varepsilon_{c S U H P F R C}\right)$ for the tensile bars when the discrete cracking approach of the 2D-NLFEM is applied varies in a wide range. To analyse this fact, the discrete cracking approach of the 3D-NLFEM has been used with the idea of trying to see if the model is able to represent more effects as its complexity increases. To do this, the characteristic $50 \%$ constitutive behaviour of the $60 \times 60, \phi 12$ tensile bar with a shinc of $80 \%$ has been implemented in the 3D-NLFEM and in the 3D-NLFEM-multicrack to generate different combinations of the FRCFAC to simulate the heterogeneity of concrete. In Figure 6.66 different runs of the 3D-NLFEMmulticrack have been represented. RUN 0 represents the analysis for the 3D-NLFEMmulticrack when the FRCFAC is 1 , this is, without the random distribution of tensile strength. RUN 1 to RUN 7 represent the random distribution of the FRCFAC generated when the 3D-NLFEM-multicrack is applied. As it can be observed the random distribution and, consequently, the heterogeneity of the UHPFRC strength is represented with different patterns to analyse its influence in the P- $\Delta \mathrm{u}$ response. 
RUN 0

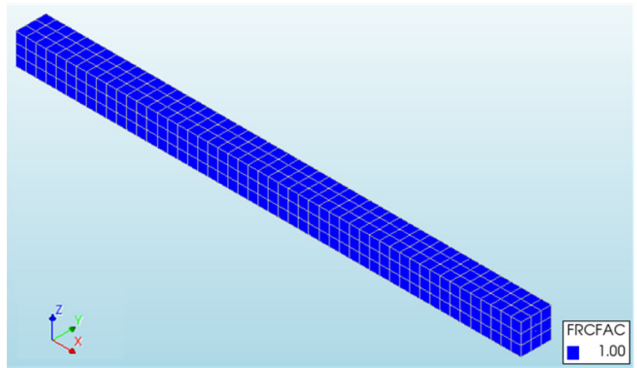

RUN 2

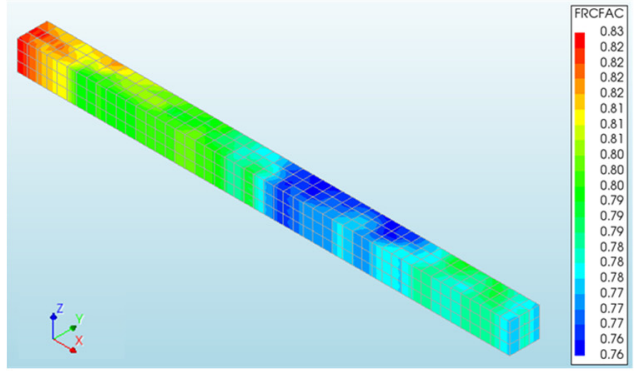

RUN 4

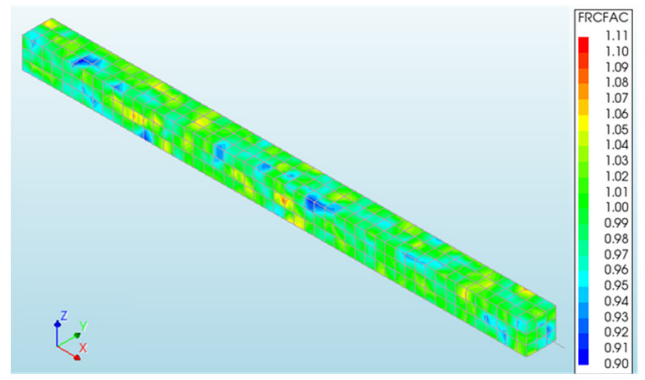

RUN 6

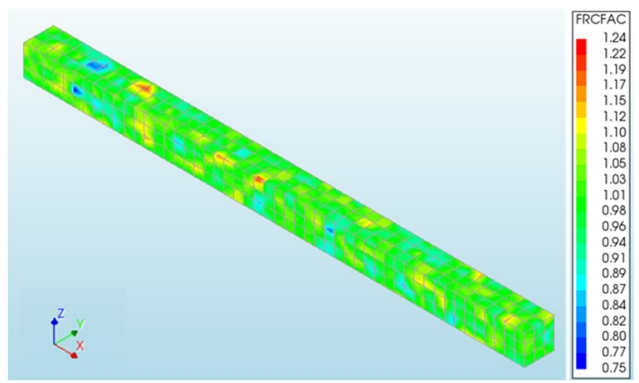

RUN 1

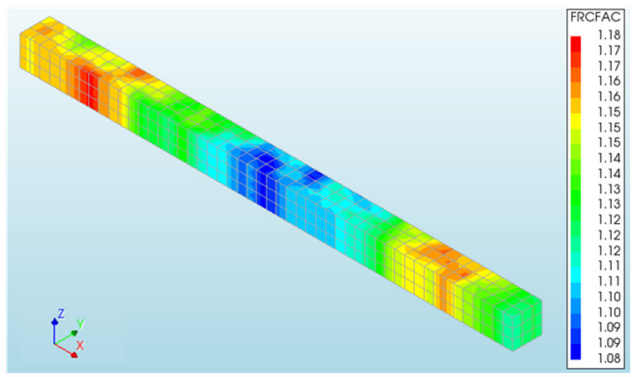

RUN 3

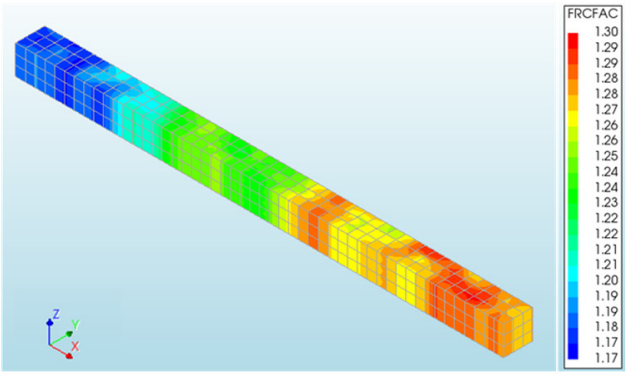

RUN 5

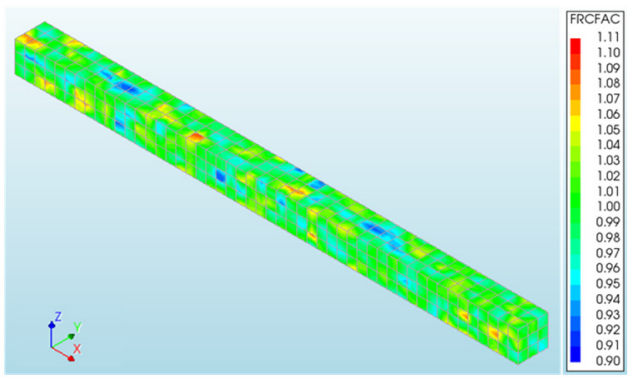

RUN 7

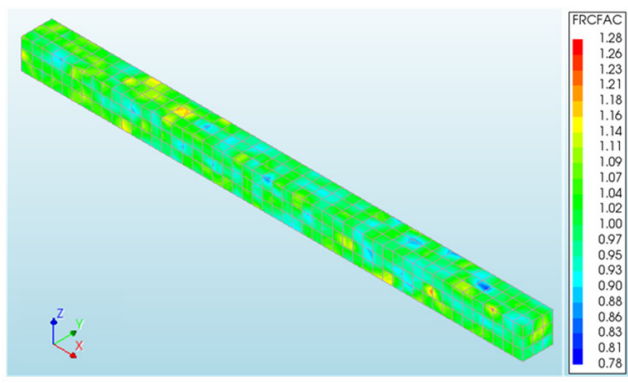

Figure 6.66 FRCFAC random distribution for the 3D-NLFEM-multicrack 60x60, $\phi 12$, $80 \%$ sh inc bar 
Table 6.11 shows the values of the correlation length (corlen) and the standard deviation (stddev) of the FRCFAC for the random field used to generate the different runs illustrated in Figure 6.66. The number of grid lines used in the Cholesky decomposition for the random field generation are also detailed: $\mathrm{Nx}$ in $\mathrm{x}$ direction, $\mathrm{Ny}$ in $\mathrm{y}$ direction and $\mathrm{Nz}$ in $\mathrm{z}$ direction.

Table 6.11 Random field in 3D-NLFEM-multicrack 60x60, $\phi 12,80 \%$ shinc bar

\begin{tabular}{|c|c|c|c|c|c|}
\hline RUN & corlen & stddev & $\mathrm{Nx}$ & $\mathrm{Ny}$ & $\mathrm{Nz}$ \\
\hline 0 (no random) & - & - & - & - & - \\
\hline 1,2 and 3 & 25 & 0.18 & 50 & 5 & - \\
\hline 4 and 5 & 0 & 0.05 & 50 & 5 & 5 \\
\hline 6 and 7 & 0 & 0.10 & 50 & 5 & 5 \\
\hline
\end{tabular}

Figure 6.67 represents the P- $\Delta \mathrm{u}$ response for the 3D-NLFEM and the different runs of the 3D-NLFEM-multicrack represented in Figure 6.66 and described in Table 6.11, compared to the experimental characteristic $50 \%$ and the discrete cracking approach of the 2D-NLFEM. The characteristic 50\% constitutive tensile parameters are used in all the applications of the model. As it is observed, if the resulting $80 \%$ shrinkage increment obtained from the 2D-NLFEM is assumed (see Table 6.10), the 3D model generates a bit different response. 
$60 \times 60 ; \phi 12 ; 80 \%$ shinc

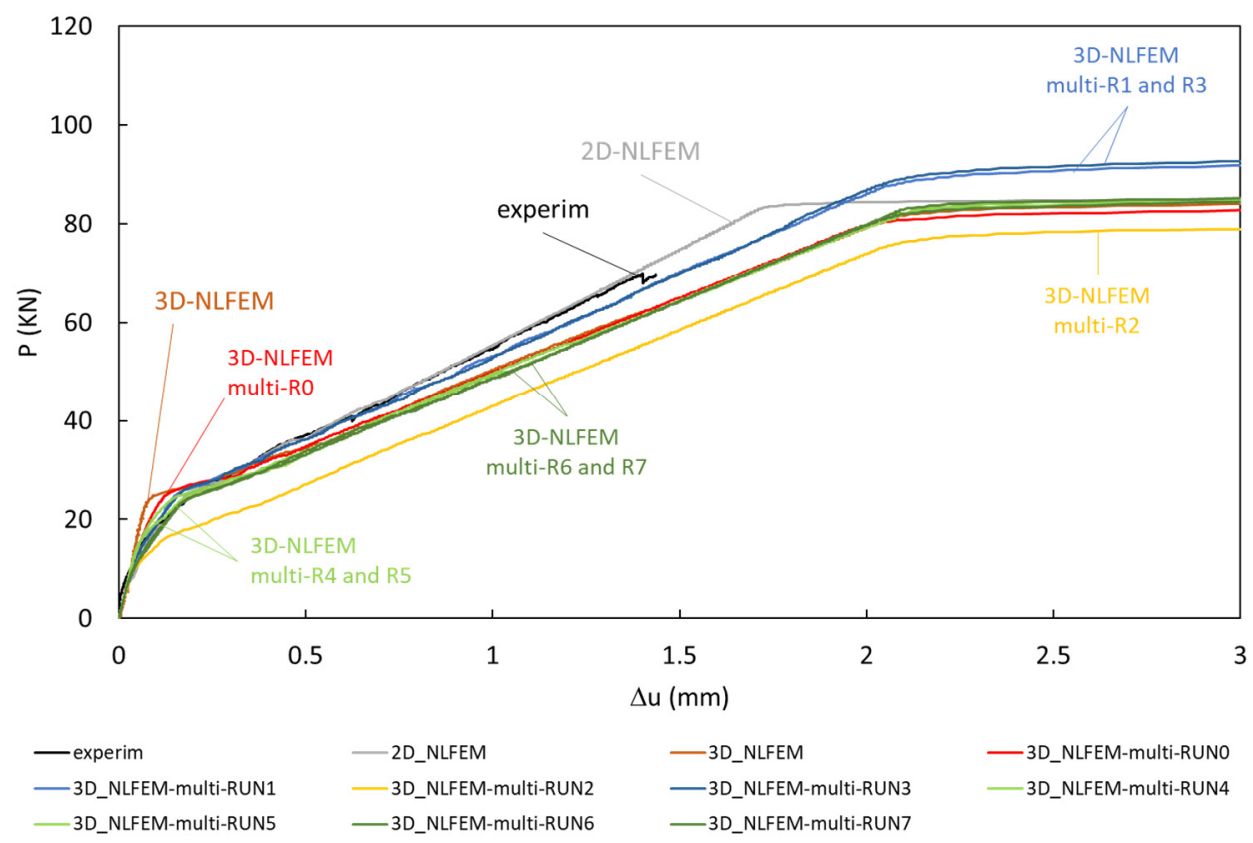

Figure 6.67 P-Au response of 60x60, $\phi 12$ tensile bar and the NLFEM with $80 \%$ of sh inc $_{\text {in }}$

As it can be observed in Figure 6.67 all the curves show the same trend. In all cases, the model response gets accurate results. If the response of the 2D-NLFEM is compared to the experimental one, it can be observed how the 2D model adjusts very accurately the experimental curve with the $80 \%$ shrinkage increment. If the same shrinkage increment is assumed for the 3D model, several situations are observed. When the 3D-NLFEM with the discrete crack in the mid-span section is used, the model response does not fit the experimental curve with the same accuracy as the 2D-NLFEM. Moreover, there is a small inaccuracy during the microcrack formation where the curve loses its linearity. It seems that the 3D-NLFEM represents a stiffer response at the linear-elastic stage. When the 3D-NLFEM-multicrack with the multiple interfaces and the random distribution of the stress by means of the FRCFAC is applied, the inaccuracy during the microcrack formation of the previous 3D-NLFEM is improved, especially for RUN 6 and 7. The 3DNLFEM-multicrack represents with a very good accuracy the stiffness of the experimental response at the linear-elastic stage. This could be produced because the multicrack model is able to represent the variation of stiffness at this stage progressively due to the interfaces that generates a smooth behaviour of the tensile bar in general. Moreover, the different runs of the 3D-NLFEM-multicrack where the random 
distribution is applied (see Figure 6.66) generate different responses for the model (see Figure 6.67). RUN 1 and RUN 3 generate a better UHPFRC as it can be observed in Figure 6.66. Consequently, their P- $\Delta \mathrm{u}$ curves are more accurate if they are compared to the experimental one (see Figure 6.67). The same deduction can be applied in the case of RUN 2 where the UHPFRC generated is the worst and, consequently, the P- $\Delta \mathrm{u}$ curve is the less accurate. In RUNs 4, 5, 6 and 7, the heterogeneity generated is more smeared along the tensile bar and the FRCFAC factor is closer to one varying in a more equilibrated sense. It could be set that the responses obtained from these runs could represent the average behaviour expected (RUN 0). Therefore, if the P- $\Delta \mathrm{u}$ response of RUNs $0,4,5,6$ and 7 of 3D-NLFEM-multicrack and, in addition, the response of 3DNLFEM, are observed, it is possible to see how they are not exactly fitting the experimental response as the 2D-NLFEM for the same level of shrinkage considered $\left(\mathrm{sh}_{\text {inc }}=80 \%\right)$. It seems that there is a gap between the $2 \mathrm{D}$ and the $3 \mathrm{D}$ models in the microcrack stabilisation phase (the second slope in Figure 6.67). This may be caused because the 3D models are able to capture other 3D effects that take place in the experimental test. This is, maybe the $80 \%$ shrinkage considered from the 2D-NLFEM is not exactly this value and in this percentage considered as shrinkage in the 2D model, other effects are hidden that are very important for this particular experimental test. Maybe the percentage of shrinkage is a bit different and the other 3D effects are acting. The consequence of these effects is considered in the 3D models and this fact could explain the difference between these two responses.

In Figure 6.68 the shrinkage value has been adjusted using the 3D-NLFEM-multicrack with the random distribution used for RUN6 and 7 in Table 6.11 of the FRCFAC for tensile strength for the same tensile bar: 60x60, $\phi 12$ (see 3D-NLFEM multi shinc $40 \%$ response in Figure 6.68). As it can be observed, the value of sh $_{\text {inc3D }}$ necessary for the 3D model is $40 \%$ that is lower than the $80 \% \mathrm{sh}_{\text {inc }}$ necessary for the 2D-NLFEM. Consequently, this difference could be due to the 3D effects (see Expression (6.8)). The variability due to the heterogeneity of concrete is considered in the variation of the FRCFAC for the tensile strength in the random field used in the 3D-NLFEM-multicrack. Therefore, in the case of $60 \times 60, \phi 12$ tensile bar, there is a $40 \%$ of sh $\mathrm{sin}_{\text {inc }}$ and $40 \%$ of $3 \mathrm{D}$ effects of the initial $80 \% \mathrm{sh}_{\text {inc }}$ obtained from the 2D-NLFEM.

$$
3 D_{\text {effects }}=s h_{i n c}-s h_{i n c 3 D}
$$




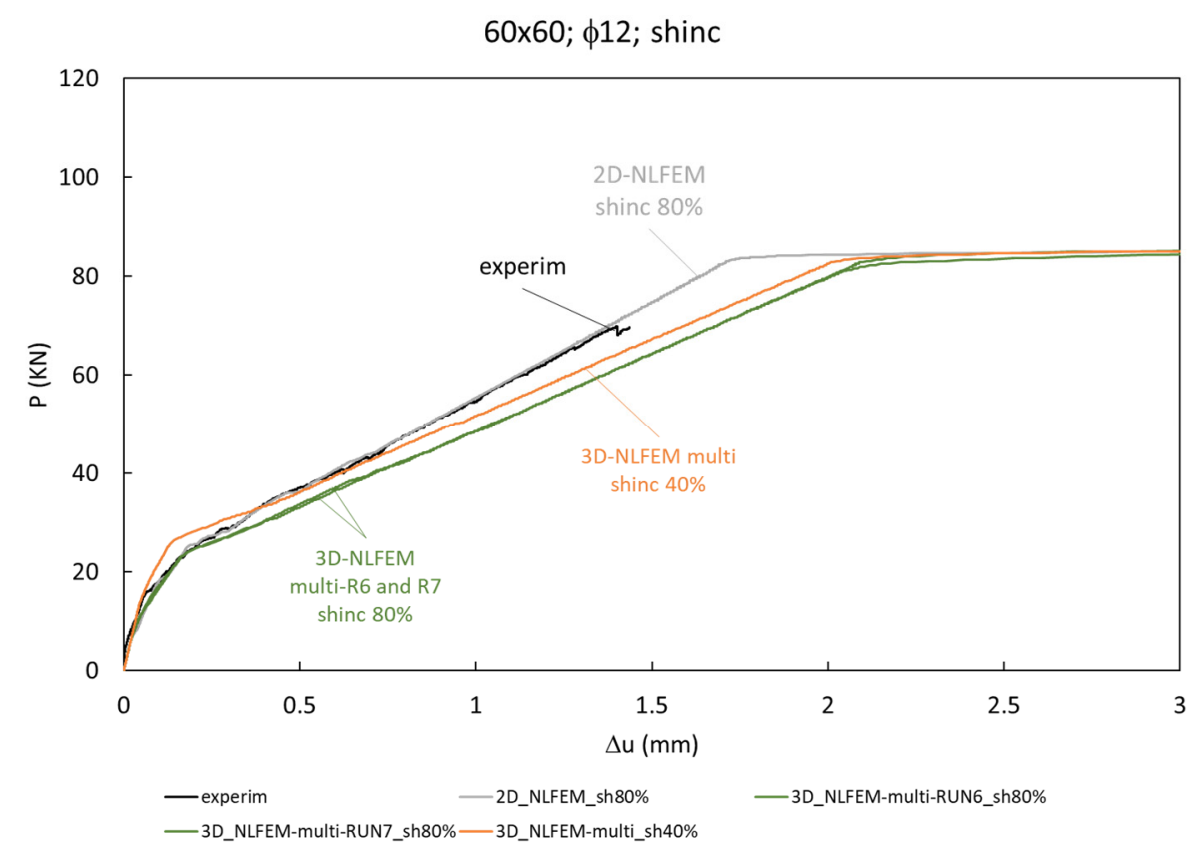

Figure $6.68 P$ - $\triangle u$ response of 60x60, $\phi 12$ tensile bar and the NLFEM with 80\% and $40 \%$ of $\operatorname{sh}_{\text {inc }}$

Therefore, the strain due to the 3D shrinkage effect is obtained using Expression (6.9) and the strain due to the 3D effects is obtained using Expression (6.10).

$$
\begin{gathered}
\varepsilon_{C S U H P F R C 3 D}=\varepsilon_{C S} \cdot\left(1+s h_{\text {inc } 3 D} / 100\right) \\
\varepsilon_{3 \text { Deffects }}=\varepsilon_{c s} \cdot 3 D_{\text {effects }} / 100
\end{gathered}
$$

In the case of $60 \times 60, \phi 12$ tensile bar, from the application of 3D-NLFEM-multicrack and Expressions (6.8), (6.9) and (6.10), and considering the $\varepsilon_{\mathrm{cs}}$ value from Table 6.10:

$$
\begin{gathered}
\varepsilon_{\text {CSUHPFRC } 3 D}=0.48 \mathrm{~mm} / \mathrm{m} \\
\varepsilon_{3 \text { Deffects }}=0.14 \mathrm{~mm} / \mathrm{m}
\end{gathered}
$$


The sum of these two strains from the 3D-NLFEM-multicrack is coincident with the value of $\varepsilon_{\mathrm{cs} U H P F R C}$ of Table 6.10 from the 2D-NLFEM application.

In Figure 6.69, Figure 6.70 and Figure 6.71 the curves adjusted with the new values of shinc3D necessary for the 3D-NLFEM-multicrack with the random distribution used for RUN6 and 7 in Table 6.11 of the FRCFAC for tensile strength are shown for the experimental tensile bars described in Table 6.8 , following the same criteria as described above for the case of $60 \times 60, \phi 12$ tensile bar. As it can be observed at the figures the 3D model adjusts accurately the experimental response with a less value of shrinkage increment $\left(\mathrm{sh}_{\text {inc33 }}\right)$ if it is compared to the shrinkage increment obtained using the $2 \mathrm{D}$ model $\left(\mathrm{sh}_{\text {inc }}\right)$. Generally, it can be denoted that the stiffness in the microcrack stabilisation phase (the second slope of the curve) for the 3D model is reduced with respect to the response of the $2 \mathrm{D}$ model. Even though this fact generates less accuracy in some cases such as $80 \times 80 ; \phi 16$, the $3 \mathrm{D}$ model is considered reliable enough.

The difference in the shrinkage increment necessary to adjust de 2D-NLFEM and the 3D-NLFEM-multicrack can be produced due to the 3D effect above described. In Table 6.12 the shrinkage increment obtained with the $2 \mathrm{D}$ model $\left(\mathrm{sh}_{\text {inc }}\right)$ and from the $3 \mathrm{D}$ model $\left(\mathrm{sh}_{\text {inc } 3 \mathrm{D}}\right)$ are compared for the tensile bars considered and the $3 \mathrm{D}$ effect obtained as the difference between the shrinkage increment from the two models.

Using Expression (6.5) for 2D-NLFEM and Expression (6.9) and Expression (6.10) for 3D-NLFEM-multicrack, it is possible to obtain the strain due to the shrinkage effect for the case of the 2D-NLFEM ( $\left.\varepsilon_{\text {csUHPFRC }}\right)$ and for the 3D-NLFEM-multicrack ( $\left.\varepsilon_{\text {cSUHPFRC3D }}\right)$ and the strain due to the 3D effects for the case of the 3D-NLFEM-multicrack ( $\varepsilon_{3 \text { Deffects }}$ ). These values are detailed in Table 6.13. As it can be observed in Table 6.13, the sum of $\varepsilon_{\mathrm{cSUHPFRC} D}$ and $\varepsilon_{3 \text { Deffects }}$ results in $\varepsilon_{\mathrm{cs} U H P F R C}$.

From Table 6.13 it can be deduced that, when using the 2D-NLFEM to model the tensile test, the calculated UHPFRC shrinkage strain $\left(\varepsilon_{C S U H P F R C}\right)$ falls within the range of [0.51, $0.96] \mathrm{mm} / \mathrm{m}$. From the other hand, when the 3D-NLFEM-multicrack is used to model the tensile test the calculated UHPFRC 3D shrinkage strain $\left(\varepsilon_{C S U H P F R C 3 D}\right)$ falls within the range of $[0.37,0.73] \mathrm{mm} / \mathrm{m}$. Therefore, the difference between the two models considered as the strain due to the $3 \mathrm{D}$ effects falls within the range of $[0.10,0.23] \mathrm{mm} / \mathrm{m}$. Consequently the $\varepsilon_{C S U H P F R C 3 D}$ range is more in line with (Fang et al. 2020; Fehling et al. 2014; Xie et al. 2018; Yoo et al. 2015a) and the model is able to quantify the 3D effects that affect this particular kind of tensile test. 

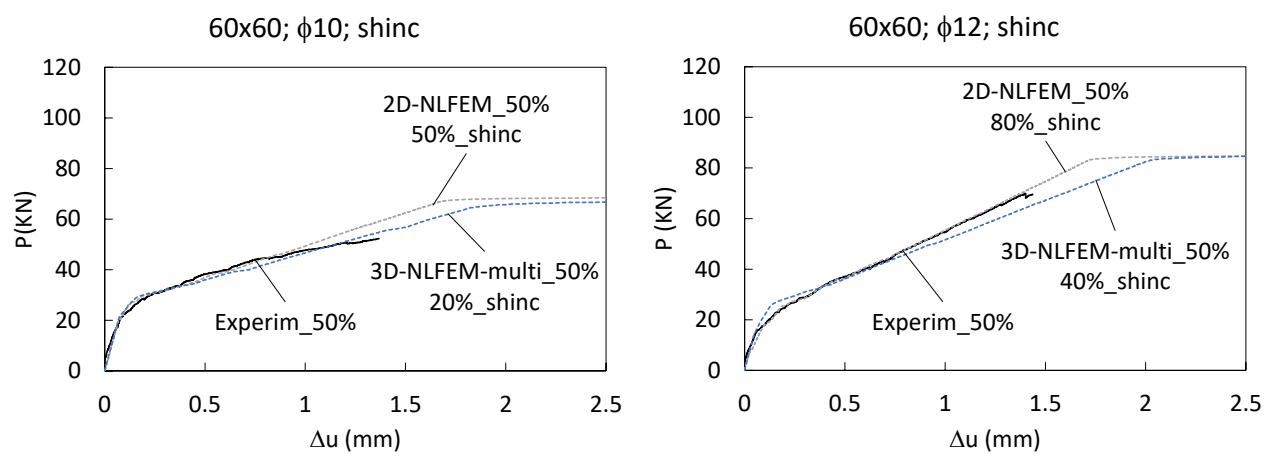

Figure $6.69 P$ - $\Delta$ u comparison for $60 x 60$ tensile bar
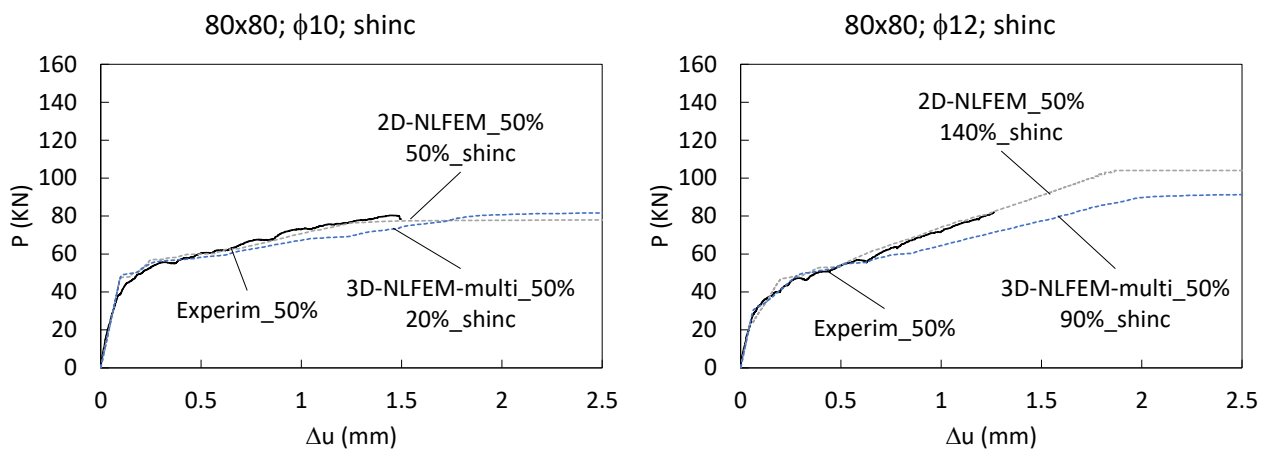

80x80; $\phi 16 ;$ shinc

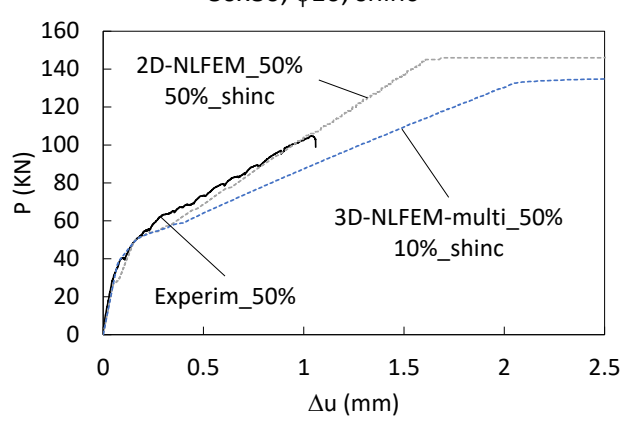

Figure 6.70 P- $\Delta$ u comparison for $80 x 80$ tensile bar 

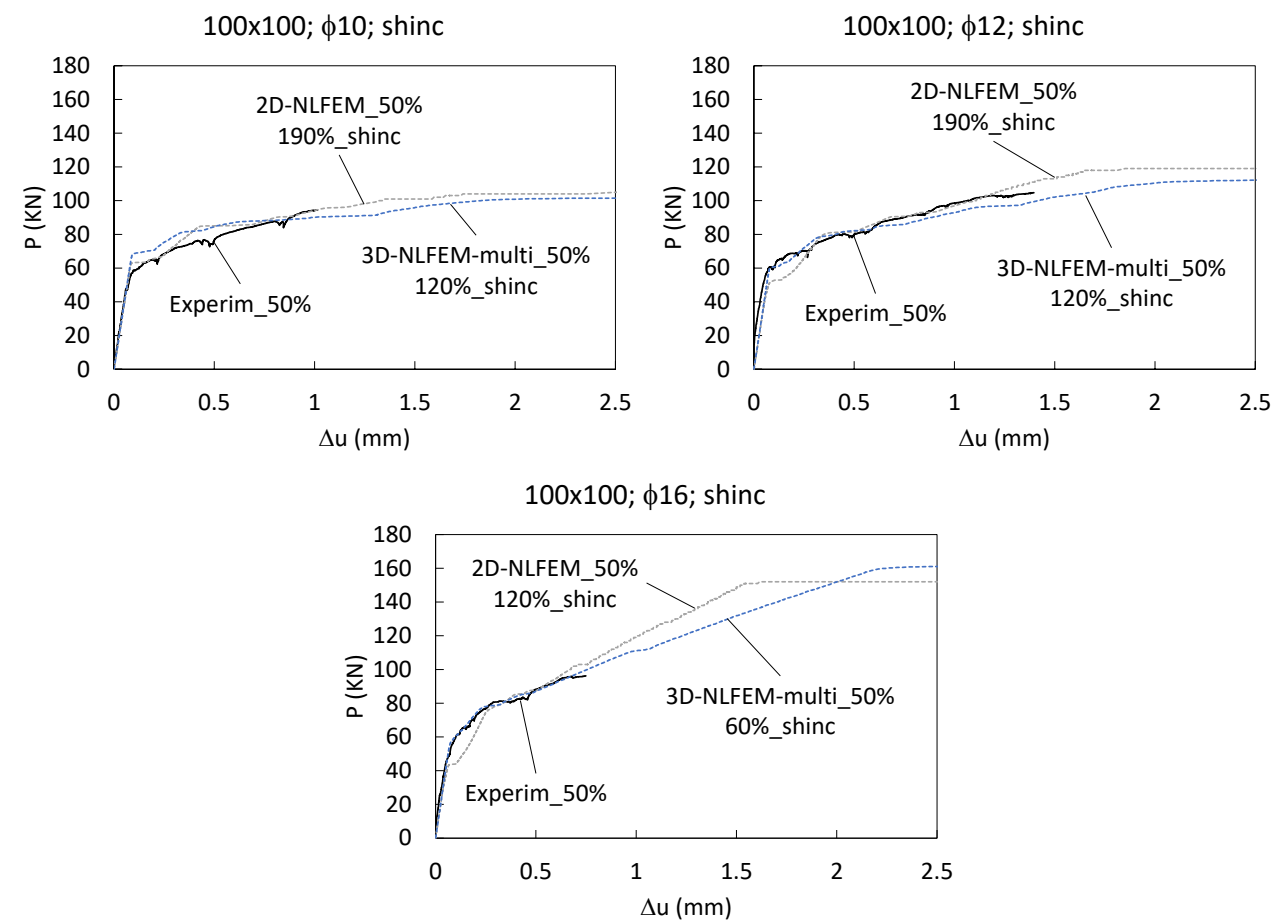

Figure 6.71 P-Au comparison for $100 \times 100$ tensile bar

Table $6.12 s_{\text {inc, }} s_{\text {inc } 3 D}$ and $3 D$ effect for tensile bars

\begin{tabular}{|c|c|c|c|c|}
\hline \multicolumn{2}{|c|}{ Tensile bar } & 2D-NLFEM & \multicolumn{2}{c|}{ 3D-NLFEM-multicrack } \\
\hline id. & As/Ac (\%) & $\mathrm{sh}_{\text {inc }}(\%)$ & $\mathrm{sh}_{\text {inc3D }}(\%)$ & 3D effects (\%) \\
\hline $60 \times 60 ; \phi 10$ & 2.23 & 50 & 20 & 30 \\
\hline $60 \times 60 ; \phi 12$ & 3.24 & 80 & 40 & 40 \\
\hline $80 \times 80 ; \phi 10$ & 1.24 & 50 & 20 & 30 \\
\hline $80 \times 80 ; \phi 12$ & 1.80 & 140 & 90 & 50 \\
\hline $80 \times 80 ; \phi 16$ & 3.24 & 50 & 10 & 40 \\
\hline $100 \times 100 ; \phi 10$ & 0.79 & 190 & 120 & 70 \\
\hline $100 \times 100 ; \phi 12$ & 1.14 & 190 & 120 & 70 \\
\hline $100 \times 100 ; \phi 16$ & 2.05 & 120 & 60 & 60 \\
\hline
\end{tabular}


Table $6.13 \varepsilon_{C S U H P F R C,} \varepsilon_{C S U H P F R C 3 D}$ and $\varepsilon_{3 D \text { effects }}$ for tensile bars.

\begin{tabular}{|c|c|c|c|c|}
\hline \multicolumn{2}{|c|}{ Tensile bar } & 2D-NLFEM & \multicolumn{2}{c|}{ 3D-NLFEM-multicrack } \\
\hline id. & $\begin{array}{c}\varepsilon_{\mathrm{cs}} \\
(\mathrm{mm} / \mathrm{m})\end{array}$ & $\begin{array}{c}\varepsilon_{\mathrm{csUHPFRC}} \\
(\mathrm{mm} / \mathrm{m})\end{array}$ & $\begin{array}{c}\varepsilon_{\text {csUHPFRC3D }} \\
(\mathrm{mm} / \mathrm{m})\end{array}$ & $\begin{array}{c}\varepsilon_{3 D e f f e c t s} \\
(\mathrm{~mm} / \mathrm{m})\end{array}$ \\
\hline $60 \times 60 ; \phi 10$ & 0.34 & 0.51 & 0.41 & 0.10 \\
\hline $60 \times 60 ; \phi 12$ & 0.34 & 0.61 & 0.48 & 0.14 \\
\hline $80 \times 80 ; \phi 10$ & 0.34 & 0.51 & 0.41 & 0.10 \\
\hline $80 \times 80 ; \phi 12$ & 0.34 & 0.82 & 0.65 & 0.17 \\
\hline $80 \times 80 ; \phi 16$ & 0.34 & 0.51 & 0.37 & 0.14 \\
\hline $100 \times 100 ; \phi 10$ & 0.33 & 0.96 & 0.73 & 0.23 \\
\hline $100 \times 100 ; \phi 12$ & 0.33 & 0.96 & 0.73 & 0.23 \\
\hline $100 \times 100 ; \phi 16$ & 0.33 & 0.73 & 0.53 & 0.20 \\
\hline
\end{tabular}

Figure 6.72 represents the relation between the sections of the bars modelled herein, they are $60 \times 60,80 \times 80$ and $100 \times 100 \mathrm{~mm}$, the diameter of the reinforcement bars, they are $\phi 10$, $\phi 12$ and $\phi 16$ and the 3D effects obtained from the application of the developed 3DNLFEM-multicrack. It seems to show an ascendant tendency: whereas the section of the tensile bar is increased for each diameter of the reinforcement bar used, the 3D effects derived from the tensile test are increased too. As it is said, this is only a tendency extracted from the specimens considered in this work. To confirm it, it would be necessary to analyse more specimens varying the bar section and the reinforcement diameter. 


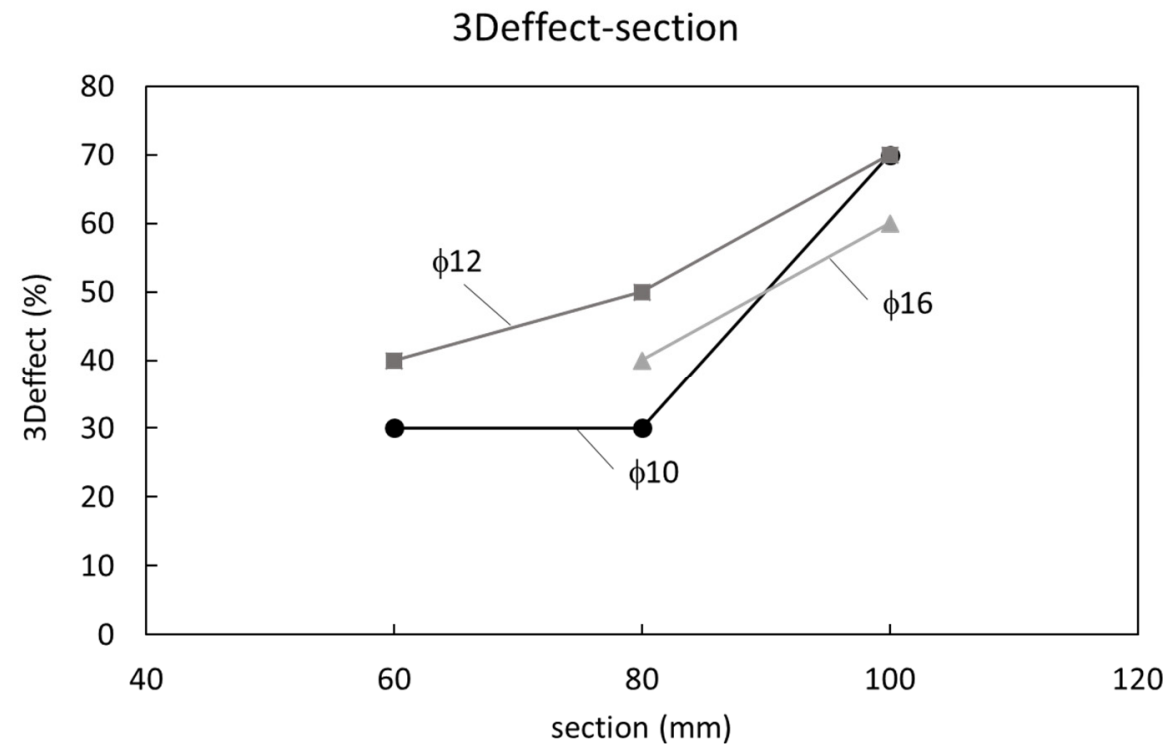

Figure 6.72 Section of the tensile bar vs 3Deffect from 3D-NLFEM-multicrack

\subsubsection{Tension stiffening analysis}

In this section the influence of tension stiffening effect on UHPFRC steel reinforced tensile bars is analysed. This is considered in the P- $\Delta \mathrm{u}$ response with two lines. One line with I stiffness represents the elastic response for an uncracked UHPFRC steel reinforced tensile bar. The other line with II stiffness represents the stiffness of the bare steel reinforcement bar, it is, considering that the UHPFRC steel reinforced specimen is fully cracked and the contribution of the UHPFRC is null. As it happens with the flexural beams in section 6.2.4.1 of this chapter, according to Bischoff (Bischoff 2008), a tensionstiffening factor $\beta$ can be obtained to define the element's member response. Setting $\beta$ equal to 1 gives a bilinear response composed by the elastic uncracked stiffness and constant tension stiffening where crack appears at $\mathrm{P}_{\mathrm{cr}}$ load, that represents an upper bound on member stiffness denoted as full tension stiffening situation. On the other hand, considering $\beta$ value of 0 gives a lower bound with no tension stiffening that essentially gives the II response, defining the no tension stiffening situation. This analysis is carried out for the UHPFRC steel reinforced bars described in Table 6.8, as it is shown in Figure 6.73, Figure 6.74 and Figure 6.75. For all of them, the stiffness $\mathrm{EA}_{\mathrm{I}}$ and $\mathrm{EA}_{\mathrm{II}}$ have been obtained following Expression (6.11) and Expression (6.12), respectively and the full tension stiffness line $(\beta=1)$ has been obtained parallel to II $(\beta=0)$ from $\mathrm{P}_{\text {cr }}$ obtained in the experimental $\mathrm{P}-\Delta \mathrm{u}$ response of each tensile bar. 


$$
\begin{gathered}
E A_{I}=\frac{E_{s} \cdot A_{s}}{L} \cdot\left(\frac{1+n \rho}{n \rho}\right) \\
E A_{I I}=\frac{E_{S} \cdot A_{s}}{L}
\end{gathered}
$$

where:

$$
n=\frac{E_{s}}{E_{c}}
$$

and:

$$
\rho=\frac{A_{s}}{A_{c}}
$$

being $L$ the initial length covered by the displacement transducers in Figure 6.56, $A_{s}$ and $E_{\mathrm{s}}$ the section and stiffness moduli of steel rebar crossing the $500 \mathrm{~mm}$ central length of the tensile bar in Figure 6.54, and $\mathrm{A}_{\mathrm{c}}$ and $\mathrm{E}_{\mathrm{c}}$ the section and stiffness moduli of the tensile bar UHPFRC.

Moreover, in Figure 6.73, Figure 6.74 and Figure 6.75 the 2D-NLFEM and the 3DNLFEM-multicrack P- $\Delta \mathrm{u}$ response obtained from Figure 6.69, Figure 6.70 and Figure 6.71 using the tensile UHPFRC characteristic parameters from the 4P-IA and softening correction for the $50 \%$ percentile (Table 6.9) have been represented to compare the prediction of the models to the experimental $50 \%$ percentile P- $\Delta \mathrm{u}$ response and to the lines above described with the objective of evaluate the model results from the stiffness point of view. 
$60 \times 60 ; \phi 10 ;$ shinc

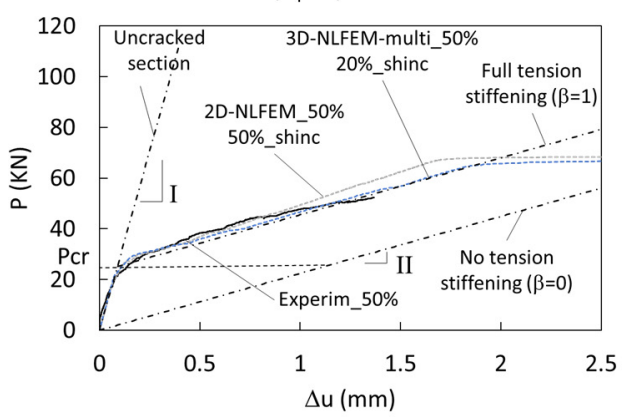

$60 \times 60 ; \phi 12 ;$ shinc

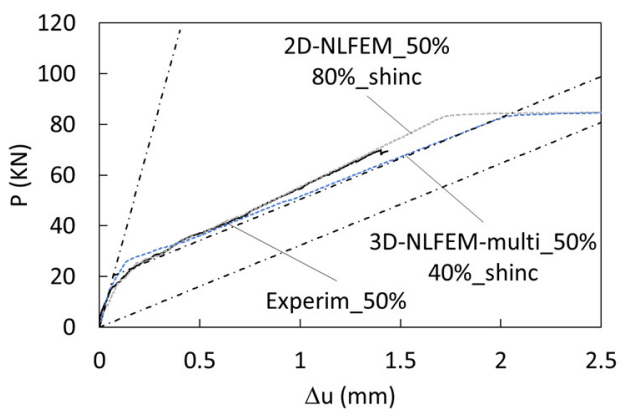

Figure 6.73 Tension stiffening analysis for $60 \times 60$ tensile bars
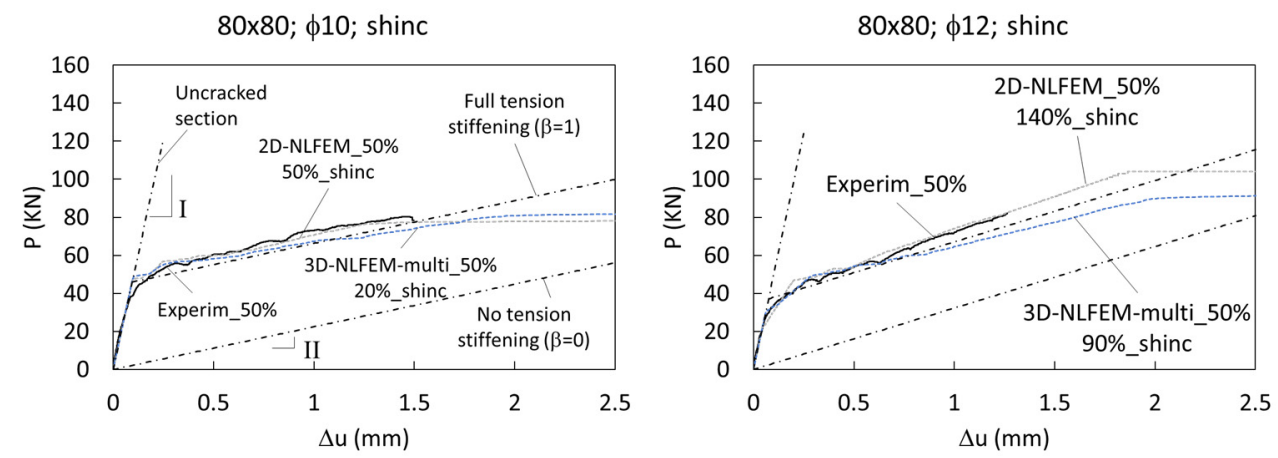

80x80; $\phi 16 ;$ shinc

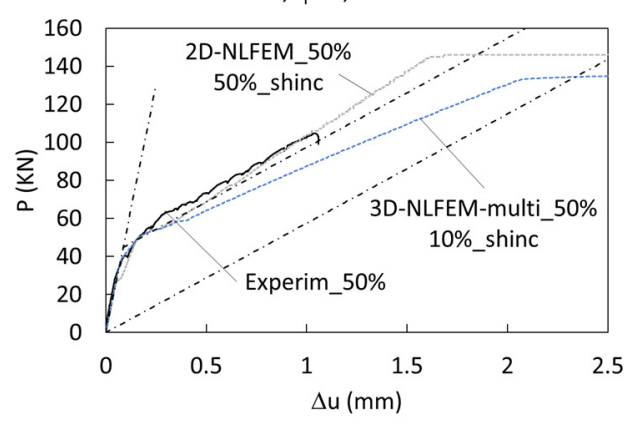

Figure 6.74 Tension stiffening analysis for 80x80 tensile bars 

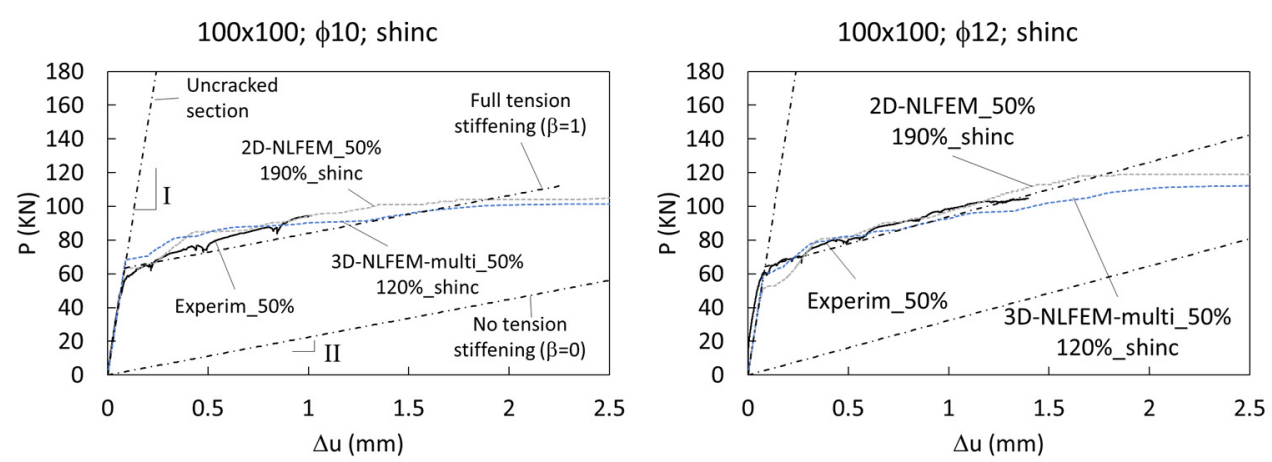

100x100; $\phi 16 ;$ shinc

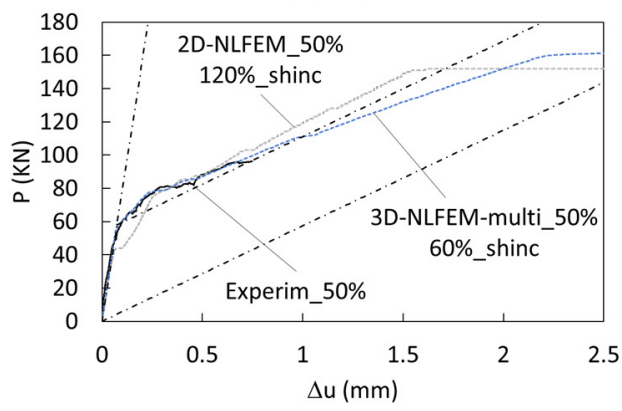

Figure 6.75 Tension stiffening analysis for 100x100 tensile bars

As it is observed in Figure 6.73, Figure 6.74 and Figure 6.75, in general terms, the experimental $\mathrm{P}-\Delta \mathrm{u}$ response and the simulations from the two models are relatively close to the full tension stiffening $(\beta=1)$ behaviour in the microcrack stabilisation phase in almost all UHPFRC tensile bars considered. There are some situations such as $80 \times 80$, $\phi 16$ tensile bar (see Figure 6.74) where the 3D-NLFEM-multicrack seems to lose stiffness in the microcrack stabilisation phase obtaining a P- $\Delta \mathrm{u}$ response in between the full tension stiffening and no tension stiffening, this is, $0<\beta<1$, while the experimental and the 2D-NLFEM follow the full tension stiffening tendency. It is true that the 3DNLFEM-multicrack could have variation associated to the random-field used in the nonlinear analysis and the 3D effects obtained that could be considered as the cause of this difference. However, if Figure 6.54 and Figure 6.56 are observed it is necessary to consider that the initial length covered by the displacement transducers involves the part where there is only one reinforcement bar (the central $500 \mathrm{~mm}$ ) but also the transition from one bar to three (at $250 \mathrm{~mm}$ from the centre at each side) and part of the three bars length (until $350 \mathrm{~mm}$ from the centre at each side). Precisely this transition could be a weak zone where some effects such as the abrupt change of stiffness due to the change 
of steel bar section and the anchorage length of the rebars can generate converge and instability problems during the test simulation in the 3D model and also uncertainties and spurious measurements by the displacement transducers during the experimental test that could explain the difference between the experimental results and the 2D-NLFEM with the 3D-NLFEM-multicrack. The effect of this weak zone could be considered included in the 3D effects that make the difference between the 2D-NLFEM and the 3DNLFEM-multicrack. The 3D model is sensitive to 3D effects and, consequently, these effects in this weak zone could have important implications in the general response of the test simulation.

However, in general terms, it could be stated that, as it happens with the reinforced flexural UHPFRC beams in section 6.2.4.1 of this chapter, it could be considered that UHPFRC exhibits full-tension stiffening behaviour in tension. Moreover, this behaviour is simulated with a good accuracy with the 2D-NLFEM and also with the complete 3DNLFEM-multicrack which adjusts in a better sense the shrinkage and is also sensitive to $3 \mathrm{D}$ effects including the consequences in the weak zone generated in the transition of the steel reinforcement section.

\subsubsection{3D-NLFEM-multicrack detailed application}

At this point, an example of the results of the 3D-NLFEM-multicrack application is presented. The objective is to show visually how the model is able to simulate with reliability the different stages of the experimental tensile test. The 100x100; $\phi 16$ UHPFRC tensile bar with $60 \%$ of $3 \mathrm{D}$ shrinkage increment $\left(\mathrm{sh}_{\text {inc3D }}\right)$ and $60 \%$ of $3 \mathrm{D}$ effects ( $\varepsilon_{3 \text { Deffects }}$ ) obtained from Table 6.12 is analysed. Figure 6.76 represents the P- $\Delta u$ response from two runs of the random analysis using the characteristics for RUN 6 and 7 described in Table 6.11. As it can be seen in Figure 6.76 the two runs offer similar results and the difference between them is only due to the material variation modelled in the random variation of the FRCFAC factor. As it happens with the flexural beams (see Figure 6.6), in the direct tensile test modelled here, similar phases can be observed in the UHPFRC's P- $\Delta \mathrm{u}$ curve represented in Figure 6.76: an uncracked phase where the response of UHPFRC bar is elastic, a microcrack formation where the response of the tensile bar starts to lose its initial stiffness, a microcrack stabilisation phase where the particularisation of the tension stiffening phenomena for UHPFRC and reinforcement takes place and the moment of collapse where the macrocrack appears and the reinforcement is yielded. Consequently, in this application, four levels are analysed to study how the experimental test would be simulated using the model: at 30 days (just before the test starts) where there is only the shrinkage effect, at $40 \mathrm{kN}$ during the elastic uncracked phase, at $90 \mathrm{kN}$ during the microcrack stabilisation phase and, although the collapse level is not reached in the experimental test, some results of the model are showed to simulate the state of the tensile bar at this moment. 


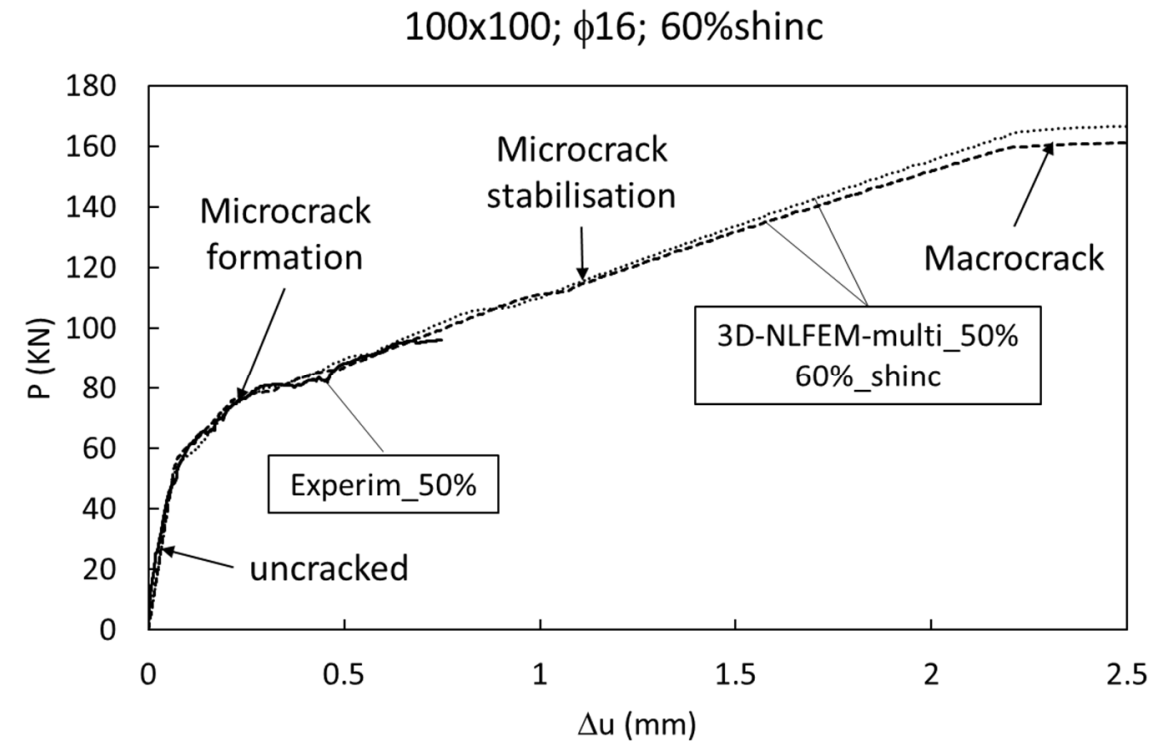

Figure $6.76 P-\Delta u$ response for the 100x100; $\phi 16$ specimen compared to the $3 D$ NLFEM-multicrack

Figure 6.77 represents the stresses in UHPFRC and in the reinforcement at 30 days when the test is going to start. These stresses are produced due to the shrinkage at 30 days. As it can be observed, there is a big concentration of stresses in concrete where the reinforcement changes the section. This can influence to a large extent in the subsequent response when the test starts. As it is expected because their definition, the same shrinkage pattern as in the solid UHPFRC elements takes place in the UHPFRC interface elements that represent the multicrack model between each vertical of the structural solid elements (see Figure 6.77). 


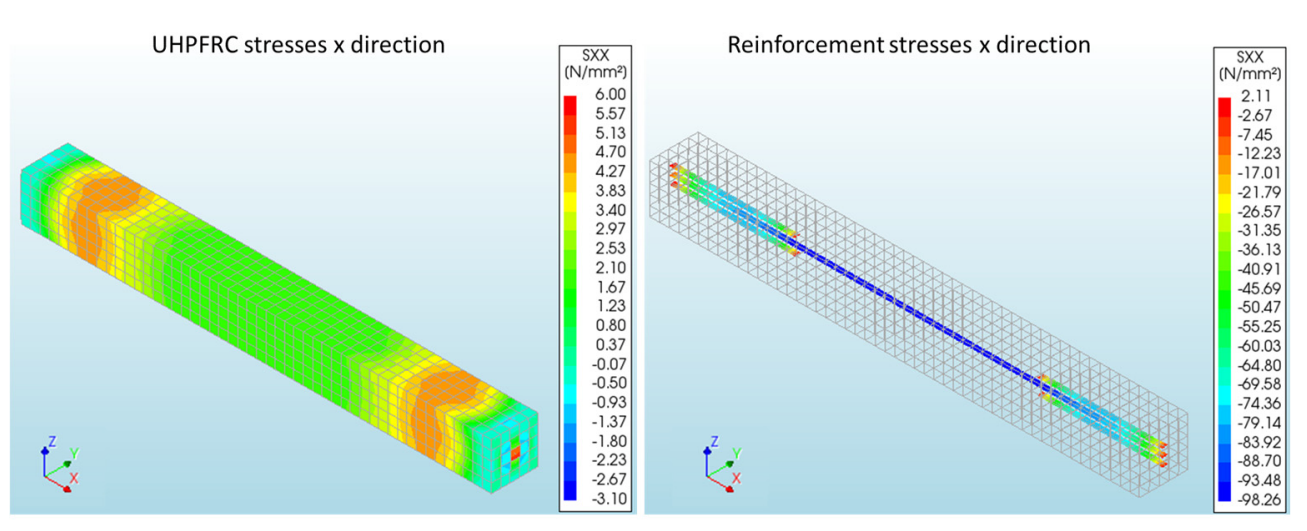

Interface stresses $\mathrm{x}$ direction

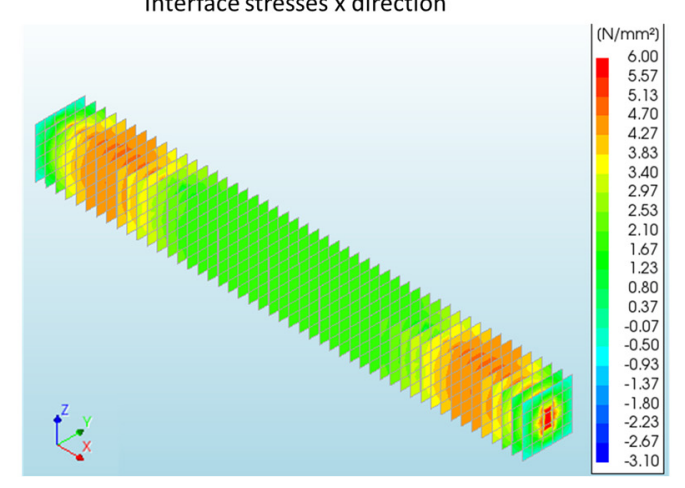

Figure 6.77 UHPFRC stresses in solid elements in $x$ direction, stresses in the reinforcement and in the interface elements at shrinkage phase

Figure 6.78 shows in more detail the influence of the change of section in the reinforcement and how it affects to the surrounding concrete when there are the three bars (Figure $6.78(\mathrm{left})$ ) at $0.12 \mathrm{~m}$ from the active extreme of the specimen and when there is only the central bar (Figure 6.78(right)) at $0.26 \mathrm{~m}$. It can be observed how this influence causes a radial effect in the stresses in the section, which is obvious in the case of the three bars and declines in the following sections when there is only the central continuous bar. Moreover it can be observed the instability generated in this part of the UHPFRC bar because when there are three bars at $0.12 \mathrm{~m}$ (Figure 6.78(left)) the stresses are reduced from the centre to the edges of the section and, when there is only one bar at $0.26 \mathrm{~m}$ (Figure 6.78(right)), the stresses are increased. It seems that there is an effect produced by the anchorage of the bars from their end to several centimetres onwards. This effect is attenuated and leads to the regularisation of stresses in the section closer to the midspan section, as it can be seen in Figure 6.79. This zone will constitute a weak zone during the test that will derive in difficulties in convergence of the non-linear analysis and, consequently, in the stability of the model during the test. 


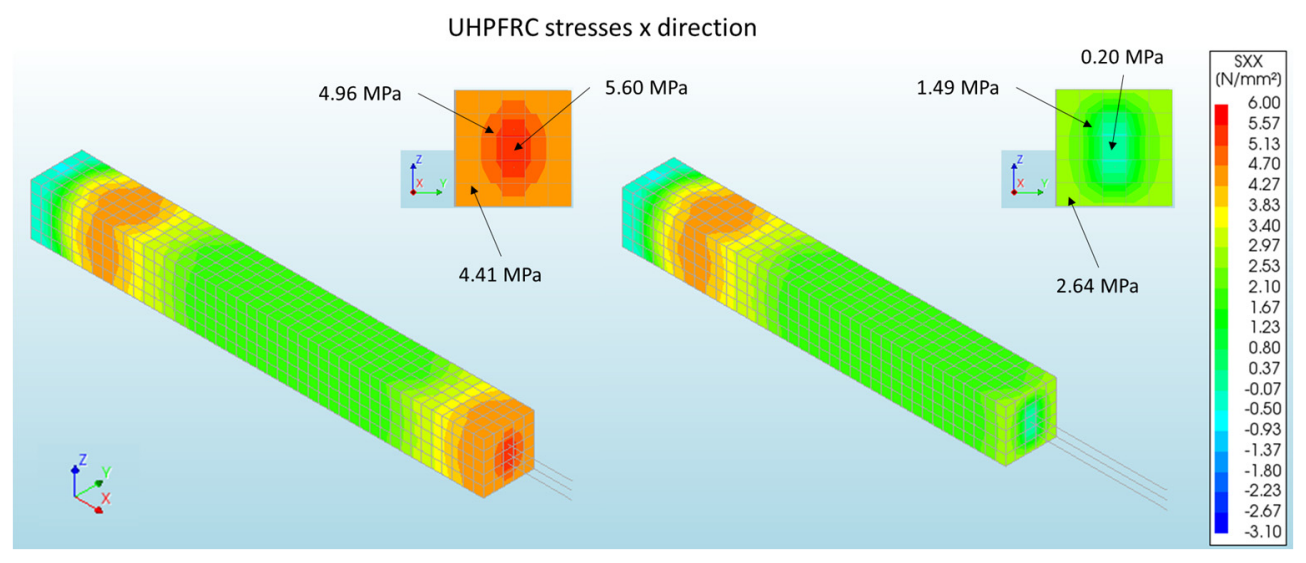

Figure 6.78 Shrinkage stresses in UHPFRC at $0.12 \mathrm{~m}$ (left) and $0.26 \mathrm{~m}$ (right) from the active extreme.

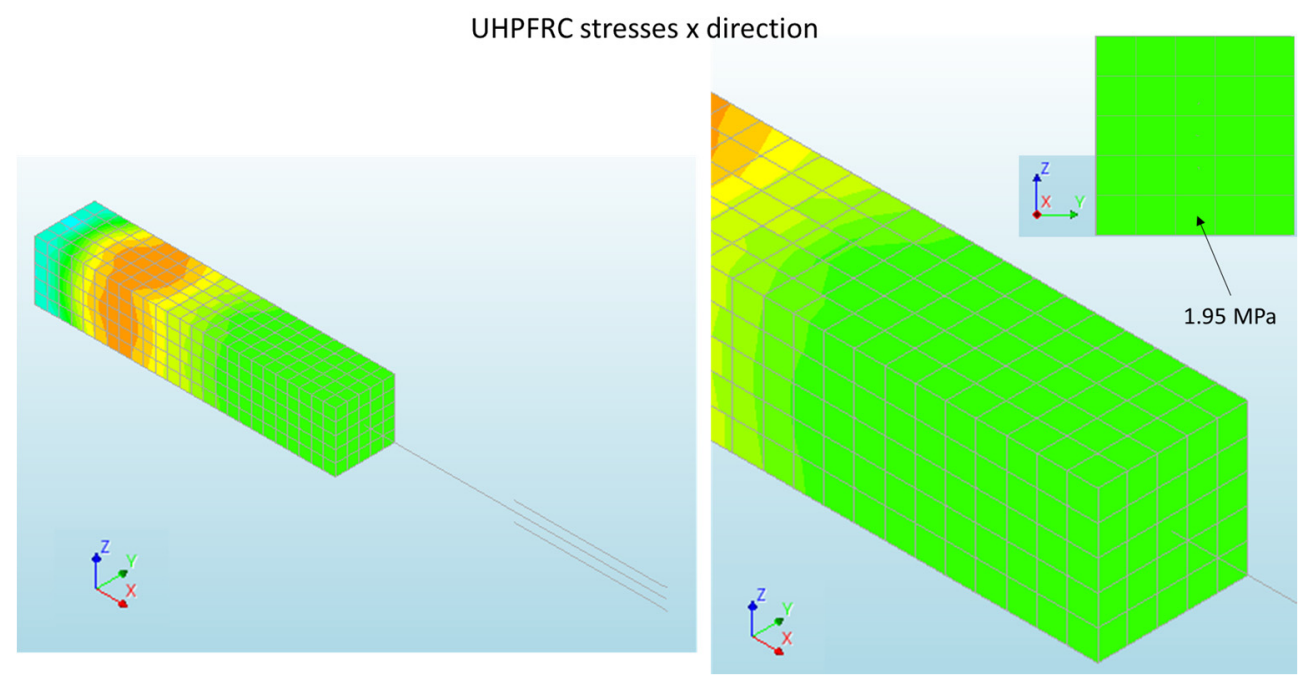

Figure 6.79 Shrinkage stresses at mid span section $(0.50 \mathrm{~m}$ from the extremes of the tensile bar).

More concentrated stresses are generated at the beginning of the specimen at the position of the bar as it is shown in Figure 6.80(left). From the section highlighted in Figure 6.80 (left) situated at $0.04 \mathrm{~m}$ from the active extreme of the specimen a very close 
concentration of stresses appears due to the shrinkage, as it can be seen in Figure 6.80(right). Again, this will be a singular zone that will lead to converge and instability problems during the test simulation. As it is observed at Figure 6.80(right) the shrinkage stresses are developed in a radial distribution from the centre to the edges of the section.

UHPFRC stresses $\mathrm{x}$ direction

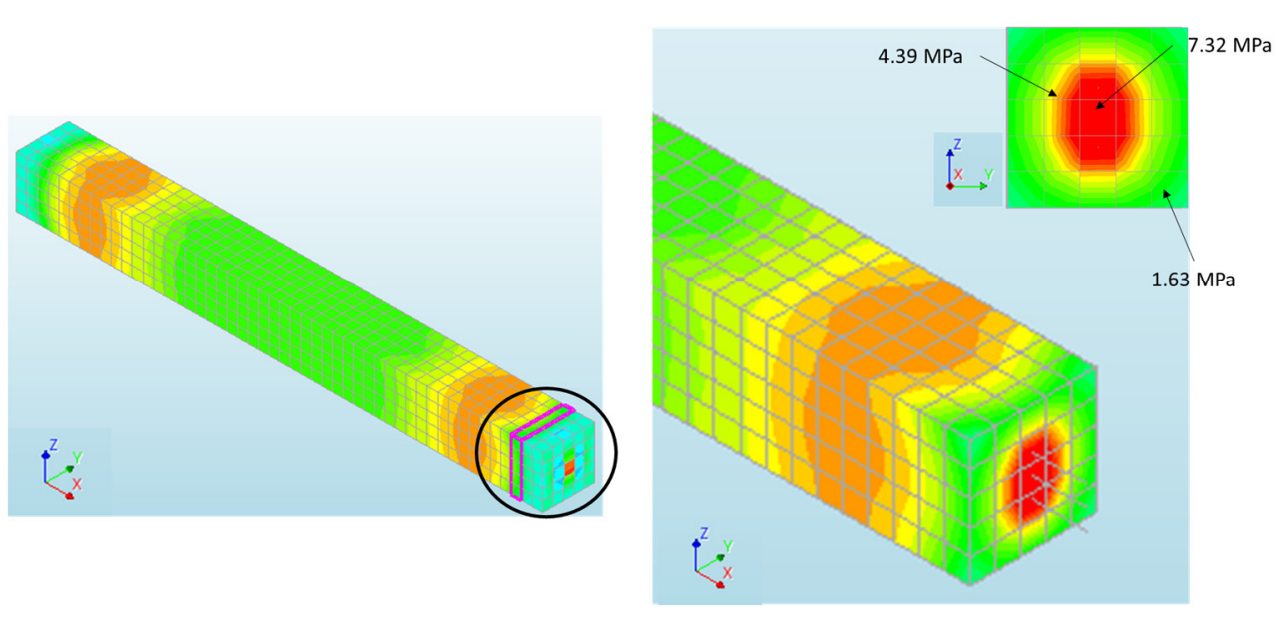

Figure 6.80 Shrinkage stresses at $0.04 \mathrm{~m}$ from the active extreme of the tensile bar.

From the analysis at this phase (shrinkage phase) it can be stated that the shrinkage influence due to the bond-slip transmission between UHPFRC and reinforcement has a very important effect in the internal stresses that are developed before the experimental test starts and this is going to cause an important consequence in the test and will determine the response of UHPFRC and the reinforcement during the experimental test. As it happens with the flexural beams, in the tensile bars UHPFRC is pre-stressed near the tensile strength and this fact will influence in its bearing capacity generating weak zones specially where there are big differences of stiffness in a concentrated band due to the change of reinforcement section. On the other hand, the reinforcement will increment its bearing capacity because it is pre-compressed before the tensile test.

Figure 6.81 represents the stresses in UHPFRC and in the reinforcement at $40 \mathrm{kN}$ during the elastic uncracked phase (see Figure 6.76). As it can be observed the stress pattern during this phase of the test is the same as the shrinkage phase but increasing the stress level due to the tensile test and influenced by the previous stage. As it is expected, the same stress pattern is generated when the interface stresses are represented in Figure 6.81. This figure constitutes a great scan of the stress profile along the tensile bar when it is compared to the UHPFRC stress representation. It can be observed how the radial distribution is generated inside the profile in the adjacent slices. Moreover, it can be 
observed how the central part of the bar remains homogeneous generating a regular stress transmission between the reinforcement bar and the UHPFRC and, therefore, a regular tensile test. The instability zone, where there is the change of steel rebar section from three bars to one, becomes evident when the flow of the principal directions is represented in Figure 6.81. This is an announcement of where the first cracks are going to take place as the load increases. In the central part of the bar, as it can be observed in Figure 6.81 this effect is attenuated and leads to the regularisation of stresses, which is the idea of this kind of tensile test.

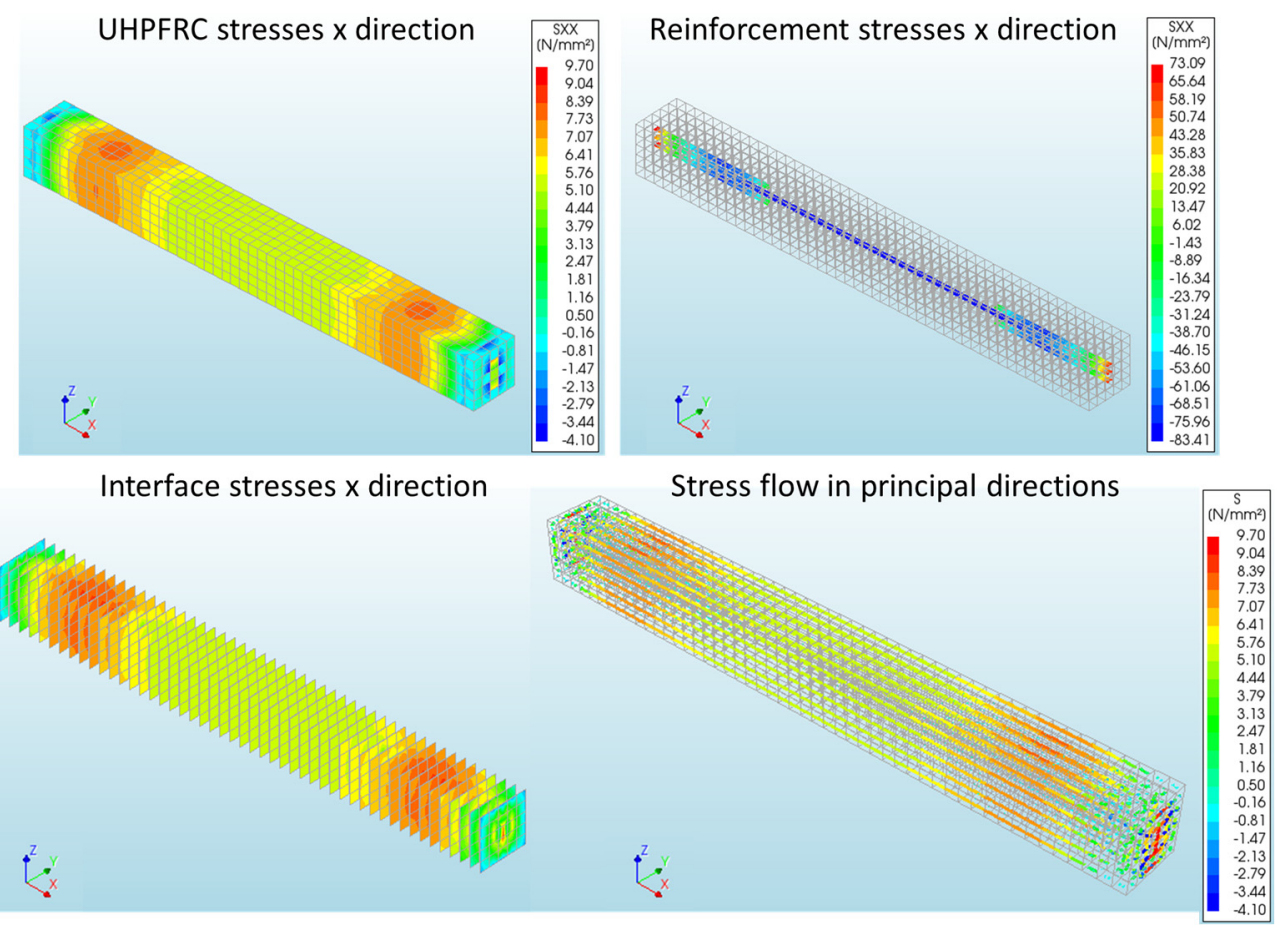

Figure 6.81 UHPFRC stresses in solid elements in $x$ direction, stresses in the reinforcement, stresses in the interface elements and stress flow in the principal directions at elastic uncracked phase (at 40kN).

Consequently, in Figure 6.82, the stresses are increased because the load is transmitted to the UHPFRC by bond-slip between the reinforcement and the surrounding concrete. In sections at $0.04 \mathrm{~m}$ and $0.12 \mathrm{~m}$ from the active extreme, where there are the three bars, the stress in the centre is increased very close to the UHPFRC tensile strength and, in this phase, the stress at $0.12 \mathrm{~m}$ section is higher than the one at $0.04 \mathrm{~m}$. As it happens in 
the shrinkage phase before described, the same effect produced by the anchorage length at section $0.26 \mathrm{~m}$ is generated. It is, it seems to exist an influence of the change of steel section that generates a decompression in the place of the three bars. Therefore, in this part of the bar, as it is explained before, there is the instability zone.
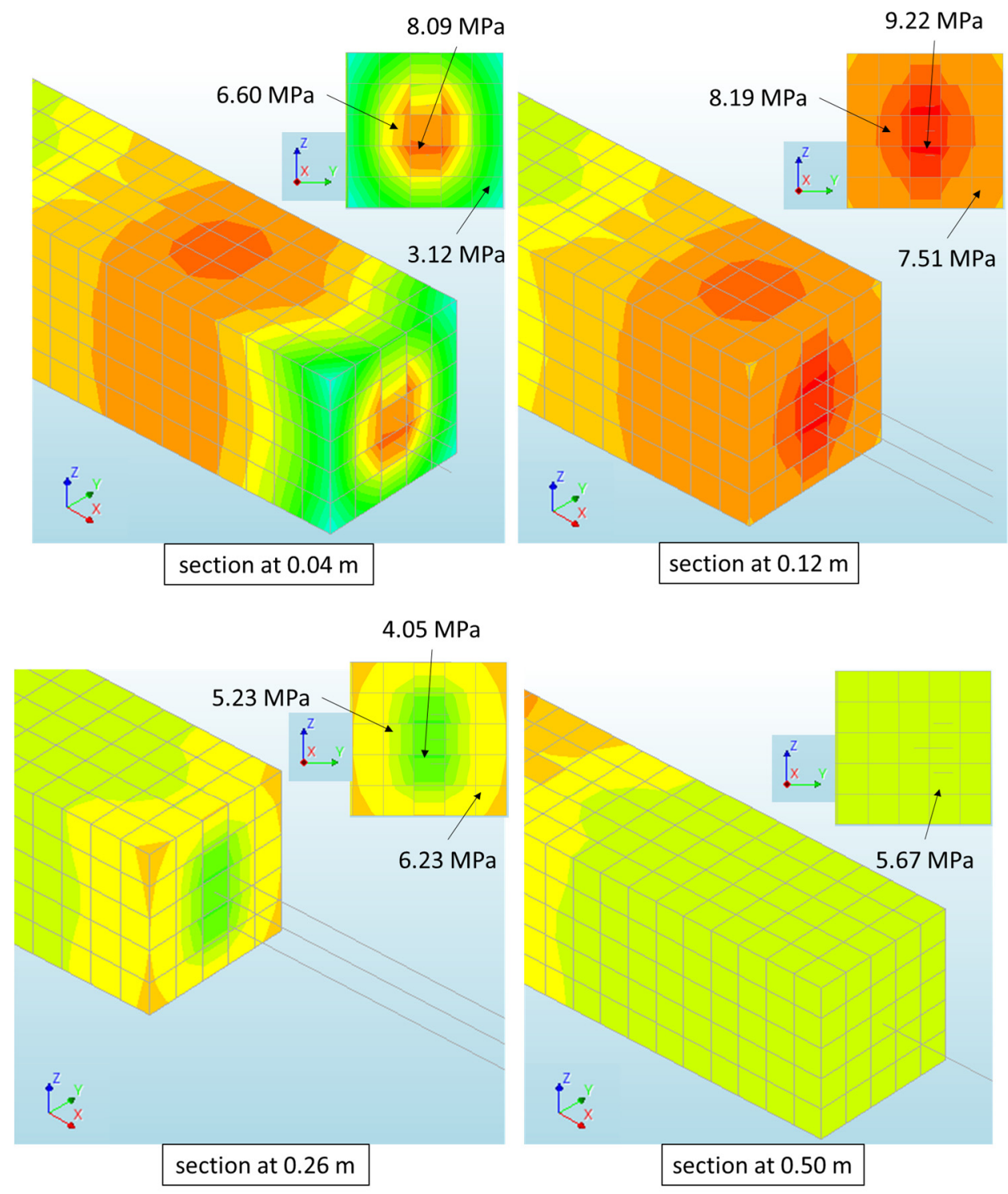

Figure 6.82 UHPFRC stresses in $x$ direction at $0.04 \mathrm{~m}, 0.12 \mathrm{~m}, 0.26 \mathrm{~m}$ and $0.50 \mathrm{~m}$ from the active extreme during the elastic uncracked phase (at 40kN) 
Figure 6.83 represents the stresses in UHPFRC and in the reinforcement at $90 \mathrm{kN}$ during the microcrack stabilisation phase (see Figure 6.76). At this phase all the central part of the bar, including the instability zone, has reached or is near the tensile strength and maybe some parts are in the descending branch of the stress-strain diagram as the tensile behaviour of the UHPFRC used in the tensile bars exhibits SS (see Table 6.9). In addition, the interface stresses are represented in Figure 6.83. In this figure it is possible to see how the stresses in UHPFRC are distributed across the sections of the bar. It can be observed that there are sections where the stresses are not uniformly distributed. Moreover the UHPFRC stress flow is represented in Figure 6.83. It can be observed that there are sections where the stress flow is distort and this distortion varies even in the same section where it appears. These could indicate that a localised crack formation is taking place at these sections.

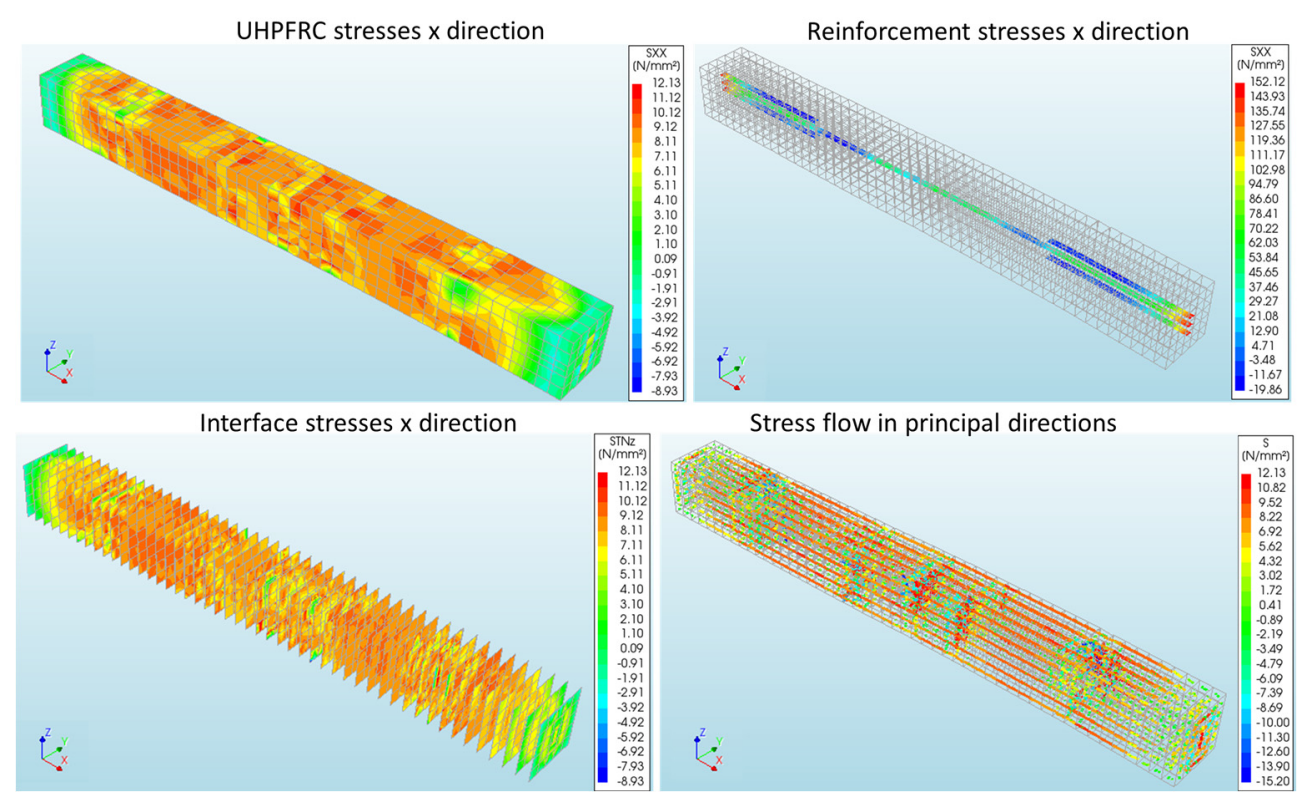

Figure 6.83 UHPFRC stresses in solid elements in $x$ direction, stresses in the reinforcement, stresses in the interface elements and stress flow in the principal directions in the microcrack stabilisation phase (at 90kN)

For more detail in Figure 6.84 the sections at $0.04 \mathrm{~m}, 0.12 \mathrm{~m}, 0.26 \mathrm{~m}$ and mid-span $(0.50$ $\mathrm{m})$ are shown. It can be observed in this figure that $0.04 \mathrm{~m}$ section has relaxed a bit the stress level with respect to the previous phase (see Figure 6.82) but, concerning the rest of sections analysed, it is not clear if they reached the tensile strength $\left(f_{t}\right)$ and therefore they are cracked or not. This is, if the value of stress represented for each section in Figure 6.84 is in the softening part of the constitutive $\sigma-\varepsilon$ diagram or it is before the peak. In Figure 6.85 cracks are represented at different crack opening widths to see how they 
are distributed along the bar. Therefore it can be seen what are the sections that are cracked. In the case of Figure 6.84, sections $0.12 \mathrm{~m}, 0.26 \mathrm{~m}$ and $0.50 \mathrm{~m}$ (mid span) are near cracking but not yet so they are before the peak $\left(f_{t}\right)$ of the constitutive $\sigma-\varepsilon$ diagram. As it is observed the crack pattern is typical of SS-UHPFRC element as it is studied before with the flexural beams at Figure 6.41, Figure 6.42 and Figure 6.48.
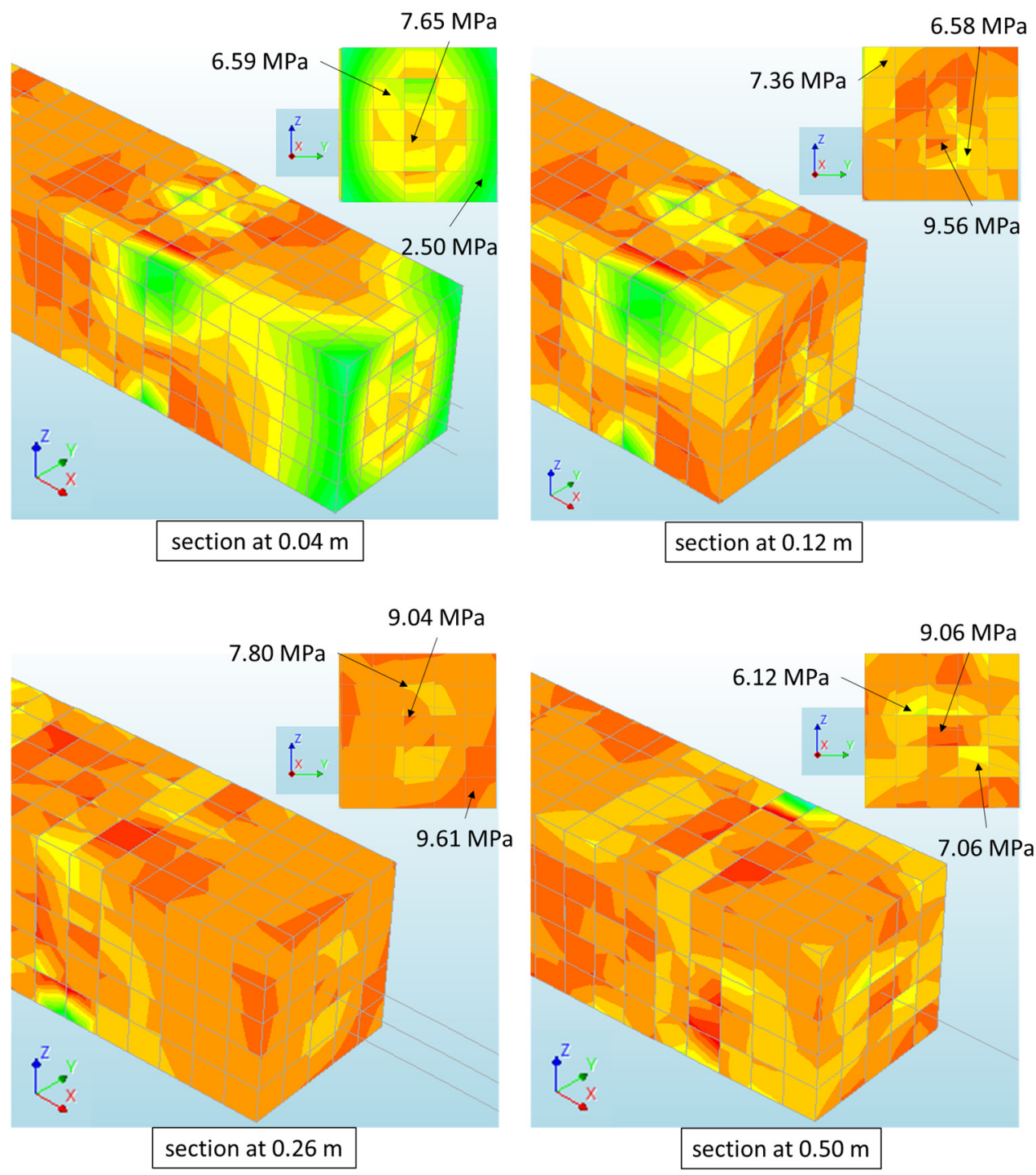

Figure 6.84 UHPFRC stresses in $x$ direction at $0.04 \mathrm{~m}, 0.12 \mathrm{~m}, 0.26 \mathrm{~m}$ and $0.50 \mathrm{~m}$ from the active extreme during the microcrack stabilisation phase (at $90 \mathrm{kN}$ ) 
As it can be seen in Figure 6.85(1) and Figure 6.85(2) cracks are very opened $(0.45 \mathrm{~mm})$ and their distribution is concentrated in specific zones. Figure 6.85(1) represents the crack pattern limited to $0.10 \mathrm{~mm}$ in order to visualise the crack distribution in detail with the colour map of the model. There, it can be observed very clearly where is situated the possible macrocrack path. Figure 6.85(2) represents the crack pattern taking into account the maximum crack opening detected $(0.45 \mathrm{~mm})$. In this case, as the colour map is coarser it can be detected only the "peaks" where the cracks are very open. Therefore, as it can be observed, the crack pattern represented in Figure 6.85(2) is embedded in the one represented in Figure 6.85(1) and details the peaks of cracks opening in it. As it is stated before, this particular crack distribution is because the UHPFRC used to cast the tensile bars exhibits SS constitutive behaviour (Table 6.9). If UHPFRC would have exhibited $\mathrm{SH}$, the crack pattern would be more smeared along the body of the tensile bar. In Figure 6.85(3) the cracked sections are represented in more detail to see how the crack is extended through the section which is affected. Figure 6.85(4) is the same representation done in Figure 6.85(3) but rotated to see the cracking profile from the other side. It is interesting to see how the crack opening profile can be distributed in different directions through the section depending on its position. It can be observed how this localised crack could be macrocrack but only in a partial zone of the section. This is, the macrocrack does not cross the entire section. There is part of the section cracked while the rest remains uncracked or in process of cracking. This generates local turns of the tensile bar in sections where this phenomenon appears. However, this fact does not affect the global mechanical response of the specimen as the NLFEM represents the P$\Delta \mathrm{u}$ curve of the tensile test very accurate as it is depicted in Figure 6.76. The crack pattern along the body of the tensile bar is not symmetric and does not follow a foreseeable distribution as it happened with the flexural beams. This demonstrates the complexity of this kind of test not only from the experimental point of view but also from the modelling one. The numerical analysis is difficult to be stabilised and the numerical convergence is hard. 


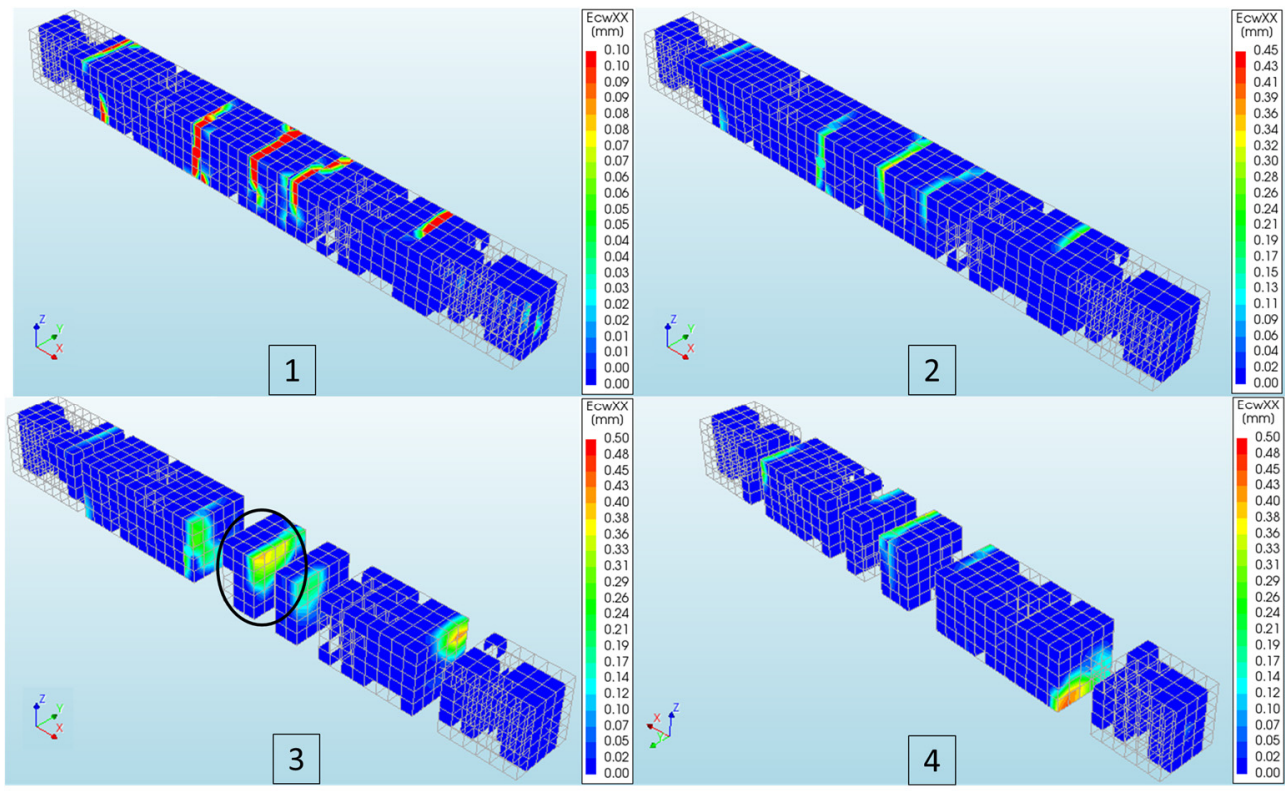

Figure 6.85 Cracking pattern in $x$ direction at the microcrack stabilisation phase (at 90kN): crack representation between 0-0.10mm (1); between 0-0.45mm (2); between 0$0.50 \mathrm{~mm}$ crack section detailed; between $0-0.50 \mathrm{~mm}$ crack section detailed rotated (4).

Figure 6.86 shows the stress distribution in the section emphasised at Figure 6.85(3) located at $0.46 \mathrm{~m}$ from the active extreme of the tensile bar and the stress-strain diagram of a node (node 6347) located in the macrocrack zone of the section. As observed the stress value of $6.95 \mathrm{MPa}$ (Figure 6.86(left)) is clearly in the softening part of the $\sigma-\varepsilon$ UHPFRC behaviour. This node has a strain value of $17 \%$ (Figure 6.86(right)) which is over $\varepsilon_{f u}=3.31 \%$ (see Table 6.9) and a crack opening of $0.41 \mathrm{~mm}$ (see Figure 6.85(3)). As it can be observed the crack is gradually opened across the section and the stresses come from the elastic branch of the $\sigma-\varepsilon$ UHPFRC behaviour, where there is no crack opening, to the softening branch, where the crack is completely open. 

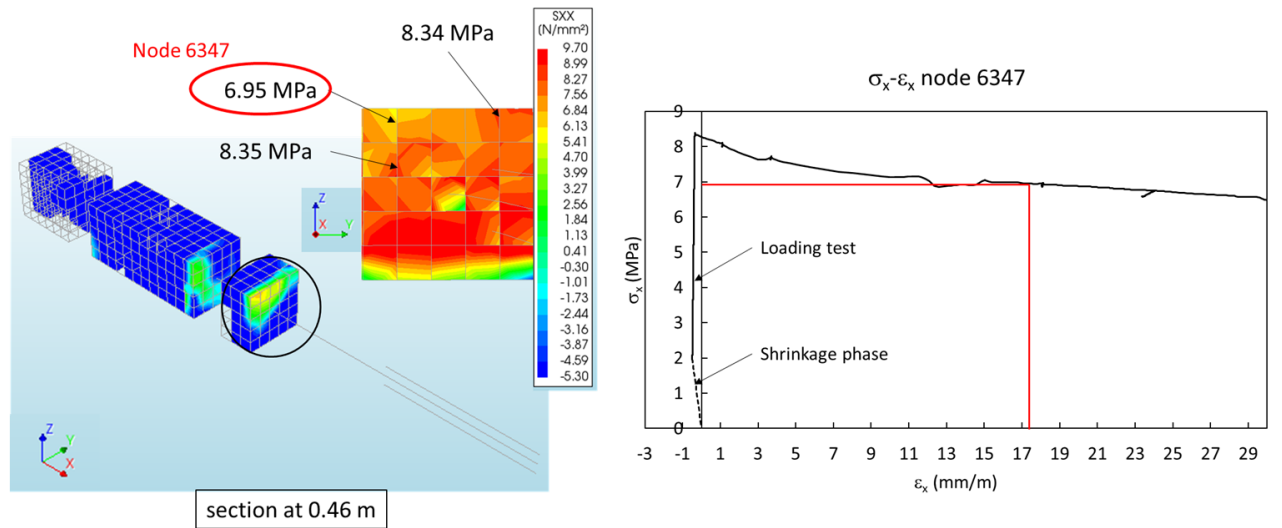

Figure 6.86 Tensile analysis of a partial macrocracked section (left) and $\sigma$-E diagram of node 6347 located in the macrocrack zone (right)

These partial macrocrack apparitions are directly related to the random distribution of the FRCFAC factor generated by the random algorithm of the 3D-NLFEM-multicrack. Figure 6.87 shows the section located at $0.46 \mathrm{~m}$ of the active extreme represented at Figure 6.86. As it can be observed in Figure 6.86(right) the tensile strength value is 8.39 $\mathrm{MPa}$ at node 6347 . If $8.39 \mathrm{MPa}$ is divided by the $f_{t}$ value $9.62 \mathrm{MPa}$ from Table 6.9, the FRCFAC factor obtained is FRCFAC $=0.87$ that is the value represented in Figure 6.87 (right) where the macrocrack is initiated in $0.46 \mathrm{~m}$ section. Therefore, this partial macrocrack phenomenon is generated from the random distribution of the FRCFAC factor by the 3D-NLFEM-multicrack that models the material heterogeneity together with the particular crack distribution due to the SS constitutive behaviour of the UHPFRC used for the tensile bars.

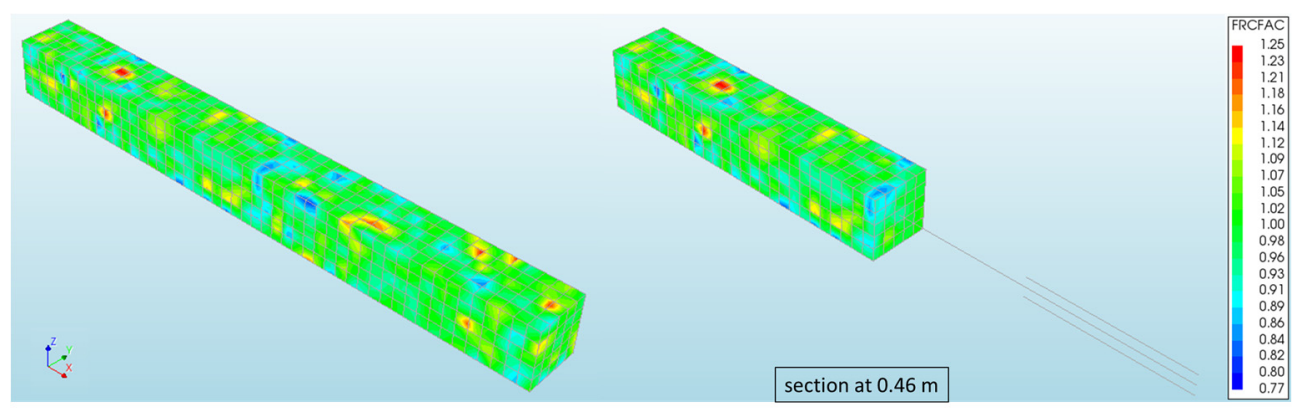

Figure 6.87 FRCFAC random distribution in all the tensile bar (left) and in $0.46 \mathrm{~m}$ section (right) 
Consequently, UHPFRC that exhibits SS constitutive behaviour and manifests relatively important heterogeneity is able to have a good global mechanical response but would develop localised cracks that could lead to durability problems. The 3D-NLFEMmulticrack is able to model these effects. This is not the case of UHPFRC with SH constitutive behaviour and high grade of homogeneity in its properties. Therefore, for UHPFRC with SS is necessary to take into account the durability by means of very well cast and poured concrete and maybe the use of particular additions related to self-healing and improvement of concrete matrix microstructure durability properties (Doostkami et al. 2020; Ferrara et al. 2016, 2017, 2018; Kim et al. 2019; Negrini et al. 2019; Roig Flores 2018; Serna et al. 2019; Wang et al. 2014).

Figure 6.88 represents the UHPFRC stresses, the stresses in the reinforcement and the interface stresses in $\mathrm{x}$ direction and the stress flow in principal directions in the moment of collapse at $167.88 \mathrm{kN}$ (see also Figure 6.76). As it is observed, UHPFRC has reached or it is near the UHPFRC tensile strength $\left(f_{t}\right)$. Even more, there could be sections where the UHPFRC ultimate tensile strength $\left(f_{t u}\right)$ could be overcome and, consequently, the macrocrack takes place. The interface stresses in $\mathrm{x}$ direction represent also a scan of the specimen through its sections. It can be observed how the stresses vary through section depth. If the stresses in the reinforcement in $\mathrm{x}$ direction are observed it can be seen how the reinforcement central bar has reached its yielding strength at different points. These points are coincident to those points of concentration of stresses depicted in the UHPFRC stress flow in principal directions image in Figure 6.88.

In addition, Figure 6.89 represents the crack opening in $\mathrm{x}$ direction in the moment of collapse at $167.88 \mathrm{kN}$ (see also Figure 6.76). Figure 6.89(1) depicts the crack opening restricted to $0.10 \mathrm{~mm}$ with the idea to emphasise the position of the cracks. It can be observed how the cracks appear at the same points where the reinforcement central bar reaches its yielding strength and the concentration of stresses in the UHPFRC stress flow takes place in Figure 6.88. Figure 6.89(2) represents the maximum crack opening (9.32 $\mathrm{mm}$ ) and its position along the specimen. It can be observed that it is an evolution of one of the cracks represented in Figure 6.89(1). Figure 6.89(3) and Figure 6.89(4) represent the progress of the cracks through the sections seen from both directions of the $\mathrm{x}$ edge. It can be observed how the macrocrack opening, represented here as a maximum crack opening of $0.5 \mathrm{~mm}$, is very extended through the sections even reaching the position of the reinforcement and, therefore, transmitting the stress to the reinforcement generating a stress peak where the steel reaches its yielding strength. Therefore, it can be stated that the 3D-NLFEM-multicrack is able to simulate the collapse moment with a great level of sense and coherence. It represents the situation that could be expected in the reality. 


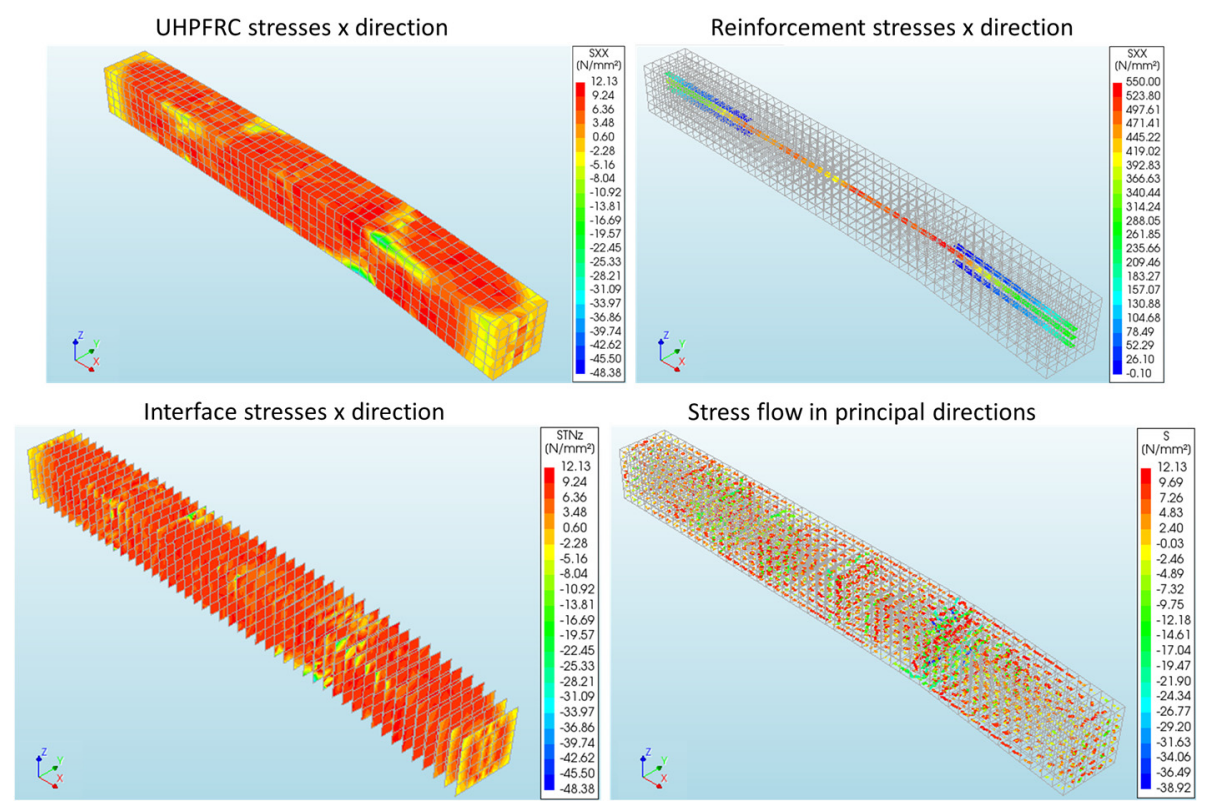

Figure 6.88 UHPFRC stresses in solid elements, stresses in the reinforcement and stresses in the interface elements in $x$ direction and stress flow in the principal directions in the collapse moment.

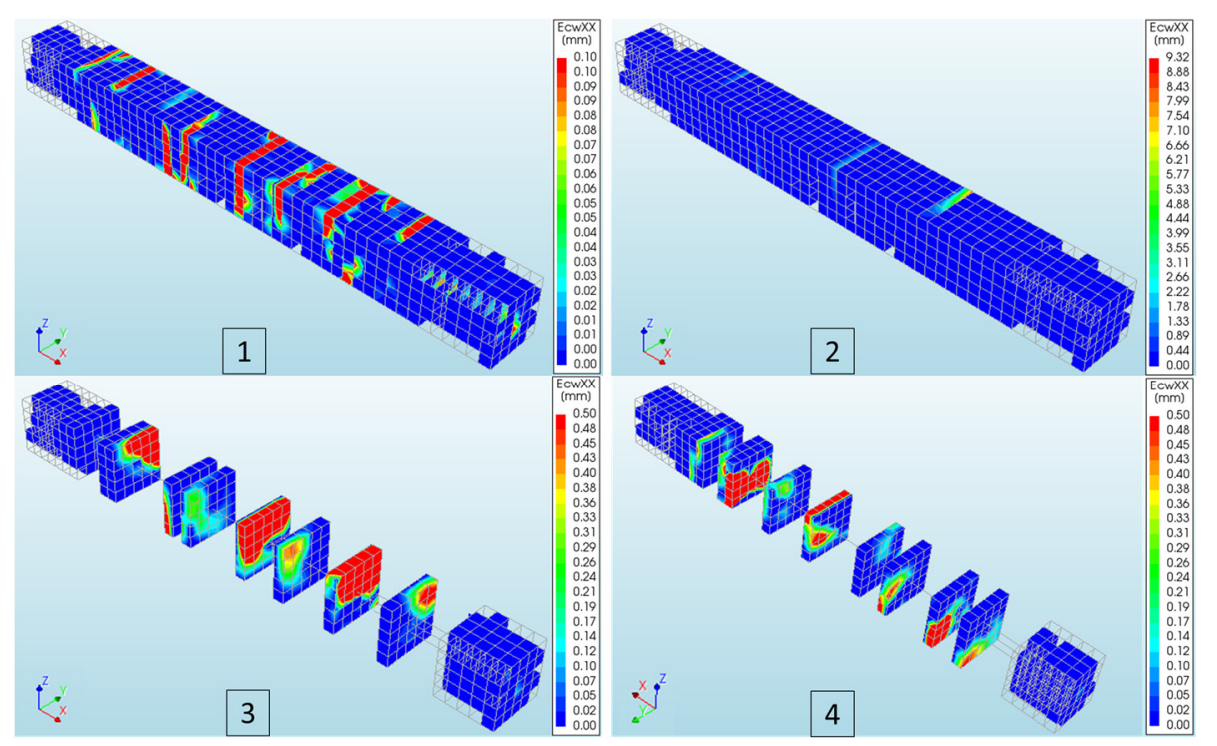

Figure 6.89 Cracking pattern in $x$ direction in the collapse: crack representation between 0$0.10 \mathrm{~mm}$ (1); between $0-0.45 \mathrm{~mm}$ (2); between 0-0.50mm crack section detailed; between 0-0.50mm crack section detailed rotated (4). 


\subsection{Chapter summary and relevant conclusions}

The first part of this chapter addresses the complete study of flexural reinforced UHPFRC tensile behaviour. An experimental programme of reinforced UHPFRC beams is carried out on two different scales. Furthermore, a non-linear finite element model (NLFEM) is developed. Finally, some aspects dealing with the design of reinforced UHPFRC cross-section with bending and axial forces under failure and serviceability conditions are addressed and compared to the beams included in the experimental programme.

After applying NLFEM to reinforced beams, the following conclusions can be drawn:

If the characteristic tensile constitutive parameters used to mechanically characterise UHPFRC are implemented into the NLFEM of reinforced beams, the numerical response accurately fits the experimental one at the $5 \%, 50 \%$ and $95 \%$ percentile levels. This result demonstrates the reliability of the developed NLFEM, as well as the coherence of the UHPFRC tensile material characterisation process.

The model is developed using two different approaches: the smeared cracking approach and the discrete cracking approach. The differences in the results between the two approaches are negligible, unlike the response obtained with the unreinforced specimens in the 4PBT as reported in previous chapter. Reinforcement has a notorious influence on the mechanical behaviour of specimens when macrocracking appears via the "tensionstiffening" mechanism.

Given its particular dosage, UHPFRC is a concrete type that undergoes a high shrinkage level. By using NLFEM, the shrinkage strain is deduced within a range of [0.70, 0.84] $\mathrm{mm} / \mathrm{m}$, which is consistent with other research works. This can generate internal stresses before test starts, which need to be taken into account given the potential influence on the beam's service response. According to the NLFEM simulation, the internal tensile stresses in the UHPFRC matrix come close to the tensile strength $\left(f_{t}\right)$. Therefore, it can be concluded that the shrinkage effect on UHPFRC is very important and, consequently, its influence on the beam's structural response is not at all negligible.

The cracking process and the cracking pattern simulated by NLFEM is completely reliable and very well represents reality in both cases: at the service and ultimate load levels. It is important to underline, as it is demonstrated here, that the cracking process and also the cracking pattern depends on the hardening ratio of the UHPFRC used to cast the element.

The flexure strength predictions of long beams are quite accurate and very dependent on the tensile force that fibres can carry out. Both beams showed a nearly full-tension stiffening response $(\beta \approx 1)$ under serviceability conditions, which simplifies the evaluation of the effective moment of inertia for the control of deflections. Consequently, 
as it is demonstrated, in beams exhibiting full-tension stiffening, flexure stiffness remains constant in the microcrack stabilisation phase with a value that can be easily and accurately predicted by assuming the fully cracked reinforced UHPFRC cross-section's flexural stiffness.

The second part of this chapter deals with the application of the NLFEM to modelling a UHPFRC direct tensile test. Samples of an experimental campaign carried out in work done in the research group have been modelled using the discrete cracking approach of the 2D-NLFEM and the 3D-NLFEM. Moreover, an evolution of the 3D-NLFEM has been addressed: 3D-NLFEM-multicrack. This improved 3D model consists on the definition of interface behaviour not only at the mid span section but also between all the 3D solid elements in the same vertical. In this sense, a composed finite element defined by a 3D solid element bounded vertically by two interface elements at each side able to represent the real UHPFRC $\sigma-\varepsilon / w$ constitutive law defined in phase 1 (see Figure 3.2) is generated. Moreover, in the analysis definition, a random variation of the FRCFAC factor that multiplies the values of the UHPFRC tension stress in the constitutive behaviour of the NLFEM has been added to better model the heterogeneity of concrete.

After applying NLFEM to tensile UHPFRC bars adopted, the following conclusions can be drawn:

The P- $\Delta \mathrm{u}$ response obtained from the application of the 2D-NLFEM and the 3DNLFEM-multicrack when the $50 \%$ percentile of tensile UHPFRC constitutive parameters obtained from the $4 \mathrm{PBT}$ and the softening correction are used in the model fits accurately the experimental P- $\Delta \mathrm{u}$ response. This demonstrates not only the reliability of the developed NLFEM, but also the coherence of the process to characterise the tensile behaviour of UHPFRC also in reinforced direct tensile tests.

When using the 2D-NLFEM to model the tensile test, the calculated UHPFRC shrinkage strain $\left(\varepsilon_{C S U H P F R C}\right)$ falls within the range of $[0.51,0.96] \mathrm{mm} / \mathrm{m}$. From the other hand, when the 3D-NLFEM-multicrack is used to model the tensile test the calculated UHPFRC 3D shrinkage strain $\left(\varepsilon_{C S U H P F R C 3 D}\right)$ falls within the range of $[0.37,0.73] \mathrm{mm} / \mathrm{m}$. Therefore, the difference between the two models considered as the strain due to the 3D effects falls within the range of $[0.10,0.23] \mathrm{mm} / \mathrm{m}$. Consequently, the 3D-NLFEM-multicrack is able to quantify the 3D effects that affect this particular kind of tensile test.

UHPFRC exhibits full-tension stiffening behaviour in tension. The 2D-NLFEM adjusts very well the experimental P- $\Delta \mathrm{u}$ response. The effect of the weak zone where there is an abrupt transition between the rebars section in the tensile test could be considered included in the 3D effects that make the difference between the 2D-NLFEM and the 3DNLFEM-multicrack. The 3D model is sensitive to 3D effects and, consequently, these effects in this weak zone could have important implications in the general response of the test simulation. Therefore, in general terms, it could be stated that, with the complete 3D-NLFEM-multicrack the shrinkage and also the 3D effects including the 
consequences in the weak zone generated in the transition of the steel reinforcement section are accurately modelled and leads to a complete model able to simulate the UHPFRC response in a tensile test.

From the 3D-NLFEM-multicrack detailed application it can be concluded that the NLFEM developed not only is able to model the behaviour of the tensile test as a whole but also as a detailed simulation through its structural response. This is, the NLFEM simulates with high level of reliability the UHPFRC behaviour at macroscale $\left(\mathrm{m} \mathrm{or} \mathrm{m}^{-1}\right)$ and at mesoscale $\left(\mathrm{m}^{-3}\right)$ levels. If different levels of the accurate $\sigma-\Delta \mathrm{u}$ structural response of the NLFEM are studied it can be observed that the model reproduces with sense and coherence what could be expected in reality at these stages: before the test starts (shrinkage influence), during the elastic uncracked phase, during the microcrack stabilisation phase and at the collapse level, taking into account the random distribution of the material properties and the crack pattern depending on UHPFRC tensile behaviour: SS or SH. It is also able to overcome local instabilities generated by differences of stiffness due to the variation of reinforcement and represents with a good accuracy the regularisation of stresses in the central part that characterise this particular kind of tensile test. The apparition of partial macrocracks due to the SS-UHPFRC and the random distribution of stresses lead to local turns that not affect the general response of the tensile bar. However, it would be necessary to take into account the generation of these partial macrocracks in terms of SS-UHPFRC durability.

From the two parts of this chapter, it can be concluded that a NLFEM applicable at 2D and $3 \mathrm{D}$ level is developed to modelling the tensile behaviour of UHPFRC for steel reinforced elements. This model considers shrinkage effects, 3D effects due to the particularities of the test and tension stiffening behaviour that lead to a very accurate results when they are compared to the experimental tests. The NLFEM becomes more accurate as it reproduces with more similarity the real UHPFRC constitutive behaviour by means of composed finite elements defined by a 3D solid element bounded vertically by two interface elements at each side able to represent the real UHPFRC $\sigma-\varepsilon / w$ constitutive law defined in phase 1 .

The flexural and direct tensile tests are modelled with reliability using the simple direct process to characterise the UHPFRC tensile behaviour from 4PBT consisting in a 4P-IA and the softening correction for the case of SS-UHPFRC. Consequently, this demonstrates not only the reliability of the developed NLFEM, but also the coherence of the process to characterise the tensile behaviour of UHPFRC in reinforced flexural and direct tensile tests. 


\section{Chapter 7}

\section{Conclusions and future research lines}

\subsection{Conclusions.}

This thesis proposes a complete methodology for numerical UHPFRC modelling from the material level to structural elements. With this proposed methodology, two main items were addressed and adequately met. The first one involved defining a proposal of a direct, simple and reliable procedure to characterise tensile constitutive UHPFRC behaviour from strain hardening to the strain softening response. The second involved defining a complete reliable numerical non-linear finite element model (NLFEM) for UHPFRC flexural and tensile elements capable of accurately simulating the response of UHPFRC specimens and reinforced structural elements.

Therefore, having characterised constitutive UHPFRC behaviour, it was implemented into an adequate theoretical material model to describe its particular cracking process and the interaction with reinforcement bars by taking into account important effects, such as shrinkage and tension stiffening, with a suitable definition of the bond between them. In order to simulate structural behaviour, the model was implemented in the finite element method to establish a robust numerical model based on the non-linear analysis. This complete model allowed the material's behaviour to be considered until its final consequences to simulate an optimised structural response in 2D and 3D that takes into account the heterogeneity of UHPFRC mechanical properties.

This section presents the main conclusions drawn from the present $\mathrm{PhD}$ document. The document is structured following a logical sequence as research was conducted. First of all, a review about the main concepts relating to UHPFRC definition and tensile 
characterisation was performed. Then, modelling basic concepts related to material constitutive models, computational methods and numerical solution strategies were tackled to set the basis of the non-linear finite element model (NLFEM) herein developed. A literature review of the main research into the UHPFRC characterisation for modelling, the calibration of the UHPFRC finite element models and their extension and application to structural elements in the last decade, was carried out.

The theoretical definition of the material model for UHPFRC at the uniaxial and multiaxial levels, and the definition of reinforcement and interface behaviour that constitute the NLFEM's material modelling, are described in detail. With all this, the implementation of the NLFEM in general and its particularisations for its numerical implementation in the commercial finite element software herein applied were completely studied.

The developed numerical 2D-NLFEM was used to establish a simple reliable direct procedure to characterise tensile UHPFRC behaviour in both cases: strain hardening (SH-UHPFRC) and strain softening (SS-UHPFRC) behaviour. Unreinforced 4PBT to experimentally characterise tensile UHPFRC behaviour was modelled and an inverse analysis method to obtain constitutive SH-UHPFRC behaviour was validated, adapted and improved to be used for SS-UHPFRC. To do so, an experimental programme of 227 4PBT UHPFRC specimens covering a wide range of SS and SH constitutive UHPFRC behaviours was developed and numerically modelled by the 2D-NLFEM. Moreover, from the experimental database generated in the experimental 4PBT programme carried out and the developed direct procedure to characterise the UHPFRC behaviour, a predicting application was created in which the parameters describing tensile constitutive UHPFRC behaviour can be directly obtained from the experimental 4PBT curve implemented as input without having to use inverse analysis methods.

After establishing and controlling tensile UHPFRC behaviour, a step forward in the structural analysis was taken by modelling the reinforced UHPFRC elements. The NLFEM was improved by incorporating important effects, such as UHPFRC shrinkage, and taking into account the tension-stiffening behaviour of UHPFRC. Presently, the NLFEM also incorporates reinforcement bars and the bond-slip behaviour between UHPFRC and reinforcement. An experimental programme composed of 36 reinforced UHPFRC flexural short beams and two full-scale reinforced UHPFRC flexural beams was carried out and modelled by 2D and 3D-NLFEM. After the NLFEM simulations, reliable results were obtained at both the service and ultimate load levels compared to the experimental ones. Some aspects of the design of reinforced UHPFRC cross-sections under bending forces are addressed and satisfactorily compared to the experimental results. Moreover, a full complete 3D-NLFEM-multicrack capable of modelling 3D effects, the random distribution of strength that simulates concrete heterogeneity and the complexity of reinforced tensile UHPFRC bars from an experimental programme from another work was developed. All in all, a complete NLFEM that is able to simulate the structural behaviour of reinforced UHPFRC elements was generated and tensile 
UHPFRC behaviour obtained by the herein developed direct procedure and implemented in the model was confirmed to be a robust coherent process for modelling.

Therefore, the main conclusions drawn from all the research work herein developed are presented below.

\subsubsection{On UHPFRC characterisation and modelling up to the present-day.}

For UHPFRC, a simplification of uniaxial tensile behaviour following a quadrilinear relation was assumed. This quadrilinear response can be divided into two main parts: bilinear behaviour expressed by means of stress-strain behaviour for part I (elastic) and part II (strain-hardening/softening); bilinear behaviour expressed in terms of stress-crack opening for part III (softening). This simplified tensile behaviour is considered the real UHPFRC $\sigma-\varepsilon / w$ constitutive law in this work.

Given their simplicity, four-point bending tests (4PBT) are considered the best tests to characterise tensile UHPFRC behaviour. Nevertheless, they require running an inverse analysis methodology to derive tensile properties based on the obtained results.

When considering the especial tensile UHPFRC behaviour, modelling works are often found in which UHPFRC behaviour is modelled by means of continuum models, such as the smeared crack model and concrete damage plasticity, and also by continuum models with discontinuities, such as the fictitious crack model and the discrete crack approach where, in the latter, crack is considered to be discrete and the rest of the material is taken as a continuum.

As observed in the literature review, in many cases the mesh size dependency problem for continuum models is addressed by calibrating the finite element size using different sizes and making comparisons to the experimental results. This could solve the problem for the particular modelled case, but this is no general criterion for continuum models.

Occasionally crack localisation plays an important role and it is necessary to set the crack position in the model. Given the model concept in other cases, cracks are modelled discretely and are activated by randomly following a set activation criterion. When such models are used, there is no mesh dependency as the crack is modelled by an interface behaviour expressed by a traction-separation law.

In order to build a reliable model capable of simulating the tensile response of UHPFRC structural elements quite accurately, following a basic sequence from the beginning at a material level to structural elements seems logical. It is necessary to adequately define constitutive tensile UHPFRC behaviour at the material level and to characterise its parameters by experimentally reliable characterisation tests. Then a suitable material model that is able to represent the particular tensile UHPFRC response is set out. The generated UHPFRC material model was implemented in the finite element method to discretise the continuum body of a structural element and to carry out a structural analysis. As the finite element technique is an extended computational method, 
commercial software is frequently used. Therefore, it was necessary to consider the aspects of implementing the material model and its interactions with the other materials making up the model for a particular software. Material models that consider particular properties, such as shrinkage, the heterogeneity of concrete properties, the structural element's geometry, the possible interaction with other geometries by interface transitions, the type and disposition of finite elements to define the mesh, boundary conditions, the definition of loads and the analysis strategy constitute the steps that lead to more or less complex and accurate FEM.

\subsubsection{On the definition and implementation of the UHPFRC model.}

Because of its heterogeneity, and to model tensile UHPFRC behaviour, it was necessary to not only set its constitutive behaviour at the macroscale level, but to also complete its definition by a cracking process characterisation model on the mesoscale.

Two modelling approaches were defined to model tensile UHPFRC behaviour: smeared cracking approach and discrete cracking approach.

The main advantage of the smeared crack model is that knowing the crack path beforehand is not necessary because the crack is smeared by a mean strain that represents the crack along the whole element length. However, this particular cracking treatment leads to mesh-size dependency, and the application of a regularisation technique or calibrating adequate element length is necessary to obtain reliable results with this model. In this work, crack bandwidth was considered a constant characteristic of the material.

To define the discrete cracking approach in this work, the model's continuous part was set by the smeared cracking approach and the discontinuous part by a stress-crack opening relation. This leads to a relatively mesh-size independent model, but previously knowing the crack path is necessary.

Both the UHPFRC material model approaches (smeared cracking and discrete cracking) defined for the uniaxial case were extrapolated to the multiaxial case for $2 \mathrm{D}$ and $3 \mathrm{D}$ modelling. As the principal crack mechanism herein considered was developed with Mode-I, the response of the fixed and rotating concept was expected to be very close which was why the fixed concept was adopted.

As the function of the steel for reinforcement resists mainly axial tensile forces, uniaxial elastoplastic bilinear stress-total strain constitutive behaviour with strain hardening was defined to be employed in truss elements where only axial elongation is considered. As reinforcement bars were discretely modelled in this work, it was necessary to define the interface behaviour between the steel from the rebars and UHPFRC surrounding them to take into account the transition influence. This was carried out by a bond-slip constitutive law. 
In order to develop the model, the finite element method was employed. The material model for UHPFRC, defined to describe its constitutive behaviour and the cracking mechanism, was adapted to the finite element method application.

In order to adapt the smeared cracking approach, the smeared crack model was applied to obtain the stress $(\sigma)$-mean total strain $\left(\varepsilon_{m, e f}\right)$ in each finite element length $\left(L_{e f}\right)$. Therefore in the FEM, the smeared crack model depended on finite element size $\left(L_{e f}\right)$. The exact finite element length that represents the exact crack energy in the crack surface curve formation is set when the finite element length is chosen that exactly fits the crack bandwidth, i.e., $L_{e f}=b_{w}$.

The material behaviour simulated by the FEM with the discrete cracking approach in the overall specimen was expected to be very close to the real stress-strain/crack opening $(\sigma-\varepsilon / w)$ material's UHPFRC constitutive behaviour.

In order to carry out the numerical implementation in this work, commercial finite element software was used. This was a key point to know how software integrated the material models and how they were used in the non-linear analysis to adapt to the particularities of the software the material models theoretically defined for UHPFRC, steel reinforcement, and the interface behaviour between them. Special attention must be paid to the smeared cracking model treatment when a finite element software package is employed. It is also important to control the definition and implementation of the two main parameters that define the smeared crack model: crack bandwidth and fracture energy.

\subsubsection{On a direct procedure to characterise tensile UHPFRC behaviour.}

The discrete cracking approach of the numerical model was more adequate for modelling tensile UHPFRC behaviour in a 4PBT without reinforcement. Even though the smeared cracking approach gave good results, it is sensitive to mesh size. It would seem that the idea lying behind the smeared crack model for distributing the crack opening in a mean total strain defined in a crack bandwidth is not reliable enough for UHPFRC. Given its particular cracking procedure, is not easy to concentrate the influence of the UHPFRC cracking process on a narrow crack band. It can be stated that crack bandwidth can change during the cracking process by changing from the microcracking stabilisation phase, where all the volumetric energy is involved, to the macrocrack apparition where, perhaps, the strain concentration in a narrow band is not as obvious as it is with conventional concrete. So is not easy to find a crack bandwidth that leads to a representative mean strain. The solution of a discrete crack represented by its own traction-separation law by maintaining the surrounding zone as a continuum seems capable of providing more accurate results. Moreover, it is important to contemplate that the 2D-NLFEM is influenced by the defined non-linear analysis strategy.

The non-linear closed-form hinge model and its derived simplified inverse analysis methods (5P-IA and 4P-IA), defined to obtain the tensile constitutive behaviour for SH- 
UHPFRC, were validated by resorting to a robust 2D-NLFEM and a set of 4PBTs of variable depth, slenderness and hinge length values.

When using the tensile parameters that resulted from an I-IA method using the presented closed-form non-linear hinge model and its derived simplified inverse analysis methods, the discrete cracking approach of the 2D-NLFEM accurately described: (a) the load deflection response; (b) bending curvatures; (c) the average longitudinal strains measured in the bending tests.

As a result, inverse analysis methodologies based on the closed-form non-linear hinge model and the proposed derived simplified inverse analysis methods are recommended to obtain the tensile UHPFRC properties in 4PBTs for SH-UHPFRC.

Given the need to establish a complete process to characterise tensile UHPFRC behaviour in either SH or SS behaviour, this process started with the experimental test which, in this work, was 4PBT given its simplicity.

In order to move from the experimental $\sigma-\delta$ response in bending to tensile behaviour, the simplified 4P-IA, developed by the research group and recently validated in this work, was used. As it was developed for UHPFRC that exhibits SH tensile response, its application to UHPFRC with SS was adapted. Consequently, an experimental programme of 227 4PBT going from SH behaviour to SS behaviour was run using UHPFRC with $120-130 \mathrm{~kg} / \mathrm{m}^{3}$ and $160 \mathrm{~kg} / \mathrm{m}^{3}$ of steel fibres. As demonstrated in the simulations done by the developed 2D-NLFEM, 4P-IA worked well for UHPFRC with $\mathrm{SH}$, but is still too conservative for SS.

A parametrical study that focused on the $\varepsilon_{t u}$ and $f_{t u}$ parameters was performed to study their influence on the $\sigma-\delta$ response using the developed 2D-NLFEM. The $f_{t u}$ parameter directly influenced the model's response and 4P-IA underestimated the $f_{t u}$ value, which gave a conservative result. However, the influence of the variation in $\varepsilon_{t u}$ was considered negligible.

The correction of 4P-IA for SS-UHPFRC was made in $f_{t u}$ terms (softening correction) after analysing 65 specimens taken from the experimental programme with different hardening ratio $(\gamma)$ values, and after calibrating $f_{t u}$ from 64 specimens take from the experimental programme. This correction led to a more accurate response in stress and energy terms and at different levels. Consequently, UHPFRC was characterised in tensile behaviour terms by following a reliable process.

Having set up a reliable method to characterise tensile UHPFRC behaviour, the characteristic $\sigma-\delta$ curve of UHPFRC from the experimental data was extracted. Therefore, the characteristic tensile behaviour parameters were obtained for UHPFRC with $120-130 \mathrm{~kg}$ and $160 \mathrm{~kg} / \mathrm{m}^{3}$ of steel fibres. These values could be a reference for UHPFRC with these amounts of fibres. 
By employing the extensive experimental programme carried out herein, a predictive application for estimating the tensile UHPFRC parameters from the $\sigma-\delta$ curve from 4PBT was developed. The prediction gave reliable results. The application is simple and direct, and avoids variability in the simplified 4P-IA due to misinterpretations, but also for applying the inverse analysis. This is undoubtedly a step forward in the methodologies followed to characterise tensile UHPFRC properties thanks to the use of predictive tools.

\subsubsection{On the modelling of reinforced UHPFRC flexural and tensile elements.}

An experimental programme of 36 reinforced UHPFRC flexural short beams and two full-scale reinforced UHPFRC flexural beams was carried out.

After applying the NLFEM to reinforced beams, the following conclusions were drawn:

If the characteristic tensile constitutive parameters used to mechanically characterise UHPFRC were implemented into the NLFEM of reinforced beams, the numerical response would accurately fit the experimental one at the $5 \%, 50 \%$ and $95 \%$ percentile levels. This result demonstrates both the reliability of the developed NLFEM and the coherence of the tensile UHPFRC material characterisation process.

The model was developed using the two different approaches: the smeared cracking approach and the discrete cracking approach. The differences in the results between the two approaches were negligible, unlike the response obtained with the unreinforced specimens in 4PBT. Reinforcement strongly influences specimens' mechanical behaviour when macrocracking appears via the "tension-stiffening" effect.

Given its particular dosage, UHPFRC is a concrete type that is submitted to a high shrinkage level. By using the NLFEM, the shrinkage strain was deduced within a range of $[0.70,0.84] \mathrm{mm} / \mathrm{m}$, which is consistent with other research works. This can generate significant internal stresses before tests start, which need to be taken into account given the potential influence on the beam's service response. According to the NLFEM simulations, the internal tensile stresses in the UHPFRC matrix come close to tensile strength $\left(f_{t}\right)$. Therefore, it can be concluded that the shrinkage effect on UHPFRC was very important and, consequently, its influence on the beam's structural response was not at all negligible.

The cracking process and the cracking pattern simulated by the NLFEM are completely reliable and very well represent reality in both cases: at both the service and ultimate load levels. It is important to underline, as herein demonstrated, that both the cracking process and the cracking pattern depend on the UHPFRC hardening ratio used to cast the element. As the hardening ratio rises and goes from SS to SH behaviour, the cracking pattern goes from a more concentrated to a more smeared crack distribution. This is a very important effect that is clearly described using the NLFEM and it indicates a major difference between the UHPFRC that exhibits SS and that with SH. 
The flexure strength predictions of long beams are quite accurate and very dependent on the tensile force that fibres can carry out. Both beams displayed a nearly full-tension stiffening response $(\beta \approx 1)$ under serviceability conditions, which simplified the evaluation of the effective moment of inertia for controlling deflections. Consequently, and as demonstrated, in those beams that exhibited full-tension stiffening, flexure stiffness remained constant in the microcrack stabilisation phase, and its value can be easily and accurately predicted by assuming the fully cracked reinforced UHPFRC crosssection's flexural stiffness.

In addition, some samples taken from the direct tensile test performed during an experimental campaign carried out in a work done by the research group were modelled by the discrete cracking approach of the 2D-NLFEM and 3D-NLFEM. Moreover, 3DNLFEM evolution was addressed: 3D-NLFEM-multicrack. This improved 3D model consisted in defining interface behaviour not only in the mid-span section, but also between all the 3D solid elements on the same vertical. Indeed a composed finite element defined by a 3D solid element bounded vertically by two interface elements on each side able to represent the real UHPFRC $\sigma-\varepsilon / w$ constitutive law that was generated. Moreover in the analysis definition, a random variation in the FRCFAC factor, which multiplied the values of the tensile UHPFRC parameters in the NLFEM's constitutive behaviour, was added to better model concrete heterogeneity.

After applying the NLFEM to the adopted tensile UHPFRC bars, the following conclusions were drawn:

The P- $\Delta \mathrm{u}$ response obtained from applying the 2D-NLFEM and the 3D-NLFEMmulticrack when the $50 \%$ percentile of the tensile UHPFRC constitutive parameters obtained from 4PBT and the softening correction were used in the model accurately fitted the experimental P- $\Delta \mathrm{u}$ response. This demonstrated not only the reliability of the developed NLFEM, but also the coherence of the process to characterise tensile UHPFRC behaviour in reinforced direct tensile tests.

When using the 2D-NLFEM to model the tensile test, the calculated UHPFRC shrinkage strain $\left(\varepsilon_{C S U H P F R C}\right)$ fell within the range of $[0.51,0.96] \mathrm{mm} / \mathrm{m}$, while the 3D-NLFEMmulticrack was used to model the tensile test, the calculated UHPFRC 3D shrinkage strain $\left(\varepsilon_{C S U H P F R C 3 D}\right)$ fell within the range of $[0.37,0.73] \mathrm{mm} / \mathrm{m}$. Therefore, the difference between both models, taken as a strain due to 3D effects, lay within the range of [0.10, $0.23] \mathrm{mm} / \mathrm{m}$. Consequently, the 3D-NLFEM-multicrack was able to quantify the 3D effects that affected this particular kind of tensile test.

UHPFRC exhibited full-tension stiffening behaviour in tension. The 2D-NLFEM very well adjusted the experimental P- $\Delta \mathrm{u}$ response. The effect of the weak zone where an abrupt transition took place between the rebars section in the tensile test could be considered to be included in the 3D effects, which contributed to the difference between the 2D-NLFEM and the 3D-NLFEM-multicrack. The 3D model was sensitive to 3D effects and, consequently, these effects in this weak zone might have important 
implications for the general test simulation response. Therefore, it can be generally stated that with the complete 3D-NLFEM-multicrack, shrinkage and also the 3D effects, including the consequences in the weak zone generated during the transition of the steel reinforcement section, were accurately modelled and led to a complete model that was able to simulate the UHPFRC response during a tensile test.

It can be concluded from the 3D-NLFEM-multicrack detailed application that the developed NLFEM was not only able to model tensile test behaviour on the whole, but also as a detailed simulation with its structural response. That is, the NLFEM reliably

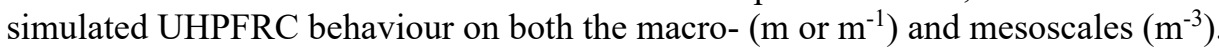

When studying the different levels of the 3D-NLFEM-multicrack's accurate $\sigma-\Delta u$ structural response, the model reproduced with good sense and coherence what could be realistically expected in these stages, namely before the test started (shrinkage influence), in the elastic uncracked phase, in the microcrack stabilisation phase and at the collapse level, by considering the random distribution of the material properties and the crack pattern depending on tensile UHPFRC behaviour: SS or SH.

The 3D-NLFEM-multicrack was also able to overcome the local instabilities generated by differences in stiffness due to variation in reinforcement, which very accurately represented the regularisation of the stresses in the central part, which characterise this particular kind of tensile test. The appearance of partial macrocracks due to SS-UHPFRC and the random distribution of stresses led to local turns, which did not affect the general tensile bar response. However, it is necessary to take into account the generation of these partial macrocracks in SS-UHPFRC durability terms.

From the two parts of the reinforced UHPFRC modelling, it can be concluded that a NLFEM applicable at the 2D and 3D levels was developed to model tensile UHPFRC behaviour for steel-reinforced elements. This model considered shrinkage effects, tension stiffening behaviour and 3D effects due to the particularities of the test, which gave very accurate results compared to the experimental tests. The NLFEM was more accurate because it reproduced real UHPFRC constitutive behaviour with more similarity by means of the composed finite elements defined by a 3D solid element that was bound vertically by two interface elements on each side, and was able to represent the real UHPFRC $\sigma-\varepsilon / w$ constitutive law.

The flexural and direct tensile tests were reliably modelled using the simple direct procedure to characterise UHPFRC tensile behaviour from 4PBT, which consisted in a 4P-IA and the softening correction for the SS-UHPFRC case. Consequently, this demonstrated not only the reliability of the developed NLFEM, but also the coherence of the process to characterise UHPFRC tensile behaviour during reinforced flexural and direct tensile tests. 


\subsection{Future research lines.}

From the research conducted in this $\mathrm{PhD}$ work, several ideas can lead to future research lines.

1. For the realistic modelling of UHPFRC structural elements, it would seem better to move towards discrete cracking approaches. The smeared crack model based on continuum models, where the crack opening in the softening constitutive behaviour was distributed in a mean total strain defined in a crack bandwidth, did not seem to be representative of the particular UHPFRC cracking process. Therefore, it could be interesting to develop the NLFEM towards the discrete cracking approach idea. It would seem preferable for UHPFRC, especially without reinforcement. It could be interesting to continue with the evolution of the 3D-NLFEM-multicrack by defining the composed finite elements bound not only vertically, but also horizontally, by the interface elements surrounding the solid elements. In this direction, several trials were run in the present work (see Annexe II) with the 2D-NLFEM of 4PBT without reinforcement, which involved computational difficulties. It might be a good idea to define different meshing zones where the density of these improved composed finite elements can be changed depending on the detail level of interest. With this, the mesh size dependency of continuum models is avoided as the discrete cracking approach is used. In Annexe II, an example of the application of the composed finite elements with interface elements in horizontal and vertical direction in the boundaries of the 2D plane stress element is shown as an attempt to go towards this enhanced model.

2. Other effects can be studied and incorporated into the NLFEM, such as creep for UHPFRC or the fibre effect. In the present work, the fibre effect in the 3DNLFEM-multicrack was considered in the random distribution of the FRCFAC factor for tensile strength. A better improvement could lie in the incorporation of an effect that considers a realistic and explicit orientation of fibres or modelling them discretely with embedded or bond-slip interface behaviour between concrete and fibre, like reinforcement, which could pose a challenging problem.

3. By considering the NLFEM with the discrete cracking approach and different mesh size zones by means of enhanced composed finite elements with not only vertical, but also horizontal interface boundaries to address the modelling of more complex UHPFRC structures. In this research, structural UHPFRC elements were modelled by flexural beams and tensile bars. With them, the model was defined and calibrated. Now a leap forward towards a complete 
UHPFRC structure using composed finite elements and by varying the mesh depending on the structure's details must be addressed.

4. The 4PBT experimental programme generates an extensive experimental loaddeflection of the mid-span curves database for UHPFRC with a wide strainsoftening and hardening range. In this research, it was used to calibrate and improve a particular inverse analysis methodology with the developed NLFEM. This experimental database and the NLFEM herein developed can be employed to calibrate any inverse analysis methodology based on 4PBT that adjusts the particularities of the experimental test carried out in this work. Therefore, they can be applied to improve inverse analysis procedures of other researchers.

\subsection{Publications deriving from this thesis}

- Mezquida-Alcaraz, E. J., Navarro-Gregori, J., \& Serna, P. (2021). Direct procedure to characterize the tensile constitutive behavior of strain-softening and strain-hardening UHPFRC. Cement and Concrete Composites, 115, 103854. https://doi.org/https://doi.org/10.1016/j.cemconcomp.2020.103854

- Mezquida-Alcaraz, E. J., Navarro-Gregori, J., \& Serna, P. (2020). Finite Element Modelling of UHPFRC Flexural-Reinforced Elements. RILEM-Fib International Symposium on Fibre Reinforced Concrete, 639-650

- E.J. Mezquida-Alcaraz, J. Navarro-Gregori and P. Serna, "Numerical validation of a simplified inverse analysis method to characterize the tensile properties in strainsoftening UHPFRC", IOP Conference Series Materials Science and Engineering, 2019.

- E. J. Mezquida-Alcaraz, J. Navarro-Gregori, J.A. López and P. Serna, "Validation of a non-linear hinge model for tensile behavior of UHPFRC using a Finite Element Model", Computers and Concrete, 2019.

- E.J. Mezquida-Alcaraz, "Finite element modelling of UHPFRC flexural-reinforced elements", 13th DIANA Users Meeting, Trondheim, Norway, 22-23 May, 2019.

- E.J. Mezquida-Alcaraz and J. Navarro-Gregori, "Finite Element Modelling of UHPFRC Elements with DIANA", webinar, DIANA FEA, 2019. https://www.youtube.com/watch?v=s6sgJ_NCGiY\&ab_channel=DIANAFEABV

- E.J. Mezquida-Alcaraz, "Finite element modelling of UHPFRC elements", 12th DIANA Users Meeting, Porto, Portugal, 11-12 October, 2018.

- E. J. Mezquida-Alcaraz, J. Navarro-Gregori, J.A. López and P. Serna, "Numerical Validation of a Simplified Inverse Analysis Method to Characterise the Tensile Behaviour of UHPFRC", Fibre Reinforced Concrete: from Design to Structural Applications, Desenzano del Garda, Italy, 2018. 


\section{Bibliography}

(fib), fédération internationale du béton/International F. for S. C. (2013). "fib Model Code for Concrete Structures 2010.” Ernst \& Sohn, 434.

(JSCE), J. S. of C. E. (2007). "Standard specifications for concrete structures." Structural performance verification.

AASHTO, L. (2017). "American association of state highway and transportation officials (LRFD) bridge design specifications." USA, 8th Ed.

"AASHTO LRFD Bridge Design Specifications." (2012). American Association of State Highway and Transportation Officials.

Abrishambaf, A., Pimentel, M., and Nunes, S. (2017). "Influence of fibre orientation on the tensile behaviour of ultra-high performance fibre reinforced cementitious composites." Cement and Concrete Research, 97, 28-40.

ACI, A. C. I. (2011). "318-11 ACI building code requirements for structural concrete and commentary." Farmington Hills: American Concrete Institute.

AFGC, S. (2013). "Bétons fibrés à ultra-hautes performances-Recommandations." $A F G C$, France.

Al-Momani, E., and Rawabdeh, I. (2008). "An application of finite element method and design of experiments in the optimization of sheet metal blanking process." JJMIE, 2(1), 53-63.

Albitar, M., Ali, M. S. M., and Visintin, P. (2018). "Evaluation of tension-stiffening, crack 
spacing and crack width of geopolymer concretes." Construction and Building Materials, Elsevier, 160, 408-414.

Aleksendrić, D., and Carlone, P. (2015). "4 - Soft computing techniques." D. Aleksendrić and P. B. T.-S. C. in the D. and M. of C. M. Carlone, eds., Woodhead Publishing, Oxford, 39-60.

Ali Dadvar, S., Mostofinejad, D., and Bahmani, H. (2020). "Strengthening of RC columns by ultra-high performance fiber reinforced concrete (UHPFRC) jacketing." Construction and Building Materials, 235, 117485.

Alkaysi, M., and El-Tawil, S. (2017). "Factors affecting bond development between Ultra High Performance Concrete (UHPC) and steel bar reinforcement." Construction and Building Materials, 144, 412-422.

Altin, S., Anil, Ö., Kopraman, Y., and Kara, M. E. (2013). "Hysteretic behavior of RC shear walls strengthened with CFRP strips." Composites Part B: Engineering, Elsevier, 44(1), 321-329.

Amin, A., Foster, S. J., and Muttoni, A. (2015). "Derivation of the $\sigma$-w relationship for SFRC from prism bending tests." Structural Concrete, Wiley Online Library, 16(1), 93-105.

Antes, H. (2010). "A short course on boundary element methods."

Aoude, H., Dagenais, F. P., Burrell, R. P., and Saatcioglu, M. (2015). "Behavior of ultra-high performance fiber reinforced concrete columns under blast loading." International Journal of Impact Engineering, Elsevier, 80, 185-202.

Argyris, J. H., and Kelsey, S. (1960). Energy theorems and structural analysis. Springer.

Arora, A., Aguayo, M., Hansen, H., Castro, C., Federspiel, E., Mobasher, B., and Neithalath, N. (2018). "Microstructural packing- and rheology-based binder selection and characterization for Ultra-high Performance Concrete (UHPC)." Cement and Concrete Research, 103, 179-190.

"AS 3600-1994. Concrete Structures." (1994). CommitteeBD/2, ConcreteStructures, Standards Australia.

Association Francaise de Normalisation. (2016a). "Concrete-Ultra-high performance fibrereinforced concrete-specifications, performance, production and conformity." NFP 18 $470: 2016$.

Association Francaise de Normalisation. (2016b). "National addition to Eurocode 2- Design of concrete structures: specific rules for ultra-high performance fibre-reinforced concrete (UHPFRC)." NFP 18 710: 2016.

Association, S. S. (2003). "SIA 260: Basis of structural design." Swiss Society of Engineers and Architects, Zurich, Switzerland.

Astarlioglu, S., and Krauthammer, T. (2014). "Response of normal-strength and ultra-highperformance fiber-reinforced concrete columns to idealized blast loads." Engineering structures, Elsevier, 61, 1-12. 
Baby, F., Graybeal, B., Marchand, P., and Toutlemonde, F. (2012). "Proposed flexural test method and associated inverse analysis for ultra-high-performance fiber-reinforced concrete." ACI Materials Journal, 109(5), 545-555.

Baby, F., Graybeal, B., Marchand, P., and Toutlemonde, F. (2013a). "UHPFRC tensile behavior characterization: Inverse analysis of four-point bending test results." Materials and Structures/Materiaux et Constructions, 46(8), 1337-1354.

Baby, F., Marchand, P., Atrach, M., and Toutlemonde, F. (2013b). "Analysis of flexure-shear behavior of UHPFRC beams based on stress field approach." Engineering Structures, 56, 194-206.

Bandelt, M. J., and Billington, S. L. (2016). "Bond behavior of steel reinforcement in highperformance fiber-reinforced cementitious composite flexural members." Materials and structures, Springer, 49(1-2), 71-86.

Bastien-Masse, M., and Brühwiler, E. (2016). "Composite model for predicting the punching resistance of R-UHPFRC-RC composite slabs.” Engineering Structures, 117, 603616.

Bathe, K.-J. (2006). Finite element procedures. Klaus-Jurgen Bathe.

Batoz, J., and Dhatt, G. (1979). "Incremental displacement algorithms for nonlinear problems." International Journal for Numerical Methods in Engineering, Wiley Online Library, 14(8), 1262-1267.

Bazant, Z. P., and Cedolin, L. (1979). "Blunt crack band propagation in finite element analysis." ASCE J Eng Mech Div, American Society of Civil Engineers (ASCE), 105(2), 297-315.

Bazant, Z. P., and Cedolin, L. (1984). "Finite element modeling of crack band propagation." Journal of Structural Engineering (United States), American Society of Civil Engineers (ASCE), 110(3), 660-662.

Bažant, Z. P., and Oh, B. H. (1983). "Crack band theory for fracture of concrete.” Matériaux et construction, Springer, 16(3), 155-177.

Bazant, Z. P., and Planas, J. (1997). Fracture and size effect in concrete and other quasibrittle materials. CRC press.

Belytschko, T., Fish, J., and Bayliss, A. (1990). "The spectral overlay on finite elements for problems with high gradients." Computer Methods in Applied Mechanics and Engineering, Elsevier, 81(1), 71-89.

Belytschko, T., Fish, J., and Engelmann, B. E. (1988). “A finite element with embedded localization zones." Computer methods in applied mechanics and engineering, Elsevier, 70(1), 59-89.

Bischoff, P. H. (2003). "Tension stiffening and cracking of steel fiber-reinforced concrete." Journal of materials in civil engineering, American Society of Civil Engineers, 15(2), $174-182$ 
Bischoff, P. H. (2008). "Discussion of 'Tension stiffening in lightly reinforced concrete slabs' by R. Ian Gilbert.” Journal of structural engineering, American Society of Civil Engineers, 134(7), 1259-1260.

Blazek, J. (2015). “Chapter 3 - Principles of Solution of the Governing Equations.” J. B. T.C. F. D. P. and A. (Third E. Blazek, ed., Butterworth-Heinemann, Oxford, 29-72.

De Borst, R., Crisfield, M. A., Remmers, J. J. C., and Verhoosel, C. V. (2012). Nonlinear finite element analysis of solids and structures. John Wiley \& Sons.

De Borst, R., and Nauta, P. (1985). "Non-orthogonal cracks in a smeared finite element model.” Engineering Computations 2 (3), 35-46.(1985).

Bourantas, G. C., Joldes, G. R., Wittek, A., and Miller, K. (2018). "Chapter 18 - Strong- and Weak-Form Meshless Methods in Computational Biomechanics.” M. Cerrolaza, S. J. Shefelbine, and D. B. T.-N. M. and A. S. in B. and B. P. Garzón-Alvarado, eds., Academic Press, 325-339.

C157, A. (2006). "Standard test method for length change of hardened hydraulic-cement mortar and concrete." annual book of ASTM standards, 4, 96-101.

Caltrans Bridge Design Academy. (2006). "LRFD Design Example B." Caltrans, Sacramento, $C A$;

Carlson, M. (2011). "Application of Finite Element Analysis for an improved musical instrument design." Fender Musical Instruments Corporation, Guitar Products Research \& Development Department, Citeseer.

Carlton, J. S. (2012). "Chapter 8 - Theoretical and Analytical Methods Relating to Propeller Action." J. S. B. T.-M. P. and P. (Third E. Carlton, ed., Butterworth-Heinemann, Oxford, 169-207.

Casanova, P., and Rossi, P. (1996). "Analysis of metallic fibre-reinforced concrete beams submitted to bending." Materials and Structures, 29(6), 354-361.

Cedolin, L., and Bažant, Z. P. (1980). "Effect of finite element choice in blunt crack band analysis." Computer Methods in Applied Mechanics and Engineering, Elsevier, 24(3), $305-316$.

Červenka, V., Jendele, L., and Červenka, J. (2013). “ATENA Program Documentation. Part 1. Theory. 2016." Cervenka Consulting sro.

Chaboche, J. L. (1982). "Le concept de contrainte effective appliqué à l'élasticité et à la viscoplasticité en présence d'un endommagement anisotrope." Mechanical Behavior of Anisotropic Solids/Comportment Méchanique des Solides Anisotropes, Springer, 737-760.

Chanvillard, G. (2000). "Characterisation of fibre reinforced concrete mechanical properties: a review." Fifth International RILEM Symposium on Fibre-Reinforced Concrete (FRC), RILEM Publications SARL, 29-50.

Chanvillard, G., and Rigaud, S. (2003). "Complete characterization of tensile properties of 
Ductal UHPFRC according to the French recommendations." Proceedings of the 4th International RILEM workshop High Performance Fiber Reinforced Cementitious Composites, 21-34.

Chao, S.-H., Naaman, A. E., and Parra-Montesinos, G. J. (2009). "Bond behavior of reinforcing bars in tensile strain-hardening fiber-reinforced cement composites." $A C I$ Structural Journal, American Concrete Institute, 106(6), 897.

Choi, S. K., Chung, W. K., Chen, B. K., and Thomson, P. F. (1993). "NUMERICAL MODELLING OF THE NON-LINEAR BEHAVIOUR OF MATERIALS WITH APPLICATIONS TO METALS.” W. B. B. T.-A. in E. P. and its A. LEE, ed., Elsevier, Oxford, 695-702.

Chu, S. H., and Kwan, A. K. H. (2019). "A new bond model for reinforcing bars in steel fibre reinforced concrete." Cement and Concrete Composites, 104, 103405.

Ciarlet, P. G., Cucker, F., and Lions, J.-L. (1990). Handbook of numerical analysis. Gulf Professional Publishing.

Clarke, M. J., and Hancock, G. J. (1990). “A study of incremental-iterative strategies for nonlinear analyses." International Journal for Numerical Methods in Engineering, Wiley Online Library, 29(7), 1365-1391.

Clough, R. W. (1960). "The finite element method in plane stress analysis." Proceedings of 2nd ASCE Conference on Electronic Computation, Pittsburgh Pa., Sept. 8 and 9, 1960.

Cook, R. D. (2007). Concepts and applications of finite element analysis. John wiley \& sons.

Cope, R. J., Rao, P. V, Clark, L. A., and Norris, P. (1980). "Modelling of reinforced concrete behaviour for finite element analyses of bridge slabs. Numerical methods for nonlinear problems I." New York: Taylor \& Francis.

Cornec, A., Scheider, I., and Schwalbe, K.-H. (2003). "On the practical application of the cohesive model." Engineering fracture mechanics, Elsevier, 70(14), 1963-1987.

Costabel, M. (1986). Principles of boundary element methods. Techn. Hochsch., Fachbereich Mathematik

Courant, R. (1943). "Variational methods for the solution of problems of equilibrium and vibrations." Bull. Am. Math. Soc, 49, 1-23.

Crisfield, M. A. (1981). "A fast incremental/iterative solution procedure that handles 'snapthrough." Computational methods in nonlinear structural and solid mechanics, Elsevier, 55-62.

Crisfield, M. A. (1983). "An arc-length method including line searches and accelerations." International journal for numerical methods in engineering, Wiley Online Library, 19(9), 1269-1289.

CT, S. I. A. (2015). "2052: Béton fibré ultra-performant (BFUP)-Matériaux, dimensionnement et exécution." Zürich: Société suisse des Ingénieurs et Architectes. 
Cui, F., Lee, H. P., and Zeng, X. (2009). "Impact analysis of shoes using the structural intensity technique." 4th European Conference of the International Federation for Medical and Biological Engineering, Springer, 2081-2084.

Cunha, V. M. C. F., Barros, J. A. O., and Sena-Cruz, J. M. (2011). "An integrated approach for modelling the tensile behaviour of steel fibre reinforced self-compacting concrete." Cement and Concrete Research, Elsevier, 41(1), 64-76.

Dafalias, Y. F., and Popov, E. P. (1975). "A model of nonlinearly hardening materials for complex loading." Acta mechanica, Springer, 21(3), 173-192.

Deluce, J. R. (2011). "Cracking behaviour of steel fibre reinforced concrete containing conventional steel reinforcement." Doctoral Dissertation.

Denarié, E., Habel, K., and Brühwiler, E. (2003). "Structural behaviour of hybrid elements with Advanced Cementitious Materials (HPFRCC)." HPRFCC-4. 4th International workshop on high performance fiber reinforced cement composites. Ann Arbor. MI. June 16-18.

DIANA (Software). (2017). “User's Manual -- Release 10.2." TNO DIANA, The Netherlands, $<$ https://dianafea.com/manuals/d102/Diana.html .

DIN EN 14651. (2007). "Test method for metallic fibre concrete - Measuring the flexural tensile strength (limit of proportionality (LOP), residual)." German Institute for Standardisation (Deutsches Institut für Normung), 19.

Doostkami, H., Roig-Flores, M., Negrini, A., Mezquida-Alcaraz, E. J., and Serna, P. (2020). "Evaluation of the Self-healing Capability of Ultra-High-Performance FiberReinforced Concrete with Nano-Particles and Crystalline Admixtures by Means of Permeability." RILEM-fib International Symposium on Fibre Reinforced Concrete, Springer, 489-499.

Dorr, K. (1980). "Ein Beitrag zur Berechung von Stahlbetonscheiben unter besonderer Berucksichtigung des Verbundverhaltens." PhD Thesis, University of Darmstadt, Darmstadtt.

Dow, J. O. (1999). "Introduction to The Strain Gradient Reformulation of the Finite Difference Method." J. O. B. T.-A. U. A. to the F. E. M. and E. A. P. Dow, ed., Academic Press, San Diego, 307-315.

Duque, L. F. M., and Graybeal, B. (2017). "Fiber orientation distribution and tensile mechanical response in UHPFRC." Materials and Structures, Springer, 50(1), 55.

Dvorkin, E. N., Cuitiño, A. M., and Gioia, G. (1990). "Finite elements with displacement interpolated embedded localization lines insensitive to mesh size and distortions." International journal for numerical methods in engineering, Wiley Online Library, $30(3), 541-564$.

Elices, M., Guinea, G. V, Gomez, J., and Planas, J. (2002). "The cohesive zone model: advantages, limitations and challenges." Engineering fracture mechanics, Elsevier, 69(2), 137-163. 
Elices, M., Rocco, C., and Roselló, C. (2009). "Cohesive crack modelling of a simple concrete: Experimental and numerical results." Engineering Fracture Mechanics, Elsevier, 76(10), 1398-1410.

Elmo, M., Bertoglio, J.-P., and Sabel'nikov, V. A. (1999). "Mixing in isotropic turbulence with scalar injection.” W. Rodi and D. B. T.-E. T. M. and E. 4 Laurence, eds., Elsevier Science Ltd, Oxford, 815-820.

EN, B. S. (2009a). "12390-5. Testing hardened concrete-Part 5: flexural strength of test specimens." British Standards Institution-BSI and CEN European Committee for Standardization.

EN, B. S. (2009b). “12390-3: 2009.” Testing hardened concrete. Compressive strength of test specimens, 19.

Erdogan, F., and Sih, G. C. (1963). "On the crack extension in plates under plane loading and transverse shear."

Euler, L. (1768). Institutionum calculi integralis volumen primum...

Fang, C., Ali, M., Xie, T., Visintin, P., and Sheikh, A. H. (2020). "The influence of steel fibre properties on the shrinkage of ultra-high performance fibre reinforced concrete." Construction and Building Materials, 242, 117993.

Fang, C., Mohamed Ali, M. S., Sheikh, A. H., and Singh, M. (2019). "Numerical and FiniteElement Analysis of Short Ultrahigh-Performance Fiber-Reinforced Concrete Columns." Journal of Structural Engineering, American Society of Civil Engineers, 145(10), 4019111.

Feenstra, P. H. (1993). "Computational aspects of biaxial stress in plain and reinforced concrete." PhD thesis, Delft University of Technology.

Fehling, E., Schmidt, M., Walraven, J., Leutbecher, T., and Fröhlich, S. (2014). Ultra-high performance concrete UHPC: Fundamentals, design, examples. John Wiley \& Sons.

Feistauer, M., Feistauer, M., Felcman, J., Felcman, J., and Straškraba, I. (2003). Mathematical and computational methods for compressible flow. Oxford University Press on Demand.

Ferrara, L., Krelani, V., and Moretti, F. (2016). "Autogenous healing on the recovery of mechanical performance of High Performance Fibre Reinforced Cementitious Composites (HPFRCCs): Part 2 - Correlation between healing of mechanical performance and crack sealing." Cement and Concrete Composites, 73, 299-315.

Ferrara, L., Krelani, V., Moretti, F., Roig Flores, M., and Serna Ros, P. (2017). "Effects of autogenous healing on the recovery of mechanical performance of High Performance Fibre Reinforced Cementitious Composites (HPFRCCs): Part 1." Cement and Concrete Composites, 83, 76-100.

Ferrara, L., Van Mullem, T., Alonso, M. C., Antonaci, P., Borg, R. P., Cuenca, E., Jefferson, A., Ng, P.-L., Peled, A., Roig-Flores, M., Sanchez, M., Schroefl, C., Serna, P., Snoeck, 
D., Tulliani, J. M., and De Belie, N. (2018). "Experimental characterization of the selfhealing capacity of cement based materials and its effects on the material performance: A state of the art report by COST Action SARCOS WG2." Construction and Building Materials, 167, 115-142.

Fischer, P. F., and Tufo, H. M. (2000). "High-Performance Spectral Element Algorithms and Implementations**This work was supported by the Mathematical, Information, and Computational Sciences Division subprogram of the Office of Advanced Scientific Computing Research, U.S. Department of Energy, ." D. KEYES, A. ECER, J. PERIAUX, N. SATOFUKA, and P. B. T.-P. C. F. D. 1999 FOX, eds., North-Holland, Amsterdam, 17-26.

Fish, J., and Belytschko, T. (1990). "A finite element with a unidirectionally enriched strain field for localization analysis." Computer methods in applied mechanics and engineering, Elsevier, 78(2), 181-200.

Fonseka, G. U., and Krajcinovic, D. (1981). "The Continuous Damage Theory of Brittle Materials, Part 2: Uniaxial and Plane Response Modes." Journal of Applied Mechanics, 48(4), 816-824.

Gálvez, J. C., Planas, J., Sancho, J. M., Reyes, E., Cendón, D. A., and Casati, M. J. (2013). "An embedded cohesive crack model for finite element analysis of quasi-brittle materials." Engineering Fracture Mechanics, Elsevier, 109, 369-386.

Gopalaratnam, V. S., and Gettu, R. (1995). "On the characterization of flexural toughness in fiber reinforced concretes." Cement and concrete composites, Elsevier, 17(3), 239254.

Gopalaratnam, V. S., and Shah, S. P. (1985). "Softening response of plain concrete in direct tension." Journal Proceedings, 310-323.

Govindjee, S., Kay, G. J., and Simo, J. C. (1995). "Anisotropic modelling and numerical simulation of brittle damage in concrete." International journal for numerical methods in engineering, Wiley Online Library, 38(21), 3611-3633.

Gowripalan, N., and Gilbert, R. I. (2000). "Design guidelines for ductal prestressed concrete beams." Reference Artical, The University of NSW.

Graybeal, B. A. (2015). "Tensile mechanical response of ultra-high-performance concrete." Advances in Civil Engineering Materials, ASTM International, 4(2), 62-74.

Graybeal, B., and Baby, F. (2013). "Development of Direct Tension Test Method for UltraHigh-Performance Fiber-Reinforced Concrete." ACI Materials Journal, 110(110), $177-186$.

Gröger, Johannes, Viet tue, Nguyen, Wille, K. (2012). "Bending Behaviour and Variation of Flexural Parameters of UHPFRC." 3rd International Symposium on UHPC and Nanotechnology for High Performance Construction Materials, kassel university press GmbH, 419-426.

Gupta, A. K., and Akbar, H. (1984). "Cracking in reinforced concrete analysis." Journal of 
Structural Engineering, American Society of Civil Engineers, 110(8), 1735-1746.

H. B. Nielsen, S. N. L. and J. S. (2002). "DACE - A Matlab Kriging Toolbox.” Informatics and Mathematical Modelling, Technical University of Denmark, DTU.

Hassan, A. M. T., Jones, S. W., and Mahmud, G. H. (2012). "Experimental test methods to determine the uniaxial tensile and compressive behaviour of ultra high performance fibre reinforced concrete (UHPFRC)." Construction and Building Materials, 37, 874 882.

Häussler-Combe, U. (2015). Computational methods for reinforced concrete structures. Wiley Online Library.

Hellweg, H.-B., and Crisfield, M. A. (1998). “A new arc-length method for handling sharp snap-backs.” Computers \& Structures, Elsevier, 66(5), 704-709.

El Helou, R. G. (2016). "Multiscale computational framework for analysis and design of ultra-high performance concrete structural components and systems." Virginia Tech.

Hillerborg, A., Modéer, M., and Petersson, P.-E. (1976). “Analysis of crack formation and crack growth in concrete by means of fracture mechanics and finite elements." Cement and concrete research, Elsevier, 6(6), 773-781.

Hoffman, J. D., and Frankel, S. (2018). Numerical methods for engineers and scientists. CRC press.

Hordijk, D. (1991). "Local approach to fatigue of concrete." Ph. D. Thesis.

Hrennikoff, A. (1941). "Solution of problems of elasticity by the framework method." $J$. appl. Mech.

Hughes, T. J. R. (2012). The finite element method: linear static and dynamic finite element analysis. Courier Corporation.

Hung, C.-C., Lee, H.-S., and Chan, S. N. (2019). "Tension-stiffening effect in steelreinforced UHPC composites: Constitutive model and effects of steel fibers, loading patterns, and rebar sizes." Composites Part B: Engineering, Elsevier, 158, 269-278.

Hung, C.-C., Li, H., and Chen, H.-C. (2017). "High-strength steel reinforced squat UHPFRC shear walls: Cyclic behavior and design implications." Engineering Structures, 141, 59-74.

Hussain, M. A., Pu, S. L., and Underwood, J. (1974). "Strain energy release rate for a crack under combined mode I and mode II." Fracture analysis: Proceedings of the 1973 national symposium on fracture mechanics, part II, ASTM International.

Ilyushin, A. A. (1946). Some problems in the theory of plastic deformation. Applied Mathematics Group, Brown University.

Japan Society of Civil Engineers. (2008). "Recomendations for Design and Construction of High Performance Fiber Reinforced Composites with Multiple Fine Cracks (HPFRCC)." Concrete Engineering Series 82. 
Ji, H., and Liu, C. (2020). "Ultimate shear resistance of ultra-high performance fiber reinforced concrete-normal strength concrete beam.” Engineering Structures, 203, 109825.

Jin, J.-M. (2015). The finite element method in electromagnetics. John Wiley \& Sons.

Jirasek, M. (1998). "Nonlocal models for damage and fracture: comparison of approaches." International Journal of Solids and Structures, Elsevier, 35(31-32), 4133-4145.

Jirásek, M. (2017). "Modeling of Localized Inelastic Deformation." Short course given by Prof. M. Jirásek at Czech Technical University, 18-22/09/2017, Prague, (September), $0-373$.

JIS, A. (2010). "1129." Methods of Measurement for Length Change of Mortar and Concrete.

JIS A 6202:2017. (2017). "Expansive Additive For Concrete." Japanese Standards Association.

Kachnov, L. M. (1958). "Time of the rupture process under creep conditions." Izv. Akad. Nauk, USSR, Otd. Tekh. Nauk, 26-31.

Kaklauskas, G., Tamulenas, V., Bado, M. F., and Bacinskas, D. (2018). "Shrinkage-free tension stiffening law for various concrete grades." Construction and Building Materials, Elsevier, 189, 736-744.

Kanakubo, T. (2006). "Tensile Characteristics Evaluation Method for Ductile FiberReinforced Cementitious Composites." Journal of Advanced Concrete Technology, Japan Concrete Institute, 4(1), 3-17.

Kang, S.-T., and Kim, J.-K. (2011). "The relation between fiber orientation and tensile behavior in an Ultra High Performance Fiber Reinforced Cementitious Composites (UHPFRCC)." Cement and Concrete Research, Elsevier, 41(10), 1001-1014.

Kang, S.-T., Lee, Y., Park, Y.-D., and Kim, J.-K. (2010). "Tensile fracture properties of an Ultra High Performance Fiber Reinforced Concrete (UHPFRC) with steel fiber." Composite Structures, 92(1), 61-71.

Kang, S., and Suh, Y. K. (2008). "Spectral Methods BT - Encyclopedia of Microfluidics and Nanofluidics.” D. Li, ed., Springer US, Boston, MA, 1875-1881.

Kerlin, T. W., and Upadhyaya, B. R. B. T.-D. and C. of N. R. (Eds.). (2019). "Appendix F State variable models and transient analysis.” Academic Press, 299-317.

Khorami, M., Navarro-Gregori, J., Serna, P., and Navarro-Laguarda, M. A. (2019). "A testing method for studying the serviceability behavior of reinforced UHPFRC tensile ties." IOP Conference Series: Materials Science and Engineering, IOP Publishing, 12022.

Khorami, M., Navarro-Gregori, J., and Serna, P. (2020). "Experimental methodology on the serviceability behaviour of reinforced ultra-high performance fibre reinforced concrete tensile elements." Strain, Wiley Online Library, 13.

Kim, D. J., Wille, K., El-Tawil, S., and Naaman, A. E. (2011). "Testing of cementitious 
materials under high-strain-rate tensile loading using elastic strain energy." Journal of Engineering Mechanics, American Society of Civil Engineers, 137(4), 268-275.

Kim, S., Yoo, D.-Y., Kim, M.-J., and Banthia, N. (2019). "Self-healing capability of ultrahigh-performance fiber-reinforced concrete after exposure to cryogenic temperature." Cement and Concrete Composites, 104, 103335.

Kitsutaka, Y. (1993). "Poly-linear approximation analysis of tension softening diagram for concrete.” Journal of Struct. Constr. Engng., Architectural Inst. of Japan, 453, 15-25.

Klisinski, M., Runesson, K., and Sture, S. (1991). "Finite element with inner softening band." Journal of engineering mechanics, American Society of Civil Engineers, 117(3), 575587.

Kobayashi, A. S., Hawkins, N. M., Barker, D. B., and Liaw, B. M. (1985). "Fracture process zone of concrete." Application of Fracture Mechanics to Cementitious Composites, Springer, 25-50.

Kodur, V., Solhmirzaei, R., Agrawal, A., Aziz, E. M., and Soroushian, P. (2018). "Analysis of flexural and shear resistance of ultra high performance fiber reinforced concrete beams without stirrups." Engineering Structures, 174, 873-884.

Koh, K., Ryu, G., Kang, S., Park, J., and Kim, S. (2011). "Shrinkage properties of ultra-high performance concrete (UHPC)." Advanced Science Letters, American Scientific Publishers, 4(3), 948-952.

Koiter, W. T. (1953). "Stress-strain relations, uniqueness and variational theorems for elasticplastic materials with a singular yield surface." Quarterly of applied mathematics, 11(3), 350-354.

Kolymbas, D. (1977). "A rate-dependent constitutive equation for soils." Mechanics Research Communications, Elsevier, 4(6), 367-372.

Krahl, P. A., Carrazedo, R., and El Debs, M. K. (2018). "Mechanical damage evolution in UHPFRC: experimental and numerical investigation." Engineering Structures, Elsevier, 170, 63-77.

Krajcinovic, D., and Fonseka, G. U. (1981). "The Continuous Damage Theory of Brittle Materials, Part 1: General Theory.” Journal of Applied Mechanics, 48(4), 809-815.

Krieg, R. D. (1975). "A practical two surface plasticity theory." Journal of Applied Mechanics, ASME, 641-646.

Kuhlemeyer, R. L., and Lysmer, J. (1973). "Finite element method accuracy for wave propagation problems.” Journal of Soil Mechanics \& Foundations Div, 99(Tech Rpt).

Lagier, F., Massicotte, B., and Charron, J.-P. (2016). "Experimental investigation of bond stress distribution and bond strength in unconfined UHPFRC lap splices under direct tension." Cement and Concrete Composites, 74, 26-38.

Lampropoulos, A. P., Paschalis, S. A., Tsioulou, O. T., and Dritsos, S. E. (2016). "Strengthening of reinforced concrete beams using ultra high performance fibre 
reinforced concrete (UHPFRC)." Engineering Structures, 106, 370-384.

Lee, J. H., Hong, S. G., Joh, C., Kwahk, I., and Lee, J. W. (2017). "Biaxial tensioncompression strength behaviour of UHPFRC in-plane elements." Materials and Structures/Materiaux et Constructions, 50(1), 20.

Leo, C., and Elzein, A. (2001). "Boundary-Only Formulations for Modeling Contaminant Transport." S. Valliappan and N. B. T.-C. M. F. for the N. M. Khalili, eds., Elsevier, Oxford, 765-770.

Leutbecher, T. (2008). Rissbildung und Zugtragverhalten von mit Stabstahl und Fasern bewehrtem ultrahochfesten Beton (UHPC). kassel university press $\mathrm{GmbH}$.

Lévy, M. (1871). "Extrait du Mémoire sur les équations générales des mouvements intérieurs des corps solides ductiles au delà des limites où l'élasticité pourrait les ramener à leur premier état; présenté le 20 juin 1870." Journal de mathématiques pures et appliquées 2e série, 16, 369-372.

Li, J., Wu, C., and Hao, H. (2015). "An experimental and numerical study of reinforced ultrahigh performance concrete slabs under blast loads." Materials \& Design, 82, 64-76.

Li, J., Wu, C., Hao, H., Wang, Z., and Su, Y. (2016). "Experimental investigation of ultrahigh performance concrete slabs under contact explosions." International Journal of Impact Engineering, Elsevier, 93, 62-75.

Liu, J., Han, F., Cui, G., Zhang, Q., Lv, J., Zhang, L., and Yang, Z. (2016). "Combined effect of coarse aggregate and fiber on tensile behavior of ultra-high performance concrete." Construction and Building Materials, 121, 310-318.

Livesley, R. K. (1975). Matrix Methods of Structural Analysis. Pergamon Press.

López, J. Á. (2017). "Characterisation of the tensile behaviour of UHPFRC by means of fourpoint bending tests." PhD Thesis, Universitat Politècnica de València, València, Valencia (Spain), (March).

López, J. A., Serna, P., and Navarro-Gregori, J. (2017). "Advances in the development of the first UHPFRC Recommendations in Spain: Material classification, design and characterization." UHPFRC 2017 Designing and Building with UHPFRC: New largescale implementations, recent technical advances, experience and standards, F. Toutlemonde \& J. ResplendinoT.Ch., ed., RILEM Publications SARL, 565-574.

López, J. Á., Serna, P., Navarro-Gregori, J., and Camacho, E. (2015a). "An inverse analysis method based on deflection to curvature transformation to determine the tensile properties of UHPFRC." Materials and Structures, Springer Verlag (Germany), 48(11), 3703-3718.

López, J. Á., Serna, P., Navarro-Gregori, J., and Coll, H. (2016). “A simplified five-point inverse analysis method to determine the tensile properties of UHPFRC from unnotched four-point bending tests." Composites Part B: Engineering, 91(Supplement C), 189-204. 
López, J., Serna, P., Navarro-Gregori, J., and Coll, H. (2015b). "Comparison between an inverse analysis procedure results and experimental measurements obtained from UHPFRC Four-Point Bending Tests." Seventh International RILEM Conference on High Performance Fiber Reinforced Cement Composites (HPFRCC7), H. G. H.W. Reinhardt, G.J. Parra-Montesinos, ed., RILEM Publications SARL, 185-192.

Lubliner, J. (1991). "A simple model of generalized plasticity." International journal of solids and structures, Elsevier, 28(6), 769-778.

Lubliner, J., Oliver, J., Oller, S., and Oñate, E. (1989). "A plastic-damage model for concrete.” International Journal of solids and structures, Elsevier, 25(3), 299-326.

Maalej, M., and Li, V. C. (1994). "Flexural Strength of Fiber Cementitious Composites." ASCE J. Materials in Civil Engineering, American Society of Civil Engineers, 6(3), 390-406.

Mahmud, G. H., Yang, Z., and Hassan, A. M. T. (2013). "Experimental and numerical studies of size effects of Ultra High Performance Steel Fibre Reinforced Concrete (UHPFRC) beams." Construction and Building Materials, 48, 1027-1034.

Mallat, A., and Alliche, A. (2011). "A modified tensile test to study the behaviour of cementitious materials.” Strain, Wiley Online Library, 47(6), 499-504.

Malvar, L. J., Crawford, J. E., Wesevich, J. W., and Simons, D. (1997). “A plasticity concrete material model for DYNA3D.” International journal of impact engineering, Elsevier, 19(9-10), 847-873.

Manzari, M. T. (2013). "Meshless Methods BT - Encyclopedia of Microfluidics and Nanofluidics.” D. Li, ed., Springer US, Boston, MA, 1-14.

Marchand, P., Baby, F., Khadour, A., Battesti, T., Rivillon, P., Quiertant, M., Nguyen, H.H., Généreux, G., Deveaud, J.-P., and Simon, A. (2016). "Bond behaviour of reinforcing bars in UHPFRC.” Materials and structures, Springer, 49(5), 1979-1995.

Matsumoto, T., Tanaka, M., and Tsukamoto, T. (2003). "Identifications of Source Distributions Using BEM with Dual Reciprocity Method.” M. B. T.-I. P. in E. M. I. V Tanaka, ed., Elsevier Science B.V., Amsterdam, 127-135.

Matthies, H., and Strang, G. (1979). "The solution of nonlinear finite element equations." International journal for numerical methods in engineering, Wiley Online Library, 14(11), 1613-1626.

Mazumder, S. (2016a). "Chapter 7 - Unstructured Finite Volume Method.” S. B. T.-N. M. for P. D. E. Mazumder, ed., Academic Press, 339-388.

Mazumder, S. (2016b). "Chapter 1 - Introduction to Numerical Methods for Solving Differential Equations.” S. B. T.-N. M. for P. D. E. Mazumder, ed., Academic Press, $1-49$.

MC90, C. (1993). "Design of concrete structures. CEB-FIP Model Code 1990." Thomas Telford, London, UK. 
McHenry, D. (1943). "A lattice analogy for the solution of stress problems." Journal of the Institution of Civil Engineers, Thomas Telford-ICE Virtual Library, 21(2), 59-82.

Mezquida-Alcaraz, E. J., Navarro-Gregori, J., Angel Lopez, J., and Serna-Ros, P. (2019a). "Validation of a non-linear hinge model for tensile behavior of UHPFRC using a Finite Element Model." COMPUTERS AND CONCRETE, TECHNO-PRESS PO BOX 33, YUSEONG, DAEJEON 305-600, SOUTH KOREA, 23(1), 11-23.

Mezquida-Alcaraz, E. J., Navarro-Gregori, J., López, J. A., and Serna-Ros, P. (2018). "Numerical Validation of a Simplified Inverse Analysis Method to Characterise the Tensile Behaviour of UHPFRC." FRC2018: Fibre Reinforced Concrete: from Design to Structural Applications Joint ACI-fib-RILEM International Workshop.

Mezquida-Alcaraz, E. J., Navarro-Gregori, J., and Serna-Ros, P. (2019b). "Numerical validation of a simplified inverse analysis method to characterize the tensile properties in strain-softening UHPFRC." IOP Conference Series: Materials Science and Engineering, IOP Publishing, 12006.

Mezquida-Alcaraz, E. J., Navarro-Gregori, J., and Serna-Ros, P. (2021). "Direct procedure to characterize the tensile constitutive behavior of strain-softening and strain-hardening UHPFRC." Cement and Concrete Composites, 115, 103854.

Mises, R. v. (1913). "Mechanik der festen Körper im plastisch-deformablen Zustand." Nachrichten von der Gesellschaft der Wissenschaften zu Göttingen, MathematischPhysikalische Klasse, 1913, 582-592.

Moratal, D. (2012). Finite Element Analysis: From Biomedical Applications to Industrial Developments. BoD-Books on Demand.

Na, C., and Kwak, H. G. (2011). "A numerical tension-stiffening model for ultra high strength fiber-reinforced concrete beams." Computers and Concrete, 8(1), 1-22.

Naaman, A. E. (2003). "Strain hardening and deflection hardening fiber reinforced cement composites." Proc. 4th Int. RILEM Workshop on High Performance Fiber Reinforced Cement Composites, Ann Abor, University of Michigan, 95-113.

Naaman, A. E., and Reinhardt, H.-W. (2006). "Proposed classification of HPFRC composites based on their tensile response." Materials and structures, Springer, 39(5), 547-555.

Naeimi, N., and Moustafa, M. A. (2020). "Numerical modeling and design sensitivity of structural and seismic behavior of UHPC bridge piers." Engineering Structures, Elsevier, 219, 110792.

Naghdi, P. M., and Trapp, J. A. (1975). "The significance of formulating plasticity theory with reference to loading surfaces in strain space." International Journal of Engineering Science, Elsevier, 13(9-10), 785-797.

Navarro Laguarda, M. Á. (2018). "Estudio del comportamiento de tirantes armados de Hormigón de Muy Alta Resistencia (HMAR). Aplicación al diseño de una pasarela sobre el barranco de las ovejas de Alicante." 
Negrini, A., Roig-Flores, M., Mezquida-Alcaraz, E. J., Ferrara, L., and Serna, P. (2019). "Effect of crack pattern on the self-healing capability in traditional, HPC and UHPFRC concretes measured by water and chloride permeability." 7th International Conference on Concrete Repair, 1-8.

Neill, S. P., and Hashemi, M. R. (2018). "Chapter 8 - Ocean Modelling for Resource Characterization." E-Business Solutions, S. P. Neill and M. R. B. T.-F. of O. R. E. Hashemi, eds., Academic Press, 193-235.

Nevo, A. (2006). "Chapter 13 - Pointwise Ergodic Theorems for Actions of Groups." Handbook of Dynamical Systems, B. Hasselblatt and A. B. T.-H. of D. S. Katok, eds., Elsevier Science, 871-982.

Ngo, D., and Scordelis, A. C. (1967). "Finite element analysis of reinforced concrete beams." Journal Proceedings, 152-163.

Oesterlee, C. (2010). "Structural response of reinforced UHPFRC and RC composite members." PhD Dissertation, ÉCOLE POLYTECHNIQUE FÉDÉRALE DE LAUSANNE.

Olesen, J. F. (2001). "Fictitious Crack Propagation in Fiber-Reinforced Concrete Beams." Journal of Engineering Mechanics, 127(3), 272-280.

Oñate Ibañez de Navarra, E. (1995). "Cálculo de Estructuras por el Método de Elementos Finitos. Análisis estático lineal.” Barcelona.

Orszag, S. A. (1969). "Numerical methods for the simulation of turbulence." The Physics of Fluids, American Institute of Physics, 12(12), II-250.

Ostergaard, L., Walter, R., and Olesen, J. F. (2005). "Method for determination of tensile properties of engineered cementitious composites (ECC),." Construction Materials : Proceedings of ConMat'05 and Mindess Symposium, 74.

Paschalis, S. A., and Lampropoulos, A. P. (2016). "Ultra-high-performance fiber-reinforced concrete under cyclic loading." ACI Materials Journal, American Concrete Institute, 113(4), 419-427.

Pedersen, C. (1996). "New production process, materials and calculation tecniques for fiber reinforced concrete pipes." PhD thesis, Department of Structural Engineering and Materials.

Pijaudier-Cabot, G., and Bažant, Z. P. (1987). "Nonlocal damage theory." Journal of engineering mechanics, American Society of Civil Engineers, 113(10), 1512-1533.

Poljak, D. (2018). "Chapter 7 - On the Use of Boundary Integral Methods in Bioelectromagnetics.” M. Cerrolaza, S. J. Shefelbine, and D. B. T.-N. M. and A. S. in B. and B. P. Garzón-Alvarado, eds., Academic Press, 119-143.

Przemieniecki, J. S. (1985). Theory of matrix structural analysis. Courier Corporation.

Pyo, S., and El-Tawil, S. (2015). "Capturing the strain hardening and softening responses of cementitious composites subjected to impact loading." Construction and Building 
Materials, 81, 276-283.

Pyo, S., El-Tawil, S., and Naaman, A. E. (2016). "Direct tensile behavior of ultra high performance fiber reinforced concrete (UHP-FRC) at high strain rates." Cement and Concrete Research, 88, 144-156.

Pyo, S., Wille, K., El-Tawil, S., and Naaman, A. E. (2015). "Strain rate dependent properties of ultra high performance fiber reinforced concrete (UHP-FRC) under tension." Cement and Concrete Composites, 56, 15-24.

Qian, S., and Li, V. C. (2007). "Simplified Inverse Method for Determining the Tensile Strain Capacity of Strain Hardening Cementitious Composites." Journal of Advanced Concrete Technology, 5(2), 235-246.

Rahdar, H., and Ghalehnovi, M. (2016). "Post-cracking behavior of UHPC on the concrete members reinforced by steel rebar." Computers and Concrete, 18.

Rapp, B. E. (2017). "Chapter 31 - Finite Volume Method." Micro and Nano Technologies, B. E. B. T.-M. M. Rapp Mechanics and Mathematics, ed., Elsevier, Oxford, 633-654.

Rashid, Y. R. (1968). "Ultimate strength analysis of prestressed concrete pressure vessels." Nuclear engineering and design, Elsevier, 7(4), 334-344.

Rigaud, S., Chanvillard, G., and Chen, J. (2012). "Characterization of Bending and Tensile Behavior of Ultra-High Performance Concrete Containing Glass Fibers." High Performance Fiber Reinforced Cement Composites 6: HPFRCC 6, G. J. ParraMontesinos, H. W. Reinhardt, and A. E. Naaman, eds., Springer Netherlands, Dordrecht, 373-380.

Riks, E. (1972). "The application of Newton's method to the problem of elastic stability."

Roelfstra, P. E., Sadouki, H., and Wittmann, F. H. (1985). "Le béton numérique.” Materials and Structures, Springer, 18(5), 327-335.

Roig Flores, M. (2018). "Self-healing concrete: efficiency evaluation and enhancement with crystalline admixtures." Doctoral dissertation. UPV, 0-239.

Rossi, P., Daviau-Desnoyers, D., and Tailhan, J.-L. (2018). "Probabilistic numerical model of cracking in ultra-high performance fibre reinforced concrete (UHPFRC) beams subjected to shear loading." Cement and Concrete Composites, Elsevier, 90, 119-125.

Roth, M. J., Eamon, C. D., Slawson, T. R., Tonyan, T. D., and Dubey, A. (2010). "Ultrahigh-strength, glass fiber-reinforced concrete: Mechanical behavior and numerical modeling." ACI Materials Journal, American Concrete Institute, 107(2), 185.

Rots, J. G. (1988). “Computational modeling of concrete fracture." PhD Thesis, Delft University of Technology, Delft.

Rots, J. G. (2002). "Comparative study of crack models." Proceedings of the 3rd DIANA World Conference, Finite Elements in Civil Engineering Applications, 17-28.

Rots, J. G., and Blaauwendraad, J. (1989a). "Rots et al. (1989) Crack Model for Concrete 
Discrete or Smeared Fixed, multi-Directional or Rotating.pdf." HERON, 34 (1), 1989, Delft University of Technology.

Rots, J. G., and Blaauwendraad, J. (1989b). "Crack models for concrete, discrete or smeared? Fixed, multi-directional or rotating?" HERON, 34 (1), 1989, Delft University of Technology.

Runge, C. (1908). "Uber eine Methode, die partielle Di erentialgleichung $u=$ Constans numerisch zu integrieren." Z. Math. u. Phys. Bd, 56, 225-232.

Russell, H. G., Graybeal, B. A., and Russell, H. G. (2013). "Ultra-high performance concrete: A state-of-the-art report for the bridge community." United States. Federal Highway Administration, United States. Federal Highway Administration. Office of Infrastructure Research and Development, No. FHWA-H, 163.

Sadd, M. H. (2014). "Chapter 5 - Formulation and Solution Strategies.” M. H. B. T.-E. (Third E. Sadd, ed., Academic Press, Boston, 95-117.

SADD, M. H. (2005). "5 - Formulation and Solution Strategies." M. H. B. T.-E. SADD, ed., Academic Press, Burlington, 83-102.

Sadouki, H., Denarié, E., and Brühwiler, E. (2017). "Validation of a FEA model of structural response of RC-cantilever beams strengthened with a (R-) UHPFRC layer." Construction and Building Materials, 140, 100-108.

Saint-Venant, B. de. (1871). "Mémoire sur l'établissement des équations différentielles mouvements intérieures opérés dans les corps solids ductiles au delà des limites ou l'élasticité pourrait les ramener à leur premier état. Saint-Venant." Journal de mathématiques pures et appliquées 2e série, 16, 308-316.

Sakr, M. A., El-khoriby, S. R., Khalifa, T. M., and Nagib, M. T. (2019). "Modeling of RC shear walls strengthened with ultra-high performance fiber reinforced concrete (UHPFRC) jackets." Engineering Structures, 200, 109696.

Selby, R. G., and Vecchio, F. J. (1993). "Three-dimensional constitutive relations for reinforced concrete." University of Toronto, Dept. of Civil Engineering, University of Toronto, Dept. of Civil Engineering, [Toronto].

Semenza, G. (2006). "Chapter 6 - Efficient organization of the matrix computations." Computational and Numerical Challenges in Environmental Modeling, Z. Zlatev and I. B. T.-S. in C. M. Dimov, eds., Elsevier, 157-200.

Serna, P., Lo Monte, F., Mezquida-Alcaraz, E. J., Cuenca, E., Mechtcherine, V., Reichardt, M., Peled, A., Regev, O., Borg, R. P., and Tretjakov, A. (2019). "UPGRADING THE CONCEPT OF UHPFRC FOR HIGH DURABILITY IN THE CRACKED STATE: THE CONCEPT OF ULTRA HIGH DURABILITY CONCRETE (UHDC) IN THE APPROACH OF THE H2020 PROJECT RESHEALIENCE." Sustainable Materials Systems and Structures SMSS 2019, RILEM Publications SARL, 764-771.

Shaoxian, B., and Shizhu, W. (2019). "Chapter 2 - Gas lubrication equations." B. Shaoxian and W. B. T.-G. T. L. and S. Shizhu, eds., Academic Press, 15-35. 
Sih, G. C. (1974). "Strain-energy-density factor applied to mixed mode crack problems." International Journal of fracture, Springer, 10(3), 305-321.

Singh, M., Sheikh, A. H., Mohamed Ali, M. S., Visintin, P., and Griffith, M. C. (2017). "Experimental and numerical study of the flexural behaviour of ultra-high performance fibre reinforced concrete beams." Construction and Building Materials, 138, 12-25.

Sluys, L. J. (1997). "Discontinuous modeling of shear banding." Computational plasticity: Fundamentals and applications, Int. Center for Numerical Methods in Eng., Barcelona, Spain, 735-744.

Solhmirzaei, R., and Kodur, V. K. R. (2017). "Modeling the response of ultra high performance fiber reinforced concrete beams." Procedia engineering, Elsevier, 210, 211-219.

Soliman, A. M., and Nehdi, M. L. (2011). "Effect of drying conditions on autogenous shrinkage in ultra-high performance concrete at early-age." Materials and Structures, Springer, 44(5), 879-899.

Soranakom, C., and Mobasher, B. (2007). "Closed-form moment-curvature expressions for homogenized fiber-reinforced concrete." ACI Materials Journal, 104(4), 351-359.

Spasojevic, A., Redaelli, D., Fernández Ruiz, M., and Muttoni, A. (2008). "Influence of tensile properties of UHPFRC on size effect in bending." Ultra High Performance Concrete (UHPC), Second International Symposium on Ultra High Performance Concrete, Ultra High Performance Concrete (UHPC), Second International Symposium on ..., 303-310.

Stach, S. (2014). "11 - Modelling fracture processes in orthopaedic implants." Z. B. T.-C. M. of B. and B. in the M. S. Jin, ed., Woodhead Publishing, 331-368.

Stang, H., and Olesen, J. F. (1998). "On The Interpretation of Bending Tests On FRCMaterials." Fracture Mechanics of Concrete Structures, (AEDIFICATIO Publishers, D-79104 Freiburg, Germany), 511-520.

Sturm, A. B., and Visintin, P. (2019). "Local bond slip behavior of steel reinforcing bars embedded in ultra high performance fibre reinforced concrete." Structural Concrete, Wiley Online Library, 20(1), 108-122.

Sturm, A. B., Visintin, P., Oehlers, D. J., and Seracino, R. (2018). “Time-dependent tensionstiffening mechanics of fiber-reinforced and ultra-high-performance fiber-reinforced concrete." Journal of Structural Engineering, American Society of Civil Engineers, 144(8), 4018122.

Suidan, M., and Schnobrich, W. C. (1973). "Finite element analysis of reinforced concrete." Journal of the structural division, 99(st1).

Swiss Society of Engineers and Architects SIA. (2016). "Sia 2052." 48.

Switek, A. (2008). "Smeared crack modelling of fracture in materials with significant bulk energy dissipation." École Polytechnique Fédérale de Lausanne, Lausanne, 0-14. 
Systèmes, D. (2009). “Abaqus/CAE User's Manual, version. 6.9." Providence, RI, USA: Dassault Systèmes Simulia Corp.

Tailhan, J. L., Rossi, P., and Parant, E. (2004). "Inverse numerical approach to determine the uniaxial tensile behaviour of a stress hardening cement composite from its bending behaviour." Fiber Reinforced Concretes-BEFIB 2004, Proceedings of the 6th International RILEM Symposium, M. di Prisco, R. Felicetti, and GA Plizzari, eds, 913922.

The European Union Per Regulation 305/2011, and Directive 98/34/EC, D. 2004/18/EC. (2004). "EN 1992-1-1: Eurocode 2: Design of concrete structures." EUROPEAN STANDARD.

Tran, N. T., Tran, T. K., and Kim, D. J. (2015). "High rate response of ultra-highperformance fiber-reinforced concretes under direct tension." Cement and Concrete Research, 69, 72-87.

Tran, T. K., and Kim, D. J. (2012). "Strain energy frame impact machine (SEFIM)." Journal of Advanced Concrete Technology, Japan Concrete Institute, 10(3), 126-136.

Tran, T. K., and Kim, D. J. (2013). "Investigating direct tensile behavior of high performance fiber reinforced cementitious composites at high strain rates." Cement and concrete research, Elsevier, 50, 62-73.

Tresca, H. E. (1869). Mémoire sur l'écoulement des corps solides. Imprimerie impériale.

Turner, M. J., Clough, R. W., Martin, H. C., and Topp, L. J. (1956). "Stiffness and deflection analysis of complex structures." journal of the Aeronautical Sciences, 23(9), 805-823.

Tysmans, T., Wozniak, M., Remy, O., and Vantomme, J. (2015). "Finite element modelling of the biaxial behaviour of high-performance fibre-reinforced cement composites (HPFRCC) using Concrete Damaged Plasticity." Finite Elements in Analysis and Design, 100, 47-53.

Uchida, Y., and Kurihara, N. (1995). "Determination of tension softening diagrams of various kinds of concrete by means of numerical analysis." Fracture mechanics of concrete structures - FraMcoS 2, AEDIFICATIO Unterengstringin, 17-30.

Vakulenko, A. A., and Kachanov, M. L. (1971). "Continuum theory of medium with cracks." Mekhanika tverdogo tela, 6(4), 159-166.

Valanis, K. C. (1978). Fundamental consequences of a new intrinsic time measure. Plasticity as a limit of the endochronic theory. IOWA UNIV IOWA CITY.

Vecchio, F. J., and Collins, M. P. (1986). "The modified compression-field theory for reinforced concrete elements subjected to shear." ACI J., 83(2), 219-231.

Vigé, D. (2010). "13 - Vehicle interior noise refinement - cabin sound package design and development.” X. B. T.-V. N. and V. R. Wang, ed., Woodhead Publishing, 286-317.

Wan, L., Wendner, R., Liang, B., and Cusatis, G. (2016). "Analysis of the behavior of ultra high performance concrete at early age." Cement and Concrete Composites, 74(15), 
$120-135$.

Wang, H., and Qin, Q.-H. (2019a). "Chapter 6 - Meshless analysis for two-dimensional elastic problems." H. Wang and Q.-H. B. T.-M. of F. S. in S. M. Qin, eds., Elsevier, $143-210$.

Wang, H., and Qin, Q.-H. (2019b). "Chapter 5 - Meshless analysis for thin plate bending problems." H. Wang and Q.-H. B. T.-M. of F. S. in S. M. Qin, eds., Elsevier, 127-142.

Wang, H., and Qin, Q.-H. (2019c). "Chapter 1 - Overview of meshless methods." H. Wang and Q.-H. B. T.-M. of F. S. in S. M. Qin, eds., Elsevier, 3-51.

Wang, W., Liu, J., Agostini, F., Davy, C. A., Skoczylas, F., and Corvez, D. (2014). "Durability of an Ultra High Performance Fiber Reinforced Concrete (UHPFRC) under progressive aging." Cement and Concrete Research, 55, 1-13.

Wille, K., El-Tawil, S., and Naaman, A. E. (2012). "Strain Rate Dependent Tensile Behavior of Ultra-High Performance Fiber Reinforced Concrete BT - High Performance Fiber Reinforced Cement Composites 6: HPFRCC 6." G. J. Parra-Montesinos, H. W. Reinhardt, and A. E. Naaman, eds., Springer Netherlands, Dordrecht, 381-387.

Wille, K., El-Tawil, S., and Naaman, A. E. (2014). "Properties of strain hardening ultra high performance fiber reinforced concrete (UHP-FRC) under direct tensile loading." Cement and Concrete Composites, 48, 53-66.

Wille, K., Kim, D. J., and Naaman, A. E. (2010). "Strain-hardening UHP-FRC with low fiber contents." Materials and Structures, 44(3), 583-598.

Wu, X., Yu, S., Xue, S., Kang, T. H.-K., and Hwang, H.-J. (2019). "Punching shear strength of UHPFRC-RC composite flat plates." Engineering Structures, 184, 278-286.

Wu, Z., Shi, C., He, W., and Wang, D. (2017). "Static and dynamic compressive properties of ultra-high performance concrete (UHPC) with hybrid steel fiber reinforcements." Cement and concrete composites, Elsevier, 79, 148-157.

Xie, T., Fang, C., Mohamad Ali, M. S., and Visintin, P. (2018). "Characterizations of autogenous and drying shrinkage of ultra-high performance concrete (UHPC): An experimental study." Cement and Concrete Composites, 91, 156-173.

Xie, T., Mohamed Ali, M. S., and Visintin, P. (2019). "Behaviour and analysis of ultra high performance fibre reinforced concrete (UHPFRC) skew slabs." Engineering Structures, 199, 109588.

Yalçınkaya, Ç., and Yazıcı, H. (2017). "Effects of ambient temperature and relative humidity on early-age shrinkage of UHPC with high-volume mineral admixtures." Construction and Building Materials, Elsevier, 144, 252-259.

Yam, L. H., and Cheng, W. H. (1993). "DYNAMIC RESPONSE OF A CANTILEVER TIMOSHENKO COLUMN DUE TO ALMOST-AXIAL IMPACT - A COMPARISON BETWEEN CONTINUOUS AND 2 DOF MODELS.” W. B. B. T.A. in E. P. and its A. LEE, ed., Elsevier, Oxford, 461-468. 
Yang, I.-H., Joh, C., and Kim, B.-S. (2012). "Flexural response predictions for ultra-highperformance fibre-reinforced concrete beams." Magazine of Concrete Research, Thomas Telford Ltd, 64(2), 113-127.

Yang, I. H., Joh, C., and Kim, B.-S. (2010). "Structural behavior of ultra high performance concrete beams subjected to bending." Engineering Structures, 32(11), 3478-3487.

Yang, J., and FANG, Z. (2009). "Flexural Behaviors of Ultra High Performance Concrete T Beams Prestressed with CFRP Tendons.” Journal of the China Railway Society, 2.

Yin, H., Shirai, K., and Teo, W. (2019a). "Finite element modelling to predict the flexural behaviour of ultra-high performance concrete members." Engineering Structures, 183, $741-755$.

Yin, H., Shirai, K., and Teo, W. (2019b). "Numerical model for predicting the structural response of composite UHPC-concrete members considering the bond strength at the interface." Composite Structures, Elsevier, 215, 185-197.

Yin, H., Teo, W., and Shirai, K. (2017). "Experimental investigation on the behaviour of reinforced concrete slabs strengthened with ultra-high performance concrete." Construction and Building Materials, Elsevier, 155, 463-474.

Yoo, D.-Y., and Banthia, N. (2015). "Numerical simulation on structural behavior of UHPFRC beams with steel and GFRP bars." Computers and Concrete, Techno-Press, 16(5), 759-774.

Yoo, D.-Y., and Banthia, N. (2016). "Mechanical properties of ultra-high-performance fiberreinforced concrete: A review." Cement and Concrete Composites, Elsevier, 73, 267280.

Yoo, D.-Y., Banthia, N., and Yoon, Y.-S. (2015a). "Effectiveness of shrinkage-reducing admixture in reducing autogenous shrinkage stress of ultra-high-performance fiberreinforced concrete." Cement and Concrete Composites, 64, 27-36.

Yoo, D.-Y., Banthia, N., and Yoon, Y.-S. (2016). "Predicting the flexural behavior of ultrahigh-performance fiber-reinforced concrete." Cement and Concrete Composites, 74, 71-87.

Yoo, D.-Y., Banthia, N., and Yoon, Y.-S. (2017a). "Experimental and numerical study on flexural behavior of ultra-high-performance fiber-reinforced concrete beams with low reinforcement ratios." Canadian Journal of Civil Engineering, NRC Research Press, $44(1), 18-28$.

Yoo, D.-Y., Kang, S.-T., Banthia, N., and Yoon, Y.-S. (2017b). "Nonlinear finite element analysis of ultra-high-performance fiber-reinforced concrete beams." International Journal of Damage Mechanics, SAGE Publications Sage UK: London, England, 26(5), $735-757$.

Yoo, D.-Y., Kang, S.-T., Lee, J.-H., and Yoon, Y.-S. (2013a). "Effect of shrinkage reducing admixture on tensile and flexural behaviors of UHPFRC considering fiber distribution characteristics." Cement and concrete research, Elsevier, 54, 180-190. 
Yoo, D.-Y., Lee, J.-H., and Yoon, Y.-S. (2013b). "Effect of fiber content on mechanical and fracture properties of ultra high performance fiber reinforced cementitious composites." Composite Structures, Elsevier, 106, 742-753.

Yoo, D.-Y., Min, K.-H., Lee, J.-H., and Yoon, Y.-S. (2014a). "Shrinkage and cracking of restrained ultra-high-performance fiber-reinforced concrete slabs at early age." Construction and Building Materials, Elsevier, 73, 357-365.

Yoo, D.-Y., Park, J.-J., Kim, S.-W., and Yoon, Y.-S. (2014b). "Influence of reinforcing bar type on autogenous shrinkage stress and bond behavior of ultra high performance fiber reinforced concrete." Cement and Concrete Composites, Elsevier, 48, 150-161.

Yoo, D.-Y., and Yoon, Y.-S. (2015). "Structural performance of ultra-high-performance concrete beams with different steel fibers." Engineering Structures, Elsevier, 102, 409423.

Yoo, D. Y., Zi, G., Kang, S. T., and Yoon, Y. S. (2015b). "Biaxial flexural behavior of ultrahigh-performance fiber-reinforced concrete with different fiber lengths and placement methods." Cement and Concrete Composites, 63, 51-66.

Yu, R., Spiesz, P., and Brouwers, H. J. H. (2014). "Mix design and properties assessment of Ultra-High Performance Fibre Reinforced Concrete (UHPFRC)." Cement and Concrete Research, 56, 29-39.

Yu, R., Spiesz, P., and Brouwers, H. J. H. (2015). "Development of Ultra-High Performance Fibre Reinforced Concrete (UHPFRC): Towards an efficient utilization of binders and fibres." Construction and Building Materials, 79, 273-282.

Yuan, J., and Graybeal, B. (2015). "Bond of Reinforcement in Ultra-High-Performance Concrete." ACI Structural Journal, 112(6).

Zhang, J., Stang, H., and Li, V. C. (2000). "Experimental study on crack bridging in FRC under uniaxial fatigue tension." Journal of Materials in Civil Engineering, American Society of Civil Engineers, 12(1), 66-73.

Zhang, Y., Zhu, Y., Yeseta, M., Meng, D., Shao, X., Dang, Q., and Chen, G. (2019). "Flexural behaviors and capacity prediction on damaged reinforcement concrete (RC) bridge deck strengthened by ultra-high performance concrete (UHPC) layer." Construction and Building Materials, Elsevier, 215, 347-359.

Zhang, Z., Shao, X. D., Li, W. G., Zhu, P., and Chen, H. (2015). “Axial tensile behavior test of ultra high performance concrete." Zhongguo Gonglu Xuebao/China Journal of Highway and Transport, Xi'an Highway University, 28(8), 50-58.

Zhou, B., and Uchida, Y. (2017a). "Influence of flowability, casting time and formwork geometry on fiber orientation and mechanical properties of UHPFRC." Cement and Concrete Research, 95, 164-177.

Zhou, B., and Uchida, Y. (2017b). "Relationship between fiber orientation/distribution and post-cracking behaviour in ultra-high-performance fiber-reinforced concrete (UHPFRC)." Cement and Concrete Composites, 83, 66-75. 
Zhu, Y., Zhang, Y., Hussein, H. H., and Chen, G. (2020). "Numerical modeling for damaged reinforced concrete slab strengthened by ultra-high performance concrete (UHPC) layer." Engineering Structures, 209, 110031.

Zienkiewicz, O. C., and Taylor, R. L. (2005). The finite element method for solid and structural mechanics. Elsevier.

Zienkiewicz, O. C., Taylor, R. L., Taylor, R. L., and Taylor, R. L. (2000). The finite element method: solid mechanics. Butterworth-heinemann. 


\section{Annexe I}

\section{Inverse analysis methodology}

As it is set in chapter 3 of the present document, the tensile constitutive behaviour of UHPFRC has been derived from unnotched four-point bending tests (4PBT). As they are flexural tests (see Figure A-I.1), 4PBTs require the use of an inverse analysis methodology to derive the tensile properties from the results obtained from them. Different inverse analysis methods have already been developed to obtain the parameters that define the UHPFRC behaviour in tension from 4PBT (Baby et al. 2012, 2013a; Gröger, Johannes, Viet tue, Nguyen, Wille 2012; Kanakubo 2006; López et al. 2015a; Maalej and Li 1994; Ostergaard et al. 2005; Qian and Li 2007; Rigaud et al. 2012; Soranakom and Mobasher 2007; Tailhan et al. 2004). Any of these methods could be used to characterise the tensile properties of UHPFRC from 4PBT experimental results.

In this work, an inverse analysis method based on a closed form non-linear hinge model that was developed properly in the research group in (López 2017) for UHPFRC that exhibits strain-hardening behaviour (SH-UHPFRC) has been chosen. A schematic explanation of this inverse analysis methodology is carried out in the present Annexe I.

Moreover, the tensile constitutive parameters obtained as a result of two experimental programmes developed in (López 2017) are used in section 5.3 in chapter 5 of the present thesis to numerically validate the iterative inverse analysis (I-IA) and the simplified fivepoint inverse analysis (5P-IA) for SH-UHPFRC. Therefore, the setup and the constitutive parameters obtained from both experimental programmes are summarised in the last section of the present Annexe I. 


\section{Closed form non-linear hinge model}

The closed form non-linear hinge model defined in (López 2017) is developed to be applied in ThirdPBT, which is a specific type of 4PBT according to the geometrical conditions established in Figure A-I.1(a). It is defined as a continuous crack model in which certain kinematic assumptions are assumed in a specific length covering the crack (hinge length), where deformations are smeared.

(a)

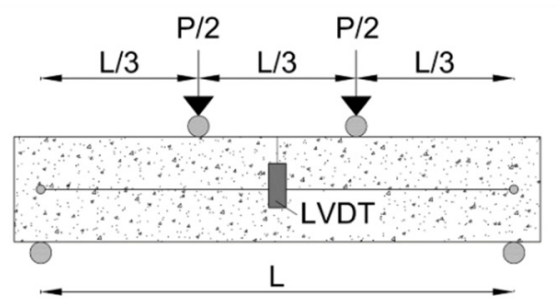

(b)

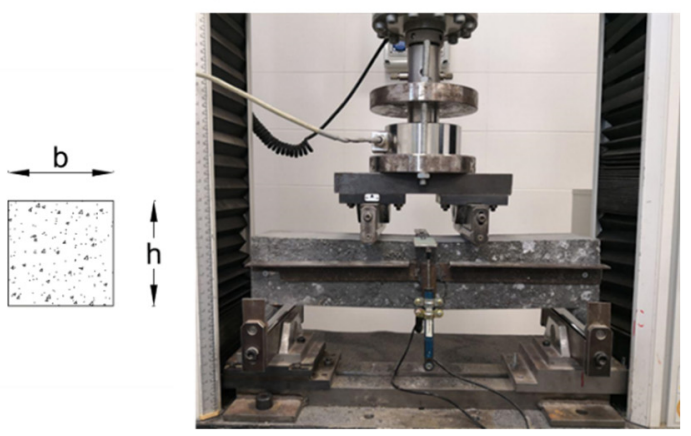

Figure A-I.1 Four-point bending test (also known as third-point bending test) used to characterise the UHPFRC tensile behaviour in this work: (a) geometry and (b) experimental setup

The non-linear hinge model can be summarised and applied in four schematic steps:

\section{Material level:}

In the hinge model, a constitutive behaviour in both tension and compression is assumed. The behaviour in tension is defined by a bilinear stress-strain law that describes the elastic and hardening response of UHPFRC and, from ultimate strength onwards, the softening tensile behaviour is described by a bilinear stress-crack opening relationship (see Figure A-I.2). The stress at the change of slope in the softening part $\left(f_{t d}\right)$ is assumed as one-third of ultimate tensile strength (Expression (A-I.1)). In compression, the constitutive behaviour is assumed linear elastic. According to this, the parameters that define the tensile constitutive UHPFRC behaviour are: cracking strength $\left(f_{t}\right)$, ultimate tensile strength $\left(f_{t, u}\right)$ and its corresponding strain $\left(\varepsilon_{t, u}\right)$, the crack opening at the change of slope $\left(w_{d}\right)$, the crack opening at zero stress $\left(w_{c}\right)$, the elastic modulus $(E)$ assumed the same both in tension and compression and the unloading modulus $\left(E^{*}\right)$. 


$$
f_{t, d}=\frac{f_{t, u}}{3}
$$

$$
\sigma-\varepsilon
$$

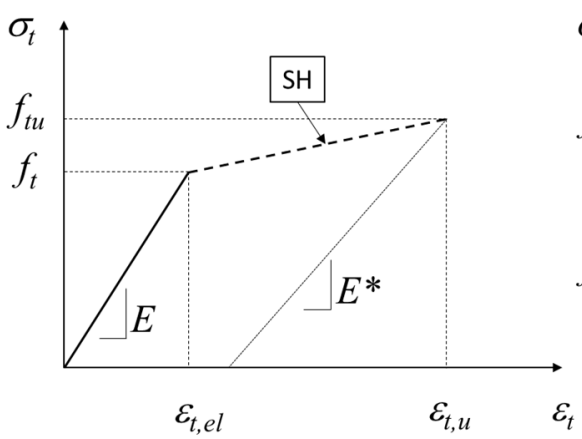

$\sigma-w$

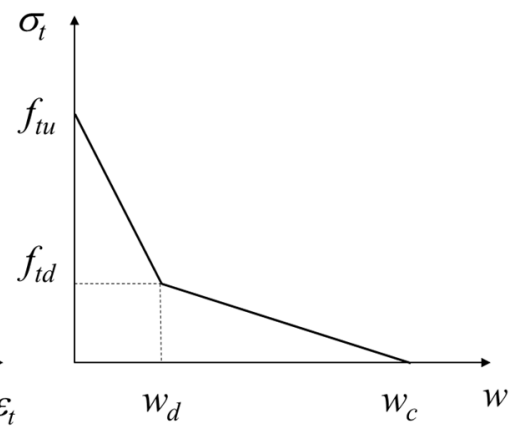

Figure A-I.2 Uniaxial tensile material behaviour adopted for SH-UHPFRC

\section{Definition of the non-linear hinge:}

The non-linear hinge model represents the average UHPFRC behaviour inside a hinge length $(s)$ where the macrocrack is considered in a smeared form. From this, the sectional hinge response can be obtained converting the softening stress-crack opening part of the material behaviour assumed into a stress-strain relationship inside the hinge using Expression (A-I.2) and Expression (A-I.3), geometrically deduced from Figure AI.3(above) assuming Expression (A-I.1). In this case, the unloading modulus $E^{*}$ is assumed as one-fifth the elastic modulus $E$ (Expression (A-I.4)).

$$
\begin{gathered}
\varepsilon_{t, d}=\frac{w_{d}}{s}+\varepsilon_{t, u}-\frac{2 f_{t, u}}{3 E^{*}} \\
\varepsilon_{t, c}=\frac{w_{c}}{s}+\varepsilon_{t, u}-\frac{f_{t, u}}{E^{*}} \\
E^{*}=\frac{E}{5}
\end{gathered}
$$




\section{Closed-form formulation:}

From the quadrilinear stress-strain relationship set in Figure A-I.3(above), five different integration scenarios are defined depending on the strain reached at the most tensioned fibre (see Figure A-I.3(below)). Using the axial force equilibrium and the bending moment equation, the moment $(M)$ - curvature at mid span $(\phi)$ relationship is determined.

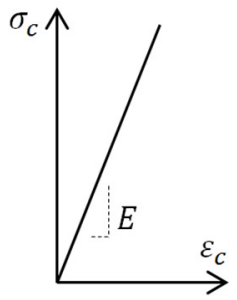

(1)

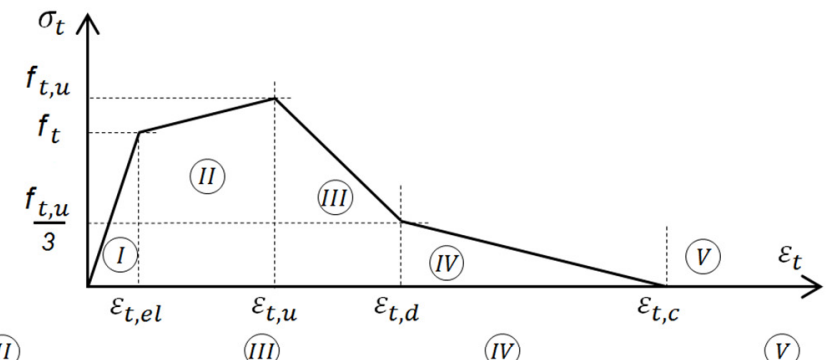

$$
\varepsilon_{A}<\varepsilon_{t, e l} \quad \varepsilon_{t, e l}<\varepsilon_{A}<\varepsilon_{t, u}
$$

$$
\varepsilon_{t, u}<\varepsilon_{A}<\varepsilon_{t, d}
$$

$\varepsilon_{t, d}<\varepsilon_{A}<\varepsilon_{t, c}$

$\varepsilon_{t, c}<\varepsilon_{A}$
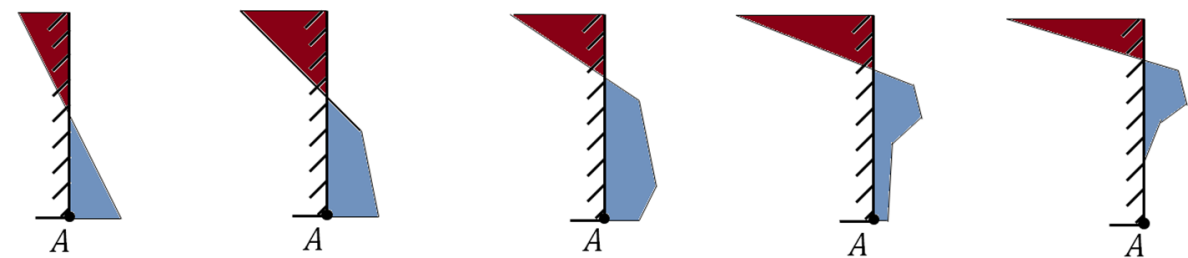

Figure A-I.3 Stress-strain relationship (above) for different stages (below) in (López 2017)

\section{Average curvature to displacement at the mid-span in a 4PBT}

Finally, the deflection at mid-span $(\delta)$ and the average curvature $(\phi)$ values at the central one-third in the 4PBT are related by Expression (A-I.5).

$$
\varnothing=\max \left(\begin{array}{c}
\frac{216}{23 L^{2}}\left[\delta-\frac{12 P}{25 E b}\left(\frac{L}{h}\right)\right] \\
\frac{72}{5 L^{2}}\left[\delta-\frac{P}{6 E b}\left(\frac{L}{h}\right)^{3}-\frac{12 P}{25 E b}\left(\frac{L}{h}\right)\right]
\end{array}\right)
$$

Therefore, the state determination of the proposed closed-form non-linear hinge model can be schematically described as follows: the constitutive tensile parameters of UHPFRC are set and the displacement at the mid-span or deflection $(\delta)$ is established as 
initial input. Then the transformation that relates $\delta$ to the average curvature $(\phi)$ is used, Expression (A-I.5). The hinge model is applied, and the bending moment $(M)$ is obtained as a result. The numerical value of the applied load $(P)$ can be obtained from $M$. Figure A-I.4 outlines the process of the above-described state determination.

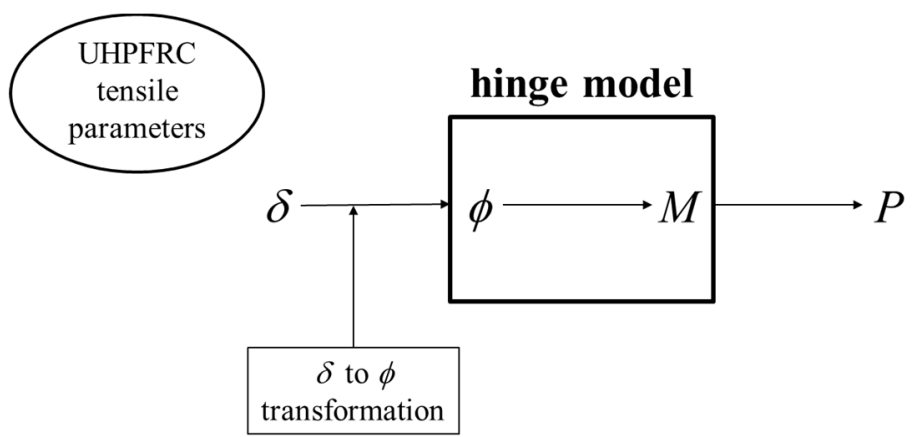

Figure A-I.4 State determination of the hinge model

The tensile parameters necessary to define the tensile constitutive response of the UHPFRC can be deduced from the application of the closed form non-linear hinge model by three ways: Iterative Inverse Analysis (I-IA), the simplified five-point inverse analysis (5P-IA) and the simplified four-point inverse analysis (4P-IA).

\section{Iterative Inverse Analysis (I-IA)}

The Iterative Inverse Analysis Method (I-IA) developed in (López 2017) to obtain the constitutive UHPFRC tensile parameters from a 4PBT consists in, using the closed-form $M-\phi$ formulation and the suggested $\delta$ to $\phi$ transformation described above, a loadcurvature iterative inverse analysis method can be proposed.

It starts from the experimental load-displacement at mid-span obtained from a ThirdPBT. For each experimental point $P_{i}-\delta_{i}$, the $\delta$ to $\phi$ transformation defined in Expression (AI.5) is used to generate the $P-\phi$ experimental curve.

After obtaining the experimental $P$ - $\phi$ curve, an initial stress-strain tensile response inside the hinge must be assumed (Figure A-I.3). Using the same curvature values $\left(\phi_{i}\right)$ set from the previous obtained experimental curve, the $M-\phi$ relationship is calculated from the tensile response using the $M-\phi$ closed formulation.

For a rectangular section, the equivalent flexural strength $\left(\sigma_{f l}\right)$ can be obtained using Expression (A-I.6). 


$$
\sigma_{f l}=\frac{6 M}{b h^{2}}=\frac{P L}{b h^{2}}
$$

Therefore, using Expression (A-I.6), equivalent flexural stress $\left(\sigma_{f l}\right)$ can be obtained from the bending moment $(M)$, and the experimental and numerical values of $\sigma_{f l}$ can be compared for each $\phi$ value. According to this, the analytical $\sigma_{f l}-\phi$ curve can be compared to the experimental curve using a numerical iterative process by varying the constitutive tensile parameters assumed to get the minimal sum of the residual squares of the $\sigma_{f l}$ for each $\phi$ value. Figure A-I.5 shows the workflow of the I-IA explained.

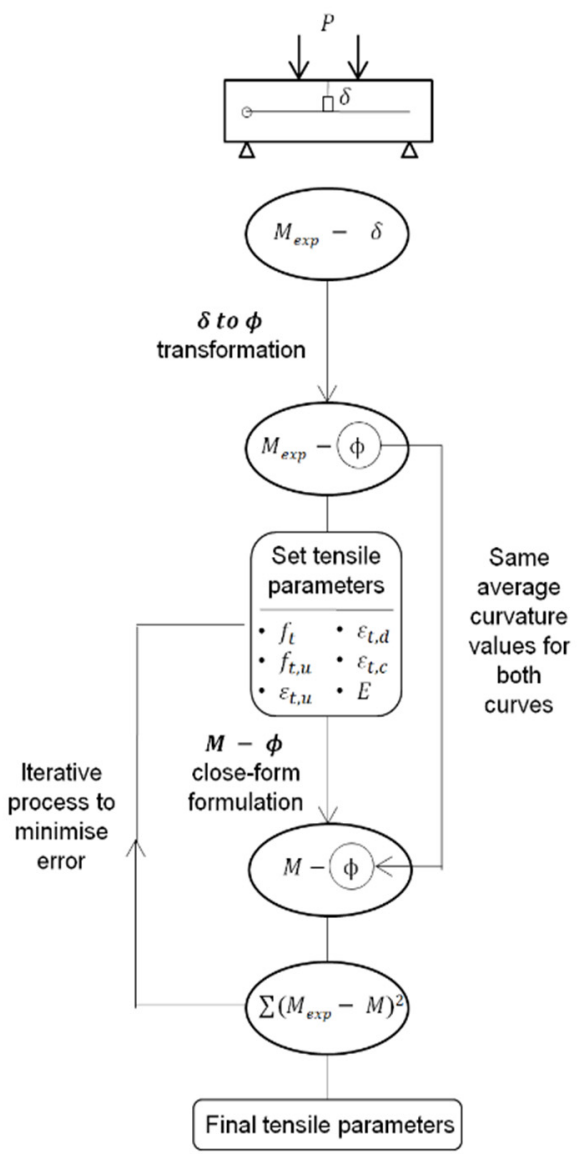

Figure A-I.5 Workflow of the I-IA in (López 2017) 


\section{Simplified five-point inverse analysis (5P-IA)}

The Simplified Five-Point Inverse Analysis Method (5P-IA) to obtain the constitutive UHPFRC tensile behaviour from a 4PBT is fully described in (López 2017; López et al. 2016). This new simplified methodology is based on the closed-form non-linear hinge model described before. The method consists on, from the selection of five specific key points extracted from the experimental equivalent bending strength-displacement at midspan curve (Figure A-I.6), the parameters that define the assumed stress-strain law inside the hinge (Figure A-I.3) can be determined by a back-of-the-envelope calculation. Then, using Expression (A-I.2) and Expression (A-I.3), the constitutive tensile behaviour of UHPFRC can be determined (Figure A-I.2).

The proposed parameters that define the constitutive tensile behaviour are: cracking strength $\left(f_{t}\right)$, ultimate tensile strength $\left(f_{t, u}\right)$ and its corresponding strain $\left(\varepsilon_{t, u}\right)$, the crack opening at the change of slope $\left(w_{d}\right)$, the crack opening at zero stress $\left(w_{c}\right)$, the elastic modulus $(E)$ and the unloading modulus $\left(E^{*}\right)$ (see Figure A-I.6).

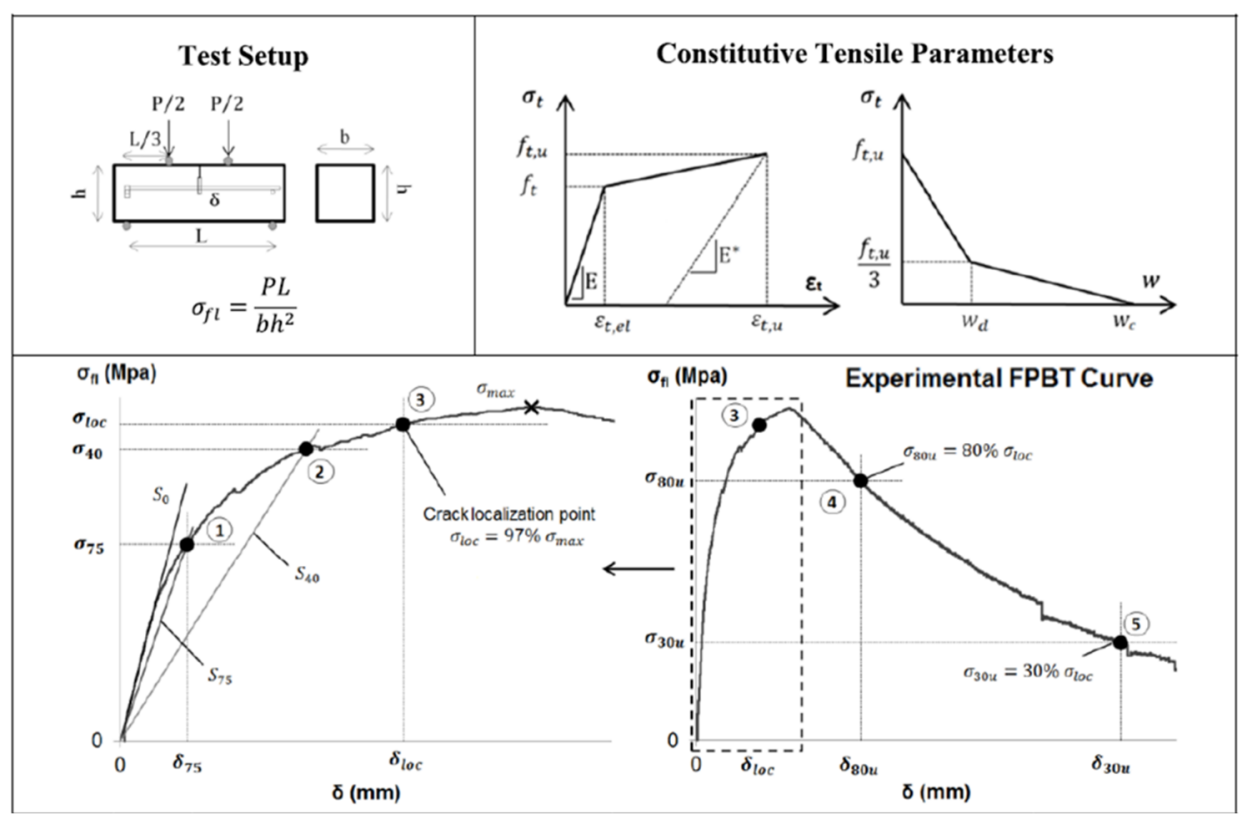

Figure A-I.6 Simplified 5P-IA (López 2017) 


\section{Simplified four-point inverse analysis (4P-IA)}

This is a simplification of the 5P-IA developed in (López 2017), in which the quadrilinear $\sigma-\varepsilon / w$ tensile behaviour proposed (Figure A-I.6) is simplified by means of a trilinear $\sigma-\varepsilon / w$ tensile behaviour.

The proposed constitutive model for UHPFRC in the 4P-IA is depicted in Figure A-I.7 according to the following parameters: elastic modulus $(E)$; the unloading modulus $\left(E^{*}\right)$; cracking strength $\left(f_{t}\right)$; ultimate cracking strength $\left(f_{t u}\right)$ and its associated strain $\left(\varepsilon_{t u}\right)$; crack opening at the intersection of the line that defines the initial slope to the $w$ axis $\left(w_{0}\right)$. The parameter $w_{0}$ in the 4P-IA can be obtained following the Expression (A-I.7). Therefore a simplified trilinear $\sigma-\varepsilon / w$ constitutive behaviour is proposed.

$$
w_{0}=\frac{3}{2} w_{d}
$$

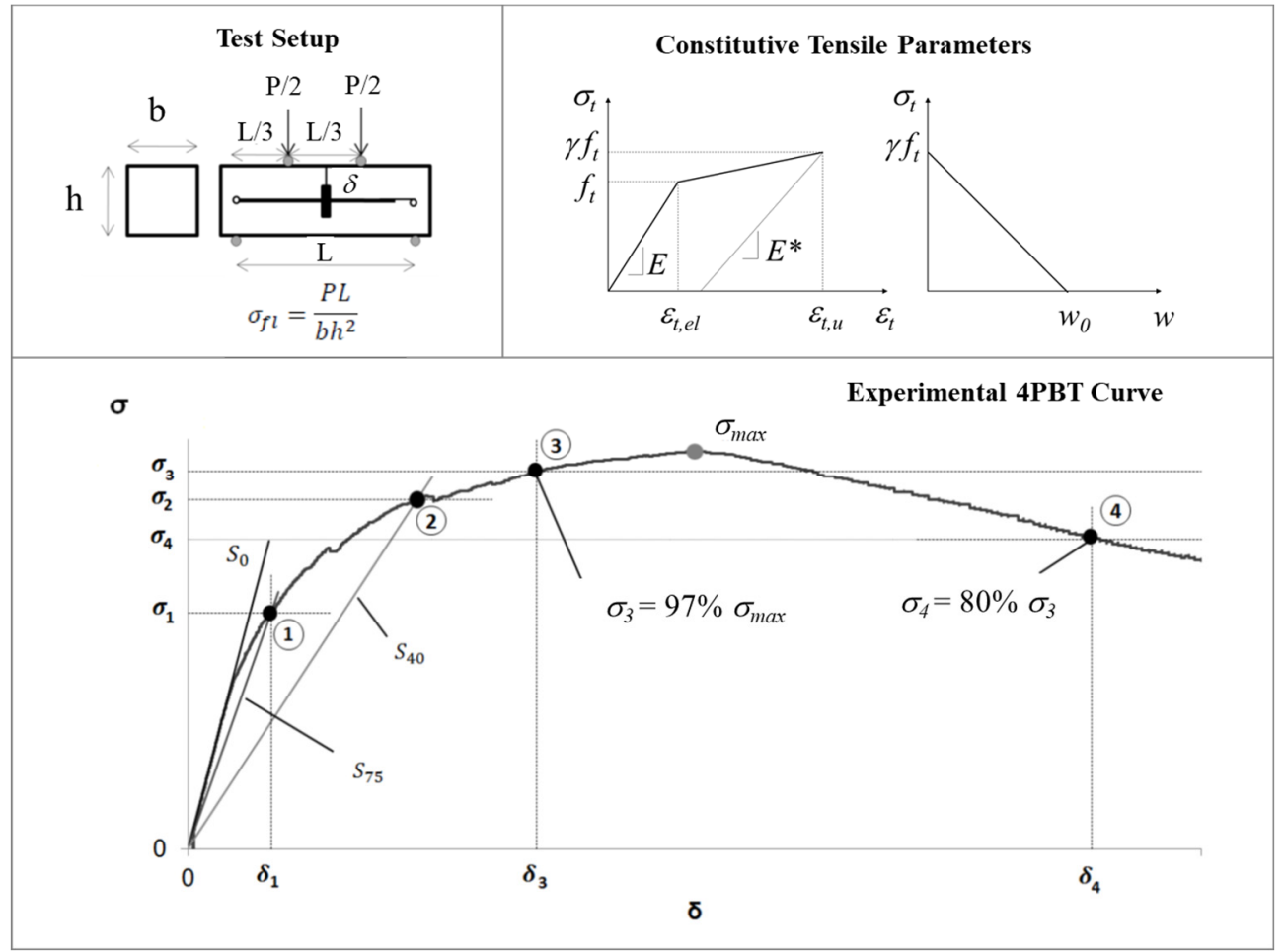

Figure A-I.7 Simplified 4P-IA. 
Annexe I: Inverse analysis methodology

\section{Experimental results for SH-UHPFRC numerical validation}

In (López 2017) two experimental programmes were carried out to experimentally validate the inverse analysis methodology there developed and above explained for UHPFRC that exhibits strain-hardening (SH-UHPFRC). The first one was designed to experimentally validate the iterative inverse analysis (I-IA) and the second one to validate the 5P-IA.

The tensile constitutive parameters obtained as a result of both experimental programmes are used in section 5.3 in chapter 5 of the present thesis to numerically validate the iterative inverse analysis (I-IA) and the simplified five-point inverse analysis (5P-IA) for SH-UHPFRC.

\section{Experimental programme for the I-IA}

For the purpose of numerically validating the non-linear hinge model and the consequent iterative inverse analysis method (I-IA) explained above, the tensile constitutive parameters obtained as a result from the experimental programme developed in Appendix I of (López 2017) are used.

In this experimental programme, three different types of square cross-section specimens were cast with a variable depth of 50,100 and $150 \mathrm{~mm}$. The $\mathrm{L} / \mathrm{h}$ ratio was constant and set at $4.5 .160 \mathrm{~kg} / \mathrm{m}^{3}$ (2\% in volume) of smooth-straight (13/0.20) steel fibres was used in an UHPC matrix with an average compressive strength of $169.9 \mathrm{MPa}$ obtained from $100 \mathrm{~mm}$ cubic specimens. Eight 50- and $100-\mathrm{mm}$ specimens, and four $150-\mathrm{mm}$ specimens, were prepared. The geometry of the specimens and the 4PBT setup are shown in Figure A-I.8.

According to Figure A-I.8, an LVDT was used to obtain the displacement at the midspan on the front side. Three LVDTs were used on the back side of the 100- and 150$\mathrm{mm}$ specimens to obtain the experimental average curvature in the central one-third. With the 50-mm deep specimens, the shorter depth let to use only two LVDTs. On the bottom side, two staggered extensometers were employed at a distance of $12 \mathrm{~mm}$ from the specimen's tensile face. The setup configuration for the 50-mm deep specimens did not allow to place these displacement transducers. 
a) $\mathrm{h}=50 \mathrm{~mm}$
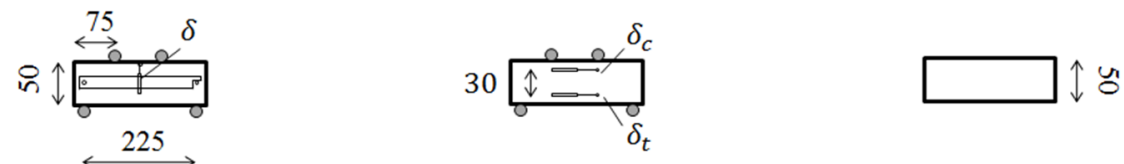

b) $\mathrm{h}=100 \mathrm{~mm}$
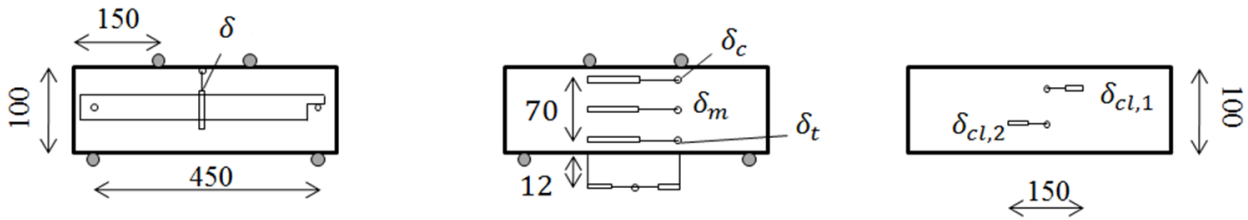

c) $\mathrm{h}=150 \mathrm{~mm}$
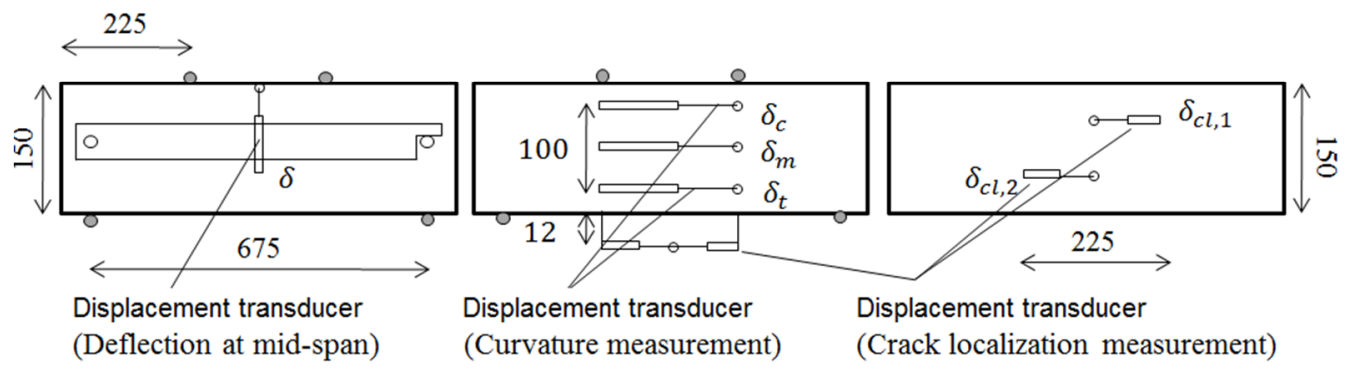

Units: $\mathrm{mm}$

Figure A-I.8 Experimental programme in appendix I in (López 2017)

The constitutive parameters obtained after applying the I-IA using the closed-form are shown in Table A-I.1.

Table A-I.1 I-IA Constitutive tensile parameters from (López 2017)

\begin{tabular}{|c|c|c|c|c|c|c|c|c|c|}
\hline \multicolumn{9}{|c|}{$\mathrm{h}=50 \mathrm{~mm}$} \\
\hline Specimen & $E(G P a)$ & $f_{t}(M P a)$ & $f_{t, u}(M P a)$ & $\varepsilon_{t, u}(\%)$ & $f_{t, d}(M P a)$ & $\varepsilon_{t, d}(\%)$ & $\varepsilon_{t, c}(\% o)$ & $w_{d}(m m)$ & $w_{c}(m m)$ \\
\hline 1 & 46 & 10.58 & 11.44 & 1.8 & 3.81 & 13.5 & 83.4 & 0.94 & 6.21 \\
\hline 2 & 47 & 10.55 & 11.45 & 3.2 & 3.82 & 20.4 & 75.0 & 1.35 & 5.48 \\
\hline 3 & 48 & 12.13 & 12.68 & 2.5 & 4.23 & 19.0 & 106.9 & 1.31 & 7.93 \\
\hline 4 & 49 & 13.84 & 14.15 & 3.2 & 4.72 & 16.5 & 75.7 & 1.07 & 5.55 \\
\hline 5 & 48 & 13.34 & 13.48 & 5.8 & 4.49 & 17.7 & 81.5 & 0.97 & 5.79 \\
\hline 6 & 46 & 9.39 & 13.33 & 3.7 & 4.44 & 19.6 & 85.7 & 1.26 & 6.26 \\
\hline
\end{tabular}


Annexe I: Inverse analysis methodology

\begin{tabular}{|c|c|c|c|c|c|c|c|c|c|}
\hline \multicolumn{8}{|c|}{$\mathrm{h}=100 \mathrm{~mm}$} \\
\hline Specimen & $E(\mathrm{GPa})$ & $f_{t}(\mathrm{MPa})$ & $f_{t, u}(\mathrm{MPa})$ & $\mathcal{E}_{t, u}(\%)$ & $f_{t, d}(\mathrm{MPa})$ & $\varepsilon_{t, d}(\% o)$ & $\mathcal{E}_{t, c}(\%)$ & $w_{d}(\mathrm{~mm})$ & $w_{c}(\mathrm{~mm})$ \\
\hline 1 & 49 & 9.96 & 12.80 & 3.9 & 4.27 & 9.7 & 35.5 & 1.00 & 4.95 \\
\hline 2 & 54 & 9.96 & 12.54 & 4.4 & 4.18 & 13.4 & 39.2 & 1.49 & 5.44 \\
\hline 3 & 54 & 10.61 & 11.86 & 5.5 & 3.95 & 16.2 & 39.8 & 1.75 & 5.35 \\
\hline 4 & 48 & 9,96 & 12.62 & 3.4 & 4.21 & 10.6 & 31.1 & 1.21 & 4.37 \\
\hline 5 & 48 & 11.81 & 15.47 & 5.1 & 5.16 & 12.6 & 33.6 & 1.30 & 4.53 \\
\hline 6 & 47 & 9.47 & 11.62 & 2.7 & 3.87 & 11.5 & 31.9 & 1.45 & 4.58 \\
\hline \multicolumn{8}{|c|}{$\mathrm{h}=150 \mathrm{~mm}$} \\
\hline Specimen & $E(\mathrm{GPa})$ & $f_{t}(\mathrm{MPa})$ & $f_{t, u}(\mathrm{MPa})$ & $\mathcal{E}_{t, u}(\%)$ & $f_{t, d}(\mathrm{MPa})$ & $\mathcal{E}_{t, d}(\% o)$ & $\mathcal{E}_{t, c}(\%)$ & $w_{d}(\mathrm{~mm})$ & $w_{c}(\mathrm{~mm})$ \\
\hline 1 & 49 & 9.96 & 14.13 & 4.3 & 4.71 & 13.8 & 24.6 & 2.37 & 4.93 \\
\hline 2 & 49 & 9.22 & 12.85 & 4.2 & 4.28 & 12.4 & 27.3 & 2.06 & 5.51 \\
\hline 3 & 49 & 10.20 & 13.67 & 5.3 & 4.56 & 14.8 & 27.0 & 2.38 & 5.23 \\
\hline
\end{tabular}

\section{Experimental validation of the simplified $5 P-I A$}

For the purpose of numerically validating the simplified 5P-IA explained above, the tensile constitutive parameters obtained as a result from the experimental programme developed in Appendix II of (López 2017) are used.

Sixteen 4PBTs on 100-mm square cross-section specimens were tested. Half of them were tested with a slenderness ratio $(L / h)$ of 3 while the other half were tested with a slenderness ratio of 4.5. The experimental displacement at mid span and its associated load were registered. The UHPFRC used had an average compressive strength of 169.89 $\mathrm{MPa}$, obtained from cubes of $100 \mathrm{~mm}$ length. A fibre amount of $160 \mathrm{~kg} / \mathrm{m}^{3}(2 \%$ in volume) of 13/0.2 steel fibres in volume was used.

The constitutive parameters obtained after applying the simplified 5P-IA are shown in Table A-I.2, Table A-I.3 and Table A-I.4.

Table A-I.2 5P-IA Constitutive tensile parameters ( $\sigma-\varepsilon$ branch) from (López 2017)

\begin{tabular}{|c|c|c|c|c|c|c|c|c|c|}
\hline \multicolumn{5}{|c|}{$\mathrm{L} / \mathrm{h}=3$} & \multicolumn{5}{|c|}{$\mathrm{L} / \mathrm{h}=4,5$} \\
\hline Esp. & $f_{t}$ & $f_{t u}$ & $\varepsilon_{t u}$ & $E$ & Esp. & $f_{t}$ & $f_{t u}$ & $\varepsilon t u$ & $E$ \\
\hline D1ג3 & 8,7 & 8,5 & 0,0048 & 53600 & D1ג4.5 & 11,2 & 11,9 & 0,0068 & 49900 \\
\hline $\mathrm{D} 2 \lambda 3$ & 10,7 & 10,7 & 0,0072 & 62500 & $\mathrm{D} 2 \lambda 4.5$ & 11,0 & 10,3 & 0,0073 & 49800 \\
\hline $\mathrm{D} 3 \lambda 3$ & 10,0 & 11,0 & 0,0066 & 61100 & D3 34.5 & 10,5 & 10,6 & 0,0059 & 42500 \\
\hline $\mathrm{D} 4 \lambda 3$ & 10,9 & 11,1 & 0,0060 & 46700 & D4 $4 \lambda 4.5$ & 10,7 & 11,6 & 0,0063 & 55300 \\
\hline D5 53 & 10,0 & 9,4 & 0,0044 & 48700 & D5 $2 \lambda 4.5$ & 11,4 & 11,4 & 0,0057 & 52300 \\
\hline D6 $6 \lambda 3$ & 11,4 & 11,0 & 0,0057 & 53800 & D6 $6 \lambda 4.5$ & 11,6 & 10,7 & 0,0035 & 53700 \\
\hline D7 73 & 11,1 & 10,8 & 0,0086 & 50700 & D7 74.5 & 11,2 & 11,5 & 0,0058 & 49600 \\
\hline D8ג3 & 10,2 & 10,4 & 0,0065 & 52800 & D8 84.5 & 11,3 & 10,1 & 0,0055 & 52100 \\
\hline
\end{tabular}


Numerical modelling of UHPFRC: from the material to the structural element

Table A-I.3 5P-IA Constitutive tensile parameters ( $\sigma-w$ branch) for $L / h=3$ from (López 2017)

\begin{tabular}{|c|c|c|c|c|c|}
\hline \multicolumn{3}{|c|}{$\mathrm{Lc}=\mathrm{h}$} & \multicolumn{3}{c|}{$\mathrm{Lc}=\mathrm{h} / 2$} \\
\hline Esp. & $\mathrm{w}_{\mathrm{d}}$ & $\mathrm{w}_{\mathrm{c}}$ & $\mathrm{Esp}$. & $\mathrm{wd}_{\mathrm{d}}$ & $\mathrm{w}_{\mathrm{c}}$ \\
\hline $\mathrm{D} 1 \lambda 3$ & 1,49 & 4,82 & $\mathrm{D} 1 \lambda 3$ & 1,54 & 5,66 \\
\hline $\mathrm{D} 2 \lambda 3$ & 1,32 & 6,53 & $\mathrm{D} 2 \lambda 3$ & 1,40 & 7,43 \\
\hline $\mathrm{D} 3 \lambda 3$ & 1,92 & 6,13 & $\mathrm{D} 3 \lambda 3$ & 1,93 & 6,91 \\
\hline $\mathrm{D} 4 \lambda 3$ & 1,44 & 5,52 & $\mathrm{D} 4 \lambda 3$ & 1,42 & 6,02 \\
\hline $\mathrm{D} 5 \lambda 3$ & 1,45 & 5,87 & $\mathrm{D} 5 \lambda 3$ & 1,44 & 6,80 \\
\hline $\mathrm{D} 6 \lambda 3$ & 1,59 & 6,24 & $\mathrm{D} 6 \lambda 3$ & 1,62 & 7,19 \\
\hline $\mathrm{D} 7 \lambda 3$ & 1,20 & 6,10 & $\mathrm{D} 7 \lambda 3$ & 1,21 & 6,58 \\
\hline $\mathrm{D} 8 \lambda 3$ & 1,59 & 5,42 & $\mathrm{D} 8 \lambda 3$ & 1,65 & 6,06 \\
\hline
\end{tabular}

Table A-I.4 5P-IA Constitutive tensile parameters ( $\sigma$-w branch) for $L / h=4.5$ from (López 2017)

\begin{tabular}{|c|c|c|c|c|c|c|c|c|}
\hline \multicolumn{3}{|c|}{$\mathrm{Lc}=1,5 \mathrm{~h}$} & \multicolumn{3}{|c|}{$\mathrm{Lc}=\mathrm{h}$} & \multicolumn{3}{|c|}{$\mathrm{Lc}=\mathrm{h} / 2$} \\
\hline Esp. & $\mathrm{Wd}_{\mathrm{d}}$ & $\mathrm{W}_{\mathrm{c}}$ & Esp. & $\mathrm{Wd}$ & $\mathrm{W}_{\mathrm{c}}$ & Esp. & $\mathrm{Wd}$ & $\mathrm{W}_{\mathrm{c}}$ \\
\hline D1入4.5 & 1,33 & 4,37 & 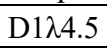 & 1,35 & 4,79 & 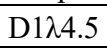 & 1,41 & 5,42 \\
\hline $\mathrm{D} 2 \lambda 4.5$ & 1,38 & 5,14 & $\mathrm{D} 2 \lambda 4.5$ & 1,32 & 5,70 & $\mathrm{D} 2 \lambda 4.5$ & 1,33 & 6,50 \\
\hline $\mathrm{D} 3 \lambda 4.5$ & 1,36 & 5,18 & $\mathrm{D} 3 \lambda 4.5$ & 1,39 & 5,60 & $\mathrm{D} 3 \lambda 4.5$ & 1,42 & 6,38 \\
\hline $\mathrm{D} 4 \lambda 4.5$ & 1,68 & 5,25 & $\mathrm{D} 4 \lambda 4.5$ & 1,60 & 5,62 & $\mathrm{D} 4 \lambda 4.5$ & 1,65 & 6,43 \\
\hline D5 24.5 & 0,90 & 5,27 & D5 24.5 & 1,00 & 5,80 & D5 24.5 & 1,06 & 6,70 \\
\hline D6 64.5 & 1,27 & 5,06 & D674.5 & 1,23 & 5,45 & D674.5 & 1,24 & 6,20 \\
\hline D7 74.5 & 1,46 & 4,79 & D7 74.5 & 1,41 & 5,20 & D7 74.5 & 1,41 & 5,94 \\
\hline D $8 \lambda 4.5$ & 1,08 & 4,83 & $\mathrm{D} 8 \lambda 4.5$ & 1,09 & 5,29 & D8 84.5 & 1,16 & 6,04 \\
\hline
\end{tabular}




\section{Annexe II}

\section{D-NLFEM-multicrack}

As it is set in the future research lines, when it is desired to achieve an accurate and a more realistic modelling of UHPFRC, it seems better to go towards discrete cracking approaches. The smeared crack model based on continuum models where the crack opening in the softening constitutive behaviour is distributed in a mean total strain defined in a crack bandwidth seems not to be representative of the particular cracking process of UHPFRC.

Therefore, it could be interesting to develop the NLFEM towards the discrete cracking approach idea. It seems to be preferable for UHPFRC, especially without reinforcement where macro-cracks will most probably occur. It could be interesting to continue with the evolution of the 3D-NLFEM-multicrack developed in chapter 6 defining the composed finite elements bounded not only vertically but also horizontally by interface elements surrounding the solid elements. In this direction, several trials have been done in the present work with the 2D-NLFEM of the 4PBT without reinforcement. This is a challenge leading to computational limitations when an important number of composed finite elements may be used. This model is called the 2D-NLFEM-multicrack.

With the 2D-NLFEM-multicrack it is possible to define different meshing zones where the dense of these improved composed finite elements can be changed depending on the interest. With this, the mesh size dependency of continuum models is avoided as the discrete cracking approach is used.

In this Annexe II, an example of application of the composed finite elements with interface elements in horizontal and vertical direction in the boundaries of the 2D plane stress element is shown as an attempt to go towards this enhanced model. The 2D- 
NLFEM-multicrack incorporates, as the case of the 3D-NLFEM-multicrack in chapter 6 , the random analysis to simulate the heterogeneity of concrete material properties by means of the FRCFAC factor that multiplies the parameters that define the tensile constitutive equation of UHPFRC.

By way of example, the 500x100x100 mm 4PBT specimen HB3C-2 with $160 \mathrm{~kg} / \mathrm{m}^{3}$ of steel fibres from the experimental 4PBT programme carried out in chapter 5 is used. The specimen is tested in a 4PBT. Then, the direct procedure by means of the 4P-IA analysis and the softening correction described in chapter 5 is applied to obtain the tensile UHPFRC constitutive behaviour. Table A-II.1 contains the tensile parameters for the HB3C-2 unreinforced specimen and the average compressive strength from the $100-\mathrm{mm}$ cubic specimens.

Table A-II.1 Mechanical UHPFRC properties for HB3C-2 specimen

\begin{tabular}{|c|c|c|c|c|c|c|c|}
\hline \multicolumn{7}{|c|}{$160 \mathrm{~kg} / \mathrm{m}^{3}$ of steel fibres } \\
\hline specimen & $\begin{array}{c}f_{t} \\
(\mathrm{MPa})\end{array}$ & $\begin{array}{c}f_{t u} \\
(\mathrm{MPa})\end{array}$ & $\begin{array}{c}f_{t u c} \\
(\mathrm{MPa})\end{array}$ & $\begin{array}{c}\varepsilon_{t u} \\
(\%)\end{array}$ & $\begin{array}{c}E \\
(\mathrm{MPa})\end{array}$ & $\begin{array}{c}w_{o} \\
(\mathrm{~mm})\end{array}$ & $\begin{array}{c}f_{c} \\
(\mathrm{MPa})\end{array}$ \\
\hline HB3C-2 & 9.85 & 8.13 & 8.60 & 4.29 & 49600 & 2.29 & 144.66 \\
\hline
\end{tabular}

As it can be observed in Table A-II.1, the UHPFRC exhibits strain-softening (SSUHPFRC) as the corrected strain-hardening ratio is less than one, as shown in Expression (A-II.1).

$$
\gamma_{c}=\frac{f_{t u c}}{f_{t}}=\frac{8.60}{9.85}=0.87<1
$$

The obtained UHPFRC mechanical parameters are implemented into the discrete cracking approach of 2D-NLFEM-multicrack. After running the model four times generating different FRCFAC distributions and, therefore, different stress distributions, some results are analysed.

Table A-II.2 shows the values of the correlation length (corlen) and the standard deviation (stddev) of the FRCFAC for the random field used to generate the heterogeneities for the different runs. The number of grid lines used in the Cholesky decomposition for the random field generation are also detailed: $\mathrm{Nx}$ in $\mathrm{x}$ direction and $\mathrm{Ny}$ in y direction. The parameters used in the random distribution shown in Table A-II.2 lead to a $10 \%$ variation of the of the FRCFAC factor. Therefore, the variation of the stress that defines the tensile constitutive UHPFRC behaviour due to its heterogeneity is estimated in a $10 \%$. Moreover, these values lead to an adequate distribution of the 
influence in the area of the specimen, as it can be seen in Figure A-II.1 for the run number 3 (R3) of the model.

Table A-II.2 Random field in 2D-NLFEM-multicrack for HB3C-2 specimen

\begin{tabular}{|c|c|c|c|c|}
\hline RUN & corlen & stddev & $\mathrm{Nx}$ & $\mathrm{Ny}$ \\
\hline R1-R4 & 5 & 0.04 & 50 & 5 \\
\hline
\end{tabular}

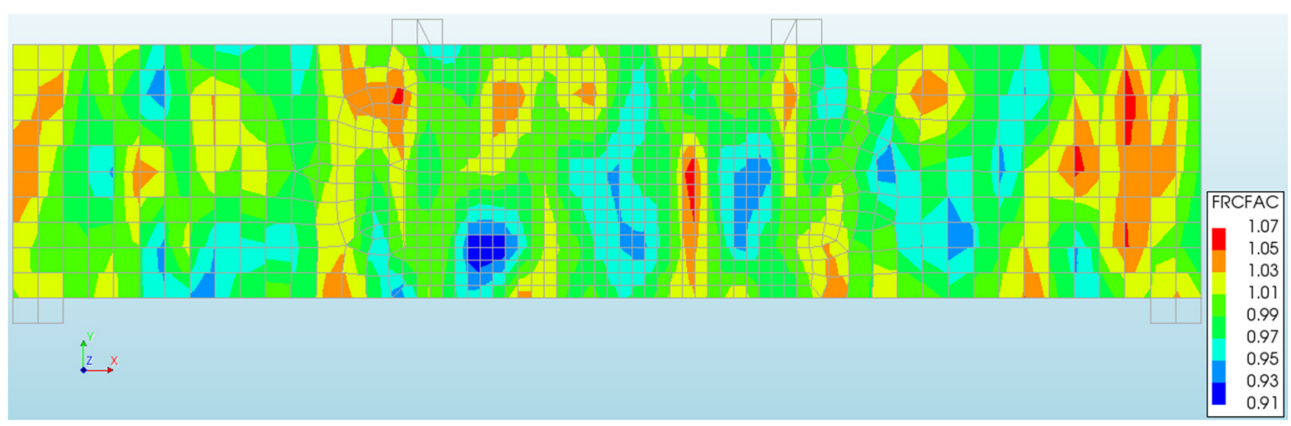

Figure A-II.1 FRCFAC distribution for R3.

Figure A-II.2 shows the stress $(\sigma)$ - deflection at mid-span $(\delta)$ response obtained as a result of each run of the 2D-NLFEM-multicrack compared to the experimental curve of the HB3C-2 unreinforced 4PBT specimen modelled. Moreover, the four levels of the experimental deflection upon maximum experimental stress $\left(\delta_{\text {бпахехx }}\right): 0.25 \cdot \delta_{\text {бmaxxх }}$, $0.50 \cdot \delta_{\text {omaxx }}, \delta_{\text {omaxexp }}$ and $1.25 \cdot \delta_{\text {omaxexp }}$ used to evaluate the accuracy of the direct procedure to characterise the UHPFRC constitutive behaviour in chapter 5 (see Figure 5.38) are represented to observe the accuracy of the model at these levels.

As it can be observed in Figure A-II.2, the model through the different runs represents with a good accuracy the experimental $\sigma-\delta$ response and the possible variability due to effects such as the fibre orientation, the heterogeneity of the UHPFRC strength, the variability of the $4 \mathrm{PBT}$.. 


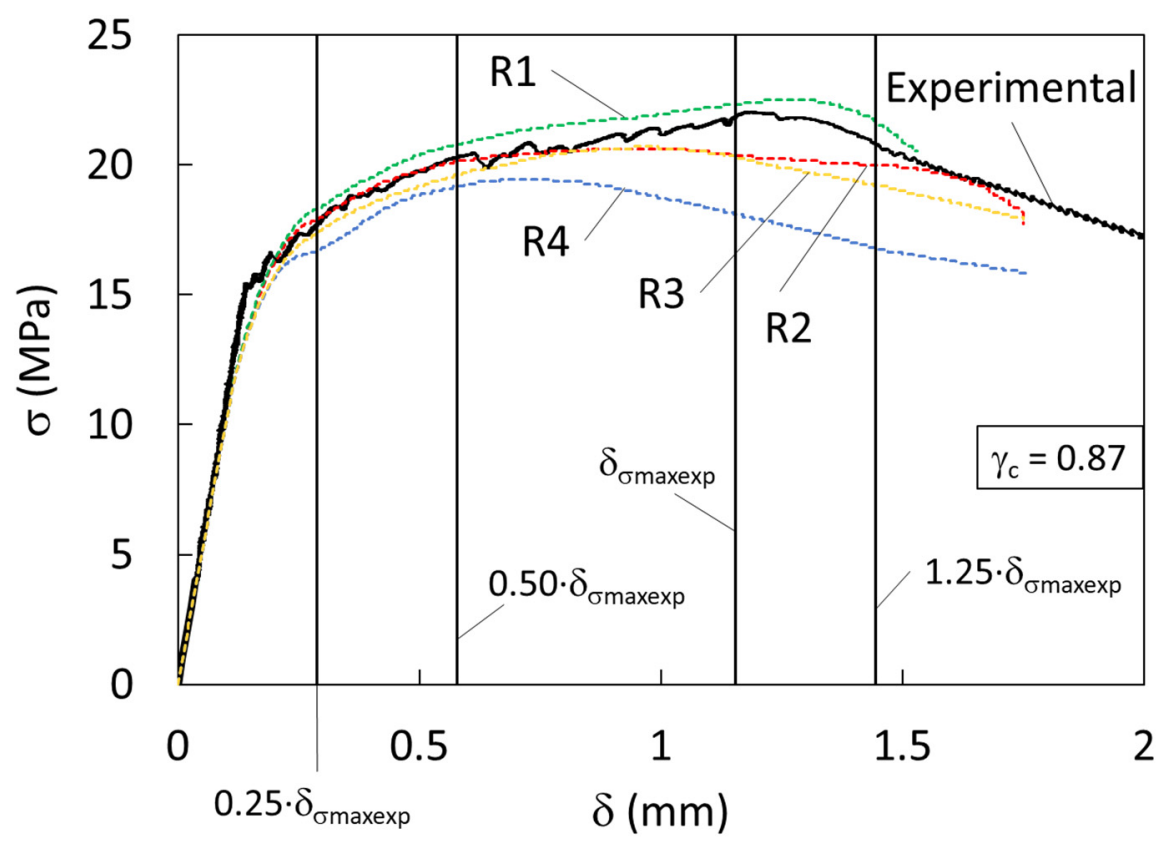

Figure A-II.2 $\sigma$ - $\delta$ response

Figure A-II.3 shows the geometry of the model. As it can be observed, the composed finite elements are situated in the central third part of the specimen. Therefore, this part is modelled with the discrete cracking approach of the 2D-NLFEM-multicrack generating a mesh of horizontal and vertical interface elements bounding the plane stress elements, as it can be observed in more detail in Figure A-II.4. As defined in this work for the discrete constitutive behaviour, tensile strength $\left(f_{t}\right)$ and ultimate tensile strength $\left(f_{t u}\right)$ are reduced by $2 \%$. For the constitutive behaviour of the plane stress element in the composed finite element, the smeared cracking approach is used. The other two extremes of the 4PBT geometry are modelled using the smeared cracking approach considering both blocks as a continuum with the idea of optimising computer efforts centring the detailed analysis into the middle one-third. 


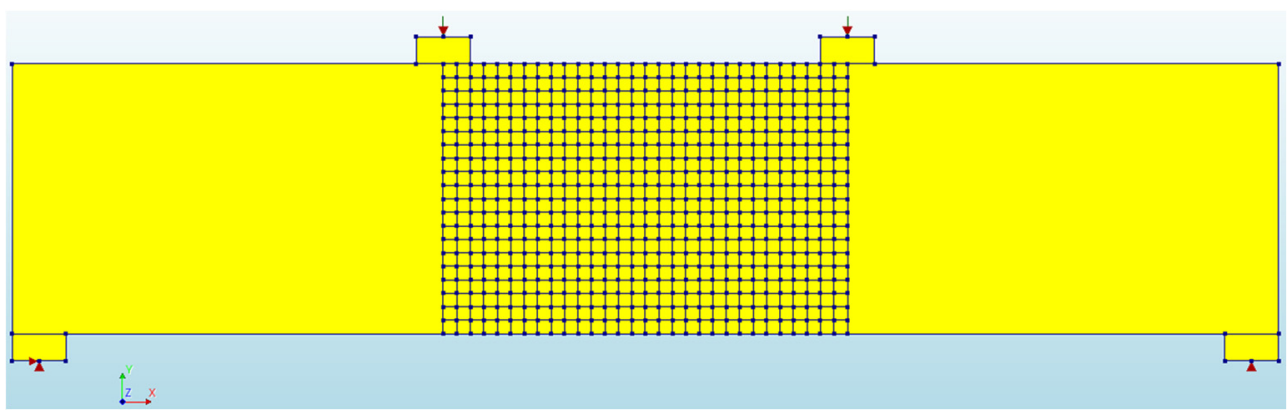

Figure A-II.3 Geometry

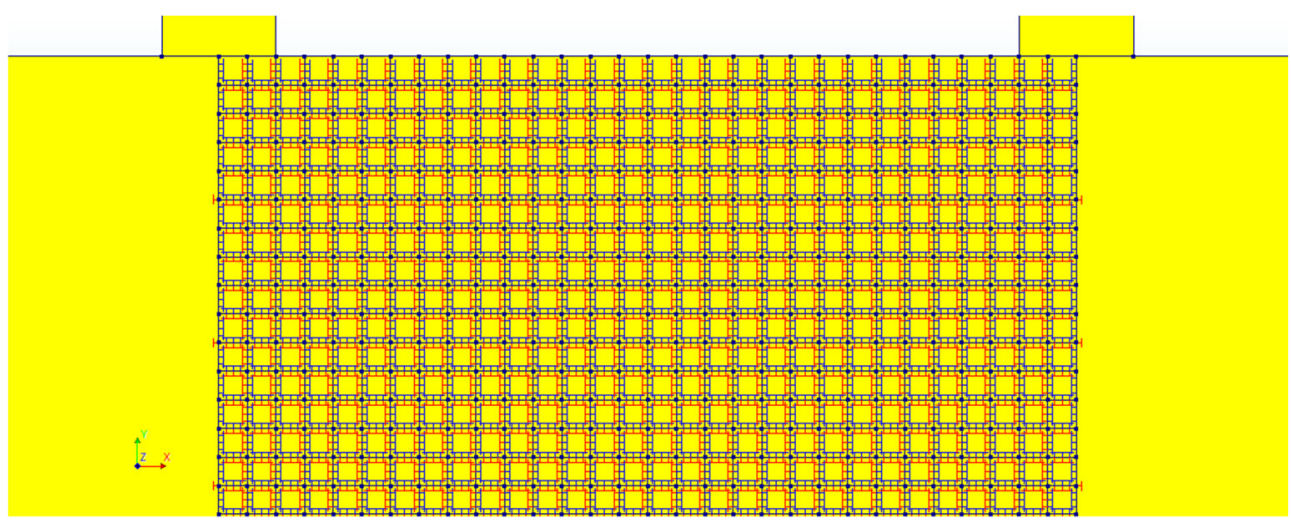

Figure A-II.4 Zoom of the composed finite elements

Figure A-II.5 shows the finite element mesh defined. The element size used for the external thirds is $10 \mathrm{~mm}$ and for the central third $5 \mathrm{~mm}$. Therefore, the size of the composed finite elements is $5 \mathrm{~mm}$. It is important to say that the maximum aggregate size used for this UHPFRC is $0.8 \mathrm{~mm}$. Therefore, the composed element size in the central third is relatively close to the aggregate size. 


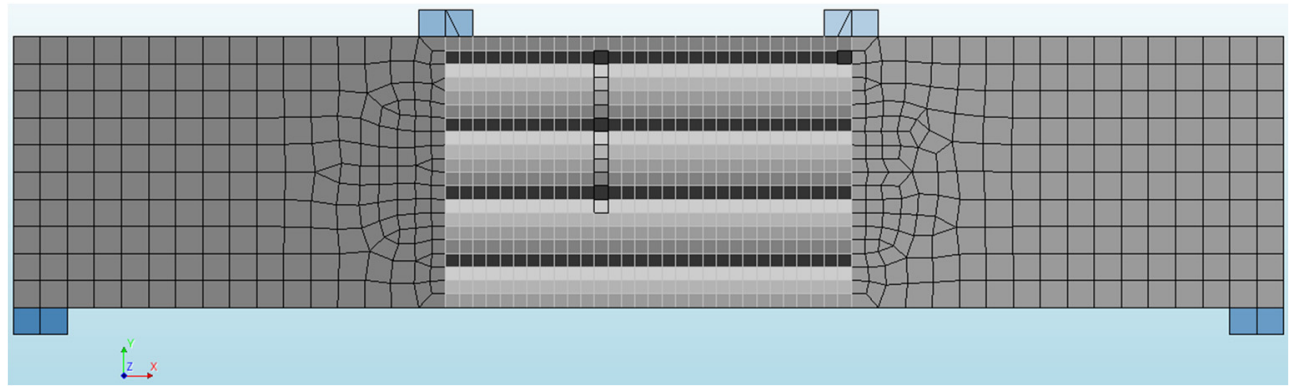

Figure A-II.5 Finite element mesh

By way of example, in the following the results of the R3 of the 2D-NLFEM-multicrack application are examined in more detail. Figure A-II.1 shows the FRCFAC random distribution for R3 generated from the random field application with the parameters described in Table A-II.2. The results obtained after the model's simulation are analysed at two levels in Figure A-II.2:

- Level 1 that corresponds to $\sigma=17.91 \mathrm{MPa}$ and $\delta=0.34 \mathrm{~mm}$ in the microcrack stabilisation phase in the ascending part of the $\sigma-\delta$ response.

- Level 2, where the macrocrack is located at collapse, representing the last point of the R $3 \sigma-\delta$ response in the descending part, with $\sigma=17.91 \mathrm{MPa}$ and $\delta=1.75$ $\mathrm{mm}$.

Figure A-II.6 shows the stress distribution at level 1 for the case of R3. This represents an expected stress simulation for a 4PBT varying from the tensile stress area between supports at the bottom of the specimen to a compressive stress at the top. If only the tensile stress range is represented, as it is shown in Figure A-II.7, it can be observed how the damage is going to be concentrated in localised zones.

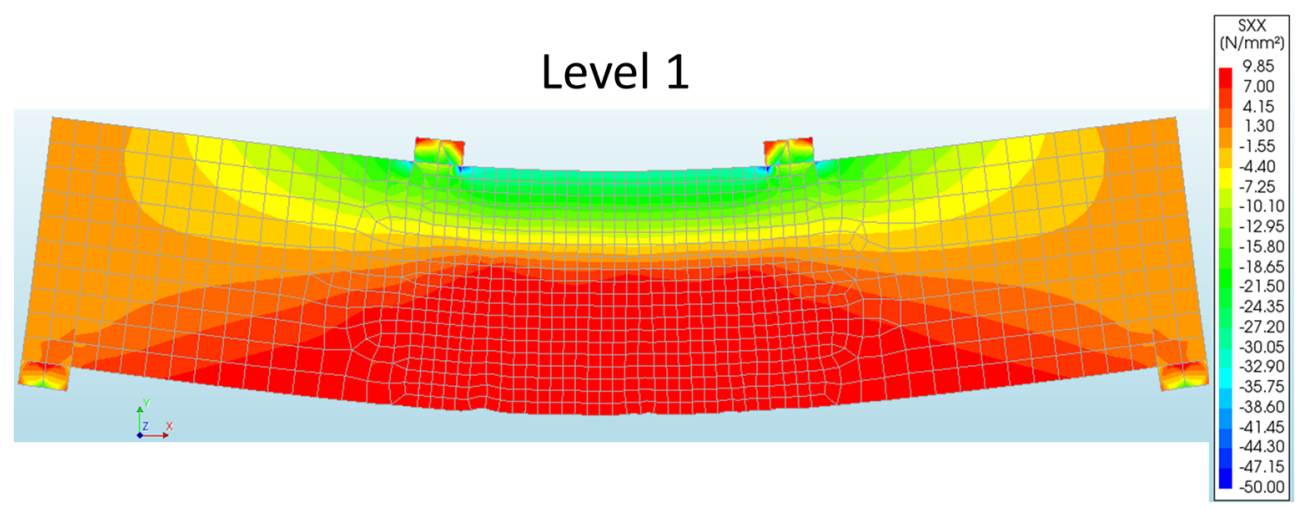

Figure A-II.6 Stresses in $x$ direction at level 1 for R3. 


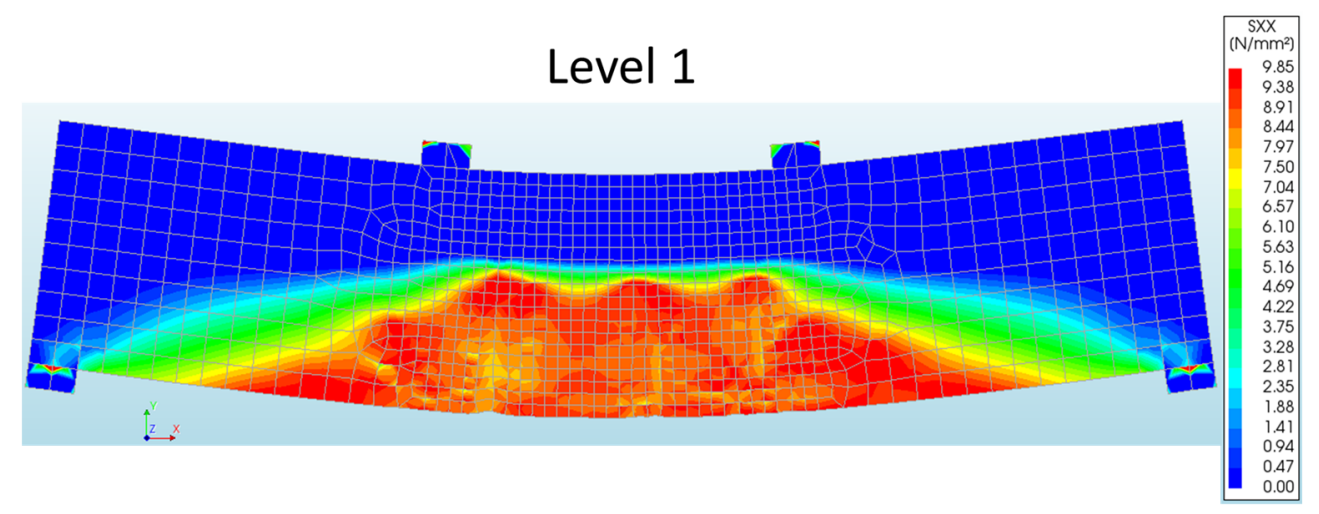

Figure A-II.7 Tensile stress range at level 1 for R3.

To better study the damage at this level, the crack pattern is represented in Figure A-II.8. It can be observed how, even though the cracking patter seems to cover all the tensile zone between the supports in the bottom of the specimen, the tendency is to concentrate the damage in localised zones. As it is explained in section 6.2.3.1.2 of chapter 6 where the crack pattern of the UHPFRC depending on the hardening ratio is addressed, it is stated that when UHPFRC exhibits strain-softening constitutive behaviour (SSUHPFRC) the cracks at the microcrack stabilisation phase are more concentrated than in case of SH-UHPFRC. In this phase, for SS, it seems that cracking pattern is smeared but it can be differentiated clear zones where cracks are more concentrated. Then, when the specimen reaches the collapse moment, it is expected that a clear macrocrack will appear from a previous localised zone developed in the microcrack stabilisation phase, as it can be observed in Figure A-II.11.

Level 1

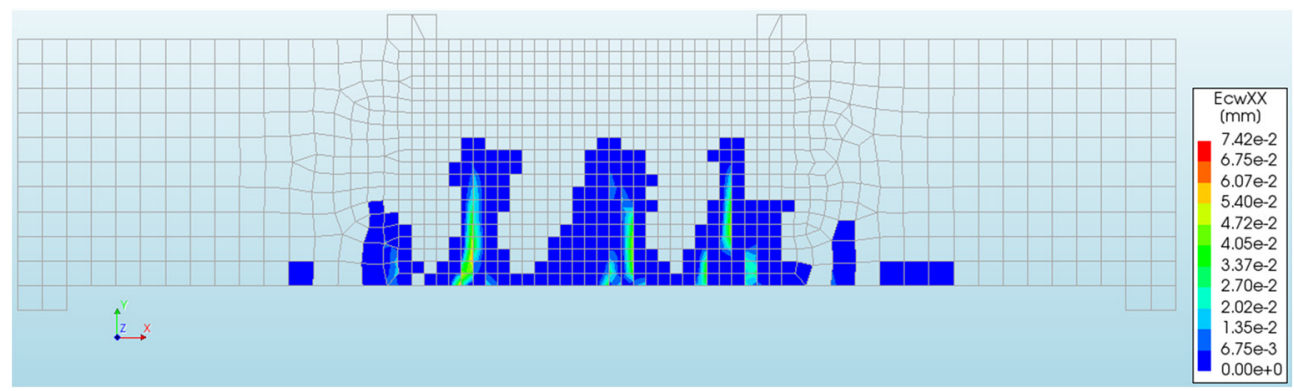

Figure A-II.8 Crack opening at level 1 for R3. 
Therefore, in level 2 the $f_{t u c}$ is exceeded in the bottom face of the beam and the specimen is collapsed, as it is observed in Figure A-II.9 where the stresses are represented and, in more detail, in Figure A-II.10 where the tensile stress range is represented. At this level, the evolution of the macrocrack expected from the crack pattern developed in previous level 1 is observed. From Figure A-II.10, it can be denoted the possible position of the macrocrack as the stresses are lower in the localisation zones due to the unloading from the crack opening.

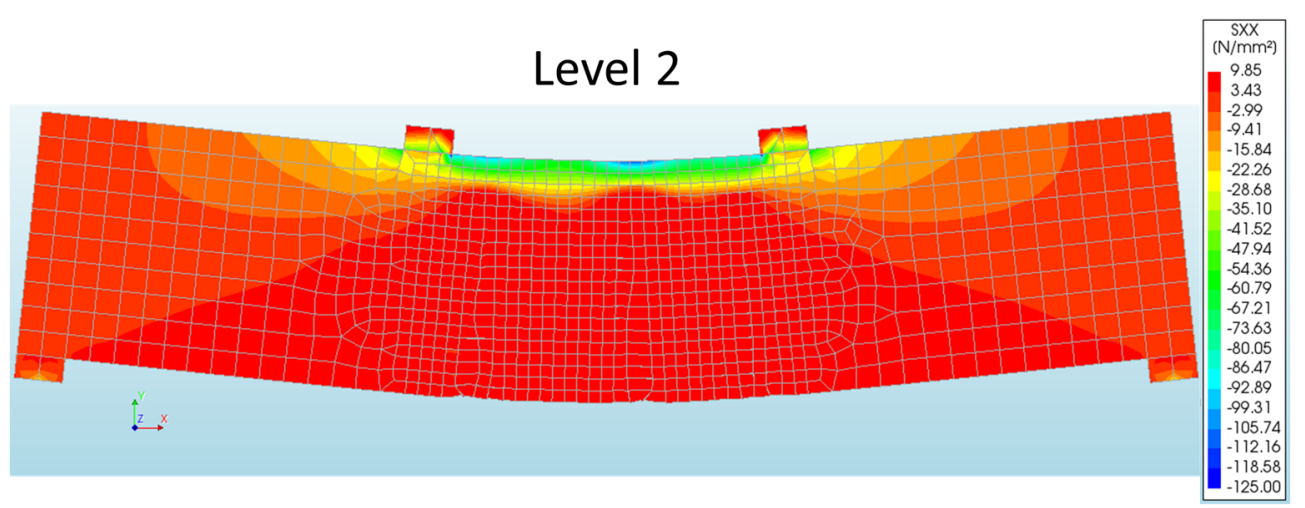

Figure A-II.9 Stresses in $x$ direction at level 2 for R3.

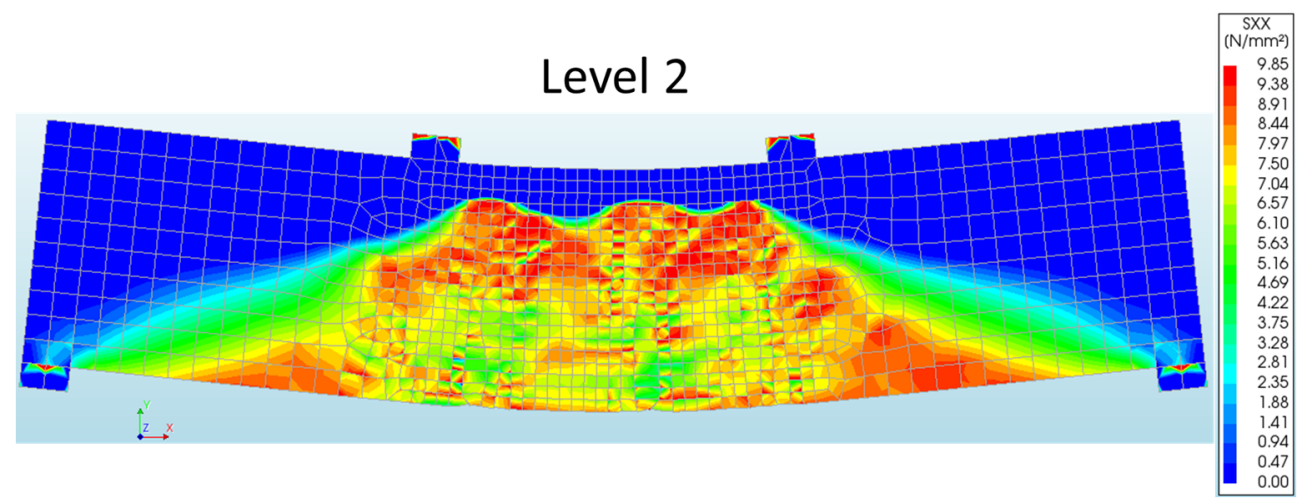

Figure A-II.10 Tensile stress range at level 2 for R3.

Again, to better study the damage at this level, the crack pattern is represented in Figure A-II.11. As it is expected from level 1 and deduced from the stress figures in level 2, the cracking pattern shown in Figure A-II.11 represents the coalescence of the microcracks in determined zones generating cracks with more entity as it is expected from level 1 for 
a specimen with SS-UHPFRC. The interfaces are opened as a consequence of the $\sigma-\mathrm{w}$ material discrete cracking approach and also the plane stress finite elements are deformed as a consequence of the $\sigma-\varepsilon$ material smeared cracking approach of the body of the 2D finite element along the macrocrack path. As observed in Figure A-II.11, a clear macrocrack is situated in the centre of the specimen from the coalescence of microcracks as an evolution of one of the localised zones. This very concentrated macrocrack can be attributed to the SS-UHPFRC constitutive behaviour obtained from the UHPFRC characterisation in Table A-II.1. As it is explained in section 6.2.3.1.2 of chapter 6 where the crack pattern of the UHPFRC depending on the hardening ratio is addressed, it is stated that when UHPFRC exhibits strain-softening constitutive behaviour (SS-UHPFRC) a clear macrocrack results from a previous zone developed in the microcrack stabilisation phase. This is the case of this example.

\section{Level 2}

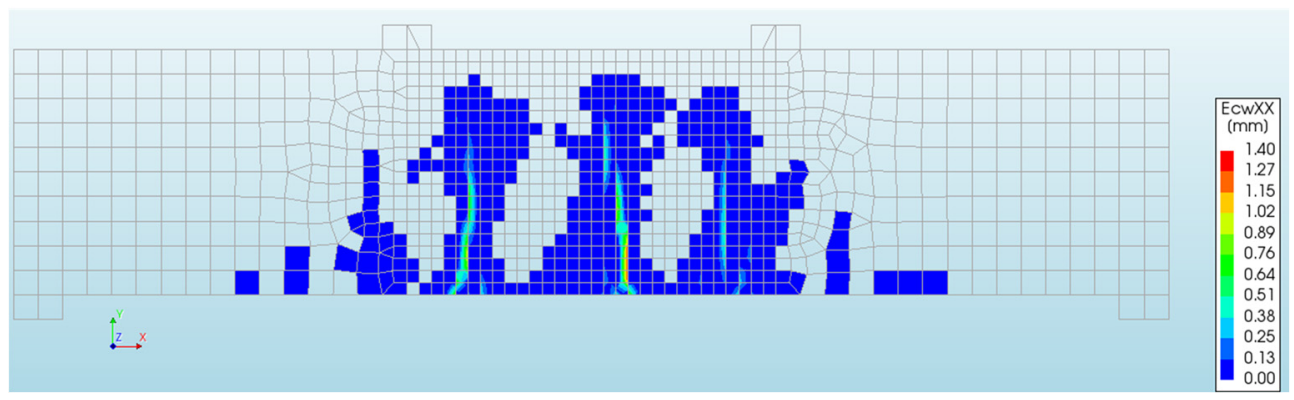

Figure A-II.11 Crack opening at level 2 for R3.

As it can be observed in the present Annexe II, the 2D-NLFEM-multicrack is a more complex model than the discrete cracking approach 2D-NLFEM (in which the discrete interface is situated only at the mid-span section), developed in chapter 5. With the 2DNLFEM-multicrack, many possibilities with the FRCFAC factor can be simulated and it is possible to study in more detail the consequences as the model is more detailed in the central third. However, if both models are compared, the computational costs of the 2DNLFEM-multicrack are very high compared to the 2D-NLFEM with the discrete interface only situated at the mid-span section. It is consumed in each run of the 2DNLFEM-multicrack used in this example about 8 times the time for 2D-NLFEM with the discrete interface in the mid-span section used in chapter 5. Each run of the 2DNLFEM-multicrack consumes too much computational time that makes it difficult to carry out without a powerful computational tool. 